\title{
THE EDGE OF EUROPE:
}

\section{HERITAGE, LANDSCAPE AND CONFLICT ARCHAEOLOGY}

\author{
by
}

\section{ROXANA-TALIDA ROMAN}

A thesis submitted to the University of Birmingham for the degree of

DOCTOR OF PHILOSOPHY

Department of Classics, Ancient History and Archaeology School of History and Cultures College of Arts and Law University of Birmingham 


\section{UNIVERSITYOF BIRMINGHAM}

\section{University of Birmingham Research Archive \\ e-theses repository}

This unpublished thesis/dissertation is copyright of the author and/or third parties. The intellectual property rights of the author or third parties in respect of this work are as defined by The Copyright Designs and Patents Act 1988 or as modified by any successor legislation.

Any use made of information contained in this thesis/dissertation must be in accordance with that legislation and must be properly acknowledged. Further distribution or reproduction in any format is prohibited without the permission of the copyright holder. 


\section{$\underline{\text { ABSTRACT }}$}

The research presented in this thesis addresses the significance of Romanian WWI sites as places of remembrance and heritage, by exploring the case of Maramureș against the standards of national and international heritage standards. The work provided the first ever survey of WWI sites on the Eastern Front, showing that the Prislop Pass conflictual landscape holds undeniable national and international heritage value both in terms of physical preservation and in terms of mapping on the memorial-historical record. The war sites demonstrate heritage and remembrance value by meeting heritage criteria on account of their preservation state, rarity, authenticity, research potential, the embedded war knowledge and their historical-memorial functions. The results of the research established that the war sites not only satisfy heritage legal requirements at various scales but are also endangered. Hence, the threats that impend upon this valuable, but yet unrecognised heritage, calls for urgent measures in view of officialising legal heritage status and thus assuring preservation of the war sites. In addition to elucidating the research question, the work identified a new coherent scale of WWI heritage research coining the notion of conflictual landscape and hence approaching a category of war heritage that has hitherto remained unexplored. 


\section{ACKNOWLEDGEMENTS}

This thesis would not have been possible without the help and support of those around me. In particular I would like to thank my supervisors Henry Chapman and John Carman for their continued support, advice and, most of all, patience.

I would like to acknowledge the financial support of the Raţiu Family Charitable Foundation which annually supports Romanian students in the UK, as well as projects promoting human rights, democracy and civil society in Romania.

I would like to thank Paul Brașcanu for granting me permission to use and reproduce materials from his impressive collection of WWI photography in this research.

For their continued personal support, I would like to thank my family Rozalia Roman, Ioan Roman, Ionuț Roman, Natalia Roman, Antonio Roman and Maria Stan.

I would like to extend a special thanks to Bogdan Bobînă from the Maramureș County Museum of History and Archaeology for his professional advice and for having encouraged me to pursue this project from the time that it was little more than a bold dream. 


\section{CONTENTS}

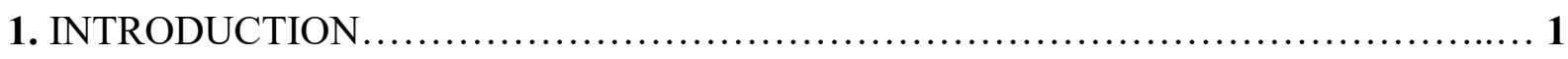

1.1. Preamble......................................................................... 1

1.2. Thesis background, research context and broader themes..................... 3

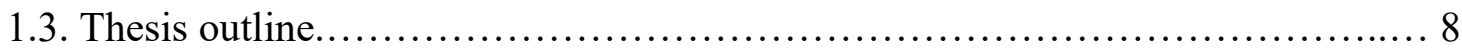

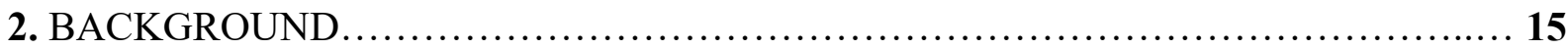

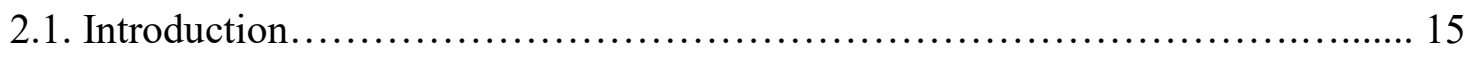

2.2. Archaeology as link between heritage and history/memory $\ldots \ldots \ldots \ldots \ldots \ldots \ldots \ldots 16$

2.3. Approaches to WWI research - First World War archaeology................. 21

2.4. WWI and remembrance............................................... 27

2.5. Memory, remembrance and its links to heritage........................... 30

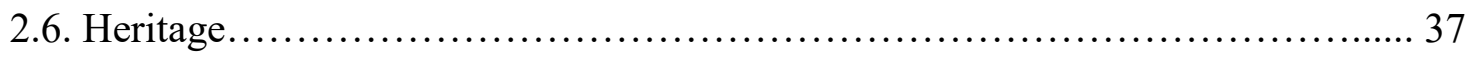

2.6.1. International heritage stakeholders............................ 37

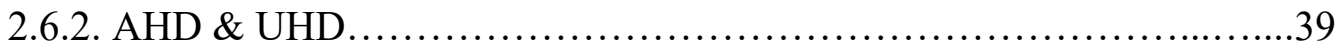

2.6.3. Laws and their place in heritage................................ 43

2.6.4. Value ascription in heritage management and conservation practice internationally................................................... 45

2.7. Conclusion......................................................... 47

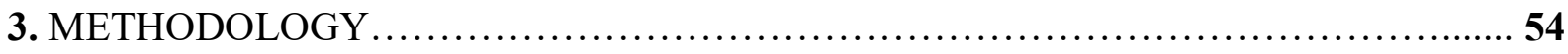

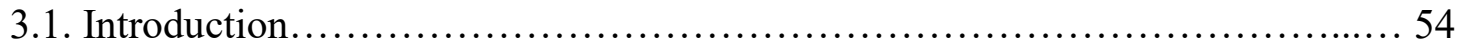

3.2. Rationale........................................................ 55

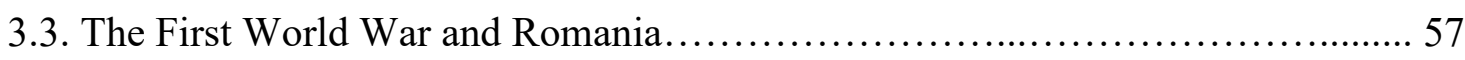

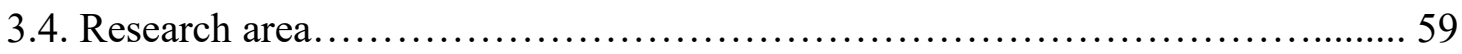

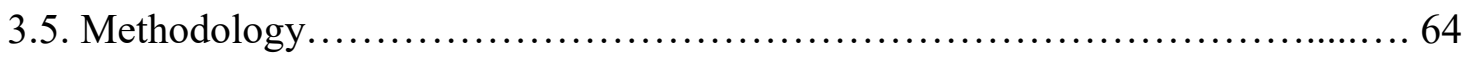

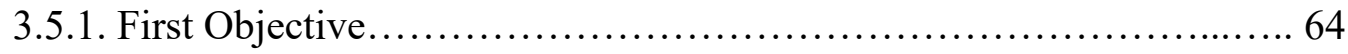


3.5.1.1. Archival research....................................... 64

3.5.1.2. Site mapping............................................. 65

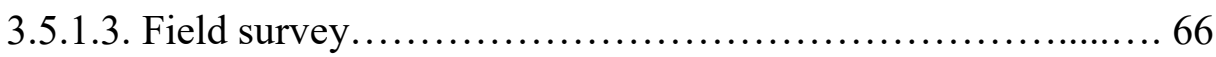

3.5.2. Second Objective.................................................. 68

3.5.2.1. Examination of Romanian heritage legislation................. 68

3.5.2.2. Textual analysis of the national heritage standards............. 69

3.5.2.3 Building of analytical evaluation sheets for the war remains... 70

3.5.2.4. Comparative analysis............................... 70

3.5.3. Third Objective............................................... 71

3.5.3.1. Examination of international heritage legislation.............. 71

3.5.3.2. Textual analysis of the World Heritage standards.............. 72

3.5.3.3 Building of hypothetical nomination for the World Heritage List of the war sites............................................................ 73

3.5.3.4. Comparative analysis................................ 73

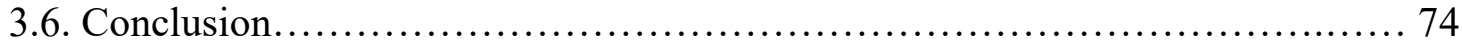

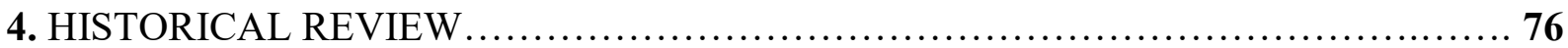

4.1. Introduction ...................................................... 76

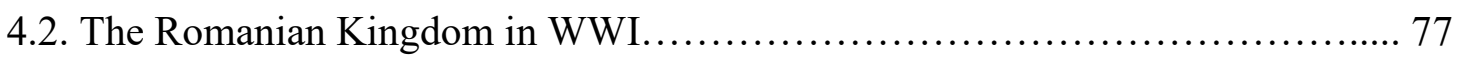

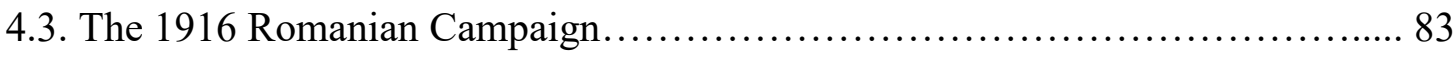

4.4. The 1917 Romanian campaign....................................... 86

4.4.1. The Mărăști Battle.................................................... 87

4.4.2. The Oituz Battle.......................................... 88

4.4.3. The Mărășești Battle............................................ 89

4.5. The 1918 Romanian campaign.......................................... 91 
4.6. The Union of the Romanian historical provinces with the Romanian Kingdom... 94

4.7. WWI in the Romanian historical provinces appendant to the Austro-Hungarian Empire.

4.8. Maramureș............................................................. 102

4.9. The Prislop Pass - the link between Maramureș and Bukovina................... 109

4.10. The Maramureș-Bukovina front............................................ 113

4.11. The imperial transport systems in Maramureș and Bukovina................. 115

4.12. The human dimension of the war - civilians and war prisoners .............. 122

4.13. WWI in literature and folklore........................................ 124

4.14. Conclusions............................................................ 129

5. ASSESSMENT OF THE MATERIAL CULTURE OF WAR IN THE PRISLOP PASS AREA/THE PRISLOP PASS CONFLICTUAL LANDSCAPE $\ldots \ldots \ldots \ldots \ldots \ldots \ldots \ldots \ldots \ldots . \ldots \ldots$

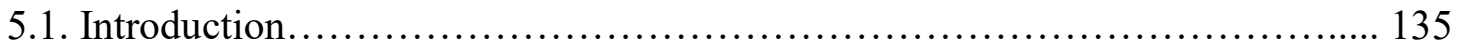

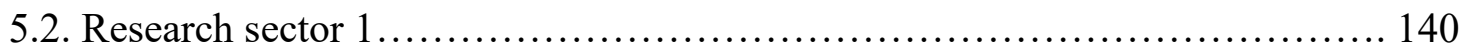

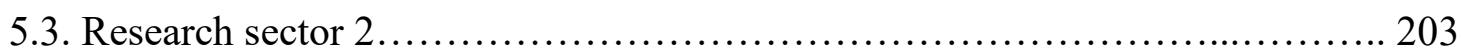

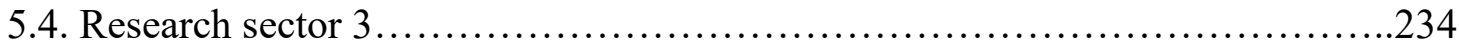

5.5. Conclusions ........................................................ 241

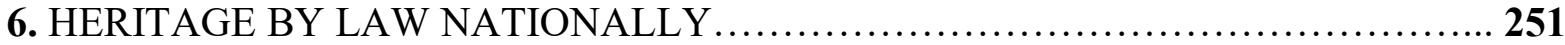

6.1. Introduction........................................................ 251

6.2. The evolution of heritage legislation in Romania............................ 252

6.3. The formation of contemporary heritage legislation...................... 261

6.4. The List of Historic Monuments.......................................... 269

6.5. Romania and the heritage arena/The Romanian Territorial Development Strategy .............................................................. 273

6.6. Conclusions ......................................................... 275 
7.1. Introduction

7.2. The link between national and international heritage legislation.............. 280

7.3. International heritage legislation..................................... 282

7.4. The European Year of Cultural Heritage..................................... 288

7.5. The World Heritage ranking process and criteria............................ 290

7.6. The Wooden Churches of Maramureș........................................ 298

7.7. Conclusions............................................................ 301

8. RESEARCH OUTCOMES.................................................. 304

8.1. Introduction ........................................................ 304

8.2. The material culture of war in Maramureș - The Prislop Pass conflictual landscape............................................................... 306

8.3. Heritage by law in Romania.............................................. 313

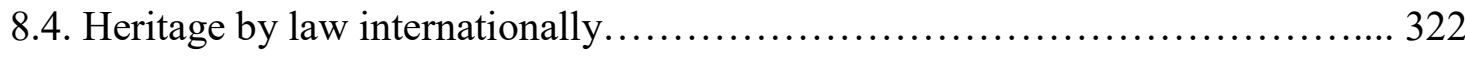

8.5. Main findings.......................................................... 342

8.6. Implications ........................................................... 350

8.7. Future research..................................................... 357

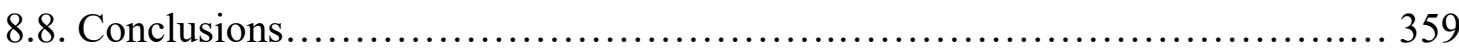

APPENDIX 1: Cultural tourism as highlighter of the versatility of heritage value.......... 365

APPENDIX 2: King Ferdinand's proclamation to all Romanians......................... 367

APPENDIX 3: The offensive in Transylvania......................................... 368

APPENDIX 4: The defence of the South Front....................................... 370

APPENDIX 5: The defence of the Carpathian Mountain passages.................... 372

APPENDIX 6: The defence of the Muntenia territory............................... 374 
APPENDIX 7: The declaration of self-determination presented by Alexandru Vaida-Voevod to the Hungarian Parliament of Austria-Hungary...

APPENDIX 8: New York Times article describing the National Assembly of Alba Iulia that decided the Great Union on the $1^{\text {st }}$ of December 1918

APPENDIX 9: Iuliu Maniu's speech in occurrence of the National Assembly of Alba Iulia Great Union, $1^{\text {st }}$ December 1918

APPENDIX 10: The resolution of the National Assembly of Alba Iulia, $1^{\text {st }}$ DECEMBER 1918 378

APPENDIX 11: The Union of Basarabia, Bukovina and Banat with Romania..... 380

APPENDIX 12: The Union of Maramureș with Romania 385

APPENDIX 13: Between two front lines, 1914/1918 - fragment describing the MaramureșBukovina front.

APPENDIX 14: Romanian National Anthem 390

APPENDIX 15: The analytical inventory sheet of the Saint Ilie Tresviteanul Church 393

APPENDIX 16: Hypothetic analytical inventory sheet of Prislop Pass war sites 398

APPENDIX 17: The historical architectural study of the parochial church Saint Prophet Ilie Tresviteanul

APPENDIX 18: Hypothetic World Heritage List nomination of the Prislop Pass war sites 


\section{FIGURES}

FIG.1. Document found by an Italian second lieutenant on a Hungarian soldier killed in SanMichelle near Gorizia representing the hanging of three Romanian civilians in a village of the county of Maramureș.

FIG.2. Landwehr-zug/WWI auto-train stationing in Prundu Bârgăului 116

FIG.3. WWI airplane in Cernăuți, Bukovina.

FIG.4. Mobile pigeons' aviaries near Cârlibaba.

FIG.5. WWI German military rafts on Vaser.

FIG.6. WWI cableway in Maramureș.

FIG.7. WWI cattle driven carriages in Bukovina.

FIG.8. Horses engaged in the transport of ammunitions during WWI in the Prislop Pass....120

FIG.9. The WWI Chiril military dog camp - Bukovina.

FIG.10. WWI dog driven carts in Bukovina - 1917 .

FIG.11. Map of the county of Maramureș within the Romanian territory... .136

FIG.12. Map of the research area within the county of Maramureș.

FIG.13. Map of research sector 1.

FIG.14. Map of research sector 2 .

FIG.15. Map of research sector 3 .

FIG.16. Prislop cableway, 1917.

FIG.17. Railway tight curb near Prislop.

FIG.18. Prislop Pass central plateau, 1917

FIG.19. WWI train reaching the top of the Prislop Pass, 1917.

FIG.20. Prislopbahn WWI Badge.

FIG.21. Prislop Pass train station.

FIG.22. WWI Prislop Pass military city, March 1916

FIG.23. General von Conta and Major General Burckhart along with a unit of the $7^{\text {th }}$ Army on the Prislop saddle, 11.09.1916.

FIG.24. General von Conta and Major General Burckhart amongst the Conta Corps quartered in the Prislop Pass, 11.09.1916. 
FIG.25. The $10^{\text {th }}$ Bavarian Division on the Prislop Pass $11.09 .1916 \ldots \ldots \ldots \ldots \ldots \ldots \ldots \ldots \ldots . . . . . . .146$

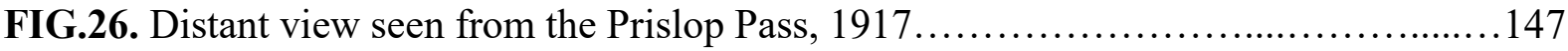

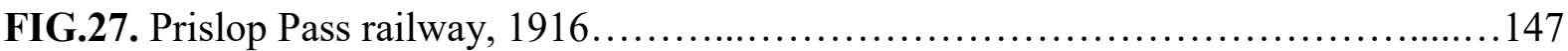

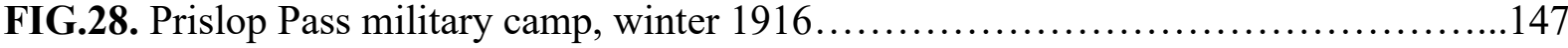

FIG.29. Felix Tarbuk von Sensenhorst - cleaning of the Prislop railway.................. 148

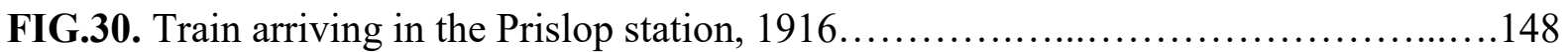

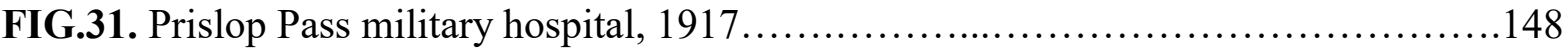

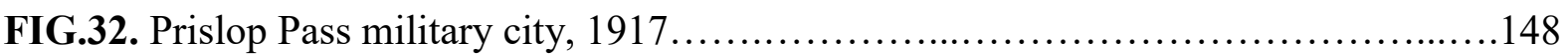

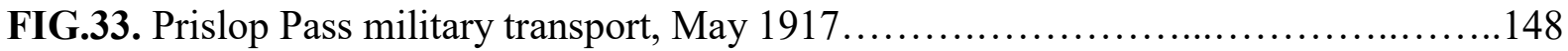

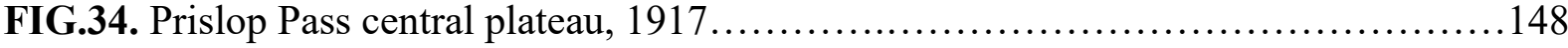

FIG.35. Prislop Serpentine railway.................................................149

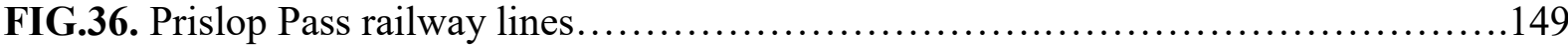

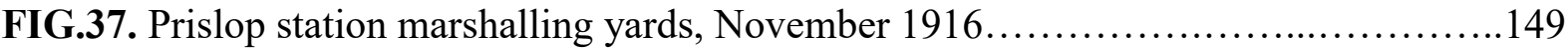

FIG.38. Skiing soldiers on top of the Prislop Pass, 1917.................................149

FIG.39. Military concert on the Prislop Pass central plateau, $1917 \ldots \ldots \ldots \ldots \ldots \ldots \ldots \ldots \ldots . . . . . . .149$

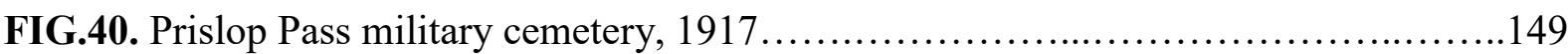

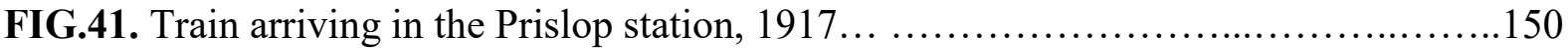

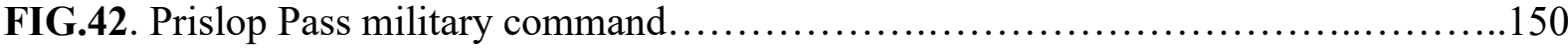

FIG.43. Red cross flag in Prislop Pass............................................. 150

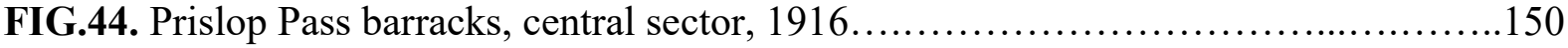

FIG.45. Prislop Pass military provisioning ........................................ 150

FIG.46. Horse drawn sleigh in Prislop German soldiers camp, 1916......................150

FIG.47. Map of field location of feature 1 to 10 - research sector $1 \ldots \ldots \ldots \ldots \ldots \ldots \ldots \ldots \ldots 1$

FIG.48. Glass medicine container A, B .......................................... 152

FIG.49. Feature 1 - rectangular building foundation A, B............................. 152

FIG.50. Feature 2 - parallel pits A, B........................................... 153

FIG.51. Earth bricks and shaped stones A, B.....................................153

FIG.52. Feature 3 - rectangular building foundation................................. 153 


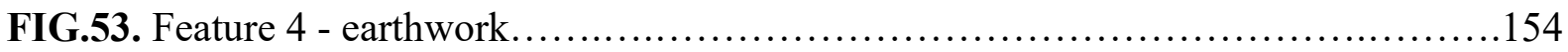

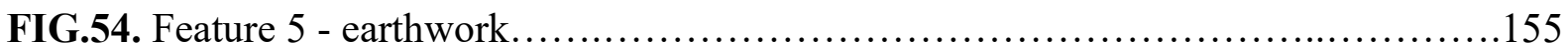

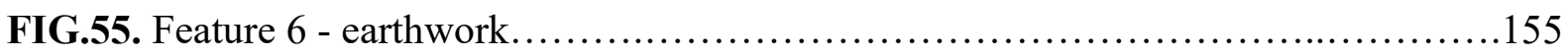

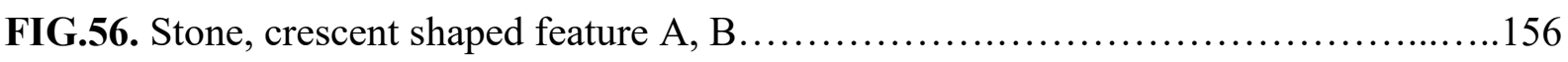

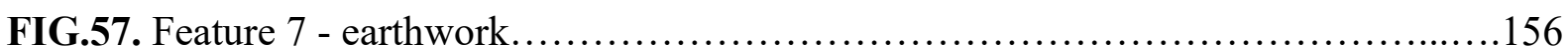

FIG.58. Feature 8 - rectangular building foundation A, B.......................... 157

FIG.59. Feature 9 - rectangular building foundation A, B............................ 157

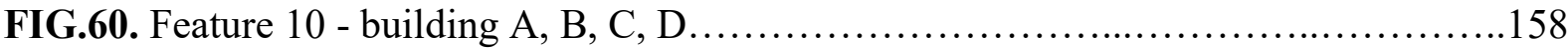

FIG.61. Map of field location of feature 11 to 22 - research sector $1 \ldots \ldots \ldots \ldots \ldots \ldots \ldots \ldots \ldots$

FIG.62. Feature 11 - rectangular building foundation A, B...........................159

FIG.63. Feature 12 - trench system A, B.......................................... 160

FIG.64. Feature 13 - pillbox A, B, C, D................................... 160-161

FIG.65. Feature 14 - earthwork................................................ 161

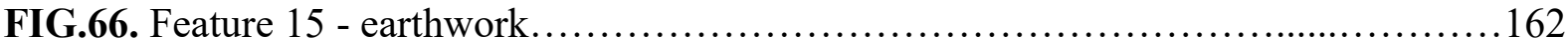

FIG.67. Feature 16 - earthwork ................................................. 162

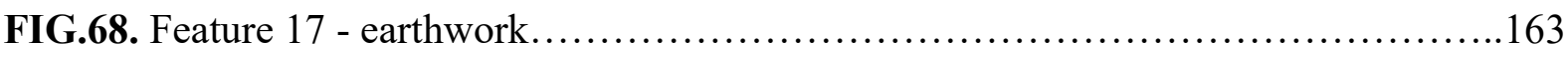

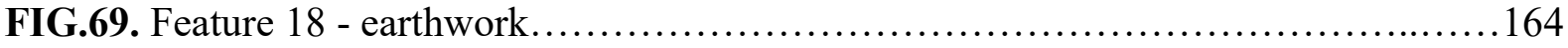

FIG.70. Feature 19 - square building foundation.................................. 164

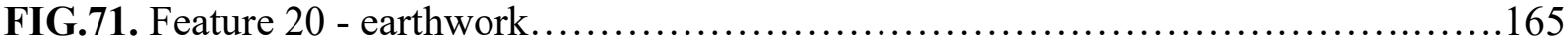

FIG.72. Feature 21 - rectangular building foundation A, B............................ 165

FIG.73. Feature 22 - rectangular building foundation A, B.......................... 166

FIG.74. Map of field location of feature 23 to 53 - research sector $1 \ldots \ldots \ldots \ldots \ldots \ldots \ldots \ldots \ldots$

FIG.75. Feature 23 - trench system A, B......................................... 167

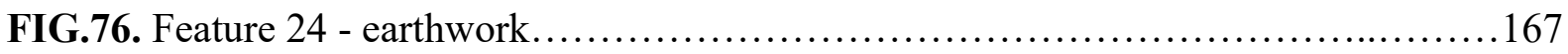

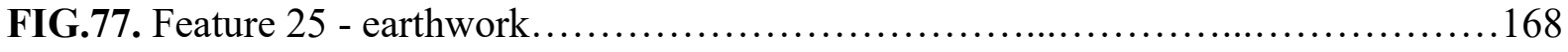

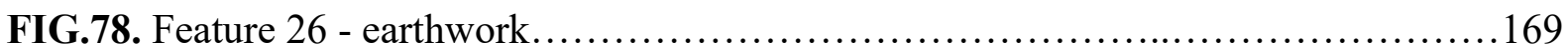

FIG.79. Feature 27 - earthwork.................................................. 169

FIG.80. Feature 28 - earthwork.................................................. 170

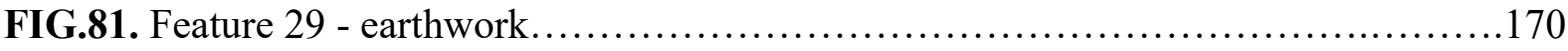


FIG.82. Feature 30 - earthwork................................................. 171

FIG.83. Feature 31 - earthwork............................................... 171

FIG.84. Feature 32 - earthwork............................................... 172

FIG.85. Feature 33 - earthwork................................................. 173

FIG.86. Feature 34 - earthwork................................................ 173

FIG.87. Feature 35 - earthwork.............................................. 174

FIG.88. Feature 36 - earthwork ................................................ 175

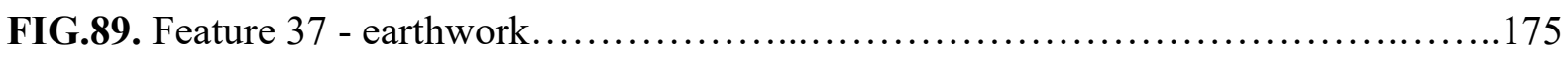

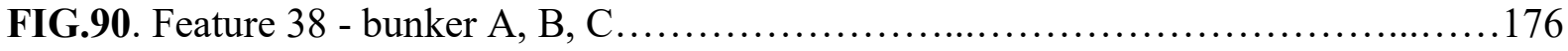

FIG.91. Feature 39 - earthwork............................................ 177

FIG.92. Feature 40 - earthwork................................................ 177

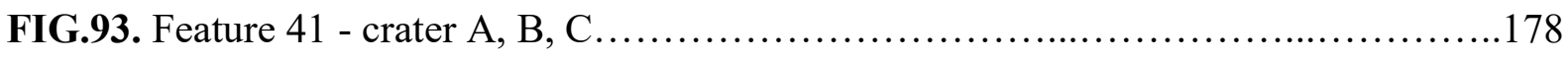

FIG.94. Feature 42 - earthwork................................................. 179

FIG.95. Feature 43 - earthwork................................................. 179

FIG.96. Feature 44 - earthwork .............................................. 180

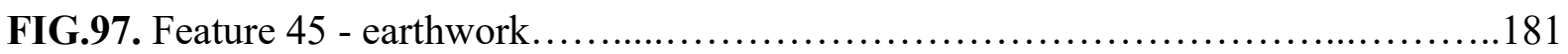

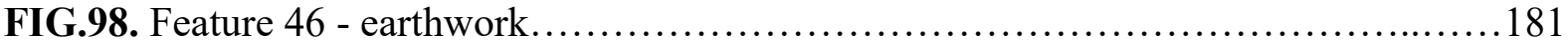

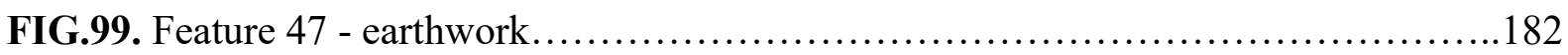

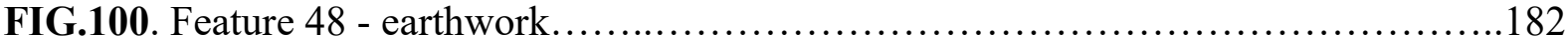

FIG.101. Feature 49 - earthwork.................................................. 183

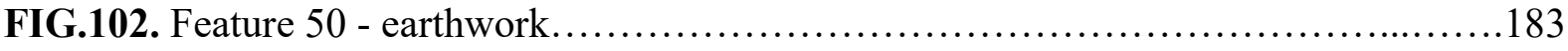

FIG.103. Feature 51 - trench system A, B........................................ 184

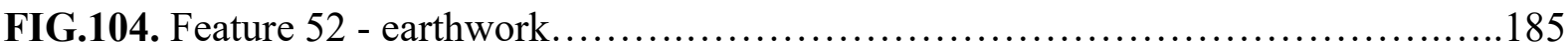

FIG.105. Feature 53 - crater A, B, C......................................... 185-186

FIG.106. Map of field location of feature 54 to 58 - research sector $1 \ldots \ldots \ldots \ldots \ldots \ldots \ldots \ldots$

FIG.107. Feature 54 - earthwork............................................. 187

FIG.108. Feature 55 - earthwork............................................. 187

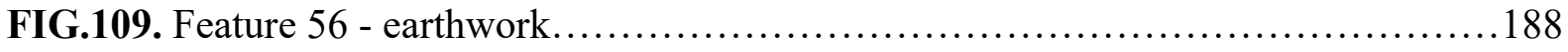

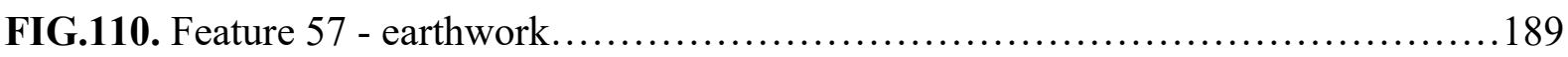


FIG.111. Feature 58 - mound A, B, C, D...................................... 189

FIG.112. WWI stone cross.................................................. 190

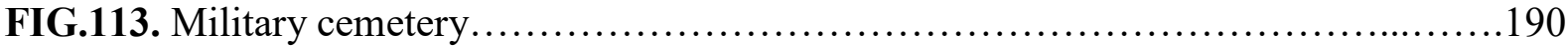

FIG.114. Map of field location of feature 59 to 71 - research sector 1 ...................191

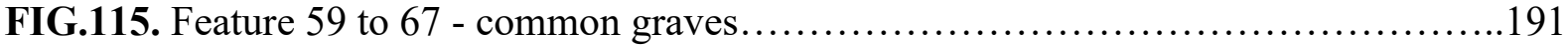

FIG.116. Feature 68 - earthwork................................................ 193

FIG.117. Feature 69 - earthwork............................................. 194

FIG.118. Feature 70 - earthwork............................................. 194

FIG.119. Feature 71 - bunker A, B, C, D, E, F................................... 195

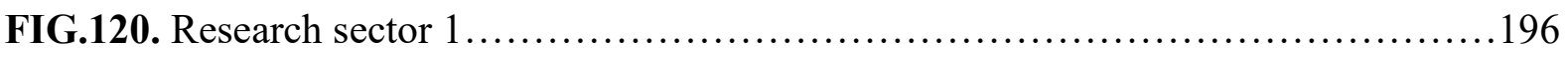

FIG.121. Rehabilitation of national road A, B, C, D................................ 196

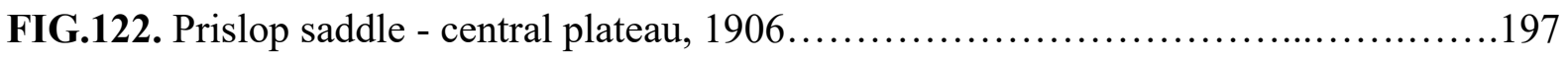

FIG.123. Construction works - Alpine chalet, 2018 A, B............................. 198

FIG.124. Schutz marke bottle.................................................. 199

FIG.125. World wars cartridges.............................................. 199

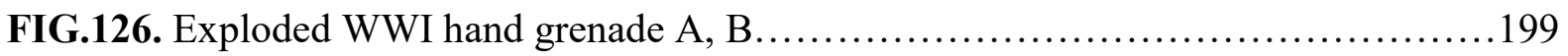

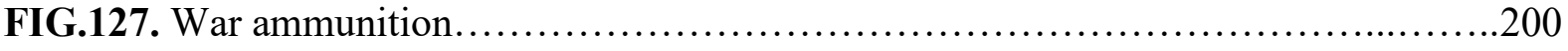

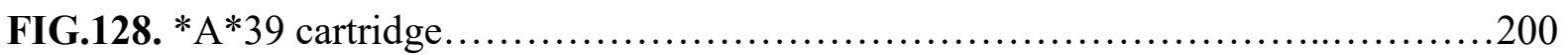

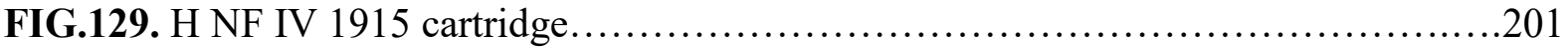

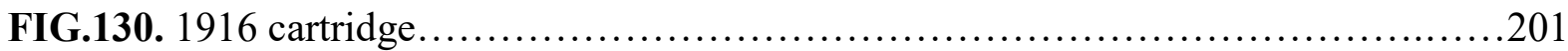

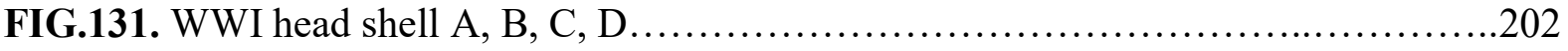

FIG.132. German heavy shell canon of Cârlibaba....................................202

FIG.133. Map of field location of feature 72 to 81 - research sector $2 \ldots \ldots \ldots \ldots \ldots \ldots \ldots . . . \ldots 3$

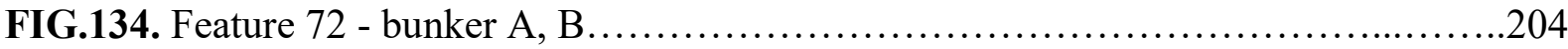

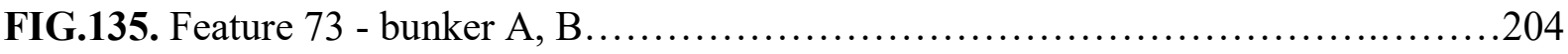

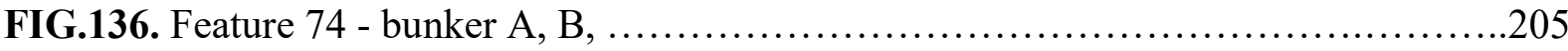

FIG.137. Feature 75 - square building foundation A, B, C......................205-206

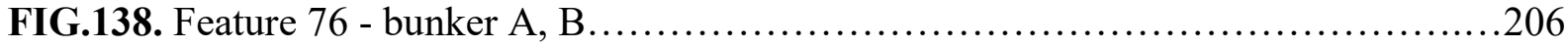

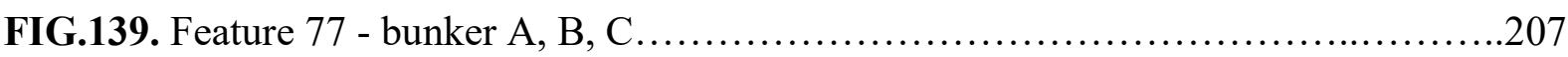


FIG.140. Feature 78 - parallel bunkers A, B, C .208

FIG.141. Feature 79 - bunker A, B, C $.208-209$

FIG.142. Feature 80 - bunker A, B, C $209-210$

FIG.143. Feature 81 - bunker A, B. 210

FIG.144. Map of field location of features 82 to 89 - research sector 2 211

FIG.145. Feature 82 --bunker A, B, C, D. 212

FIG.146. Feature 83 - bunker A, B. .212

FIG.147. Feature 84 - bunker A, B, C 213

FIG.148. Feature 85 - bunker A, B. 214

FIG.149. Feature 86 - bunker A, B. .214

FIG.150. Feature 87 - bunker A, B, C 215

FIG.151. Feature 88 - bunker A, B, C 216

FIG.152. Feature 89 - bunker A, B, C, D. 217

FIG.153. Map of field location of features 90 to 103 - research sector 2 218

FIG.154. Feature 90 - bunker A, B, C, D, E .219

FIG.155. Feature 91 - trench system A, B .220

FIG.156. Feature 92 - earthwork A, B, C .220

FIG.157. Feature 93 - bunker A, B. .221

FIG.158. Feature 94 - pile of concrete 221

FIG.159. Feature 95 - pile of concrete .222

FIG.160. Feature 96 - earthwork A, B 222

FIG.161. Feature 97 - bunker A, B, C .223

FIG.162. Feature 98 - concrete platform. 224

FIG.163. Feature 99 - bunker A, B. .225

FIG.164. Feature 100 - bunker A, B, C, D, E, F, G, H, I, J, K, L, M $226-229$

FIG.165. Feature 101 - bunker A, B, C, D, E 230

FIG.166. Feature 102 - bunker A, B, C, D, E $231-232$

FIG.167. Feature 103 - bunker A, B, C, D, E, F .233

FIG.168. Map of field location of feature 1 to 103 - research sector 1 and 2 .234 
FIG.169. Map of field location of the trench systems recorded in sector $3 \ldots \ldots \ldots \ldots \ldots \ldots . .235$

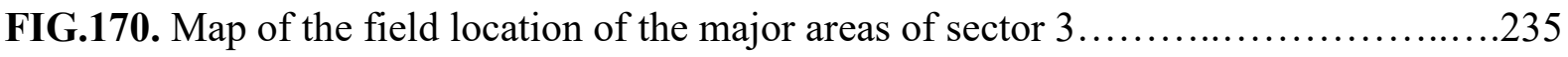

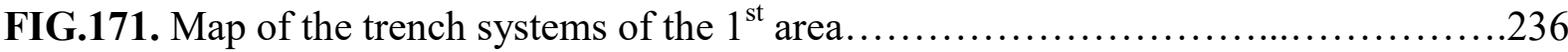

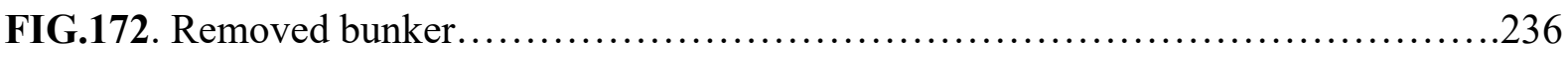

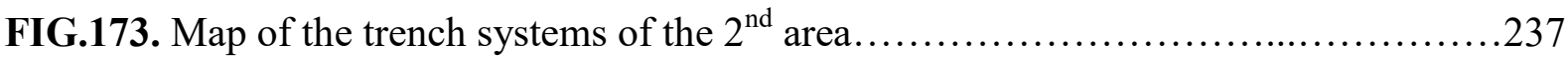

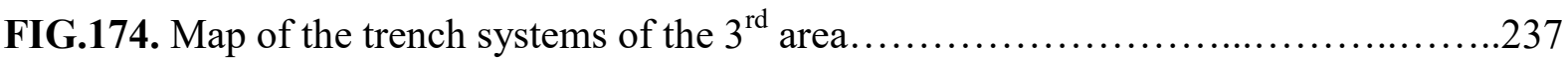

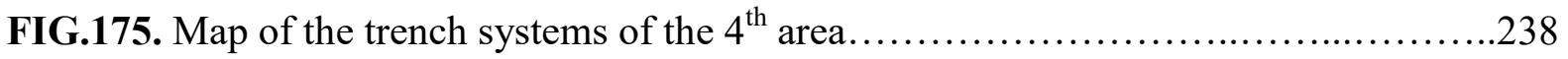

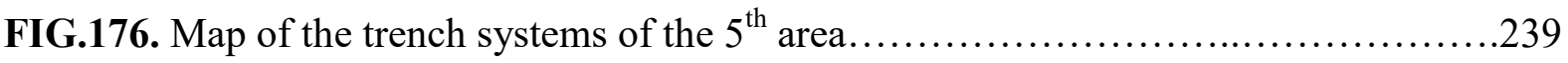

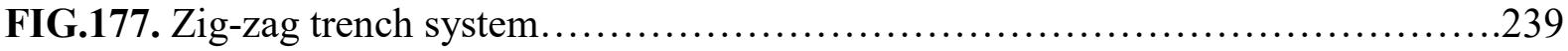

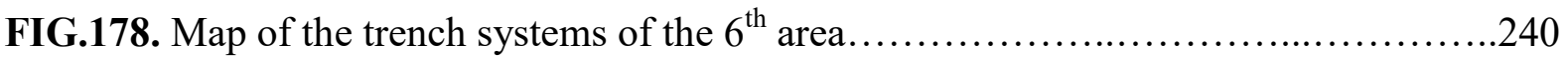

FIG.179. ICOMOS evaluation process.........................................292

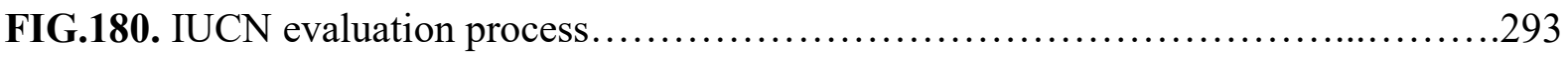

\section{TABLES}

Table 1. Comparison between historical archaeology and contemporary archaeology........18

Table 2. Catalogue of material remains typologies...................................243

Table 3. Comparison between the heritage ranking scores of Saint Ilie Tesviteanul church of Borșa and Prislop Pass conflictual landscape.

Table 4. Comparison between the French-Belgian, Slovenian and Romanian WWI heritage nominations against the World Heritage criteria..................................... 324

Table 5. Layers of significance of the Prislop Pass conflictual landscape................351

\section{ABBREVIATIONS}

AHD - Authorized Heritage Discourse

EYCH - European Year of Cultural Heritage

ICOMOS - International Council on Monuments and Sites

IUCN - International Union for Conservation of Nature

LHM - List of Historic Monuments

UHD - Universalized Heritage Discourse

UNESCO - United Nations Educational, Scientific and Cultural Organization

WHL - World Heritage List

WHS - World Heritage Site 


\section{CHAPTER 1 - INTRODUCTION}

\subsection{Preamble}

Once upon a time there was a Great War, a war that crashed the great empires, freed nations, reshaped borders, but first and foremost a war that changed the face of the earth forever. Such war changed the concept of war itself, upgrading it to total war and acquainting history with the phenomenon of mass dying. In the whirlpool of the war the nations mingled and collided, and the confusion of Babylon descended upon the war fields. Some fought for freedom, some fought for power, but the great majority fought because they had no other choice; dead or alive, the exit was through fire and there was simply no other way out. So, the earth trembled and for four years darkness descended upon the nations, but when the sun rose again new countries arose on the Eastern Front.

In the aftermath of the war, for a long time, historians narrated a dissociated story, a story about two separate fronts. Still, there is only one all-inclusive tale, a tale told by the earth itself, a tale about the significance of WWI sites as places of remembrance and heritage. That is because the Great War not only reshaped balances of power, redefined borders and wrote fundamental pages of national history for several states, but also shaped the identity of the land, redefining landscape. The Great War inaugurated a procedure of environmental incisions that branded the places of war with the world war mark, a hallmark that rooted conflict in the earth, not only as ground strategy but also in anticipation of threats from the air. Bunkers, trench systems, mine craters, common graves were all carved wounds in the landscape, wounds that in time turned into scars giving the natural environment pride and personality, converting space into place. 
Nature itself played a part in this plot by growing poppies to remind the world of its sons lost in battle, and ever since the red poppy became a symbol of warfare remembrance for every war that followed. So, these places of war became soul keepers of a war long gone, but whose avatars reach us to this day. For decades the land wore its scars with pride, honouring the memory of the fallen and listening to their silent voice in hope that one day it would arise to be heard. This poses a question: a century after the end of the Great War, if you could give voice to those who lost theirs, would you do it? If the earth itself reached to you and urged you to listen to its story, would you do it? Would you?

I did, and that is why my research explores the significance of WWI sites. The aim of this research is to understand the relevance of Romanian WWI sites as places of remembrance and heritage. The centenary of the end of the Great War emphasised the necessity of approaching WWI remains, and hence their adjacent war sites, as potential heritage objects. The work, which was conceived as a pilot project for the heritage management of the WWI remains on the Eastern Front (on account of historic peculiarities and the contemporary political similarities between the countries of the region), is designed to contribute to the work of the authorities that have legal responsibility to decide the preservation or allow obliteration of these places of war. Furthermore, the work holds capacity to inform decision-makers, private and public agencies, and the general public about the heritage extent of war sites, thus providing them with a scientific basis for dealing with and deliberating upon the heritage status of these war remains and, inductively, on the management of the material culture of war.

The sites of conflict reveal stories of international relations, societies, cultures, mentalities, traditions, institutions and people against the background of the land, all of which come 
together, intersect and inhabit the same space. The various dimensions of the considered landscapes mingle together in a tacit narration about the Edge of Europe.

\subsection{Thesis background, research context and broader themes}

At a symbolic level, the war sites preserve an evocative power that trespass the common boundaries of materiality. With the passing of time WWI earthworks and buildings have become architectonical features representative of the symbology and phenomenology of the Great War. War architecture can be approached as a cultural artefact filled with the untold stories of a lost world. Although it is widely accepted that architecture mirrors its source of emanation, the study of WWI architecture as footprint of the generative society was never approached scientifically, leaving an entire archive of meanings unexplored but embedded in buildings and earthworks that narrate a story about the actions, goals, dreams and dramas of the war actors. Architectural structures produced by the industrialised war build up an architectural style representative of a highly peculiar age of human history in addition to the encapsulation of warfare knowledge and remembrance value, constituting a gap in our knowledge that is still to be filled.

The international dissemination of President Woodrow Wilson's Fourteen Points not only anticipated the age of human rights but also seeded a new international mentality that later spread worldwide. In this way the Great War can be approached as world war, as its implications reached actors and had major consequences on people not directly involved in the conflict at the time it occurred. By instigating the dissolution of the great empires the Great War created circumstances that allowed completion of a historical process, which culminated in the emancipation of the Eastern Front nations and the freedom of East European peoples, thus setting the scene for a new world order. In such an optic, WWI can be 
viewed as the collision of two worlds; a war between a declining world and a potential world, each fighting for the prevalence of what they believed to be idealistically just.

Work conducted so far on the Eastern Front fails to cover the heritage and remembrance dimension of the war sites. Historical circumstances of the Galician Front nations impacted negatively on the research capacities of the East European states. Until recent times international researchers were unable to conduct research within the region due to restrictive regulations and inaccessible archives, and there was little contact with the West. Scientifically speaking, Eastern Europe was internationally invisible for a long time. Nationally, the communist propagandistic strategy (Denize, 2009) heavily abused the patriotic repertoire triggering a process of vulgarisation of national discourse, which was a main factor leading to the overall neglect of late modern war sites. Achieving the aim of understanding the relevance of Romanian WWI sites as places of remembrance and heritage constitutes a step towards filling a gap in our knowledge of the war and its consequences, as well as raising an awareness that could result in improving East European heritage practices. The present research provides a methodological model for other countries of the region that face similar difficulties in managing their war heritage and remembrance (Gheyle, et al., 2014).

At international level there seems to be a significant difference between the low visibility of the Eastern Front in opposition to the prominence of the Western Front. While large-scale works have been conducted for the Western Front, in terms of memory and memorialisation, we have little similar knowledge of the Eastern Front. The WWI Eastern Front also remains largely unexamined, both in terms of archaeological works and heritage studies, so that its capacity to inform us about the conflict remains unexplored. 
By examining the relevance of Romanian World War I sites as places of remembrance and heritage, the present research will provide a representative case study of the Eastern Front situation concerning the heritage management of war remains, as well as clarifying their significance as places of remembrance at a national level. The war and its consequences had major impacts on countries such as Romania, so understanding more about its conduct and remembrance (Misztal, 2003) will be significant to policy makers and heritage agencies in Romania and elsewhere in Europe.

In 2018 Romania celebrated a hundred years of National Unity, alongside celebrating the end of the First World War. This created a need to question the significance of any remaining war traces. The fate of material remains of the war, in terms of preservation and legal protection, depends on elucidation of their heritage status. Until now, no East European World War I site has been granted official heritage status, despite the fact that for several nations of the region this war meant national unity and liberation from foreign domination. Consequently, there is a strong case for conducting research on the Galician Front from a heritage perspective.

In Romanian national history, the Great War represents a cultural landmark that stands for having achieved the aspirations of national unity, independence and self-determination, thus qualifying the places of war as "lieux de memoire". Beyond this strong national significance, the Romanian case is emblematic of a larger phenomenon concerning the socio-political background and historical circumstances that impacted upon, and fuelled, the participation of several East European nations in WWI (Jukes, 2002). Like other nations of the region, Romania was literally forged in the industrial war, $1^{\text {st }}$ of December 1918 marking the Great Union of all Romanians. 
The research area of this study holds the potential to highlight all these aspects. Maramureș was among the last territories freed from foreign domination and united to "the Mother country" de facto in 1919 (Batin, 2014) in the aftermath of heavy fights conducted, physically, against the Hungarians and, diplomatically, against the Great Powers (Ardelean, 2016). The Mountains of Maramureş are part of the county of Maramureş, situated in North Romania near the present border with Ukraine and marking the last frontier of the European Union. At the beginning of the twentieth century, these mountains were surrounded by three empires: the Czarist Empire, the Austro-Hungarian Empire, and the German Empire. Before the war, on the mountains' northern crest, stood an imperial boundary stone in the shape of a triple-faced obelisk of white marble, each facet adorned with a metal plaque pointing in the direction of one of the great empires.

Maramureș is, notably, a Romanian historical province where war did not begin in 1916 as in the rest of the Romanian Kingdom; nor did it factually end there in 1918. The continuation of physical and diplomatic fights after the Great War constitutes additional reasons for selecting this region for the present study alongside the central criterion of providing a representative case study illustrating the condition of such multi-ethnic imperial provinces during the war. The difficult position of the local population in Romanian historical provinces during WWI, their divergent histories, the peculiar conditions of Romanian soldiers in the multi-ethnic imperial army, loyalty dilemmas, persecutions, the exclusion from memorialisation of the overall population caught in this difficult position, along with the resulting alterity of the borderline places of war, recommend Romania as a suitable case study and Maramureș as an adequate study area for the understanding of the legacy of the Eastern Front in its extreme complexity, diversity and alterity. The need to conduct this research is further advocated by the fact that the Mountains of Maramureș present a rich variety of examples of the material 
culture of war, which builds up a rare case of conflictual landscape that is still visible to the naked eye. The concept of conflictual landscape denotes a land that has been influenced throughout time by conflict, and visibly shaped by it; a land that has been historically disputed and contested due to its position or geography and which, as a result of that historical conflictual state, was mutilated during the world wars giving birth to a reinvented landscape. The world wars' projection of violence onto the land, whose traces over time became the marks of those wars (trench systems, bomb craters, bunkers, etc.), has created a conflictual landscape that not only preserves the traces of a very particular kind of war, in a unique spatial context, but also highlights that the land itself was the agent of conflict and object of rivalry that fuelled the war.

From a remembrance perspective (Connerton, 1989; Moriarty, 1999; Winter, 1999; Bushaway, 2001; Misztal, 2003), war remains became potential, genuine and inclusive war monuments, able to hold not only national and local significance but also to gather fragmented memories (Traverso, 2012), and becoming representative in a frame larger than that of the national state. Unlike classic war monuments that were built to commemorate a precise and often restricting category (Nelson and Olin, 2003), WWI remains are evocative of all the war's participants, regardless of the role they played. This work aims to test the concept of monumental landscape of the places of war in order to fill a gap artificially constructed in WWI standard rhetoric, bypassing the classical commemoration of historically representative characters, fallen soldiers or local heroes. The Great War was a complex phenomenon whose call to arms echoed among both the masses and individuals, soldiers and civilians, a summons that gathered and collided empires, nations, armies, weaponry, humans, animals and, above all, land. Hence, the landscape dimension allows the reconciliation of WWI memories by providing space for the mutual completion of common consciousness and 
individual memories and congregating a myriad of layers that were authentically built in time and by time. From the perspective of sites of memory/heritage, the places of war gather together a wide range of collective symbols/meanings and warfare knowledge/testimonials that can shed new light on the war itself, highlighting its peculiarities and contradictions.

The present work has the capacity to inform us about a dimension of the Great War that, until now, has remained unexplored. In countries like Romania there is an urgency to elucidate the heritage status of these war remains before development irremediably alters the traces of war. Understanding whether they are worthy of being legally protected, regionally, nationally and/or internationally, and implicitly preserved for further study, is of great relevance and stands as a precondition of our understanding the war from a still poorly explored perspective, which might remain the case if the sites are permanently altered or destroyed.

\subsection{Thesis outline}

The overall aim of the research presented in this thesis was to explore the significance and relevance of Romanian WWI sites as places of remembrance and heritage. In order to address this aim, the research was divided into three main objectives. The first objective regards the investigation of WWI material evidence in Maramureș in order to establish the nature of the evidence by recording material evidence of the war within the research area. The second objective regards the investigation of the heritage legal framework in Romania and examines the premises for granting heritage status at national level in order to allow the assessment of the places of war as heritage. The third objective regards investigation of the international legal framework and examines the premises for granting World Heritage status, allowing assessment of the international significance of WWI sites and contextualisation of the Romanian case in the wider heritage debate. The structure of the thesis informs the 
achievement of the main objectives, each chapter responding to specific needs meant to elucidate the research question. Each sub-question covers relevant thematic areas at different levels of analysis, which work together in building up the different layers of the research focus. The thesis is organised in a logical progression with the findings of each chapter constituting the raw materials to inform the subsequent.

Chapter 2 reviews the relevant literature in order to contextualise the work within wider thematic debates, identify gaps in the field of study, and allow construction of the research method. The slant of the research implies dealing with the material culture of war and thus with cultural memory, which, on the one hand, calls into question WWI memory and remembrance and, on the other, relies on archaeology as a means of investigating the past and heritage as barometers of official value recognition/assignment.

Chapter 3 presents the aims and methods of the research. In order to address the aim of examining the significance of Romanian WWI sites as places of remembrance and heritage, the methodology was designed to address its three subsidiary objectives. The research design is incremental, with the results of each stage affecting the next one. Hence, the literature review allows construction of the methodology, the methodology allows construction of the research method; the research method prescribes the need to develop historical contextualisation, the historical context allows the identification and characterisation of the research area upon which the field work is conducted; the field work identifies and records the material culture of war which provides the basis for the assessment of the war sites as heritage at national/international level, while the exploration of the national heritage legal framework ends up conjoined with international heritage, which is interdependent with national laws. Structurally, the work that begins with the identification and analysis of the Maramureş war 
sites will follow the path of national and international heritage legislation and debate to finally re-conduct the results to the case study in a concentric manner.

Chapter 4 provides the historical and socio-political context of the case study, and hence of Romania, against the background of the Eastern Front's circumstances. In 2018 Romania celebrated 100 years of National Unity alongside commemorating the end of the First World War. The Romanian case is emblematic of a larger phenomenon in terms of socio-political background and the historical circumstances that impacted upon/fuelled the participation of several East European nations in WWI. Like other nations of the region, Romania entered the war in hope of recovering its lost territories and putting an end to foreign domination. Romanian territories under foreign domination were summoned to aid the great empires' war efforts, a situation that was simultaneously reflected along the Galician front. Furthermore, in the aftermath of the world wars many nations of the region became part of the communist bloc, following a common historic trajectory that led to the overall neglect of late modern war sites. The chapter pertaining to the achievement of Objective 1 allows the identification of the research area and informs the immaterial characterisation of the war sites. By providing context in relation to the intangible significance of places of war the chapter underpins the subsequent part of the research, which engages with the nature of the physical evidence.

Chapter 5 provides the recording and analysis of war remains throughout the research area in order to determine the material evidence of WWI in Maramureş. The work constructs the first gazetteer of Romanian WWI sites and provides the first scientific investigation of the material culture of war adjacent to the Eastern Front. Recording the war remains allows the establishment of levels of preservation and authenticity as part of their characterisation. Examination of the influence exerted by geography and development upon the preservation of the war sites informs the identification of heritage threats in the area. Study of the content and 
characteristics of the material culture present in the research area provides the material basis to which the immaterial significance, which emerged from the previous chapter, unites enabling the assessment of the war sites as heritage. Together, the two chapters dedicated to the achievement of Objective 1 and thus to the historical, symbolic and material characterisation of the places of war, extrapolate the tangible and intangible characteristics of the material culture of war in order to provide raw data for subsequent parts of the research.

Chapter 6 addresses Objective 2, which is meant to inform the assessment of places of war as heritage at national level, by investigating the Romanian heritage legal framework and the adjacent ranking mechanism. Understanding the legislative evolution of Romanian heritage and its characteristics allows for the contextualisation and characterisation of the heritage ranking process, thus underlining national premises for granting heritage status and providing valuable insights into why war relics are not legally protected in Romania. The relevance of the war sites for local and national identity is extrapolated from the present-day significance conferred on the Great War. The present significance is explored on account of/in relation to the national legislative initiatives adopted at the time of the centennial of the Great Romanian Union and of the end of WWI. The chapter enables assessment of the significance of the war remains within the national legal framework and in comparison to other heritage items, in order to clarify their potential and worth from an official heritage perspective.

Chapter 7 addresses the third objective, pertaining to the assessment of the international significance of WWI sites and thus to contextualising the Romanian case in the broader heritage debate. Symmetrically to the previous chapter, dedicated to heritage as decreed by Romanian law, this chapter looks at internationally applied laws around heritage, being concerned with international heritage legislation, its main stakeholders, the selection norms and ranking criteria of the notorious World Heritage status together with emergent new trends 
in the field of World Heritage. Examination of the international heritage legal framework, and of the premises/criteria of the World Heritage status, allows understanding of international heritage standards and provides common ground for comparison of Romanian war sites to similar international cases. The common ground between the national and international heritage legislation is provided by the heritage obligations of international emanation subscribed to by Romania and which translate into national heritage practices and regulations. Thus, international relations instruments provide a link between national heritage legislation and the international heritage framework that regulates heritage worldwide; but it also implies inevitable interdependence. The World Heritage standards used as gauge of international heritage assertions/practices enable the war sites to be assessed as heritage. The present-day assertion of international heritage and global practices derives from the examination of the programs and policies promoted during the European Year of Cultural Heritage and the event's popularity. The chapter clarifies the international significance of WWI sites as places of heritage.

Chapter 8 is dedicated to discussion and conjunct interpretation of the previous chapters' findings, and hence to the thesis's conclusions in elucidating the significance of Romanian WWI sites as places of remembrance and heritage. The results of the chapters covering the three main objectives, which guide the overall approach throughout the research, provide the basis for discussion against the background rendered by the literature review. Reflecting the structure of the thesis, the chapter dedicates sections to each objective and concludes by discussing the combined emerged data. The chapter starts by engaging with the dimension of the material culture of war within the research area, anchoring the memorial-symbolic characterisation of the places of war to physical aspects of the war sites. The resultant display of overall results from Chapters $4 \& 5$ not only elucidates tangible and intangible traits of the 
material remains of war, but also allows their reading as heritage. The second part of the chapter reflects upon the Romanian heritage legal framework and on the official legal process of heritage creation. Examination of the criteria on which the legal assessment of heritage relies, and of the mechanism activated when institutionalising heritage in Romania, reveals the reasons why certain categories of heritage receive legal protection as a result of being granted legal heritage status while others do not. It elucidates the heritage value of the war sites at national level. The third part of the chapter considers the international significance of WWI sites as derived from investigation of the international legal framework, examination of the premises of World Heritage status, and the conduction of comparative analysis. By reflecting upon the criteria that inform World Heritage status and the related ranking procedure, the work underlines the features of the heritage-making process at international level. It highlights the international significance of WWI sites as places of remembrance and heritage. The fourth part draws upon interpretation of the previous sections' findings, discussing them collectively against the theoretical framework provided by legislation and in relation to broader themes/debates and coverage gaps emphasised in Chapter 2. The chapter addresses the aim of the thesis by reuniting the three main objectives that inform the research question, and contextualising the results within wider heritage/memory debates.

The final part of the chapter is organised in a logical progression from stating the research's significance to uncovering its implications for similar sites on the Eastern Front, its contribution to the overall field of study, and recommendations for future work. Wider significance of the work is offered by the fact that it has constructed a methodology for the assessment of heritage that goes beyond war sites, extending to and having implications for other categories of yet unrecognised heritage. It can be used as a pilot project for the investigation of WWI sites on the Eastern Front and thus for the management of the material 
culture of war. It emphasises the necessity of approaching war sites at landscape scale and highlights the monumental value of the conflictual landscape dimension, advocating the preservation of the landscape itself as heritage. The work constitutes a new approach to the material culture of war, which combines heritage knowledge with conflict archaeology and landscape, both enlarging overall understanding of the war and opening new windows on the study of the war/material culture in an interdisciplinary perspective. 


\section{CHAPTER 2 - BACKGROUND}

\section{$\underline{\text { 2.1. Introduction }}$}

The research presented in this thesis focuses on exploring the significance of Romanian WWI sites as places of remembrance and heritage. It suggests that the content of the research is made up of WWI material culture and cultural memory, whereas the framework of the research is grounded in the field of heritage. Therefore, the present chapter will deal on the one hand with WWI memory, remembrance and heritage and, on the other, with archaeology as a means of investigating the material culture of war.

Approaching WWI remains in the Romanian context is made accessible by similar work conducted internationally, which makes up the broader context of WWI heritage. The approach taken aims to contextualise the research within wider international debates and to inform the construction of the methodology and the selection of the working methods. The nature of the research question on the one hand implies the archaeological consideration of the war sites since there is a need to identify, record and interpret the material remains. On the other hand, it implies their assessment as heritage thereby requiring an understanding of what heritage is and how it is constructed, assessed, legitimised and legalised, and consequently also needing to deal with memory, commemoration.

The structure of this chapter mirrors the overall structure of the thesis, thus pursuing the aim of examining the field of research relating to the study of WWI sites and the adjacent body of studies that allows their framing as heritage. The first part of the chapter explores archaeology as a link between heritage-history-memory and the international research approaches to WWI material culture, providing the frame of a progressive discourse moving from the archaeological perspective on material remains to WWI remembrance and memory. Albeit the 
archaeological common concern with material culture, in both its material and immaterial dimension, the multitude of potential archaeological fields entitled to deal with the material remains of the Great War brought about the necessity of critically reviewing the various branches of archaeology, both historical and contemporary, in order to identify the most suitable methodology for the recording and investigation of the Romanian WWI material remains.

The need to reflect upon both the material and immaterial dimension of war remains provides links to the second part of the chapter, which explores interconnections between memory/remembrance and heritage. Furthermore, the review of the meanings attributed to heritage is meant to clarify the concept of value in relation to heritage. The understanding of the official framework against which the assessment of heritage occurs stands as a precondition for understanding the heritage making process.

The national and international legal dimension of heritage management and practices provides the necessary context for understanding heritage debates at different levels of analysis. The work constructs an itinerary, moving from heritage to critiques of heritage in order to scrutinize the theme of WWI remains in a heritage perspective against the background of the wider heritage debate, while simultaneously emphasising the limitations of the heritage field.

\subsection{Archaeology as link between heritage and history/memory}

It is common belief that heritage is able to shed light upon a past blurred by time and to animate history (Lowenthal, 1996). The problem is that heritage relies on present perceptions and interpretation of the past whereas history claims to rely on facts, which generates an apparent incompatibility. In fact, both heritage and history engage at some level with the 
practice of storytelling, the only difference being that heritage holds a greater complexity as it is self-aware of reflecting culture and identity with all the derivative implications. Nonetheless the symbiosis of history and heritage is not automatic but in need of a mechanism of reconciliation that relies on "an approach, a set of methods, ideas and perspectives which are used to investigate the past through its material remains" (Bailey, et al., 2009, p.2).

Concretely, such necessity converges in requiring a science able to study the material culture within an optic that is greater than the interest for the material traits, taking into account "the ideas, thoughts and social relationships in which these objects are embedded and which they represent-both in the past and in the present" (Carman, 2009, p.192). Archaeology is such a discipline, as it studies the past through its material culture as well as engaging with the material culture of the past as part of the present. Archaeological engagement with both the materials and the culture fuels the wheels of heritage (Samuels, 2008) as "heritage is inevitably more intangible a phenomenon than tangible, and yet that its intangibility needs to attach to something tangible in order to exist at all" (Carman, 2009, p.193). Hence it can be argued that, in this context, archaeology provided the condition for the emergence of heritage in the same way that modernity represented "the condition of the possibility of archaeology" (Thomas, 2004, p.202).

Gradually as the war phenomenon grew more distant and intricate, archaeology rose as a decoder of the past. The material remains complement the understanding of the war phenomenon and bring new light, not just on natural landscapes but on human landscapes as well. WWI sites started to be approached as heritage in the nineties when the archaeological value of war remains were first acknowledged and conspicuous public and political support aided the promotion of research projects and professional excavations (Saunders, 2007). The 
openness to reconsidering humanity's collective past was favoured by socio-political circumstances that occurred at the end of the Cold War. The mutually beneficial bond that formed, between tourism and preservation, incentivised a willingness to fund archaeological works (Butler and Suntikul, 2012) along with developing heritage legislative frameworks for the protection of sites of conflict (Schofield, et al., 2002).

The difficulty of dealing with the war remains and their interpretation introduced the exigency of developing proper means through which to approach the subject matter. The archaeological ability to simultaneously interpret the past by decoding the material culture, and the interrelationships of past and present emergent from the immaterial dimension of significance and symbolism (Labadi, 2013), provided a viable solution. Table 1 presents various historical and contemporary archaeological approaches that mainly present different methodological variations and, thus, shades of focus.

Table 1. Comparison between historical archaeology and contemporary archaeology

\begin{tabular}{|c|c|}
\hline Historical archaeology & \\
\hline $\begin{array}{l}\text { Historical archaeology is an archaeological } \\
\text { branch considered capable of complementing } \\
\text { history, and was relegated by Hume to the } \\
\text { role of handmaiden of history (Hume, 1964). } \\
\text { In reality, its reach is much more than a mere } \\
\text { means to aid history, arising as an important } \\
\text { discipline that not only integrates history but } \\
\text { also questions and challenges different } \\
\text { historical accounts by relying on "diverse } \\
\text { sources of evidence to produce fine-grained } \\
\text { contextualised and nuanced studies of } \\
\text { objects, places and people" (Hicks, 2004, } \\
\text { p.102). Historical archaeology can test the } \\
\text { veracity of historical accounts, thus holding } \\
\text { the power to contest and rectify history and } \\
\text { potentially even has the power to generate } \\
\text { new histories from new perspectives such as } \\
\text { those of colonialism, slavery, migration and } \\
\text { capitalism (Little, 2007). Still, the critical } \\
\text { observation of the field reveals a series of } \\
\text { challenges that range from the classical focus }\end{array}$ & $\begin{array}{l}\text { The need to study the late modern and } \\
\text { contemporary past by taking into account all } \\
\text { their complexities, inconsistencies and } \\
\text { paradoxes has led to the development of } \\
\text { interdisciplinary approaches, amongst which } \\
\text { are various combinations of history, } \\
\text { archaeology, anthropology and an emerging } \\
\text { field of studies dedicated to material culture } \\
\text { (Miller, 1998; Harrison and Schofield, 2010; } \\
\text { Holtorf and Piccini, 2011). The emergence of } \\
\text { contemporary archaeology has occurred } \\
\text { against such a background, under the } \\
\text { influence of English post-processualism that } \\
\text { changed the focus from understanding of the } \\
\text { past towards elucidation of the present } \\
\text { (Graves-Brown, 2000; Buchli and Lucas, } \\
\text { 2001). The roots of this new field of } \\
\text { archaeology are anchored in the 'now' and } \\
\text { 'us' as means of decoding the hidden } \\
\text { meanings of the present (Gould and Schiffer, } \\
\text { 1981). The main themes of the field mirror }\end{array}$ \\
\hline
\end{tabular}


on data collection and classification to the pursuit of shedding light on rather simplistic issues and engaging with poor interpretative endeavours (West, 1999). On the same track the fact has been highlighted that historical archaeology "linked when appropriate to the use of documents, has a vital and as yet hardly fulfilled role in extending our understanding" (Leech, 1999, p.31).

A further affiliate of historical archaeology is documentary archaeology. The term was introduced by Beaudry whose reflection on historical archaeology inaugurated a new version that changed the optic of servitude, claiming that the discipline represented more than mere historical illustration and extending it to incorporate $360^{\circ}$ materiality, regardless of being stored in archives or in the ground (Beaudry, 1998). Although since its debut scholars were warned of the need to engage critically with material culture used as a source of knowledge, this field also generated benefits paralleled by various challenges, like those derived from usage of historical maps (Seasholes, 1998; Shieles, 2007) and military records (Babits, 1988) for instance.

Another alternative approach of historical archaeology is represented by the so-called 'text-aided' archaeology (Little, 1992). This form of archaeology does not only rely on historical documents but also makes use of ethnographic materials and oral testimonies and inverts prior tendencies by placing written evidence in the service of archaeology. The distinctiveness of this specific field is the use not only of patterns but also of the variance emerging from the interaction of archaeological and documentary sources as a resource to generate deeper knowledge. This alternative approach was also believed able to show history in a more realistic light by taking into account its selective nature and opening a window to the plurality of possible accounts and interpretations of the past.

Critiques of documentary archaeology have contested the novelty of its arguments, which those topics that drive and inform present interest in the field of heritage: rememberingforgetting, disappearance-disclosure, presence-absence and, last but not least, production-consumption. The topics are centred "upon the critical consequences of presencing absence in the recent past bringing forward or indeed materialising that which is excessive, forgotten or concealed" (Buchli and Lucas, 2001, p. 171).

The peculiarities of the studied period sets a requirement "to be more self-aware and critically reflexive by understanding the nature of contemporary society and its engagement with the material world, as well as our recent and deeper past" (Harrison and Schofield, 2010, p.282). The field's expertise begins in "the present and works backwards in time, being sensitive to the influence of the materiality of the past which constantly intervenes in the present' (Harrison and Schofield, 2010, p.283). The sphere of stories of our recent past has a multiplicity of voices; its sources are uncountable and present in every aspect of our lives, making this unusual closeness and immediacy the agent of alienation. The fact that excessive information equates disinformation introduces the leitmotif of the absent past that is to be re-iterated by archaeology in a process of volitive remembering.

At the intersection of all the above forms of archaeology lies the field of conflict archaeology. Conflict archaeology broadly engages with three major time-frames: the historical frame, starting from 1500 onwards (Hicks and Beaudry, 2006), the recent past, dedicated to the 1900-1950 period (Stevenson, 2001; Schofield and Johnson, 2006) and the contemporary past, (Harrison and Schofield, 2010) which deals with the remaining period. However, these periods, especially the last ones, are deeply interconnected. The definition of conflict archaeology is slippery as it raises debates about its archaeological or anthropological nature or percentages of influence (Schofield, 2005; Saunders, 2012). The first 


have been perceived as no more than
continuation of the subordinate relationship
that marked the original attempt to build a
bridge between the two disciplines, along
with the claim of exclusivity in dealing with
alternative histories (Moreland, 2001). The
primary contestation emerged from an
inclination to credit material resources,
especially written documents, as evidence of
the past. Nonetheless, the view regarding
conceptualisation of the difficult alliance
between different forms of materials, such as
documents and archaeological evidence,
converged in an agreement upon the need for
an holistic and organic interpretation of the
various sources that play distinct roles at
different levels but which are all necessary to
reflect a collective past (Hall, 2000;
Moreland 2001; Wilkie, 2006).

Moreland 2001; Wilkie, 2006). sedimentations of its disciplinary interests converged around topics pertaining to the world wars and the Cold War (Schofield, 2005), but the discipline aspires to grow wider and build stronger networks of interconnections (Carman, 2013). Furthermore, recent trends in conflict archaeology re-organised periodisation of the field of study into: prehistoric conflicts (Keegan, 1994; Bridgford, 1997; Oosterbeek, 1997; Wakely, 1997), medieval battlefields (Scott, et al., 1989; Ford, 2005; Carman, 2005; Carman, 2006; Foard and Morris, 2012), and modern conflict archaeology (Schofield, 2005; Forbes, et al., 2009; Carman, 2013).

Battlefields and war sites imply specific reflections upon the encounter of humans and technologies against the background of the landscape. The material remains of modern/contemporary conflicts, along with the sites themselves in their simultaneously human and natural landscape vests, also raise the attention of heritage practitioners concerned with present meanings about the past. The potential extent of the field drove scholars to advocate a "more holistic social archaeology of warfare" (Gilchrist, 2003, p.5) inclusive of civilians and soldiers, spaces and people, materiality and symbolism. Hence the strong interconnections between heritage and modern conflict archaeology become evident in the mingling dimension of space, memory and experience (Schofield, 2005).

"Modern conflict archaeology focuses on the idea of conflict as a multifaceted phenomenon, which may leave a variety of physical traces in many different places, all or most of which can possess multiple meanings that may change over time. [...] Modern conflict archaeology sees objects and landscapes not as separate entities, but as complexly embedded and inter-connected materialisations of the human experience of conflict. [...] Archaeology is concerned with the long afterlife of places and things multivalent legacies that stretch out into the future, and which change their form and 


\begin{tabular}{|l|l|}
\hline & $\begin{array}{l}\text { meaning as they collide with new social, } \\
\text { cultural, political, economic and ideological }\end{array}$ \\
realities. Nowhere is this more apparent than \\
in the physical consequences of industrialised \\
conflict - the force which has shaped, and \\
continues to shape the modern world" \\
(Saunders, 2012, pp. xi-xiv).
\end{tabular}

It emerges that archaeology is a tree of many branches, not all of which are equally suitable to deal with conflict in general and with the peculiarities of WWI in particular. For this reason, First World War Archaeology was excluded from the above account as being entitled to more in-depth attention given the focus of the present work.

\subsection{Approaches to WWI research - First World War archaeology}

First World War Archaeology is likely to be the most well-rooted archaeological approach to WWI research. The legitimation of archaeology as a means of investigating recent conflicts brought into the mainstream the need to consider plural war accounts as they emerged from investigated physical remains and thereby incentivised new war heritage perspectives. What makes the Great War great is not just its extent, nor the inauguration of the war-industry symbiosis and of mass-dying, but rather the complex political, nationalistic and ethnic motifs that informed the war and culminated into numerous identity claims, leading to the creation of new states and the restructuring of old political traditions. The legacy of this age of transition rests imprinted in the sites of memory, fuelling a highly significant dimension of cultural heritage. Hence, as soon as scholars realized that WWI remains constitute a bridge between history, memory and heritage, besides being a contester/tester of the veracity of official historical accounts and a multiplier of history, archaeology gained prominence as a means of investigating the war.

"Great War archaeology is a complex endeavor [...] for it deals with the actions and consequences of modern industrialised war on a global scale. It is the archaeology of 
new worlds brought into being at terrible cost between 1914 and 1918 - worlds that have transformed themselves ever since, within which we still live today, and with whose legacies we still struggle [...] Great War archaeology is, ultimately, the archaeology of us, and it is only just beginning" (Saunders, 2007, p. vi).

For the past hundred years historical versions have proliferated internationally, mainly focused on the history of the winners and of the military-politically significant, which led to overemphasis of the Western Front. Because of the focus on the Western Front, for a long time WWI was understood exclusively in terms of the Western Front, which raises questions about the characteristics/implications of the war in other places and about the overall understanding of the war. In line with the above approach, WWI archaeology initially inherited such a focus, the Western Front being targeted by the great majority of conducted works (King, 1998; Saunders, 2002; Pollard and Banks, 2008; Robertson and Kenyon, 2008; Brown, 2009; Brown and Osgood, 2009; Hanson, 2011) and, hence, WWI heritage was broadly constructed through this historical version. Nonetheless it is worth mentioning that archaeological research on WWI is a relatively new field, that has only been scientifically approached for about two decades, which inevitably leads to coverage gaps. From its initial focus on the Western Front WWI archaeology expanded to larger horizons, enlarging its area of investigation to sites in Britain, Italy (especially in the $\mathrm{N}$ and $\mathrm{NE}$ where the Italians fought the Austro-Hungarian armies during WWI), Slovenia (the Isonzo front), Turkey (Gallipoli), and Jordan (the initial focus on the figure of Lawrence of Arabia was complemented starting from 2005 by the Great Arab Revolt Project). Nonetheless, several fronts remained mainly unapproached.

"Vast areas of the old Eastern Front (and especially the Balkan region) have so far remained virtually untouched. What reveals the anthropological nature of Great War archaeology, and the more inclusive nature of modern archaeology itself, is the realization that war affects different areas in different ways, and can leave a variety of distinctive physical traces. Each of these has its own significance, and each can contribute 
a piece to the jigsaw of how the war was experienced and remembered by ordinary soldiers and civilians during the war and afterwards" (Saunders, 2007, p.202).

Still the discipline is constantly developing and broadening its field of interest, which, like the focus of the present work, opens up new areas of research that in time will develop and accumulate to build a more holistic understanding of the war phenomenon.

The distinct archaeology of the Great War relied on the valorisation of the material culture and memory duet (Saunders, 2003; Saunders, 2004), which, along with a solid theoretical grounding, allowed the field to overcome its initial limitations. Important contributions to the study of material culture of the Great War also came from the field of conflict archaeology, which opened a window on the understanding and acknowledgement of plural historical accounts and the several layers and dimensions of memory. In the category of novel contributions to the field it is worth mentioning Wilson's embodied memory (Wilson, 2007), Fraser and Brown's engagement of forensic techniques (Fraser and Brown, 2008), Bagwell's diary excavations (Bagwell, 2012) and Winterburn's "hierarchy of conflict space" (Winterburn, 2012). Such perspectives nuanced and raised attention towards "a sometimesforgotten material reality" of "a constantly and swiftly changing terrain where trenches and fortifications were continually adapted to new threats and needs" (de Meyer and Pype, 2009, p.378).

The material remains of the Great War are highly diversified, ranging from human remains to earthworks, weaponry and trench art, which, along with various forms of commemoration found in their proximity, label sites with the contested landscape mark (Forbes, et al., 2009). People engaged in the study of WWI look at an immensely variegated range of materials ranging from letters, photographs, memoirs, journals, trench art, innumerable earthworks, trench systems, dugouts, bomb craters, tunnels, graves, hospitals, bunkers, ordinance, human 
remains and conflict landscapes, etc., placed above and beneath the soil, on land and underwater, both on European ground and elsewhere. All those material remains concur in creating a huge network of conflictual landscapes depicting a fresco of the Great War and of the people who experienced it - a great number of whom did not live to tell their story vocally as veterans - but whose remains nonetheless narrate a profoundly meaningful story that is just starting to emerge from beneath the ground and be united to the voice of their sheltering land.

The treatment of the material culture of the war is dependent upon current assertions of cultural heritage. When and where ground-imprinted war legacies are contemplated as heritage the material remains of war are researched by archaeological excavations, exhibited in private collections and museums - beyond classic exhibitions of war materials, recent additions in the display of war heritage in Belgium and France also valorised trench and field museums - and are given increasing mass media attention.

\begin{abstract}
"Any effort to investigate the material culture of the First World War is, by definition, a social archaeology of the conflict that cuts across many sections of society, each with its own interests, motives, prejudices and knowledge. [...] The First World War does not stand alone as a single indisputable legacy that we are only now discovering; it is a heritage that we are all creating and shaping as we come into contact with new and different understandings and presentations of its physical remains, and of the personal experiences embodied in them" (Saunders, 2007, p.176).
\end{abstract}

A distinct feature of WWI archaeology is that it generates deep bonds with memory and commemoration in a perpetual game of mutual influences, making it constitute a "memorymaking activity" (Saunders, 2007, p.230). WWI archaeology above all seeks to comprehend life during the war, the personal and common experiences of a broad range of war actors that in one way or another sustained the war effort and whose imprint was left behind in a multitude of conflict landscapes that concur in recomposing the truth extension of the war phenomenon. The contribution that has been offered by archaeology to the interpretation/study/understanding of the Great War transformed the array of significance of 
the industrial war and revised its legacies, merging them together with the material remains into an extending compendium of WWI heritage.

The "battlefields of the First World War hold a much higher cultural significance than their mere physical presence. This layering of superimposed landscapes, allows different perspectives to be understood. However, these perspectives of the landscape as physical places and cultural images only recently developed, coinciding with the emergence of modern, professionalized archaeology and the beginning of the meticulous study of warfare" (Gonzalo, et al., 2014, p.22).

The fact that WWI archaeology, unlike battlefield archaeology, is not limited to the study of battlefields greatly increases our understanding of the war by conferring new insights into aspects of the war that surpass the boundaries of militarised historical accounts.

"When considering the landscapes of First World War battlefields it is vital to look from
the perspective of what Clifford Geertz called thick description. This entales approaching
an element, such as the battlefield, from several angles and considering numerous
interpretations and meanings that it may embody. [...] Nowadays, battlefields are
especially complex because of the fact that they are cultural images as well as physical
places, where memorials and preserved parts of the desolated landscape serve to remind
us of the First World War and all the human cost that came with it" (Gonzalo, et al.,
2014, p.21).

According to Gonzalo's et al. article about The Archaeology and Anthropology of the First World War representations of the Great War in present-day society are particularly noted due to their capacity to reinforce cultural significance.

"Portrayals of the battlefields through media such as paintings and poetry destroyed the conventional pre-war idea of romanticised heroics and bucolic landscapes, instead replacing it with the grim reality of the worlds of the likes of Wilfred Owen and Siegfried Sassoon. Therefore, the battlefields became new landscapes with new meanings, embodying the cultural significance of acts of war" (Gonzalo, et al., 2014, p.21-22).

The authors further emphasise the influence on international relations of soldiers' cooperating with each other, using the famous football match played in no-man's-land during the Christmas truce as an argument. The quoted episode was interpreted by the authors as highly symbolic and was framed as proof of the human feelings of soldiers and the 
pointlessness of international power games. Since such interpretation is strictly centred on accounts of the Western Front, it infers an imperative need to revisit the poetry, literature, ethnographic compositions and war sites related to the Eastern Front legacy, in order to rebalance such war accounts and broaden the holistic understanding of the war. By integrating and contrasting the works of soldiers from different fronts a less monolithic and unanimous dimension of the feelings and motivations of those who fought the war can be derived. Ultimately, one aim of WWI archaeology is to bestow plural perspectives on the war, and thus allow deeper understanding of its significance and outreach.

R.J. Wilson draws attention to how French and Belgian battlefields evoke images of devastation, sorrow, and endless compassion in the collective memory, especially in countries such as Britain. Wilson argues that "the popular memory in Britain of the Western Front should be acknowledged as a version of the past chosen and preferred above others" (Wilson, 2007, p.228). This gives WWI archaeology the hard task of bringing to light other shades of the past which are less popular and consensual and to make them coexist with the "preferred versions" (Fiske, 1987, p.65) like the notorious rhetoric of soldiers' victimhood that is widely engaged in reference to the Western Front. Consequently, it emerges that WWI archaeology and conflict archaeology in general must have the capacity to handle myths, memories, popular conflict perceptions and war leitmotifs, along with the material remains themselves, while questioning and recomposing them in an informed manner. Archaeological agendas must be able to derive a meaningful interpretation of material culture that can enrich our understanding of the overall war/conflict phenomenon, and to elude the reiteration of historical clichés. Gonzalo et al.'s article illustrates how even well-argued works of scientific standards can unwittingly fall into the trap of reiterating popular clichés. Most examples used by the authors to sustain this argument, from soldiers' victimisation, to desolate landscapes 
and the famous football match, build up popular myths whose origin is deconstructed and largely explained in Wilson's article.

The "dominance of the memory of the Western Front and its perception as the definition of the Great War in Britain" (Wilson, 2007, p.230) and elsewhere is criticized by historians dealing with the deconstruction of popular memory (Beckett, 2013) following the lead of Hobsbawm's invention of tradition.

\begin{abstract}
The fact that despite "evidence to the contrary, it is the Western Front and the British role in it that is still assumed to be the Great War" leads to remembering WWI "in contrast to World War II, which is viewed as a good war, a necessary war: the Western Front is remembered as a senseless tragedy. It is these factors that have constituted a dense and impenetrable insular mythology concerning the battlefields, and have perhaps ensured that the British sections of the Western Front are seen not just as the only battlefield, but as the whole war" (Wilson, 2007, p.231).
\end{abstract}

An antidote to distortion of the perceived image of the war phenomenon is the rebalancing of the war account by integrating scientific studies of the Western Front with the study of the Eastern Front and secondary fronts. If it is true that the study of battlefields, in both their physical and cultural dimensions, came as an important addition to understanding the war, it is also true that breaking the war phenomenon into separate self-sufficient fronts is liable to lead to the creation of a fractal camp of knowledge. Consequently, the generalisations made during the reconstruction of the war phenomenon through heritage and remembrance discourses will lead to an unbalanced and distorted version of the re-iterated past, particularly if one version is misguidedly allowed to be promoted as the only existing one.

\title{
2.4. WWI and remembrance
}

The memory phenomenon that originally grasped the attention of scholars in the first stage focused on its political dimension, highlighting the mechanisms of mobilisation of the past so as to justify the present status quo (Hobsbawm and Ranger, 1983). It is within this broader 
dimension of memory studies that we can best frame the theme of conflict memory (Gillis, 1994; Evans and Lunn, 1997; Ashplant, et al., 2000; Muller, 2002). Nationalistic master narratives were engaged "to create, modify, or sanction the public meanings attached to historical events deemed worthy of mass celebration" (Anderson, 1983, p.116) propelling war commemoration to the position of spinal cord of the national state. Although, through this lens, it could seem automatic for war memorials to catch the eye of researchers, in reality few studies have focused on the argument in all its complexity and even fewer have dignified them with critical attention (Moriarty, 1999, p. 655). The main binaries have converged in the study of large-scale artistic war memorials (Penny, 1981; Moriarty, 1995) on the one hand and, on the other, in the notorious concept of political propaganda (Parker Pearson, 1982; Mosse, 1990; Sherman, 1999) ostracising other forms and categories of memorials. This tendency left no space for considering actual war sites as holding potential monumental value at an official level.

Against a background of wider remembrance assets ranging "from present future to present pasts" (Huyssen, 2000, p.21) the act of remembering has colonised the public scene, adorned with a great diversity of new facets and actors. A broader remembrance space has been created; one able to shelter complex, interconnected and variegated war histories (Moriarty, 1999). Various anniversaries, the opening of war archives, with generous media exposure, have contributed to a developing tendency to conciliate history with memory (Winter and Prost, 2005) especially in relation to the Great War.

Historical, political, tactical or logistic views of the past, and its approaches to war, were flanked by studies and interpretations centred on the cultural memory of conflict, although the first pioneers of the field perceived the two fields as antagonistic (Fussell, 1975). WWI considerably dominated the European scene concerning memorialisation during the $20^{\text {th }}$ 
century as "for many people, but especially for Europeans, the narrative of this century is unthinkable without the memory of the Great War" (Connerton, 1989, p.20). The unprecedented scale of WWI memorialisation, and the complexity of the issues it raised, made the topic remarkably popular amongst researchers. Scholars approached the subject from a plurality of angles and derived as many explanations for the process itself, from the social inability to metabolise mass dying (Mosse, 1990; Bushaway, 1992), to introducing alternative graves in response to the deceased body's absence (Sherman, 1999) and to the expiation of guilt (Winter, 1995). The contradictions of the memorialisation process were also mirrored along with the reflection of the social issues they inherently carried (Mansfield, 1995). This field developed a body of studies concerned with the objects and subjects of commemoration in an optic of multiple meanings and interpretations, but still under the premise of an unmediated experience of conflict (King, 1998). Winter argues that in this assertion, war memorials not only simultaneously promote remembering and forgetting but also incarnate social assets that are indubitably doomed to fade away as lieux de mémoire (Winter, 2006). Nonetheless, reality proves otherwise as memorialisation is an ongoing process that evolves and mutates in time (Wilson 2013), causing the significance of war memorials to change or even transform. It is, in fact, this adaptability that prohibits the mental correspondents (along with their entire sphere of meanings) of the physical monumentalisation of conflict to spontaneously combust when their creators pass away. In recent times more and more actors have claimed their rights to memorialisation in line with a general social trend towards inclusiveness. Various individual groups who have been silenced in the past have demanded a public voice, and recognised space for their various histories. The time distance incenses memorialisation omissions rather than healing wounds, due to a 
sense of permanent historical erasure that occurs when personal memory starts to blur, and common memory evicts a group's presence.

\subsection{Memory, remembrance and its links to heritage}

Dealing with WWI heritage authomatically creates a need to deal with an entire range of memory scales and perspectives on memory that coalesce in building the intangible dimension of heritage, which is an important aspect of heritage value. Whether we consider it in light of individual memory (McCarroll, 2018) or collective memory (Ros, 2012), living memory (Finney, 2017) or cultural memory (Molloy, 2016), historical memory (Wang, 2018) or social memory (Fentress and Wickham, 1992), the Great War depicts a wide range of memory facets and calls upon the mobilisation of various typologies of memory.

In the context of the First World War, memory not only pays a tribute to the past but, through the wealth of its forms of expression, it reflects the significance and complexity of the industrial war (Winter, 2017), capturing snapshots of that past and projecting them in the countless layers of the material culture of war. That is because memory is a "place wherein the past can revive and survive; it is a place for places" (Casey, 2000, p.187). In other words, memory, which is primarly of intangible nature, is always anchored to materiality in one way or another, whether it refers to things, places, people or the events of a past timeframe.

Different things hold different meanings for different people; hence, WWI memory holds different meanings for different cultures, different nations and even for different people within the same nation/society/community. The variety of memory activated in relation to the Great War is all part of that outstanding alterity that this particular war evokes, and which in the field of heritage has gradually translated into making people more open to inclusiveness. Hence, not only has the recognition of concurrent memory scales informed and augmented the 
heritage worth of WWI material culture over the past century, but it has also come to hold broader social implications. The acknowledgement of plural, perfectly-valid memory scales has emphasised the innumerous levels, actors and meanings of the war, which have ultimately condensed in the need to consider all the above aspects when offically reiterating the past by means of official heritage recognition.

In a way, it is memory that legitimates heritage recognition and justifies the need for heritage in reiterating meanings and values extrapolated from the past and reproposed in the present. Such memory-generated significance feeds a fundamental dimension of personal/group identity, developing a conceptual understanding of who we are as a consequence of maturing an understanding of who we were.

"Memory is the faculty that enables us to form an awareness of selfhood (identity), both on the personal and on the collective level. Identity, in its turn, is related to time. A human self is a diachronic identity, built of the stuff of time. This synthesis of time and identity is effectuated by memory" (Assmann, 2008, p.109).

The formation and maintenance of both individual and group identity is dependent on memory, that is on that capacity to remember ourselves and others, and to relate to things as emergent from a complex process of mediation and negotiation of a past instant in time and space (Connerton, 1989). Memory, not even personal memory, does not occur in vitro, therefore is never purely individual but always mediated by external factors such as cultural ascriptions and social interactions. This socialy and culturally filtered fresco of the past is not confined to what we might cherish about the past but goes beyond, extending to whatever has touched us in good or bad ways; what marked our existence and conditioned or influenced who we later become. 
Existent interconnections between memory and heritage have fuelled the transfer of traits from one to another, making heritage a past preservation endeavour heavily reliant on the ability to keep the past alive. "The point about heritage objects - what makes them heritage, rather than anything else - is that they represent intangible qualities we value. But heritage does not only consist of objects: it consists of memories of objects" (Carman, 2009, p.197), of places, of people and of activities that summon the reification of a past event. John Carman claims that, on the one hand this process implies remembrance and memorialisation and, on the other, it relies on fictionalisation of the past, hence on the use of imagination as an interpretative tool.

\footnotetext{
"Heritage sites, objects and places thus represent not things but the memory of things. The things they act to remember are always things that are gone: events, activities, people collectively or individually. They carry ideas and associations and values that are not concrete and cannot be measured or assessed in concrete terms: the physical description of a place, object or site is not a statement of its value or meaning" (Carman, 2009, p.200).
}

The necessity of rethinking the assessment of meanings and values has elucidated the phenomenon of memory seen as a catalyser of social and cultural movements. The last decade of the $20^{\text {th }}$ century witnessed the advent of the "memory boom" and of the "memory industry" (Rosenfeld, 2009, pp. 124-125). The first notion refers to the multiplication of public contentions centred on the past, while the second made an object of study out of the very controversies raised by the claim of appropriation and interpretation of the past. The "upsurge of memory" prospered in response to the proliferation of modern life's sense of loss (Nora, 2002) and of the assets of globalisation, which dangerously impended upon people by threatening to silence forever their yet unspoken accounts of the past. On this trail, concurrent histories amount to "unmastered pasts" (Rosenfeld, 2009, pp.126-127) that struggle to mirror plural identities although often ending by instigating conflict, highlighting apparently 
irreconcilable stories and emphasising rivalry legacies within society or amongst societies in a vivid display of memory and countermemory (Legg, 2005). The contemporary battle over meaning not only relates to heritage, identity, justifications of power or authority at different levels, briefly with the creation of present value systems designed to shape the future, but also with the re-creation of the past to fit such aims.

Against the dangers brought about by new international balances of powers that emanated from supranational structures, and by the imposture of alien notions of heritage, societies and communities have mobilised memory. Collective memory raised a shield against alienation of the past and, with it, alienation of identity, by acting to "bring[ing] the past to matter in the present" (Halbwachs, 1992, p. 40). The lieux de mémoire (sites that have been set to preserve the memory of the events) act to fill a void created by the absence of the "milieux de mémoire" (social environments of memory) in order to regain access to a past world out of which we were banished by time (Nora, 1996, p.12). The collective memories themselves are various and can be approached at different levels.

In the exordium, collective memories were relegated as a phenomenon of national level, cultivated by states so as to sustain internal cohesion (Benedict, 1991) due to the fact that they were heavily dependent upon memory and myth since "there can be no identity without memory (albeit selective), no collective purpose without myth" (Smith, 1986, p.2). The same discourse applies to other scales as well, such as that of universal level, which like nationalism requires cohesion to be built with the aid of a master narrative. Although the adequacy of this dimension of collective memory raised fervent contestations, as it was believed that "a timeless global culture answers to no living needs and conjures no memories" (Smith, 1995, p.24), it is nonetheless not just an existing, valid memory scale but also one that 
has registered notable growth and influence during the last decades. Theorists of the cosmopolitan memory contest "fixation on the nation-state as the sole possible (and imaginable) source for the articulation of authentic collective memories" (Levy and Sznaider, 2002, p. 89), since it implicitly leads to the denial of memory in a frame other than that of the state. On the other hand, the encouragement of global memory and the development of a technical and moderate frame for specialist memorialisation debates might result in the sterilisation of local and national peculiarities. This tendency is particularly visible in the study of symbolically charged features like that of the war memorial, which tends to be "abstracted, decontextualised and robbed of its potent connection to the cultural and political conflicts which have underpinned and inspired it" (Asplant, et al., 2000, p.6).

"All human beings act within certain culturally shaped background expectations and understandings, often not conscious, about what reality is" (Verdery, 1999, p. 34). In times of war there is a disruption of the fabric of the culturally ascribed reality by means of "a situation of overwhelming, extreme, and violent pressure" (Winter and Sivan, 1999, p.29), which alters the valences of normality, opening a vortex to the unknown and distorting social internal balances. Memory is "a faculty rather than a place" (Wertsch, 2002, p.17) and as such enacts a processual endeavour to recreate and re-establish order, sense and meaning in the chaos of fatality and unknown producing new knowledge and retaking control over the randomness of war. Memory requires mnemonic landscapes that are coagulated as a cultural construct that helps the past to be "imaginatively reconstructed along narrative lines guided by bodily experience and cultural models of memory and self" (Kirmayer, 1996, p. 191).

Halbwachs identifies a parallel between the mental spaces and the material spaces that people inhabit arguing that in order to create the conditions of remembering there is a need of social frameworks able to hold re-iterated narratives of time and space (Halbwachs, 1992). Even 
what we regard as personal memories are in fact an interactive product due to the connection with other people's memories (Assmann, 2010, p.41) and social assets. "The primary locus of memory is found not only in body or mind but in an intersubjective nexus that is at once social and collective, cultural and public" (Casey, 1996, p.21). Hence social and cultural mechanisms exercise a marked influence on memory holding a remarkable capacity of memory stimulation or inhibition (Kirmayer, 1996). The various remembrance trends are indicative of such capacity and can be easily spotted in the creation of historical selfawareness, which is subject to a process of filtration of a past that established who, what and how it is remembered. The variation of the filters in time, in direct proportion with mutations of social ethos and political trends, makes memory a dynamic process. "Different eras develop distinctive mnemonic forms and content $[\ldots]$ while these representations were previously determined almost exclusively through the community of the nation-state, processes of globalization, in their concrete manifestations as well as in their ideological aspirations, have greatly contributed to the reconfiguration of memory cultures" (Levy and Sznaider, 2006, p.26). It follows that it is the needs, aspirations, and knowledge that societies hold in the present that dictates the re-iterated version of the past (Connerton, 1989) in accordance with the current collective symbols of a given society and having the sites of memory ${ }^{1}$ at the very heart of the reiteration process.

The unpreceded growth registered by thanatourism, whether oriented to primary sites of death like WWI battlefields or secondary sites of commemoration like war memorials (Wight, 2006), can be seen as a response to the fear of identity loss and is a remembrance exercise designed to prevent obliteration. Although the Great War granted a great variety of personified spaces and objects to commemoration of deaths, a phenomenon that spread all

\footnotetext{
${ }^{1}$ In this assertion sites of memory stand not only for the narratives of the past, discourses and commemoration, but also for social practices such as rituals and memorials, institutional practices and cultural artefacts.
} 
over Europe and beyond, the scholastic study of WWI memorials made a fixation of Britain and France on such a scale that it constitutes a historical trend that is largely still ongoing.

The rhetoric of memory and countermemory flourished in the light of reflections upon the process of memory articulation under the sign of the "by whom, where, in which context, against what" guidelines (Davis and Starn, 1989). Memory, as it was conceived in the 1960s, suffered a series of shifts that made "memory's late modern associations with fantasy, subjectivity, invention, the present, representation and fabrication appear to outweigh its modern associations with history, community, tradition, the past, reflection and authenticity" (Radstone, 2000, p.98). The reconsideration of personal memory was also taken into account against the frame of socio-cultural ascriptions, emphasising a distinction between the remembrance process and the act of remembering. The evolution of memory meanings registered various stages, each reflecting the needs of specific periods (Radstone, 2005); for instance, the advent of veterans' tourism and pilgrimage to battlefields in the interwar years or Russian family genealogies promoted by the state archives in recent years. In a certain way, memory became a container of all sorts of social issues; an umbrella concept that sheltered the voice of race, ethnicity, religion, class, gender; a sort of pretext to retrospectively give expression to and reflect upon an entire range of social pulsations. "The new materialization of memory thus grounds the elevation of memory to the status of a historical agent" (Klein, 2000 , p. 136). For a long time, role categories in relation to war were fixed on the valences of victims, survivors and heroes in the human dimension and on winners, losers and aggressors in the national dimension. The idea of justification of the present state of things based upon past legacies lead to a great group/community mobilisation to obtain public recognition of their own experiences of the war. This phenomenon is particularly marked in reference to the Great War due to the transmutation of living memory into cultural memory. The fading away 
of the direct experience of the Great War leads the remembrance phenomenon shift from social to cultural (Purseigle and Macleod, 2004). If commemoration is an antidote for forgetting and a ticket to cultural representation, then WWI commemoration should not be relegated to "mourning for the dead of the Great War" (Winter, 1995, p.7) and the celebration of combatants, but should be also extended to non-combatants and survivals as well. Furthermore, it should be allowed to reflect the experience of the war, the phenomenon itself with its overall significance, ambiguity, contradictions, implications, and actors. Commemoration does not begin and end with the erection of memorials, but it goes beyond, landing in the proclivity to extrapolate meaningful stories from the memory embedded in all WWI material culture. The meanings hidden in materiality hold a capacity to encompass that "socially constructed space in which and about which subjects and words normally used in everyday life are not spoken" (Winter, 2010, p.4) as the socially dictated silence is not equivalent to forgetting nor is it an absent figure of the remembrance arena.

\subsection{Heritage}

\subsubsection{International heritage stakeholders}

The violence that marked the first half of the twentieth century triggered the foundation of the United Nations Educational, Scientific and Cultural Organization (UNESCO) in 1946. The Preamble of UNESCO's Constitution stated that "since wars begin in the minds of men, it is in the minds of men that the defences of peace must be constructed" by relying on the "intellectual and moral solidarity of mankind" (UNESCO, 1946). Ever since its creation the organisation has advocated the power of education and promoted research to help society overcome racist behaviours. 
In 1972 UNESCO adopted the Convention Concerning the Protection of the World Cultural and Natural Heritage (World Heritage Convention), advocating the necessity of institutionalising an international legal frame for the recognition and protection of outstanding heritage sites (Smith, 2006) and stressing the central role that place and heritage plays worldwide in the sedimentation of social identity. The World Heritage List, one of the most notable emanations of the convention, became a universal indicator of the kind of resources that qualify for preservation in view of benefiting future generations (Schmitt, 2009) by reaching the standard of Outstanding Universal Value (OUV) that was concomitantly coined. The OUV imprint was set to mirror exceptional core values that go beyond national grounds to incarnate the common human interests of present and future generations (UNESCO, 1972). Although the World Heritage advocating activity and ranking procedure is overseen by UNESCO it is nonetheless a conjunct effort supported by international heritage stakeholders, amongst which the International Centre for the Study of the Preservation and Restoration of Cultural Property (ICCROM), the International Council on Monuments and Sites (ICOMOS) and the International Union for Conservation of Nature (IUCN) play a leading role.

Due to its global popularity the World Heritage label became a high rank heritage brand that greatly benefits its protected sites in terms of publicity and fame. However, the UNESCO status can be problematic and contradictory. On the one hand it prescribes a standard of conservation and preservation but, on the other, it encourages excessive commercial exploitation of the heritage resources (Labadi and Long, 2010). It has no authority over national sovereignty but it can bind the will of the states concerning heritage policies by means of the symbolic power of the overly-popular heritage brand (Askew, 2010). Also, the mechanism of inclusion in the World Heritage List is subject to a political mechanism that is in itself highly questionable as it relies on the capacity of the states to file successful 
applications, which results in greatly privileging those who have a strong and competitive administrative capability. Nonetheless the WHS label "is part of a distinctive place-making endeavour - one that strives to rework territorial conceptions in the minds of its global populous through the promotion of new and universally understood intellectual and cultural conceptualisation of the world" (Di Giovine, 2009, p.77).

\subsubsection{AHD \& UHD}

Changes that occurred in the field of heritage, especially due to scholastic interest raised by the subject, led to an assertion of heritage that surpasses the rigidities of the institutional heritage framework. The main themes populating the heritage debate today are a consequence of the age of rights, and of the resulting change brought about in society. Today's heritage dilemmas were not contemplated as such in the past, nor even acknowledged, as it was the legal normativity that produced the heritage discourse (Lowenthal, 1998). Heritage used to be legalised, objectified and authorised top down at institutional level and "it is only in the last few decades that the word heritage has come to mean more than a legal bequest" (Graham, et al., 2000, p.1). The Authorized Heritage Discourse (AHD) that emerged in Europe at the end of the nineteenth century emanated from the institutionalisation of heritage. The AHD, once universalised, soon became not just a trendsetter but the trend itself, which led several scholars to contest its monopoloid power that "validates a set of practices and performances, which populates both popular and expert constructions of heritage and undermines alternative and subaltern ideas about heritage" (Smith, 2006, p.11). Furthermore, it is claimed that AHD tends to "reduce the debates about heritage to specific technical issues" eluding "any real engagement with debates about how heritage is involved in the production of identity, power and authority" (Harvey, 2001, p. 320). Critiques also call into question the servitude of heritage to the empowerment and justification of social regimes and identity claims (Dirks 
1990; Harvey, 2000; Waterton, 2010). Nevertheless, it would have been highly unlikely for any kind of initiatives regarding the protection, conservation or financing of heritage to develop in absence of the institutional heritage framework and it is self-evident that without the official background against which present-day heritage debates flourish there would have been no space at all for these debates.

The promotion of a certain version of history, mainly the history of the winners and the politically significant, the invention of traditions (Hobsbawm and Ranger, 1983), the proliferation of a dangerously selective version of the past (Harvey, 2001) that is dissociated from the core context and presented as a fact of general validity that condenses in the heritage knowledge, constitute the main binaries on which power and authority leaked into heritage. Consequently, it is on the trail of instrumentalisation of the past that the contestations of AHD are most coherently crystalised. Instrumental reconstruction of the past seems to impend even on the collective memory, which is influenced and altered by the process of negotiation of the past and the derivative understanding of it (Samuel, 1994). The fragmented and sterilised account of the past propagated through the AHD requires a revival of the subdued knowledges (Smith, 2006), denied historical accounts and repressed memories in order to reach its purpose of representing/reflecting the past. In absence of that the invented traditions, which are "not of historical fact but of a sanctioned version of history that was used to legitimize contemporary authority" (Harvey, 2000, p.54), will fuel a subjugation and sanctioning mechanism (Misztal, 2003) that will silently impact on everyday life. Systems of authority and social order legitimised by reinterpretations of the past (Waterton, 2010), along with the speculation of power continuums (Jonker, 1995), were heavily criticised by scholars highlighting the pressing need to overcome stigmatisation of that conspicuous part of the past that was cut out of the mainstream. 
The exordium of heritage occurred in the "context of the developing narrative of nationalism and of a universalizing modernity" (Smith, 2006, p.18) from which it inherited both the nostalgia of the past and the aspiration to universality. Being derived from a process of sedimentation of practices and knowledge the AHD inherited a motion predisposition, being peculiarly sensitive to changes in society. Although its nature may seem static AHD is actually quite reactive to social change, therefore it evolves and mutates along with society. The socio-political circumstances created after WWII favoured the globalisation of a version of heritage imbued with the values of western culture (White, 2006; Harvey 2009). Mobilisation of the past was performed with the aid of international politics and organisations that upgraded the AHD to the rank of universalised heritage discourse - UHD (Hammami, 2012) - to serve the cause of global heritage. The rationale that stood behind the creation of a common heritage was the idea that humanity possesses a set of common values, representing all peoples throughout the world, making it appropriate to invest global society with the responsibility of safeguarding heritage. Although it is undeniable that UHD increased awareness of the need of valuing and protecting heritage it also raised several problems by conditioning the way people, specialists and non-specialists, interact with heritage (Smith, 2006) as a reverberation of the canonisation of heritage practices and guidelines (Starn, 2002). The defiance created between the declarations of principles of the first heritage conventions and the practice itself, along with the challenges of universal/global heritage, raised fervent critiques (Bennett, 2004). Such contestations benefitted the heritage discourse leading to more contextual and inclusive international initiatives like The Burra Charter (Waterton, et al., 2006), the 2001 Declaration on Creative Diversity, the 2003 Convention for the Safeguarding of Intangible Cultural Heritage, and the 2005 Faro Convention. 
The idea of UHD and the resultant heritage cluster might erroneously suggest the existence of universal consensus upon the subject, which is obviously not the case, and the acceptance of one general heritage. In fact, heritage should always be thought of as plural and that is because, even when heritage is not dissonant, there are still several assertions of heritage at several scales that function simultaneously going from local to national, regional or global. The quest for meanings follows a crescendo or decrescendo of mobilisation of the past, dependent upon its contextual needs and actors, in a highly dynamic process of perennial adaptation. "The global and the local then became sites for constructing contrasting methods of analysis, which are perpetually played off against each other in rather sterile ways" (Swyngedouw, 1997, p.143). However, such outcome should not come as a surprise in relation to heritage debates as the field itself is founded upon juggling definitions of a perceived past (Harvey, 2001), which is subsequently subject to reification (Lowenthal, 1985). This should not minimise the importance of heritage nor should the dissensions be seen as being negative. In fact, it was exactly the lack of agreement that helped the field develop against a favourable context of major social openness to human rights.

Heritage in its dimension of "symbolic representation of identity" (Smith, 2006, p.30) was bound to produce a myriad of outputs none of which can actually be discarded as meaningless. It is, after all, competition over attributing meanings through the reinterpretation of the past that fuels the motor of heritage worldwide. The fact is that "not only what is interpreted, but also how it is interpreted and by whom, will create quite specific messages about the value and meaning of specific heritage places and the past it represents" (Tunbridge and Ashworth, 1996, p.27). Conclusively we should never lose track of the fact that society and societies are not homogeneous which leads to different versions of dissonance in time and 
space. Furthermore, the fact that heritage bears the latent seed of the tyranny of both minorities and majorities brings about the imperious necessity of contextualisation.

\subsubsection{Laws and their place in heritage}

Different cultures/nations develop different assertions of heritage which materialise in different sets of practices and regulations (Messenger and Smith, 2010). "The common thread however, lies in the adoption of law - of whatever kind and however written - as the key method of dealing with cultural heritage" (Carman, 2015, p.52). The existence of law as leading authority in the field of heritage management, regardless of its source of emanation and means of expression, in many cases results in being the only common ground between national heritage systems. Law also stands as the only liable guarantor of the preservation of cultural resources as a result of the fact that it holds the necessary authority and consistency to dispose the enforcement of heritage regulations. Consequently, the nationally-based legislative frameworks exercise various degree of agency on cultural resources and heritage practices by means of policies and regulations (McManamon and Hatton, 2000).

The sustainable management of heritage resources heavily relies on the rule of law as legislative authority results in being the most suitable way to govern the heritage administration processes in the perspective of public interest (Cleere, 1989). The highly heterogeneous field of international heritage legal traditions, which translate into diverse heritage practices and standards, makes comparison between states hard to manage and conduct. John Carman argues, in reference to archaeological heritage management, that in order to successfully conduct comparison between international practices a series of factors, such as the nature of the legislative system, traditions and historical evolution, must be taken into account (Carman, 2015, p.57) to allow understanding of the existing differences between 
various national heritage legal systems and, hence, inform the grounding of adequate comparative premises.

Heritage management and conservation practices preserve the imprint of national legal traditions even when applying international heritage legislation which leads to a great diversity of heritage interpretations and legal systems. Nonetheless the evolution of heritage management (Sebastian, 2009) registers a development towards a global dimension of common heritage concerns, especially in reference to archaeological resource management. The international heritage legal framework accommodates a set of inter-states' agreements regarding a "common standard of treatment for certain classes of objects, either generally or in defined sets of circumstances [...] designed to operate globally - such as those promulgated by the United Nations or UNESCO - or regionally" (Carman, 2015, p.63). The importance of international law derives from the promotion of global heritage standards, not only meant to guide heritage practices internationally, but which are liable to implementation at national level subsequent to the ratification of/adherence to international agreements/conventions/treaties which confers them factual normative power. Accordingly, the primary weakness of international law resides precisely in its implementation regime, which is dependent on the willingness of states to voluntarily subscribe to external heritage prescriptions/directives and translate them into internal regulations.

A key reference point in dealing with heritage legislation and hence with heritage preservation policies and practices, regardless of the level of analysis, is the value system that informs the assessment of local, national or global heritage. What different people/communities/societies value about the past informs the sedimentation of different assertions of heritage and influences; not just what they choose to preserve as heritage but also how they choose to 
preserve heritage (Smith, et al., 2010). The historical development of the legislative/administrative systems currently in use worldwide highlights the roots of todays approaches to heritage and heritage management developed from a wide range of ideological and political systems (Cleere, 1984).

\subsubsection{Value ascription in heritage management and conservation practice, internationally}

The key concept to the understanding of heritage and the subsequent need of protection and conservation is the ascription of value by society (De la Torre, 2002). The ambiguity of terms such as heritage and value triggers a series of issues. If we look at heritage as inheritance from the past meant to serve the future (Ashworth, 1997), as a fusion of history, policy and identity (Herbert, 1995), or a process of selection operated by society in view of highlighting the values it wishes to develop, negotiate and hand on to future generations (Smith, 2006), then we are forced to question not just the term itself but also its source of emanation as, through this lens, heritage is a cultural anthology of the perception that a given society has of itself. A society's self-perception is a dynamic mechanism, and so is heritage, as its significance changes in time. The ascription of meaning, and therefore of value, is subject to the pulsation of social trends which are heterogeneous in time and space as a consequence of the fact that values are remarkably volatile, being the product of ascription of meanings by ever evolving groups/communities. The mutation of values through time and the great diversity of values in space and even within the same space lead scholars to question the very existence of value in heritage (Pearce, 2000; Avrami, 2009; Smith, 2009; De la Torre, 2013). That is because value is produced not by the object in question but by external factors that attribute value to the object on the basis of its social resonance and significance (De la Torre, 2002). Furthermore, the characteristics of an object such as material, age, size, - the countable tangible features used as criteria to assess heritage - have no inherent value prior to the ascription of 
significance by people (De la Torre, 2013). In congruence with the above, Spennemann claims that value in heritage is equivalent to the projection of social/community/group ethos on the heritage object (Spennemann, 2006).

In 1979, the Australian ICOMOS Charter for Places of Cultural Significance (Burra Charter) institutionalised social value as an additional category. The Burra Charter shifted the assessment of value in heritage from the strict material-based approach to the nuances of cultural significance that stand as a pillar of the identification of social value in a given place (Australia ICOMOS, 2013). The idea of heritage value produced by significance rather than by materiality itself, in a dynamic process of ascription of meanings and importance, mounted into a flourishing field of research that highlighted the subjective and variable character of the phenomenon (Johnston, 1992; Walker, 1998; Smith, 2009)

The assignment of value to heritage sites is intimately connected to the practice of characterisation which emanates from an ongoing process of place shaping. Value embraces both tangible and intangible factors, being constructed on a multitude of physical and mental layers that people inhabit with body, mind and soul making heritage an emotional protraction of history, memory and collective taste from the past into the present in view of both serving and surviving the future.

\footnotetext{
"What underlies is a desire to capture our overall feeling for the totality of a place - not just to collect facts about who built that building, what style it is, whether it is rare, what an archaeological site can tell us about our predecessors or how a designed park reflects 18th-century taste, but about what the place as a whole means to us" (Grenville and Fairclough, 2004-5, p. 2).
}

Even though the process of value ascription is subject to political negotiation (Graham, et al., 2000; Smith 2006) heritage remains the product of the synergy of the various degrees of agency exerted by the people (Hooper-Greenhill, 2000). The result of this acknowledgment is 
that even the "dominant ideas about the heritage values of authentic material culture and the built environment are being rewritten and redefined within a cultural process that privileges the performativity of doing and being, rather than the possession of, or association with, material objects" (Smith, 2006, pp. 237).

The side effect of embracing a plurality of meanings, values, actors and approaches that gravitate around the present assertion of heritage lies within the emergence of dissonant heritage (Tunbridge and Ashworth, 1996; Bruce and Creighton, 2006). The dissonance derives from the inconsistency of heritage interpretations and disagreement upon heritage meanings when confronted with the classical opposition between the pandemic social constructs of 'us and them', against the background of the much advertised "common values, common purpose and common interests" of heritage (Ashworth, et al., 2007, p.31).

"Heritage is clearly a problem, and becomes so as soon as different people attach different values to it. The values which we hold can be envisaged as a series of lenses placed in front of our eyes, which correspond to our various attributes, each of which alters our perception of what is heritage" (Howard, 2003, p.211).

In fact, it is the very association of the terms heritage and value that raises dilemmas as the ambiguity and versatility of such notions are incompatible with attempts to canonise practices and nail definitions (see Appendix 1).

\subsection{Conclusion}

The topics debated throughout this chapter emanate directly from the needs of research dealing with the significance of Romanian WWI sites as places of remembrance and heritage. Approaching WWI material remains in a determinate spatial and cultural context automatically implies dealing with a series of factors derivative of both the nature of the subject matter and its interconnections with the conceptual paradigms of notions, such as heritage, memory, remembrance, past and value. Therefore, in order to study war sites, one must be able to document the material evidence; hence the need for a science that allows the 
best possible way of doing that arises, which justifies the first part of the chapter dedicated to archaeology and WWI research. Further, to deal with war remains from a perspective of heritage/memory, one has to understand what memory/heritage is, what role remembrance plays, the connection between memory, remembrance and heritage, and how they interact, how heritage is constructed/legalised at present, and how it evolved over time; last but not least, what value means in relation to heritage? Understanding the mechanisms that fuel the heritage making process, and feed the numerous dimensions of memory, is of vital importance for this reaserch, as it relies on the ability to rationalise heritage and memory in order to allow the operationalisation of the concepts in a way that enables their application to the case study, thus empowering the assessment of war sites as heritage.

The study of material remains, as means of investigating the past, needs a discipline able to investigate both the tangible and intangible character of materials and to engage with material culture of the past as part of the present. Archaeology, especially conflict archaeology, responds to such needs, operating as a decoder of the past by deciphering the hieroglyphs of material remains and bringing new perspectives on human and natural landscapes. Prevalence given to the study of the Western Front lead to the emergence of a WWI fractal camp of knowledge marked by the proliferation of an unbalanced version of the re-iterated past. Integrating the war heritage discourse with the legacy of the Eastern Front would rebalance war knowledge and benefit its overall understanding, especially in the context of an emerging tendency to broaden the focus of WWI archaeological study beyond the limits of the Western Front.

This chapter emphasised a need to look at WWI material culture in countries such as Romania due to a lack of study of the Eastern Front and of secondary fronts. That is because WWI is a global event in which war theatres other than the Western Front played an important part. 
Significant archaeological work and WWI heritage studies have mostly focused on France and Belgium, resulting in the war phenomenon being mainly understood in terms of the Western Front. There is a difference between the various WWI fronts in terms of study and understanding but, so far, there has been no research on the Eastern Front in terms of war heritage. The present work, therefore, aims to fill a gap in our understanding of the war. The Eastern Front remains archaeologically unapproached; hence there is no knowledge of the existent physical remains of war. The chapter infers that the importance of the material culture of the Eastern Front has never been considered in relation to other fronts, such as the Western Front, and therefore its legacy remains as yet unintegrated in the overall war account.

Approaching WWI remains in Romania from a heritage perspective implies developing an understanding of the general conceptual field of heritage and its inevitable connections with memory and remembrance. There is an inseparable bond between contemporary heritage and memory as heritage does not represent the sum of the things it curates, but it condenses the memory of the things that are to be remembered. The creation of value systems in the present, to underpin forging the future, requires a re-creation of the past in line with a proposed scenario highlighting the memory phenomenon as a catalyser of social and cultural movements. Re-invention of the past is characteristic of all power structures, be they national or supranational, as such structures are dependent upon sustaining a viable master narrative so as to assure general social cohesion. Inductively, in their battles over meaning, societies and communities have mobilised memory against a loss of identity brought about by alienation of the past, and by the sterilisation of local and national idiosyncrasies in the proliferation of the global memory trend.

The construction of historical awareness springs from a dynamic process of filtration of the past in line with the social ethos convergent in perpetually re-iterated sites of memory. The 
needs of nationalistic master narratives, especially in the context of $20^{\text {th }}$ century conflicts, have nailed war memorials, especially those considered to hold artistic value, to the core of national state commemorative traditions, whilst ostracising other forms and categories of memorial. The potential monumental value of the actual places of war has remained scientifically unexplored, despite their ability to hold greatly diversified memories and having wide-spectrum commemorative potential. The hypothesis of framing war sites as monuments/memorials is a response to the growing claims to memorialisation rights and widespread inclusiveness, providing voice and space for plural, alternative memories/histories that coalesce to reflect a more authentic reiteration of the past.

At European level the study of the WWI commemoration focused in particular on war memorials, mostly in the context of western countries such as France, Belgium and Britain although it spread endemically throughout the continent. As far as the Great War is concerned, the memory discourse has long been imprinted on the binaries of victims/survivors/heroes at human scale and winners/losers/aggressors at national scale. Nonetheless, maturation of the remembrance process, that evolved from social to cultural, brought a necessity to overcome traditional minimalist representations and reflect upon the war phenomenon bearing in mind the entire spectrum of meanings, ambiguities, contradictions, implications and actors embedded in its material culture.

Internationally, the current heritage framework emerged in reaction to conflict, in particular to the unprecedented violence and destructive nature of the world wars. The main international heritage stakeholders - UNESCO, ICOMOS, ICCROM, IUCN - dictate the pulsation of worldwide heritage at official level through the World Heritage List. The WHL is the prime instrument of validation and implementation of the Authorised Heritage Discourse (AHD) and of the Universalised Heritage Discourse (UHD). The global proliferation of AHD 
promoted a heritage formula that blurred alternative heritage manifestations/claims and assertions. Power and authority contaminated heritage by means of the so-called heritage knowledge, which promoted the invention of traditions, highly selective interpretations of the past dissociated from the core context and a historical version shaped to the will of the winners and politically significant. Critiques contest the AHD instrumentalisation of the past that led to fragmentation and sterilisation of the past, and emphasised the imperative need to revive the submerged knowledge, denied historical accounts and repressed memories of those whose voices were silenced until the present day.

Restriction of the memory space of expression, and denial of heritage representation, stands as an indicator of the speculation of power continuums and the attendant stigmatisation of that conspicuous part of the past that was instrumentally excluded from the mainstream. Regardless, AHD still remains reactive to the social mutations and inductively evolves alongside society. The fact that socio-political circumstances arising in the aftermath of WWII privileged the universalisation of a heritage assertion of western-centric emanation demands the revision of UHD, which misleadingly suggests consensus upon the existence of a global single monolithic heritage. Nonetheless, heritage is always plural, having overlapping strata ranging from local to national, regional or global and presenting various levels of dissonance in time and space.

Despite the fact that the World Heritage label confers augumentation of the protection, publicity and fame of its protected sites by means of the outstanding universal value brand, scholars have highlighted its contradictory and controversial nature. In terms of procedural contestation of the WHL, the main critique has pointed to the ranking mechanism reliant on a strong and competitive administrative capacity as well as political power of States Parties. Such practice converges in over-representation of the developed states and under- 
representation of underdeveloped or developing states, ending up by privileging political power and economic capacity over heritage value itself.

The value systems inform the assessment of local, national or global heritage as the degree of importance that a certain aspect of the past holds for a certain group is what informs the choice of what must be preserved, and how. Hence, different people have different assertions of heritage regulated by different sets of laws and therefore enact differing standards and practices. Frequently, the only common ground between various national heritage systems is the adoption of law as a way of managing heritage. The high degree of differentiation between national heritage systems makes comparison a complicated endeavor in the absence of common standards. Thus, before conducting comparative analysis of international cases, a common ground must be assured either by examining the background factors influencing the assertion of heritage and its attendant practices, or by comparing international cases against the background of the World Heritage standards. In spite of the fact that heritage practices preserve the imprint of national legal traditions, even when applying international heritage legislation, the existence of a global dimension of common heritage concerns and accepted universal value/standards is undeniable.

The value standard inflected for heritage is highly volatile since contemporary heritage mirrors society's self-perception, making value subject to a dynamic mechanism of perpetual evolution and restructuring. Heritage has demonstrated evolution from the rigidity of material-based approaches to the versatility of the concept of cultural significance, shifting focus from tangible characteristics to intangible social resonance. The definition of heritage by significance rather than by materiality itself has brought about the proliferation of a plurality of meanings, values and actors providing fertile ground for the manifestation of dissonant heritage. Synthetically, heritage has become a collection of tangible and intangible 
factors displayed on a multitude of physical, mental and emotional layers that project snapshots of history and memory from the past into the present in line with current social ethos.

In conclusion, the present work is situated in the field of heritage. The current assertion of heritage has strong interconnections with memory and remembrance especially in relation to WWI remains. In the present research WWI material culture needs to be assessed as heritage hence the necessity for archaeological investigation arises and conflict archaeology seems to provide the most suitable tool for the study of the war remains. The work targets the study of war sites as instances of heritage in the context of the Eastern Front because there is a gap in our knowledge about the war due to lack of research on the Eastern Front, neither examining the material remains of war, nor the heritage value of WWI material culture; hence, its war legacy has never been re-integrated into the overall war account, marking a significant deficiency in general understanding of the war phenomenon. 


\section{CHAPTER 3 - METHODOLOGY}

\subsection{Introduction}

The research question of this work centres on the significance of Romanian war sites pertaining to the Great War with the aim of understanding the relevance of Romanian WWI sites as places of remembrance and heritage. In view of properly exploring the various valences and dimensions of the subject matter, the main research question was deconstructed into three main objectives as follows:

- The first objective regards the investigation of WWI material evidence in Maramureș in order to allow recording of the material evidence of the war within the research area

- The second objective regards investigation of the heritage legal framework in Romania and examines the premises for the granting of heritage status at national level in order to allow the assessment of the places of war as heritage

- The third objective regards investigation of the international legal framework and examines the premises for the granting of World Heritage status in order to allow assessment of the international significance of WWI sites and contextualisation of the Romanian case within the wider heritage debate

Each objective covers relevant thematic areas at different levels of analysis that, together, concur to build up different layers of the main research aim. In providing answers to the questions, methods from different research fields were engaged. For that reason, the first part of the research deals with conflict archaeology (Hakan, 2005; Schofield, 2005; Carman, 2007; Scott, 2007; Pollard and Banks, 2008; Harrison and Schofield, 2010; Bleed, 2011) and landscape archaeology (Van Hollebeeke, 2014; Gillings and Pollard, 2016); the second deals 
with heritage and remembrance at national level (Opriş, 1986; Iorgovan, 2002); and the third deals with heritage and remembrance from an international perspective (Winter, 1995; De La Torre, 2002; Di Giovine, 2009). A more detailed methodological framework will be presented below in the methodology section.

\subsection{Rationale}

The overall aim of the research is to examine the relevance of Romanian World War I sites as places of remembrance and heritage. The centenary celebration of the end of the Great War emphasised the necessity to approach the war remains as potential heritage objects. The urgency and importance of the present work derives from its capacity to inform decision makers, private and public agencies, and the general public about the heritage extent of the war sites and therefore provide them with a scientific basis to use when dealing with and deliberating upon the heritage status of the war relics. The relation between the material and immaterial dimension of the places of war and their meanings in time and space (Boyd and Linehan, 2013) is intimately connected to the dynamics of remembrance. The study of the material culture of war highlights an anthropological nexus between multi-layered landscapes and significant cultural functions (Saunders, 2004), indicating that at symbolic level war sites

preserve an evocative power that exceeds the common boundaries of materiality. If approached as sites of memory the places of war together proffer a wide range of collective symbols particularly relevant for the Romanian national master narrative and beyond.

In Romanian national history, the Great War represents a cultural landmark that stands for the achievement of the aspirations of national unity, independence, and self-determination, so qualifying the places of war as a "lieux de memoire" (Nora, 1996; Nora, 1997; Nora, 1998). The research presented in this thesis deals with Romanian WWI sites, examining their 
relevance as places of remembrance and heritage, and tracing their evolution in terms of cultural significance from the end of the Great War up to the present day. Considering its specific characteristics, the Romanian case holds the potential to fill a gap in our knowledge of the war. By informing a scarcely researched dimension of the Great War this work provides an asset to the future management of the war remains. The study of WWI Romanian heritage is likely to bring a valuable contribution to the work of authorities when facing the responsibility of legally determining their preservation and valorisation, or allowing their obliteration.

The previous chapter highlighted the existence of a significant difference between the low visibility and visitability (Dicks, 2003) of the Eastern Front in opposition to the prominence of the Western Front. While large-scale works are widely available about the Western Front (Gibson and Ward, 1989; Hynes, 1992; Tarlow, 1997; Saunders, 2002; Smith, 2003; Saunders, 2007; Theodosiou, 2010; Wilson, 2013), the WWI Eastern Front remains largely unexamined from this perspective and its potential to inform us about the conflict therefore remains unexplored. The war and its consequences had major impacts on countries such as Romania and understanding more about its conduct and remembrance (Misztal, 2003) holds great significance for policy makers and heritage agencies both in Romania and elsewhere in Europe.

Studying the significance of the Romanian war sites as places of remembrance and heritage implicitly brings about the need to consider the status of war sites elsewhere. The state of Romanian war remains is representative of the situation at the Eastern Front where war sites are still largely neglected at official and academic levels as indicated by the lack of scientific studies conducted on remains of the conflict, the heritage status and management of the war remains. The Romanian case is also emblematic of a larger phenomenon in terms of the socio- 
political background and the historical circumstances that impacted upon/fuelled the participation of several East European nations in WWI (Jukes, 2002). Like other nations of the region, Romania entered the war in hope of recovering its lost territories and putting an end to foreign domination. The Romanian State was forged in the conflictual whirlpool of the First World War, $1^{\text {st }}$ December 1918 marking the Great Union of all Romanians. Bearing in mind the historic peculiarities and the contemporary political similarities between countries of the region, the present work could become a pilot project for the heritage management of WWI remains on the Eastern Front.

\subsection{The First World War and Romania}

Romania celebrated a hundred years of National Unity in 2018, alongside the end of the First World War. This raised a need to question the significance of the remaining war relics. The fate of the material remains of the war in terms of preservation and legal protection depends upon the elucidation of their heritage status. Currently no East European World War I site has been granted official heritage status, despite the fact that for several nations of the region the war meant national unity and liberation from foreign domination. Consequently, there is a strong case for conducting research on the Galician Front from a heritage perspective.

With the passing of time WWI earthworks and buildings have become representative architectonical features. The Great War not only reshaped balances of power, redefined borders and wrote fundamental pages of national history for several states, but also shaped the identity of the land, redefining the landscape (Gheyle, et al., 2014). Throughout time, conflicts have produced warfare specificity (Keegan, 1994), different historic periods producing different forms of conflict and every form of conflict having its own idiosyncrasies, a sort of signature left behind. If medieval conflicts were "signed" with castles, we can 
legitimately claim that World War I was "signed" with earth works and bunkers. The Great War inaugurated a procedure of environmental incisions that branded places of war with the world war mark, converting the dug-in defenses for both terrestrial and airborne warfare (Lindqvist, 2001) into a hallmark that rooted the conflict within the earth. Bunkers (Virilio, 2008), trench systems, mine craters were all carved wounds in the landscape, wounds that in time turned into scars bestowing the natural environment with pride and personality, converting space into place (Hoelscher and Alderman, 2004).

From a remembrance perspective (Connerton, 1989; King, 1998; Moriarty, 1999; Winter, 1999; Bushaway, 2001; Misztal, 2003,), the war remains became potential genuine and inclusive war monuments holding not only national and local significance but also gathering together fragmented memories (Traverso, 2012), becoming representative in a frame larger than the national state. Unlike classic war monuments that were built to commemorate a precise and often restricting category (Nelson and Olin, 2003), WWI remains evoke all war participants regardless of the role they played in the war. In the guise of war monuments, the war relics would transcend traditional conceptual demarcations, not only by going beyond the rhetoric of winners/transgressors/victims/heroes but also by going beyond the frame of the national state to overcome contemporary representational dilemmas. Considering the hypothesis of framing war sites as potential war monuments is likely to be a valuable approach particularly, but not exclusively, for nations of the Eastern Front. That is because the histories of the Eastern Front are more problematic and ambiguous, generating considerable difficulties when applying traditional historic war labels that have been shaped to fit the conceptual frame of the Western Front (Cowley, 2003; Winter and Prost, 2005; Winter, 2006; Hart, 2013). The condition of several nations of the Eastern Front at the beginning of WWI generated a state of alterity, which was inherited by the places of war making their 
representation impossible within the nuances of classical war rhetoric. The socio-political circumstances that triggered the war effort of such nations hold subtle nuances that elude the monolithic repertoire of traditional war reiterations. Approaching these war sites with the wrong set of instruments, or ignoring their importance, not only alters the significance of the war itself but also the perceived implications of the war, seen from the perspective of world war. Furthermore, splitting the war phenomenon into two separate fronts impinges upon its most intimate characteristics thus blurring the socio-political complexity of WWI and mutual interconnections between the two fronts. The strong interrelations between the fronts are particularly highlighted by war sites holding a high degree of alterity, such as those of the Romanian historical regions. If, on the one hand, the liberation of these provinces from foreign domination represented the main motivation for the Romanian state to enter the war, on the other hand, such choice was a difficult one as the majority of the male population of the Romanian territories annexed by the Austro-Hungarian empire was already enrolled in the imperial army and territories inhabited by civilians were about to be converted into open battlefields, leaving the native population at the mercy of enemy forces. Similar dilemmas were the norm for most nations of the Eastern Front that had territories under imperial domination during the Great War, and was the main reason for massive desertions from the multi-ethnic Austro-Hungarian army, which makes a strong case for an holistic approach to the study of WWI remains.

\subsection{Research area}

Areas like that constituting the focus of this research have a marked alterity, which has led to the lack of previous research. They form a sort of grey area, a reign of silence derived both from their alterity as well as from the difficulty of tracing and accessing historical sources internationally, together with their unavailability at national level. These places are 
characterised by a lack of national army activity in the area and the conduction of operations in loco by enemy armies. This reflects the case of the present research area where the Romanian army did not conduct fights, the front was held by the Austro-Hungarian army which occupied the area at the time and fought against the Romanian national army after 1916.

Due to unfavourable historical circumstances the nationalistic rhetoric generally tended to neglect the war sites, and this particular category of sites received even less consideration. Even now these places of war do not only illustrate overall war dynamics, at least as far as the Eastern Front is concerned, but also reflect vibrant human landscapes where the local population worked alongside war prisoners to build war facilities for the occupying army. They also reflect the condition of the population under foreign domination at the beginning of the war and who entered the war in 1914, simultaneously with their invaders, unlike the rest of Romania that only entered the war in 1916. The male population of the Romanian historical regions under foreign domination were enrolled in the Austro-Hungarian Army and sent to fight in different war theatres all over Europe, ending up fighting against their own conationals after adherence of the Romanian Kingdom to the Entente. The complex circumstances that resulted from the atypical relations existent within and between the populations of the empires engendered intimate, insoluble interconnections between the two fronts as, in both cases, the fronts were made rather of people than of geographic features. This conjuncture converged in a solid mutual influence between the two fronts that were actually expressions of the same war and, as such, cannot be rigorously treated separately without causing serious distortions.

The research area chosen for this study is able to highlight all these aspects. The Mountains of Maramureş are part of the county of Maramureş situated in North Romania near the current 
border with Ukraine. Maramureş was among the last territories to be freed from foreign domination and united to "the Mother country" de facto in 1919 (Batin, 2014), in the aftermath of heavy fights conducted, physically, against the Hungarians and, diplomatically, against the Great Powers (Ardelean, 2016). At the beginning of the twentieth century, the mountains were surrounded by three empires: the Czarist Empire, the Austro-Hungarian Empire and the German Empire. Before the war, on the northern crest of the mountains, there was an imperial boundary stone in the shape of a triple-faced obelisk made of white marble, each facet adorned with a metal plaque pointing in the direction of one of the great empires. Locals claim that the stone still exists, forgotten deep in the mountains, although the plaques were presumably removed after the war.

Maramureș is also one of the Romanian historical provinces for which the war did not factually end in 1918, nor did the actual liberation of the liberated territories occur automatically at the end of the war. The continuation of physical and diplomatic fights after the end of the Great War constitute additional reasons for selecting the region for the present study, along with the criterion of providing a representative study area through which to advocate the need for better understanding of the Eastern Front's legacy and its intimate relations with the Western Front. The difficult position of the local population in Romanian historical provinces during WWI, their divergent histories, the unusual conditions of Romanian soldiers in the multi-ethnic imperial army, their loyalty dilemmas, persecutions, the exclusion from memorialisation of the overall population and the negation of their contribution to the war, along with the resulting alterity of the borderline places of war, recommend Romania as a suitable case study and Maramureș as an adequate study area for understanding Eastern Front WWI sites as heritage.

The Mountains of Maramureş are the only place in the whole county where war relics are still 
visible to the naked eye. During WWI, the Central Powers and the Entente established their front line on the crest of Maramureş Mountains. A fortified line of pillboxes and trenches, two military railways (Leordina-Poienile de sub Munte-Luhe and Borşa-Prislop-CârlibabaIacobeni), roads, a funicular railway and two towns of barracks (on the Prislop Pass and on Copilaşu Mounatin) were built in just a few months with a workforce of thousands of Russian and Italian prisoners and locals. At the end of the war, the two military camps were abandoned, the railway line Borşa-Iacobeni remained abandoned for a decade and then it was dismantled and moved on Vaser. The defence line of the Maramureş Mountains was restored during WWII as part of the fortified Arpad line (Filipascu, 1997). In the aftermath of the conflict the war remains were integrated into the landscape either by being abandoned to their fate or converted into local resources, as was the case with military access routes that were converted to forest roads.

The precise study area chosen as a case study, due to the existence of representative war remains, is the Prislop Pass and the adjacent area. This zone still preserves visible bunkers and earth works, a military road, remains of historical buildings, a military cemetery and common graves. Local memory has registered the cemetery as housing high-ranking Austro-Hungarian army officers, which, along with the historically-certified presence of military command in the area and the attestation of prominent historical military and political personalities visits to the sites, builds up a solid premise.

The Prislop Pass is an early route that connects Maramureş to Moldavia and is the highest passing of the Oriental Carpathians making it a particularly strategic position. The research area was selected by taking into account multiple rationales ranging from the existence of visible war remains, accessibility and the importance of this location in the economy of war, 
to the strategic position and designation that made this location static over several years of the conflict. A military camp was permanently located in the Prislop Pass for strategic and logistic purposes. It seems that this position provided logistic support to this section of the front line and monitored access routes into the county. Also, the earthworks and fortifications of the Prislop Pass were built in such a manner as to allow visual contact between the various positions. In the centre of the pass, in the backyard of a monastery, is a military cemetery built to honour Romanian, German, Russian, and Polish soldiers. Still, although the orthodox clergy claim that the cemetery was built to shelter the bones of fallen soldiers of the world wars that were discovered in loco in the late 90's during the building of the monastery, historical photographs reveal that the cemetery already existed on the same spot at the end of WWI.

The Prislop WWI earthworks were rebuilt during WWII as part of the Arpad line, demonstrating continuity of conflict between the Great War actors - the liberated nations and successors of the imperial powers - that survived the end of the Great War within the same environmental settings. The world wars' continuum is proven, not just by re-ignition of the same conflictual sparks that seemed to be extinguished at the end of WWI, but also by reiteration of the same geostrategic difficulties of the small countries that were previously caught between the former great powers and which remained vulnerabile in a regional context characterised by the dominance and threat of the avatars of the great empires, whose shadows continued to loom over their survival. 


\subsection{Methodology}

\subsubsection{First Objective}

The research methodology was designed to address each of the three objectives. The achievement of the first objective, related to documentation of the material evidence of World War I within the research area, was dependent on conducting archival research, site mapping and field survey. The in-depth documentation of the war's material remains relied on the above methods due to the necessity to both physically identify the specific research area and allow for the historical and symbolical characterisation of the places of war. The part of the research corresponding to the first objective served not only to record WWI material remains throughout the chosen research area, but also to extrapolate tangible and intangible characteristics of material culture in order to allow assessment of the war sites as heritage against the background of the historical context.

\section{$\underline{\text { 3.5.1.1. Archival research }}$}

An in-depth historical documentation of the research area was undertaken against the background of the overall Romanian war effort. This approach was justified by the need to determine the historical value of the sites, which is a precondition of the ascription of value to the surviving war remains. Both primary and secondary sources (mainly authors who had first-hand experience of the war), national and international works were used to construct the historical context without falling into the trap of nationalistic approaches. With the aid of archival research, military records, historical maps, journals, letters, memoires and monographs were traced and examined in order to build up the research context. The emerged data was analysed and organised into conceptual categories to provide raw material for future steps of the research, in addition to establishing the precise delimitation of the research area. 
WWI front line photographic collections pertaining to the research area were traced and selected from international archives and private collections. Analysis of old historic photographs enabled the extrapolation of prominent landscape features that were used as waypoints in the field surveys. Insights gained, with the aid of these sources, into aspects of the front line, such as logistics and environment, enabled comparison of the data against information from the written sources, in order to test its veracity.

The need to understand the memorial-symbolic value of the war sites brought about the exigency of rigorously exploring the socio-political background of WWI in Romania. In order to capture the symbolic value of the war sites the work had to engage not just with the documentation of the war effort and the main political documents produced at the time of the 1918 Great Union but, additionally, with the study and analysis of ethnographic collections of songs, the national anthem, WWI poetry and literature. The work presented above was a necessary precondition for determining intangible dimensions of the war remains, which constitute a fundamental component of heritage value. The content of the historical documents and narratives was analysed to extrapolate the contemporaneous meanings that the Great War held, in the Romanian context, and which have continued to be held over the past hundred years.

\subsubsection{Site mapping}

A preliminary mapping of the sites was made by relying on historic maps, topographic elevation maps and aerial photography. The data was processed in GIS with the purpose of recomposing the front-line landscape (Gillings, et al., 2000; Chapman, 2006; Masters and Stichelbaut, 2009; Pearson, 2012) within the research area. The datasets created during the archival research allowed the exact location of some of the features of the front-line area to be 
traced, plus the generation of a map that was used during the field survey. In addition, the location of war remains within the research area was examined.

Changes that the sites underwent during the several campaigns of field research and changes that became evident from analysis of satellite imagery demanded a brief reflection upon the conditions that caused war remains to be preserved in certain areas while being removed from others. As a result, and given the purposes of the research, it became relevant to develop an understanding of the potential influence exerted by geography on the war sites and of the implications and impact that development is likely to have upon the preservation of war remains. Furthermore, the emerging patterns can be explored to see if they match any international trends, although it exceeds the scope of the present work. For instance, recent studies have considered how the remains of the Spanish Civil War are preserved and protected in poorly inhabited areas and largely removed from intensely populated or farmed areas, suggesting that the development component has direct influence upon the preservation of war relics (Molina-Burguera, 2010). If the above hypothesis turns out to be viable in our case as well, then the focus on the Romanian World War I remains, as instances of heritage, at once reflects more general dynamics by questioning the relationship between the preservation/disappearance of war relics and the development ratio of the area.

\subsubsection{Field survey}

The archival and site mapping work provided the basis for selecting an area for targeted fieldwork aimed at characterising the surviving physical remains relating to WWI. The Prislop Pass area and the adjacent zone of the Maramureş Mountains were surveyed during a series of field walks along the front line that emerged from the previous data. A GPS device was used to track the researched area and waypoints were taken for any WWI remains 
discovered. Identified sites were measured, described and photographed, charted and analytical standard records - level 2 recording - were made for every one of them (Bowden, 1999).

Once the identification and registration stage was completed, the resulting data was stored for further analysis. The findings were contextualised, compared, and integrated with data from the written sources and photographic collections. Front-line GIS maps were updated with the results of the field survey and further analysis was conducted upon the newly-generated records.

Documentation of the material remains of war within the research area allowed the understanding of the kind of materials dealt with, the state of their preservation and the density of the relics and earthworks. Such knowledge facilitated prompt identification of the material remains of war and their location within the larger contextual landscape. The judicious documentation of the war sites was a fundamental precondition for further analysis.

To properly examine the research area in a way that allowed due understanding of the war landscape, a recording strategy was developed. Documentation of the war sites was made at three different tiers within the research area. The area was divided into three research sectors since, on one hand was the requirement to highlight the morphology of the conflictual landscape in a way that illustrated connections between the war sites and the vastness and complexity of the earthworks' networks and, on the other, the huge amount of materials spread over an impressively large area needed to be covered by one person in a limited timeframe. The current roads, that have emerged from the ex-military roads, were used as guide lines for the recordings. The first sector comprises the centre of the Prislop Pass, which is also where the Austro-Hungarian military camp was sheltered. In this area all visible features were 
recorded. In the second sector, which is somewhat larger, only large concrete remains mainly bunkers and their adjacent trench systems - were recorded, while the third sector was dedicated to the recording of large trench systems. All the sectors were surveyed during the field campaigns but the trenches of the third area were recorded prior to the survey in order to test the possibility of relying on GIS for conducting of large-scale earthworks registration work.

\subsubsection{Second objective}

The second objective was to investigate the national heritage legal framework and to establish the premises for granting heritage status in Romania, with a view to allowing the assessment of the war sites as heritage. The aim of the research pertaining to achievement of the second objective is firstly, understanding the Romanian heritage legislative evolution and characteristics and, secondly, the contextualisation and characterisation of the criteria according to which Romania declares heritage. The emphasis of mechanisms that are activated for granting legal heritage status, as it emerges from exploration of the national heritage context and legislation, allows for reading of the war remains registered in the previous part of the research within a perspective of heritage. Therefore, due to specific characteristics of the Romanian heritage, achieving the second objective was dependent upon examination of Romanian heritage legislation, textual analysis of national heritage standards and building analytical evaluation sheets for the war remains to allow for comparative analysis.

\subsubsection{Examination of Romanian heritage legislation}

Relevant Romanian legislation was identified - starting from the introduction of the first historical notions of heritage up to the present legal framework - and analysed with the 
purpose of understanding the nature of official heritage management in Romania. The historical evolution of heritage in Romania was considered by exploring the content of all the official Lists of Historic Monuments (1955, 1975, 1991, 1992, 2004, 2010, 2015) in relation to the County of Maramureş as well as the legal framework that produced them. The mechanisms activated in order to grant legal protection to historical features were explored and the selection criteria for the historical monuments were extrapolated.

\subsubsection{Textual analysis of the national heritage standards}

Up to now, no Romanian war site has been officially granted heritage status and hence the WWI sites lack terms for comparison on the basis of similarity from the point of view of national heritage. Therefore, in order to test the selection criteria for granting heritage status a different standard was used to replace the absent cases. Amongst Maramureş' various heritage categories, churches are both the most representative and well-represented category, so this category was selected to examine application of the selection criteria prescribed by the national regulations.

Analytical evaluation sheets used by the Ministry of Culture in the process of evaluation of the heritage value of churches were reproduced in order to allow comparison with the heritage value of war sites in the discussion chapter. Still, in order for this objective to be achieved, the field for development of the analytical records of the places of war had to be prepared. This implied evaluation of the symbolic value of the war sites and, thus, analysis of the immaterial significance of the material remains became compulsory. The present-day significance conferred on the Great War in Romania was assessed by exploring the national legislative initiatives adopted at the time of the centennial of the Great Romanian Union and the end of WWI. 


\subsubsection{Building analytical evaluation sheets for the war remains}

The findings from previous parts of the research were used to build the analytical evaluation sheets for the war sites identified during the field survey, relying on the same official templates that have been used for declaring the churches historical monuments and abiding by the same rules and regulations. The evaluation sheets serve the purpose of drawing upon the potential heritage worth of the war sites within Romanian heritage frameworks. This also allows for the comparison of the war sites to other heritage categories at national level, and allows for both comparison and integration with similar heritage categories at an international level. Such an approach favours the investigation of both the national and international heritage standards emergent from examining the national heritage criteria and World Heritage criteria, emphasising differences, similarities and interrelations.

\subsubsection{Comparative analysis}

The results of previous sections facilitated comparative analysis between the World War I sites considered as a potential heritage category and the churches category. This section of the work provided valuable insights on why war relics are not legally protected in Romania and on their relevance for local and national identity, while simultaneously highlighting the legal procedure that must be activated in order to grant them heritage status.

The study of national legislation inevitably ends up converging with international legislation. Romania has ratified international heritage agreements and must, therefore, abide by international rules governing the field of heritage. As a member state of the European Union Romania is also bound to follow regional agreements in the field of heritage. Consequently, it becomes necessary to examine international legislation in the field of heritage. Furthermore, as the work aims to explore the significance of WWI sites as places of remembrance and 
heritage at various levels of analysis from local to national and international, it inductively has to deal with the UHD and, implicitly, with the World Heritage standard.

\subsubsection{Third objective}

The third objective aims to assess the international significance of WWI sites and provide context for the Romanian case in the wider heritage debate by investigating the international legal framework and examining the premises for World Heritage status. The research pertaining to achievement of the third objective aims to supply understanding of the legislative evolution and characteristics of international heritage, as well as contextualisation and characterisation of the criteria according to which World Heritage status is granted. The emphasis deducted from the mechanisms activated for granting legal heritage status, as it emerges from exploration of the international heritage context and legislation, allows the building of a hypothetic nomination for the Romanian war sites. Simulation of the inscription of the places of war on the World Heritage Tentative List allows comparison of the subject matter to other international war sites that made it into the Tentative List, on the one hand and, on the other, to different Romanian heritage categories that have been granted World Heritage status, like the Wooden Churches of Maramureș. The specific characteristics of international heritage, especially in relation to World Heritage status, required examination of the international heritage legislation, the textual analysis of World Heritage standards, the building of a hypothetic nomination of the war sites for the World Heritage List, and the conduction of comparative analysis.

\section{$\underline{\text { 3.5.3.1. Examination of international heritage legislation }}$}

Relevant international heritage legislation was identified - starting from implementation of the first international conventions regarding heritage protection in the event of an armed 
conflict, up to the present legal framework - and analysed with the purpose of understanding the nature of official heritage management internationally. The historical evolution of international heritage was considered by exploring the content of the main heritage-related conventions and also the legal framework that produced them. Mechanisms that are activated when granting World Heritage status have been explored and the selection criteria for historical monuments have been extrapolated. The framework of international heritage legislation and global practices (Carman, 2015), derived from examination of international laws, treaties and conventions, was completed with the frame of emergent new heritage trends extrapolated from programs and policies promoted during the European Year of Cultural Heritage.

\subsubsection{Textual analysis of World Heritage standards}

From the review of the international heritage (Lowenthal, 1998; Skeates, 2000; Carman, 2002; Smith, 2004; Price, 2005; Harrison, et al., 2008; Sørensen and Carman, 2009; Smith and Waterton, 2009; Harrison, 2010; Vecco, 2010; Silverman, 2011; Harrison, 2012; Biehl and Prescott, 2013; Macdonald, 2013) and remembrance (McIntyre, 1990; Bushaway, 1992; Halbwachs, 1992; Forty, 1999; Boorman, 2005; Harrison, 2013), debates highlight the strengths and weaknesses of the field, its potential and especially its challenges. The need for taking into account the international significance of WWI sites inevitably entails dealing with Authorized and Universalized Heritage Discourse as a consequence of being dependent upon the World Heritage status. The monopoly held by the UNESCO heritage label, as the only

official international assertion of heritage accepted worldwide, auto-selects analytic variables of the research, narrowing down the choices to the content of the World Heritage List. Additionally, the great diversity of international legislation, which makes comparison between the legislation of different states and implicitly of adjacent heritage a difficult 
endeavour, further informs the above choice. Although no WWI sites have yet been granted heritage status, recent additions to the UNESCO Tentative Lists (UNESCO, 2018) demonstrate an international interest towards their recognition within World Heritage values. Such submissions will be examined and reproduced to allow the examination of the World Heritage criteria and their application, and also to provide international terms of comparison for the Romanian case. Furthermore, the case of the Wooden Churches of Maramureș, which were included in the World Heritage List in the 1990s, will provide further terms of comparison for the war sites studied here, aiming to integrate the frame of the World Heritage perspective and link it back into the case study.

\subsubsection{Building a hypothetical nomination for the World Heritage List of the war sites}

The findings of previous parts of the research were used to build a hypothetical nomination for the studied Romanian war sites, abiding by UNESCO rules/regulations and using the official templates required to submit applications for the World Heritage List. The hypothetic nomination serves the purpose of drawing upon the potential heritage worth of Romanian war sites within the international heritage framework. This enables comparison of the war sites to other heritage categories at international level and, further, it allows both comparison and integration with national heritage categories that have been granted World Heritage status, favouring the investigation of interconnections between national and international heritage and nominally qualifying them for integration.

\subsubsection{Comparative analysis}

The results of the previous sections have facilitated comparative analysis of the Maramureş case in relation to WWI sites pertaining to other countries within the frame of the UNESCO World Heritage standard. This section of the research provides valuable insights concerning 
the international significance of WWI sites while simultaneously highlighting the limits and limitations of the achievement of World Heritage status at procedural level. Furthermore, the comparison of the war sites to the Wooden Churches of Maramureș sanctions testing the application, evolution and content of the UNESCO standards and, additionally, it re-integrates the case study into the local-national-international layer matrix whilst simultaneously emphasising their solid interconnections.

\subsection{Conclusion}

In addressing the aim of examining the significance of Romanian WWI sites as places of remembrance and heritage, the methodology was designed to address its three subsidiary objectives. Objective 1 sought to explicitly identify the material evidence of WWI in Maramureș. This is a fundamental precondition of this study, as it is conducive to understanding which factual material remains of war are to be considered for further analysis. Understanding the nature of the evidence within the research area is likely to increment our understanding of sites along the Eastern Front by allowing us to develop patterns to be engaged when identifying similar war sites along the front line. Furthermore, it allows evaluation of the levels of preservation of the material remains, thus providing an essential component for assessment of their heritage value. Also, by analysing the location of the war remains, we can examine the influence that geography and development exerts upon preservation of the sites.

Objective 2 sought to facilitate assessment of the places of war as heritage at national level by investigating the Romanian heritage legal framework and examining the premises for granting heritage status at national level. Understanding the precise criteria, according to which Romanian legislation determines what is worthy of heritage status and what mechanisms are 
activated in declaring heritage, seemed to be the next logical step. This section of the research clarifies the significance of war remains within the national legal frame and allows comparison with other heritage items, shedding light on their potential and worth from an official heritage perspective.

Objective 3 sought to expedite assessment of the international significance of WWI sites and provide context for the Romanian case by investigating the international legal framework and examining the premises of World Heritage status. Understanding how war remains relate to the UNESCO heritage standards, and therefore to the UHD/AHD, allows contextualisation of the present research within the international heritage debate and also provides terms of comparison for the results of previous parts of the work.

The research design is incremental, with the results of each stage affecting the next. Structurally, the work that begins with the analysis of the Maramureş war sites will follow the path of national and international heritage legislation and debate to finally re-conduct the results to the case study in a concentric manner. The subsequent chapters of this work will present results derived from the methodologies applied to the three objectives around which the research design was structured in order to address the central aim. By recomposing the findings of the different layers of analysis, comparing, contrasting, and discussing them together in an integrated way, the relevance of Romanian World War I sites as places of remembrance and heritage will emerge and be elucidated. 


\section{CHAPTER 4 - HISTORICAL REVIEW}

\subsection{Introduction}

This chapter informs the achievement of the research's first objective pertaining to contextualisation of the research area within the larger WWI frame. Nonetheless, it also has strong relevance to the second and third objectives, which relate to the national and international significance of the war sites as, on the one hand, it provides the historical context for their historical and physical characterisation and, on the other, it allows the symbolic characterisation of the places of war, which is a fundamental condition for the assessment of heritage. The work conducted throughout this chapter enables the extrapolation of tangible and intangible features of the studied material culture against the background of the historical context, so preparing the field for the future parts of the research. Understanding the historical and socio-political context of Romania and of Maramureș during the Great War stands as a precondition for achieving the aims of the present work as it opens a window to understanding a multi-layered past and its reiterative forms of engagement, leading to decoding the significance of the war places at various levels of analysis.

Within the context of the overall Romanian war effort the alterity of the Romanian historical provinces in general, and of Maramureș in particular, emerges in line with a more general transnational East European tendency derived from the peculiar circumstances of the nationalities who were under imperial dominion at the start of WWI. The need to consider the social dimension of the war in addition to the standard military approach is connected to the need to determine the historical and memorial value of the war sites as part of the process of value ascription of the war remains. 
Examination of the war sites as places of remembrance and heritage is dependent upon the emphasis of the immaterial valances of material culture. Study of the socio-political background of the Romanian territories, especially Maramureș, during WWI is compulsory to understand the memorial-symbolic value of the war sites that constitute the focus of this research. The complexity of the intangible dimensions of the war remains brought about the need to also explore ethnographic collections of songs, the national anthem, WWI poetry and literature in addition to engaging with documentation of the Romanian war effort and the main political documents produced at the time of the 1918 Great Union. Reading the material culture, not just through the lens of historical documents but also of ethnographic and literary narratives, allows desciphering the meanings that the Great War held in the Romanian context at the time of the war, and which are still perpetuated today.

In terms of structure, the first part of the chapter deals with the Romanian involvement in WWI focusing on the military and political dimension of the war: the reasons behind the decision to enter the war, the military operations, the diplomatic endeavours and the Great Romanian Union. The second part of the chapter is dedicated to the war effort of Romanian historical provinces appendant to the Austro-Hungarian Empire, especially Maramueș and Bukovina, focusing primarily on their role in the economy of war and on the human dimension of the war.

\subsection{The Romanian Kingdom in WWI}

At the beginning of WWI important historic Romanian provinces were under foreign domination. The great majority were annexed to the Austro-Hungarian monarchy. The Romanian Kingdom decided to remain neutral in the first two years of conflict as political leaders were trying to speculate the best possible alliance that would allow them to recover 
Ardeal, Crișana, Maramureș, Bessarabia, Banat and Bukovina. The geostrategic position of the Romanian Kingdom made it an important potential ally both for the Allies and the Central Powers. Such consideration resulted in efforts made by both sides to seal an alliance with the Romanians. Nevertheless, the Romanian political leaders saw the war as a great opportunity to achieve their long-aspired national goals of unity, sovereignty and independence. The main political goal of Romanian involvement in the conflict was to be the achievement of the Romanian national unitary state (Ceaușescu, 1989).

In spite of the fact that the war eventually suppressed the German Empire, the Russian Empire, the Austro-Hungarian Empire and the Ottoman Empire, at the beginning of the war there were few men who dared to believe that the great empires surrounding the Romanian territories were likely to fall. The Romanian territories constituted an object of rivalry between the empires that were all animated by expansionist ambitions that converged in annexation plots concerning different parts of the Romanian territory (Hitchins, 2013). King Carol I of Hohenzollern, along with the leadership of the conservative and liberal parties supported alliance with the Central Powers, as that block was reputed to be Europe's most powerful economic and military force. Moreover, on $18^{\text {th }}$ October 1883 , Romania had signed a secret bilateral alliance with Austro-Hungary. Without doubt, the King's origins played an undeniable role in such a choice. Nonetheless, the decision to join the Triple Alliance was mainly a strategic requirement meant to avoid the diplomatic isolation of Romania in case of an alliance between the Russian and Austro-Hungarian empires, and consequently the partition of the Romanian territory (Rădulescu-Zoner, 1977). The alliance, that lasted for thirty years, marked the course of Romanian external policy. Although it did have certain benefits, at least in a first phase, it gradually turned out to be very unpopular amongst the people. Public opinion developed an increasingly hostile attitude towards Austro-Hungary as 
it supported the cause of their lost brothers - the Romanian population that inhabited historical Romanian territories annexed to the empire.

Although before the start of the First World War Romanian international relations were mostly influenced by its alliance with the Triple Alliance, after the Balkan wars, Romania started growing apart from the Austro-Hungarian directives, privileging relations with Germany and promoting a process of co-ordinating its national position with Italy (Bărbulescu, et al., 1998). The interest manifested by the Entente for the Balkan crisis triggered a process of re-orientation of Romanian foreign policy towards the Entente. Still, initially, Russian interests in the area prevailed upon Romanian territorial claims in terms of international relations and neither France nor Great Britain was willing to grant Romania security warrants against the Russian Empire (Vesa, 1980). Nevertheless, once the possibility of war became imminent, the issue of winning Romania onto the Entente side became essential.

The Romanian leadership, aware of the expansionist tendencies of its neighbours and desirous of recovering its lost territories, decided not to honour its alliance with the Austro-Hungarian Empire. The 1883 alliance was disregarded on the basis of the "casus foederis" clause and the neutrality of the Romanian Kingdom was proclaimed (Calafeteanu, 1986).

After the beginning of the war, the German emperor summoned King Carol to abide by its duty as an ally. On the other side, the Entente offered Romania recognition of its territorial rights in the Hungarian imperial areas inhabited by Romanians as an incentive to join the alliance. The attitude of the Romanian political elite was far from homogeneous. There were two sides, each supporting one of the two international blocks (Ceaușescu, 1989). Obviously, the king and a small group of politicians supportive of Germany inclined to support the Triple 
Alliance, while the great majority of political leaders and public opinion were in favour of joining the Entente. However, both sides convened with regard to the necessity of avoiding going to war, until more favourable circumstances emerged (Bărbulescu, et al, 1998).

On the $3^{\text {rd }}$ August 1914 a Crown Council was brought together at the Peleș Castel in Sinaia. The Crown Council debated two potential options: the first, promoted by the king and the leader of the Conservative Party, agitated to enter the war alongside the Central Powers without delay; while the second, supported by the majority of politicians, opted for maintaining the state of neutrality. To the great disappointment of King Carol, the position of the majority, represented by the Prime Minister Ionel Brătianu and supported by public opinion, prevailed (Duca, 1981). The publicity release issued by the council after its meeting stated that, almost unanimously, the Council had decided that the Romanian state should take all measures to protect its frontiers; in other words, armed war expectancy. The state of neutrality was recommended until the evolution of the war allowed a higher degree of predictability, which would advance the fulfilment of the national goals. After the Crown Council the Romanian political leaders initiated a process of diplomatic scrutiny, meant to identify the best moment for entering the war and negotiate the best possible position (Scurtu, et al., 2001).

The Romanian Kingdom ratified a secret agreement with the Russian Empire in Saint Petersburg, known as the Sazonov-Diamandy Convention, on $1^{\text {st }}$ October 1914. Russia committed to stand as a guarantor of Romanian territorial integrity and recognised Romanian legitimate rights over the Austro-Hungarian provinces inhabited by Romanians. As far as the issue of Bukovina (a Romanian historical province contended with the Russians) was concerned, the two sides agreed that in delimitating the borders between the two states the principle of nationalities should be applied (Calafeteanu, 1986). 
The Austro-Hungarian Empire was also making efforts to persuade Romania to enter the war on its side. The adherence offer from the Austro-Hungarian government was conferred in Bucharest on $29^{\text {th }}$ June 1915 by count Ottokar Czernin. The Austro-Hungarian proposition mainly consisted of the integral retrocession of Bukovina, the recognition of Romanian rights in Bessarabia and a series of concessions regarding the status of the Romanian population in Transylvania.

During the negotiation stage, while still maintaining the state of neutrality, the Romanian Kingdom started preparing for war. Undoubtedly, one of the main reasons impending upon the neutrality decision was the state of the army (Torrey, 1978). The Romanian army needed reorganisation and presented serious deficiencies in several sectors: the army was lacking military staff, services, equipment, armoury, munitions, medicines, and it had serious organisational issues (Gane, 1936; Stan, 1996; Ionescu, 2013). The liberal government, instated in 1914, understood the imperative need to restructure and modernise the army before going to war. General Dumitru Iliescu, sub-chief of the Armed Forces General Staff, declared that at the beginning 1914 the army was facing a serious resource shortage crisis and that practically everything required to support the war effort was missing (Iliescu, 1924). On such premises, and aiming for augmentation of the war capacity, the Ministry of War and Armed Forces General Staff devised a plan for reforming the army (Serviciul Istoric al Armatei, 1934). Combat capacity was to be enhanced by updating four main military dimensions, each regulated by an individual plan. The first plan was to complete, transform, and repair the weaponry, ammunitions, and war materials. The second plan was to complete all categories of equipment, to assure the subsistence of men and livestock in all military formations, and it contemplated the creation of large supply centres to provide for such needs. The third plan 
regarded the army sanitary system, and the fourth regarded deployment of human resources to the operative army and its services (Dumitrescu, 1924).

In order to stick to the reform plan, Romanian military leaders had to overcome two major issues: the impossibility of adequate internal production of war materials and the unavailability of external supply. Neither of the two coalitions was willing to honour the Romanian supply demands given its uncertain position. The shortage of supplies translated, in practical terms, into utilising a great diversity of arm calibres which negatively impacted the troops' instruction and hardened the flow of ammunition supplies during the war (Armata Română, 1987). Consequently, the army was restructured leaving unsolved major limitations concerning the arsenal, the training of military leadership in adequate modern tactics, and the instruction of troops in the subsequent procedures. Nevertheless, the neutrality period converted the Romanian army into a functional war apparatus (Kirițescu, 1989). In this manner Romania added to its strategic geographical position, which edged both blocks involved in the conflict, the aid of an operative army of 600.000 men becoming a very attractive ally and creating a stronger negotiation position as there was common conviction amongst antagonist blocks that Romania held the key to the war's outcome. The German field marshal, Paul von Hindenburg, was persuaded that Romanian action would have been enough to decide the fate of the First World War (Torrey, 1980).

Although the Entente offer was a far better choice for Romanian interests, there was a

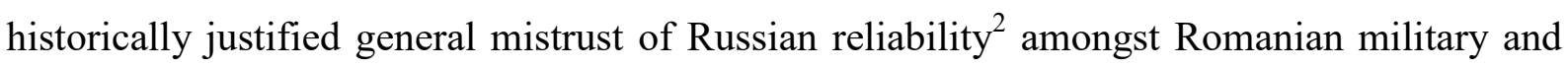
political leaders. This induced the Romanian Prime Minister, Ionel Brătianu, to decline the

\footnotetext{
${ }^{2}$ In 1878, at the end of the Romanian Independence War, Romania lost the south of Basarabia to the Russian Empire, although on $4^{\text {th }}$ April 1877 the Russians had signed a convention with the Romanian government stipulating that if the Romanian Kingdom granted the tsarist troops free passage over Romanian territory on their way to the Danube, the Russians would maintain the territorial integrity of the Romanian state and assure its defence (Marshall, 1992).
} 
Entente's offer until Russia officially granted Romania its territorial claims and certifiably agreed to the clauses of the Romanian adherence (Terraine, 1997). The end of the war revealed that the Romanian caution was not only justifiable but also prescient as, on $11^{\text {th }}$ August 1916, France and Russia had signed a secret agreement to prevent Romanian participation with full rights at the future peace conference, while France and Great Britain also had a secret agreement, in July 1916, stipulating that the Salonican army was only to support the Romanian war effort if it concomitantly attacked Bulgaria (Keegan, 1999).

\subsection{The 1916 Romanian Campaign}

Romania eventually signed the treaty with the Entente on $4^{\text {th }}$ August 1916 . The tragedy of the situation was that Romania, by dwelling upon the issue of joining the Allies, postponed the actual decision until it was too late, and instead of participating in the consolidation of a great success in June exposed itself in August to an impetuous German revenge (Falls, 1959; Terraine, 1997).

Still, although the fate of Bessarabia remained somehow uncertain, Russia, England, France and Italy finally agreed to grant Romania its territorial claims. In exchange, Romania had to attack Austro-Hungary no later than $28^{\text {th }}$ August. In the given circumstances this represented a great diplomatic achievement as testified by the Romanian political leaders who witnessed the signing of the treaty.

The Prime Minister "had managed to consecrate through an international act, bearing the signatures of the greatest European powers, the secular rights of the Romanian nation upon the territories inhabited by the Romanians of the Habsburg Monarchy. Whatever happened, winners or losers, it was for the first time in the history of the Romanian nation that the Romanian territorial claims were officially recognized. Even if an uneven fate would forbid Romania to accomplish its goals, due to the recognition of the Allies an important step toward their accomplishment was made. They penetrated the universal consciousness, converting from the patrimony of a small kingdom to integrant part of the future organization plans of the main European powers" (Duca, 1981, p.255). 
The Crown Council decided that Romania was to enter the war on the side of the Entente, and transmitted a declaration of war to the Austro-Hungarian Empire on the $27^{\text {th }}$ August 1916 (Mamina, 1997). The Allies agreed to launch a simultaneous offensive on Salonica and promised to provide Romania 300 tons of war materials per day. On $28^{\text {th }}$ August, Germany declared war on Romania while Turkey made its declaration of war on $30^{\text {th }}$ August. The day after, Bulgaria attacked Romania without a war declaration, which was to be issued only on the $1^{\text {st }}$ September 1916 (Beckett, 2013).

During the Crown Council, the new King's attitude towards choosing allies was quite different from that of its predecessor. At the beginning of the meeting, King Ferdinand announced that the decision to enter the war alongside the Entente had already been taken and that he had not summoned the political and military leaders to ask for advice but to request their support (Hamilton, et al., 2003). The meeting closed after the Prime Minister's discourse, with no official communiqué.

Ionel Brătianu stated that "in the life of the nations there are affirmations of rights which weigh more than transient triumphs and there are gestures of abdication, of moral desertion, that compromise the future of nations for centuries to come. In such a situation lays Romanianism today... and if not today, then tomorrow we shall reap the fruits of this oblation and affirmation of right" (Duca, 1981, p.282).

In the afternoon of the same day, general mobilisation was decreed and the state of siege was proclaimed. On $28^{\text {th }}$ August 1916, the same day on which the war against Austro-Hungarian Empire was officially announced, King Ferdinand released a proclamation (see Appendix 2), issued to all Romanians, encouraging the people to fight for their long-awaited national unity and for the freedom of their enslaved brothers (Ferdinand, 1922).

The initial strategy of the ensuing 1916 Romanian military campaign, known as Hypothesis Z, was faithfully subordinated to achievement of the political goal of national unity (Serviciul 
Istoric al Armatei, 1934). The Z Hypothesis planned simultaneous engagement of military operations on two fronts. A strategic offensive was to be launched on the northern and northwestern front while the southern front was to prepare for defensive war. The Transylvanian offensive was planned as three stages, with a maximum length of thirty days, at the end of which the Romanian army should have reached the Ciucea-Caransebeș alignment to engage battle with the enemy. In accordance with the plan, four armies were to be constituted at the time of the general mobilisation decree: the First Army, the Second Army, the Third Army and the Northern Army (Cioflină, 1996). The fact that the army units were formed only after general mobilisation was decreed, impacted negatively on the plan's execution. It was impossible for the armies to successfully manage their own creation concomitantly with conducting the planned operations. This led to hesitant and mainly improvised operations in most of the army units, with only the exception of the Northern Army of General Prezan (Otu, 2011).

Practically, the 1916 Romanian campaign included four main strategic operations (Beckett, 2013), as follows: 1 - the offensive in Transylvania (see Appendix 3); 2 - defence of the south front (see Appendix 4); 3 - defence of the Carpathian Mountains passages (see Appendix 5); 4 - defence of the Muntenia territory (see appendix 6).

The 1916 Romanian campaign can be considered to have concluded on $6^{\text {th }}$ December when the German troops occupied the Romanian capital city (Petin, 1932) forcing the Romanian government and the army to retreat to Moldavia. Regardless of their tactical victory, the Central Powers failed in their attempt to obtain Romanian capitulation. At the end of 1916, although two-thirds of Romanian national territory was under foreign occupation, the Romanian Army continued to fight. 


\subsection{The 1917 Romanian campaign}

Battles continued in 1917 with repeated German attacks in the Eastern Carpathians. Nonetheless, the triangle defence of the $4^{\text {th }}$ Romanian Army prevented the conquer of Moldavia. The army was reorganised and a new campaign plan was envisioned taking into account, not just national political exigencies, but also the allies' requests, the new configuration of the front line and the objectives of the three Russian Armies present on Romanian grounds.

On $5^{\text {th }}$ February 1917, General Alexandru Averescu noted in his journal, regarding the situation in Moldavia, that there was a high rate of mortality in all social strata due to low temperatures, starvation and exanthematous typhus (Murgescu, 2001, p.276). Meanwhile the Germans managed to exploit the Ploiești oilfields, extracting over a million tons of oil by the end of the war, and to confiscate millions of tons of grain from the Romanian peasantry, providing the army with fundamental resources that turned out to be vital for the German war effort (Keegan, 1999).

During the Chantilly Conference the Entente decided their 1917 operation plan. An offensive operation was to take place in the spring on the Romanian front, with the actual organisation of manoeuvres being left to the discretion of the Russian military authorities. The initial plan was agreed by Russian and Romanian commandments in March and aimed to block enemy forces by means of separate but continuous attacks by the allied armies to prevent the movement of German troops between the fronts. The Russians were supposed to start their offensive in Galicia in March, while the offensive on the Romanian front was due in April, but the outbreak of the Russian revolution inferred with the Russian-Romanian campaign plan (Kirițescu, 1989). 
The operation plan was eventually finalised during the Russian-Romanian Commandment Conference in Iași on $30^{\text {th }}$ May $/ 12^{\text {th }}$ June. Once again there was opposition between the strategical views of General Prezan and General Averescu, although this time the Prezan's realistic position prevailed. The plan envisioned a main strike against the $9^{\text {th }}$ German Army in the Nămoloasa sector, to be carried out by the $1^{\text {st }}$ Romanian Army along with the $4^{\text {th }}$ Russian Army. A secondary strike was to be conducted by the $2^{\text {nd }}$ Romanian Army in the Mărăști sector, aiming to immobilize enemy forces in support of the operations of the right flank whilst executing the main strike (Ioanițiu, 1929).

\subsubsection{The Mărăști Battle}

The operation was not carried out as planned, as the Mărăști offensive became the main battle after the first part of the plan was set aside. General Averescu issued Operation Order no.1638 appointing the $2^{\text {nd }}$ Army to conduct an offensive in the Putna valley. The troops, co-ordinated by General Arthur Văitoianu, were in charge of breaking the enemy lines along a 13 km-wide sector of the front. The battle started with the attack of the artillery divisions on $22^{\text {nd }}$ July. Their mission was to destroy and destabilise the enemy defence line's engineering works, breach the barbed wire network, and destroy the enemy artillery batteries (Ceaușescu, 1989).

The infantry offensive started after the artillery attack on $24^{\text {th }}$ July. Romanian soldiers passed through the breaches prepared by the artillery and engaged the enemy in a face to face bayonet fight. In the first day of battle Romanian troops created an opening in the front line $10 \mathrm{~km}$ wide and $3 \mathrm{~km}$ deep, took two thousand prisoners and captured large amounts of weaponry and munitions. The next day, Romanian troops reached the Dealu Mare-VizanteaLivezi alignment and occupied the Mărioarei Hill, while the $8^{\text {th }}$ Russian Army group reached the Livezi-Vidra alignment (Dabija, 1936). 
Simultaneously, on the Galician front the Russian offensive was facing catastrophic outcomes. The City of Tarnopol was occupied by the Central Powers, who had switched to offensive on the entire Galician front. The Russian Supreme Command decided to retreat the $40^{\text {th }}$ Russian Army Corps from the Romanian front in order to engage it on the Bukovina front. At the request of their Russian ally, the front of the $2^{\text {nd }}$ Romanian Army was extended in order to support the Russian war effort in Bukovina, consequently suspending the Mărești offensive on the $25^{\text {th }}$ July (Ioaniţiu, 1929).

General Averescu considered that the current location of the troops was a bad position for defence and asked General Prezan's permission to continue the offensive until a suitable defence position could be reached. Permission was granted, and the battles continued successfully on $26^{\text {th }}$ and $27^{\text {th }}$ of July. Although the soldiers were fighting energetically to push the front further, on $28^{\text {th }}$ July General Averescu issued Order no. 2050 stopping the offensive due to the objective, established by the Romanian General Head Quarters of stabilising the front on the Măgura Cașinului - Seciului Mountain - Sboina Neagră - Tiua Neagră - Tiua Golașă - Tulnici - Bârsești - Sării Valey, having been achieved. The Battle of Mărăști ended on $1^{\text {st }}$ of August after having produced a $30 \mathrm{~km}$-long by $20 \mathrm{~km}$-deep breach in the enemy frontline and having recovered territory of more than 500 square $\mathrm{km}$ and thirty settlements (Ceaușescu, 1989).

\subsubsection{The Oituz Battle}

The battle of Oituz started on $8^{\text {th }}$ August in reaction to attempts by the Gerok Army Group to breach the Romanian defence in the Trotuş Valley. The Central Powers were planning to crash the Russian-Romanian defence system in the Oituz Valley. The general offensive was designed to conquer the territory of the region in order to allow troops to reach von 
Mackensen divisions that were engaged in an offensive on the Siret Valley (Cupsa, 1967). The offensive plan envisioned a simultaneous double attack, with a main strike to be carried out by the $8^{\text {th }}$ Army Corps on the Ferestrău-Grozești-Onești trajectory and a secondary strike to be delivered by the $70^{\text {th }}$ Honvezi Division on the Târgu Ocna trajectory (Dabija, 1936). Resistance against the offensive of the Central Powers was assured by the Romanian $2^{\text {nd }}$ Army supported by Russian troops, and four extra battalions were positioned at Câmpuri as a reserve for the $2^{\text {nd }}$ Army (Băldescu, 1934).

Strategically speaking, the complex military operations that lasted until the $22^{\text {nd }}$ August were successful for the Romanian side. The battles that took place on the Slănic, Oituz and Cașin valleys stopped the Austro-Hungarians from penetrating into the Trotuş valley and blocked their way to Onști and Adjud, preventing their connection with armies that were fighting the Romanians at Mărășești (Kirițescu, 1989).

\subsubsection{The Mărășești Battle}

The complex military operation that took place between $24^{\text {th }}$ July and $21^{\text {st }}$ August 1917 , in the area between the Siret and Putna rivers on the Mărășești-Muncelu alignment, known as the Mărășești Battle, was the greatest Romanian battle during WWI. The defence of the RussianRomanian troops against the German offensive braked the Central Powers offensive ambitions in the area assuring stability of the adjacent front line. The Mărășești defeat inaugurated a period of exclusively defensive operations for the Central Powers on the Romanian front, that lasted until the end of the war (Armata Română, 1987).

The Central Powers aimed to proceed along the Siret valley in the direction of Adjud with the aim of reaching the $1^{\text {st }}$ Austro-Hungarian Army that was engaged in battle at Oituz. The 
overall purpose of the manoeuvres contemplated by the Austro-Hungarian campaign plan was to force Romania to capitulate by executing a simultaneous attack in the Nămoloasa sector and on the Oituz valley. If Romania had been pulled out of the war the Central Powers could have reached the south of Russia in present day Ukraine and gain access to the region's resources (Kirițescu, 1989).

On the other side, Romanian military authorities were planning a strategic counter-offensive relying on the support of their Russian allies. The main operation was to be executed by the $1^{\text {st }}$ Romanian Army in the Nămoloasa sector followed by a change of direction towards South-West to strike the enemy from the flank and back. Concomitantly, the $4^{\text {th }}$ Russian Army was to attack from the North, while on the South-West side of the front the Romanian Cavalry units, along with the $6^{\text {th }}$ Russian Army, were to engage in battle with the GermanBulgarian-Turkish troops in order to free the plains of Brăila (Ioanițiu, 1929). The operation was not carried out as planned because disastrous Russian outcomes in Eastern Galicia and Bukovina necessitated removal of five Russian army corps from the Romanian front and their engagement into battle on the Galician front. The $1^{\text {st }}$ Romanian Army acted as substitutes for the withdrawn Russian units and launched an offensive at Mărășești, thus obliging the Central Power to reconsider their initial plan.

In the light of favourable developments on the Galician and Bukovinian fronts the Central Powers decided to launch an offensive on the Focșani-Adjud trajectory (Kirițescu, 1989). The Battle, which lasted twenty-nine days, culminated in the defeat of the Central Powers, but the cost of the victory in human lives was huge: the $1^{\text {st }}$ Romanian Army lost 27,410 soldiers (dead, missing, wounded) and the $4^{\text {th }}$ Russian Army lost 25,620 soldiers (dead, missing, wounded). Despite an unavailability of official data regarding the Central Powers' losses, 
Constantin Kirițescu estimates that the losses of the $9^{\text {th }}$ German Army alone amount to $60-$ 65,000 men (Dabija, 1936).

The 1917 Romanian campaign was marked by Russian internal tensions preceding the October revolution. The Brest-Litovsk Treaty left Romania in a state of total isolation and completely surrounded by enemy forces. The conquest of power by the Bolsheviks in Russia, and the consequent disarmament and dissolution of the Russian Army, created a void of power for the Entente on the Eastern Front between the Baltic Sea and the Black Sea (Constantiniu, 1997). The violation of the 1916 military convention, by the Russians, had disastrous consequences for the Romanian Kingdom. Without their Russian ally it was practically impossible for Romania to face the pressures from the Central Powers and defend what was left of its territory. After sealing the November Russian-German armistice and the negotiations conducted with the Archduke Joseph August of Austria by the commander of the Russian troops in Moldavia, Ion I.C. Brăteanu, leader of Romanian Government, decided to sign a truce with the Central Powers on $26^{\text {th }}$ November 1917 (Bold and Ciupercă, 2010).

\subsection{The 1918 Romanian campaign}

Despite the Romanian Army's efforts during the 1917 campaign and its overall good results, the negative evolution of the Galician front and loss of their Russian ally forced Romania into an armistice with the Central Powers. During the last quarter of 1917 Russian troops had become a threat to Romania as conflicts between the Bolsheviks and Russian officers that remained faithful to the Czar were bursting out more and more frequently. Conflicts between the Russian troops in Moldavia grew so out of hand that it eventually required the Romanian Army to disarm and neutralise the Russian units. After the Bolsheviks' coup d'état Romania remained alone, encircled by the forces of the Central Powers. Furthermore, on $3^{\text {rd }}$ December 
1917, the Russian Government lead by Lenin arrested the Romanian representative in Petrograd, Constantin Diamandy. By mid-January all diplomatic connections between the two countries were suspended by the Russians. The new Russian leadership also confiscated the Romanian National Treasury which had been trusted in the custody of the then Russian ally during the 1917 campaign (Ciobanu, et al., 2000).

The Brest-Litovsk Peace, and consequent arrival of the German troops in Ukraine, sealed the fate of the Romanian 1918 campaign isolating Romania and relegating it to the size of a small island encircled by conspicuous numbers of enemy troops. Additionally, all supply lines were cut off at a time when the provisions of the Romanian Army were running out. Although the overall desire of the Romanian military leadership was to keep fighting, during the Crown Council that decided the opening of negotiations with the Central Powers, it was brought to their attention that the remaining food supply and ammunition stock could only support war effort for a maximum of seven days more battle. Under such conditions, the preliminary treaty was convened in Buftea in March 1918 and signed in Bucharest at the beginning of May (Otu, 2017). This imposed a need to accept very unfavourable peace conditions as the Romanian Kingdom, left without allies and surrounded by enemy armies, was in no position to negotiate.

The Buftea-Bucharest treaty between Romania on the one hand and Germany, AustriaHungary, Bulgaria and Turkey on the other hand, decided the re-establishment of peace and amity, and decreed the demobilisation of the Romanian armed forces. Nevertheless, the draconic peace conditions went beyond ulterior territorial expropriation, with the loss of navigation control on the Danube and loss of the Carpathian Mountain passages totalling an additional 5,600 square $\mathrm{km}$ in favour of the Austro-Hungarian Empire, and fixed the premises 
for uprooting 72,500 Romanians who inhabited the area. The treaty, that was actually a dictat, obliged all Romanian oilfields to be leased out to Germany for the following ninety years, ordered evacuation of the Romanian population from the occupied territories, imposed juridical and official protection equal to that accorded to the Romanian Orthodox faith to the Roman Catholic, United Greek, Bulgarian Orthodox and Protestant churches, as well as to Muslim and Jewish faiths, and naturalisation of populations without nationality within Romanian territory.

Romania was not only losing control over its own economy in favour of Germany who gained monopoly over the Romanian petroleum industry, its grain trade, wood management and railways network, but was also put at risk of undercover colonisation. The dictat also imposed payment of a large war debt to the Central Powers and denied Romania the right to compensation for the war damages inflicted upon its territory. The Central Powers stated in the treaty that only "after the ratification of the peace treaty, the army of occupation will no longer make requisitions, either in money or products of any kind" (U.S. Department of State, 1918). By means of compensation, the Central Powers agreed not to oppose the union of Bessarabia with Romania which occurred on $27^{\text {th }}$ March 1918, although this agreement was not formally stipulated in the treaty (Hitchins, 2013).

It was under these circumstances that the Romanian Parliament ratified the treaty in June, but King Ferdinand never actually promulgated the treaty, allowing its annulment six months later (Bianu, 1926). The reluctance of the Romanian King to sign the treaty created the conditions for Romania to re-enter the war on $10^{\text {th }}$ November 1918 and assured its status of 'belligerent state' at the subsequent Peace Conference. By $1^{\text {st }}$ December 1918 all Romanian 
historical provinces were formally united, so giving birth to modern Romania, historically known as Greater Romania.

After the official Romanian Union of $1^{\text {st }}$ December 1918, Romania had to actually free most of its historical provinces from foreign occupation, engaging in the 1919 RomanianHungarian War. The Romanian Union proclamation was endorsed by the Treaty of Versailles in accordance with the right to self-determination, as intended in the Fourteen Points of Thomas Woodrow Wilson (Scurtu, et al., 2001).

\subsection{The Union of the Romanian historical provinces with the Romanian Kingdom}

The $1^{\text {st }}$ December 1918 remained in Romanian national history as the apotheosis of the Romanian fight for freedom, national unity and self-determination, as it symbolically marked the maturation of a long historical process that eventually managed to gather into one single state all the historical provinces inhabited by Romanians. The Great Union fulfilled the political motifs for Romanian involvement in the Great War. The achievement of these longlasting national ideals was made possible by multiple historically favourable factors that occurred at the end of WWI. For the peoples of the Eastern Front, the collapse of the great empires and promotion of the principles of nationality and self-determination at international level, meant the affirmation of long denied national rights.

The Romanian National Council was established in Paris on $24^{\text {th }}$ August 1918. The Council was recognised by France, the United States of America, Great Britain and Italy as the legitimate representative of the interests of the Romanian nation of Austria-Hungary. A congress of the Czech, Slovakians, Polish, Romanians, Croatians and Ruthenians of AustriaHungary was held in New York on $2^{\text {nd }}$ September, adopting a resolution that demanded the 
dissolution of the empire and the freedom of its people (Out, 2017). On $18^{\text {th }}$ October 1918 the Romanian politician Alexandru Vaida-Voevod presented to the Hungarian Parliament of Austria-Hungary a declaration of self-determination (see Appendix 7). In his speech to parliament he highlighted the fact that "the representatives of the small nations have been looking forward to seeing the attitude of the leading circles of the monarchy towards Wilson's points and that the non-Hungarian nations received with unspoken enthusiasm the news that the Austro-Hungarian Minister of Foreign Affairs submitted his peace offer to Washington, [..] giving official recognition to the fact that they were no longer nationalities but nations" (Căzănișteanu, 1984, p.367).

On $16^{\text {th }}$ October 1918 Charles I of Austria issued a manifesto to his people designed to reorganise the imperial territory into a six-state federation (Austria, Hungary, Czech Republic, Serbia, Poland and Ukraine). The manifesto was not well received by the king's subjects who started to establish national councils in order to negotiate directly with the Entente (Nistor, 1928, p.78-79). The volunteer corps of Transylvania and Bukovina, made up of Romanians from the two regions that were active in the Austro-Hungarian Army and had either been taken prisoners or deserted and surrendered to the Entente, responded to King Charles initiative by demanding the union with the Romanian Kingdom of all territories inhabited by Romanians. The volunteers were led by the Romanian politician Iuliu Maniu who had been negotiating the return of the war prisoners with the Romanian allies. Due to his diplomatic actions, countries such as Italy, France and Russia allowed the creation of Romanian legions from amongst the Austro-Hungarian war prisoners. On $5^{\text {th }}$ October 1918 Iuliu Maniu, who had gathered 70,000 Transylvanian soldiers in Vienna, started leading them back to Transylvania. 
The new government, installed in Budapest on $18^{\text {th }}$ October, broke the union agreement with Austria, which led to the official dissolution of the Austro-Hungarian state. Simultaneously, the Central Romanian National Council was created in Budapest. Three days afterwards, the Council transferred its headquarters to Arad and started negotiations with the Hungarian government lead by Karolyi Mihaly. The Budapest and Viennese governments recognised the Council's legitimacy. In the following period the Central Romanian National Council became the engine of the Romanian fight for freedom and unity, representing the interests of all Romanians. On $6^{\text {th }}$ November 1918 general mobilisation was decreed by the new Romanian government, which was constituted the same day under the leadership of General Constantin Coandă. Romania issued a war declaration to the Central Powers on $10^{\text {th }}$ November. The following day, King Charles of Austria issued a proclamation relinquishing all participation in affairs of state, recognising the people's right to decide upon the future of the state, and releasing his subjects from their oath of loyalty to the crown (Horne, 1923).

The day after the proclamation the first Romanian troops entered Hungary. On $13^{\text {th }}$ November the Hungarian government signed the Belgrade armistice with the French General Franchet d'Esperey who was in charge of the Entente's eastern army. The armistice established frontiers between Hungary, Serbia and Romania, leaving the Banat region under Serbian rule and the territory of Crișana, Maramureș (including Satu Mare, Oradea, Beiuș, Arad) and central Transylvania under Hungarian rule, disregarding the provisions of the 1916 Bucharest Convention. The Hungarian Government and the Central Romanian National Council conducted negotiations until $15^{\text {th }}$ November without managing to reach an agreement. Under these circumstances the Council decided to redraw from negotiations and organise The Great National Assembly of Transylvanian Romanians which was to be presided over by The Great Council of Transylvanian Romanians (Roszkowsk and Kofman, 2015). During the 
following twelve days the members of the Council were elected. Between $13^{\text {th }}$ and $20^{\text {th }}$ November the Romanian Army conquered several mountain passages in the region of the north-eastern Hungarian border in order to occupy a quarter of Transylvanian territory as stipulated in the Belgrade agreement, while on $25^{\text {th }}$ November the city of Târgu-Mureș was freed. On $28^{\text {th }}$ November the hundred elected members of the General Congress of Bukovina voted in favour of the union with Romania ${ }^{3}$ (Nistor, 1928).

On $1^{\text {st }}$ December 1918 the National Assembly of Alba Iulia took place, deciding the Union of the old Romanian historical provinces with Romania. The assembly, which made the pages of The New York Times (see Appendix 8), was a plebiscite of all Romanians who inhabited former Austro-Hungarian provinces and who were deprived of their rights by the dual monarchy (Bulei, 1996).

Iuliu Maniu's speech (see Appendix 9) given on this occasion, vividly reflects the general emotion spreading amongst members of the assembly and the spirit of the talks centred around achieving the freedom of nations, emancipation of all peoples, minority rights and democracy (Murgescu, 2001, p.284). King Ferdinand issued a decree on $24^{\text {th }}$ December 1918 accepting union of the historical provinces with Romania as provided by the decision of the assembly in the Resolution of the National Assembly of Alba Iulia (see Appendix 10), which had been adopted on $1^{\text {st }}$ December (Scurtu, 1993, p.141).

There still remained a standing issue about actual control over the historical territories, since the Entente had forbidden the conduct of military operations during peace negotiations with

\footnotetext{
${ }^{3} 87$ deputies voted in favour, amongst which were 74 Romanians, 7 Germans, 6 Polish; while the 13 Ukrainian deputies withdrew before the final vote.
} 
Hungary. Consequently, de facto, the Romanians had no authority to the north of the Mures line where the army was billeted.

The communists proclaimed the Soviet Hungarian Republic on $21^{\text {st }}$ March 1919 under the lead of Bela Kun. Hungarian communist forces decided to attach the Romanian and Czechoslovakian troops in Transylvania in a plan to co-ordinate their operations with Russian troops that were also attacking Bessarabia and Ukraine with a view to combining the two armies. The Entente requested Romania to make use of its armed forces against the Hungarian soviet threat and, in July 1919, the Romanian Army started the counteroffensive against the forces of Bela Kun. By $3^{\text {rd }}$ August 1919 the Romanian troops had not only freed all Romanian historic provinces but had also occupied Budapest. The Romanian Army retreated from the Hungarian capital city in November, distributing food supplies to the starving population on its way back home (Mărdărescu, 2009).

The Treaty of Trianon finally regulated the border between Romania and Hungary on $20^{\text {th }}$ June 1920, while on $10^{\text {th }}$ August 1920 the Treaty of Sevres regulated the northern and southwestern Romanian border, resolving its territorial issues with Poland, Czechoslovakia and Yugoslavia. The outcome was a painful resolution for Romania as it meant giving up part of the territory of Maramureș and Banat and abandoning the Romanians who inhabited these territories. Hungary considered the Treaty of Trianon as a dictat and continued fighting to annul it between the two wars. Romania was identified as the number one enemy, as the Hungarian elites were longing for the privileges held in Romania during the imperial age. After the fall of the Austro-Hungarian monarchy the resulted states formed alliances, such as the Little Entente, in order to increase their influence on the international relations scene and oppose the revision of the peace treaties (Dașcovici, 1936). 
A synthesis of the union of Basarabia, Bukovina and Banat with Romania, along with the adjacent socio-political and regional context is made available in Appendix 11, while the case of Maramureș is presented in appendix 12.

\subsection{WWI in the Romanian historical provinces appendant to the Austro-Hungarian}

\section{$\underline{\text { Empire }}$}

While the first part of this chapter presented the participation of the Romanian Kingdom in WWI and the circumstances that dictated the course of the events, the second part of the chapter highlights the war effort of the Romanian historical provinces in general, and of Maramureș and Bukovina in particular. Despite the fact that the Romanian Kingdom entered WWI in 1916, for the people of the Romanian historical provinces appendant to the AustroHungarian empire the war started two years earlier (Iorga, 1915). The condition of the Romanian population of the empire worsened after the beginning of the war due to the enrolment of a conspicuous percentage of the active male population and further deteriorated, at first, due to the reluctance of the Romanian Kingdom to enter the war and afterwards due to its entrance alongside the Entente (Zorin, 1995). Although scientific works about the overall condition of the population of the historical provinces and their fight for national emancipation during WWI are mainly lacking, there is an abundance of memoirs and local monographies that highlight the nuances of the war with regard to these regions, allowing the extrapolation of valuable information.

In 1923 Teodor V. Păcățian published an important statistic about the Romanians of the historical provinces, relying on data he began gathering starting from 1915 and which he continued after the war with the aid of local administration. According to the author, 2,979,614 Romanians inhabited the Romanian historical provinces under Austro-Hungarian 
domination at the beginning of the war, out of which 449,796 Romanians were called to arms and sent to war under the imperial flag, while 34,578 were recruited for auxiliary services. From the centralised data it emerges that 42,739 soldiers died in battle, 11,275 soldiers died in jail/captivity, 24,406 soldiers remained disabled after the war, 37,898 soldiers were wounded but with potential for recovery, and 29,839 people were gone missing, leaving behind 38,630 widows and 79,226 orphans (Păcățian, 1923). The actual numbers must have been much higher since these statistics relied on data transmitted by the local administrations of the historical provinces, which was suffering a process of restructuration in the aftermath of the war.

After the beginning of the war, on $30^{\text {th }} / 31^{\text {st }}$ June 1914, the Austro-Hungarian Empire decreed the general mobilisation of all the male population aged between 21 and 42 years old. The great majority of Romanian soldiers from Transylvania were assigned to the first line Infantry Regiment: 2 Brașov, 31 Sibiu, 33 Arad, 37 Oradea, 5 Satu Mare, 43 Caransebeș, 50 Alba Iulia, 51 Cluj, 61 Timișoara, 62 Târgu Mureș, 63 Bistrița, 64 Orăștie, 85 Sighet, 82 Oradea and a small number to the Honved Regiments: 21 Cluj, 22 Târgu Mureș, 23 Sibiu, 32 Dej, 4 Oradea, 12 Satu Mare, 24 Brașov, and Batalion 23 Alpine Hunters (Brașcanu, 2015, pp.1214). A relevant description about the condition of the Romanians of Ardeal, who were amongst the first formations to be sent to battle, can be found in Octavian Tăslăuanu's 1915 account of their experience, stating that:

\footnotetext{
"At the time, our attention was pointed to Romania. We were waiting for a glance of hope like the blind awaits a ray of light. Then the news about the decision of the Crown Council came decreeing the Romanian neutrality. We felt like a flock without shepherd, which any day could be herded to the camps of slaughter. All our plans glimmered like strongholds built by children, our soul darkened and our heart blead. The Carpathians were close, and it was not hard to pass the frontier. This thought was tempting, but neither of us could make the choice to leave Ardeal and let the fate of so many thousands of Romanians at the mercy of foreigners just to save ourselves. We were also tempted by the idea of passing the mountains with the entire battalion, but the peasantry seeing that Romania was not getting involved, would have hardly abandoned their household, wives
} 
and children, leaving them pray to the vengeance of the Hungarian state" (Tăslăuanu, 1915, p.24).

Priorities when choosing whether or not to stay were intricate and complex (Pușcariu, 1978). At first the policy of the Austro-Hungarian leadership was oriented towards creating and maintaining the illusion of openness and cohesion in order to cultivate a sense of belonging and avoid the rebellion of the numerous nationalities of the empire. During this period Romanian military formations were even allowed to include the current Romanian national hymn in their repertory, wear badges in the colours of the Romanian flag and, for the first time since the creation of the dual monarchy, the Romanian language was used in officially issued documents, even on the mobilisation orders (Ciorogariu, 1926). The Hungarian propaganda and persuasion campaign, along with the official attitude of the Romanian Kingdom, that encouraged the Romanians of the provinces dominated by the AustroHungarians to fulfil their duty to the emperor, disoriented the population. Furthermore, loyalty to the emperor, whose authority at the time was second only to God, was strongly promoted both by the church and by the Romanian King (Maior, 2004). These circumstances, along with the threat of military courts, martial law, persecutions against those suspected of nationalism, and heavy police surveillance in all social sectors, persuaded Romanians to engage in the fight for a purpose and ideal which eluded their understanding and will (Nemoianu, 1933).

Subsequently, as the war evolved and grew more and more bitter, the contradictions of imperial policy became more and more evident while the facade of benevolence faded away. There was a systematic campaign of persecution against the Romanian population in Transylvania, meant to dissuade soldiers from leaving the Austro-Hungarian army for fear of reprisals. When the Romanian Kingdom finally entered the war alongside the Entente and the Romanian troops began the Transylvanian campaign, approximately 10,000 Romanian 
civilians from Ardeal were deported across the Tisza River (in the proximity of Szolnok) and employed in forced labour in mines and factories, about 500 were sent to the concentration camps of Taplosulye and Ostffyajsznyfaja, and 257 Romanians were sentenced to death (Șerban, 1998, p.211). Charges of treason and turbulence hung over the life of every Romanian in Ardeal, especially after 1916. Leaders of the Austro-Hungarian Army emitted an order to institute instant martial trials for acts of disobedience, which led to instantaneous hanging or shooting of the accused. In 1917-1918 broad social surveys were organised to investigate the phenomenon of desertion, especially of Romanian war prisoners suspected of having deserted to the enemy, with a view to confiscating their belongings back home and ceasing war aid for their families. Although initially Romanian soldiers fulfilled their duty to the bicephalic monarchy animated by the belief that through their sacrifice they would prove themselves worthy to the Hungarians, persuading them that they deserved better treatment and imagining that through this sacrifice they would redeem justice for the Romanian nation (Nistor, 1922), once confronted with the atrocities of the battlefield such idealism was soon seen for what it was, a striking naivety.

\subsection{Maramures}

The region of Maramureș bordered the Galician front and as a consequence was affected by the war and its side effects from beginning to end of the war, and even after. The war vortex brought into the region the avatars of chaos: herds of refugees from Galicia, famine, deprivations, epidemics and death. Most of the male active working force was mobilised and sent away, the animals traditionally used in field labour were massively confiscated, and even the churches bells were melted down to build cannons, leaving the local population in a desperate situation. Furthermore, the oppression policy applied towards the Romanian population was backed up by a systematic denationalisation campaign that imposed the 
abolishment of Romanian schools, banished the Romanian press, and instated the death penalty for nationalistic feelings (Achim and Socolan, 1968). To this were added persecutions against those considered traitors and reprisals against the social contacts of deserters, although the justification of reprisals against the population as an antidote to the phenomenon of mass desertions was largely propaganda. The confusion and lack of efficient organisation that reigned in the multi-national imperial army, and the constantly growing deficit of personnel on the Galician Front, translated in a practice of transfers between regiments that were difficult to trace or officially account for, as is seen from various war accounts. For instance, 1,513 soldiers of the 85 Regiment Sighet sent to serve in other units were declared deserters, when in fact the number did not exceed 150 (Batin, 2014, p.139).

Given constant abuses against the Romanian population and the overall evolution of the war, the Hungarian leadership grew worried about the potential outcome and prepared a worst-case scenario designed to soften international public opinion in case they lost the war. In January 1917 Count Tisza coerced Metropolitan Mihaly to sign a document with the following content in the name of the Romanians:

\footnotetext{
"We, the secular and cleric representatives of the Romanians, reject the statement that we are under foreign domination. We are citizens, we are as equally entitled as the Hungarians, and we have old traditions of faith to the throne and country. We do not want to be freed, we annexe to the indestructibility of our Hungarian country. We, the Romanians of Hungary, want at all costs to live under the dominion of the holy Hungarian crown" (Albani, 1938, p.44).
}

The Metropolitan declared that he had signed the declaration out of fear of becoming the executioner of his people as the Hungarians had threatened to decimate the population if the Romanian eminences refused to sign the document (Filipașcu, 1997, p. 200). Still, not only did the conspiracy negatively impact the combativeness of Romanian soldiers enrolled in the imperial army, but it also brought further militarisation to Maramureș as it increased the numbers of the military police who were mobilised to track down deserters. It is estimated 
that, by the end of the war, 60,000 Romanian prisoners were present on the Italian front, more than 100,000 in Germany (Alsace-Lorraine, Bavaria), Bulgaria, Austria, Hungary, Turkey and 120,000 in Russia. Nonetheless, it is noteworthy that the rate of mortality amongst the prisoners was very high, especially in Alsace-Lorena where it reached 40\% (Nouzille, 1997, p.21) and in Turkey where it was about 50\% (Nicolescu, et. al., 2006, p.117).

The unsolved constitutional problems of the monarchy were vividly highlighted against the background of the war. The mounting animation of the national conscience of people of the empire made the military leaders consider the redistribution of military units in order to estrange soldiers from their native lands, especially after the Romanian Kingdom entered the war (Gunther, 1976). As noted in Tăslăuanu's memoir, whose battalion fought in the battle of Lemberg in 1914, Romanian battalions were sent straight to the first-line combat as they arrived on the battlefield, to be decimated by the Russian artillery. Amongst the Russians there were many soldiers from Bessarabia so, from the beginning, soldiers from Ardeal and Bukovina were fighting against their own conationals.

"Everywhere you looked there were only fresh graves with crosses made out of branches, destroyed Russian weaponry, piles of ammunition and unburied corpses. [...] We cursed the forest and the fate that co-erced brother to kill brother. [...] From Halici to here we encountered only Romanians; the region of Ardeal had been relocated to Galicia" (Tăslăuanu, 1915, pp.71-73).

Not only was the sense of duty to the crown soon eroded by these conjunctures, but they also caused the mistreated survivors to harbour the desire for vengeance in their hearts. Consequently, a manifest resistance gradually coagulated against the authorities that were undertaking mobilisation efforts, such as the reservists' refusal to enrol and the desertion of some units even before being sent to battle. Such episodes, sporadic at first, greatly increased under the influence of extremely harsh measures undertaken against the Romanians, both soldiers and civilians. 
"In several isolated areas of Transylvania, especially in the Apuseni Mountains, the Năsăud Mountains and the Mountains of Maramureș, in the wooden areas of the Meridional Carpathians armed troops emerged [...] A statistic of the Hungarian military police dated $12^{\text {th }}$ June 1918 shows that these groups amounted to 38,000 people in 1916, 81,000 people in 1917 and 44,600 people in the first 3 months of 1918" (Șerban, 1998, pp.208).

A specific form of protest, especially in the conterminous areas of Transylvania, was passing the border to Romania through the unmapped paths of the mountains. It was estimated that in 1915 alone the number of young males fit for military service that passed through the Carpathians was more than 26,000 , further increased by tens of thousands who joined the Romanian army in 1916 during the retreat from Transylvania. Therefore, the total number of soldiers from Ardeal who served in the Romanian army between 1916-1918 amounted to approximately 100,000 souls (Șerban, 1998).

The atmosphere of the Austro-Hungarian army faithfully reflected the socio-political realities of the monarchy. Although, theoretically, the imperial army was supposed to be unitary, the Austrian Landwehr (meaning defence of the country) and the Hungarian Honvedseg (meaning defender of the homeland), were entities conceived to protect the interests of the two states, separately and individually. These groups of home guards were perceived as such only by Austrians and Hungarians, because for other people of the empire they were actually repression tools meant to keep the conquered obedient and subdued (Averescu, 1937). In 1916 the French publication "Le Miroir" published an article entitled "Le Règne de la Terreur en Autriche-Hongrie" (FIG.1) recounting how "from the beginning of the war thousands of Czechs, Romanians, Ruthenians, generally all subjects of the dual monarchy suspected of irredentist feelings, were executed in Austro-Hungary after being convicted in hasty trials" (Le Miroir, 1916). 
FIG.1. Document found by an Italian second lieutenant on a Hungarian soldier killed in San-Michelle near Gorizia representing the hanging of three Romanian civilians in a village of the county of Maramures (Image available: https://gallica.bnf.fr/ark:/12148/bpt6k6522748t/f12.image)

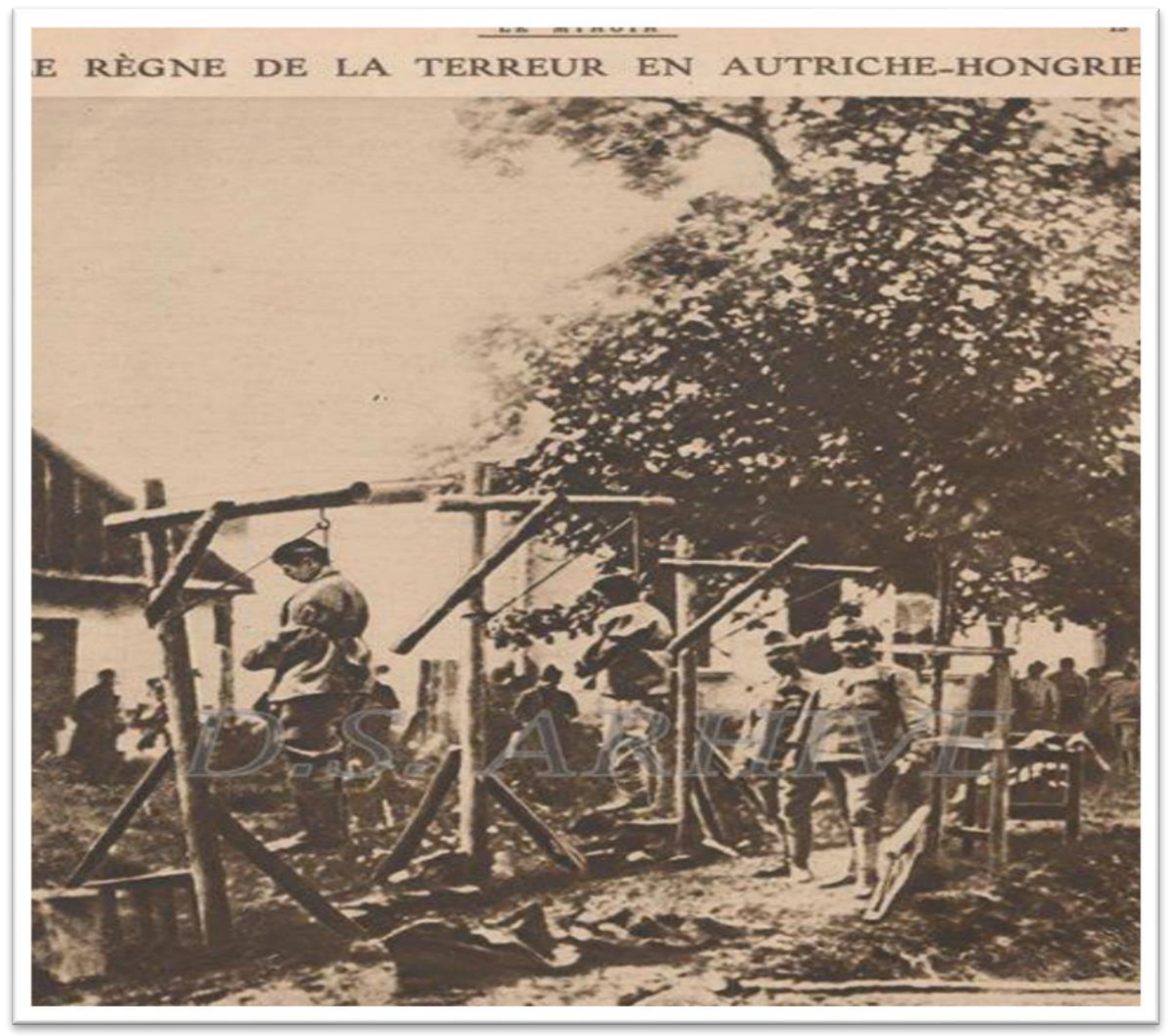

Even the Austro-Hungarian leadership was aware of the flawed treatment to which other nationalities were subject in all aspects of life, including military service. In 1907, the head of the imperial rmy general staff stated in a petition to the emperor that "every recruit, regardless of his nationality, has to feel he has equal rights with the others within the armed forces and nothing must give him the impression that there are privileged people” (Stone, 1966, p.98). Still, the fact that almost $90 \%$ of the officers were either Austrians or Hungarians while more than $50 \%$ of soldiers belonged to other nationalities hardly promoted the idea of fair treatment or sent the message of equal imperial citizenship. Tăslăuanu testified that there was a huge gap between the body of officers and the soldiers, and a dreadful hatred. 
If, on the one hand, the Hungarian officers hearing that Romania was preparing to enter the war against the Central Powers unleashed their anger and frustration on soldiers of Romanian nationality (Tăslăuanu, 1915, p.349), on the other hand, leading figures of the Second Reich, such as the Minister of External Affairs, Gottlieb von Jagow, and Marshal von Hindenburg, pleaded for the concession of rights for Romanians of the historical provinces in order to assure their loyalty and prevent the alliance of the Romanian Kingdom with hostile forces. "The concessions towards the Romanians [...] might be uncomfortable for the Hungarian leadership, but how much do some difficulties of internal affairs count in relation to the total collapse of the empire" wondered von Jagow (Tisza, 1932, p.34).

The English historian Robert William Seton-Watson also conducted a vivid campaign, that spanned more than a decade, on the issue of the nationalities in the Austro-Hungarian Empire particularly advocating the cause of Romanians in Transylvania (Seton-Watson, 1929). Failure to resolve the problem of the nationalities within the monarchy "continuously pressed on the conscience of the young officers and soldiers. The sons of those nations who kept fighting in the parliament one against other could not cooperate in the national atmosphere of the Habsburg army, which in its turn was suffocated by the dynastic artificial patriotism" (Jaszi, 1966, p.145).

These difficult circumstances, along with the adherence of Romania to the Entente and the death of the emperor, encouraged a considerable number of Romanian soldiers in the imperial army desert to the enemy, from 1916 onwards. On $3^{\text {rd }}$ April 1917 the Russian government approved the creation of a Romanian volunteer corps composed of 30,000 war prisoners (Ardelean, 2016). The Romanian authorities negotiated with its allies the creation of national legions in the prisoner-of-war camps and by 1917 they had already gathered 15,000-20,000 prisoners in the Darnita camp who joined the Romanian army after $8^{\text {th }}$ June. On $3^{\text {rd }}$ June a 
Romanian delegation comprising Vasile Lucaciu, Vasile Stoica and Ion Moța arrived in Washington to present the Romanian political and military position to the American government and gain the consensus of public opinion (Giurescu, 2010). The cause of the volunteer legions was energetically and internationally advocated by Vasile Lucaciu, a priest from Maramureș who became one of the most prominent Romanian political figures of the time. As a result of Lucaciu's campaign in the U.S.A. Theodor Roosevelt declared that "the United Nations supports the emancipation of the nationalities and firmly supports the Romanian Kingdom in its right claims" (Ardelean, 2016, p. 576).

Similar campaigns were conducted in Russia, France and Italy with the aim of creating volunteer corps and promoting the Romanian cause internationally. Also, it is worth mentioning that Lucaciu's fight for national emancipation began years before the war. Lucaciu had already advocated the Romanian cause at the First Universal Race Congress in 1911, against the background of the freedom of peoples, largely promoted by the participants, especially in relation to the East European nations. In his speech about the role of the Romanian nation in the regional and European context he argued that "the Romanian nation was a restless sentinel of culture and national civilisation in the Eastern Europe" (Românul, 1911). Angello de Gubernatis, Giuseppe Sergi and Emile Arnaud were quoted as supporters of the Romanian cause by the newspaper Românul on $2^{\text {nd }}$ August 1911 demonstrating that the problem of the nationalities was a well-known reality years before the Great War, and that intellectuals from all around the world were already conducting a diplomatic fight to solve the nationalities issue in favour of the peoples' rights. 


\subsection{The Prislop Pass - the link between Maramures and Bukovina}

More than 10,000 men from Maramureș were enrolled in the Austro-Hungarian army, the majority of whom served in the Infantry Regiments 5, 12, 85 Sighet (Tomi, 2005), while soldiers from the neighbouring Bukovina region were mainly enrolled in Regiment 41 Cernăuți. They were sent to battle on the Galician Fronts, Serbia, Ukraine, and Italy, participating in the battles of Lemberg, Doderdo, Manilova and Piave. The common graves of Regiment 85, where the majority of soldiers from Maramureș were enrolled, can be found in the cemeteries of Manilowa, Ikwa, Wzaocko, Cas Meneguzza. The bones of several soldiers of the Austro-Hungarian Army were sheltered in the Italian memorials of Monte Grappa (10,146 soldiers who perished the battle of Piave) and Trento, where the Ossuary of the Austro-Hungarian Empire is located (Batin, 2014).

The first battles of the Russian invasion in the Carpathians occurred in the region of Maramureș, starting from September 1914. Russian incursion was perceived as a great threat for the empire as not only did the Russians occupied two thirds of the Galician Front at the time, but it also brought the war to Hungary, making Romanian historical territories annexed to the empire an open battlefield. On $4^{\text {th }}$ of October 1914 the Russians conquered the city of Sighet, but they were defeated over the following days with the aid of the Polish legion and forced to retreat (Magyaroszag, 1914). The Russian offensive revealed a meticulous knowledge of the invaded territory obtained with the aid of a systematic campaign of espionage that preceded the invasion (Batin, 2014, p.22). The threat of invasion haunted the region, producing hordes of refugees that fled away leaving their possessions behind to fall prey to systematic thefts. The situation did not differ much for those who stayed in loco as the Russians instigated the phenomenon of systematic robberies (Ghergheș, 2017). Such 
casualties, along with forced expropriations and repression policy established by the Hungarians, lead to a marked impoverishment of the population of the region (Dan, 2008).

After the rejection of the first Russian invasion, the Bavarian troops occupied the peaks of the Mountains of Maramureș and the Austro-Hungarian army, led by General Konta, established its headquarters in Vișeu de Sus and located its military hospitals and main cemetery in Borșa. From this point onwards, travel from Maramureș to Hungary and vice versa required a special passport issued by the German commandment. The front line was established along the Carpathian Mountains in the proximity of Borșa, Vișeul de Sus, Poienile de sub Munte and Frasin. On the heights of Copilașul and Prislop real cities of barracks were built, provided with electricity and a long highway, which communicated along the crest of the mountains with the highways Borșa-Iacobeni, Copilaș-Poienile de sub Munte and Vișeu-Lutoasa. Villages in the area were peppered with soldiers and within a few months the people became acquainted with the horrors of war. The German troops were particularly harsh with the civilian population, which was permanently confronted with requisitions, subscription to war debts and forced public corvée (Filipașcu, 1997).

On $17^{\text {th }}$ December 1914, during the visit of Emperor Franz Josef to Vatra Dornei, it was decided to build a railway to serve the armies along the front line. This initiative was part of the strategic plans of the $7^{\text {th }}$ Army, led by General Pflanzer-Baltin, in preparation for the offensive against the Russians in Bukovina. The chosen route was Iacobeni-Prislop-Borșa because the county of Maramureș had been connected to the imperial railway since 1872 via the Satu-Mare-Sighet railway, and from 1895 another railway system connected Sighet to Stanislau as well as to Borșa and Vișeu (functional since 1913), making the chosen route a particularly valuable strategic node for the empire by assuring its connection to Bukovina. Furthermore, Iacobeni was the provider of manganese for the Transylvanian foundries and a 
direct connection to Borșa constituted a huge advantage in the imperial war economy (Percivale, 2000).

Simultaneously, the Austrians started a counter-offensive against the Russians in Bukovina, which concluded in February 1915 with the taking over of Cîmpulung, Siret, Suceava and Cernăuţi. Heavy fights were conducted on the Austro-Hungarian-Russian, Eastern Front, for which reason the German army also came to Prislop to assist its allies in defending a crucial geostrategic position (Brașcanu, 2013). In January 1915 the Russian armies penetrated the Valley of Bistrița Aurie through the Lucina Pass, attempting to create a breach in the mountains. They occupied Cârlibaba and headed to the Prislop and Rotunda Passes, threatening the Austro-Hungarian army for which the two positions were of strategic importance. An immediate attack was required in order to save the road to Borșa and the railway, a task assigned to the $2^{\text {nd }}$ Brigade of the Polish legionaries. On $18^{\text {th }}$ of January 1915 Polish soldiers, led by captain Marian Januszajtis, reached the Prislop Pass, despite twometer-high snowdrifts and temperatures below $30^{\circ}$ Celsius. After three days of heavy fighting, on $22^{\text {nd }}$ January 1915, the Polish soldiers victoriously entered Cârlibaba, uniting their forces with the Austro-Hungarian army, taking 60,000 Russian prisoners, and allowing the Austrians to take over the region of Bukovina (Mihali, 2013, pp.43-45). Starting in February 1915 German and Austro-Hungarian troops were permanently quartered in the Prislop Pass.

"The display of the Austro-Hungarian and German troops in the field, after the $15^{\text {th }}$ February 1915, in the proximity of objectives of military and economic importance, the reorganization of the military camps in strategic areas and work points, the execution of engineering works and the construction of wooden shacks with the purpose of establishing railway stations, clearly suggests the existence and application of a plan 
regarding the construction of the Iacobeni-Tibău-Borșa railway through the Prislop Pass” (Brașcanu, 2013, p.421).

Therefore, this date can be seen as marking the beginning of the construction of the railway that was projected and built by Felix von Tarbuk Sensenhorst, Valko Victor and Dienstl Karoly, a hypothesis also supported by the fact that the first written traces about the railway made their appearance in the media starting from $21^{\text {st }}$ February 1915 (Brașcanu, 2013, p.422).

The railway that had a $760 \mathrm{~cm}$ gauge and covered over $52 \mathrm{~km}$ in Maramureș and $28 \mathrm{~km}$ in Bukovina was finalised in May 1916, by the harsh labour of war prisoners and the local workforce. Works on the Prislop-Cârlibaba sector were executed by the Austro-Hungarian army within six months, while the Borșa-Prislop section was commenced by the German army led by General V. Konta (Von Rango, 1929). The railway line had seventeen stations: Iacobeni, Ciocănești -km 6, Botoș - km 12, Valea Stânei - km 18, Cârlibaba - km 23, Țibou km 30, Irva Leșului -km 38, Vâlcănescu - km 41, Măgura - km 43, Prislop - km 49, Vârful II km 51, Vârful I - km 55, Vistel - km 57, Strâmtura Schit - km 62, Gura Fântânii - km 67, Vișeu - km 73, and Borșa - km 77 (Mihali, 2013). The railway started in Iacobeni at an altitude of $835 \mathrm{~m}$ and climbed up along the Valley of Bistrița Aurie to the top of the Prislop Pass, where a four line interchange and revision station was erected close to the military unit in charge of its construction, maintenance and management. On the heights of the pass a town of barracks was built and illuminated by electric generators, to shelter more than 560 men for about three years. From an altitude of approximately $1416 \mathrm{~m}$ the line descended towards Borșa, situated at $526 \mathrm{~m}$ above sea-level, on a steep slope with tight curves. Operational centres were established at the Iacobeni and Cârlibaba mines and the billeted troops were tasked with defending these objectives, augmenting the production of manganese, lead and silver ores and dispatching it over the mountains to plants in Transylvania. In the military 
camps of Cârlibaba, Prislop and Borşa over 2,000 soldiers were billeted with the aim of strengthening the front line and defending the newly-built railway. During the war the railway was used to transport troops, weaponry, ammunition and provisions of all kinds required by the $11^{\text {th }}$ Army Corps $(51$ Honveds Infantry Division, 30 Infantry Division, 54 Austrian Landwehr Division, $1^{\text {st }}$ Regiment Feld-Kanonen, 202 Honveds Division, etc.) of the $7^{\text {th }}$ Army present in the area.

"Although the trains were composed of only four to six coaches, a fairly large amount of ores (129,328 tons of manganese extracted from Iacobeni and Vatra Dornei), spare parts and cast-iron products founded at a factory in Iacobeni, all sorts of cereal bags and many other items were transported. At one point the transport of live-stock (cattle, pigs, sheep) was also attempted, but this idea was soon discarded leaving the flocks to be herded over the mountains" (Brașcanu, 2013, p.465).

The railway line was inaugurated in 1915 on the occasion of the emperor's birthday $\left(18^{\text {th }}\right.$ August) as a worksite line operated with animal traction, and was finalised for stream train traffic on $1^{\text {st }}$ May 1916. It operated until December 1918 when most of the rolling stock was taken to Debrecen and the Prislop facilities burned down (Mihali, 2013, pp. 47-48). According to Paul Brașcanu, construction of the railway and its adjacent facilities was possible due to the effort of 4000 Russian war prisoners, and of the locals who worked in particularly harsh conditions.

"The elders narrated that, on the peak of Prislop, near the military camp established in 1915, there was a cemetery where dozens of Russian prisoners slain by illness and exhaustion along with the soldiers killed in battle in the mountains were buried. Most of their names are unknown and the wooden crosses are long rotten; today - only sparse mounds looming through the grass carpet can tell you that here eternally rest defeated and winners, heroes and martyrs, turned to dust" (Brașcanu, 2013, p.424).

\subsection{The Maramures-Bukovina front}

The role of Maramureș in the economy of war, and of the Prislop Pass for that matter, can only be fully understood as part of a bigger picture of the front-line system and strategy in the area, and therefore must be treated in relation to the adjacent region of Bukovina. Actually, the whole area was contaminated by war due to the fact that, in 1914 while the Austro- 
Hungarian troops were engaged in battle in the Cracovia-Lemberg sector and were struggling to defend the east of Galicia, the northern border of Bukovina remained defended only by the 43 Division and by the military police corps led by Eduard Fischer. By $11^{\text {th }}$ September the imperial troops had been defeated in Galicia and forced to retreat to the alignment of the Carpathians. In August 1914, Northern Bukovina was invaded by the Russians and conquered up to the Siret river bank. The first battles between the Russian and Austro-Hungarian troops occurred near Noua Suliță along the Rătchina stream, land located between two empires, sending to Cernăuţi the first cargo of wounded.

"On $23^{\text {rd }}$ of August 1914 the Russians entered the village Boian; they immediately spread around the village breaking into 84 establishments/shops, robbing them of the goods, throwing in the alley the things they could not take along and setting on fire several houses" (Brascanu, 2015, p.16).

The situation in Galicia, largely dominated by the Russians, led to the isolation of Bukovina, by cutting off its connections to the Austro-Hungarian Empire. At the end of 1914, since the front line was established in the direction of Huszt-Sighet-Borșa-Cârlibaba-Mestecăniș, the Austro-Hungarians found themselves in desperate need of new transport routes in order to supply troops blocked in Bukovina and sustain the war effort in this strategic region. It was within these perimeters that construction of the Iacobeni-Prislop-Borșa railway was decided.

The strategic importance of this front line is further proven by the interest in the area shown by great historic personalities such as Carol IX, Wilhelm II, the Archduke of Austria Karl Franz Josef, the Kaiser Wilhelm II, the Feldmarschall Hermann Kovess von Kovesshaza - the last Supreme Commander of the Austro-Hungarian army and Feldmarschall Friedrich Archduke of Austria and Duke of Teschen. Czar Nicholas II of Russia, General A.A. Brusilov, the Great Duke Mihail Alexandrovici Romanov, the Archduke Leopold Salvador, and of course Generals Pflanzer-Baltin, Conrad von Hötzendorf, Paul von Hindenburg, 
Mackensen, etc, also made their presence felt in loco as illustrated by WWI photography (Brășcanu, 2015, pp.72-100).

In August 1916, just before Romania entered the war alongside the Entente, the battles were proceeding with intensity in Bukovina. The Eastern Front was stable on the alignment Cârlibaba-Iacobeni-Vatra Dornei-Bârnărel-Todireni-Șaru Dornei-Lucaciu-Tamăul and only Cârlibaba, Vatra Dornei, Dorna Cândrenilor, Iacobeni and Poiana Stampei were still unconquered by the Russians. From this point onwards, the Romanian army officially became 'the enemy' along with the Russians, instigating the Austro-Hungarians to perpetrate a season of great persecution towards both the Romanian population beyond the front line and Romanian soldiers enrolled in the imperial army. Ironically, on $8^{\text {th }}$ December 1917 , the Russians ceased being 'the enemy' and armistice was declared in Bukovina. Not only did disarmament of the Russians leave the Romanian army in a difficult situation and their chaotic retreat cause great disorder in the region, but it also brought about the breaking of diplomatic relations with the Romanian Kingdom and the confiscation of the Romanian national gold deposit that had been placed in custody in Moscow, providing the AustroHungarians with strategic advantages and setting the terms for the war to continue (Kirițescu, 1925).

\subsection{The imperial transport systems in Maramures and Bukovina}

Taking into account the urgent multiple needs of the army, to sustain the supply of huge quantities of weaponry, ammunition, food, medicines and, at the same time, to relocate troops and ordnance and evict the wounded, strong railway links behind the frontline became vital. The steam locomotive was discovered to be the best transport solution to satisfy both the 
logistic demands of the front line, and of the weapon plants that had to be constantly provided with prime materials to support the war effort (Brașcanu, 2015, p.327-468).

Nonetheless, sustaining the war economy required the development of a widespread and highly functional transport network encompassing various means of transport. The need to adapt to challenging roots lead to the adoption of hybrid transport solutions in the region, such as the Landwehr-zug (FIG.2). The auto-train was a particular vehicle able to travel both on railways and normal roads. The train ran on electricity and benzene and was able to carry five to ten carriages with a capacity of 6 tons per carriage, at a maximum speed of $26 \mathrm{~km} / \mathrm{h}$.

FIG.2. Landwehr-zug/WWI auto-train stationed in Prundu Bârgăului (Brașcanu, 2015, p.367)

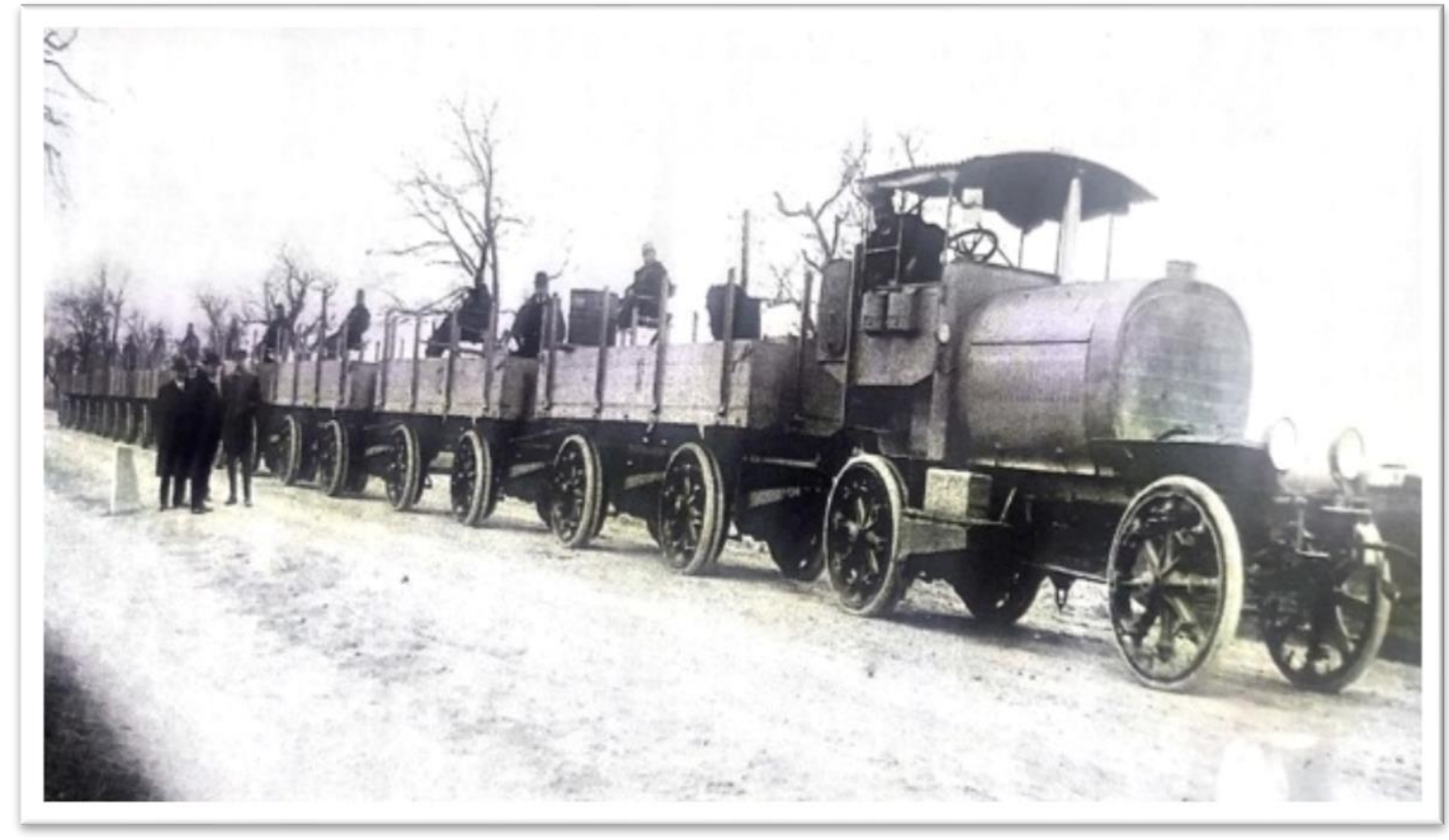

Although the railway assured the main means of transport between the empire and the frontline, the region was also served by other forms of transport that supported the war effort, and which are worthy of a brief mention. In the category of air transport, the first airplanes (FIG.3) that visited the sky over Bukovina were of German and Russian manufacture, built for the transport of observers, military photographers and, of course, bombs. Due to the 
instability of the frontline over the course of the conflict, the only airbase that could be located with certainty in the region is that of Cernăuți. Zeppelins were also engaged in the area for the same purposes, the most famous base being that of the Ballonkompanie 14 situated in Dorosăuți on the banks of the river Nistru.

FIG.3. WWI airplane in Cernăuți, Bukovina (Brașcanu, 2015, p.298)

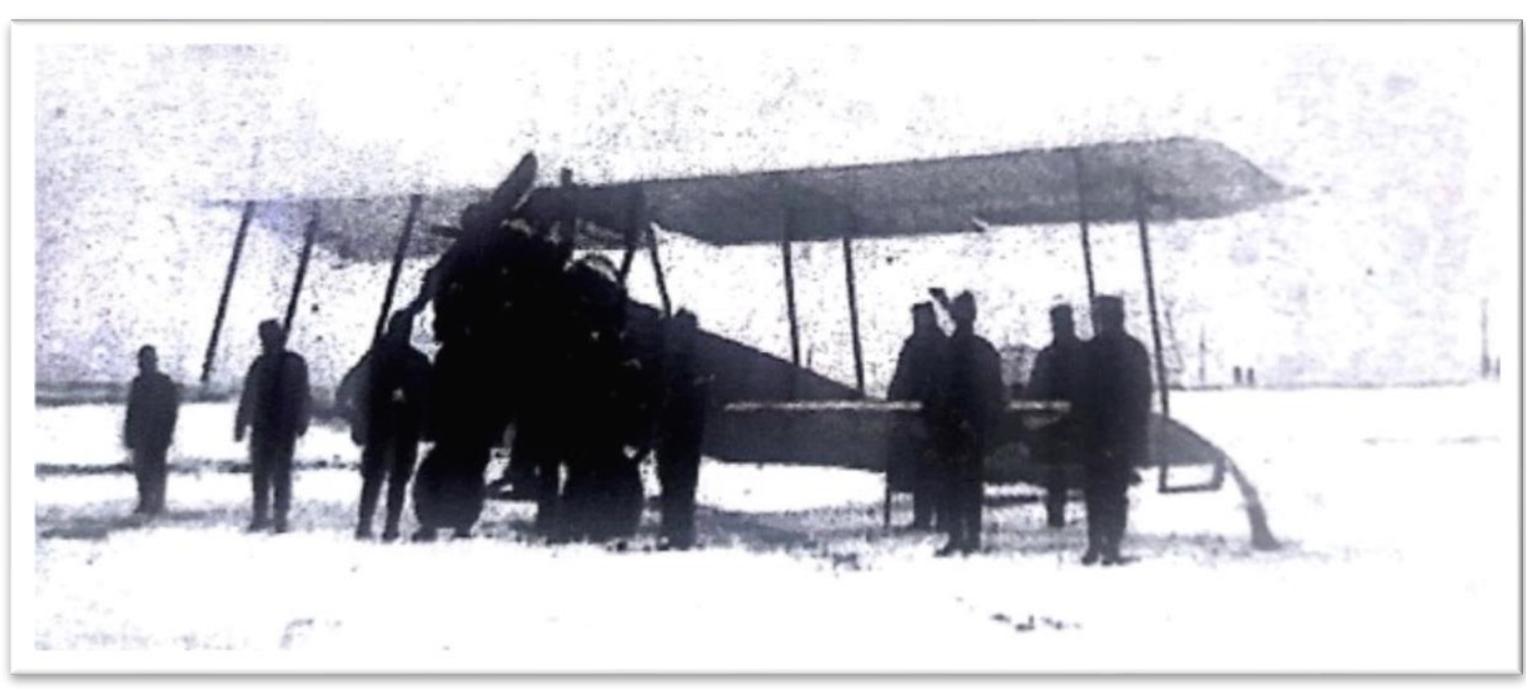

Air transport also relied on a different kind of service providers: carrier pigeons. Such animated actors were used to carry messages from base to battlefields, and vice versa, and the Germans even used them as photographers to spy on the enemy. ${ }^{4}$ Pigeons, which became the norm for every army group of the Eastern Front, were present in this region in Cârlibaba, Vatra Dornei, Rădăuți, Putna, etc. During important operations they were taken to the battlefield and released in large numbers, of which only a few carried messages, the others being released to confuse enemy hunters (FIG.4). The phenomenon must have been quite intense and effective since the authorities of Bukovina ordered the killing of all domestic pigeons on $14^{\text {th }}$ May 1916 in order to prevent espionage and communication with the enemy (Brașcanu, 2015, pp.299-310).

\footnotetext{
${ }^{4}$ During the autumn of 1914 the Germans bought the invention of Julius Neubronner, inventor and pioneer of photography, who invented the technique of aerial photography using carrier pigeons.
} 
FIG.4. Mobile pigeon aviaries near Cârlibaba (Brașcanu, 2015, p.313)

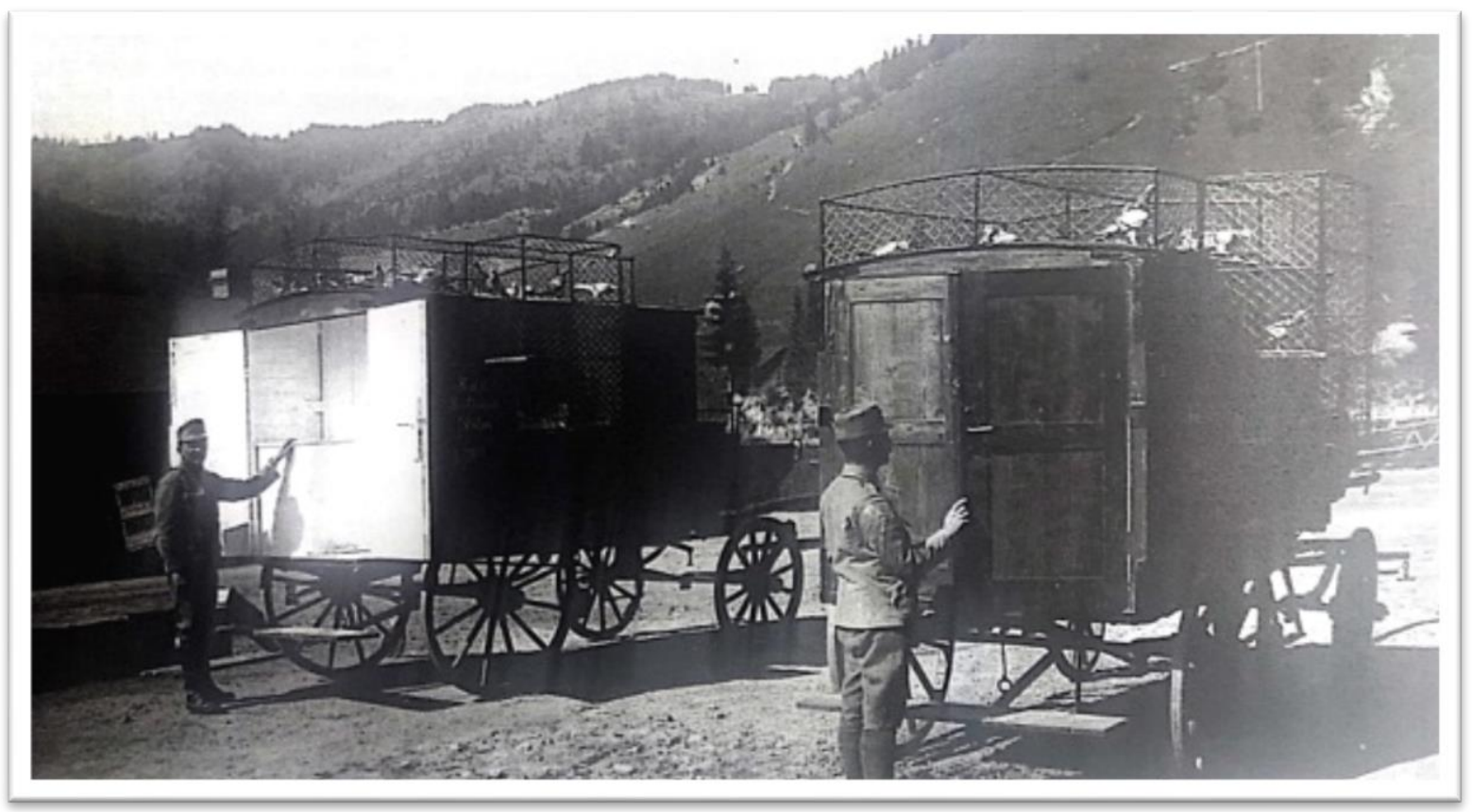

Water transport, on the rivers, was carried out using small boats and rafts (FIG.5). They transported assorted materials for rebuilding broken bridges, as well as logs, timber, ammunition, weaponry and various vehicles (Andreica, 2015, pp.109-234).

FIG.5. WWI German military rafts on Vaser (Andreica, 2015, p.159)

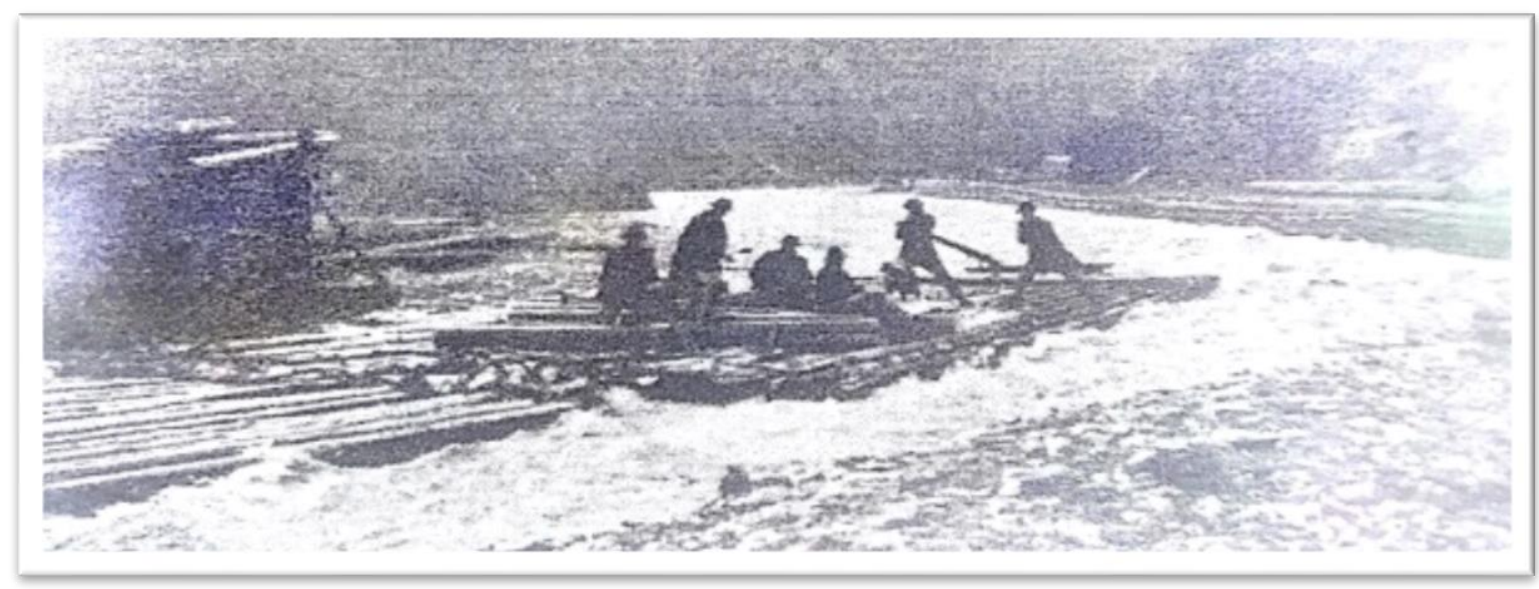

Another form of transport, which turned out to be useful in an area characterised by hardly accessible mountainous landforms, was the cableway (FIG.6). Cableways were built on the Borșa-Prislop-Kârlibaba-Mestecăniș-Iacobeni-Bârnărel-Crucea alignment due to their 
versatility on rugged terrain and their favourable construction-operation-maintenance cost balance. This form of transport proved to be particularly useful and efficient for supplying mountain-top outposts and for evicting the wounded (Braşcanu, 2015, pp.469-477).

FIG.6. WWI cableway in Maramureș (Brașcanu, 2015, p.471)

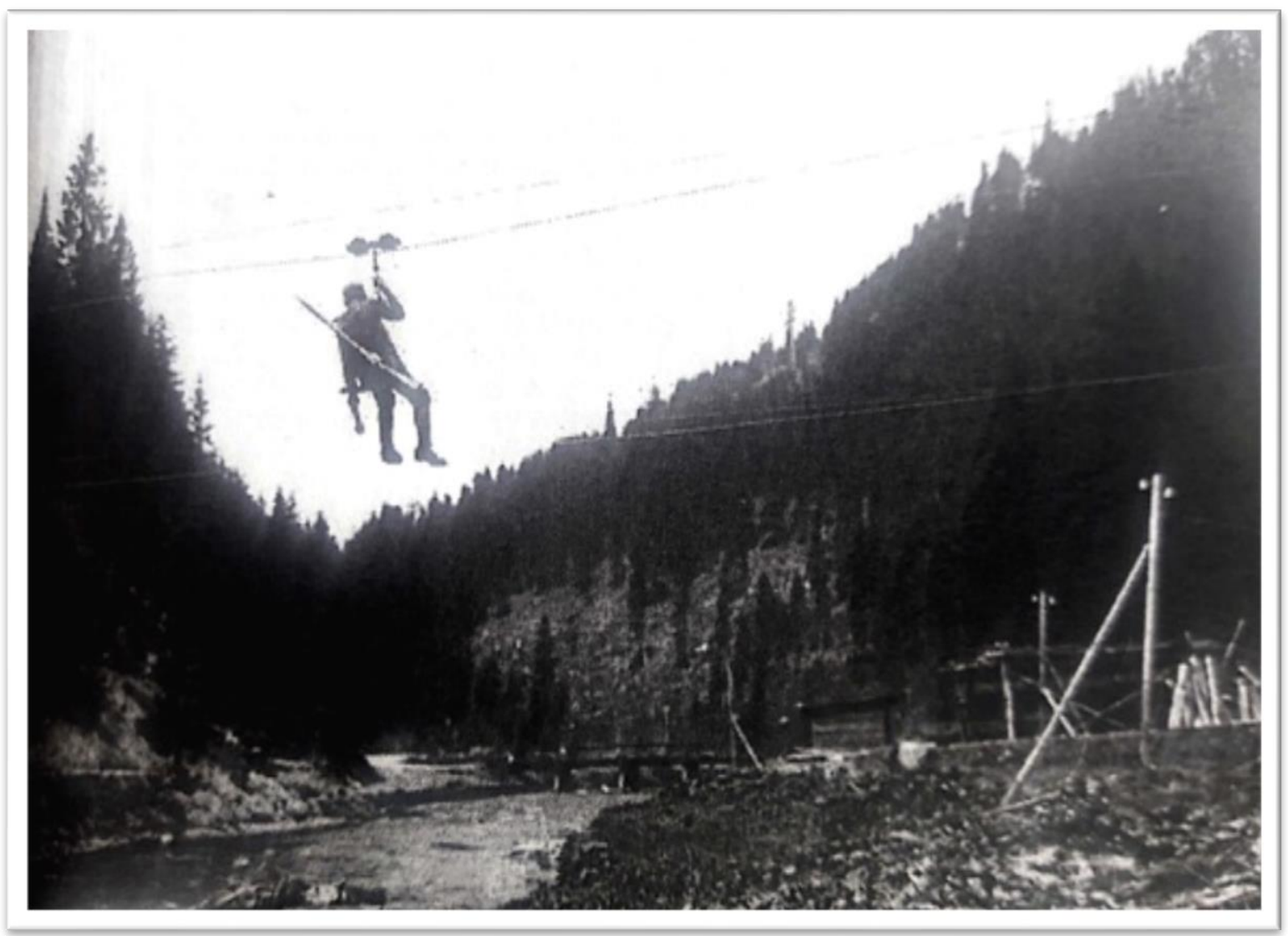

Still, the most remarkable and endearing transporters were animal-powered ones, employing cattle (FIG.7), horses (FIG.8) and dogs (FIG.9-10). The so-called utilitarian dogs were used to transport mail, ammunition and medicine. In addition, they had guarding duties, attacking roles during the battles, and were a priceless help during patrols. During the course of the war working shepherd dogs were confiscated from their owners in this region and put to work pulling small carts. Unfortunately, it was estimated that the rate of mortality amongst the 'man's best friend' was huge: approximately a million utilitarian dogs died during WWI (Brașcanu, 2015, pp.478-481). 
FIG.7. WWI cattle-driven carriages in Bukovina (Brașcanu, 2015, p.316)

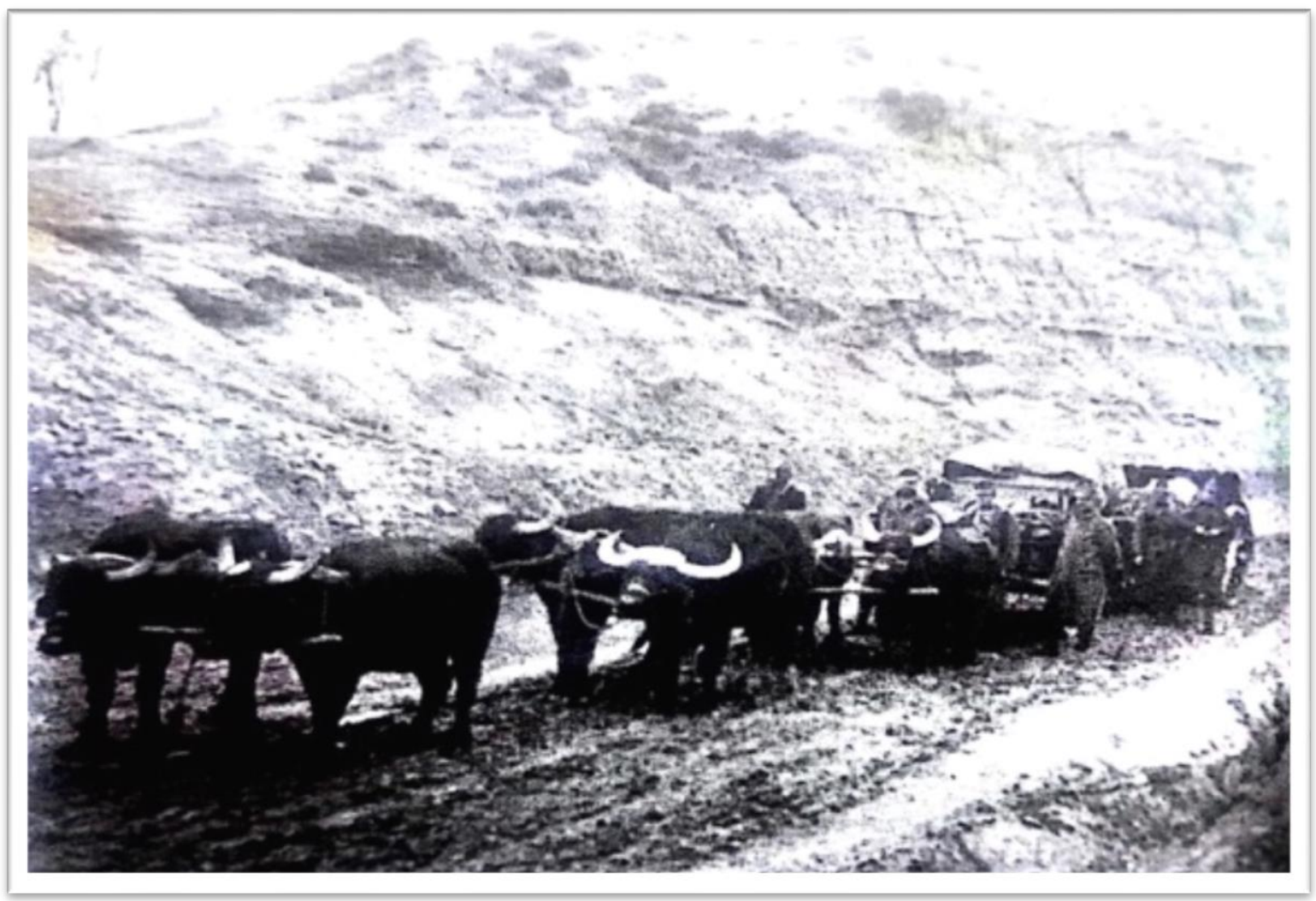

FIG.8. Horses engaged in the transport of ammunitions during WWI in the Prislop Pass (Brașcanu, 2015, p.316)

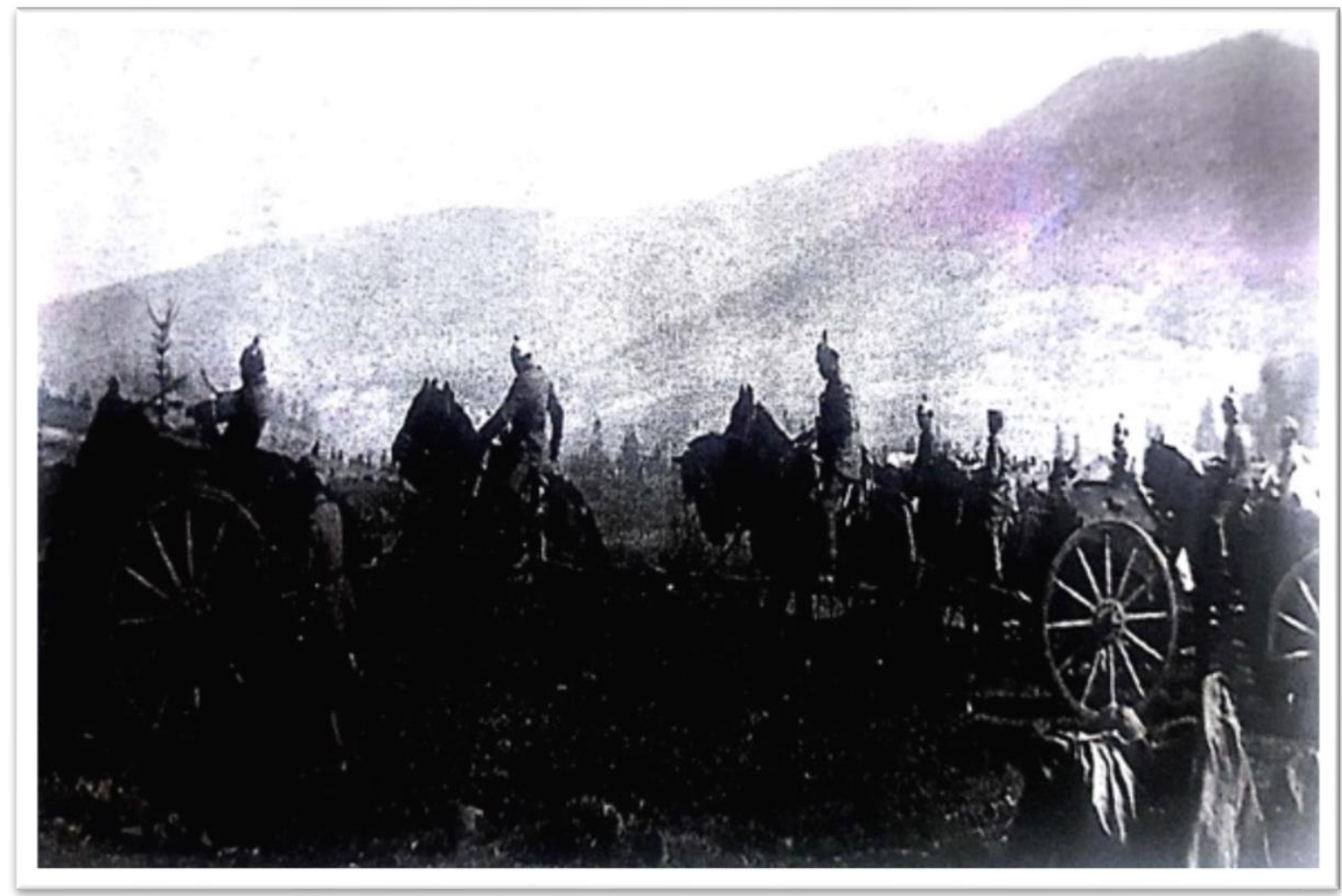


FIG.9. The WWI Chiril military dog camp - Bukovina (Brașcanu, 2015, p.479)

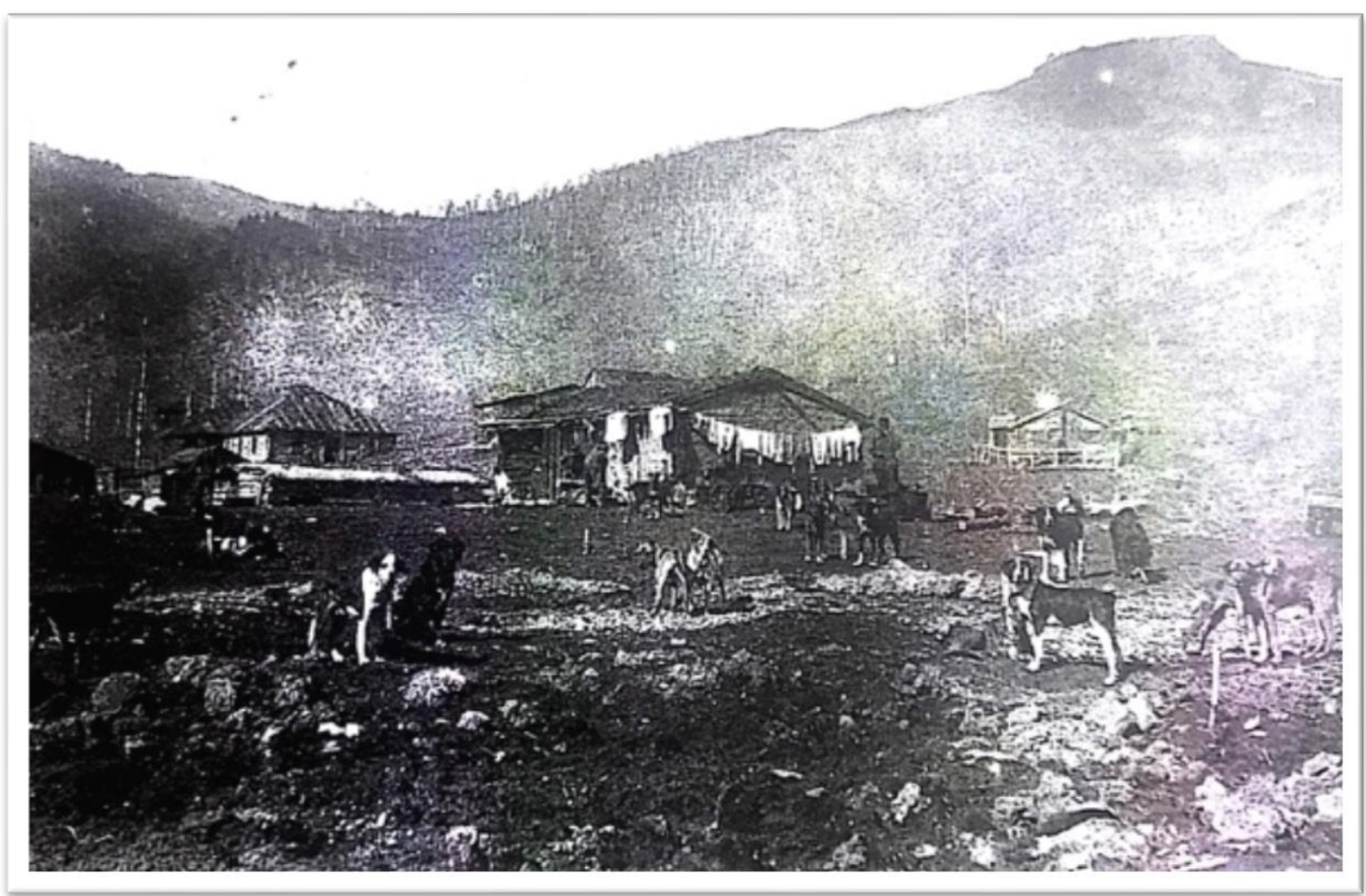

FIG.10. WWI dog driven carts in Bukovina -1917 (Brașcanu, 2015, p.480)

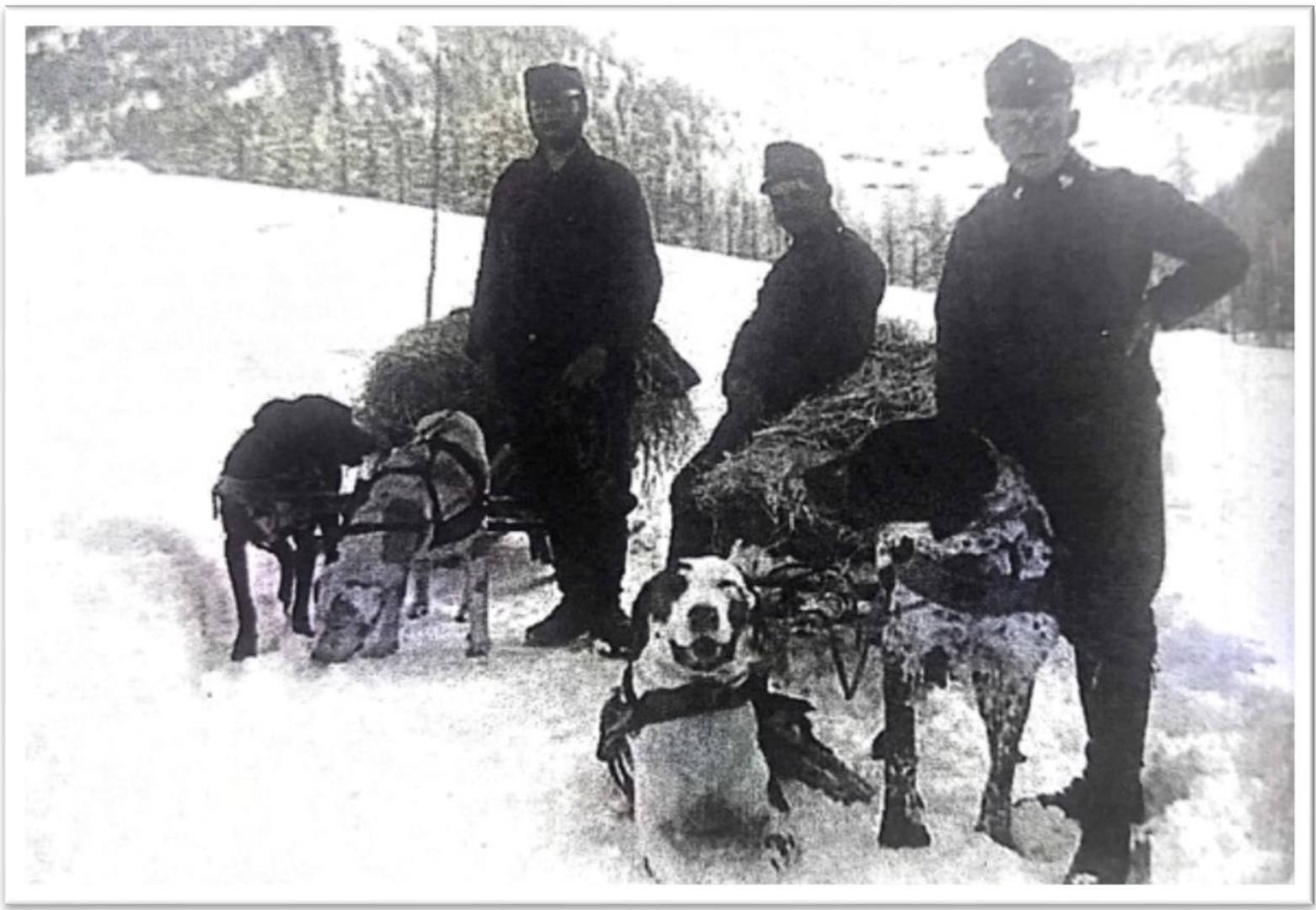




\subsection{The human dimension of the war-civilians and war prisoners}

The great strategic role of the railway system and its interconnections between Maramureş and Bukovina through the Prislop Pass, along with a retrospective view of the human dimension of the war, is skilfully illustrated by Doctor-Lieutenant Stanca Dominic in his memoir Between Two Front Lines, 1914 - 1918 (see Appendix 13). In this region of the frontline there were few differences between being a Romanian soldier in the imperial army, a Romanian civilian (Plămădeală, 1986) or a war prisoner; they all faced abuses, retaliation, hunger, forced labour and executions.

The lack of connections between the empire and Bukovina before the building of the railways, and travel difficulties encountered by carts in the mountainous regions, made the military impose frequently on the workforce of the locals. The contribution of the locals was both necessary and compulsory, leading to a situation where those who did not meet the conditions for recruitment, including women and children, were obliged to pay their contribution to the war effort in labour: trench digging, transport facilitation, road construction, loading, etc. All in all they carried out the same kind of labour as war prisoners, the only difference being that locals were more frequently engaged since they cost less - they did not require feeding or guarding. It is known that during the war the female population had to substitute the roles of the conscripted men by working the fields and fulfilling other male-specific chores, but whereas in other countries like Germany, Russia and France they were helped by the war prisoners (Bărlea, 2004), in our region it was the other way around: it was the civilians who 'helped' the war prisoners.

In Maramureș and Bukovina the Austro-Hungarian army repeatedly collected different goods like food, money, clothing items and prime materials from the population, and requisitioned 
gold, silver, antimony, copper, lead, bronze, animals, harnesses and cereals. In 1914 sixty million crowns were confiscated from churches in Bukovina, and in 1915 and 1917 two church bell collections were organised. On several occasions forced 'war loans' were requested; in other words the population was obliged to financially contribute to the war effort (Brașcanu, 2015, pp.497-500).

The war produced a great number of refugees in this area of the frontline. After the first Russian invasion the Austro-Hungarian army became draconian towards the local population whom they considered massively disloyal. Priests, teachers, peasants from all over the region were hanged, imprisoned, beaten, mocked (Slusanschi, 1915). The executed were left hanging for days on the side of the road or in public squares. Many were sentenced to death without trial on the basis of fraudulent testimonies or mere suspicion.

Women and children were also targets of cruelty based on prejudice and vengeance. The first record of a child execution goes back to $17^{\text {th }}$ October 1914 when a military policeman named Drescher hanged a child by the name of Constantin Stroșciuc. Equally renowned for their cruelty and hostility towards Romanians were Troubey, Tuberger, Lackinger, Garber and of course Eduard Fischer who claimed to know only three nations in Bukovina: Germans, Jews and traders (Brașcanu, 2015, pp.534-539). Impressive photographic collections of WWI photography and historical documents about refugees, war prisoners, requisitions, and the executions, whose analyses have provided a conspicuous part of the information in this part of the chapter, can be found in Paul Brășcanu works: Drum de fier prin praf de pușcă și ploaie de stele and Tunuri la porțile Bucovinei. 


\subsection{WWI in literature and folklore}

The war triggered pervasive long-lasting effects in the Romanian collective consciousness which translated into a well-represented field of literature and folklore. The human dimension of the war in all its complexity, from the dramas of the refugees, of the war prisoners, of the local population who remained in loco, of the Romanian soldiers in the Austro-Hungarian army, the conspiracies, the reprisals, the executions, are all abundantly represented in literature, especially in relation to the Romanian historical provinces annexed to the AustroHungarian empire. Many such writings have become classics of Romanian literature and many folkloric creations, born from the experience of the Great War, are still found at the top of the list of famous Romanian patriotic songs.

The best example of a Romanian historical and psychological novel, inspired from the circumstances of the Romanian soldiers in the Austro-Hungarian army, is Liviu Rebreanu's classic Forest of the Hanged. The novel, translated into twenty-one languages, is set within the frame of the inner drama of the main character, Apostol Bologa, presenting a war fresco depicted as a colossal collective crime, a generator of misery, suffering and death. Although the author dedicated the novel to his little brother, Emil Rebreanu, who was executed by Austro-Hungarians on the Romanian front in 1917, André Bellessort stated in the first edition of the French version that the novel occupies a singular place in WWI literature as it concerns all nations, the true battlefield being in the heart of man (Gusti, 1944).

Emil Rebreanu was enrolled in the Austro-Hungarian army in 1914, and by 1915 he was promoted to sub-lieutenant. He fought in Russia, on the Galician Front and on the Italian front and was decorated with the gold medal (the highest decoration awarded to Romanians in the imperial army) for bravery (Dumitru, 2009). In 1916 he was transferred to the Romanian front 
where he had to face an irreconcilable inner conflict between his sense of duty as a soldier and his national Romanian conscience. He decided to desert to the enemy and join his co-nationals in their fight for national emancipation, but aware of the implicit risks he cautiously wrote down his will, in anticipation of what he knew might happen (Naroș, 2013). He tried to access the Romanian side of the front on the $10-11^{\text {th }}$ May 1917 after having escaped from the infirmary, taking along with him the plans of the Austro-Hungarian troops, but he was caught and sentenced to death for desertion and espionage. On $14^{\text {th }}$ May he was hanged in front of the soldiers, many of whom were Romanians like him and brought along to watch. Witnesses relate that Emil pushed the executioner away and shouted to the soldiers "Long live Greater Romania!” immediately before his execution (Ministerul Apărării Naţionale, 1996, p.14; Rebreanu, 2000).

Similar episodes, which became recurrent themes of Romanian nationalism, have given birth to the national master narrative. For more than a hundred years Romanian folkloric creations have continued narrating the story of liberty that transcends individual life and death to culminate in an apotheosis of national emancipation, following the example of writings generated by the Great War. Its epic thread has coursed through the centuries, regrouping and reinterpreting every single sacrifice that was ever made in the name of freedom, like a brick placed in the service of supreme national aspirations. Nonetheless, the above phenomenon does not qualify as a practice of post-hoc historical rationalisation as it reflects the perpetuation of the authentic content of the original declarations that were adopted throughout the country at the time of the Great Union, and of historical documents that testify to the Romanian fight for emancipation during WWI, and even before the war. An example of the authentic writing that reflects this phenomenon is a poem found in the haversack of a soldier killed in the autumn of 1918, in the trenches of Mount Sorica in the Carpathians: 
"Don't cry, Mother Romania, That I will die without oblation! A bullet headed for your chest, With my chest I dissuaded...

Don't cry, Mother Romania! It's our turn to fight And from the land that burns us We'll not renounce a slice!

Don't cry, Mother Romania! We're perishing for justice; Thy offspring through the ages Will honour us, we know it!

Don't cry, Mother Romania! Hoard all that's good under the sun; Invite us to the fest when done When Romania will be Greater!"5

On the trail of folkloric creations, the most representative example is, without any doubt, the present Romanian National Anthem. Through the centuries this war song has become a symbol of the Romanian fight for freedom and national unity, a key element of national identity that accompanied Romanian soldiers during crucial historic trials and that became a metaphoric compendium of Romanian history. This was also the war song that the Romanians of Austro-Hungary were allowed to sing when enrolling in the imperial army at the beginning of the war. Although it has eleven stanzas, the short version played today on official occasions only reproduces four, which are translated below while the full version is available in

\section{Appendix 14.}

"Awaken thee, Romanian, from thy deadly slumber That the barbaric tyrants afflicted upon you And now or never tailor a fate that's torn assunder To which thy dreadful foes shall pay a tribute.

And it is now or never to prove thyself to all And show that in thy veins a Roman blood still flows, In our hearts forever, we glorify a call

Triumphant in all battles, the Trajan name bestows.

\footnotetext{
${ }^{5}$ The translation from Romanian to English was made by the author of the thesis.
} 
Behold, all mighty shadows, Michael, Stephen, Corvin,

The Romanian nation, thy future progeny,

With weapons in thy hands and fire from within,

'Life in liberty or death!' they all decree.

Clerics arise thy crosses, thy Christian army steer,

Most holy is thy purpose for freedom is thy stand.

Better to die in battle, with glory without fear,

Than live enslaved anew in thy ancestral land."

"Go Cross the Carpathians Romanian troops" is another folkloric creation particularly dear to Romanian people which was intonated by the Romanians on various battlefields during WWI. It is attested that the nowadays 10 stanzas march had only 3 stanzas in its original version. The original battle song was inherited, passed from generation to generation to the day and made famous nationwide, by the man choir of Finteușul Mare, a village of the county of Maramureș, that was founded at the end of the Great War by Valer Dragoș, Gavril Bogdan and Nistor Dragoș in occurrence of the Romanian Great Union. The march is also documented in relation to the Romanian Legion of Transylvanian and Bukovinian Volunteers who also sang a version of the battle song ${ }^{7}$ in the winter of 1919 (Ghisa, 2009, p.163). The original 3 stanzas version is reported below.

\footnotetext{
"Go cross the Carpathians Romanian troops

To arms, with flowers and fronds

The triumph awaits you, your brothers await too

Their hearts with the thoroughfares bonds

The Ardeal, The Ardeal, The Ardeal is calling for us

Without us there is hope no more!

Child go kiss your parents and go kiss your brothers

And then we shall all march to war

Ahead! Ahead with swords in your hands,

The just boundaries to revive

Let's cross the Carpathians, we'd still claim Ardeal

If we were to be buried alive".
}

\footnotetext{
${ }^{6}$ The translation from Romanian to English was made by the author of the thesis.

7 "The Ardeal, the Ardeal, the Ardeal, calls us/ We dream of it since we were children / Let's pass the Carpathians/ We want the Ardeal/ Even if it means being buried alive!"

${ }^{8}$ The translation from Romanian to English was made by the author of the thesis.
} 
The decline of the Austro-Hungarian empire, the causes of the decay that was endemically spreading before the war and the misery of the Romanian population in Transylvania under Hungarian rule were also made the subject of Hungarian literature. The Transylvanian trilogy, written by Miklos Banffy between 1934 and 1940, was re-edited in English by Everyman's Library in 2013 with an introduction provided by the English historian Hugh Thomas. The historical background provided by Thomas mentions a Romanian invasion in the Hungarian countryside in 1919, talks about how he envisions that the Treaty of Trianon reduced "the size of Hungary by giving Transylvania to Romania, Slovakia to the new Czechoslovakia, CroatiaSlovenia and part of the Banat, an ancient Hungarian territory, to the new Yugoslavia" (Banffy, 2013, p.XVI) and suggested that "the worst disaster in the history of the twentieth century was the break-up of the Austro-Hungarian Empire" as "the collapse of that enterprise brought tragedy, not happiness (Banffy, 2013, p.XX-XXI)”.

Such an historical account of marked imperialist tendencies is highly dissonant with what emerges from previous parts of this research. Romanian historic documents confute Thomas's theory and account for the achievement of national emancipation by will of the people which by no means can be framed as a negative outcome. Furthermore, the Romanians did not invade the Hungarian countryside, but they actually took over Budapest on $4^{\text {th }}$ of August 1919 in reaction to Bela Kun's communist offensive in Romania, who was relying on a joint offensive of the Russian Bolshevik Soviets in Bessarabia. The actions undertaken by the Romanian Army at the time rescued Hungary, Austria and Czechoslovakia ${ }^{9}$ from communism. In November 1919, the Romanian Army left the Hungarian capital starting the retreat towards the borders established by the Paris Peace Conference.

\footnotetext{
${ }^{9}$ The units who fought in Czechoslovakia, were made of the volunteer legions from Ardeal led by luliu Maniu.
} 


\subsection{Conclusions}

"The First World War was, during the century that passed since its beginning, one of the most intense chapters of the historical writing, especially inside the nations that fully lived the event and bared the consequences" (Cârja, 2016, p.8). In the Romanian historiography the Great War and the Romanian Great Union are highly interconnected themes that constitute the most significant chapter of national history and therefore also become a leitmotif of historical writing. Achievement of the Great Union was the engine that fuelled the involvement of the Romanian Kingdom in the Great War and marked the conclusion of a historical process of national emancipation that had begun way before the outburst of war. In fact, the problem of the nationalities was a well-known reality years before the beginning of WWI and an international diplomatic fight meant to solve the issue of nationality to the advantage of people's rights was already in place.

Historical documents reveal that the restless desire of territorial reunification motivated Romania to enter the war in hope of exploiting the world conflict to advance its long-term aspiration for national emancipation. Geography played an important role in the quest for national unity, which stood as the holy grail of Romanian political and military strategy during the Great War. If, on the one hand, its geostrategic position aided Romania in its negotiations with the two antagonist blocks during the neutrality stage, on the other hand, it greatly influenced its conduct during the war in both a national and international context. The Entente's lack of power, created on the Eastern Front between the Baltic Sea and the Black Sea after the dissolution of the Russian army following the Brest-Litovsk Treaty, brought disastrous consequences for the Romanian Kingdom, which found itself completely isolated and encircled by enemy forces, with all supply lines cut off and scarce provisions. The loss of 
the Russian ally, which was in fact the only available ally in the area, forced Romania to a very disadvantageous armistice with the Central Powers. The Buftea-Bucharest treaty fixed draconic peace conditions for the Romanian side because Romania was in no position to negotiate. King Ferdinand did not promulgate the treaty, so creating the conditions for Romania to re-enter the war and participate as a belligerent state at the subsequent peace talks. The Romanian fight for freedom, national unity and self-determination culminated in the Great Union bringing to completion a historical process that began years before the beginning of the WWI. The $1^{\text {st }}$ of December 1918 marked the union of all Romanians in a single state historically known as Greater Romania, fulfilling the political ambitions that motivated Romanian involvement in the Great War. The Romanian Union proclamation was endorsed by the Treaty of Versailles in accordance with the right to self-determination of the people. The advent of a new international mentality, promoting the principles of nationality and self-determination, permitted the affirmation of the long-denied national rights of the peoples of the Eastern Front.

As far as the human dimension of the Romanian historical provinces appendant to the AustroHungarian Empire is concerned, it is worth mentioning that their war experience holds marked peculiarities in relation to the Romanian case but also highlights the general condition of those multi-ethnic people who were subjected to imperial rule. The fate of the Romanian historical provinces during the Great War was greatly influenced by decisions taken by the Romanian Kingdom and by the course of the war on the Romanian front. The enrolment of Romanian soldiers in the Austro-Hungarian army was dependent upon a series of circumstances, culminating with the Romanian decision to remain neutral at the beginning of the war, recommendations from the church and the Romanian king that soldiers should fulfil their duty to the emperor, and was also influenced by threatening the charge of treason, 
military courts and reprisals. The official attitude of the Romanian Kingdom at the beginning of the war, along with the Hungarian propaganda and persuasion campaign, disoriented the population, persuading it to engage in the fight for a purpose and ideal which eluded their understanding and will. By allowing the Romanian military formation to sing patriotic songs such as the Romanian national anthem, whose basic message was the promotion of freedom from foreign domination at all costs (see Appendix 14), by allowing soldiers to wear badges in the colours of the Romanian flag, and by using the Romanian language in official imperial communications, the Austro-Hungarians led the Romanian people to believe that they were finally being granted recognition of their national rights and that they were heading towards freedom.

The contradictions of the war fought under the imperial flag, the moral dilemmas, the persecutions, the resistance, and the fight for national rights are all accounted for by the chosen case study. The fact that the region of Maramureș bordered the Galician front, and also gated the way to the heart of the empire, made the region a victim to the war and its side effects from start to finish. Furthermore, within the frame of the bicephalic monarchy there were few differences between the conditions of a Romanian soldier in the imperial army, a Romanian civilian or a war prisoner, as de facto they all faced similar abuses, humiliation, retaliation, hunger, forced labour and executions. Despite the Austro-Hungarian leadership making efforts to create the illusion of imperial cohesion and equality at the begining of the war to avoid rebellion from numerous nationalities of the empire, the war reality emphasised the contradictions and the imperial army faithfully reflected the socio-political realities of the monarchy. In Maramureș this translated into massive confiscations, requisitions, subscription to war debts, forced public corvée, abolishment of Romanian schools, banishment of the 
Romanian press, instant death penalty for nationalistic feeling, and marked militarisation of the region.

Russian invasion into the Carpathians started in Maramureș in September 1914, after they had already occupied two-thirds of the Galician Front. The Russian threat lead the Central Powers to position troops on the peaks of the Mountains of Maramureș, establish the AustroHungarians headquarters in Vișeu de Sus, and locate their main military hospitals and cemetery in Borșa. Real cities of barracks were built on the heights of Copilașul and Prislop, while the front line was established along the line of the Carpathian Mountains in the proximity of Borșa, Vișeul de Sus, Poienile de sub Munte and Frasin. The Borșa-PrislopIacobeni railway was built in preparation for the offensive in Bukovina against the Russians. The railway was a particularly strategic node for the empire, as it not only assured connection with Bukovina, but also connected the local mines (providers of manganese and other metals) with the Transylvanian foundries. The requirement of strong railway links behind the frontline became necessary due to the overwhelming need of the army to sustain the supply of huge quantities of weaponry, ammunition, food and medicines and, in addition, to relocate troops and ordnance, and to evict the wounded.

The Prislop Pass military command provided the link between Maramureş and Bukovina playing a great strategic role in the economy of war. The railway line inaugurated in August 1915, to celebrate the emperor's birthday, operated until December 1918 when most of the rolling stock was taken to Debrecen and the Prislop facilities were burned down. Several thousand war prisoners, locals and soldiers were engaged in the construction and maintenance of the railway and the adjacent facilities. The particularly harsh conditions in this area translated into a high mortality rate for soldiers, prisoners and civilians alike, whose story is still narrated by the "sparse mounds loomed through the grass carpet" (Brașcanu, 2013, p.424). 
More than 10,000 men from Maramureș were enrolled in the Austro-Hungarian army and sent to battle on the Galician fronts, Serbia, Ukraine, and Italy, participating in the battles of Lemberg, Doderdo, Manilova and Piave. The oppressive policy, the reprisals and persecutions against Romanians, both soldiers and civilians, led to the gradual coagulation of a manifest resistance. Desertion to the enemy occurred as a specific form of protest against the AustroHungarians after the adherence of Romania to the Entente. Vasile Lucaciu, a priest from Maramureș, played an important part in leading several international diplomatic campaigns that not only allowed the creation of Romanian national legions in prisoner-of-war camps across several countries, which later joined the Romanian army and engaged in battle against the Central Powers, but also persuaded the international community to support the Romanian cause.

The complex social and historical circumstances of the war had a strong impact on the Romanian collective consciousness generating a fecund field of war writings. Nuances of the human dimension of the war were skilfully captured in literature and folklore, converting the dramas of refugees/war-prisoners/soldiers/local population and their quest for freedom and national unity into leitmotifs of the Romanian national master narrative. The fight for freedom and self-determination constituted the most sacred cause of the Romanian people and is still regarded in this light a hundred years after the end of the war and achievement of the Great Union.

The emphasis on preferring to choose death over continuing to live under foreign domination emerges from all Romanian folkloric creations and WWI literature. Nonetheless, it is fundamental to understand that the Romanian assertion of freedom and self-determination had intimate interconnections with, and was always envisioned in relation to, the dimension of the land. 
A hundred years ago most East European nations were agrarian societies and, as such, their whole existence revolved around the land. Romanian peasants conducted their lives in such communion with the land that, when conquered, they did not lose simply a means of existence but were deprived of a fundamental part of who they were. Ethnographic studies reveal the existence of a profound bound between rural communities and their lands, which made almost every activity they conducted a form of ritual that sacralised the work of the peasantry. The land, perceived as pater patriae, was a part of the nation alongside the people. Such aspects were faithfully reflected in all the declarations and resolutions adopted in occurrence of the Great Union and were amongst the primary reasons that made the peasants of Transylvania reluctant to abandon their lands to join the Romanian Army and which animated the Romanian army to fight to the death to defend national territory instead of adopting modern war techniques focused on the annihilation of the enemy's human resources.

Despite the general tendency to filter history through the lens of present knowledge and beliefs when engaged in reading the past, it is worth remembering that at the time of the Great War people knew nothing about rights as we today perceive them. If it is true that the Romanians fought the war in the name of freedom and national rights, it is also true that for them all these notions became condensed in the re-appropriation of their ancestral land. In this regard it can be argued that, for countries such as Romania, WWI was truly the last land war as its most intimate cause appears to have been the land in itself, not as a resource but as a semi-personified entity that stood as a guarantor of what they deemed to be rightfully theirs: it personified their rights. 


\section{CHAPTER 5 - ASSESSMENT OF THE MATERIAL CULTURE OF WAR IN THE}

\section{PRISLOP PASS AREA/THE PRISLOP PASS CONFLICTUAL LANDSCAPE}

\subsection{Introduction}

This chapter provides the results from the recording and analysis of the war remains throughout the research area in view of achieving Objective 1, determining what constitutes material evidence of WWI in Maramureş. Prior to this work, there was no existing gazetteer of Romanian war sites, hence, a catalogue of the war remains had to be created to allow the conduction of further work

The importance of this part of the research lies in its capacity to enable assessment of the level of preservation of the war remains and enabling their characterisation. Examination of the content and characteristics of material culture present in the research area provides the material basis with which to unite the immaterial significance emergent from the previous chapter, with the aim of providing data with which to build the analytical record of the war remains (see chapter 6).

The chapter presents the results from having recorded the traces of war in the chosen research area, forming what was previously referred to as war sites. Furthermore, the approach allows examination of the influence exerted by geography and development upon the preservation of the war sites. In order to facilitate the reader's understanding of the geography of the area, a map of the location of the Maramureș County within the Romanian territory (FIG.11) and a map of the location of the research area within Maramureș (FIG.12) are presented below. 
FIG.11. Map of the county of Maramureș within the Romanian territory (Author, 2018)

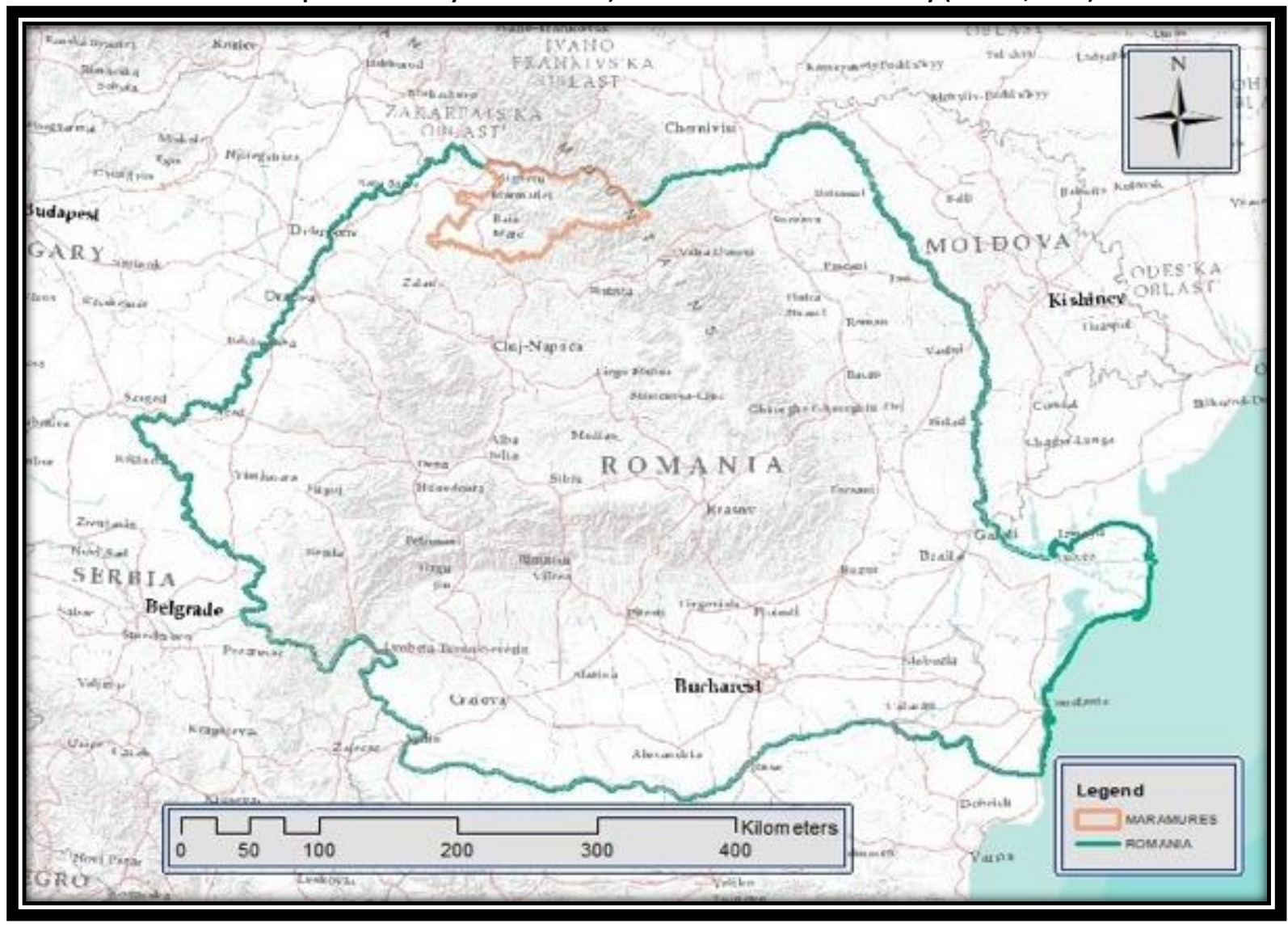

FIG.12. Map of the research area within the county of Maramureș (Author, 2018)

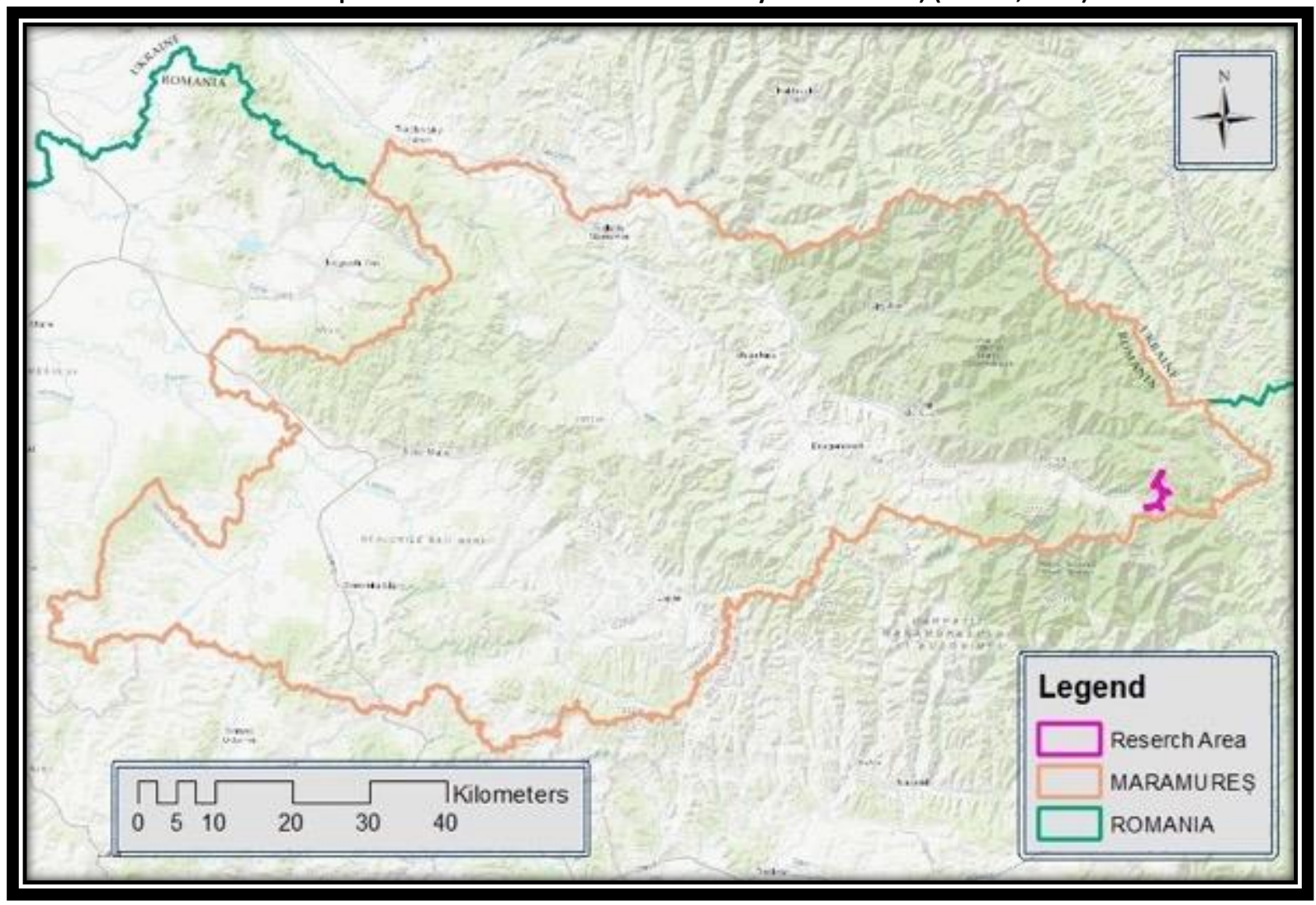


The studied area was divided into three research sectors, each corresponding to different recording levels that reflect decreasing scales of detail from the recording of all visible war traces at one end of the scale to simple registration of large-scale earthworks at the other. Current roads, built on ex-military roads, were used as guidelines for the recordings. The above recording strategy was justified, on the one hand, by the need to highlight the morphology of the conflictual landscape in a way that illustrates the connections between above-ground war remains and the vast complexity of networks of earthworks, and, on the other hand, by the fact that a huge amount of materials spread over an impressively large area were to be covered by one person in a limited amount of time.

FIG.13. Map of research sector 1 (Author, 2018)

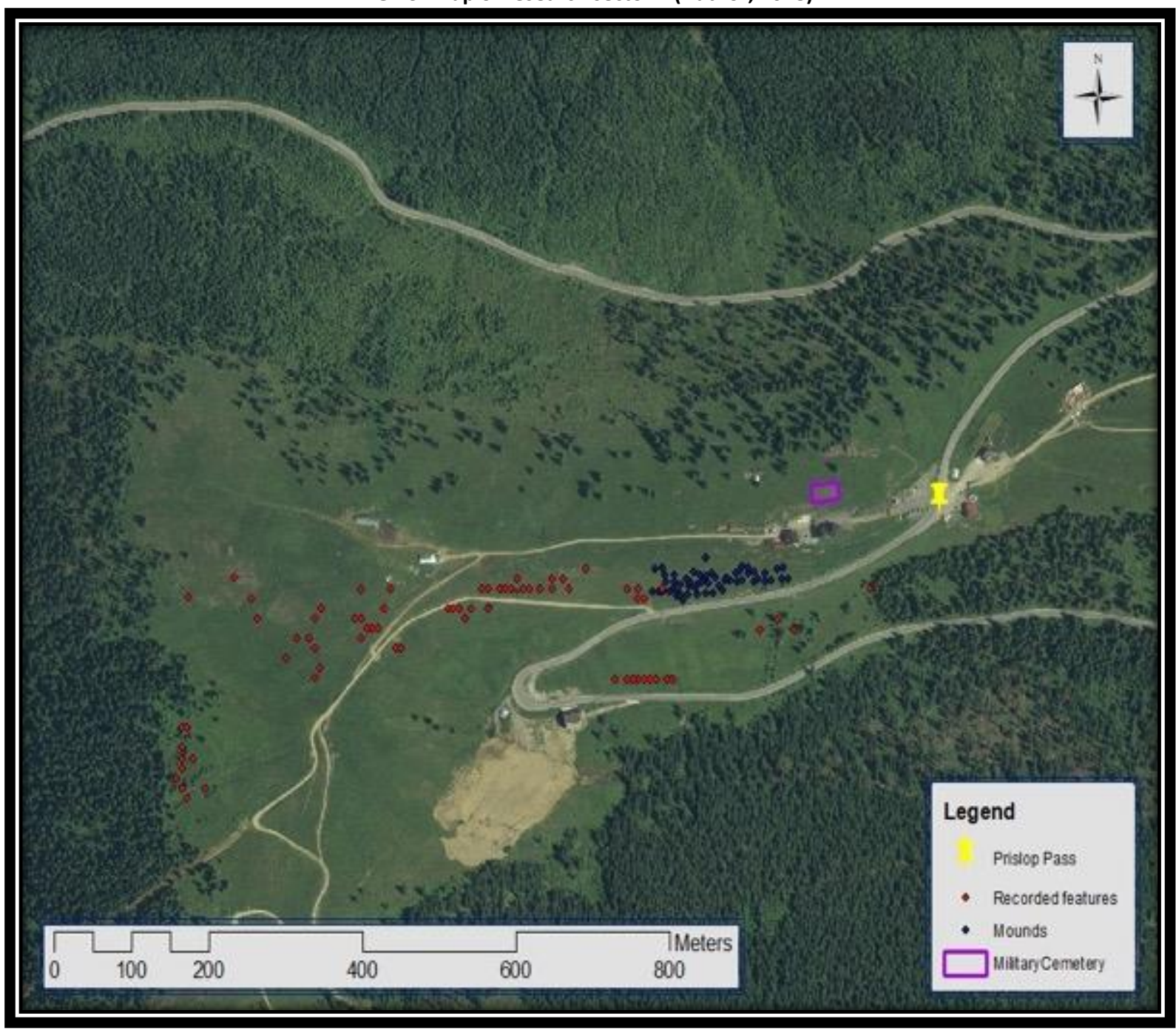


The first research sector (FIG. 13), which extends around the Prislop Pass, focuses on the area where the WWI city of barracks was located, counting an elevated concentration of material remains. The military command of the Prislop line, known at the time of the war as "KuK Kommando der Prislopbahn" (Kulhanek, 2009), constitutes the sector with the highest degree of recording details and recorded features accounting for all visible human interventions on the environment.

FIG.14. Map of research sector 2 (Author, 2018)

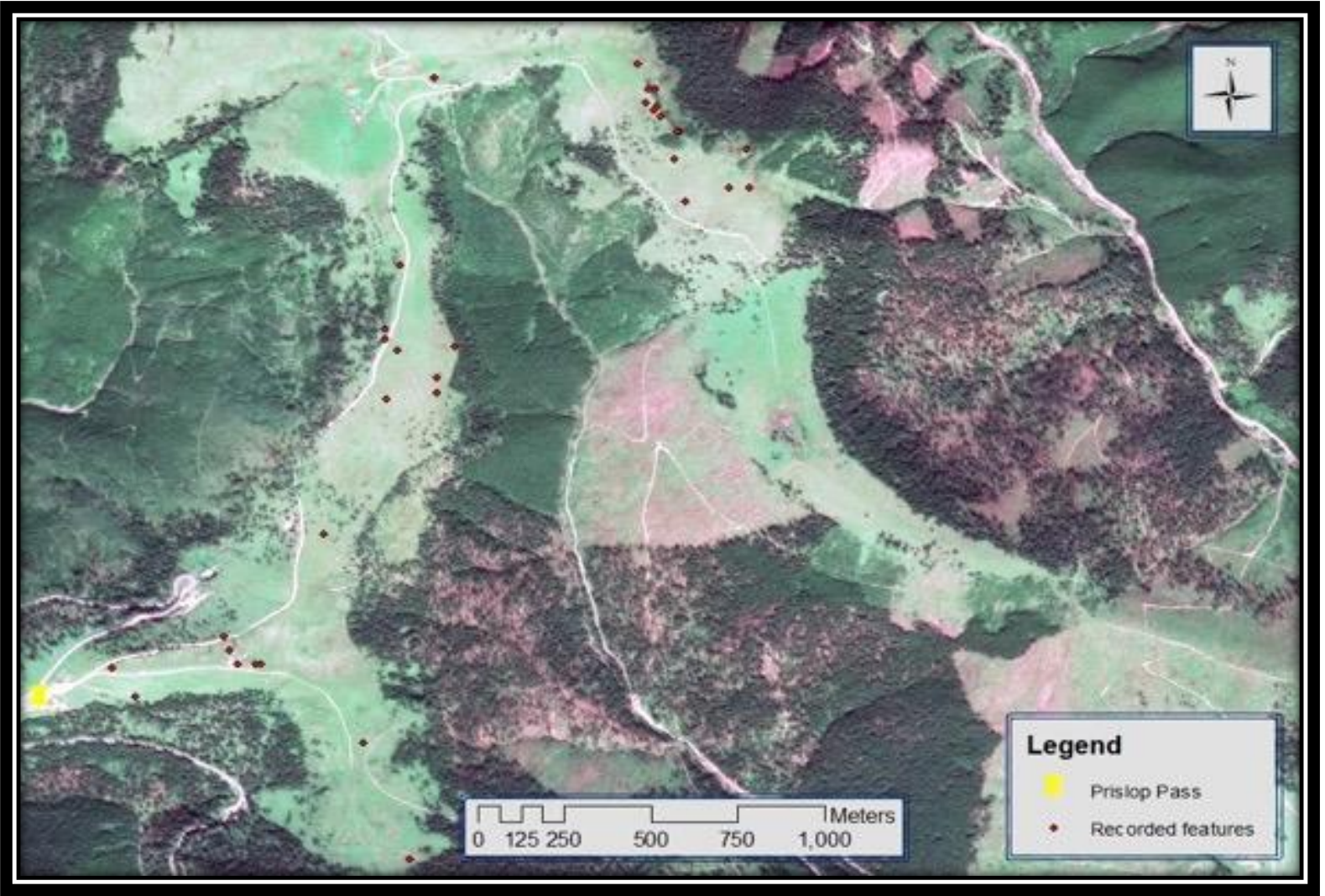

The second research sector (FIG.14) continues with the recording of large concrete remains (mainly bunkers) and the adjacent trench systems following the development of the defence system in the contiguous area by taking the road system, called Mackensen's road/the war road by the locals, as a reference point. Mackensen's road was chosen as a reference point because local memory reports that the road owes its existence to the necessities of the military fortifications line. 


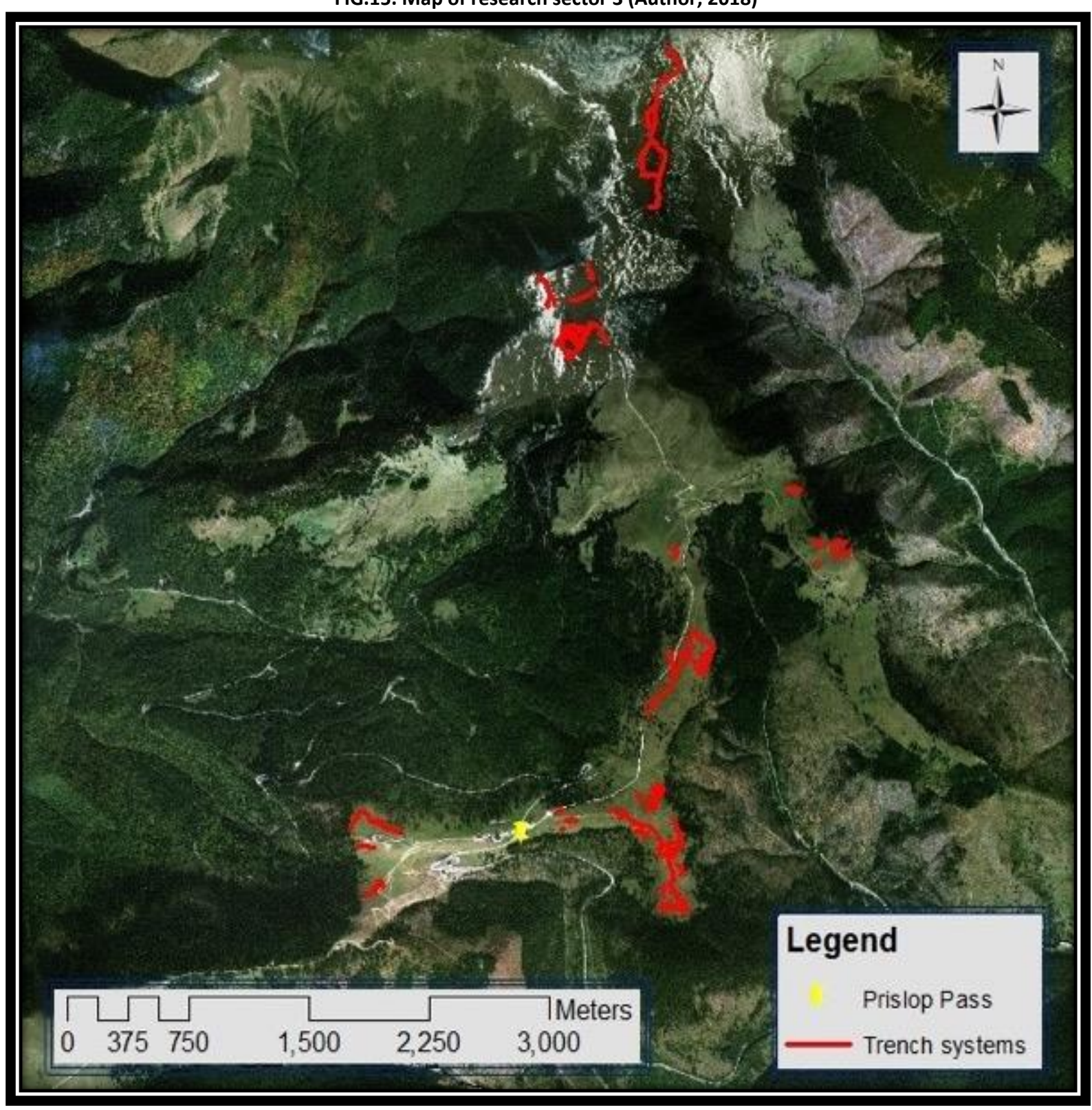

The third research sector (FIG.15), which is also a continuation of the defence system, shows the strategic display of earthworks on the crest of the nearby mountains and emphasises their massive extent. The third sector, which is dedicated to recording the large-scale earthworks, reports on the display of trench system networks that spreads endemically in a vast part of the research area from the central/ $1^{\text {st }}$ sector towards north. ${ }^{10}$

\footnotetext{
${ }^{10}$ The road was followed northwards because the territorial limit of the county of Maramureș is to the south.
} 
An inventory of the individual components of each of the three sectors is made available throughout the chapter, followed by a conclusion section that discusses the emergent data. By doing so, the present chapter completes the section of the thesis dedicated to the material, historical and symbolical characterisation of the places of war, extrapolating the tangible and intangible characteristics of the material culture, with a view to allowing the assessment of the war sites as heritage in the discussion chapter. Therefore, the chapter constructs a gazetteer of war sites informing assessment of what they represent, their state of preservation and authenticity, and highlighting the existing preservation threats.

\subsection{Research sector 1}

Localisation of the former city of barracks' exact position was achieved by relying on WWI photography and postcards retrieved from public archives, including Europeana Collections, the Austrian State Archives, or private collections that added significantly to the descriptions found in previously quoted monographies and memoirs. Also, the work of a particular category of collectors who edited a journal entitled The Railway Philatelist furnished an abundance of information on the subject as it reproduced WWI postcards and historical maps of the Borșa-Prislop-Iacobeni railway, recorded in most documents with its Austrian name Prislopbahn (the line of Prislop). A revision and synthesis of such articles can be found in Gabriel Mărgineanu and Șerban Lacrițeanu book Railway Premiers and the Evolution of Traction Activities on the Regional C.F. Iași 1870 - 2000, in the chapter about the IacobeniBorşa war line through the Prislop Pass.

\footnotetext{
"Several images of the quoted works along with those reproduced in this chapter display steam locomotives in Borșa, Prislop or Cârlibaba, identified as being part of the MAV 492.000 and KuKHB 4000 (KuK HB - Kaiserische und Konigliche Heeresbahnen,
} 
Austrian Military Railways). The great majority of the analyzed images were imprinted on postcards made by a specialized department of the Austrian army which was quartered in Obcinele Mestecănișului in the period between 1915-1918, many photos of peculiar collections. The postcards known as real-foto (photographs of places without image processing) were used for the correspondence between the frontline soldiers and those back home, which was allowed in order to create a climate of trust in the military actions" (Mărgineanu and Lacrițeanu, 2016, p.324).

Further photographic evidence about the military edifications (FIG. 22, 18, 26, 31, 32, 44, 46) the railway (FIG. 17, 19, 20, 27, 35, 36, 37), the logistics (FIG. 28, 33, 34, 45), the climatic conditions $(16,17)$, the red cross sanitary station (FIG.43), the train station (FIG.21, 31), the construction and development in time of the military command (FIG.23, 24, 25, 29, 38, 39, 42), the transportations (FIG.30, 41) and the living conditions, can be found in Professor Helmut Kulhanek's articles "Prislop Bahn - The military railway Borșa-Iacobeni. Particular novelties in the light of philatelic ${ }^{11}$ documents" (Kulhanek, 2009), "Prislop Bahn - the military railway Borșa-Iacobeni, updates 1" (Kulhanek, 2017), "Prislop Bahn - the military railway Borșa-Iacobeni, updates 2” (Kulhanek, 2017), while an abundance of WWI military maps including this location can be found on the HUNGARICANA website, in the section dedicated to 1914-1918 WWI military maps.

The images, along with those reproduced below, bear evidence of the existence and veracity of features described in the previous chapter, such as the utilisation of the labour of local woman (FIG. 21), of the existence of the funicular in the Prislop Pass (FIG. 16), of the military hospital (FIG. 43, 31), of the troops and military leadership (FIG. 23, 24, 25, 42) of the military cemetery (FIG. 40), of the number of rail lines in the Prislop Pass (FIG. 30, 36),

\footnotetext{
${ }^{11}$ The Romanian word designates a branch of philately that specifically deals with postcards.
} 
of the type of buildings and their location (FIG. 22, 32), and of the importance of the Prislop

Pass in the economy of war.

FIG.16. Prislop cableway, 1917 (Image available:

http://www.bildarchivaustria.at/Pages/ImageDetale.aspx?p iBildID=15665125)

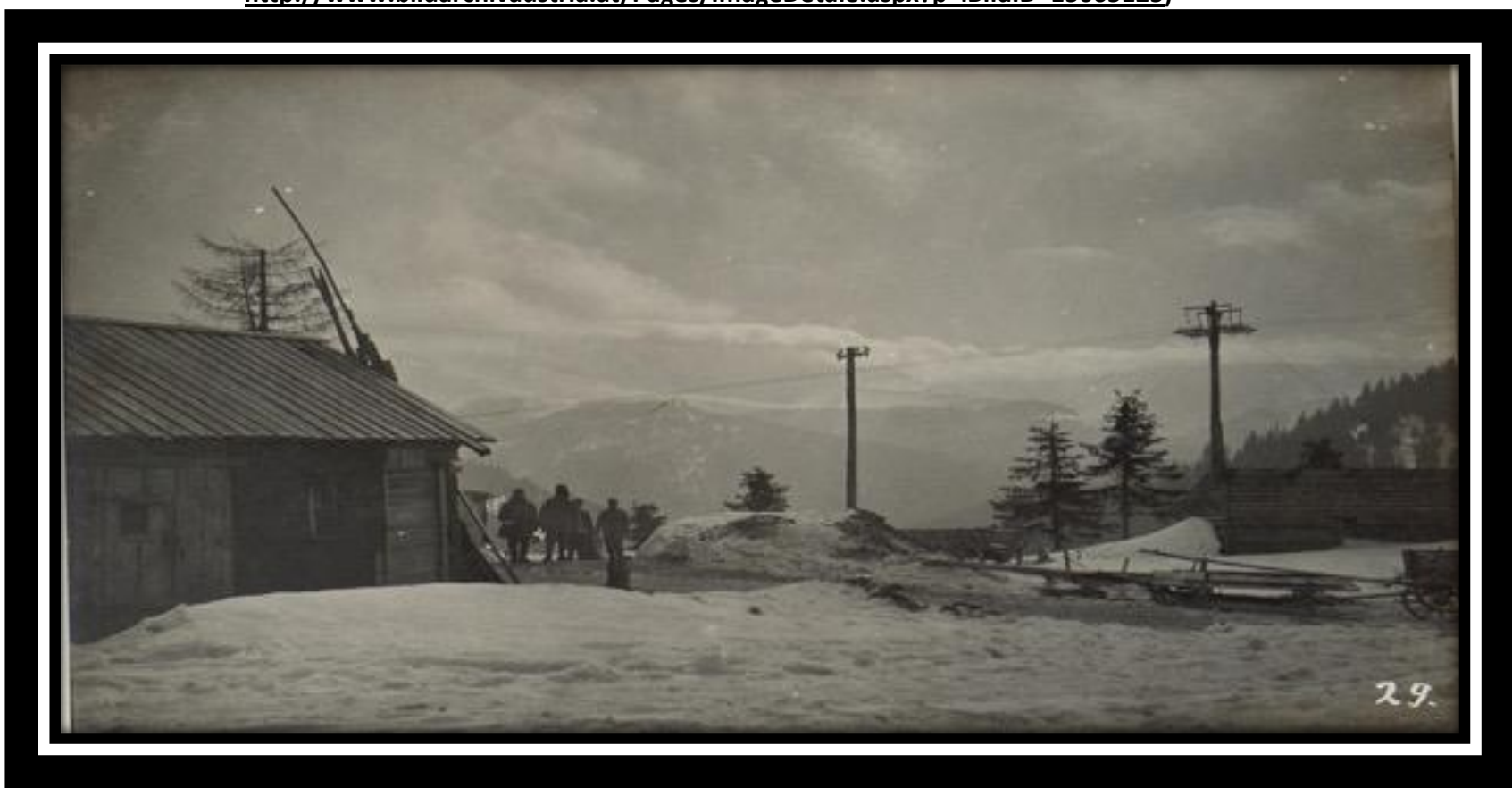

FIG.17. Railway, tight curve near Prislop (Image available: http://www.bildarchivaustria.at/Pages/ImageDetale.aspx?p_iBildID=15665132)

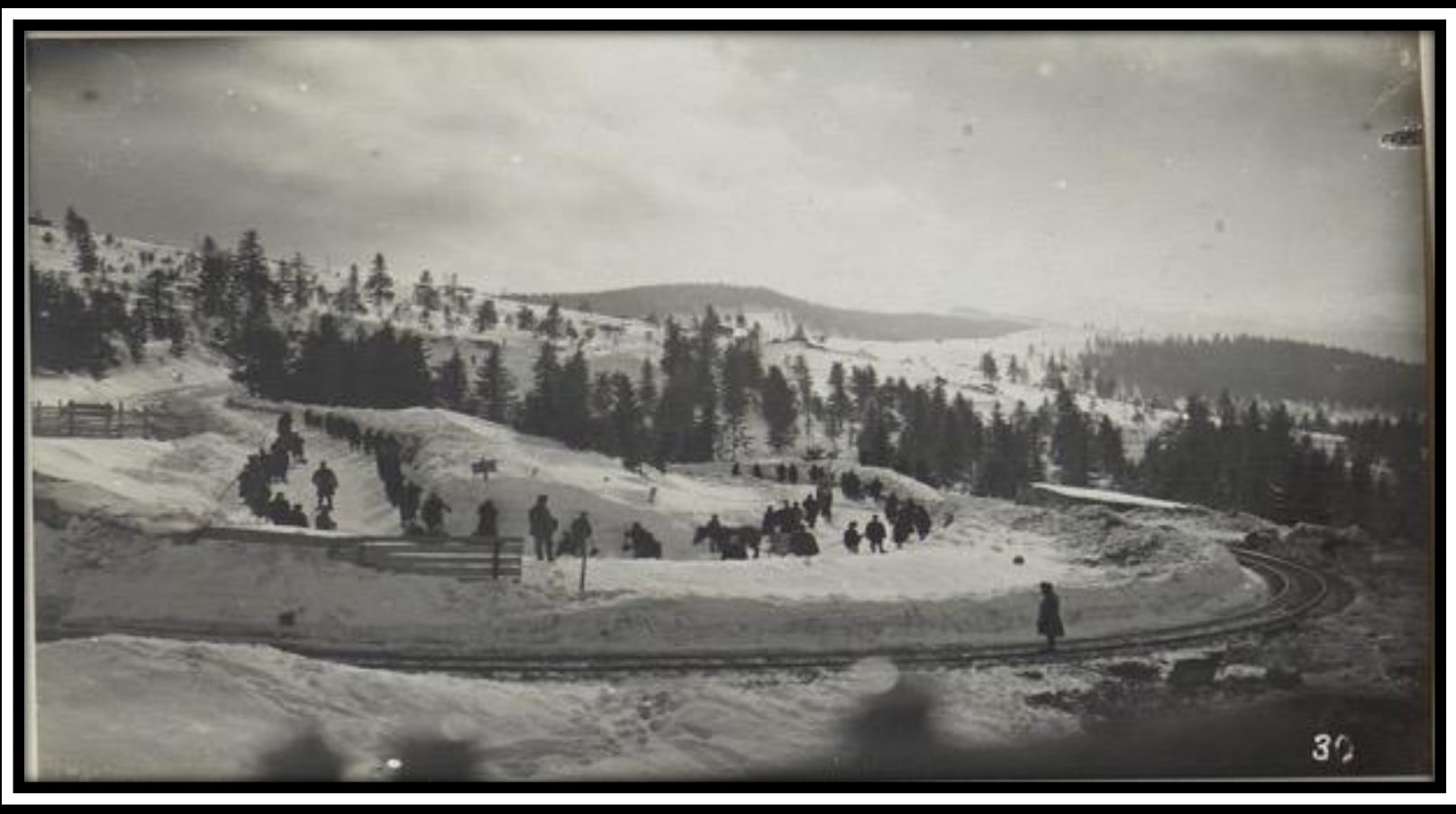


FIG.18. Prislop Pass central plateau, 1917 (Image available:

http://www.bildarchivaustria.at/Pages/ImageDetale.aspx?p iBildID=15665118

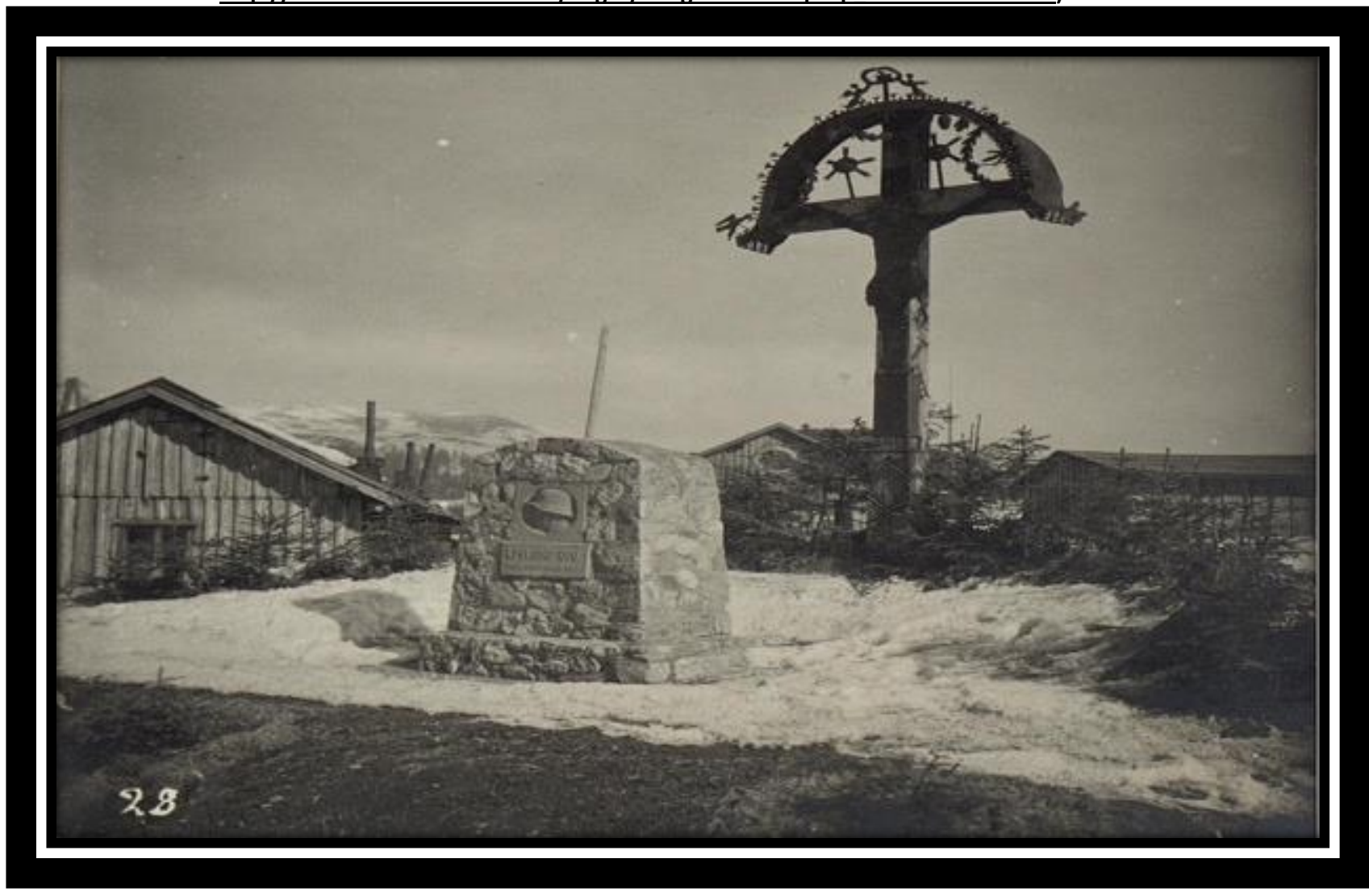

FIG. 19. WWI train reaching the top of the Prislop Pass, 1917 (Image available:

http://www.bildarchivaustria.at/Preview/15665139.jpg)

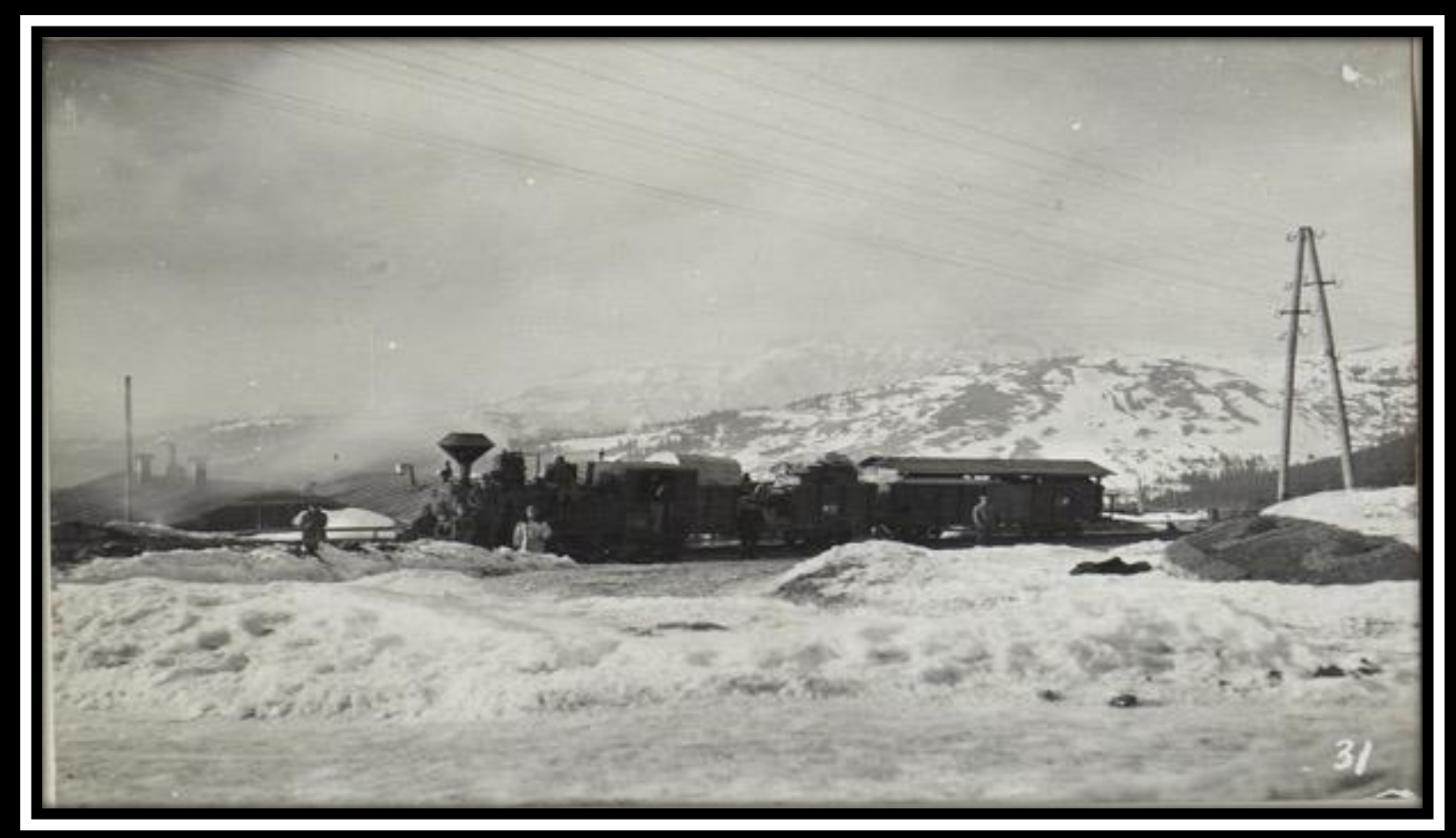


FIG. 20. Prislopbahn WWI badge (Image available:

http://www.bedo.hu/index.php?azon=archiv\&kkod=0\&akod=3\&asor=11\&list meret=25\&list kezd=400)

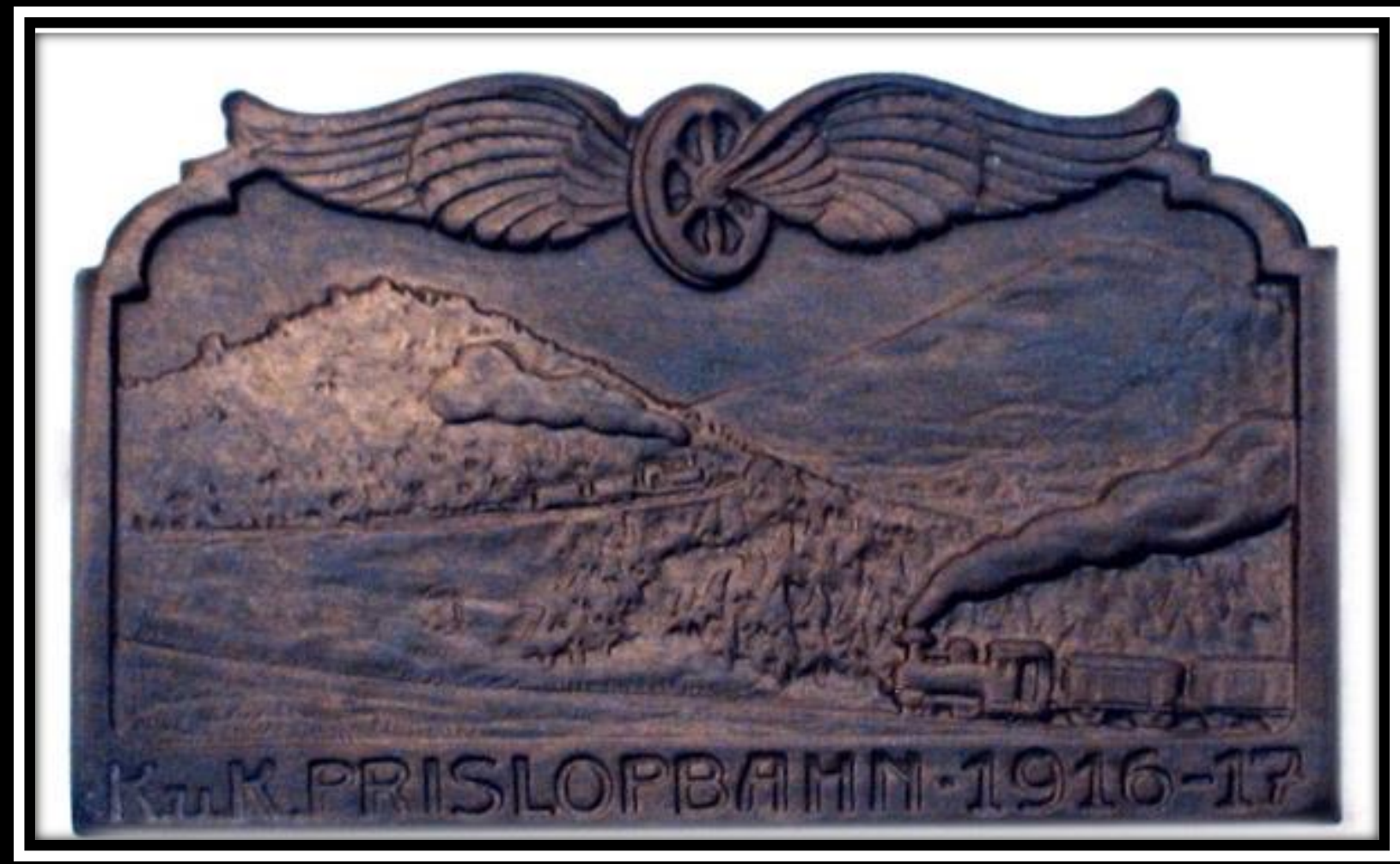

FIG.21. Prislop Pass train station (Image available:

http://www.bildarchivaustria.at/Pages/ImageDetale.aspx?p iBildID=15453319)

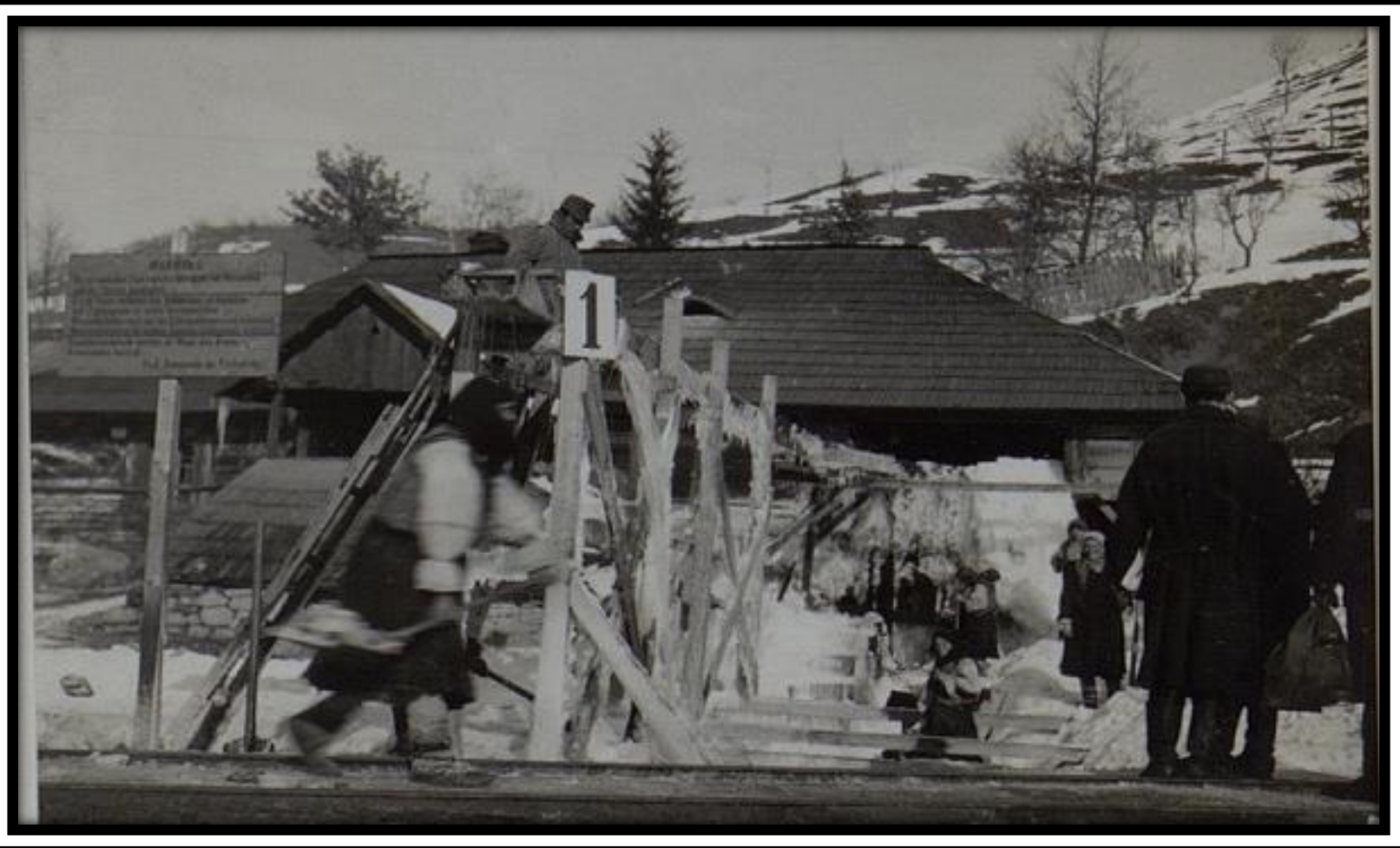


FIG.22. WWI Prislop Pass military city, March 1916 (Image available:

https://teofil-ivanciuc.weebly.com/home/oraselele-militare-din-pasul-prislop-si-de-pe-muntele-copilasu)

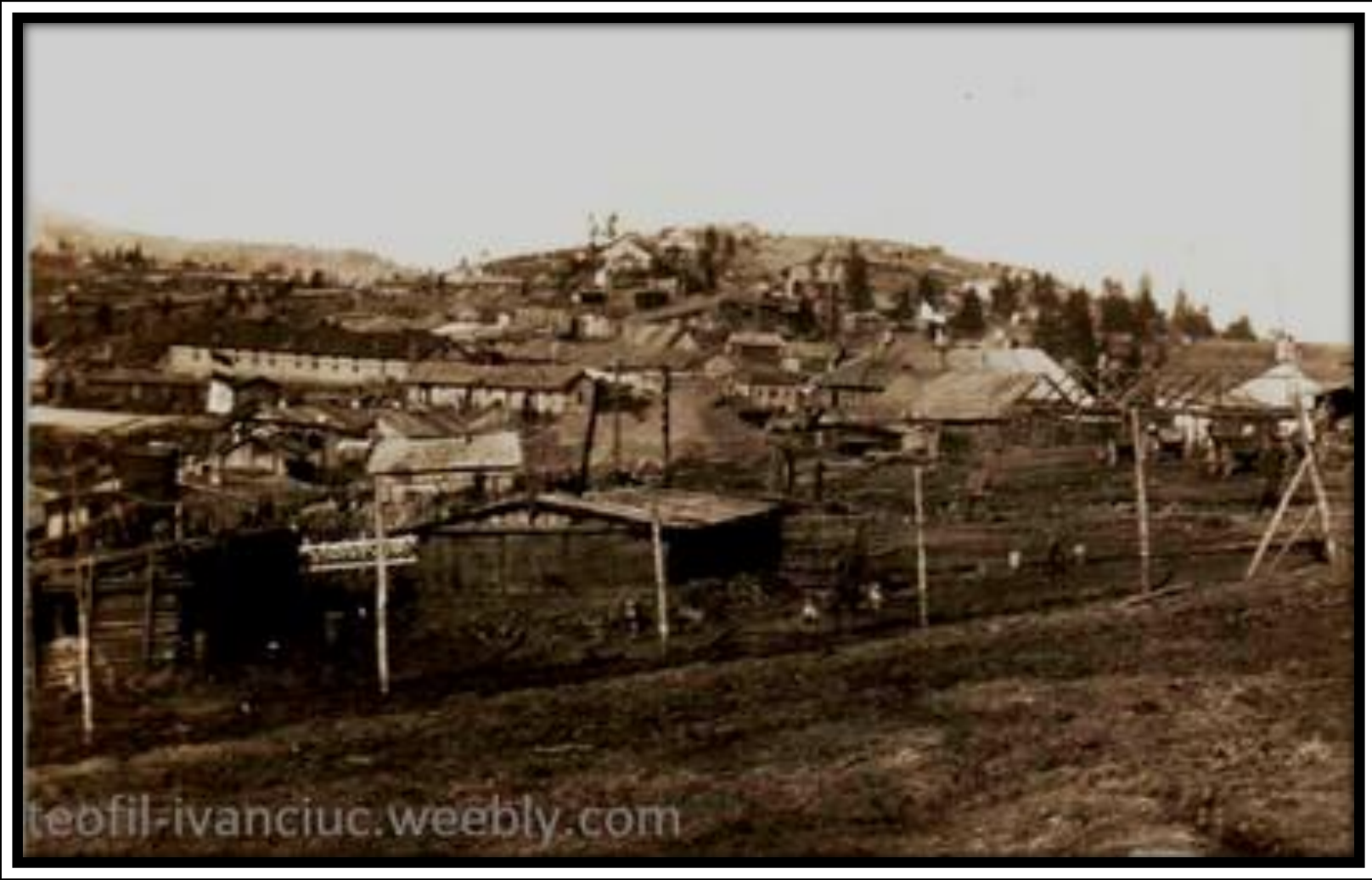

FIG. 23. General von Conta and Major General Burckhart along with a unit of the $7^{\text {th }}$ Army on the Prislop saddle, 11.09.1916 (Image available:

https://www.europeana.eu/portal/en/record/9200291/BibliographicResource_3000073510630.html)

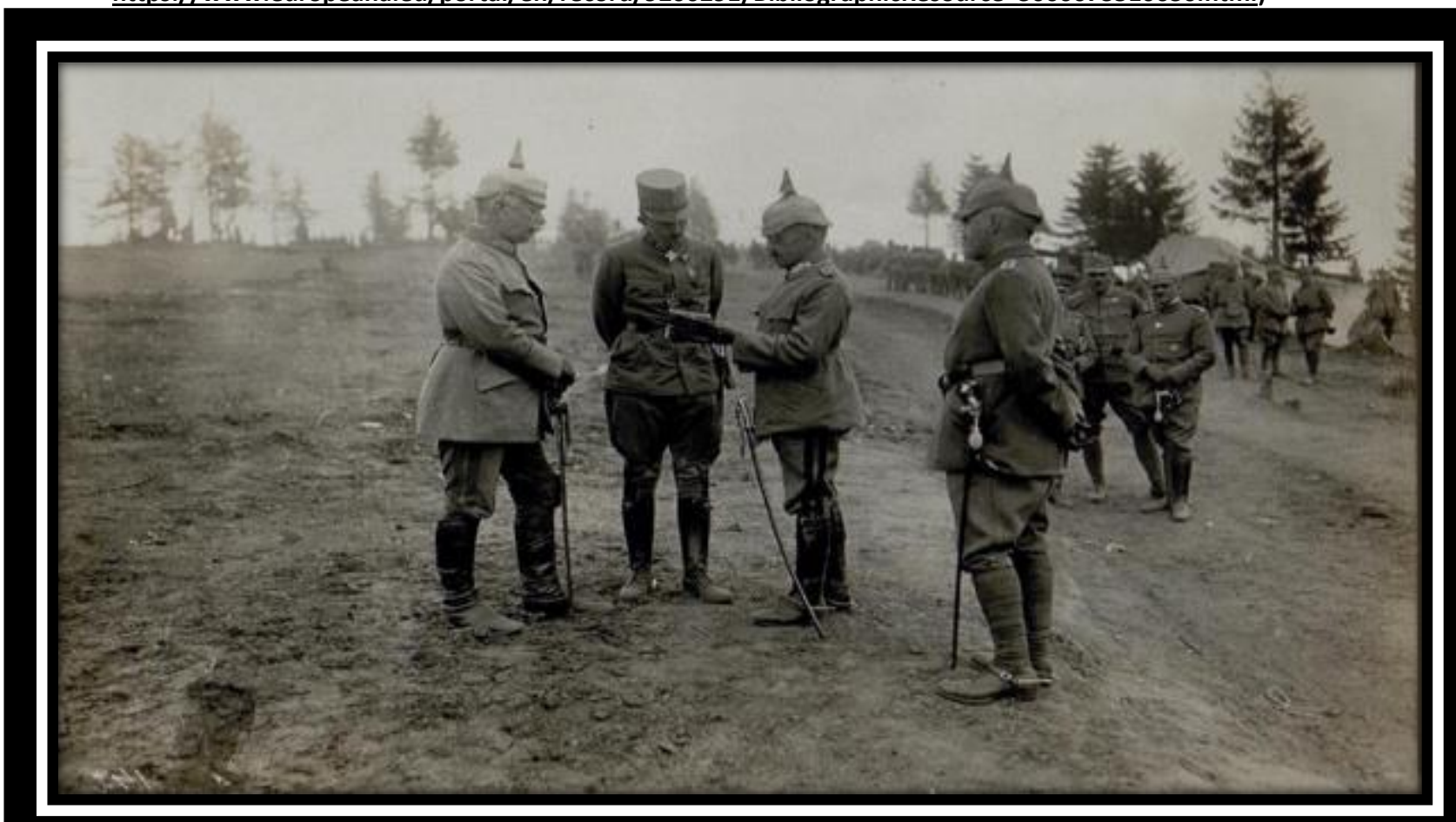


FIG. 24. General von Conta and Major General Burckhart amongst the Conta Corps quartered in the Prislop Pass

11.09.1916 (Image available:

https://www.europeana.eu/portal/en/record/9200291/bildarchivaustria_at Preview 15550272.html?q=Prislopsattel)

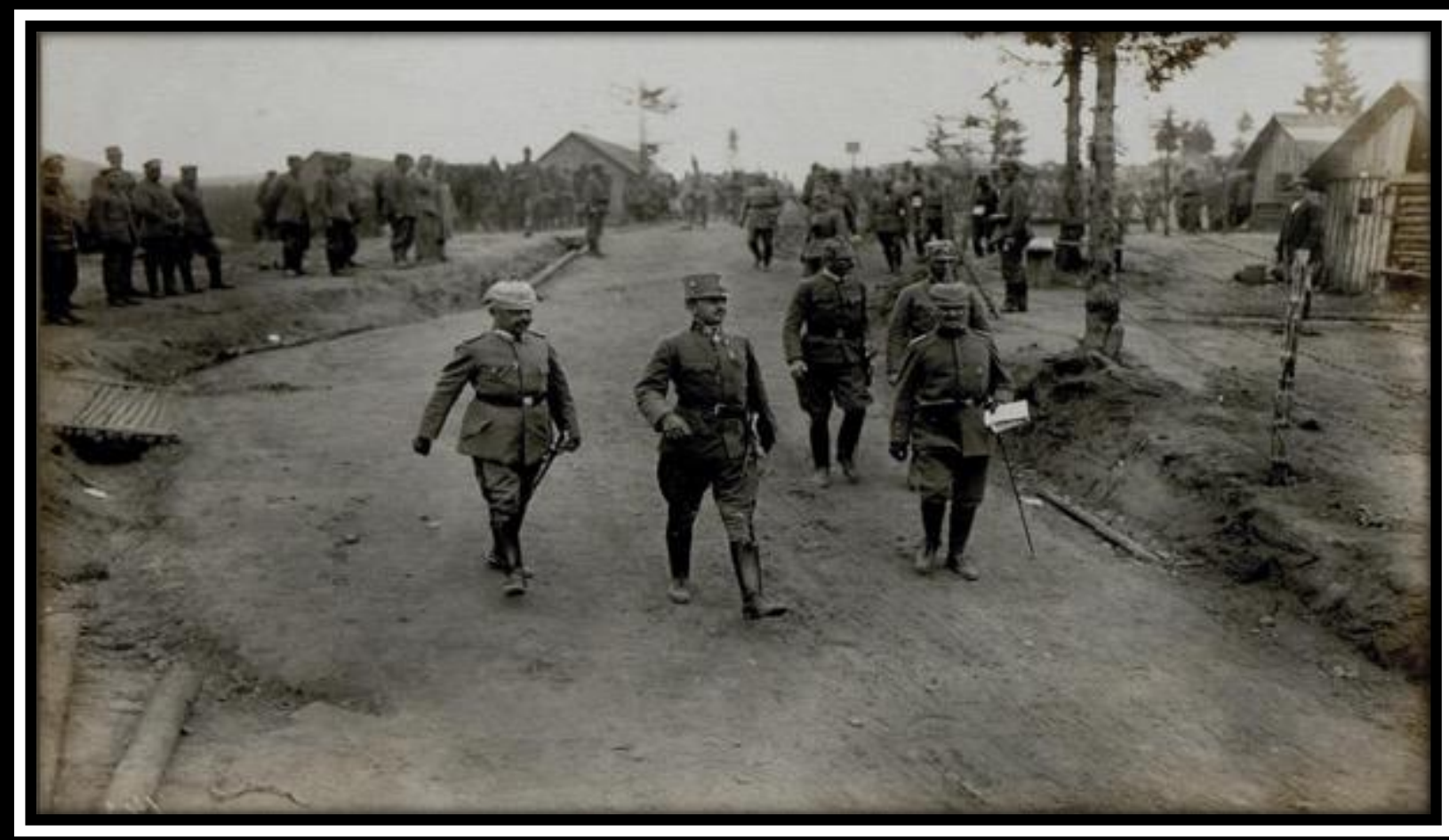

FIG. 25. The $10^{\text {th }}$ Bavarian Division on the Prislop Pass 11.09.1916 (Image available: http://www.bildarchivaustria.at/Pages/ImageDetail.aspx?p iBildID=15550251)

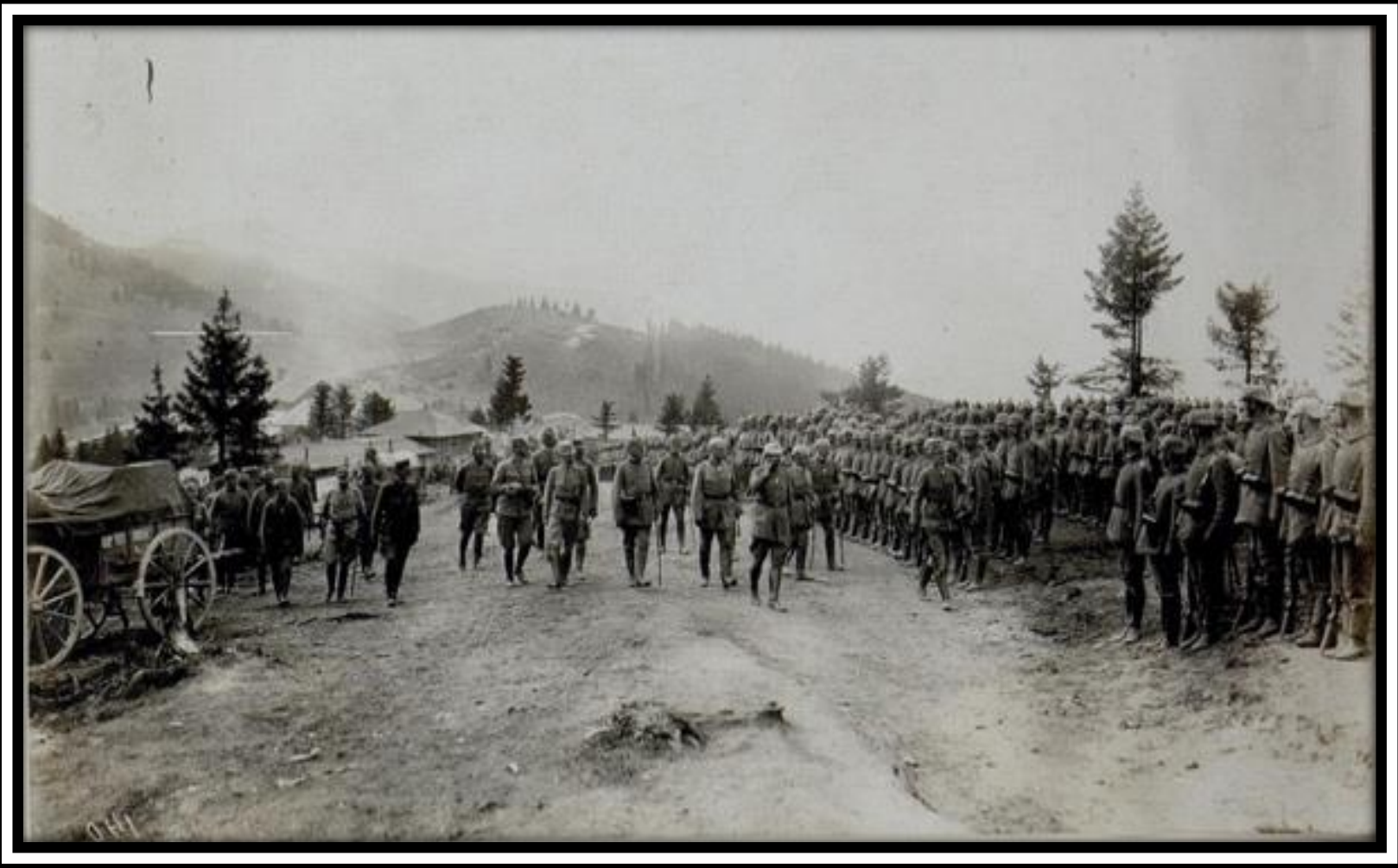


FIG. 26. Distant view seen from the Prislop Pass, 1917 (Image available: http://www.bildarchivaustria.at/Pages/ImageDetale.aspx?p iBildID=15665510)

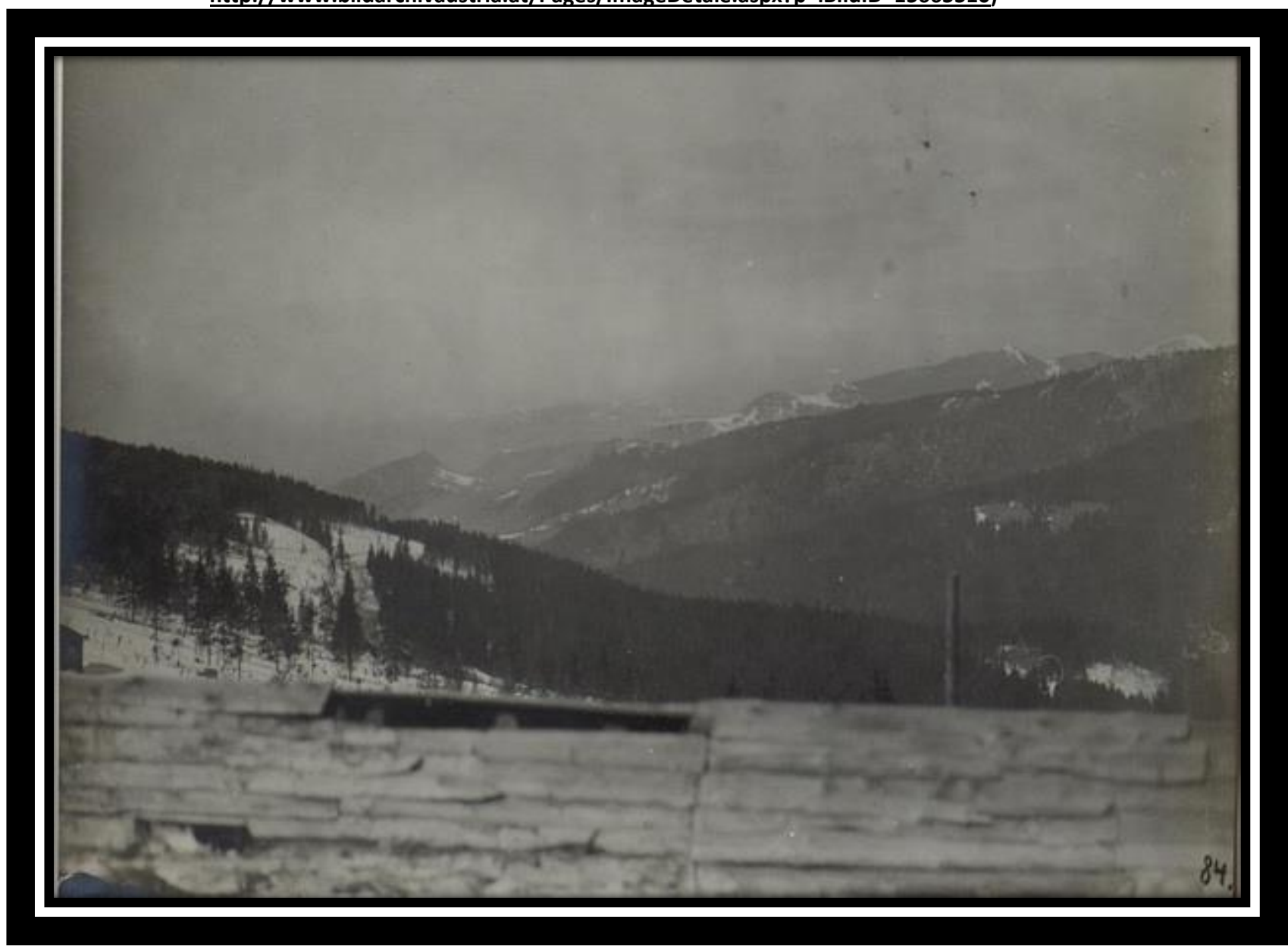

Several other images of the Prislop Pass during WWI (image 25-44) were gathered by Paul Brașcanu in an impressive collection of war illustrations partially reproduced below.

FIG.27. Prislop Pass railway, 1916 (Brașcanu collection, 2016)

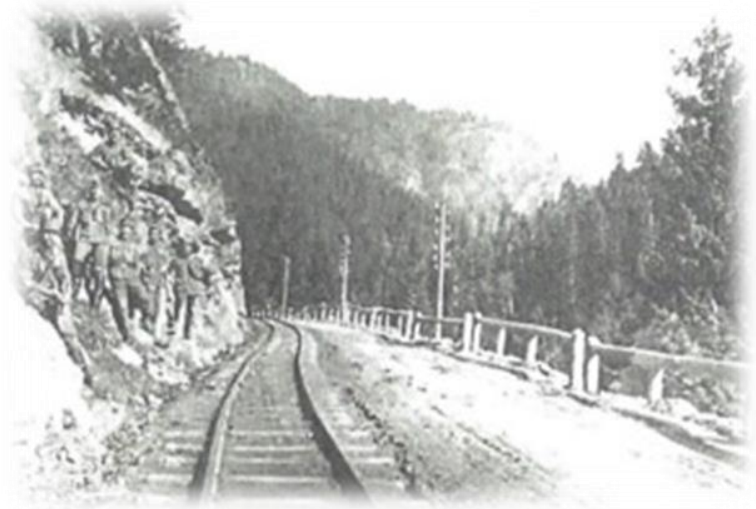

FIG.28. Prislop Pass military camp, winter 1916 (Brașcanu collection, 2016)

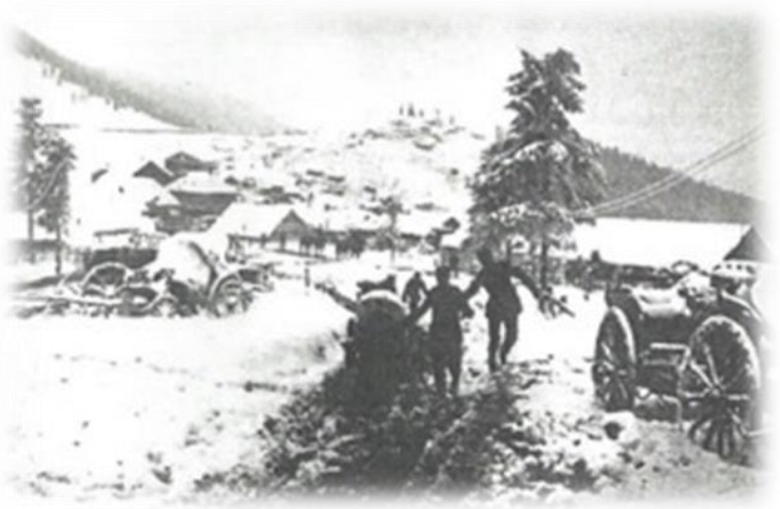


FIG. 29. Felix Tarbuk von Sensenhorst-cleaning of the Prislop railway (Brașcanu collection, 2016)

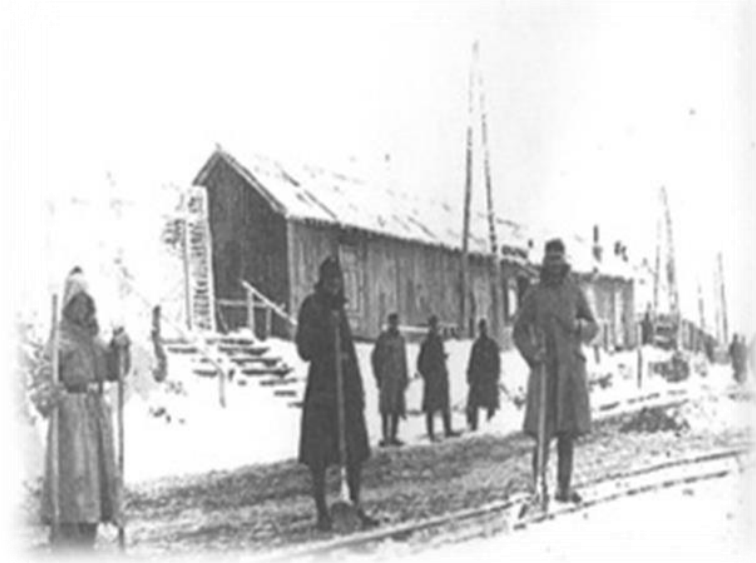

FIG. 31. Prislop Pass military hospital, 1917 (Brașcanu collection, 2016)

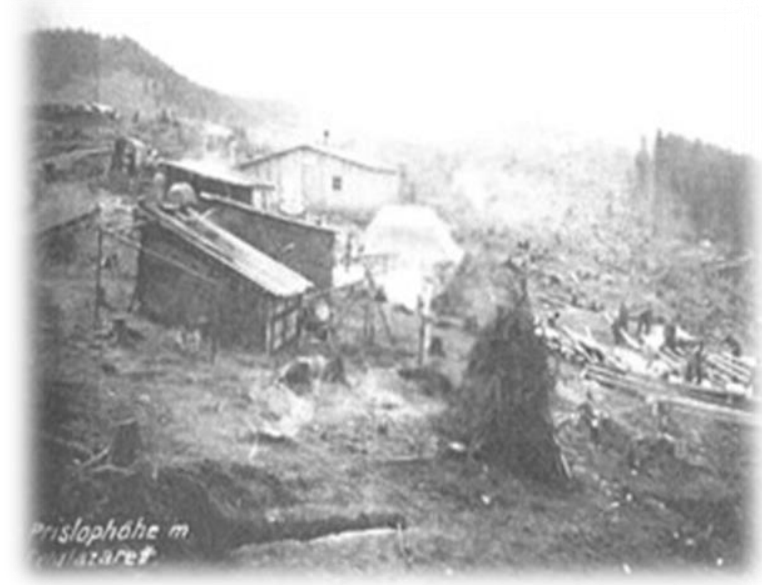

FIG. 33. Prislop Pass military transport, May 1917(Brașcanu collection, 2016)

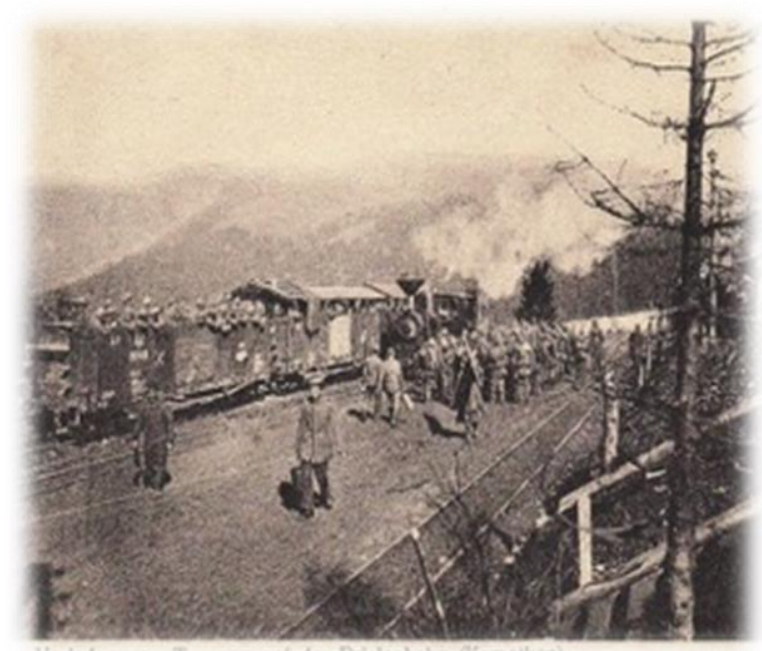

FIG. 30. Train arriving in the Prislop station, 1916 (Brașcanu collection, 2016)

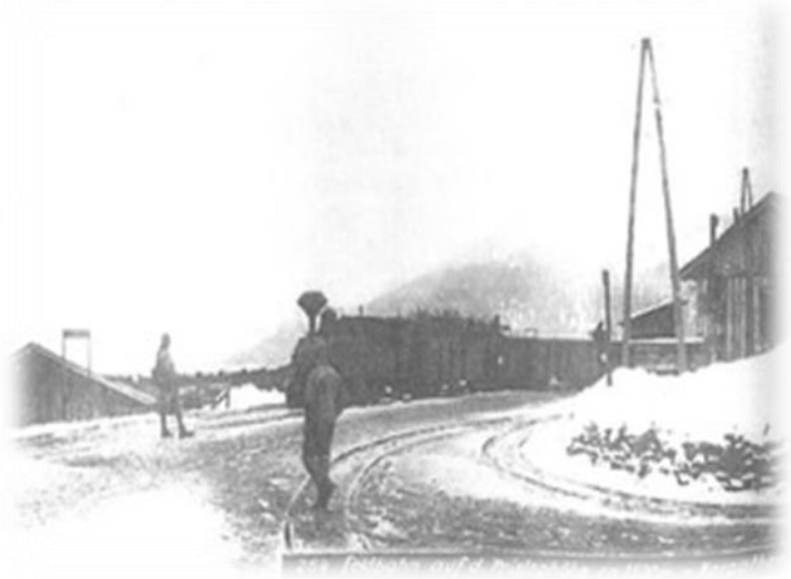

FIG. 32. Prislop Pass military city, 1917 (Brașcanu collection, 2016)

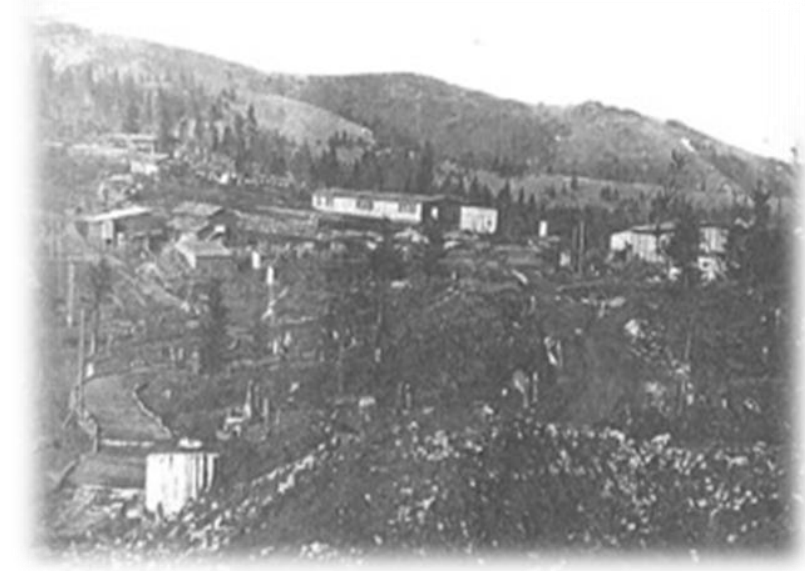

FIG. 34. Prislop Pass central plateau, 1917 (Brașcanu collection, 2016)

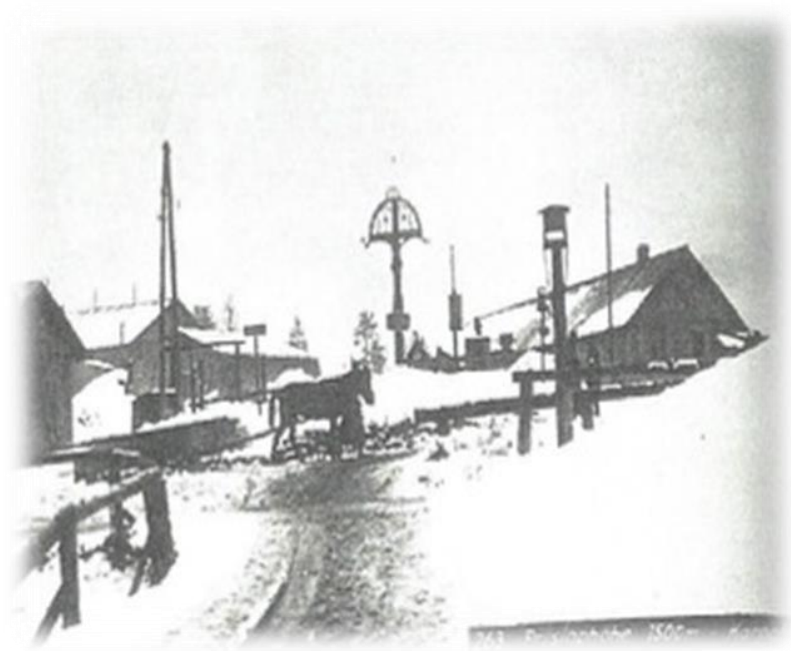


FIG. 35. Prislop Serpentine railway (Brașcanu collection, 2016)

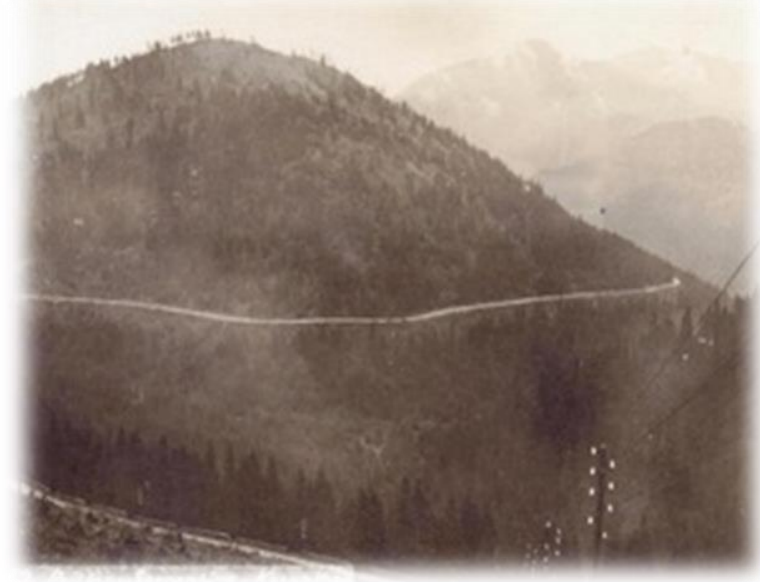

FIG. 37. Prislop station marshalling yards, November 1916 (Brașcanu collection, 2016)

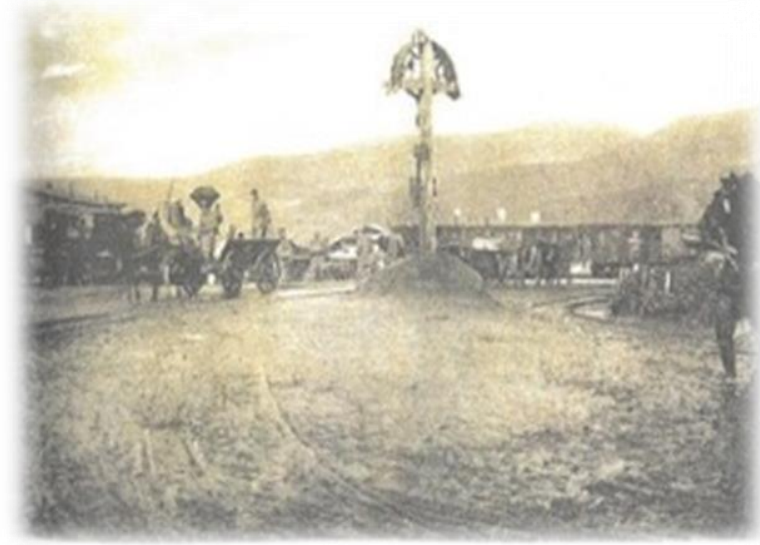

FIG. 39. Military concert on the Prislopp Pass central plateau, 1917 (Brașcanu collection, 2016)

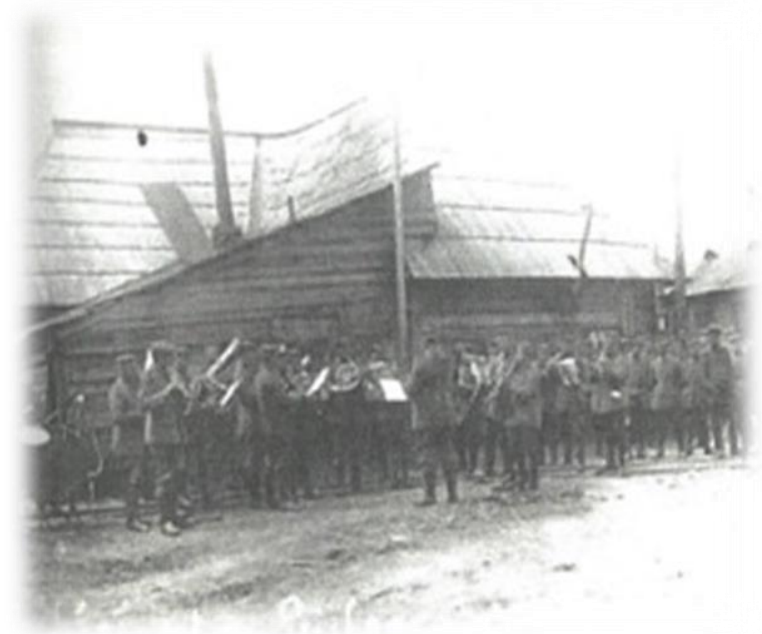

FIG. 36. Prislop Pass railway lines (Brașcanu collection, 2016)

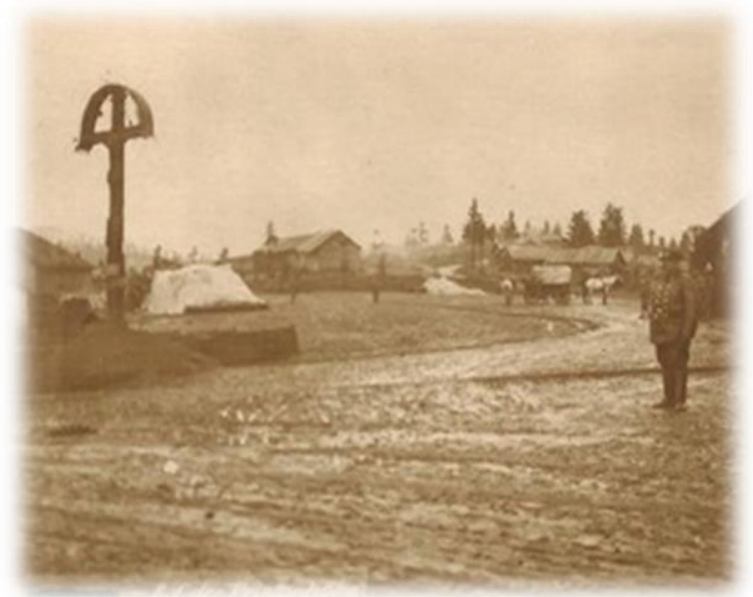

FIG. 38. Skiing soldiers on top of the Prislop Pass, 1917 (Brașcanu collection, 2016)

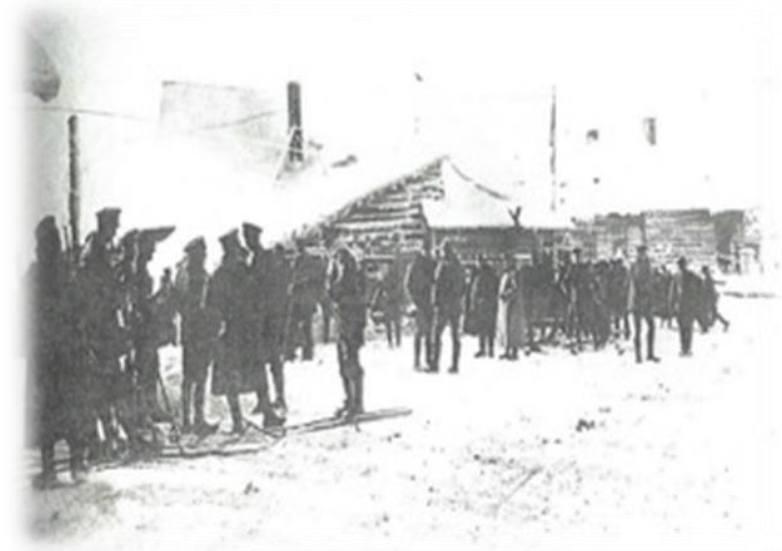

FIG.40. Prislop Pass military cemetery, 1917 (Brașcanu collection, 2016)

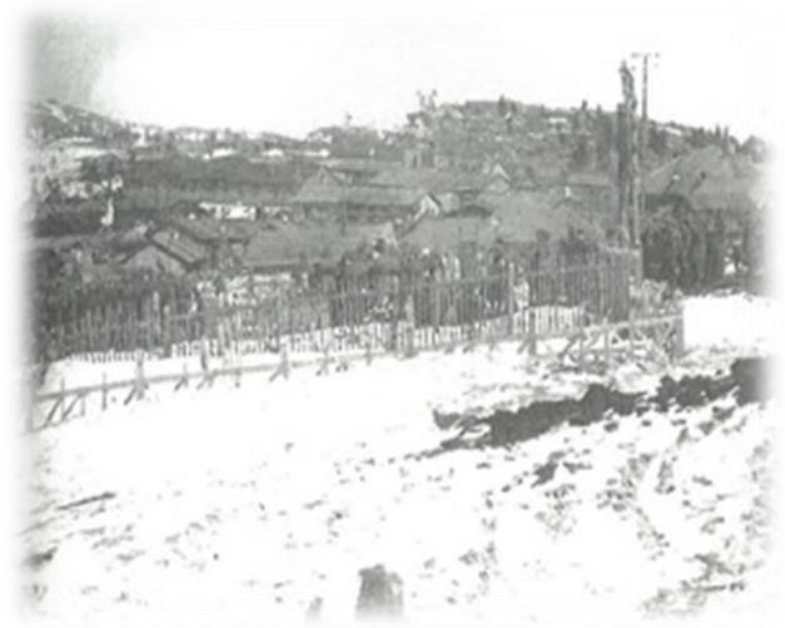


FIG. 41. Train arriving in the Prislop station, 1917 (Brașcanu collection, 2016)

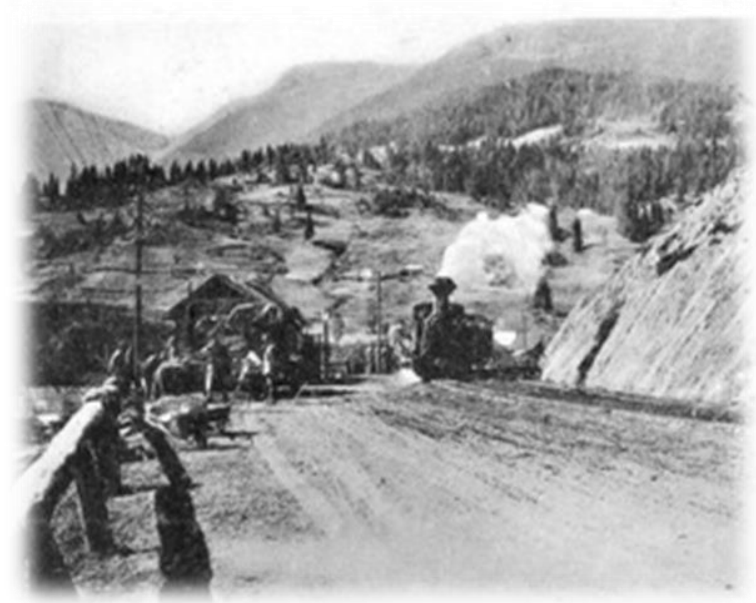

FIG. 43. Red cross flag in Prislop Pass (Brașcanu collection, 2016)

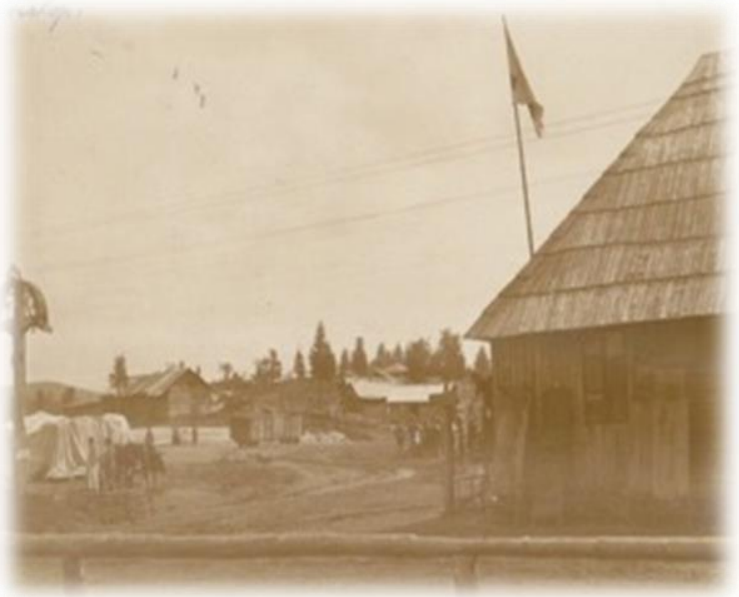

FIG. 45. Prislop Pass military provisioning (Brașcanu collection, 2016)

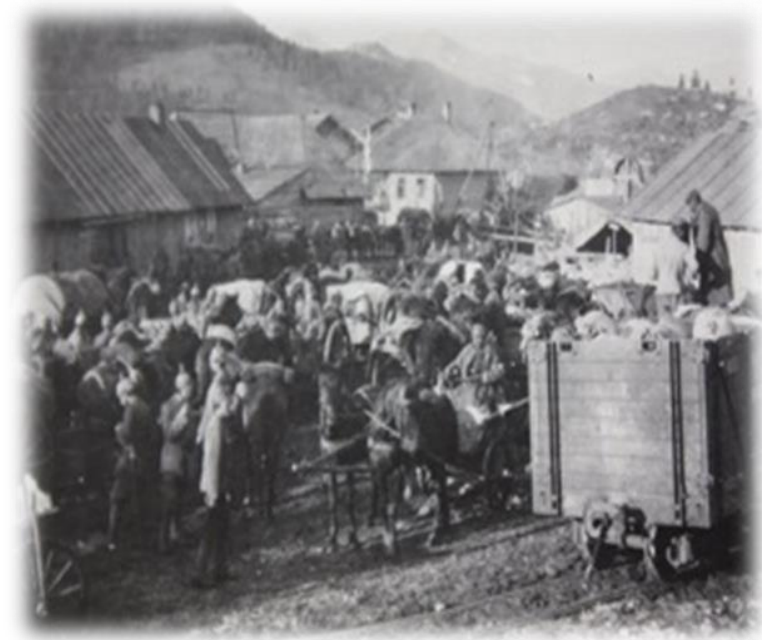

FIG. 42. Prislop Pass military command (Brașcanu collection, 2016)

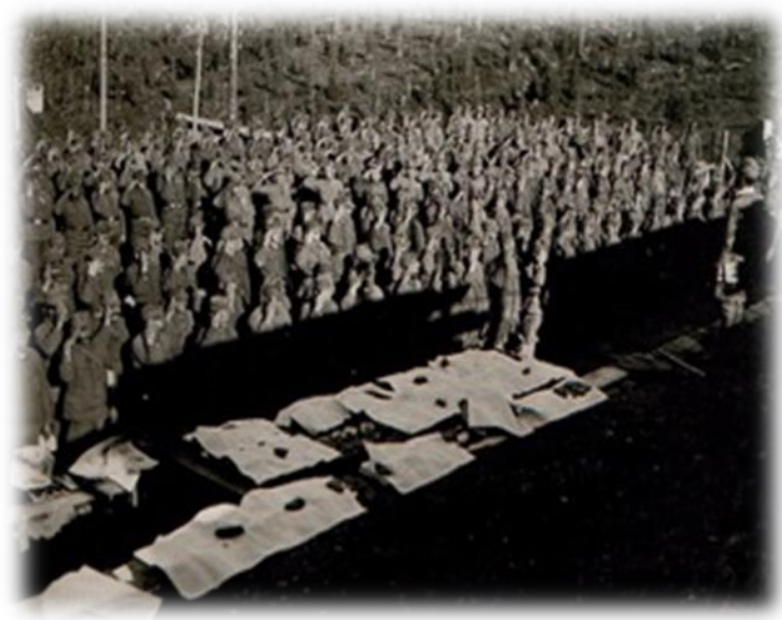

FIG. 44. Prislop Pass barracks, central sector, 1916 (Brașcanu collection, 2016)

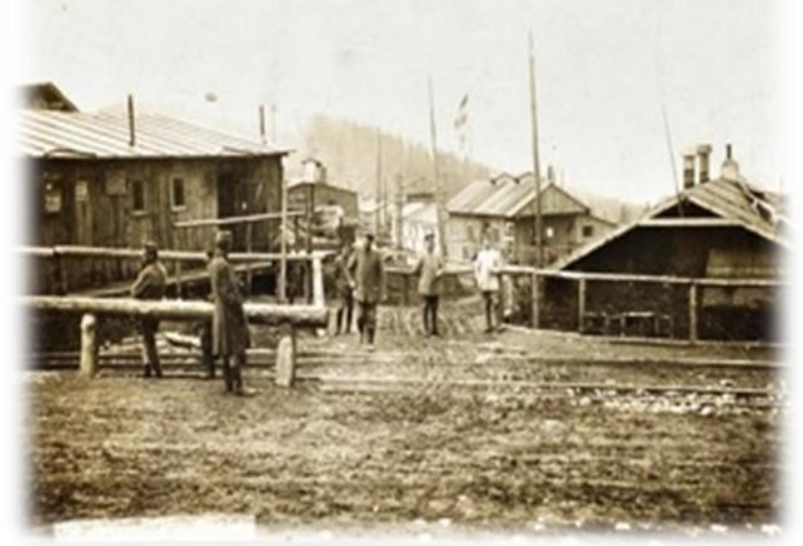

FIG. 46. Horse drawn sleigh in Prislop German soldiers camp, 1916 (Brașcanu collection, 2016)

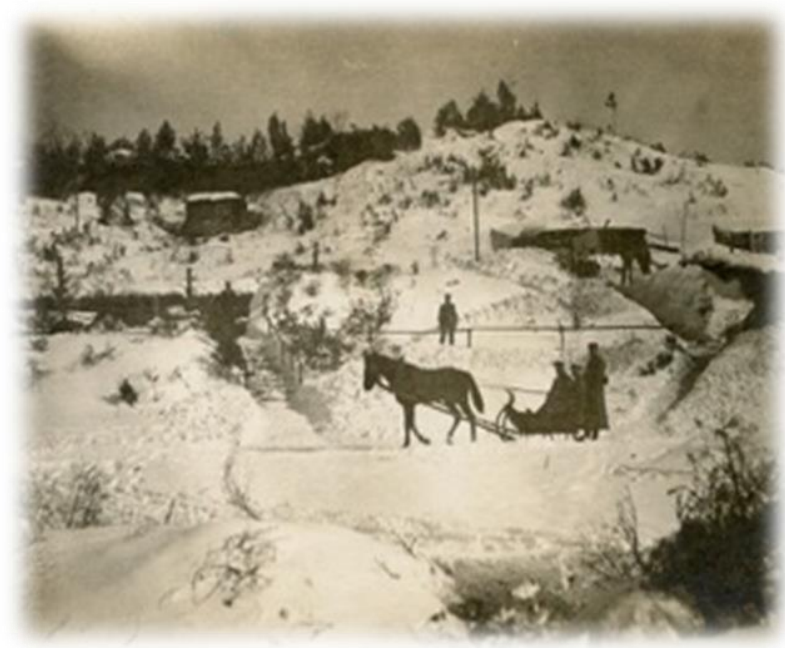


An inventory of the features recorded in the first research sector is reproduced underneath. These features represent traces of human intervention upon the environment which correspond to the traces left by the construction of the city of barracks and its defence system, the military earthworks, along with embankment works for the railway that passed through the pass. FIG.47 represents a map of the field location of features 1 to 10 , along with the position of this section of the field (yellow rectangle) within research sector 1 (red rectangle).

FIG. 47. Map of field location of feature 1 to 10 - research sector 1 (Author, 2018)

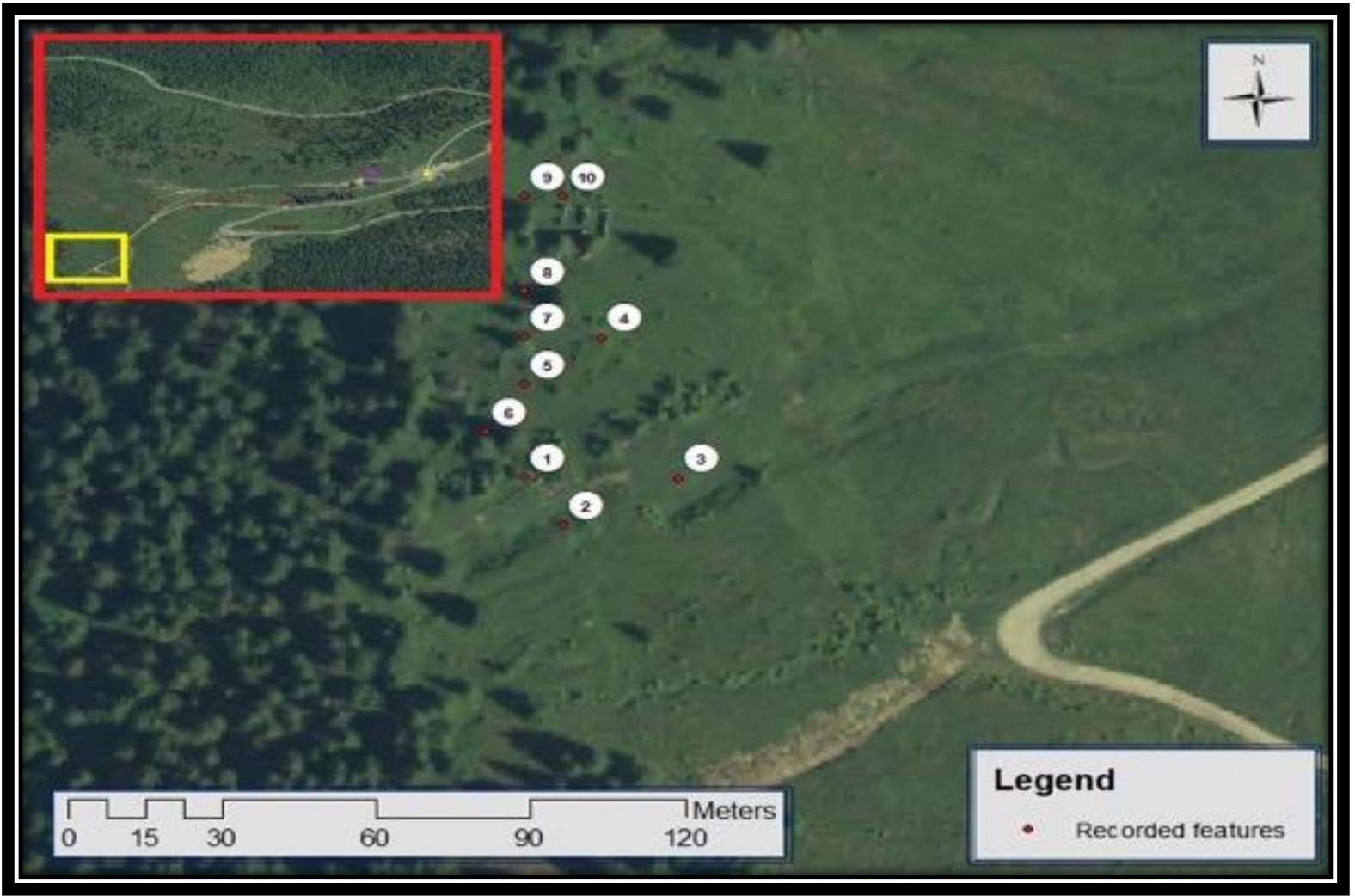

Feature 1 represents a rectangular building foundation, situated at $47,60636^{\circ} \mathrm{N}-24,84439^{\circ} \mathrm{E}$, at an altitude of $1430 \mathrm{~m}$ (FIG.49 A, B). It has a length of $30 \mathrm{~m}$, a width of approximately $7 \mathrm{~m}$ and is made of stone with joints of cement and gravel. Massive embankments were necessary to allow it to be built on this spot. You can see on the satellite imagery that embankment works were conducted to allow the construction of the foundation on the hill side and to assure an access route to it. The foundation was largely covered by vegetation and a soil layer 
of about $10 \mathrm{~cm}$, especially in the upper part in the direction of the hill. While making measurements in this location a blue glass recipient was found on the upper right corner of the building. The recipient looked like an old medicine container and had the number ' 30 ' engraved on the bottom (FIG.48 A, B).

FIG. 48. Glass medicine container (Author, 2017)
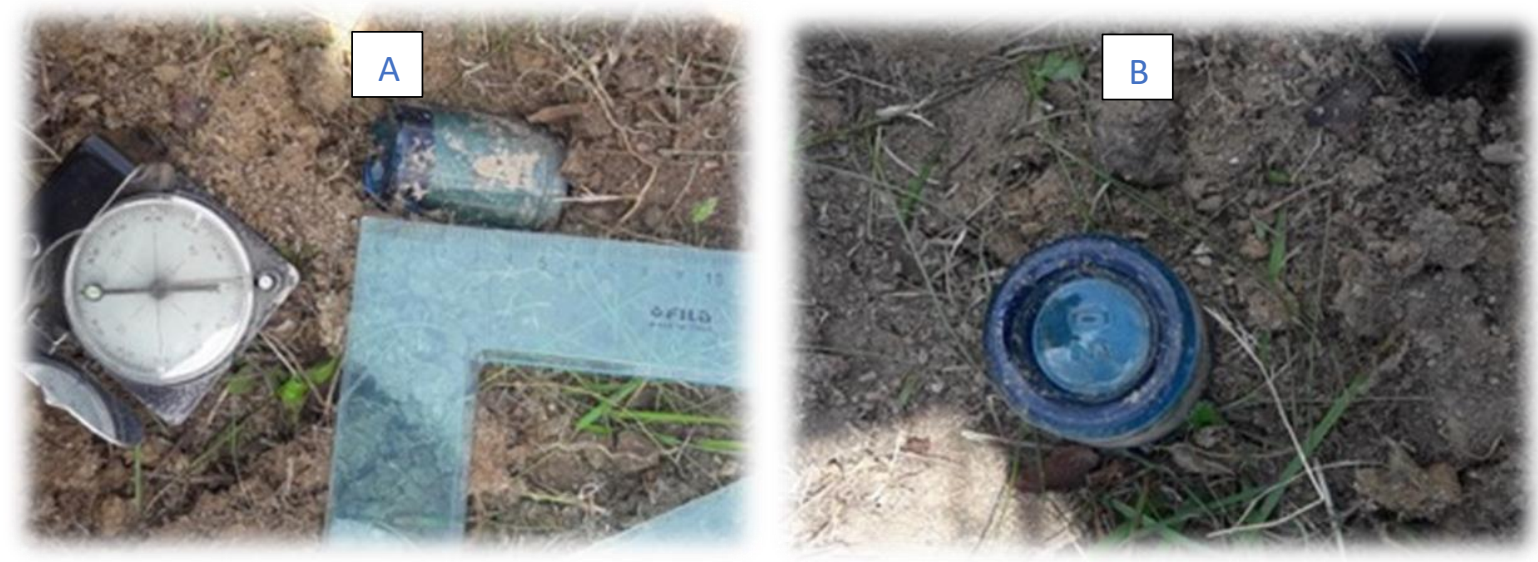

FIG. 49. Feature 1 - rectangular building foundation (Author, 2017)
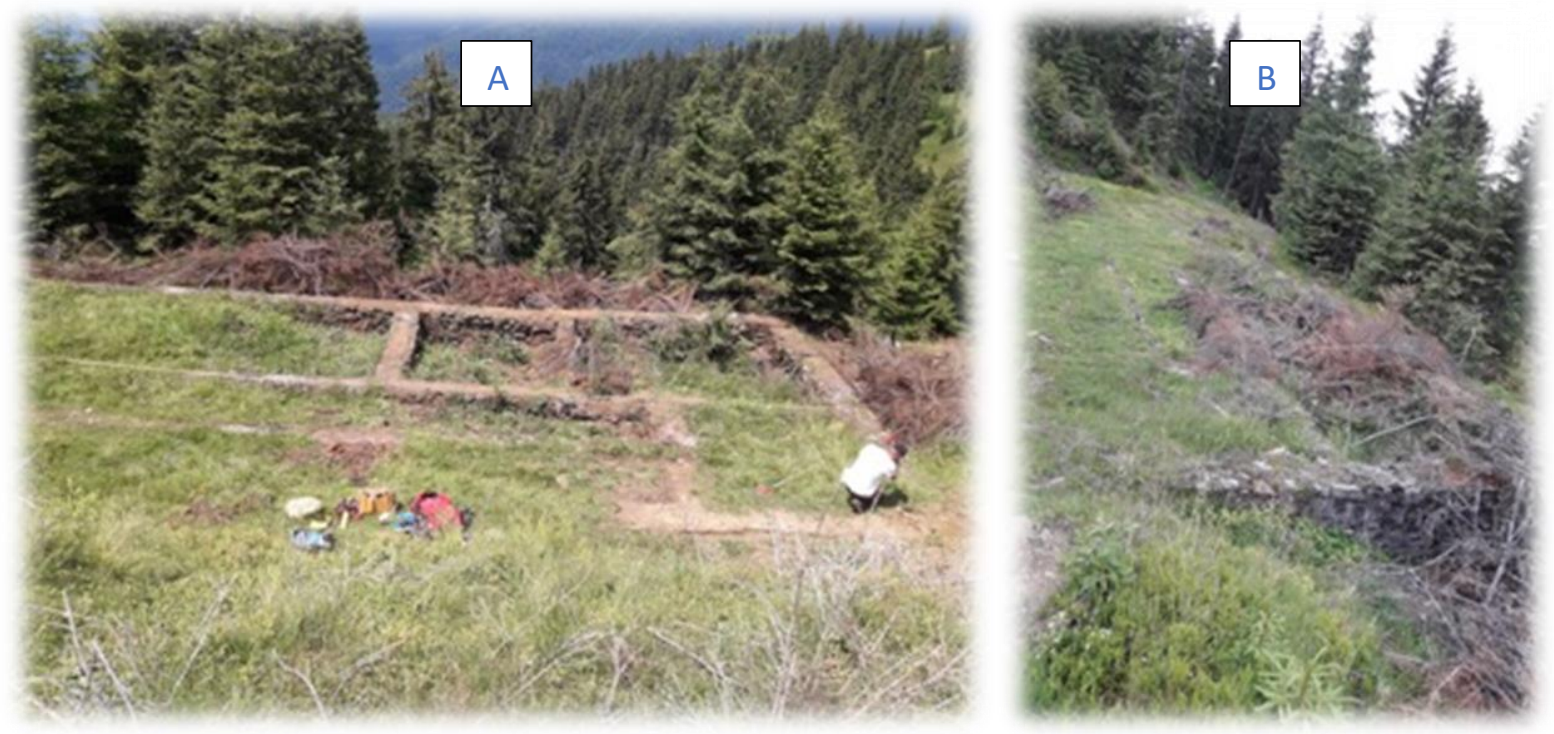

Feature 2 represents two earthworks, situated at $47,60627^{\circ} \mathrm{N}-24,8445^{\circ} \mathrm{E}$, at an altitude of $1435 \mathrm{~m}$. There are two parallel pits (FIG.50 A, B) situated on the hill above Feature 1, with a length of $4 \mathrm{~m}$, a width of $4 \mathrm{~m}$ and approximately $1,10 \mathrm{~m} \& 0,80 \mathrm{~m}$ meters deep respectively. Earth bricks and shaped stones (FIG.51 A, B) can be found in the pits and around them. 
FIG. 50. Feature 2 - parallel pits (Author, 2017)
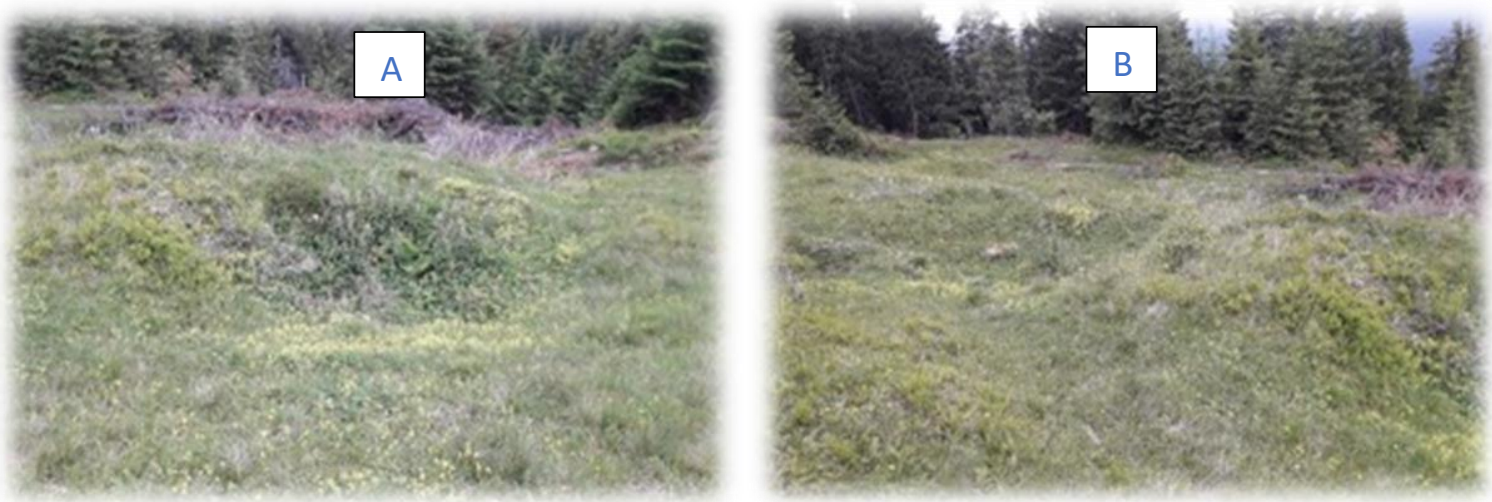

FIG. 51. Earth bricks and shaped stones (Author, 2017)
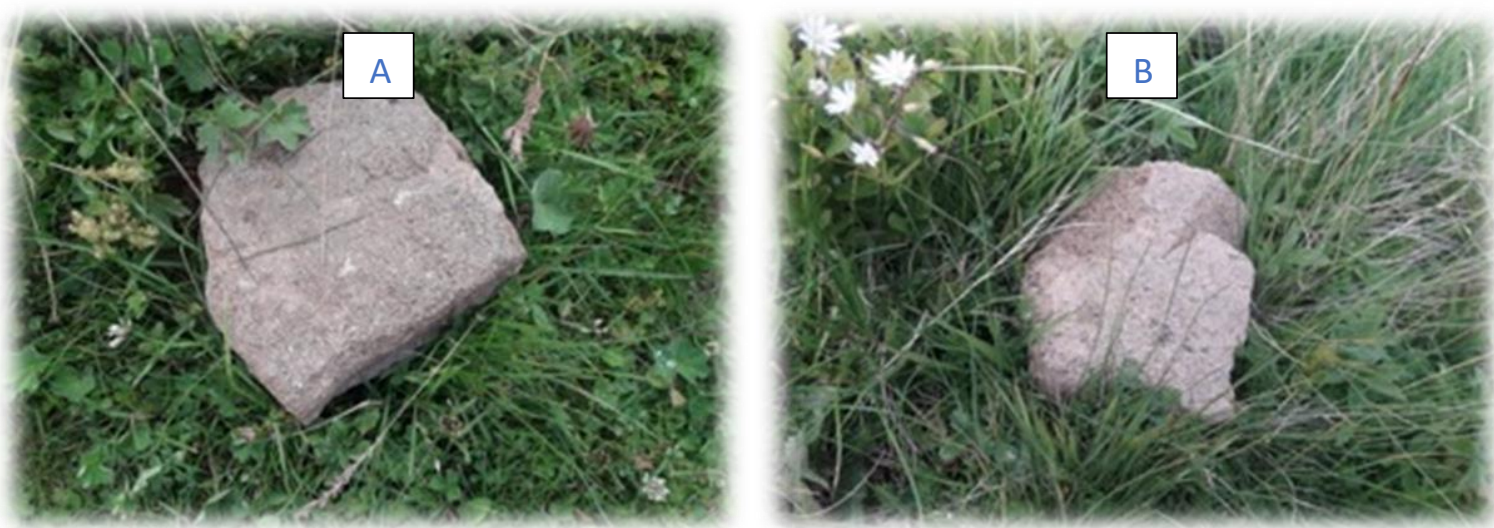

Feature 3 represents a rectangular building foundation, situated at $47,60639^{\circ} \mathrm{N}-24,8448^{\circ} \mathrm{E}$, at an altitude of $1432 \mathrm{~m}$, that has a length of $30 \mathrm{~m}$ and a width of $7 \mathrm{~m}$ (FIG.52 A, B). It has the same characteristics as Feature 1 in terms of building materials and necessary embankment works.

FIG. 52. Feature 3 - rectangular building foundation (Author, 2017)
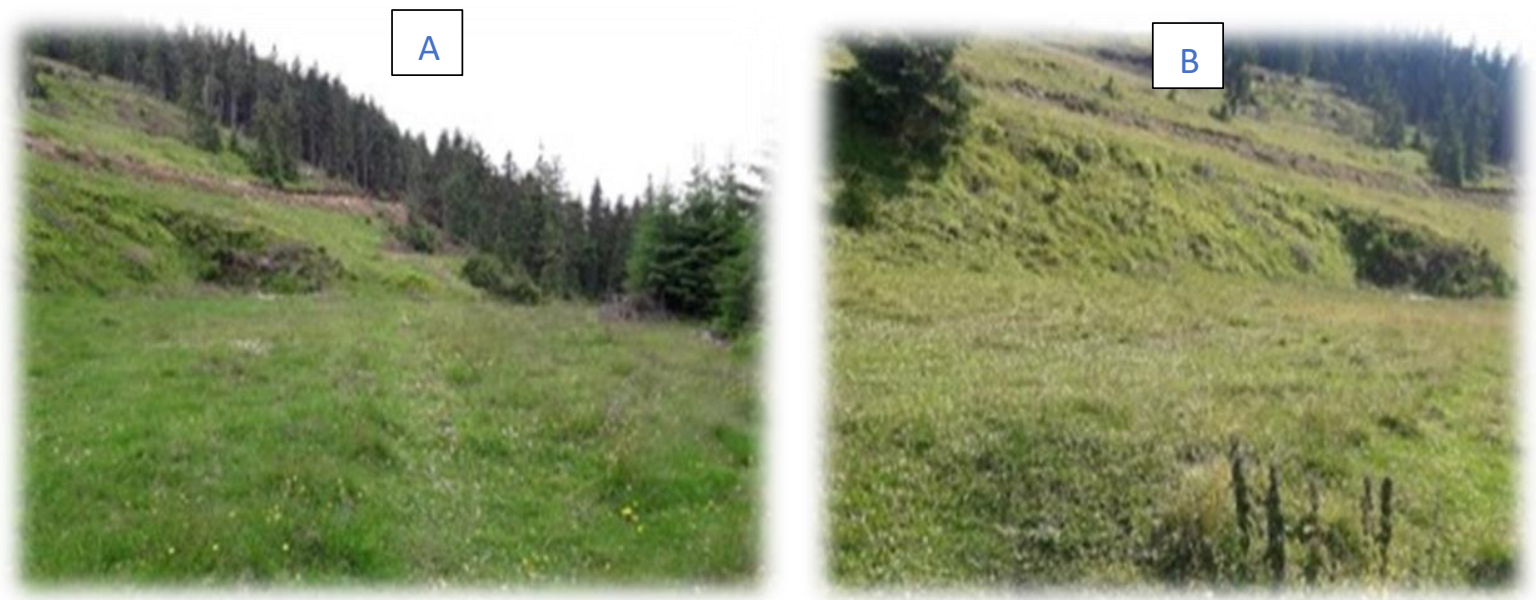
Feature 4 represents a 3 -sided earthwork, situated at $47,60670^{\circ} \mathrm{N}-24,84462^{\circ} \mathrm{E}$, at an altitude of $1420 \mathrm{~m}$ (FIG.53). The earthwork consists of an embankment excavated in the hill slope with a length of $5 \mathrm{~m}$, a width of $5 \mathrm{~m}$ and a maximum depth of 1,50 m. In upper right side of the earthwork there is a pit of $2 \mathrm{~m}$ length, $2 \mathrm{~m}$ width and $80 \mathrm{~cm}$ deep. Shaped stones and earth bricks can be seen on the site of the earthwork, which is oriented to the NW.

FIG. 53. Feature 4 - earthwork (Author, 2017)

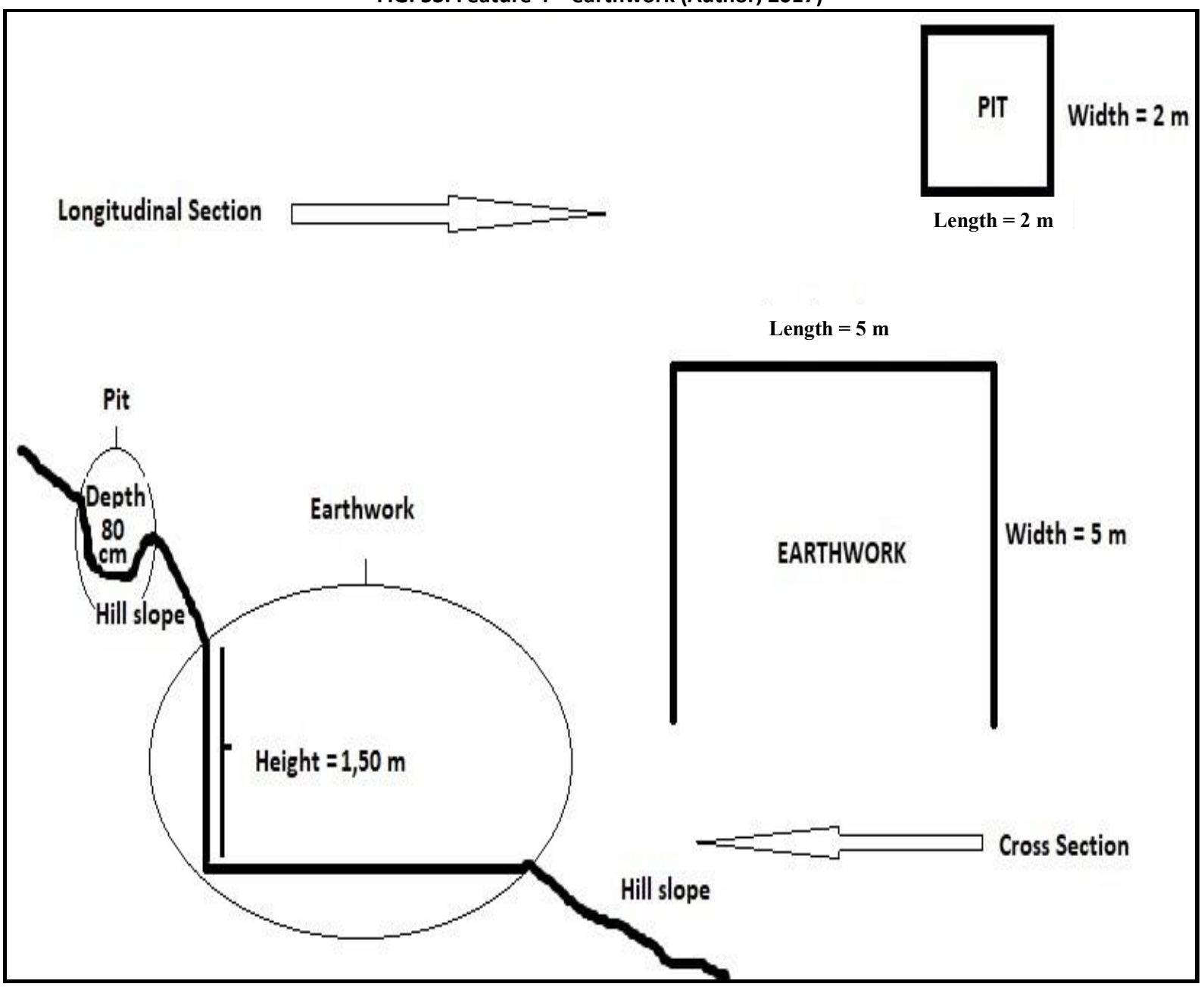

Feature 5 represents a 3 -sided earthwork, situated at $47,60655^{\circ} \mathrm{N}-24,84437^{\circ} \mathrm{E}$, at an altitude of 1419 m (FIG.54). The earthwork consists of an embankment excavated in the hill slope with a length of $4 \mathrm{~m}$, a width of $3 \mathrm{~m}$ and a maximum depth of $1.30 \mathrm{~m}$. Shaped stones can be seen on the site of the earthwork which is oriented to the NW. 
FIG. 54. Feature 5 - earthwork (Author, 2017)

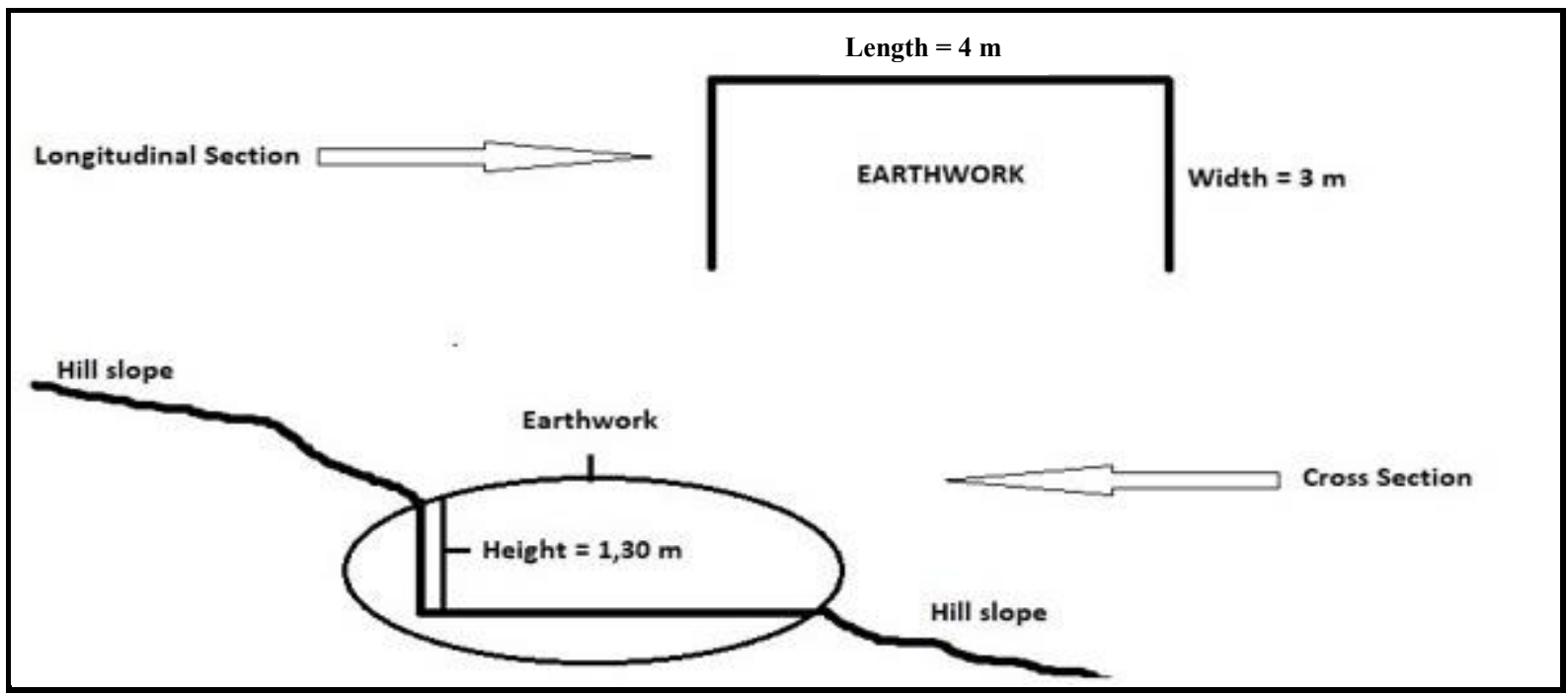

Feature 6 represents a 3 -sided earthwork, situated at $47,60649^{\circ} \mathrm{N}-24,84426^{\circ} \mathrm{E}$, at an altitude of 1419 m (FIG.55). The earthwork consists of an embankment excavated in the hill slope with a length of $5 \mathrm{~m}$, a width of $5 \mathrm{~m}$ and a maximum depth of $1.50 \mathrm{~m}$. In upper right side of the earthwork there is a pit of $2 \mathrm{~m}$ length, $2 \mathrm{~m}$ width and $1 \mathrm{~m}$ deep. Also, on the spot, near the pit a stone, crescent-shaped feature can be seen (FIG.56 A, B). Shaped stones can be seen on the site of the earthwork which is oriented to the NW.

FIG. 55. Feature 6 - earthwork (Author, 2017)

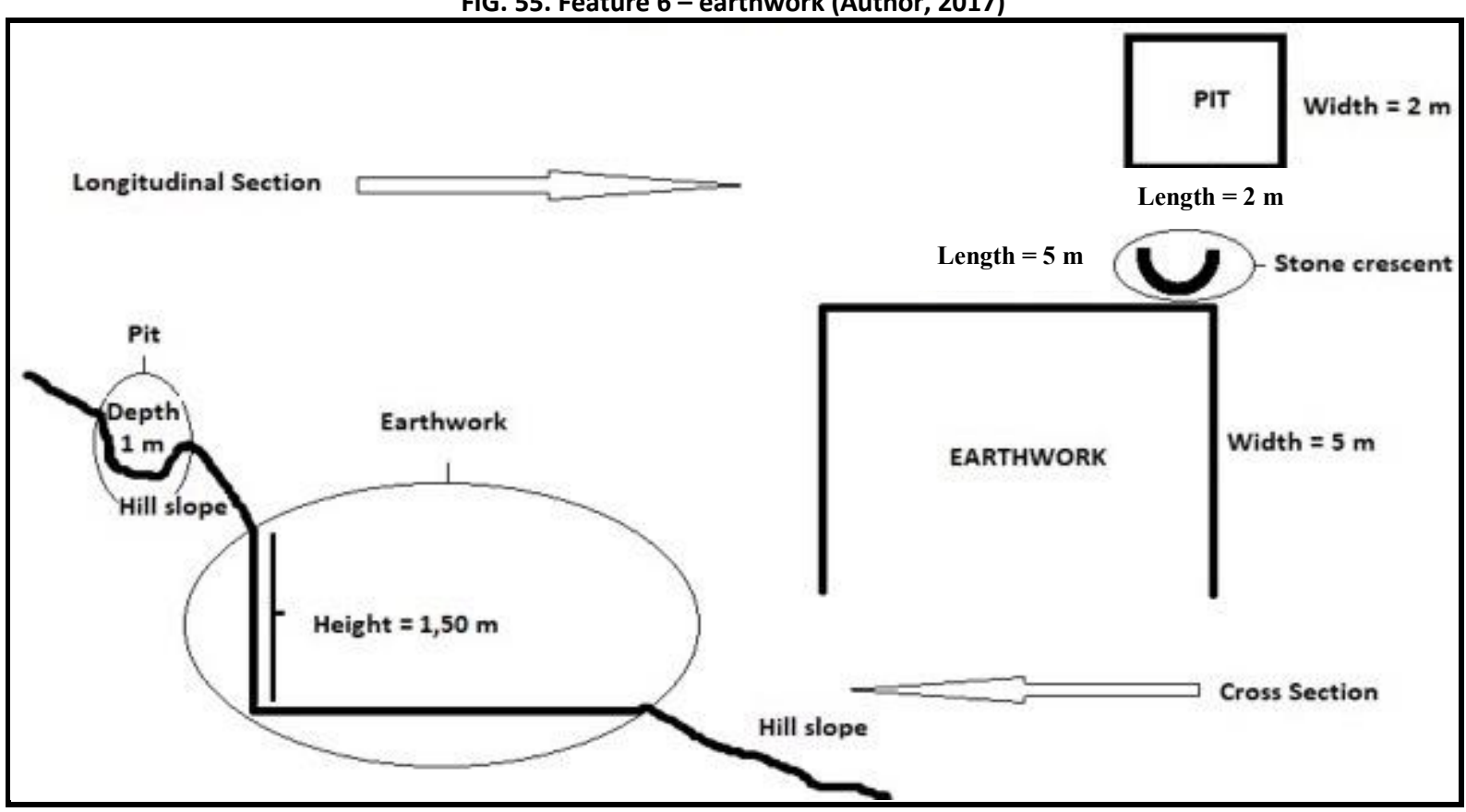


FIG. 56. Stone, crescent-shaped feature (Author, 2017)
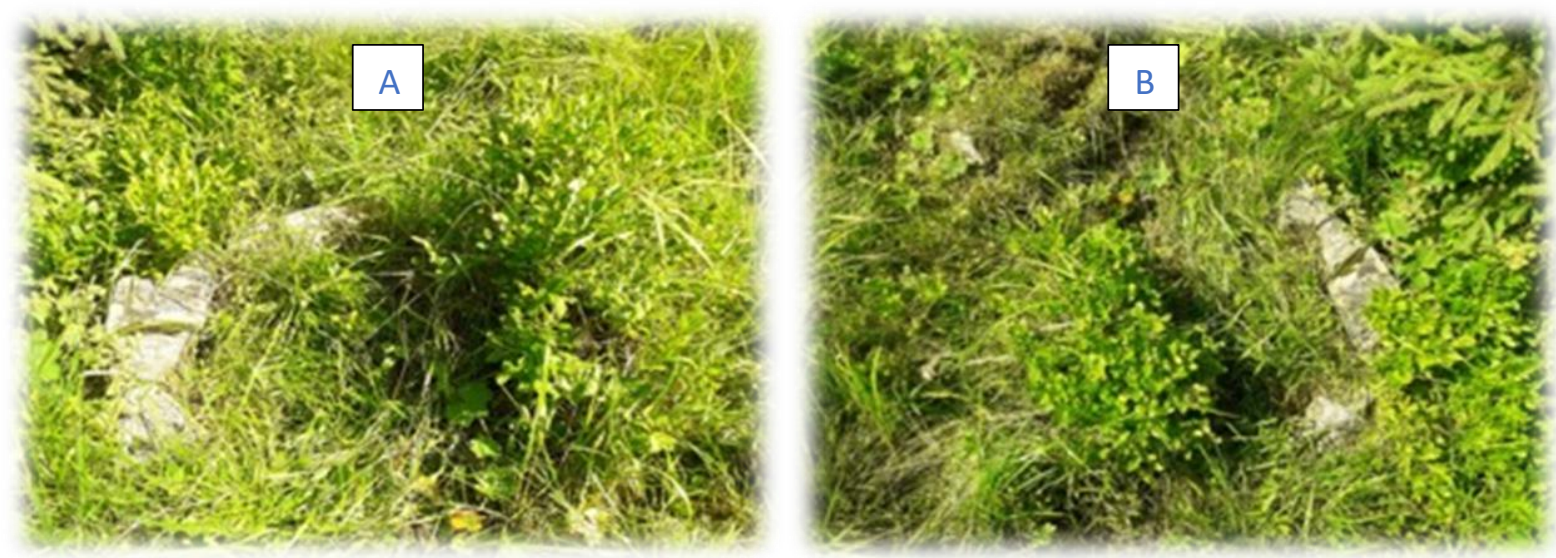

Feature 7 represents a 3 -sided earthwork, situated at $47,60672^{\circ} \mathrm{N}-24,8444^{\circ} \mathrm{E}$, at an altitude of $1420 \mathrm{~m}$ (FIG.57). The earthwork consists of an embankment excavated in the hill slope with a length of $4 \mathrm{~m}$, a width of $3 \mathrm{~m}$ and a maximum depth of $1.30 \mathrm{~m}$. Shaped stones can be seen on the site of the earthwork which is oriented to the NW.

FIG.57. Feature 7 - earthwork (Author, 2017)

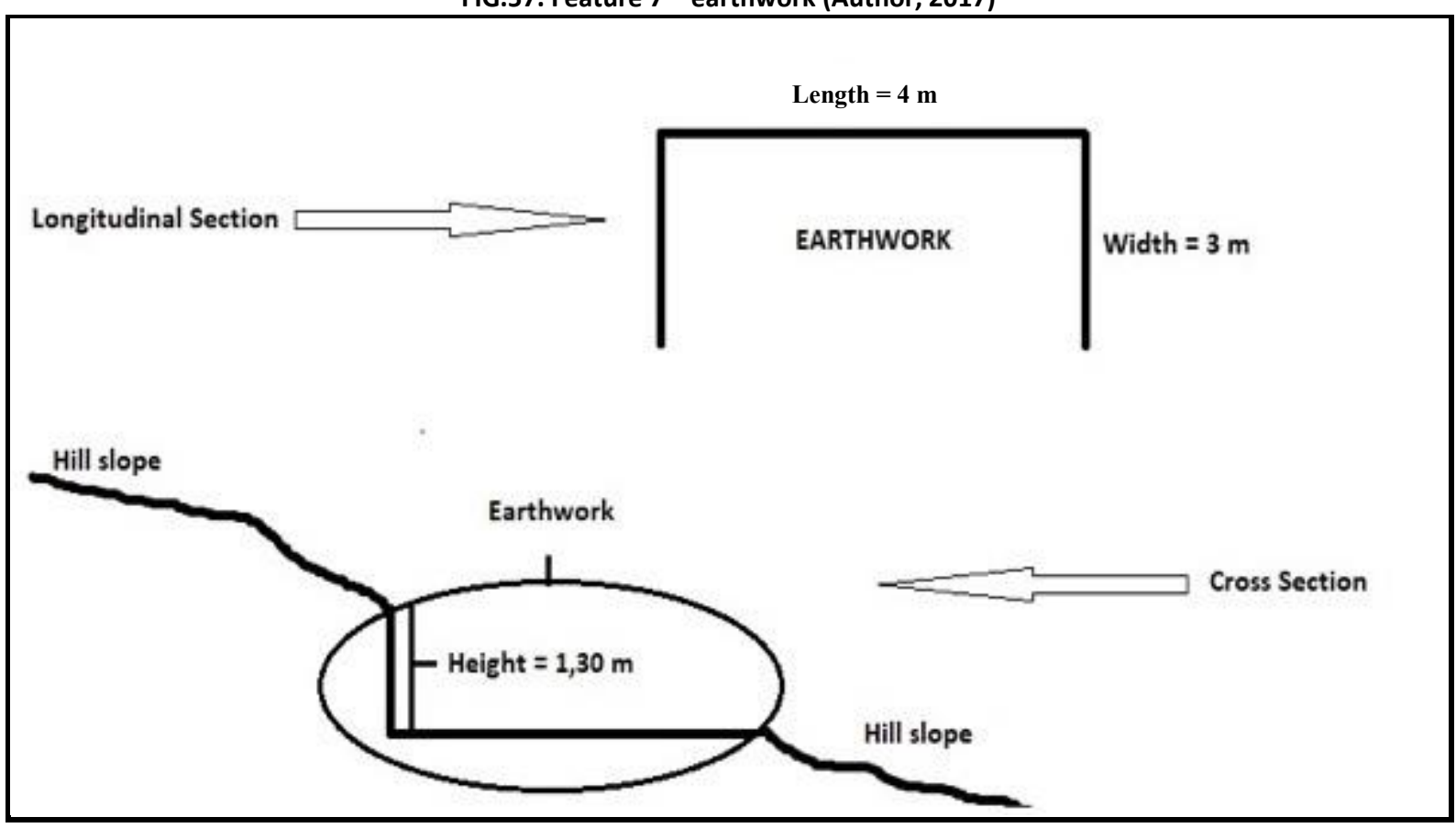

Feature 8 represents a rectangular building foundation, situated at $47,60684^{\circ} \mathrm{N}-24,84444^{\circ} \mathrm{E}$, at an altitude of $1415 \mathrm{~m}$ (FIG.58 A, B). The foundation of $20 \mathrm{~m}$ length and $5 \mathrm{~m}$ width is covered by vegetation and shaped stones can be seen on the spot. 
FIG. 58. Feature 8 - rectangular building foundation (Author, 2017)
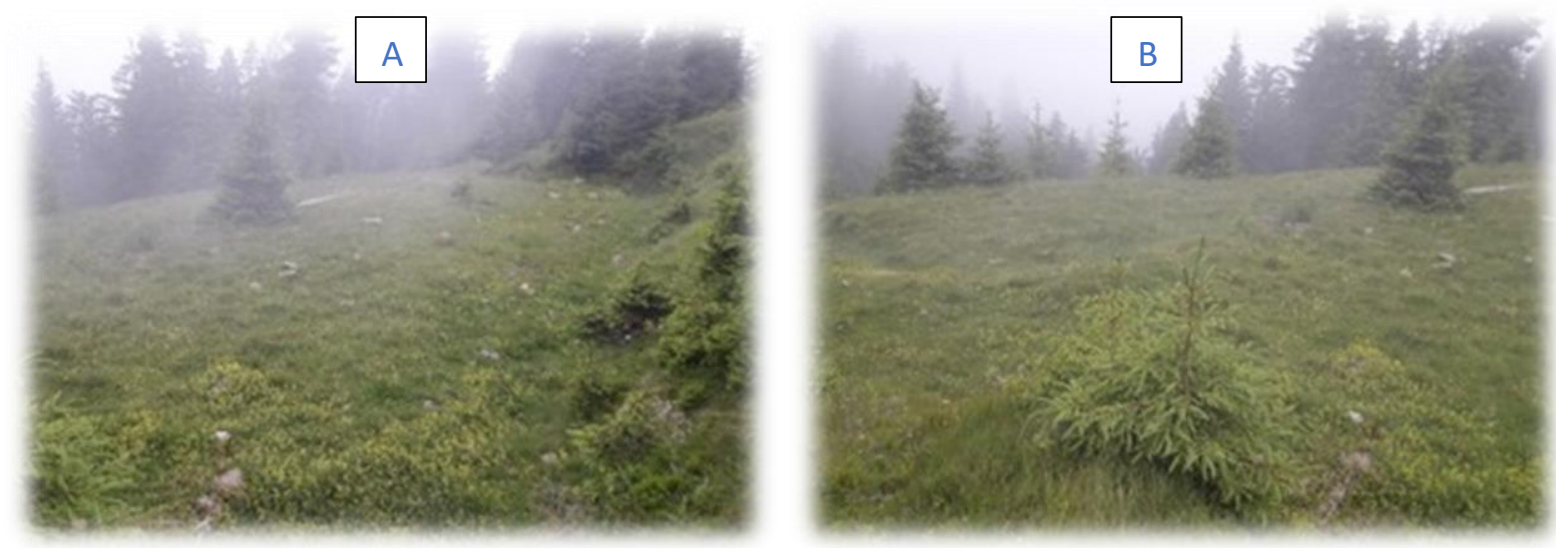

Feature 9 represents a rectangular building foundation, situated at $47,60698^{\circ} \mathrm{N}-24,84439^{\circ} \mathrm{E}$, at an altitude of $1414 \mathrm{~m}$ (FIG.59 A, B). The foundation of $13 \mathrm{~m}$ length and $4 \mathrm{~m}$ width is covered by vegetation and shaped stones can be seen on the spot.

\section{FIG.59. Feature 9 - rectangular building foundation (Author, 2017)}
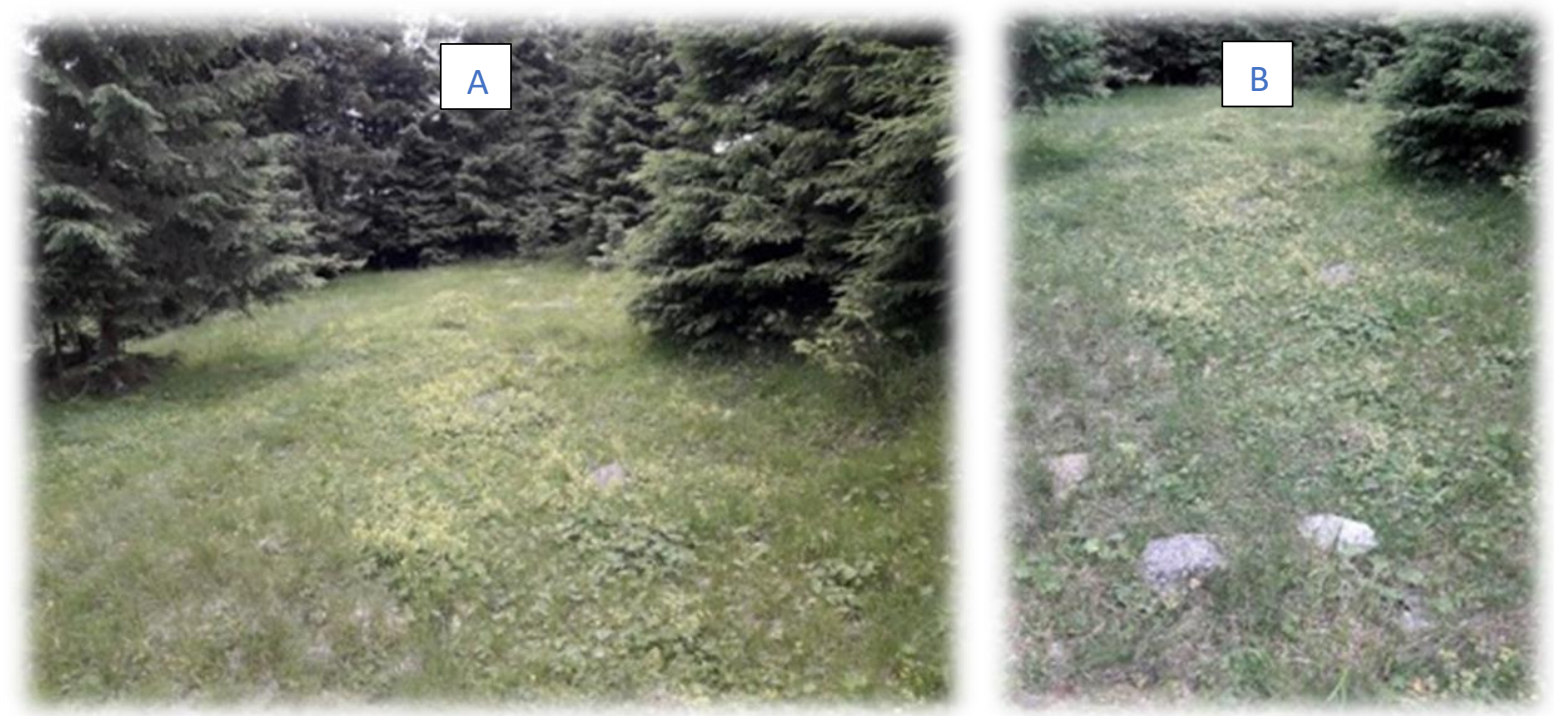

Feature 10 represents a building, situated at $47,60695^{\circ} \mathrm{N}-24,84454^{\circ} \mathrm{E}$, at an altitude of 1416 m (FIG.60 A, B, C, D). The building has rectangular shape and is oriented to NE - SW. The buildings' walls are largely preserved, having a maximum height of $2.85 \mathrm{~m}$. On the western side a part of the wall has collapsed. The building is made of shaped stones with joints of cement and gravel. 
FIG.60. Feature 10 - building (Author, 2017)
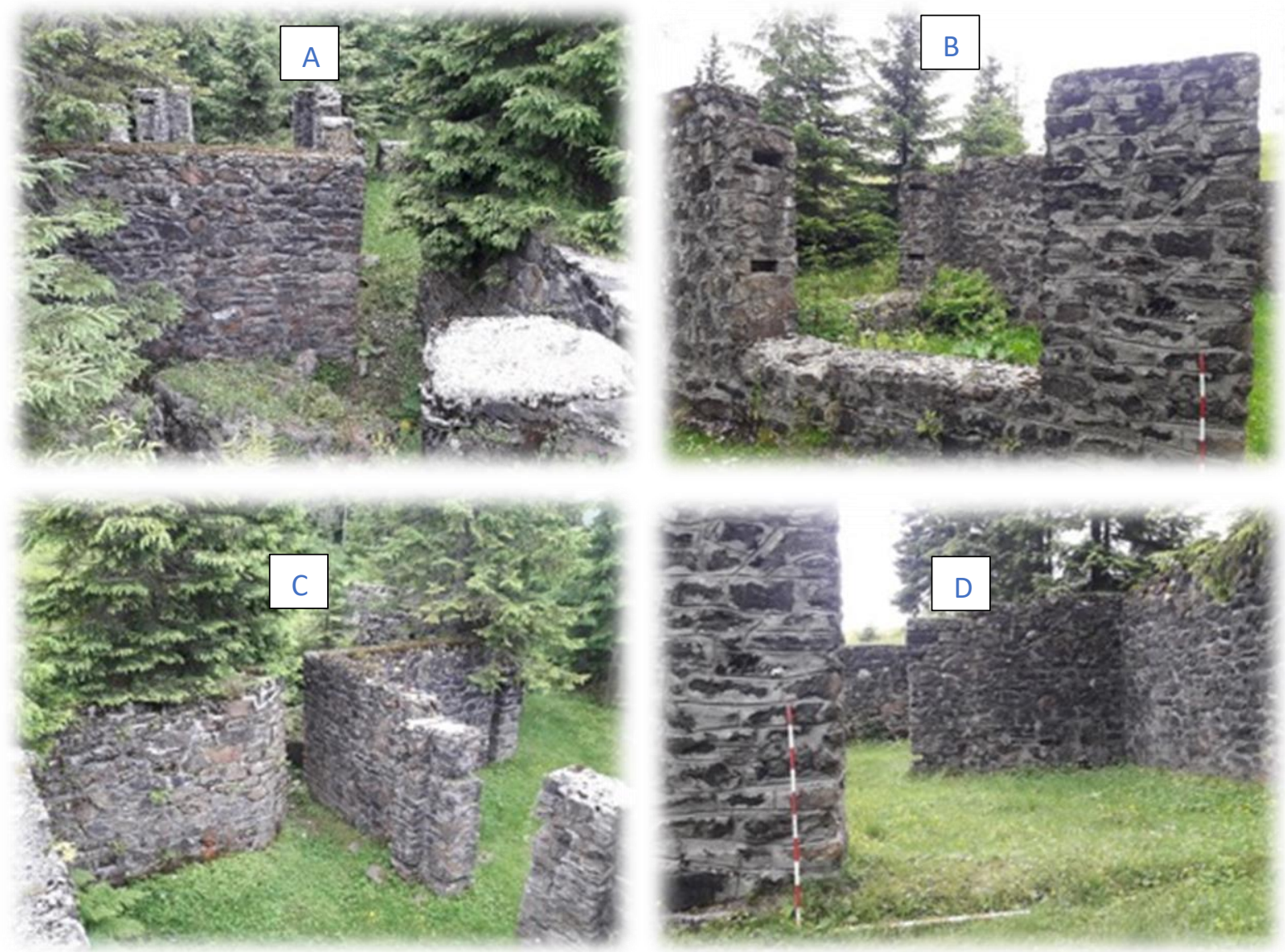

FIG.61 represents a map of the field location of Features 11 to 22 along with the position of this section of the field (yellow rectangle) within research sector 1 (red rectangle).

FIG.61. Map of field location of feature 11 to 22 - research sector 1 (Author, 2018)

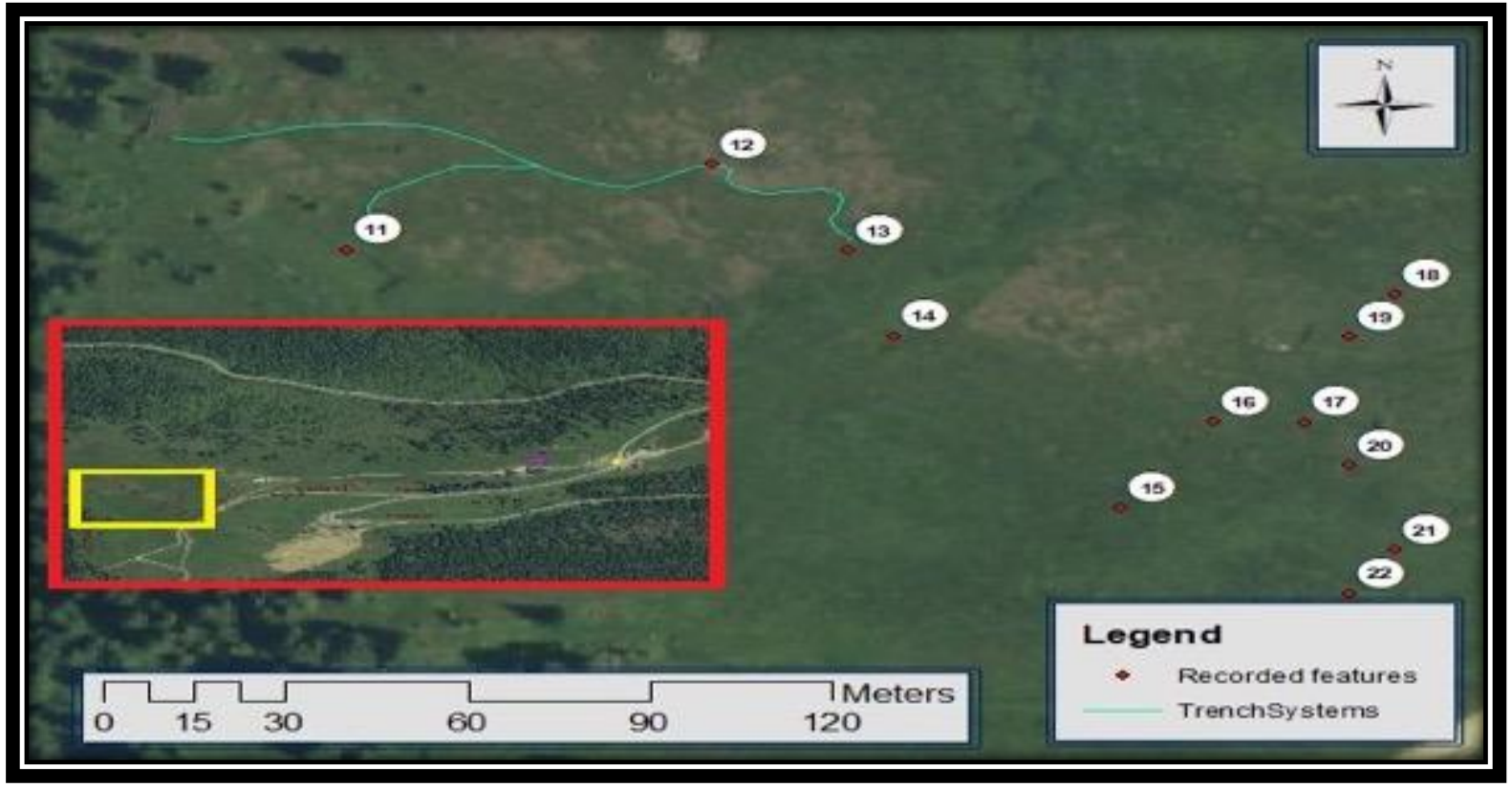


Feature 11 represents a rectangular building foundation, situated at $47,60832^{\circ} \mathrm{N}-24,8445^{\circ} \mathrm{E}$, at an altitude of $1420 \mathrm{~m}$ (FIG.62 A, B). The foundation is made of shaped stones with joints of slaked lime and gravel. The foundation is built on an embankment excavated in the hill slope and it has a length of $25 \mathrm{~m}$ and a width of $9 \mathrm{~m}$. A second embankment is present near the lower side of the building. This side of the foundation has regular square holes near the ground level where probably timber beams were inserted, indicating a potential extension of the building or a platform for the railway.

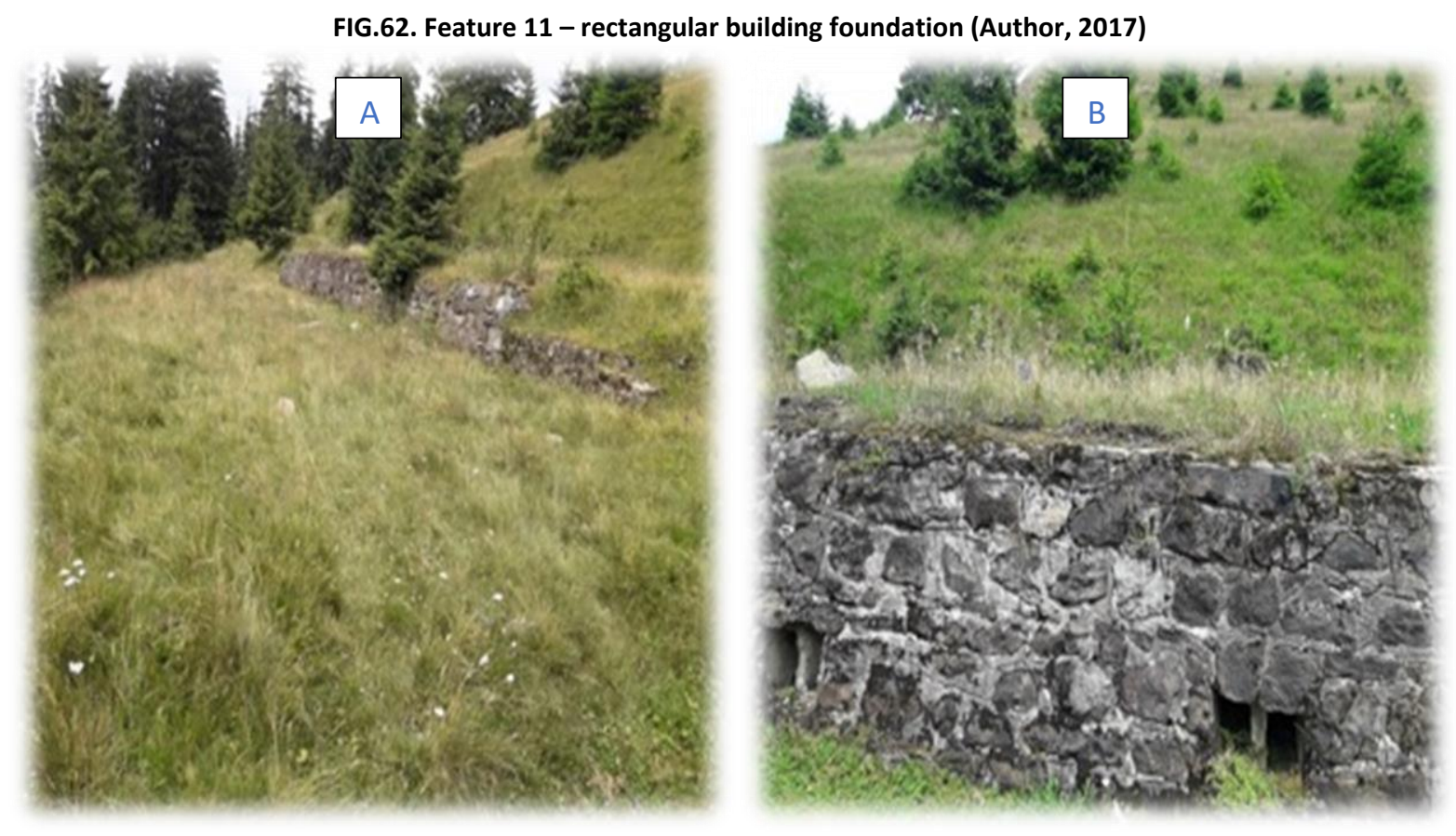

Feature 12 represents a trench system, whose highest point is situated at $47,60847^{\circ} \mathrm{N}-$ $24,84525^{\circ} \mathrm{E}$, at an altitude of $1440 \mathrm{~m}$ (FIG.63 A, B). The trench starts from above the prior building foundation and leads to a machine gun nest to the right. The trench has a $2 \mathrm{~m}$ width and is approximately $1.10 \mathrm{~m}$ deep. At a distance of $1 \mathrm{~m}$ from the upper side of the trench there is a pit with a length of $1.50 \mathrm{~m}$, a width of $1.50 \mathrm{~m}$ and approximately $1 \mathrm{~m}$ deep. At a distance of $2 \mathrm{~m}$ from the pit there is an earth mound. Traces of shaped stone and cement made of lime and gravel can be seen on the site. 
FIG.63. Feature 12 - trench system (Author, 2017)
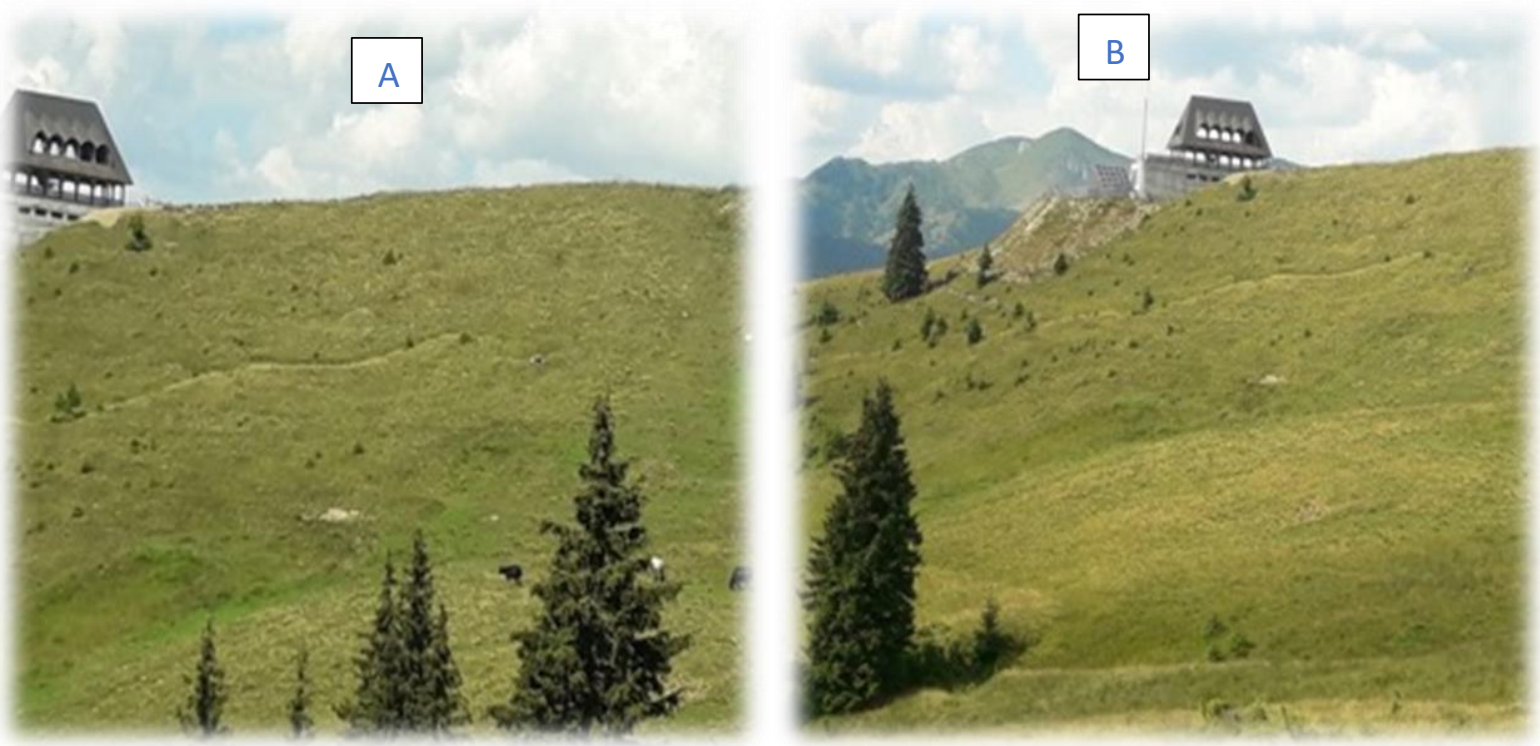

Feature 13 represents a pillbox (FIG.64 A, B, C, D), situated at $47,60834^{\circ} \mathrm{N}-24,84559^{\circ} \mathrm{E}$, at an altitude of $1432 \mathrm{~m}$. The pillbox is a dug-in guard post made of concrete, equipped with a loophole, $62 \mathrm{~cm}$ long and $22 \mathrm{~cm}$ high, on the front side. It has a crescent shape if seen from above, the top having a central dimeter of $60 \mathrm{~cm}$. The width of the walls is of $20 \mathrm{~cm}$, it has a height of $60 \mathrm{~cm}$ and the distance at its extremities is of $1.60 \mathrm{~m}$.

FIG.64. Feature 13 - pillbox (Author, 2017)
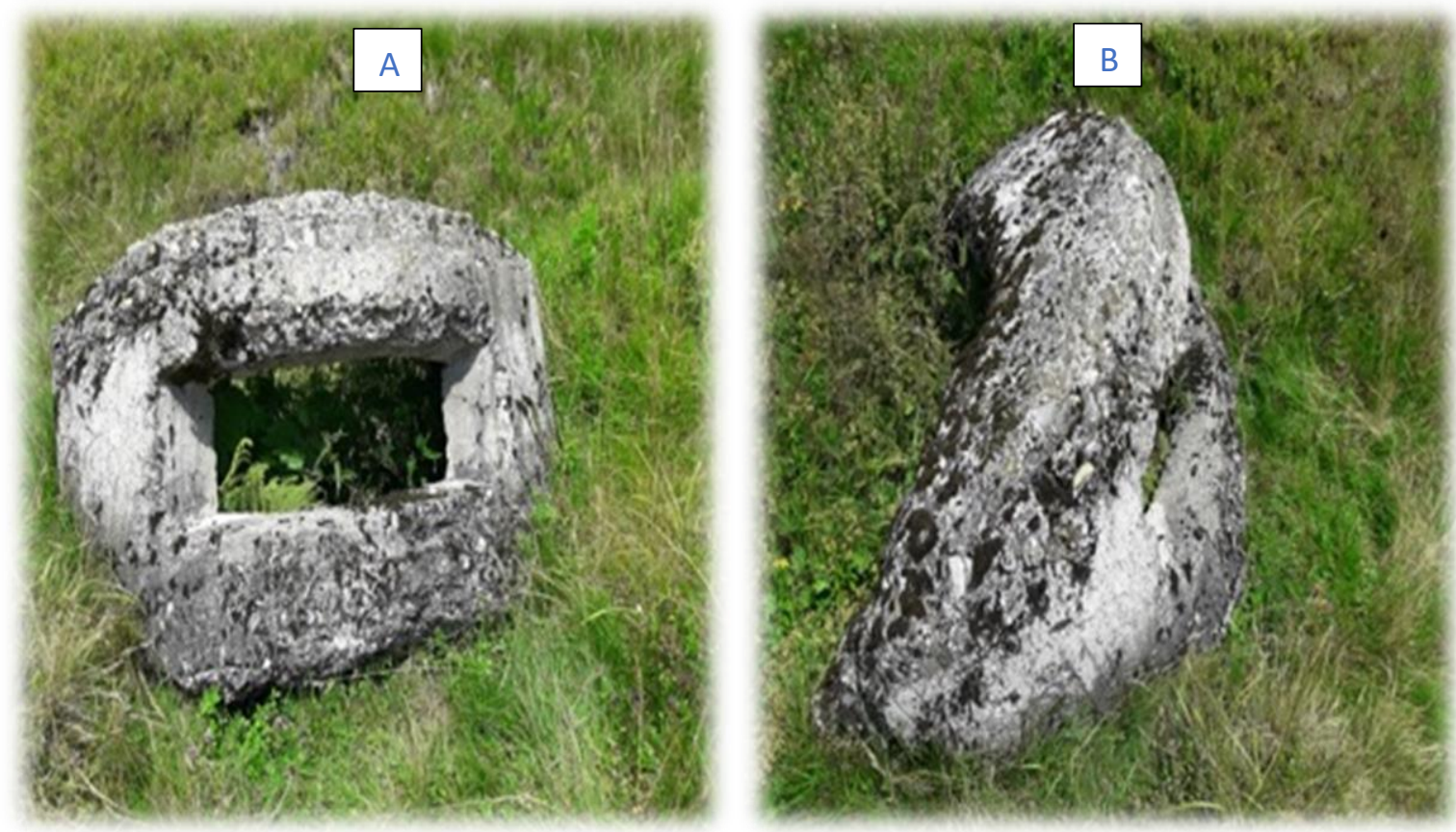

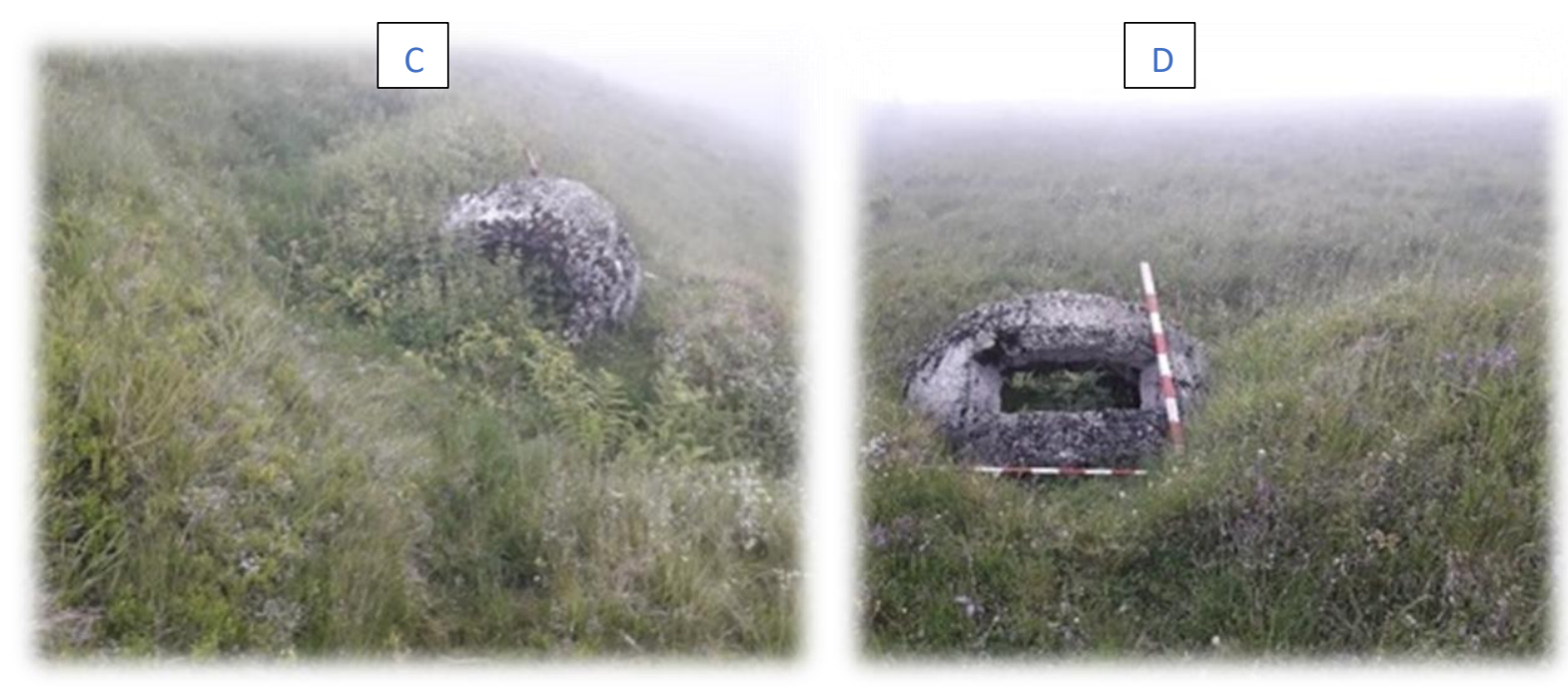

Feature 14 represents a 3 -sided earthwork, situated at $47,60806^{\circ} \mathrm{N}-24,84574^{\circ} \mathrm{E}$, at an altitude of $1418 \mathrm{~m}$ (FIG.65). The earthwork consists of an embankment excavated in the hill slope with a length of $6 \mathrm{~m}$, a width of $4.30 \mathrm{~m}$ and a maximum depth of $1.50 \mathrm{~m}$. Shaped stones can be seen on the site of the earthwork which is oriented to the SW.

FIG.65. Feature 14 -e arthwork (Author, 2017)

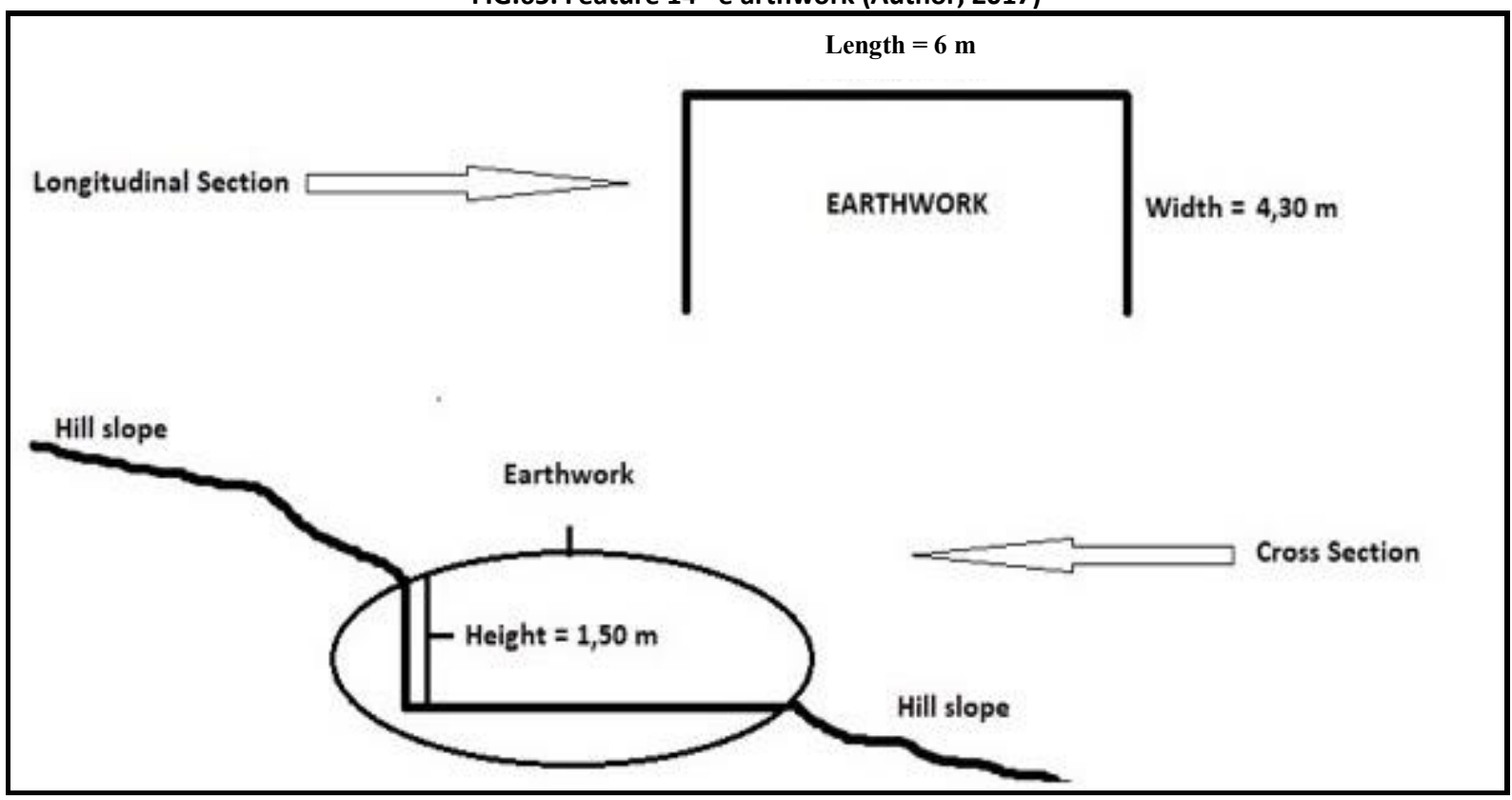

Feature 15 represents a 3 -sided earthwork, situated at $47,60769^{\circ} \mathrm{N}-24,84622^{\circ} \mathrm{E}$, at an altitude of $1411 \mathrm{~m}$ (FIG.66). The earthwork consists of an embankment excavated in the hill slope with a length of $3 \mathrm{~m}$, a width of $3 \mathrm{~m}$ and a maximum depth of $1.30 \mathrm{~m}$. Shaped stones can be seen on the site of the earthwork which is oriented to the SW. 


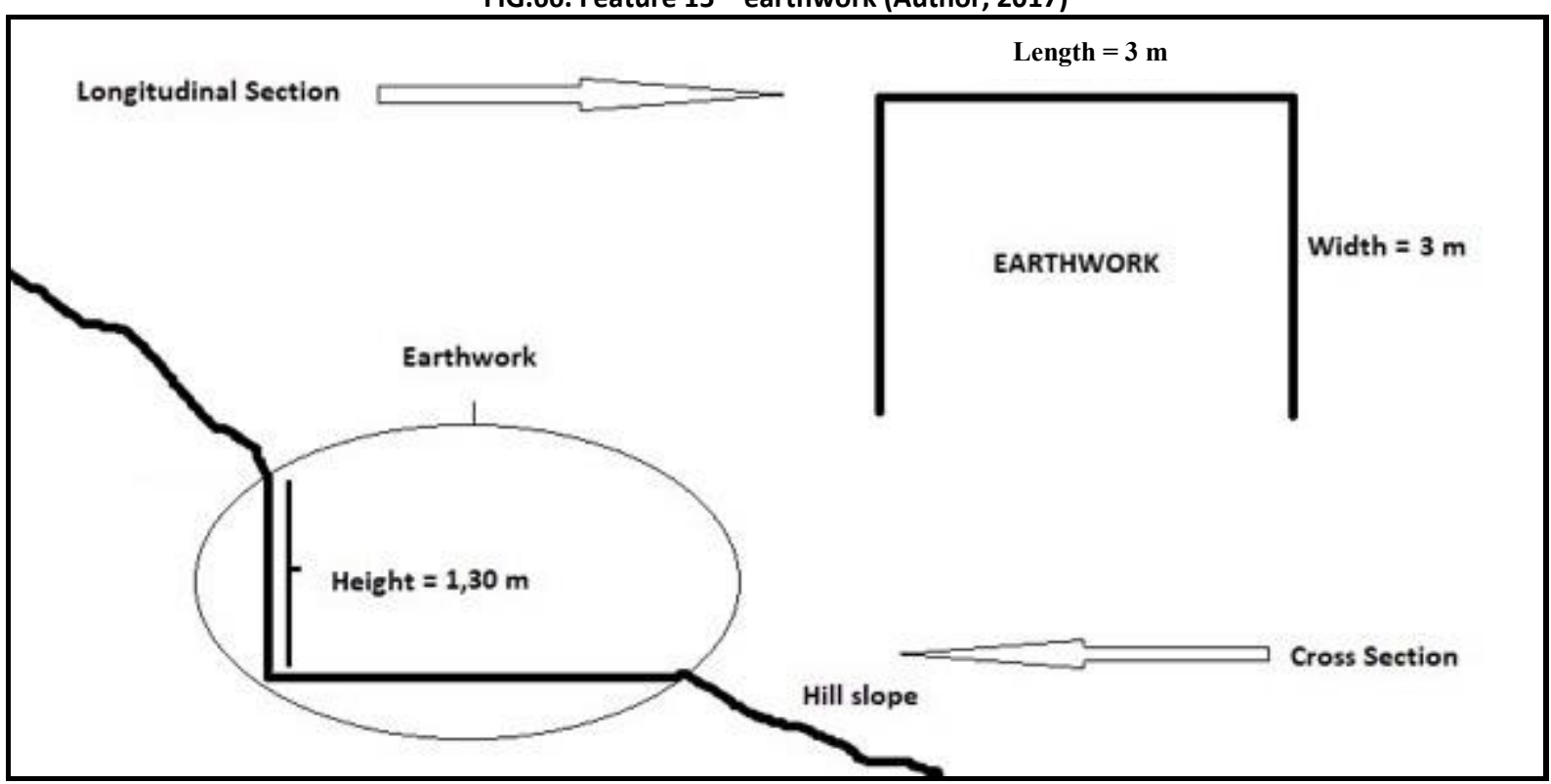

Feature 16 represents a 4 -sided earthwork, situated at $47,60789^{\circ} \mathrm{N}-24,84642{ }^{\circ} \mathrm{E}$, at an altitude of $1431 \mathrm{~m}$ (FIG.67). The earthwork consists of an embankment excavated in the hill slope with a length of $5 \mathrm{~m}$, a width of $2 \mathrm{~m}$ and a maximum depth of $1.30 \mathrm{~m}$. It has a channelshaped entrance on the upper right side and unlike the previous cases it has the lower, frontal side consolidated. Shaped stones can be seen on the site of the earthwork which is oriented to the SW.

FIG.67. Feature 16 - earthwork (Author, 2017)

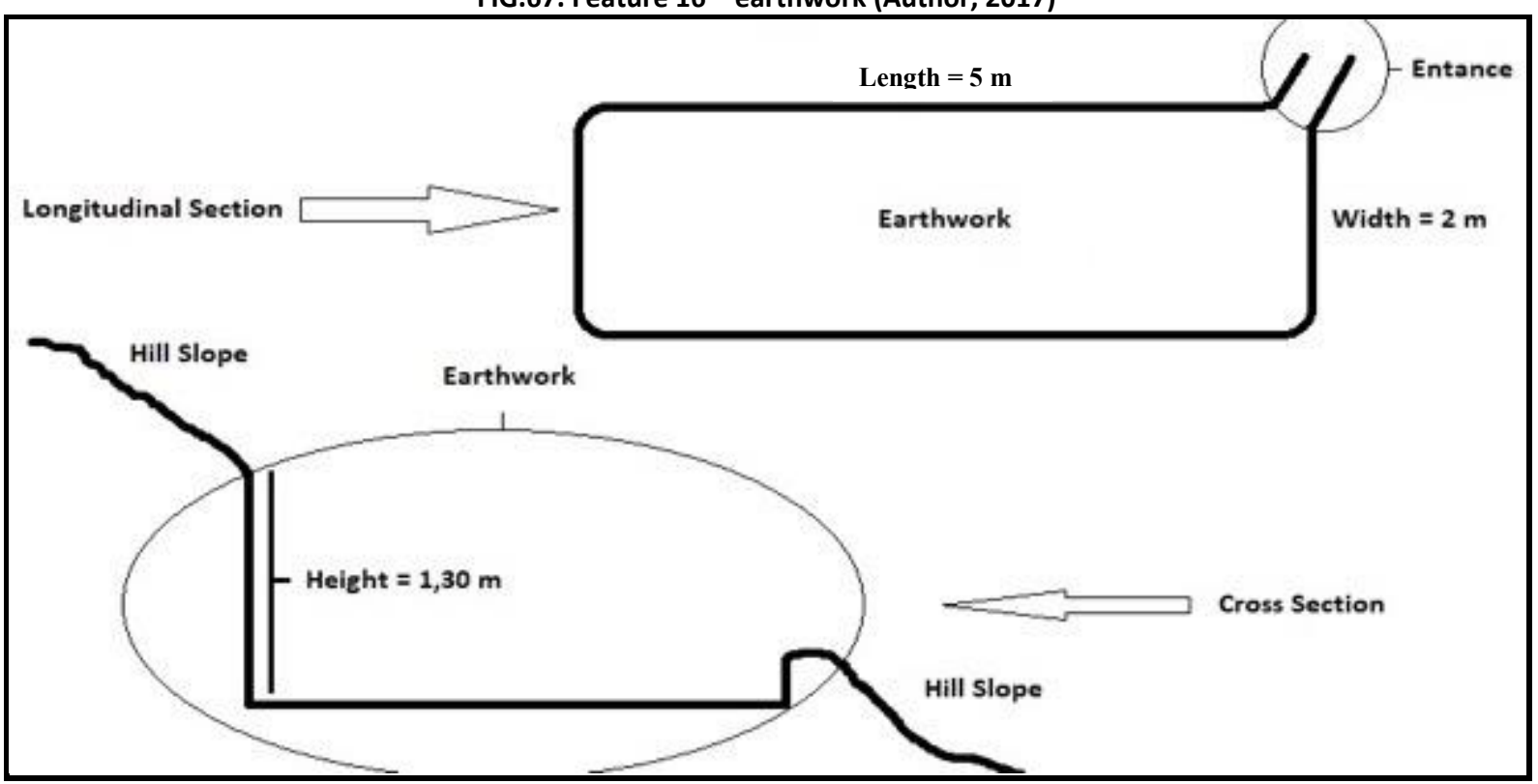


Feature 17 represents a 3 -sided earthwork, situated at $47,60785^{\circ} \mathrm{N}-24,84661^{\circ} \mathrm{E}$, at an altitude of $1431 \mathrm{~m}$ (FIG.68). The earthwork consists of an embankment excavated in the hill slope with a length of $8 \mathrm{~m}$, a width of $5 \mathrm{~m}$ and a maximum depth of $1.50 \mathrm{~m}$. Shaped stones can be seen on the site of the earthwork which is oriented to the S-SW.

FIG.68. Feature 17 - earthwork (Author, 2017)

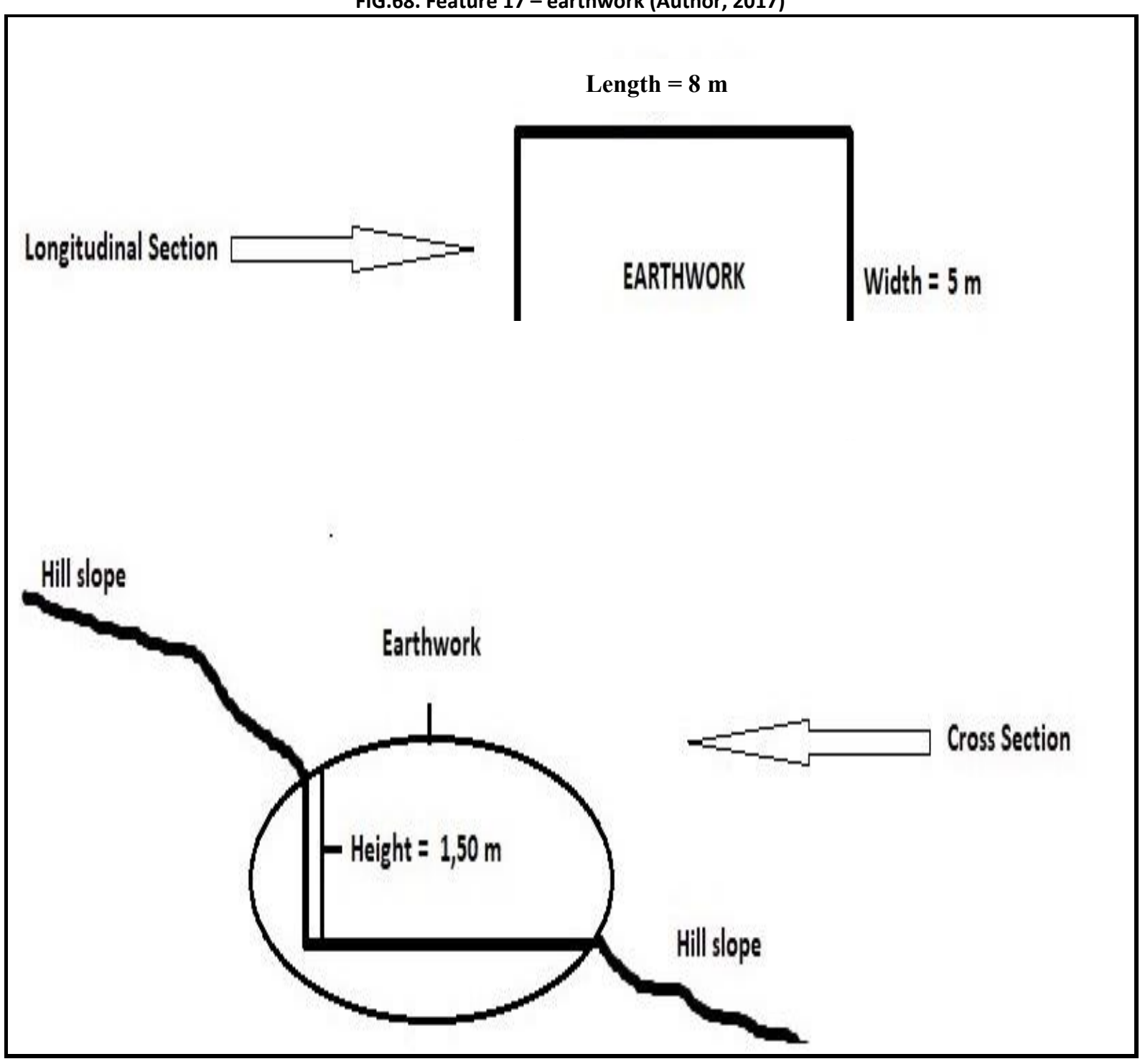

Feature 18 represents a 3 -sided earthwork, situated at $47,60821^{\circ} \mathrm{N}-24,84675^{\circ} \mathrm{E}$, at an altitude of 1434 m (FIG.69). The earthwork consists of an embankment excavated in the hill slope with a length of $10 \mathrm{~m}$, a width of $6 \mathrm{~m}$ and a maximum depth of $1.70 \mathrm{~m}$. Shaped stones can be seen on the site of the earthwork which is oriented to the S-SW. 
FIG.69. Feature 18 - earthwork (Author, 2017)

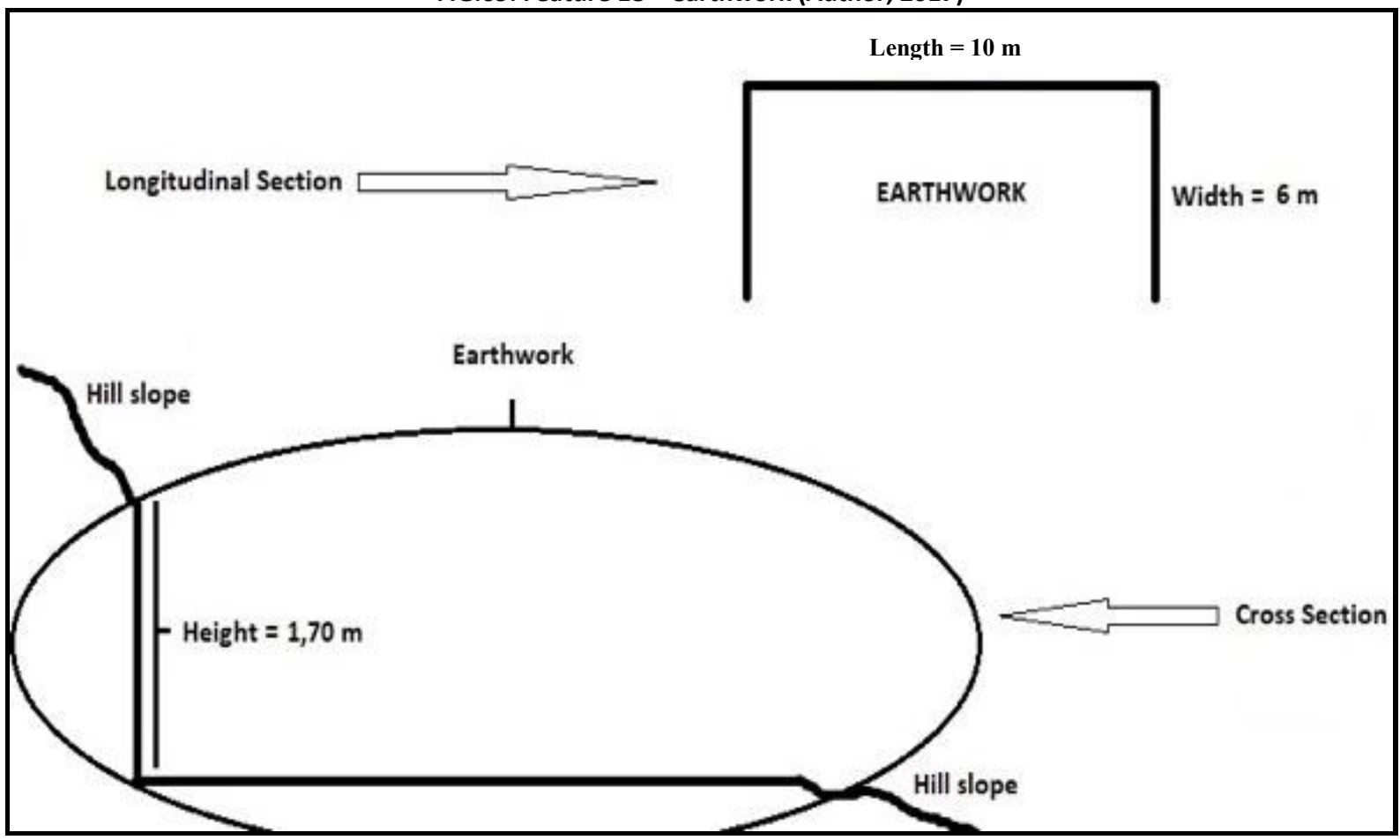

Feature 19 represents a square building foundation (FIG.70 A, B), situated at $47,60809^{\circ} \mathrm{N}-$ $24,84665^{\circ} \mathrm{E}$, at an altitude of $1440 \mathrm{~m}$. The $6 \mathrm{~m} \times 6 \mathrm{~m}$ foundation is made of cement and gravel and is covered with a layer of bitumen. The foundation is constructed on an embankment excavated in the hill slope, with a maximum depth of $1.80 \mathrm{~m}$. Shaped stones can be seen on the site of the foundation which is oriented to the S-SW.

FIG.70. Feature 19 - square building foundation (Author, 2017)
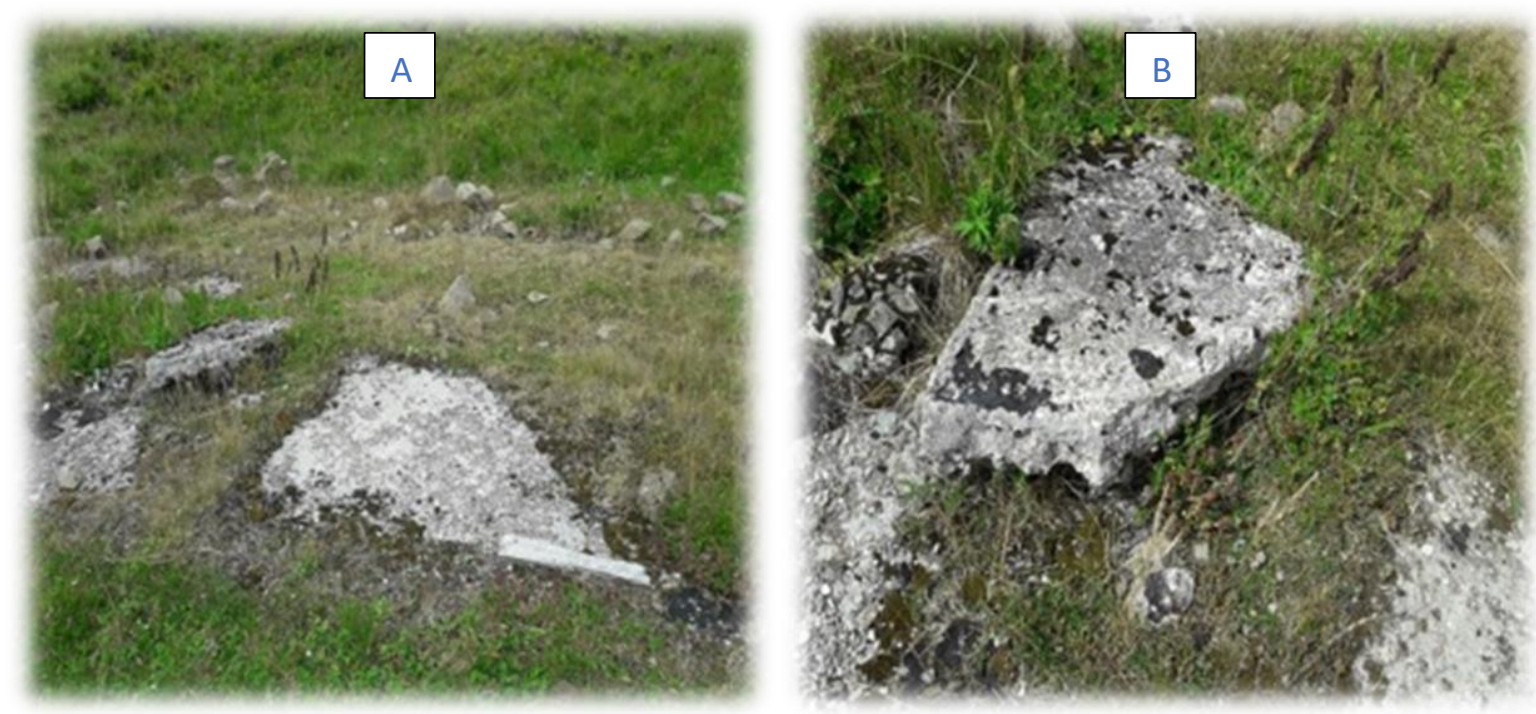
Feature 20 represents a 3 -sided earthwork, situated at $47,60781^{\circ} \mathrm{N}-24,84666^{\circ} \mathrm{E}$, at an altitude of $1431 \mathrm{~m}$ (FIG.71). The earthwork consists of an embankment excavated in the hill slope with a length of $8 \mathrm{~m}$, a width of $5 \mathrm{~m}$ and a maximum depth of $1.30 \mathrm{~m}$. Shaped stones can be seen on the site of the earthwork which is oriented to the S.

FIG.71. Feature 20 - earthwork (Author, 2017)

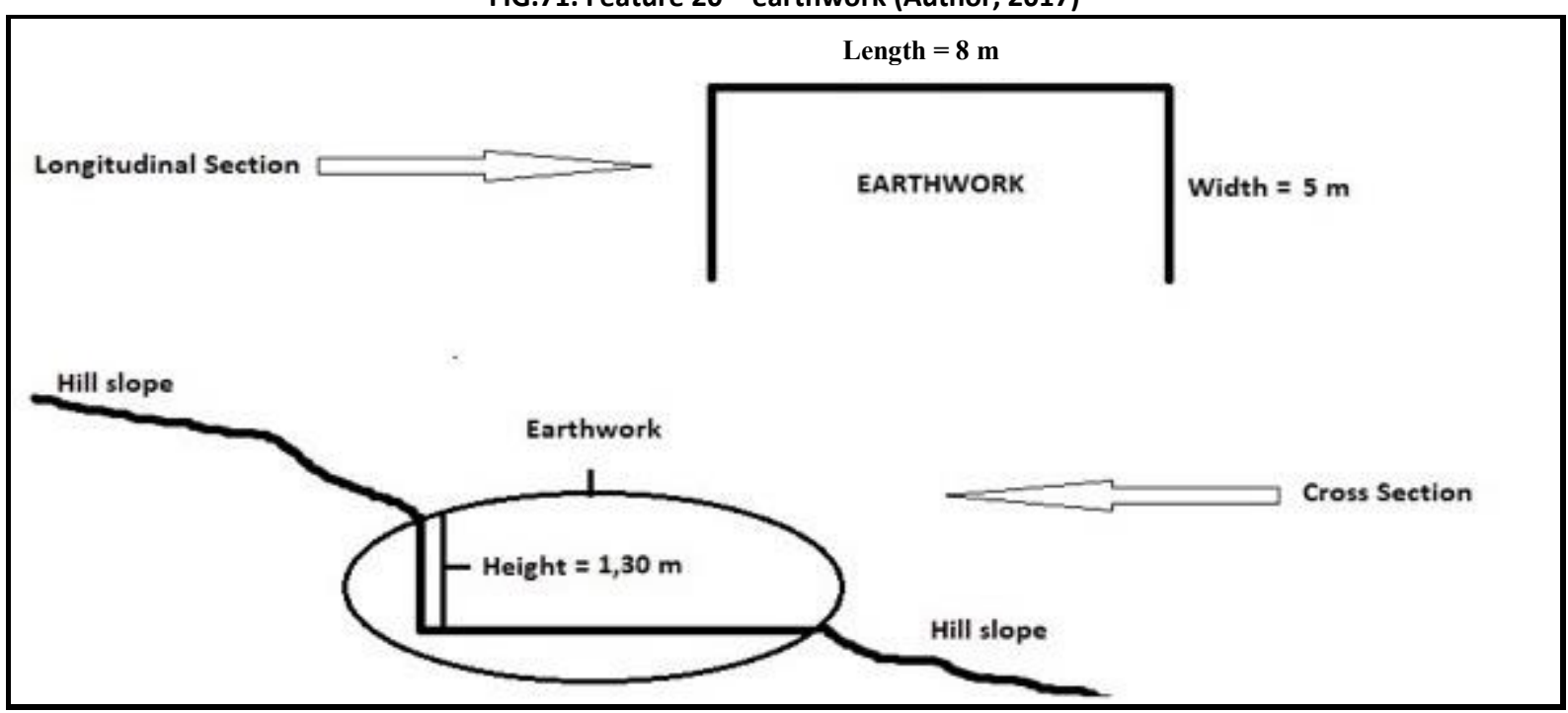

Feature 21 represents a rectangular building foundation, situated at $47,60756^{\circ} \mathrm{N}-24,84684^{\circ} \mathrm{E}$, at an altitude of $1428 \mathrm{~m}$ (FIG.72 A, B). The foundation of $26 \mathrm{~m}$ length and $6.50 \mathrm{~m}$ width is made of stone with gravel joints. No embankments were needed in this case as the foundation was built on plane ground parallel to the next feature.

FIG.72. Feature 21 - rectangular building foundation (Author, 2017)
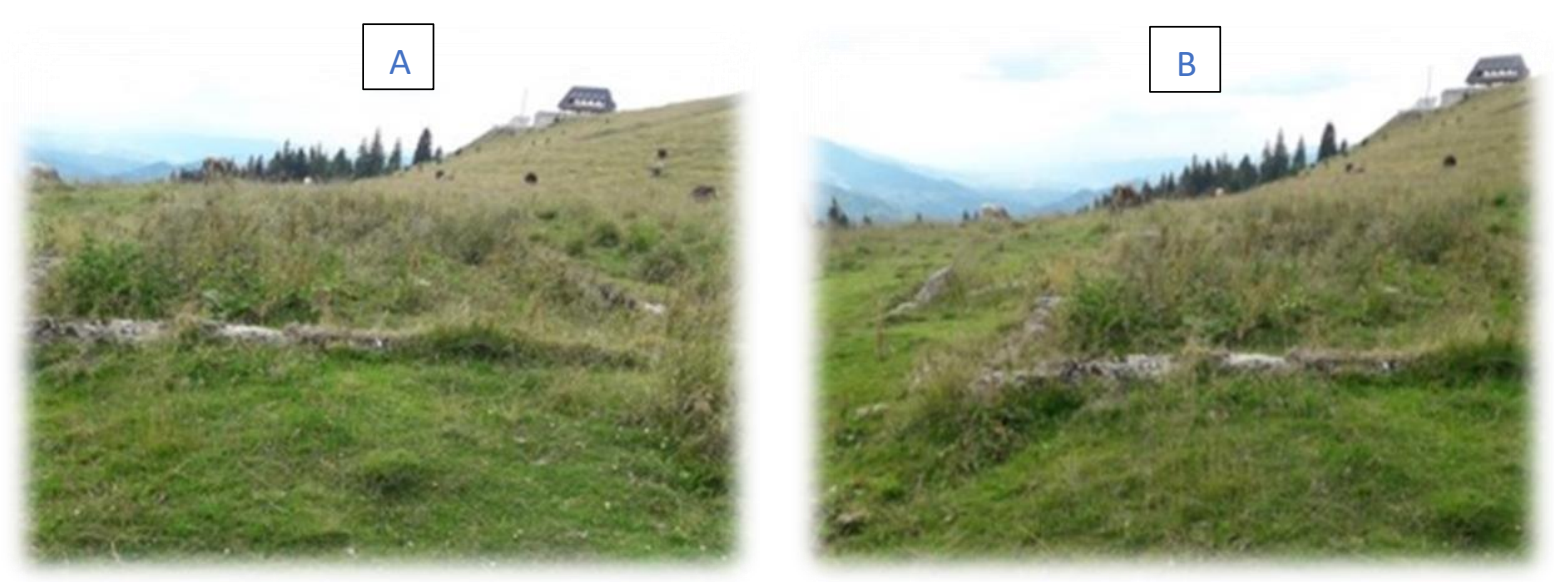
Feature 22 represents a rectangular building foundation, situated at $47,60749^{\circ} \mathrm{N}-24,84674^{\circ} \mathrm{E}$, at an altitude of $1429 \mathrm{~m}$ (FIG.73 A, B). The foundation of $6.80 \mathrm{~m}$ length and $5.80 \mathrm{~m}$ width is made of concrete and it was built on plain ground in the proximity of the previous feature.

FIG.73. Feature 22 - rectangular building foundation (Author, 2017)

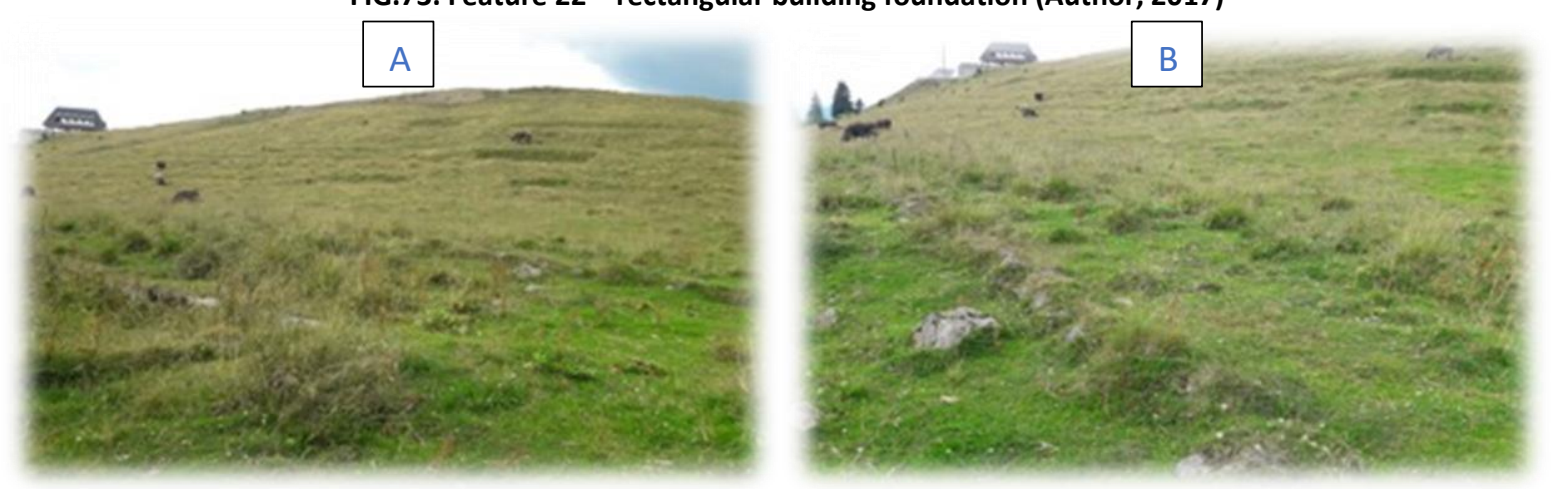

FIG.74 represents a map of the field location of feature 23 to 53 along with the position of this section of the field (yellow rectangle) within research sector 1 (red rectangle).

FIG.74. Map of field location of feature 23 to 53 - research sector 1 (Author, 2018)

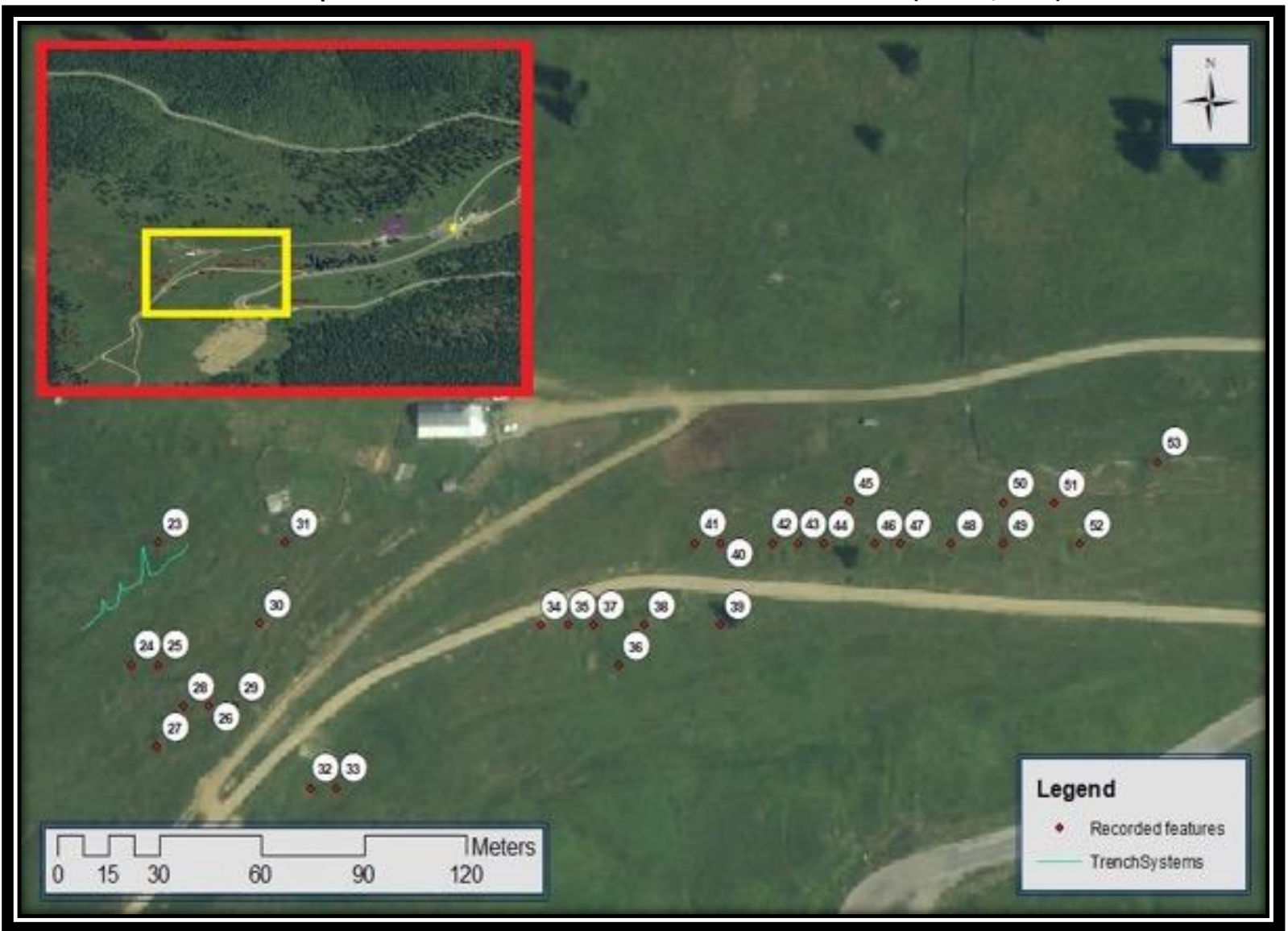


Feature 23 represents a section of a trench system (FIG.75 A, B), whose highest point is situated at $47,60844^{\circ} \mathrm{N}-24,84754^{\circ} \mathrm{E}$, at an altitude of $1439 \mathrm{~m}$. The trench has a width of $2 \mathrm{~m}$ and is approximately $1.10 \mathrm{~m}$ deep. It consists of a series of wave-shaped curves that end in dug-in posts orientated to the SE, S and S-SW.

FIG.75. Feature 23 - trench system (Author, 2017)
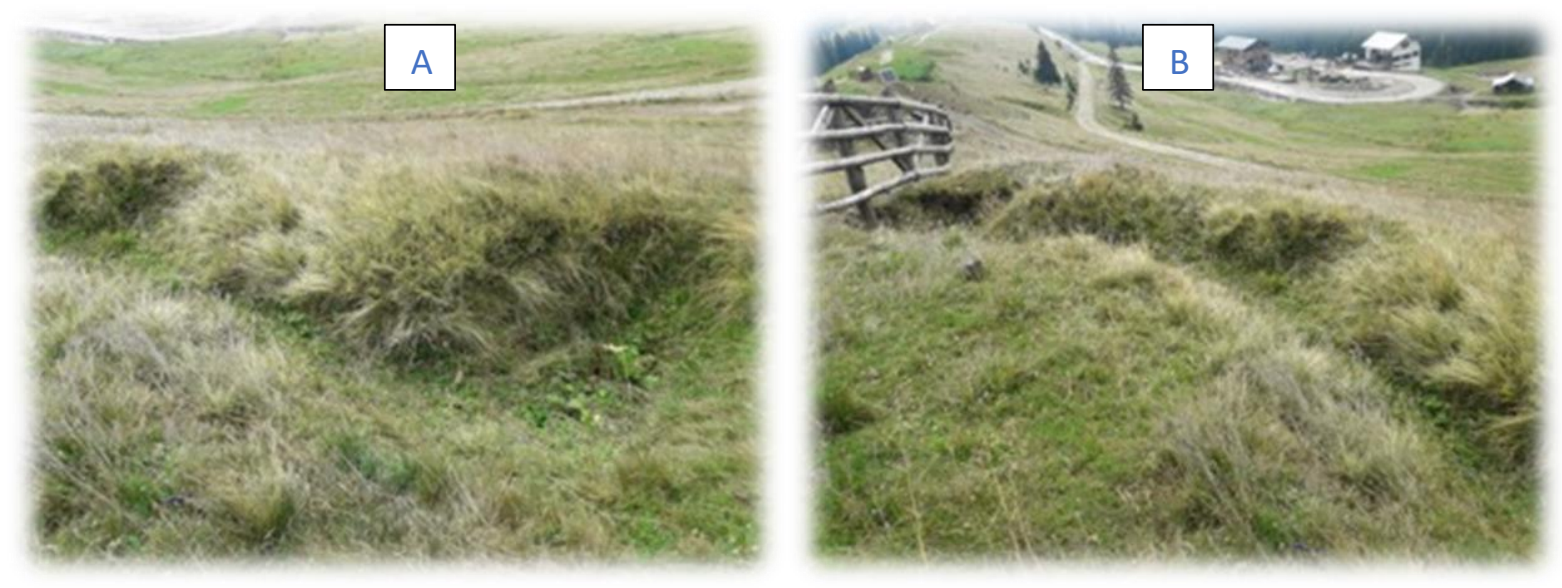

Feature 24 represents a 4 -sided earthwork, situated at $47,60807^{\circ} \mathrm{N}-24,84742^{\circ} \mathrm{E}$, at an altitude of 1438 m (FIG.76). The earthwork consists of an embankment excavated in the hill slope with a length of $5 \mathrm{~m}$, a width of $5.60 \mathrm{~m}$ and a maximum depth of $1.60 \mathrm{~m}$. The entrance is on the frontal side to the right. Inside the earthwork on the left side near the entrance there is an egg-shaped pit. Shaped stones can be seen on the site of the earthwork which is oriented to the SE.

FIG.76. Feature 24 - earthwork (Author, 2017)

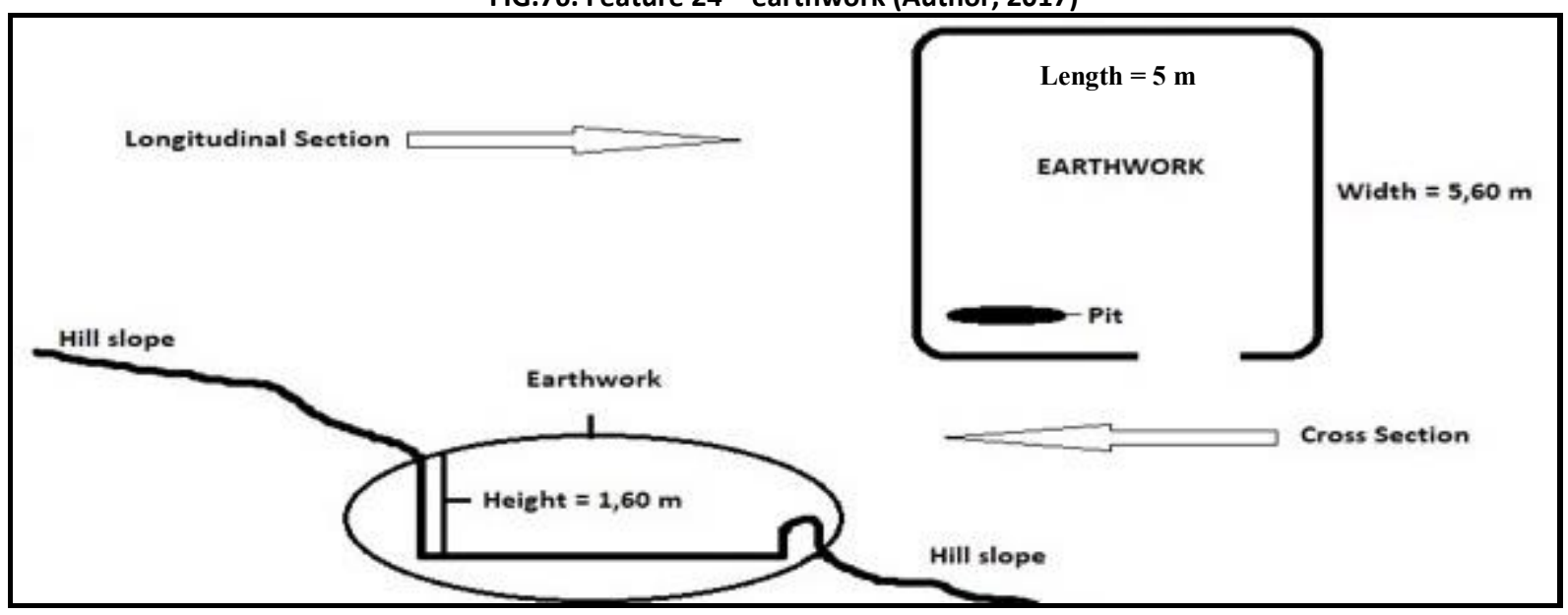


Feature 25 represents a 3 -sided earthwork, situated at $47,60813^{\circ} \mathrm{N}-24,84751^{\circ} \mathrm{E}$, at an altitude of $1438 \mathrm{~m}$ (FIG.77). The earthwork consists of an embankment excavated in the hill slope with a length of $3.50 \mathrm{~m}$, a width of $5 \mathrm{~m}$ and a maximum depth of $1.50 \mathrm{~m}$. Shaped stones can be seen on the site of the earthwork which is oriented to the SE.

FIG.77. Feature 25 - earthwork (Author, 2017)

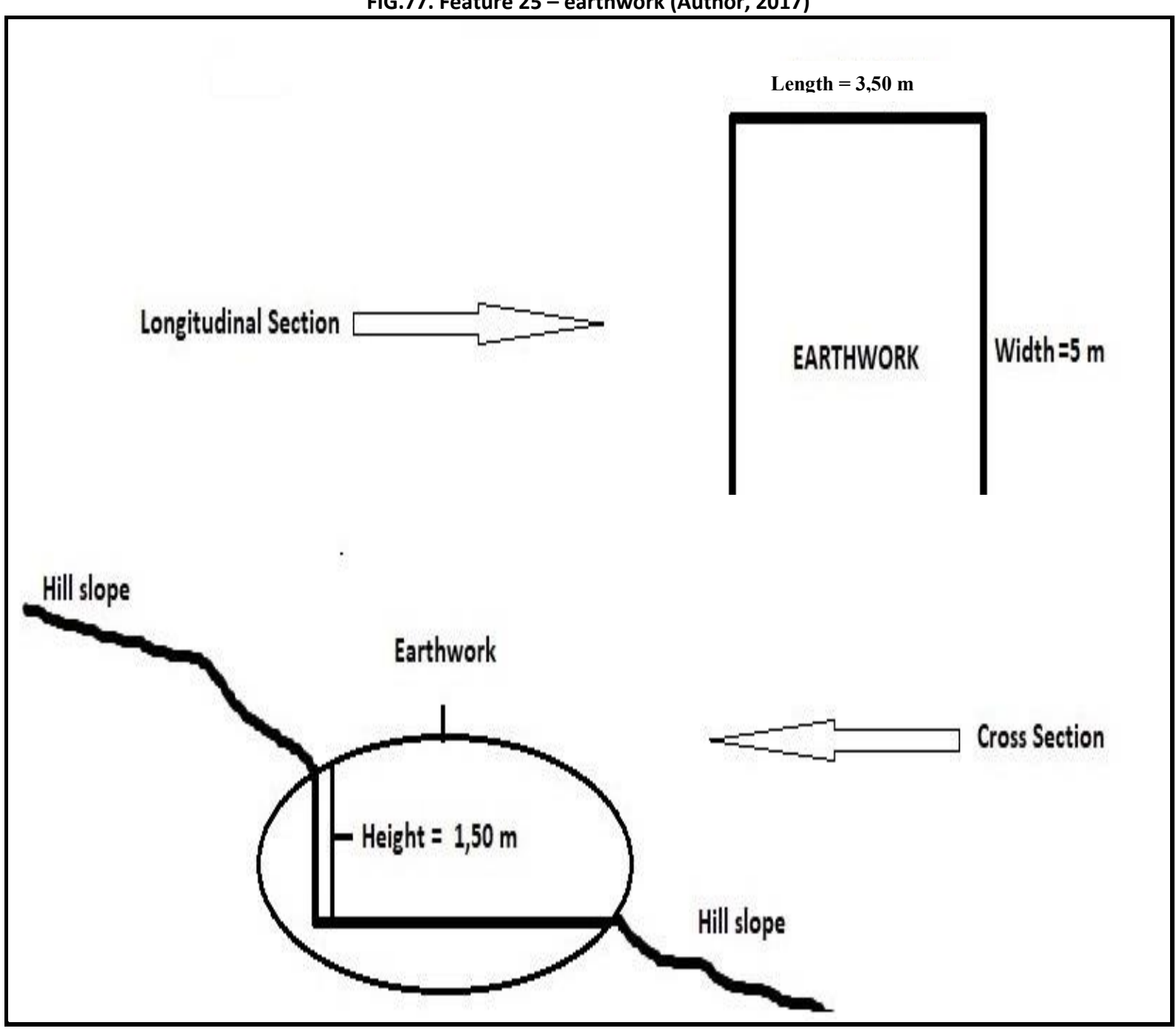

Feature 26 represents a 4 -sided earthwork, situated at $47,60804^{\circ} \mathrm{N}-24,84768^{\circ} \mathrm{E}$, at an altitude of 1437 m (FIG.78). The earthwork consists of an embankment excavated in the hill slope with a length of $13 \mathrm{~m}$, a width of $5 \mathrm{~m}$ and a maximum depth of $1.60 \mathrm{~m}$. The entrance is on the frontal side almost central, slightly to the right. Shaped stones can be seen on the site of the earthwork which is oriented to the S. 


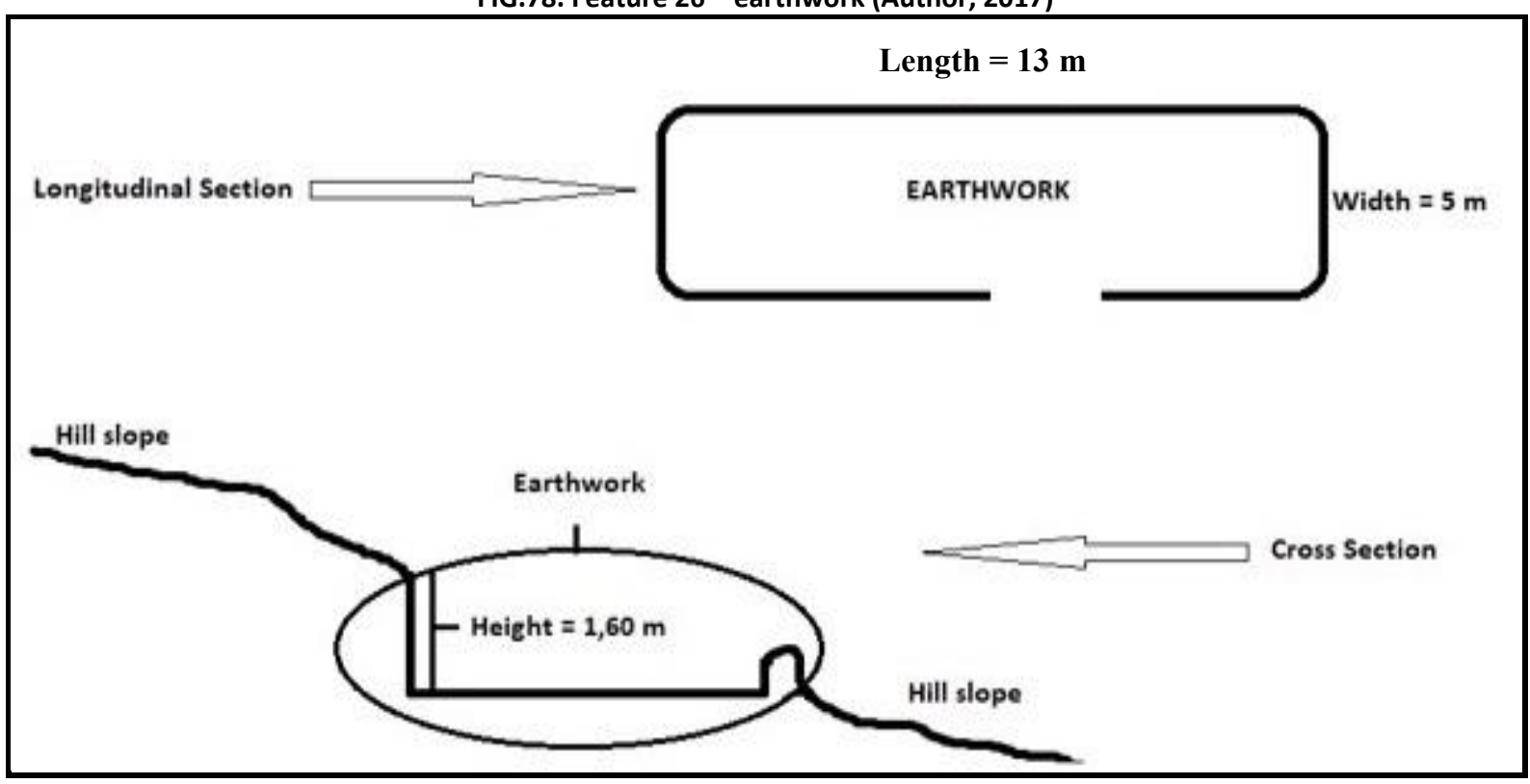

Feature 27 represents a 2 -sided earthwork, situated at $47,60792^{\circ} \mathrm{N}-24,84751^{\circ} \mathrm{E}$, at an altitude of $1428 \mathrm{~m}$ (FIG.79). The earthwork consists of an embankment excavated in the hill slope with a length of $12 \mathrm{~m}$, a width of $5 \mathrm{~m}$ and a maximum depth of $1.20 \mathrm{~m}$. The long side follows the line of the hill to the North and the right side was reinforced to the East forming a $90^{\circ}$ angle with the hill.

FIG.79. Feature 27 - earthwork (Author, 2017)

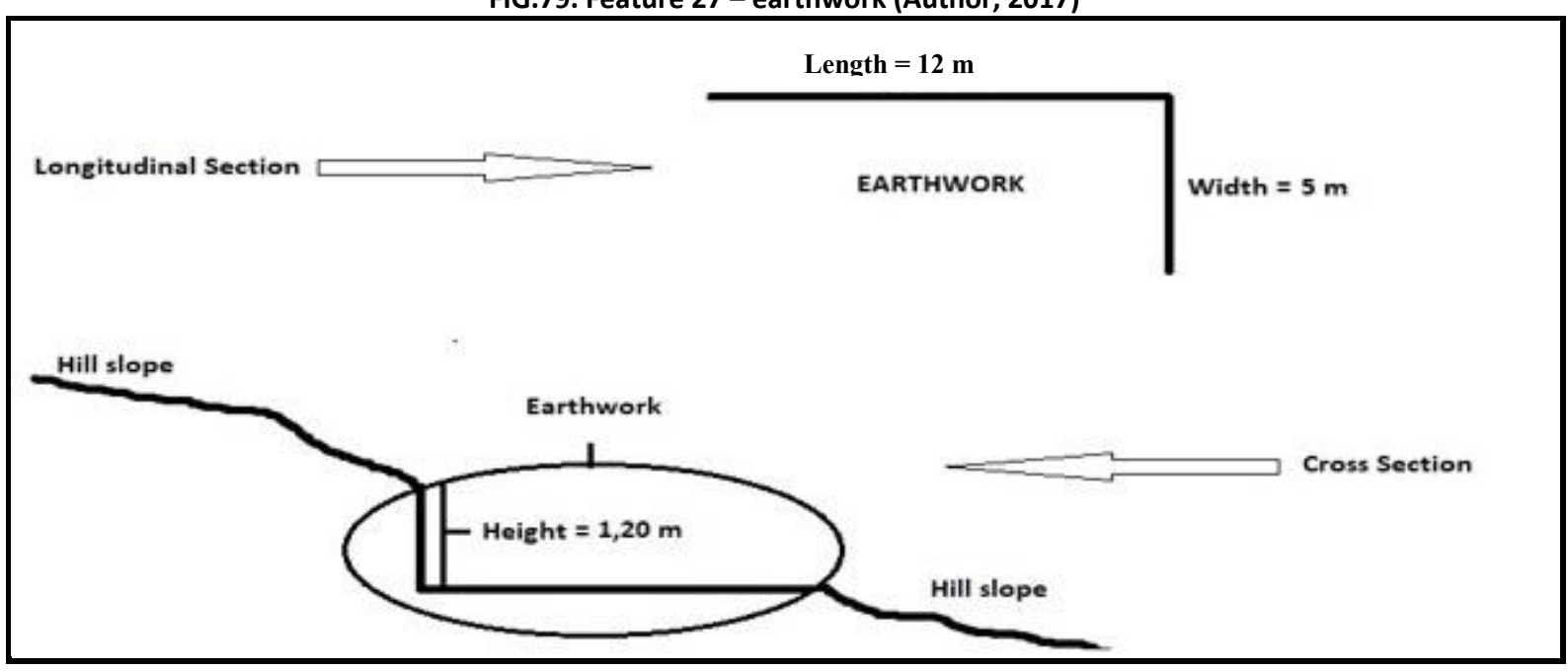

Feature 28 represents a 3 -sided earthwork, situated at $47,60797^{\circ} \mathrm{N}-24,84762^{\circ} \mathrm{E}$, at an altitude of 1432 m (FIG.80). The earthwork consists of an embankment excavated in the hill slope 
with a length of $5 \mathrm{~m}$, a width of $5 \mathrm{~m}$ and a maximum depth of $1.70 \mathrm{~m}$. Shaped stones can be seen on the site of the earthwork which is oriented to the S-SE.

FIG.80. Feature 28 - earthwork (Author, 2017)

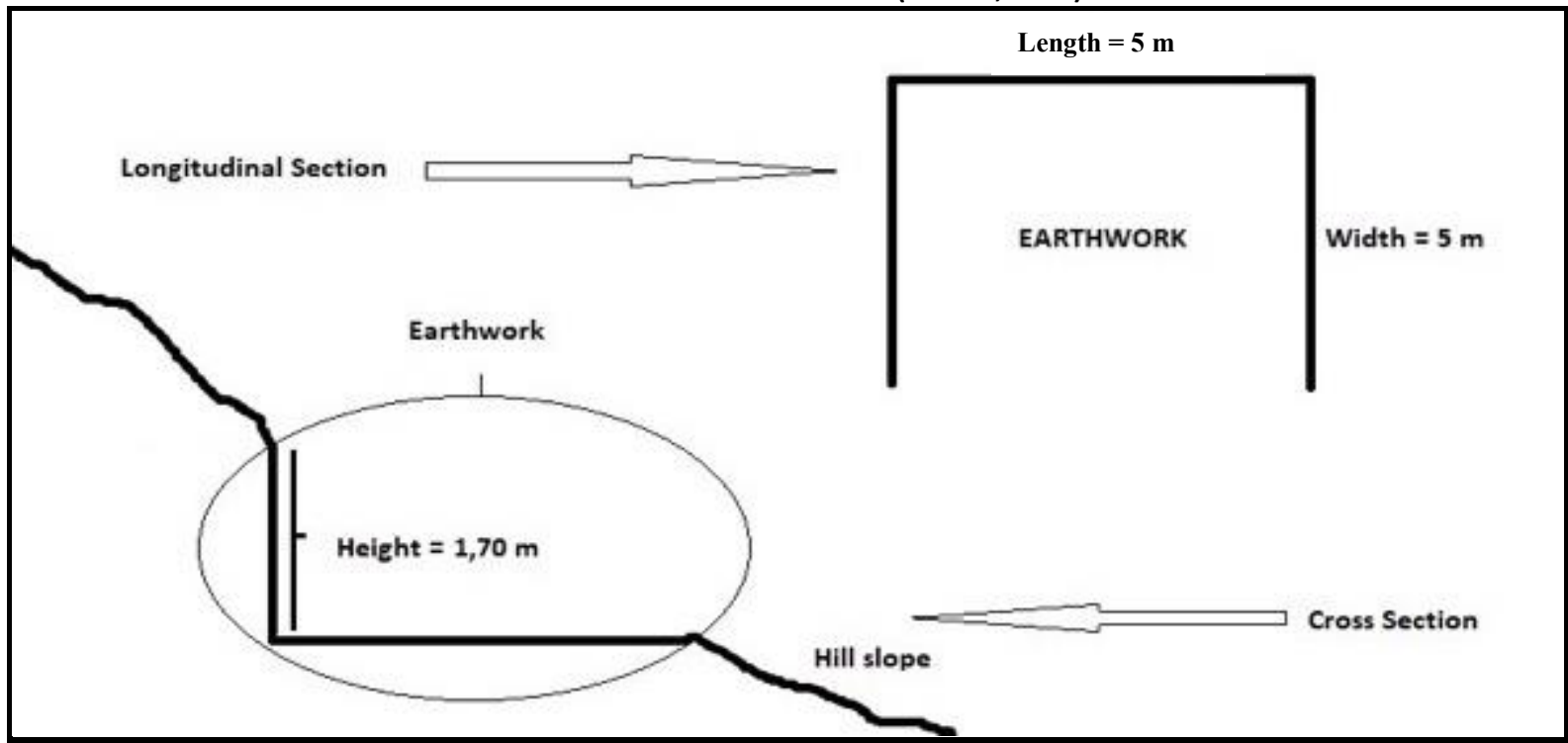

Feature 29 represents a 3 -sided earthwork, situated at $47,60798^{\circ} \mathrm{N}-24,84775^{\circ} \mathrm{E}$, at an altitude of $1423 \mathrm{~m}$ (FIG.81). The earthwork consists of an embankment excavated in the hill slope with a length of $12 \mathrm{~m}$, a width of $6 \mathrm{~m}$ and a maximum depth of $1.80 \mathrm{~m}$. Shaped stones can be seen on the site of the earthwork which seems to be oriented to the S-SE.

FIG.81. Feature 29 - earthwork (Author, 2017)

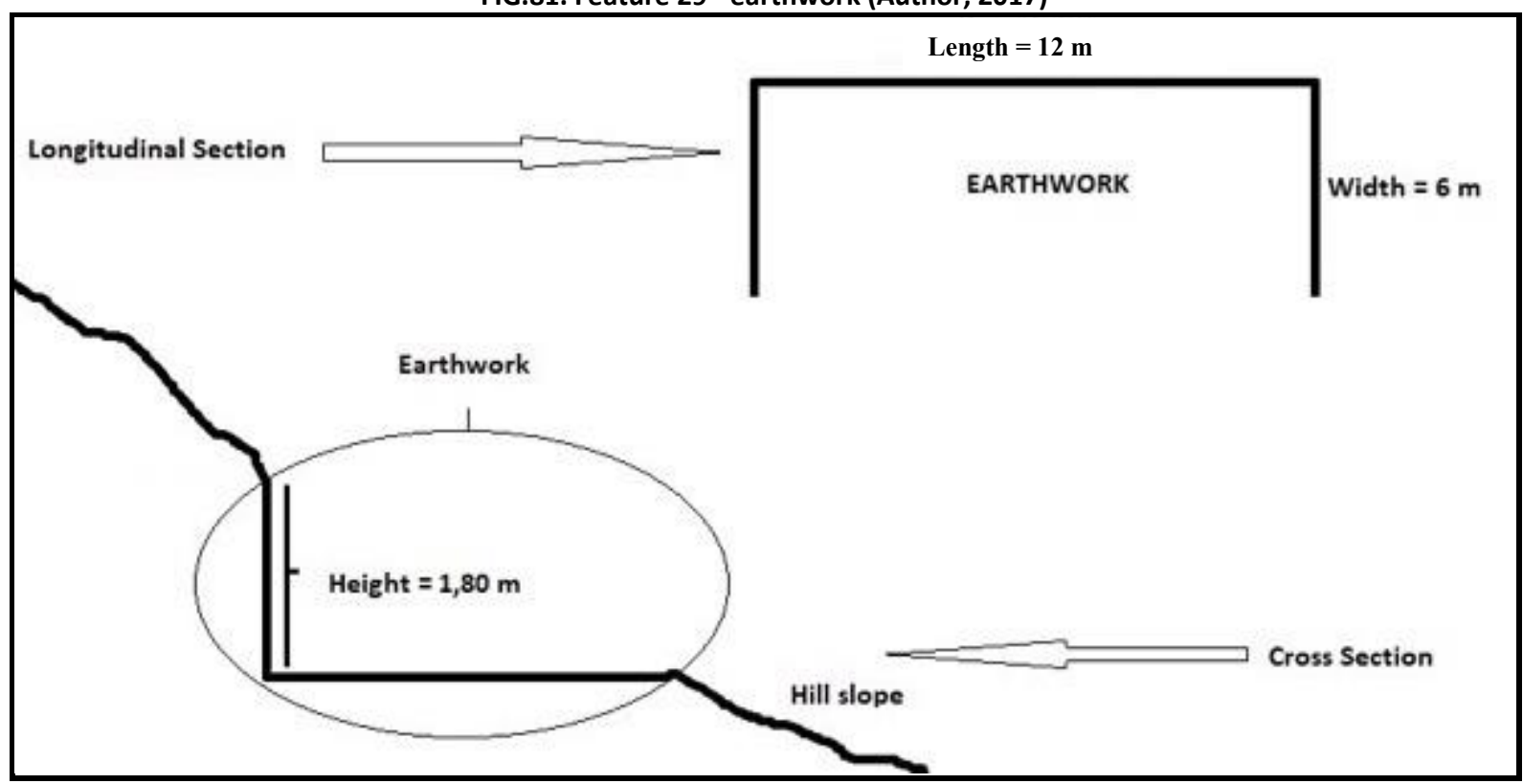


Feature 30 represents a 3 -sided earthwork, situated at $47,60817^{\circ} \mathrm{N}-24,84792^{\circ} \mathrm{E}$, at an altitude of $1430 \mathrm{~m}$ (FIG.82). The earthwork consists of an embankment excavated in the hill slope with a length of $14 \mathrm{~m}$, a width of $3 \mathrm{~m}$, a maximum depth of $1.10 \mathrm{~m}$ and is oriented to the SE. The right side is incomplete due to landslide, having a remnant width of approximately $1 \mathrm{~m}$.

FIG.82. Feature 30 - earthwork (Author, 2017)

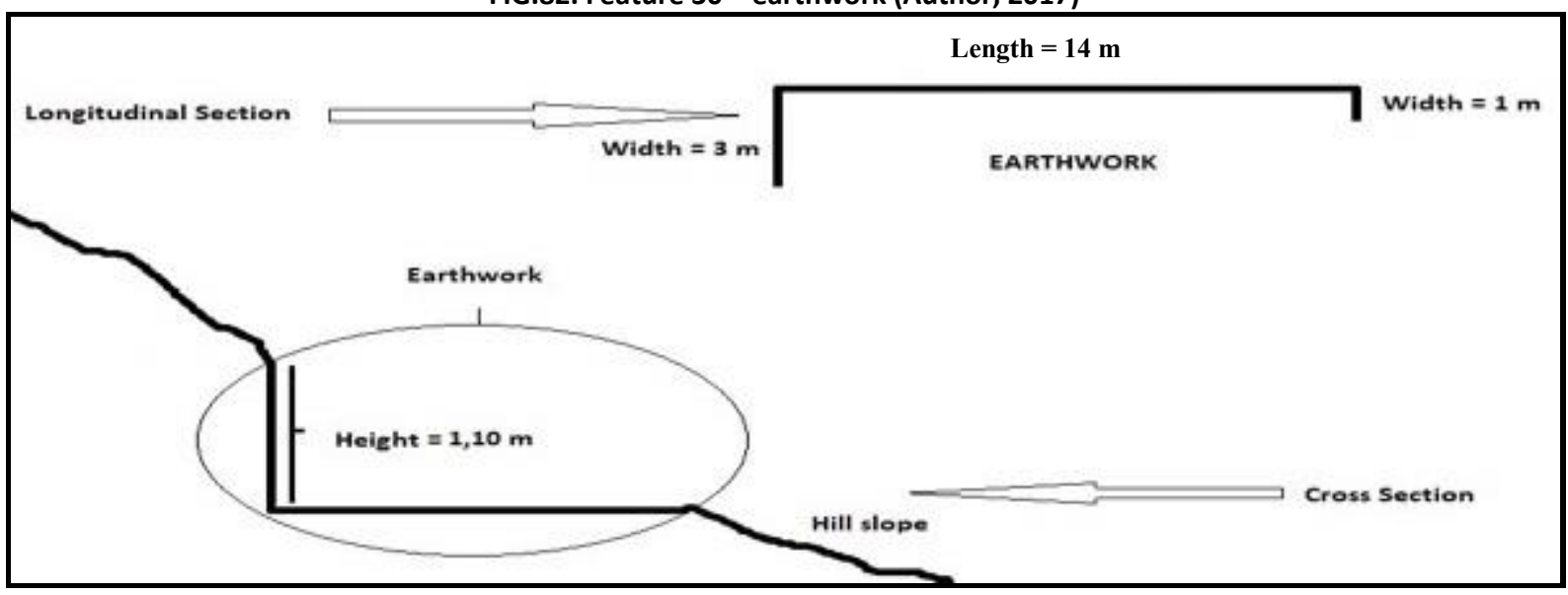

Feature 31 represents a 4 -sided earthwork, situated at $47.60836^{\circ} \mathrm{N}-24.84804^{\circ} \mathrm{E}$, at an altitude of 1432 m (FIG.83). The earthwork consists of an embankment excavated in the hill slope with a length of $4 \mathrm{~m}$, a width of $4 \mathrm{~m}$ and a maximum depth of $1.30 \mathrm{~m}$. The entrance is at the joint of the frontal and the right side. Shaped stones and traces of cement and gravel can be seen on the site of the earthwork which is oriented to the SE.

FIG.83. Feature 31 - earthwork (Author, 2017)

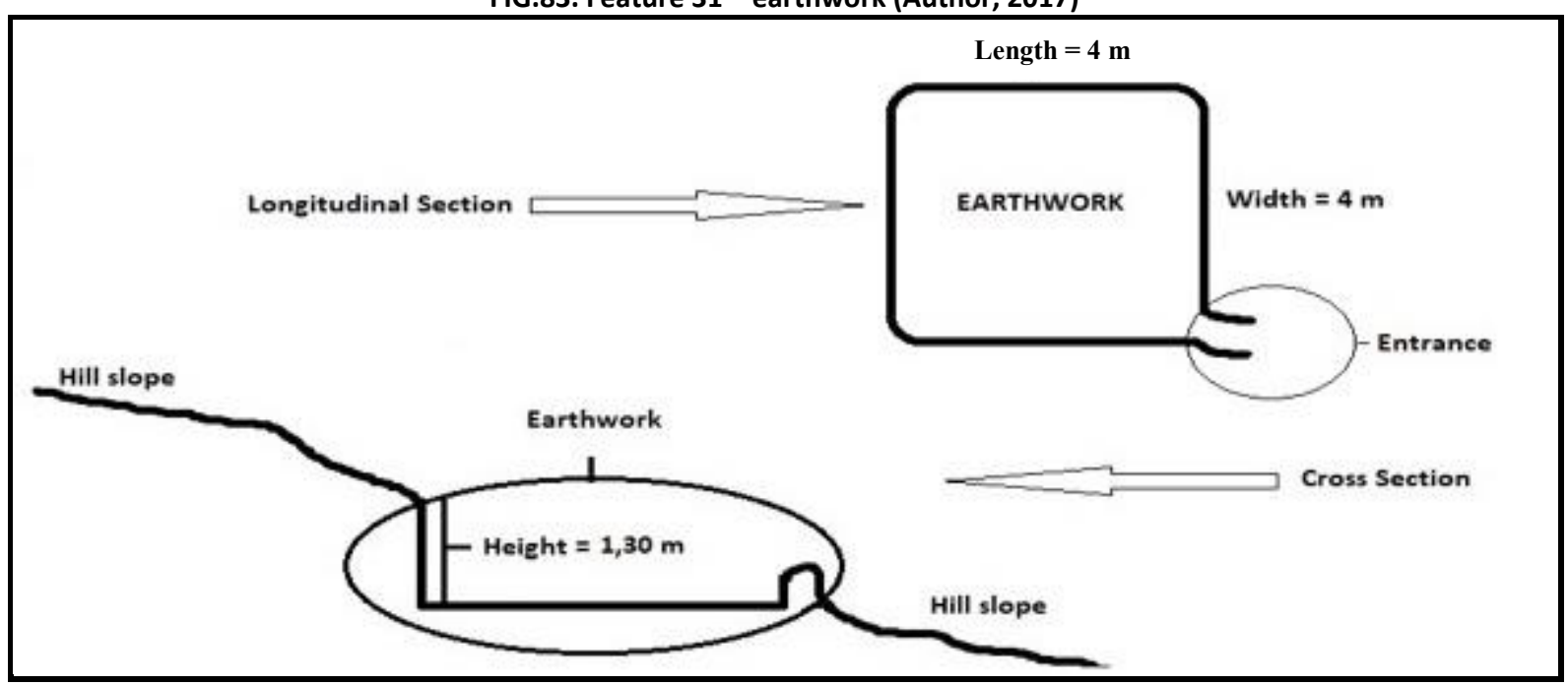


Feature 32 represents a 2 -sided earthwork, situated at $47.60776^{\circ} \mathrm{N}-24.84806^{\circ} \mathrm{E}$, at an altitude of $1419 \mathrm{~m}$ (FIG.84). The earthwork consists of two consolidated sides that form a $90^{\circ}$ angle with the hill slope, having a length of $5 \mathrm{~m}$, a width of $6 \mathrm{~m}$ and a maximum depth of $1.30 \mathrm{~m}$. Shaped stones can be seen on the site of the earthwork which is oriented to the SE.

FIG.84. Feature 32 - earthwork (Author, 2017)

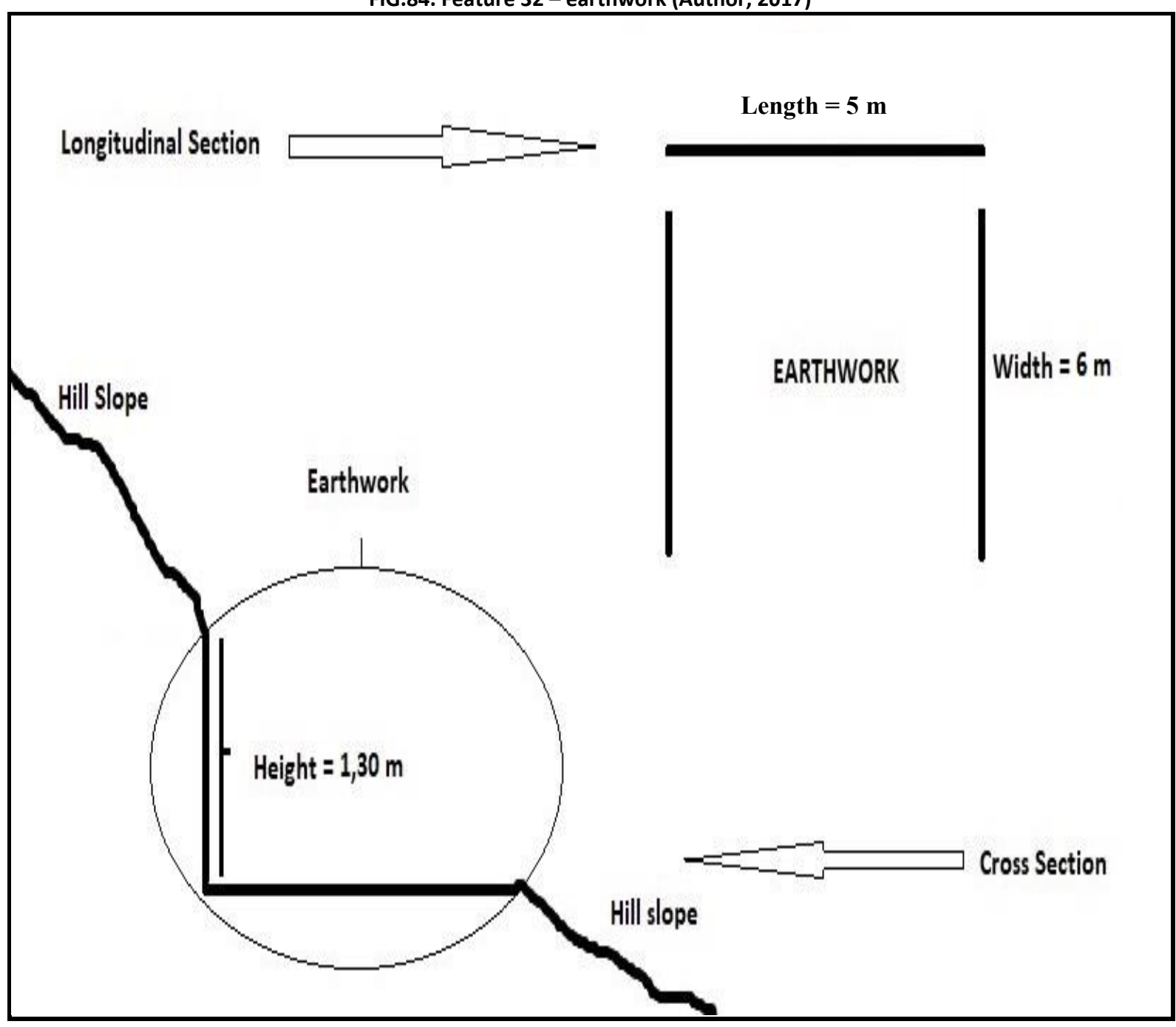

Feature 33 represents a 4 -sided earthwork, situated at $47.60779^{\circ} \mathrm{N}-24.84820^{\circ} \mathrm{E}$, at an altitude of $1422 \mathrm{~m}$ (FIG.85). The earthwork consists of an embankment excavated in the hill slope with a length of $5 \mathrm{~m}$, a width of $5 \mathrm{~m}$ and a maximum depth of $1.30 \mathrm{~m}$. The entrance is on the frontal side to the right. Shaped stones and traces of cement and gravel can be seen on the site of the earthwork which is oriented to the SE. 


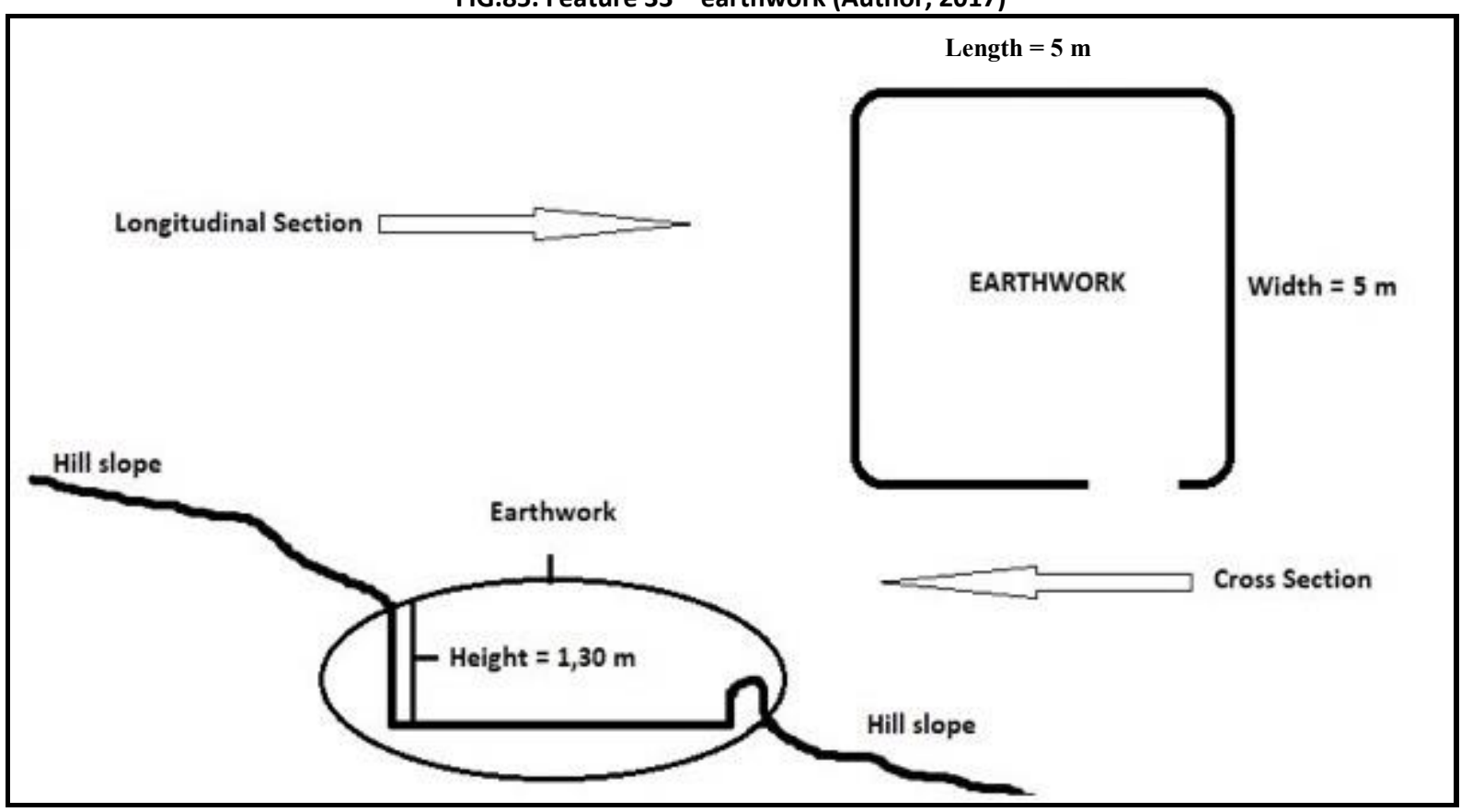

Feature 34 represents a 4 -sided earthwork, situated at $47.60815^{\circ} \mathrm{N}-24.84898^{\circ} \mathrm{E}$, at an altitude of $1418 \mathrm{~m}$ (FIG.86). The earthwork consists of an embankment excavated in the hill slope with a length of $3 \mathrm{~m}$, a width of $3 \mathrm{~m}$ and a maximum depth of $1.20 \mathrm{~m}$. The entrance is on the frontal side to the right. Shaped stones can be seen on the site of the earthwork which is oriented to the SE.

FIG.86. Feature 34 - earthwork (Author, 2017)

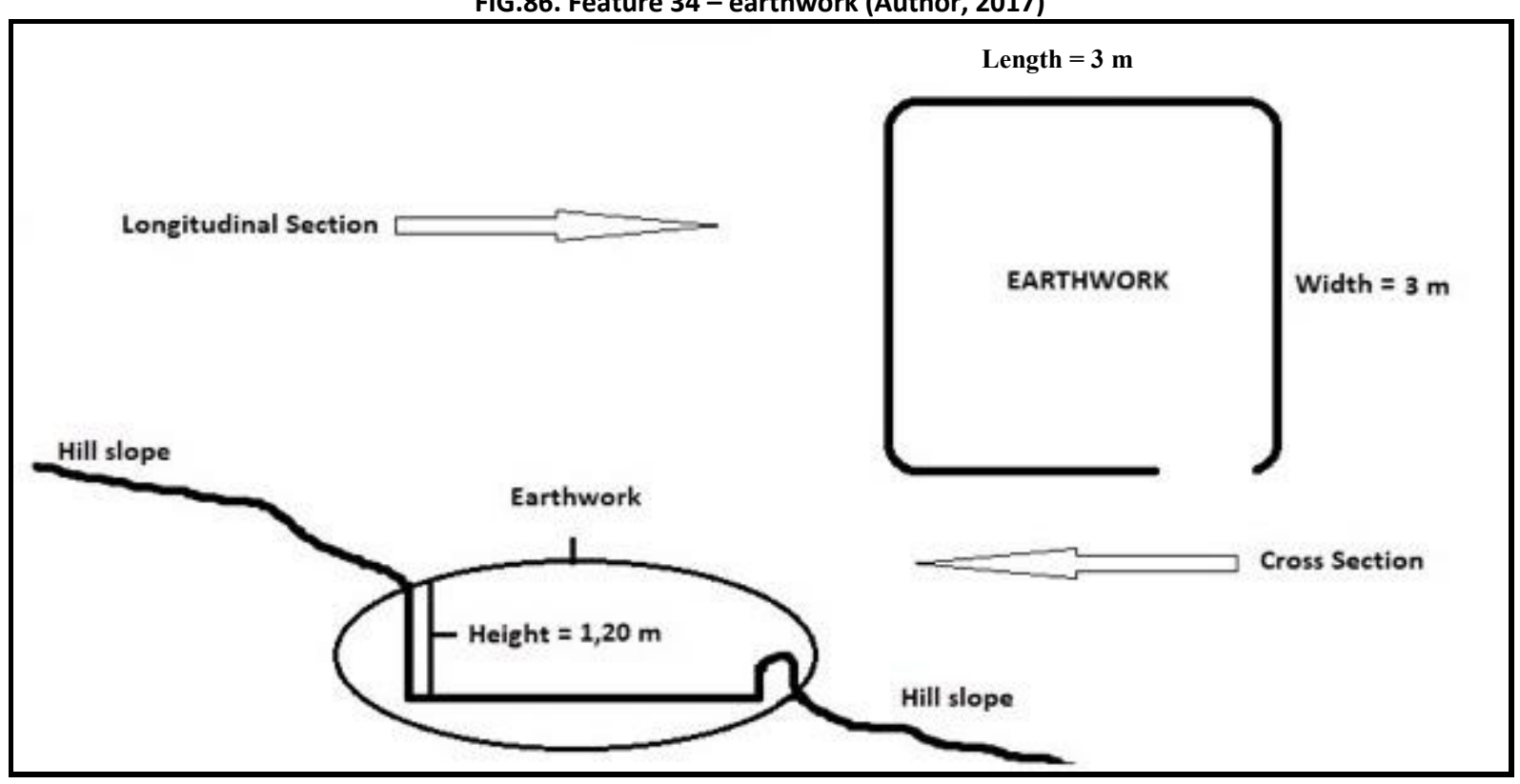


Feature 35 represents a 4 -sided earthwork, situated at $47.60818^{\circ} \mathrm{N}-24.84910^{\circ} \mathrm{E}$, at an altitude of $1422 \mathrm{~m}$ (FIG.87). The earthwork consists of an embankment excavated in the hill slope with a length of $4 \mathrm{~m}$, a width of $4 \mathrm{~m}$ and a maximum depth of $1.30 \mathrm{~m}$. The entrance is central on the frontal side. Shaped stones can be seen on the site of the earthwork which is oriented to the S-SE.

FIG.87. Feature 35 - earthwork (Author, 2017)

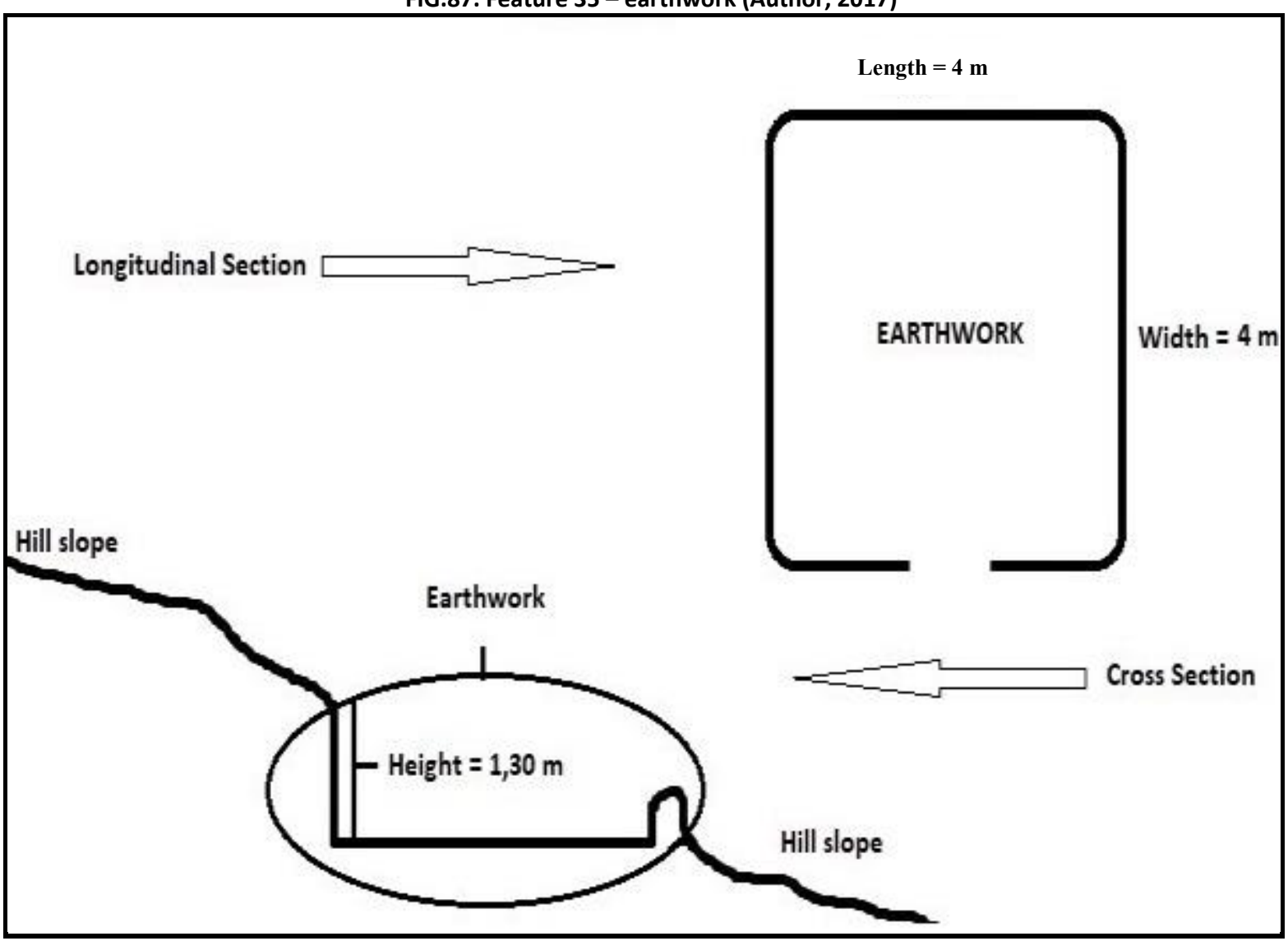

Feature 36 represents a 2-sided earthwork, situated at $47.60807^{\circ} \mathrm{N}-24.84925^{\circ} \mathrm{E}$, at an altitude of $1413 \mathrm{~m}$ (FIG.88). The earthwork consists of an embankment excavated in the hill slope with a length of $6 \mathrm{~m}$, a width of $5 \mathrm{~m}$ and a maximum depth of $1.20 \mathrm{~m}$. The long side follows the line of the hill to the North and the left side was reinforced to the West forming a $90^{\circ}$ angle with the hill. The earthwork is oriented to the S-SE. 


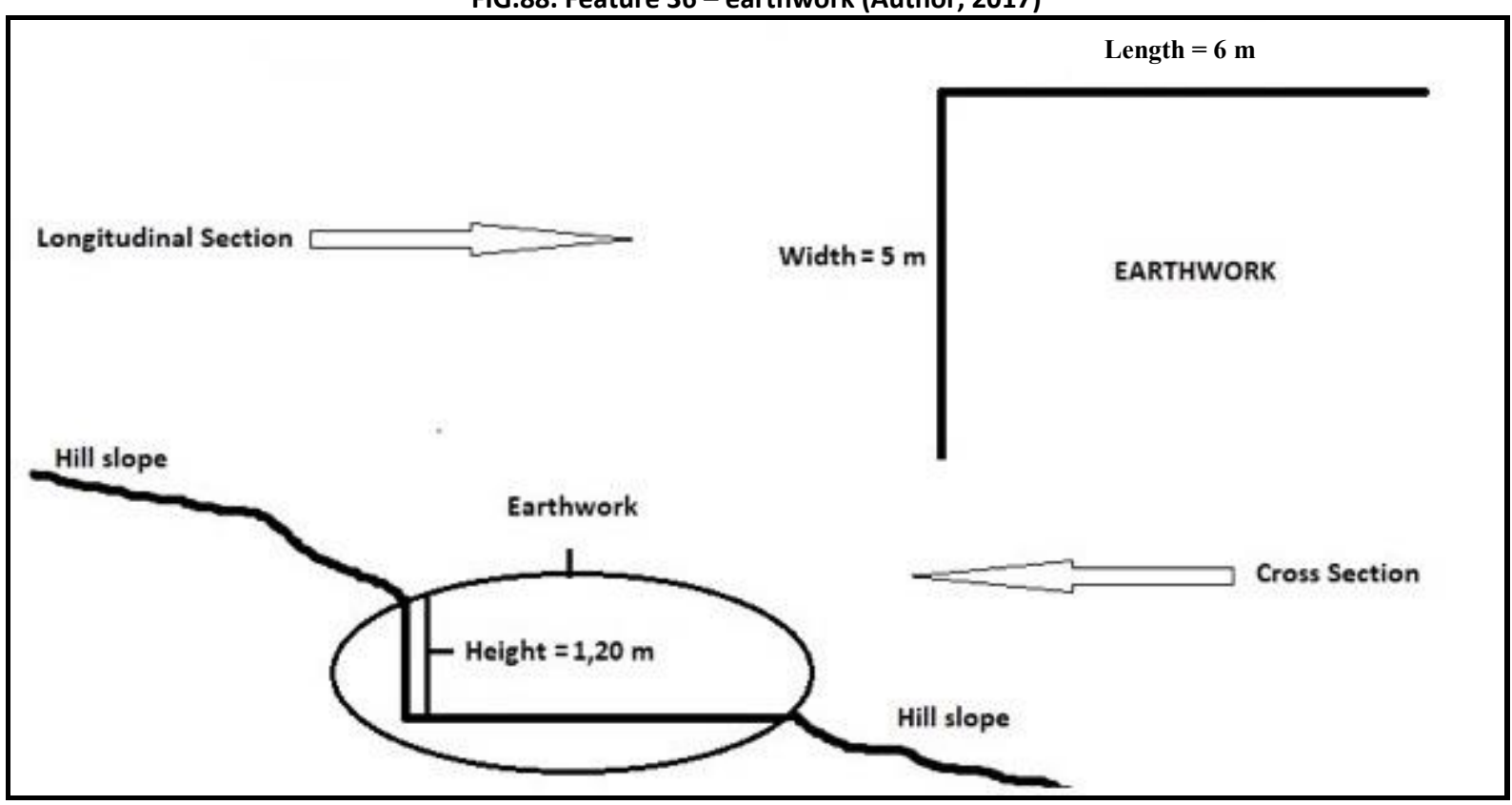

Feature 37 represents a 3 -sided earthwork, situated at $47.60818^{\circ} \mathrm{N}-24.84920^{\circ} \mathrm{E}$, at an altitude of 1419 m (FIG.89). The earthwork consists of an embankment excavated in the hill slope with a length of $4 \mathrm{~m}$, a width of $4 \mathrm{~m}$ and a maximum depth of $1.10 \mathrm{~m}$. Shaped stones can be seen on the site of the earthwork which is oriented to the S.

FIG.89. Feature 37 - earthwork (Author, 2017)

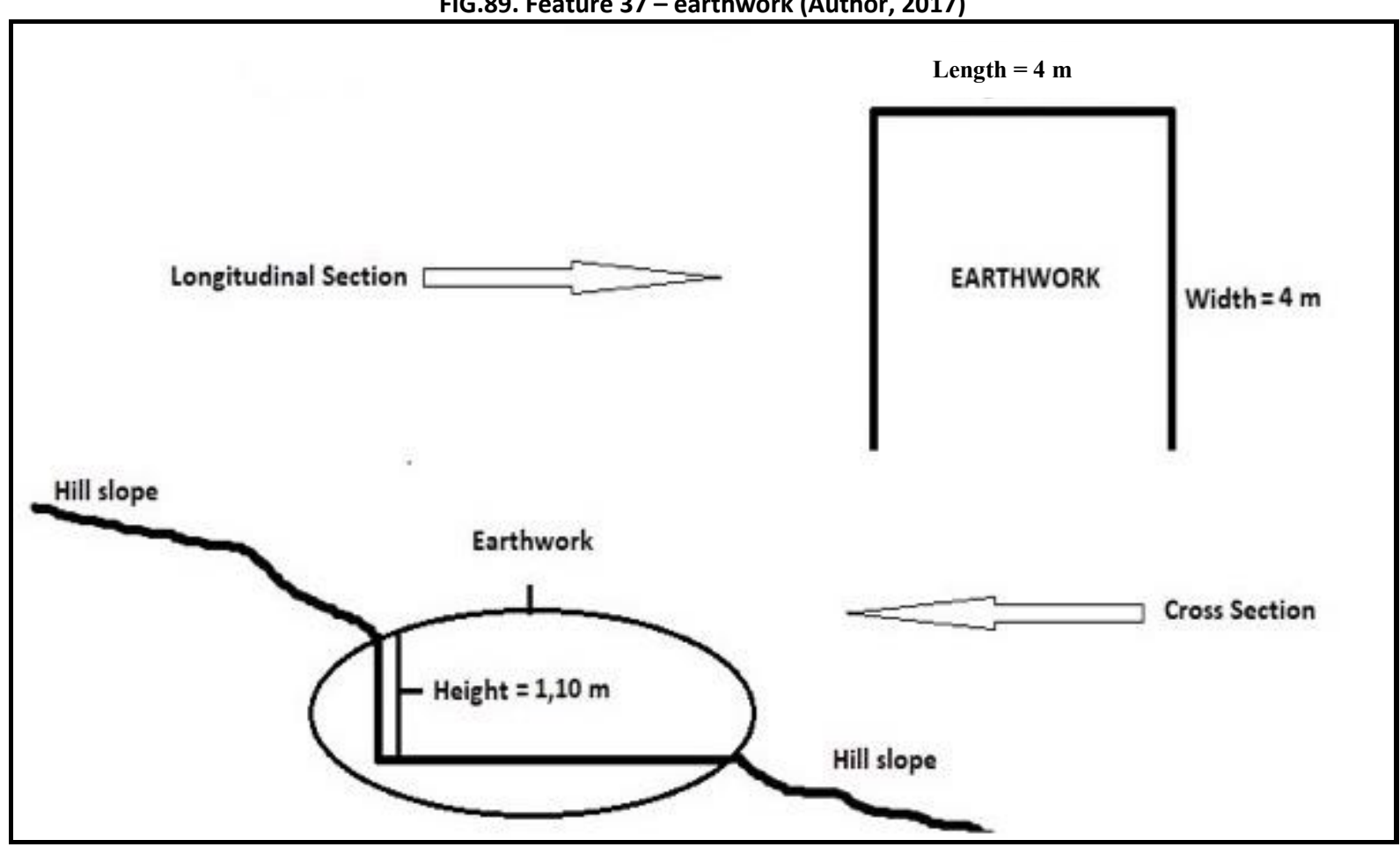


Feature 38 represents a bunker (FIG.90 A, B, C), situated at $47.60823^{\circ} \mathrm{N}-24.84940^{\circ} \mathrm{E}$, at an altitude of $1417 \mathrm{~m}$. The bunker, made of reinforced concrete, was severely damaged by an explosion. Nevertheless, the underground walls preserved their shape and position allowing the measurement of a length of $10.50 \mathrm{~m}$ and a width of $5.50 \mathrm{~m}$. The bunker, constructed near the lower side of a road has a maximum depth of $2.50 \mathrm{~m}$. There is a fragment of a trench system leading to the bunker and shaped stone with joints of cement and gravel can be seen on the site.
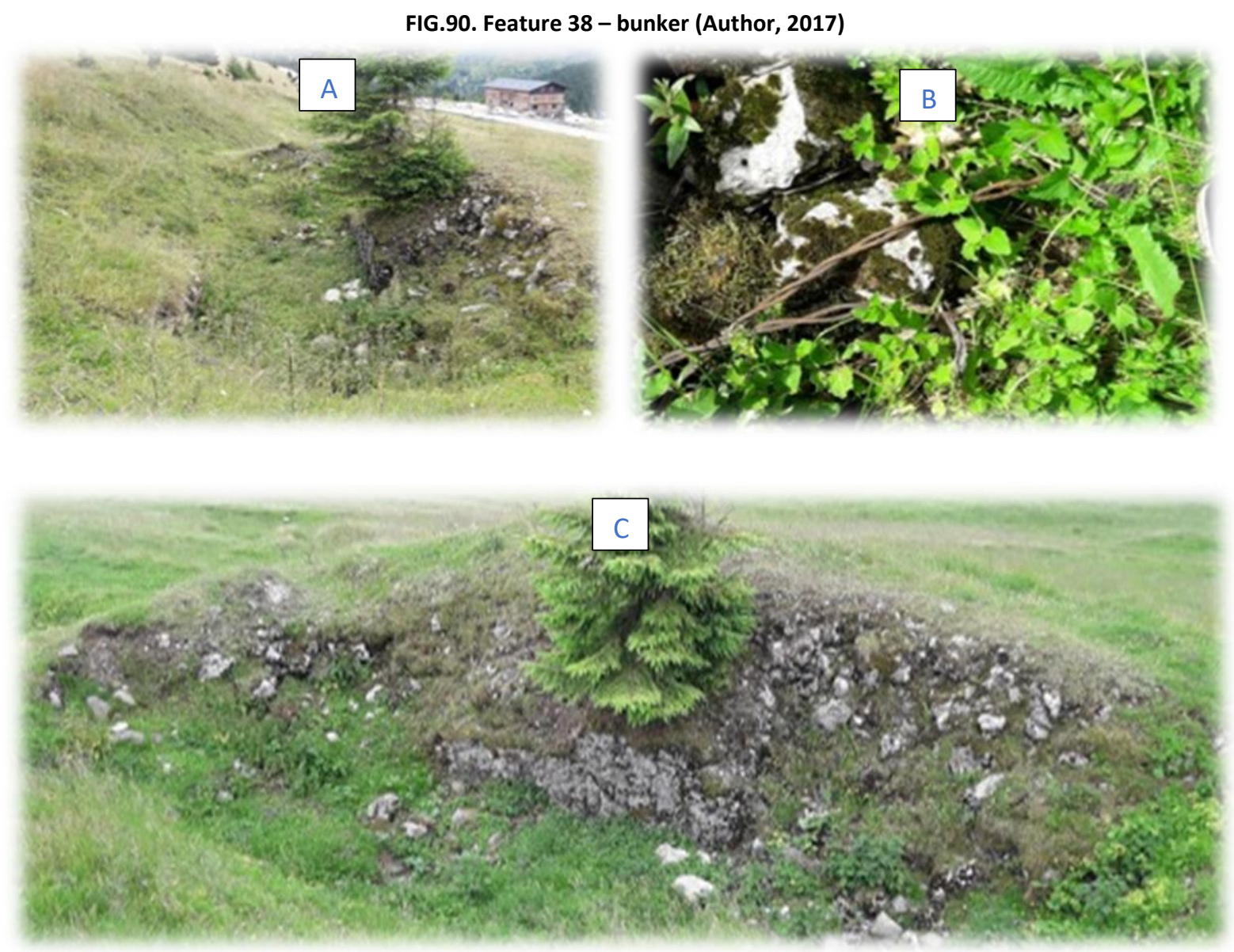

Feature 39 represents a 2 -sided earthwork, situated at $47.60822^{\circ} \mathrm{N}-24.84968^{\circ} \mathrm{E}$, at an altitude of $1418 \mathrm{~m}$ (FIG.91). The earthwork consists of two consolidated sides having a length of 7.5 $\mathrm{m}$, a width of $4 \mathrm{~m}$ and a maximum depth of $1.40 \mathrm{~m}$. The left side forms a $90^{\circ}$ angle with the hill slope to the North and a $90^{\circ}$ angle with the frontal side to the South. The frontal side is 
divided into two halves forming a central entrance prolonged towards the exterior. Shaped stones can be seen on the site of the earthwork which is oriented to the SE.

FIG.91. Feature 39 - earthwork (Author, 2017)

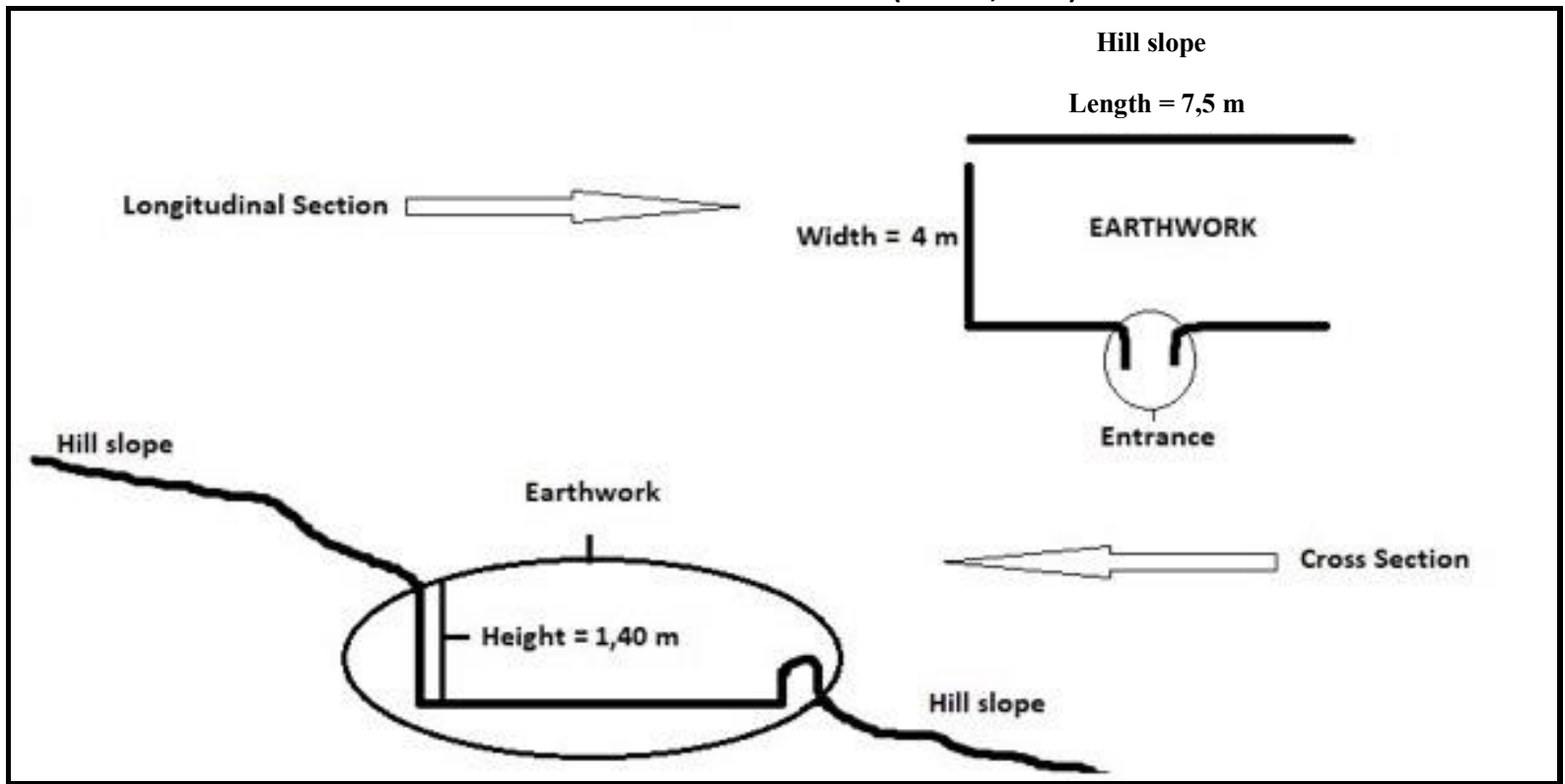

Feature 40 represents a 3 -sided earthwork, situated at $47.60839^{\circ} \mathrm{N}-24.84970^{\circ} \mathrm{E}$, at an altitude of 1420 m (FIG.92). The earthwork consists of an embankment excavated in the hill slope with a length of $4.50 \mathrm{~m}$, a width of $3 \mathrm{~m}$ and a maximum depth of $1.20 \mathrm{~m}$. Shaped stones can be seen on the site of the earthwork which is oriented to the E-SE.

FIG.92. Feature 40 - earthwork (Author, 2017)

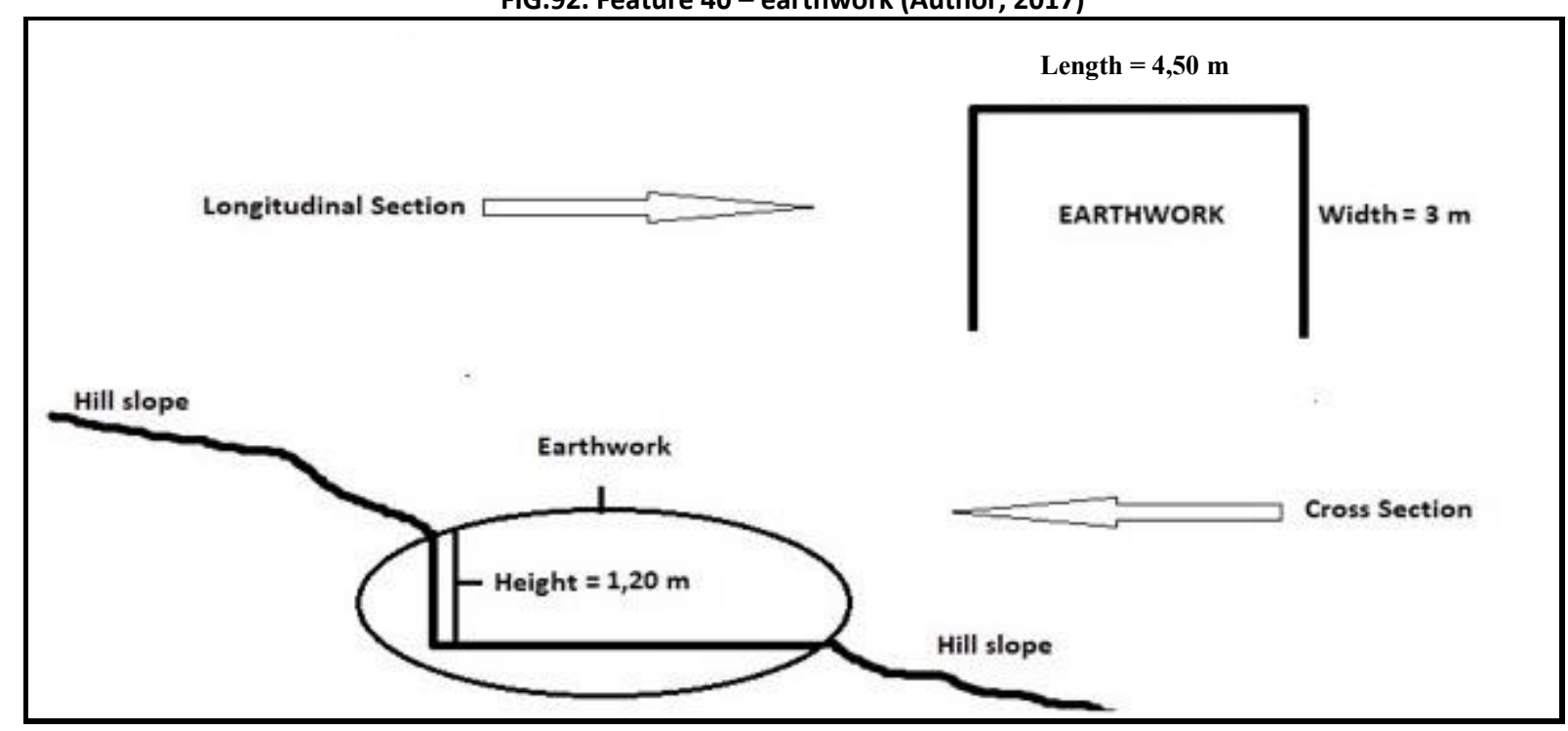


Feature 41 represents a large crater, situated at $47.60843^{\circ} \mathrm{N}-24.84961^{\circ} \mathrm{E}$, at an altitude of 1420 m (FIG.93 A, B). The crater has a crescent shape (FIG.91 C), with a maximum length of $14 \mathrm{~m}$ and maximum width of $13 \mathrm{~m}$. The crater is oriented to the $\mathrm{S}$.

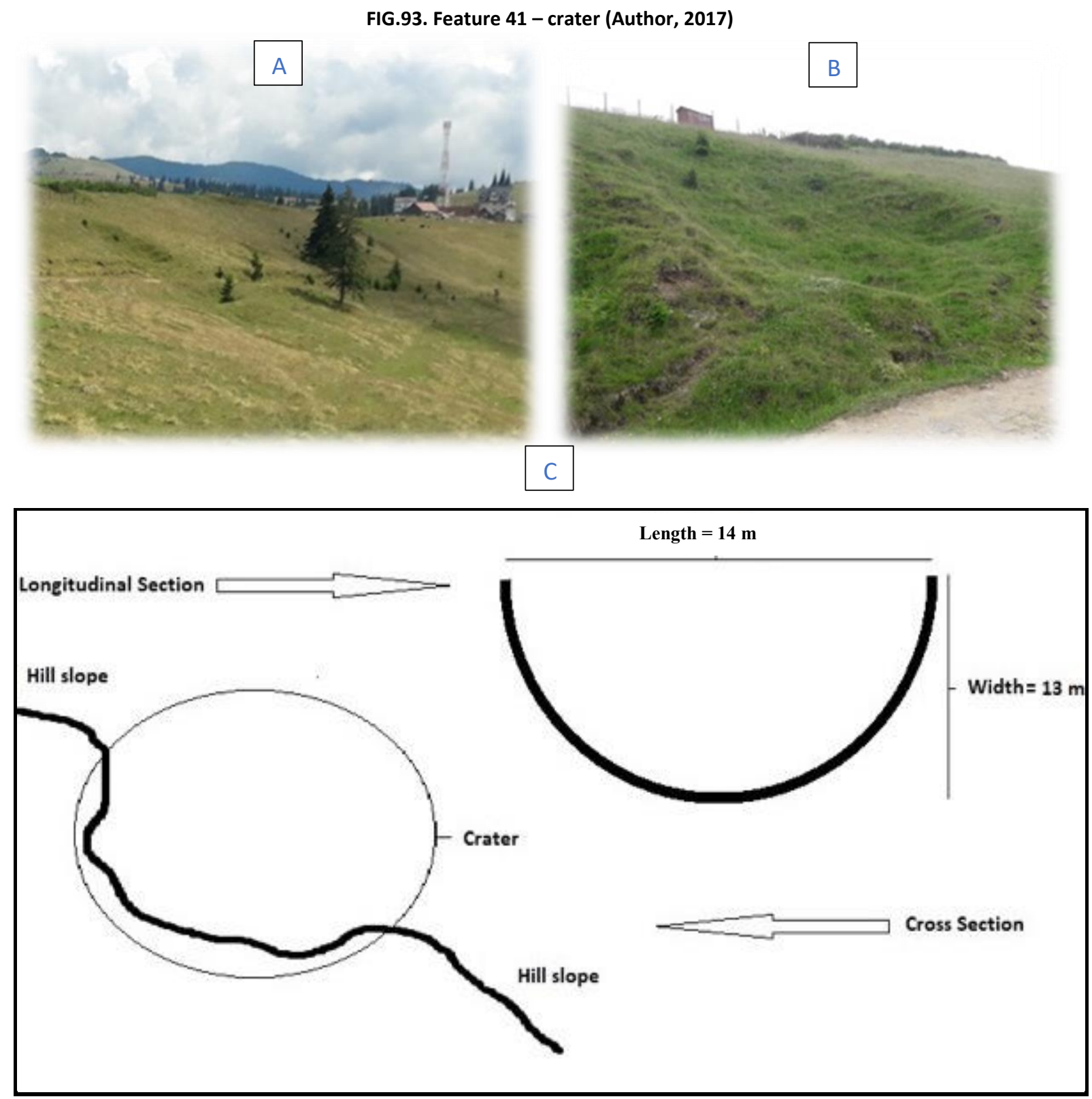

Feature 42 represents a 3 -sided earthwork, situated at $47.60839^{\circ} \mathrm{N}-24.84993^{\circ} \mathrm{E}$, at an altitude of 1419 m (FIG.94). The earthwork consists of an embankment excavated in the hill slope with a length of $3.50 \mathrm{~m}$, a width of $5 \mathrm{~m}$ and a maximum depth of $1.30 \mathrm{~m}$. Shaped stones can be seen on the site of the earthwork which is oriented to the S. 


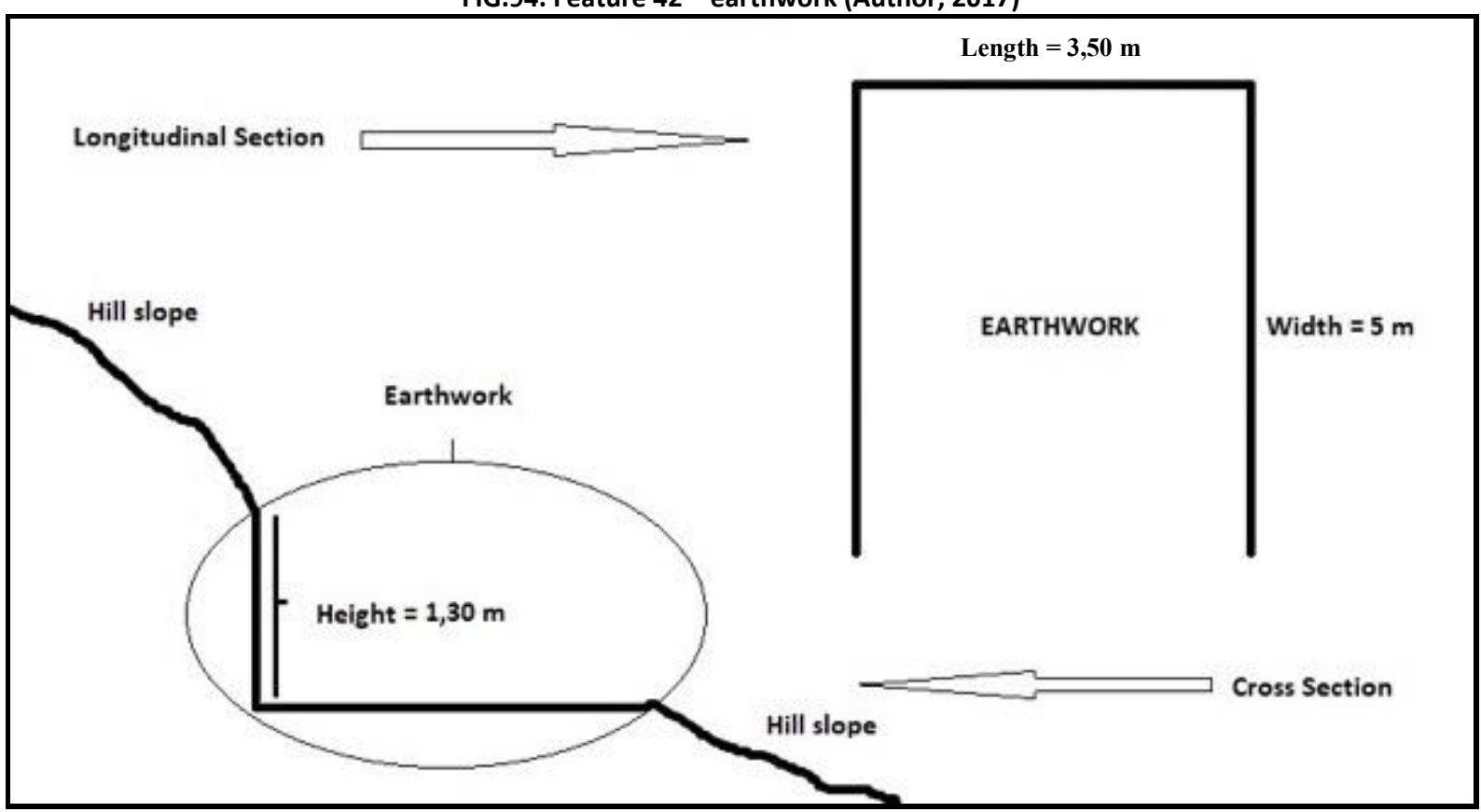

Feature 43 represents a 3 -sided earthwork, situated at $47.60841^{\circ} \mathrm{N}-24.85001^{\circ} \mathrm{E}$, at an altitude of 1419 m (FIG.95). The earthwork consists of an embankment excavated in the hill slope with a length of $3.50 \mathrm{~m}$, a width of $5 \mathrm{~m}$ and a maximum depth of $1.30 \mathrm{~m}$. Shaped stones can be seen on the site of the earthwork which is oriented to the S. This earthwork is part of a system along with feature 42 , feature 44 and feature 45 .

FIG.95. Feature 43 - earthwork (Author, 2017)

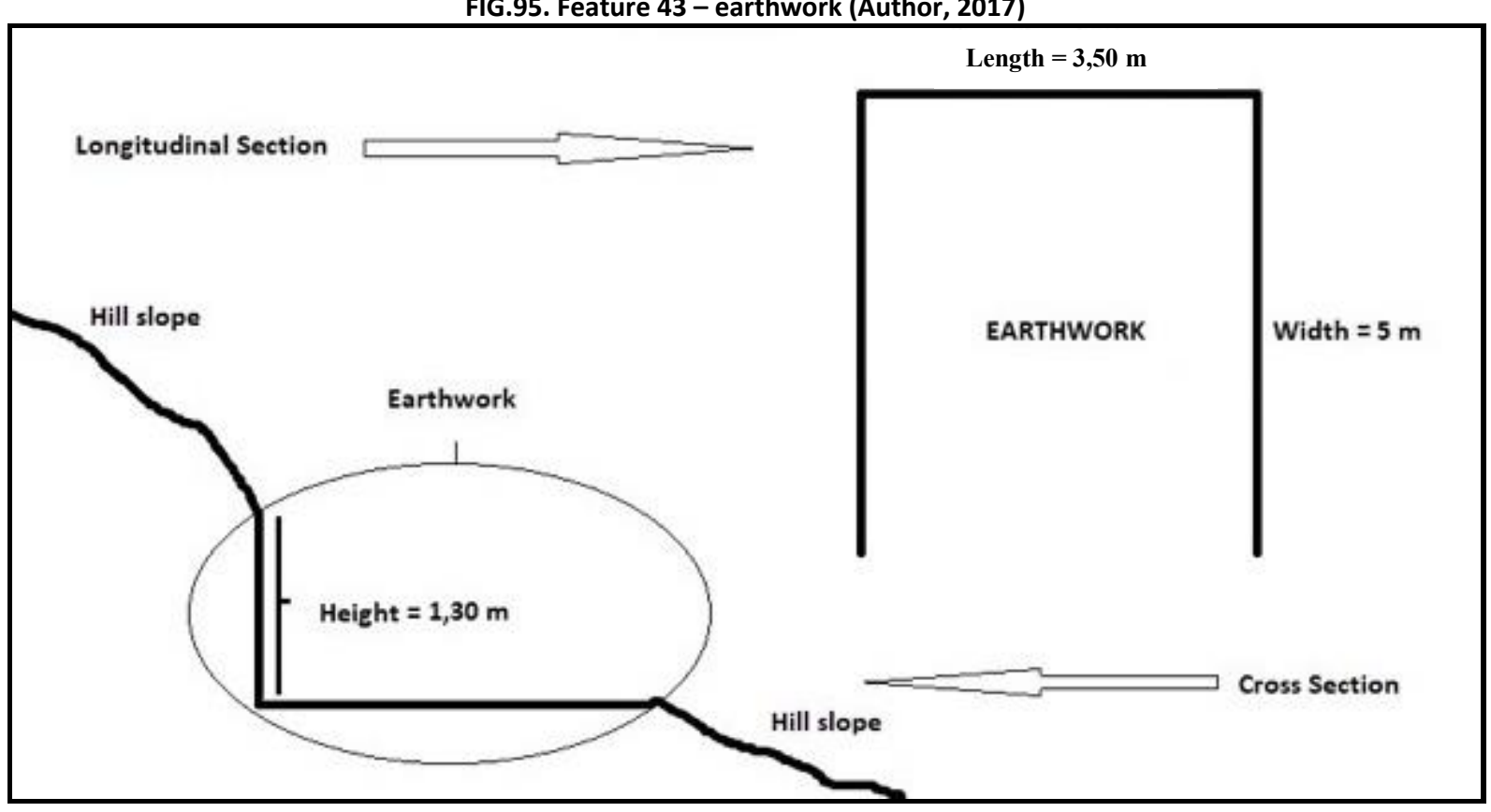


Feature 44 represents a 3 -sided earthwork, situated at $47.60843^{\circ} \mathrm{N}-24.85008^{\circ} \mathrm{E}$, at an altitude of 1419 m (FIG.96). The earthwork consists of an embankment excavated in the hill slope with a length of $3.50 \mathrm{~m}$, a width of $5 \mathrm{~m}$ and a maximum depth of $1.30 \mathrm{~m}$. Shaped stones can be seen on the site of the earthwork which is oriented to the S-SE.

FIG.96. Feature 44 - earthwork (Author, 2017)

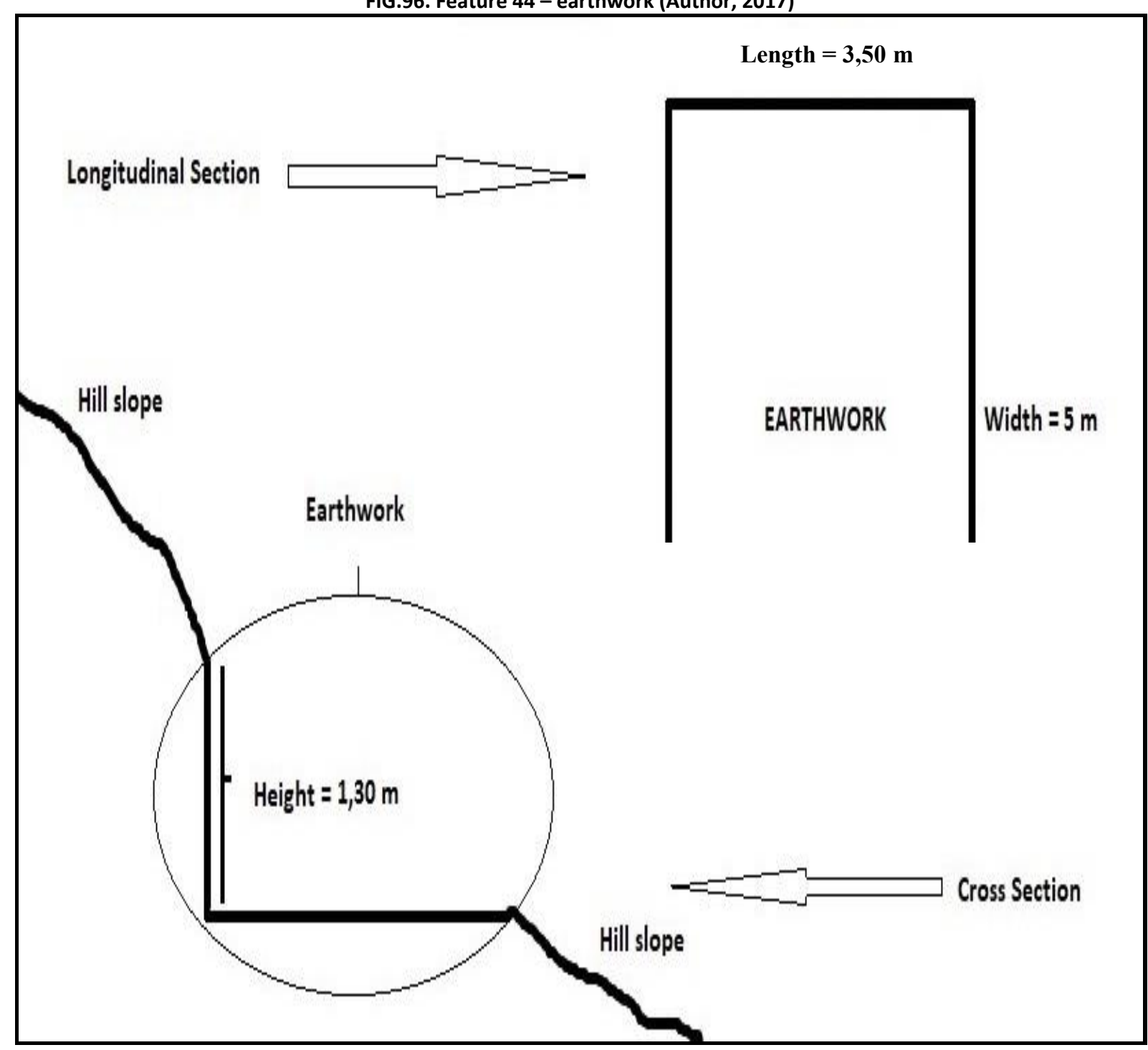

Feature 45 represents a 3 -sided earthwork, situated at $47.60845^{\circ} \mathrm{N}-24.85015^{\circ} \mathrm{E}$, at an altitude of 1422 m (FIG.97). The earthwork consists of an embankment excavated in the hill slope with a length of $3.50 \mathrm{~m}$, a width of $5 \mathrm{~m}$ and a maximum depth of $1.30 \mathrm{~m}$. Shaped stones can be seen on the site of the earthwork which is oriented to the S-SE. 


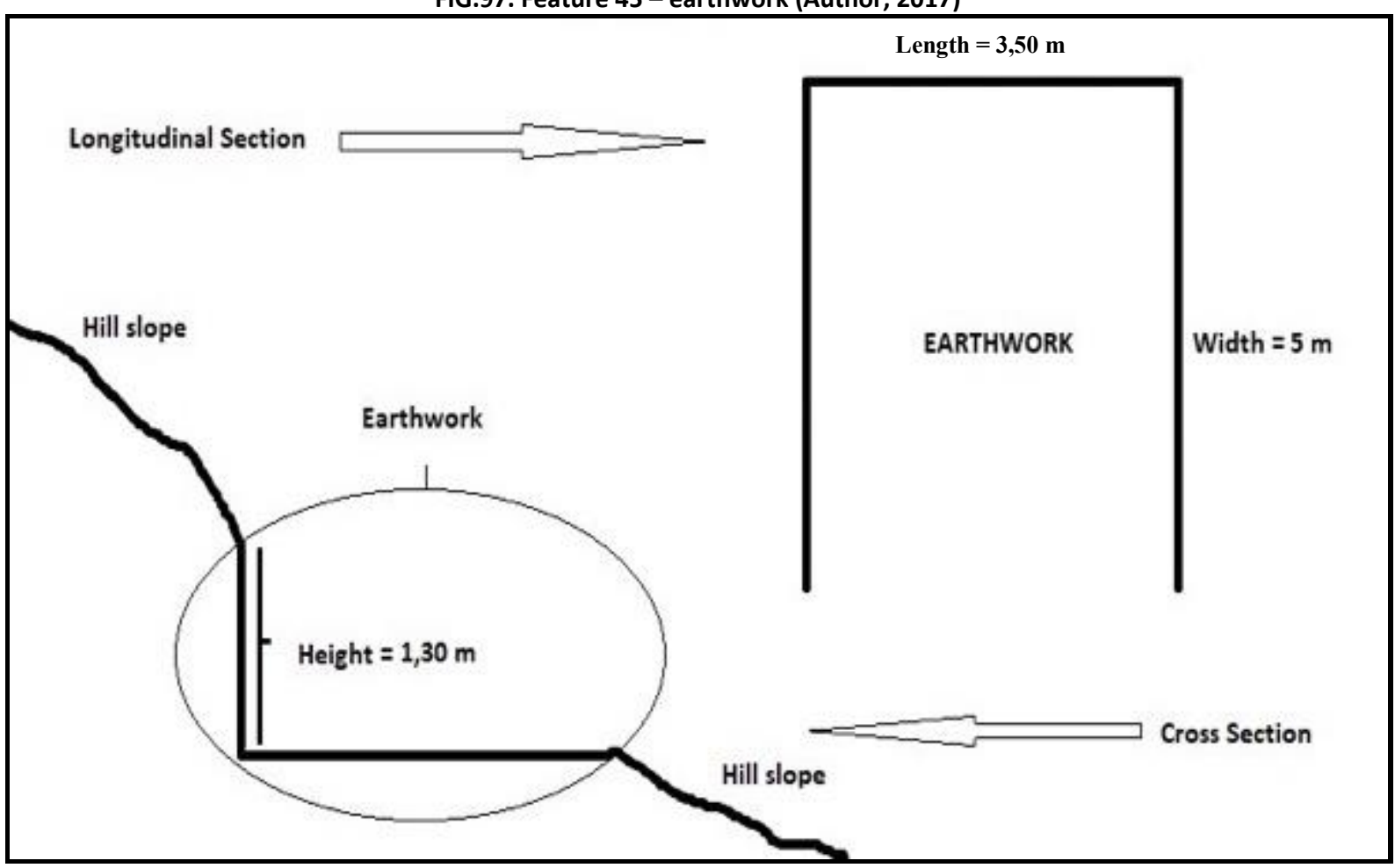

Feature 46 represents a 3 -sided earthwork, situated at $47.60837^{\circ} \mathrm{N}-24.85026^{\circ} \mathrm{E}$, at an altitude of 1420 m (FIG.98). The earthwork consists of an embankment excavated in the hill slope with a length of $4 \mathrm{~m}$, a width of $4 \mathrm{~m}$ and a maximum depth of $1.30 \mathrm{~m}$. Shaped stones can be seen on the site of the earthwork which is oriented to the S-SE.

FIG.98. Feature 46 - earthwork (Author, 2017)

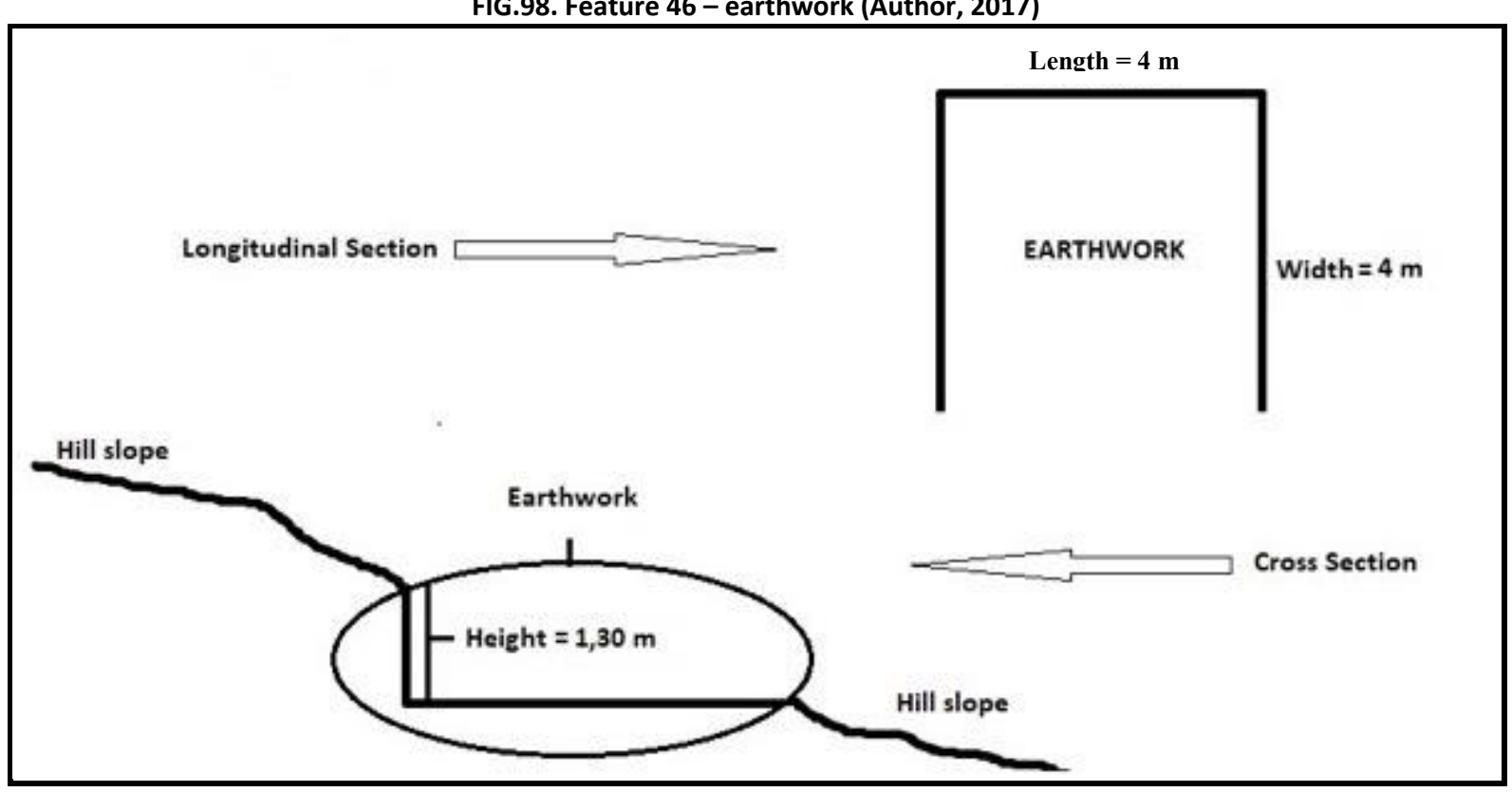


Feature 47 represents a 3 -sided earthwork, situated at $47.60842^{\circ} \mathrm{N}-24.85038^{\circ} \mathrm{E}$, at an altitude of 1420 m (FIG.99). The earthwork consists of an embankment excavated in the hill slope with a length of $4 \mathrm{~m}$, a width of $4 \mathrm{~m}$ and a maximum depth of $1.30 \mathrm{~m}$. Shaped stones can be seen on the site of the earthwork which is oriented to the S-SE.

FIG.99. Feature 47 -earthwork (Author, 2017)

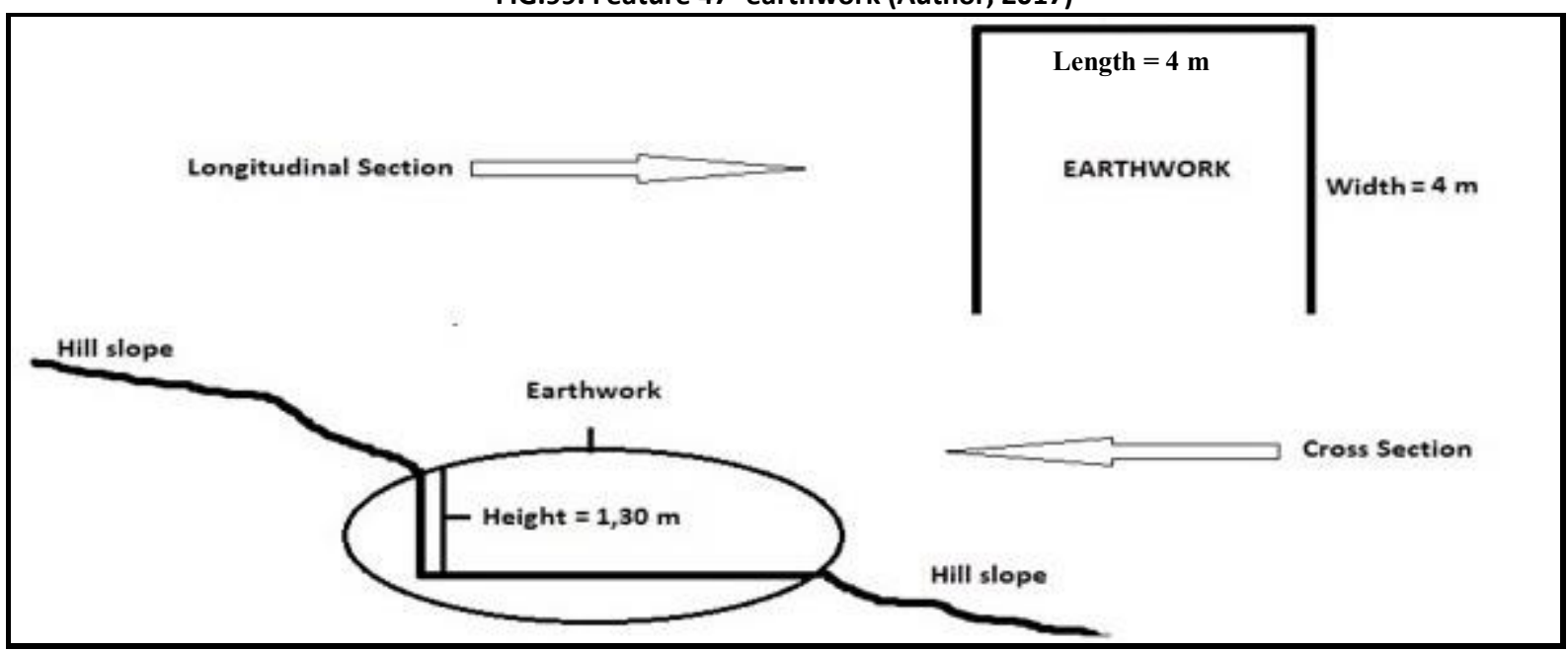

Feature 48 represents a 3 -sided earthwork, situated at $47.60835^{\circ} \mathrm{N}-24.85060^{\circ} \mathrm{E}$, at an altitude of $1425 \mathrm{~m}$ (FIG.100). The earthwork consists of an embankment excavated in the hill slope with a length of $11 \mathrm{~m}$, a width of $5 \mathrm{~m}$ and a maximum depth of $1.60 \mathrm{~m}$. Shaped stones can be seen on the site of the earthwork which is oriented to the S-SE.

FIG.100. Feature 48 - earthwork (Author, 2017)

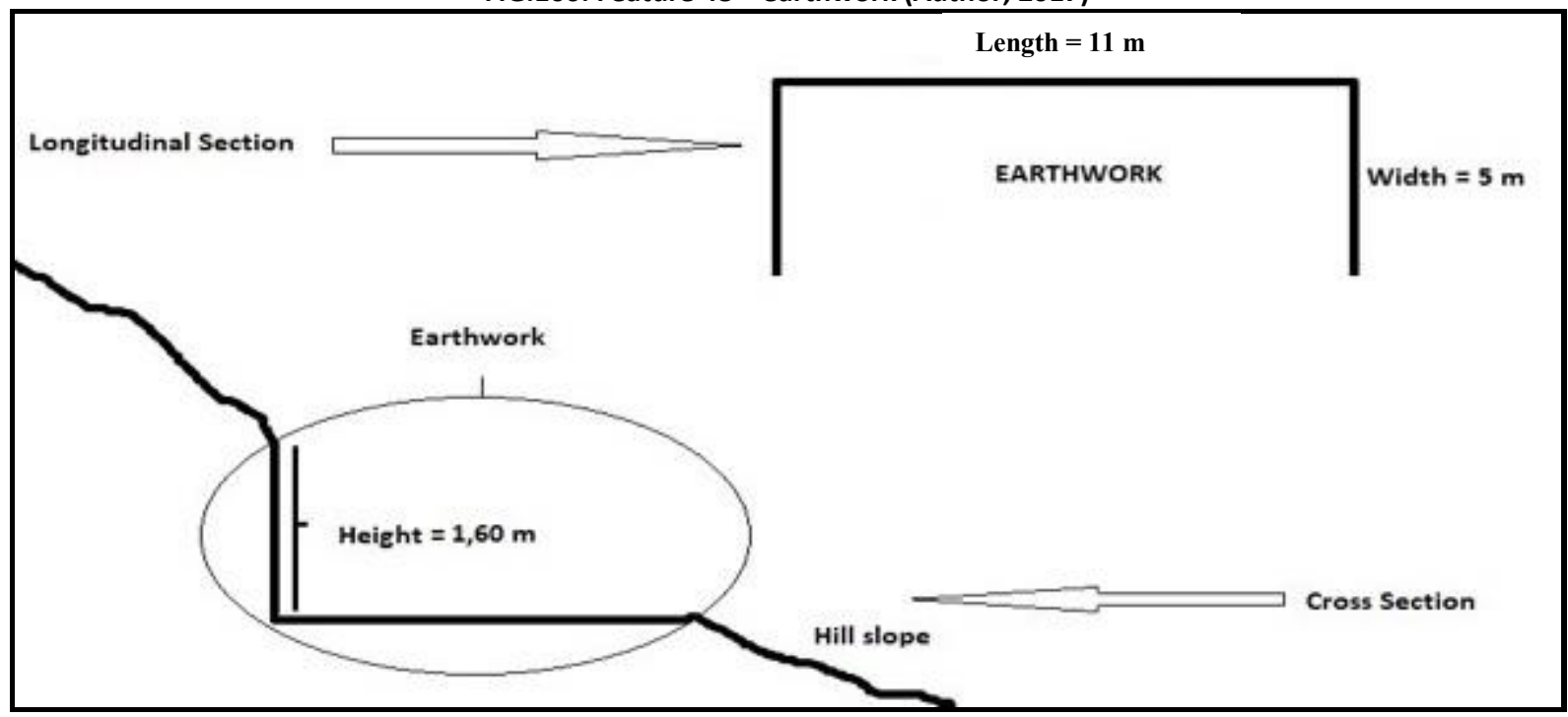


Feature 49 represents a 3 -sided earthwork, situated at $47.60842^{\circ} \mathrm{N}-24.85081^{\circ} \mathrm{E}$, at an altitude of 1422 m (FIG. 101). The earthwork consists of an embankment excavated in the hill slope with a length of $18.50 \mathrm{~m}$, a width of $4.50 \mathrm{~m}$ and a maximum depth of $1.60 \mathrm{~m}$. Shaped stones can be seen on the site of the earthwork which seems to have S orientation.

FIG.101. Feature 49 - earthwork (Author, 2017)

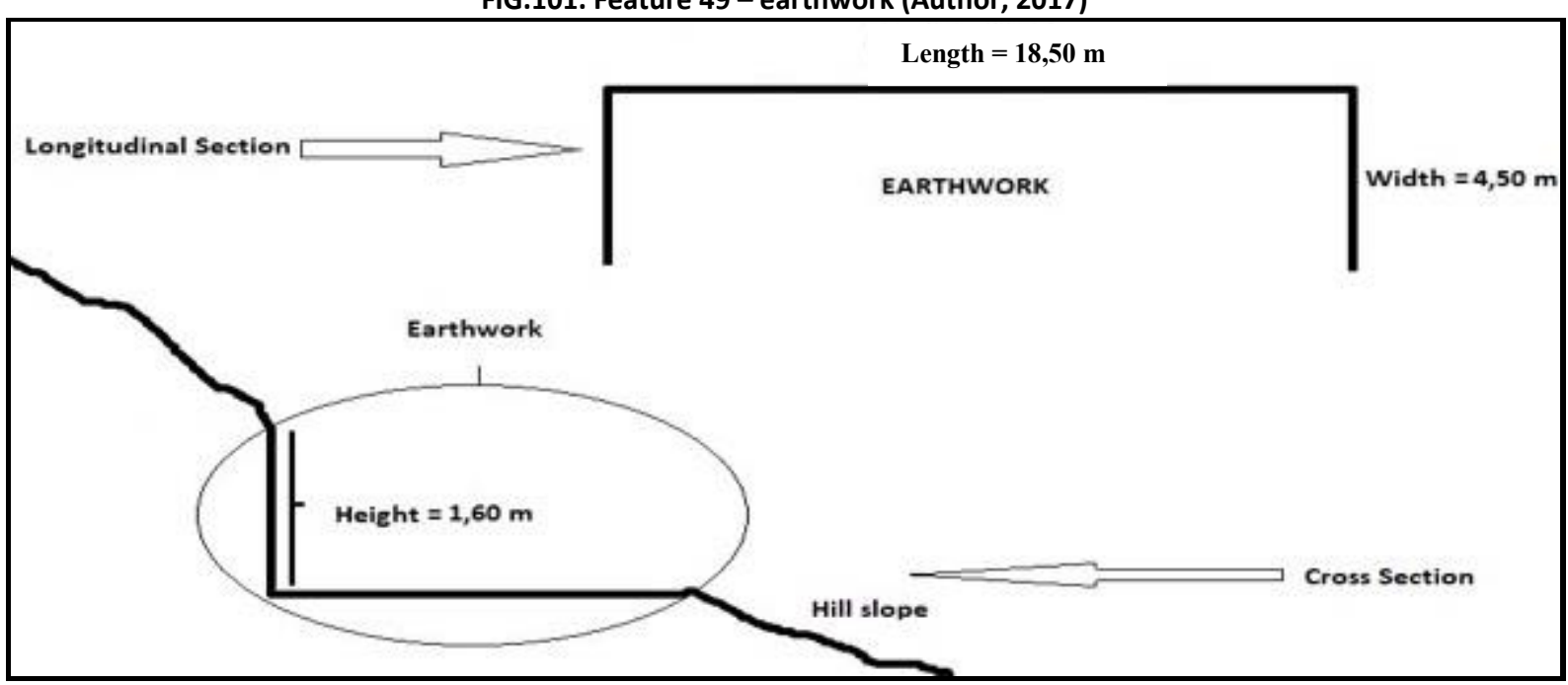

Feature 50 represents a 4 -sided earthwork, situated at $47.60846^{\circ} \mathrm{N}-24.85079^{\circ} \mathrm{E}$, at an altitude of 1422 m (FIG.102). The earthwork consists of an embankment excavated in the hill slope with a length of $8 \mathrm{~m}$, a width of $4 \mathrm{~m}$ and a maximum depth of $1.50 \mathrm{~m}$. The entrance is on the frontal side to the right. Shaped stones can be seen on the site of the earthwork which is oriented to the S-SW.

FIG.102. Feature 50 - earthwork (Author, 2017)

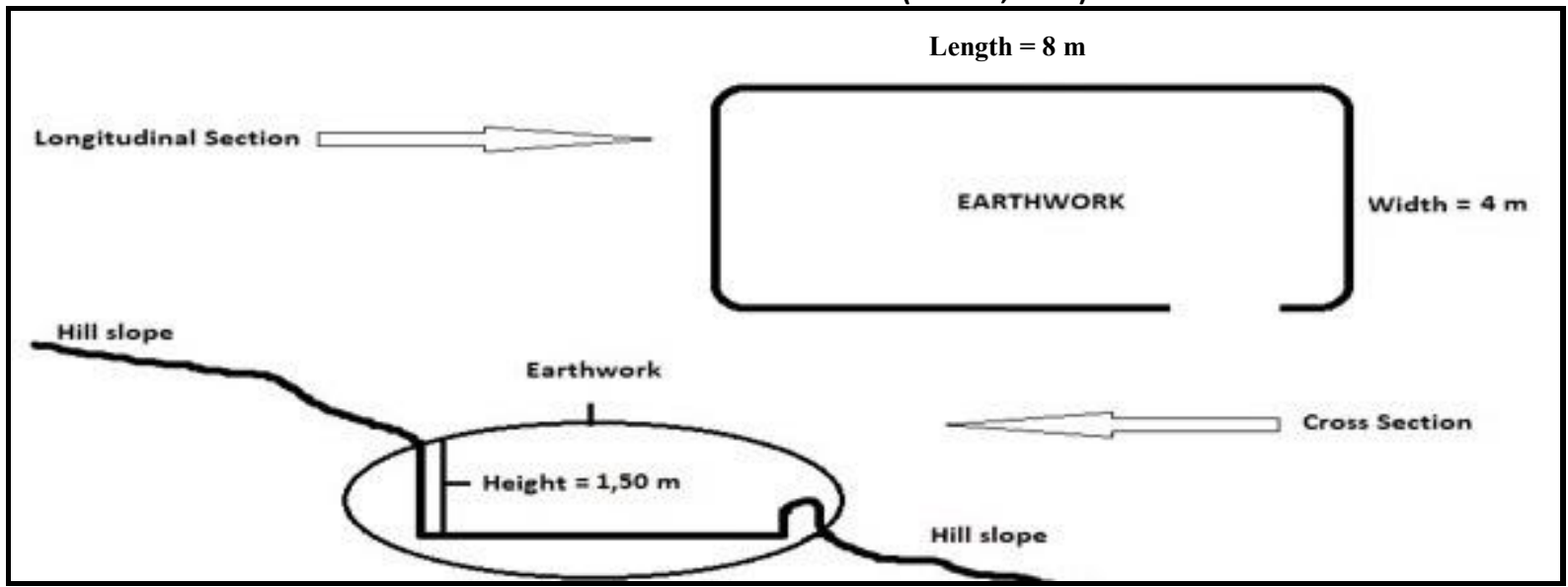


Feature 51 represents a section of a trench system, whose highest point is situated at $47.60851^{\circ} \mathrm{N}-24.85096^{\circ} \mathrm{E}$, at an altitude of $1423 \mathrm{~m}(\mathrm{FIG} .103 \mathrm{~A}, \mathrm{~B})$. The trench section is 4.50 $\mathrm{m}$ long, $2 \mathrm{~m}$ wide and is approximately $1.10 \mathrm{~m}$ deep. Shaped stones can be seen on the site of the trench section which presents a recess on the upper side.

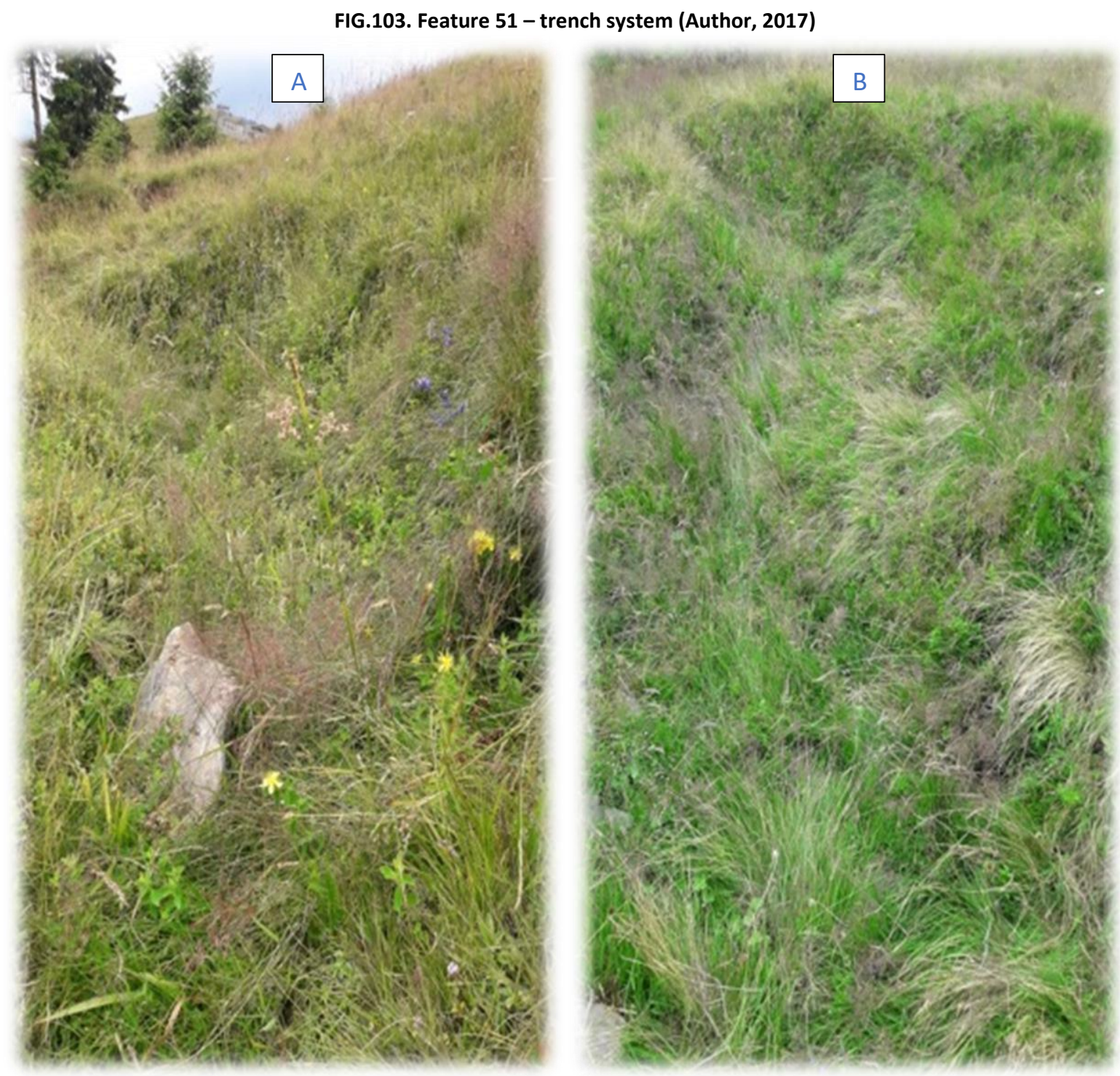

Feature 52 represents a 3 -sided earthwork, situated at $47.60839^{\circ} \mathrm{N}-24.85111^{\circ} \mathrm{E}$, at an altitude of $1420 \mathrm{~m}$ (FIG.104). The earthwork consists of an embankment excavated in the hill slope with a length of $3 \mathrm{~m}$, a width of $6 \mathrm{~m}$ and a maximum depth of $1.80 \mathrm{~m}$. Shaped stones can be seen on the site of the earthwork which is oriented to the SW. 


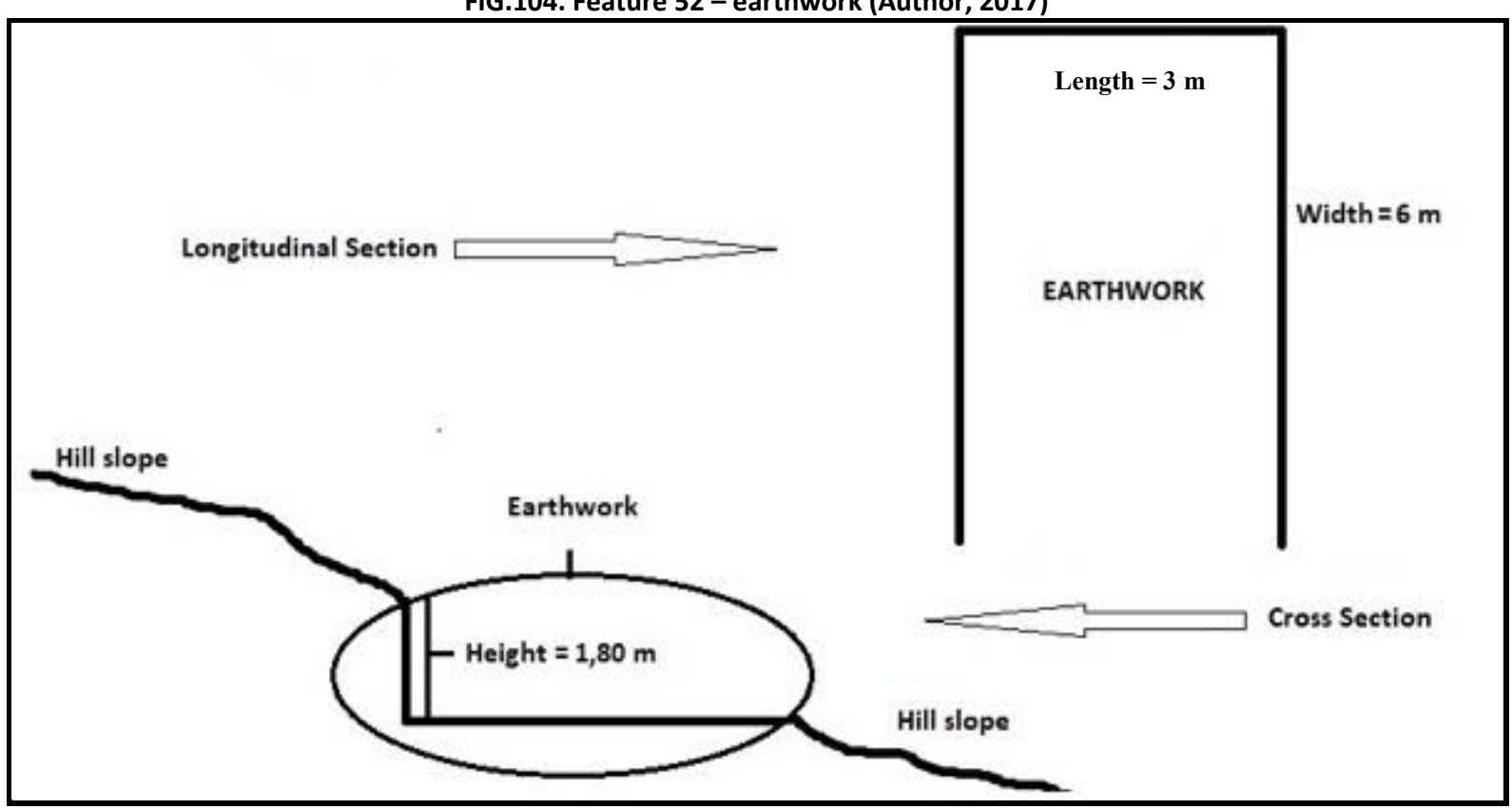

Feature 53 represents a large crater, situated at $47.60858^{\circ} \mathrm{N}-24.85140^{\circ} \mathrm{E}$, at an altitude of $1421 \mathrm{~m}$ (FIG.105 A, B). The crater has an uneven egg shape and is bumped towards the left (FIG.105 C). It has a maximum length of $13 \mathrm{~m}$ and maximum width of $11 \mathrm{~m}$. The crater is oriented to the $\mathrm{S}$.

FIG.105. Feature 53 - crater (Author, 2017)
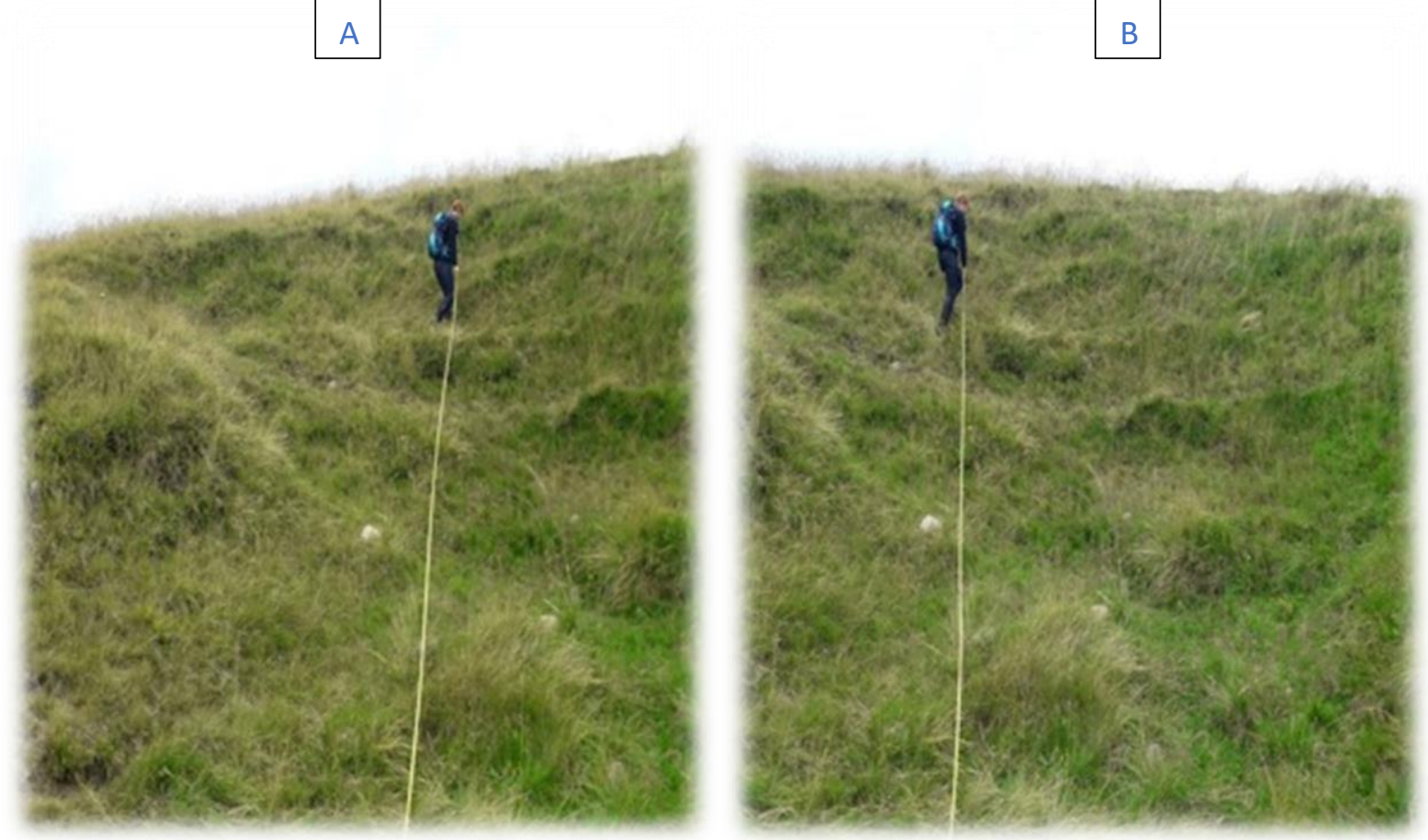


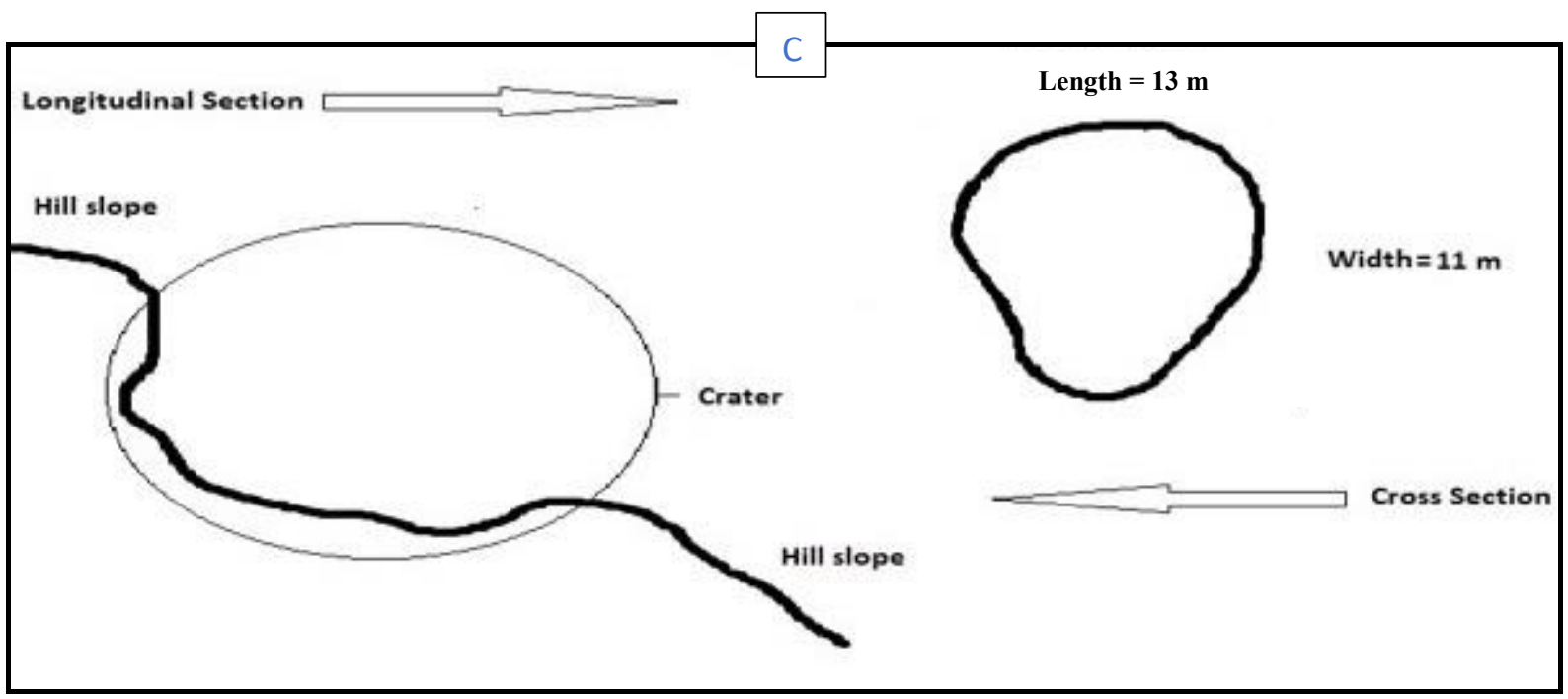

FIG.106 represents a map of the field location of feature 54 to 58 along with the position of this section of the field (yellow rectangle) within research sector 1 (red rectangle).

FIG.106. Map of field location of feature 54 to 58 - research sector 1 (Author, 2018)

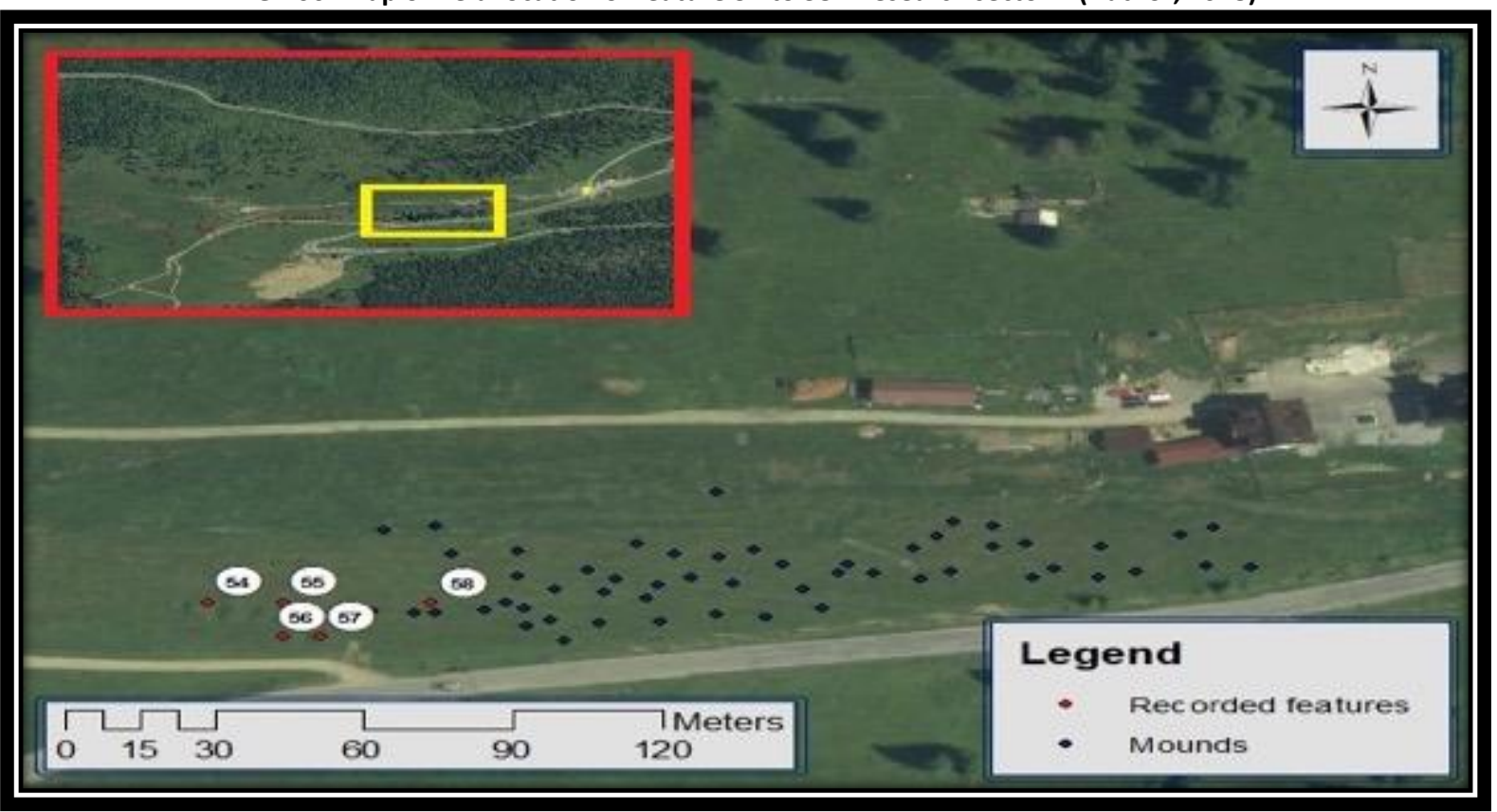

Feature 54 represents a 4 -sided earthwork, situated at $47.60836^{\circ} \mathrm{N}-24.85211^{\circ} \mathrm{E}$, at an altitude of $1409 \mathrm{~m}$ (FIG. 107). The earthwork consists of an embankment excavated in the hill slope with a length of $4 \mathrm{~m}$, a width of $5 \mathrm{~m}$ and a maximum depth of $1.60 \mathrm{~m}$. The entrance is on the frontal side to the left. Shaped stones can be seen on the site of the earthwork which is oriented to the S-SW. 


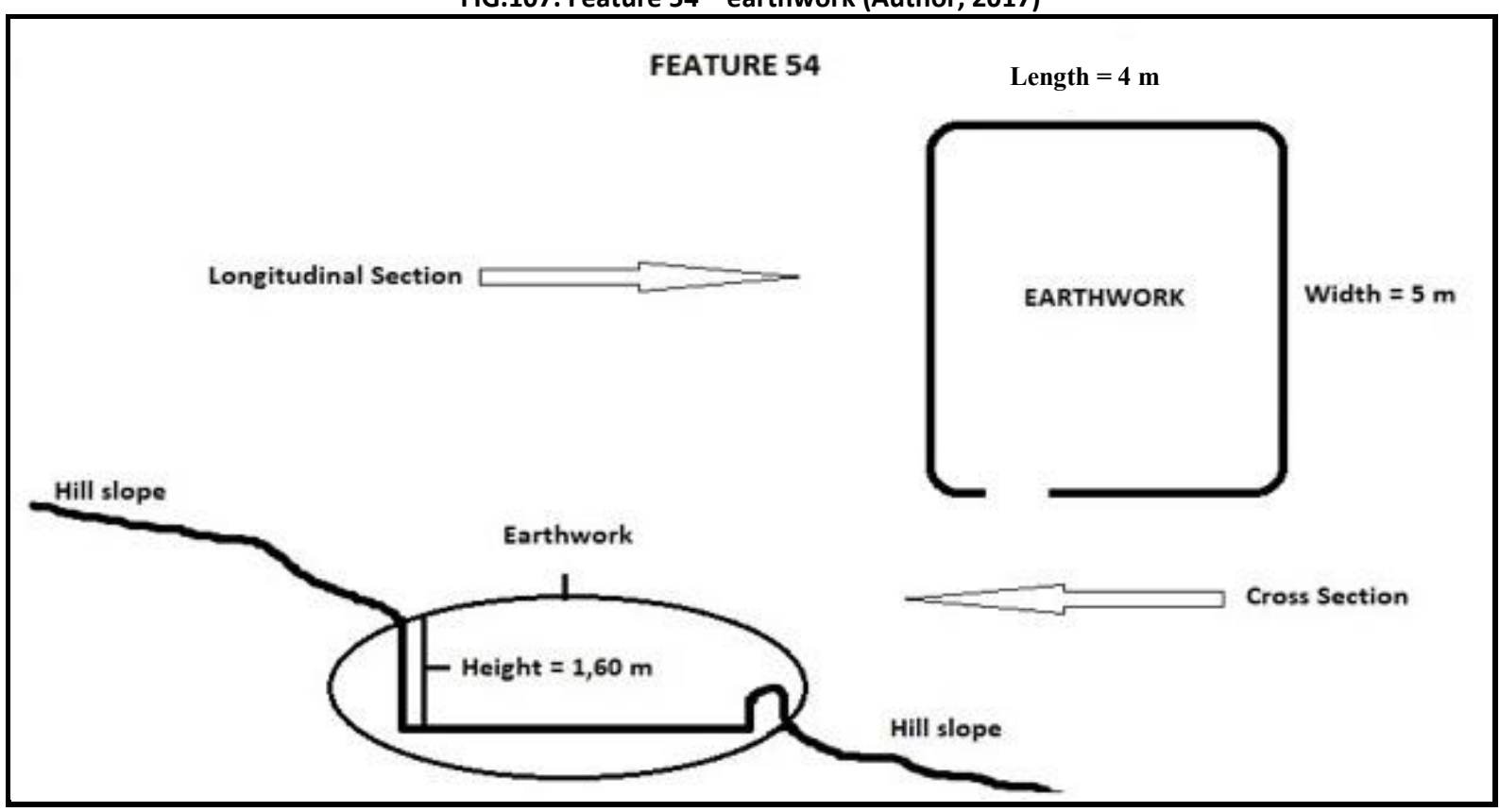

Feature 55 represents a 3 -sided earthwork, situated at $47.60837^{\circ} \mathrm{N}-24.85226^{\circ} \mathrm{E}$, at an altitude of $1406 \mathrm{~m}$ (FIG.108). The earthwork consists of an embankment excavated in the hill slope with a length of $5 \mathrm{~m}$, a width of $6 \mathrm{~m}$ and a maximum depth of $1.80 \mathrm{~m}$. Shaped stones can be seen on the site of the earthwork which is oriented to the S.

FIG.108. Feature 55 -earthwork (Author, 2017)

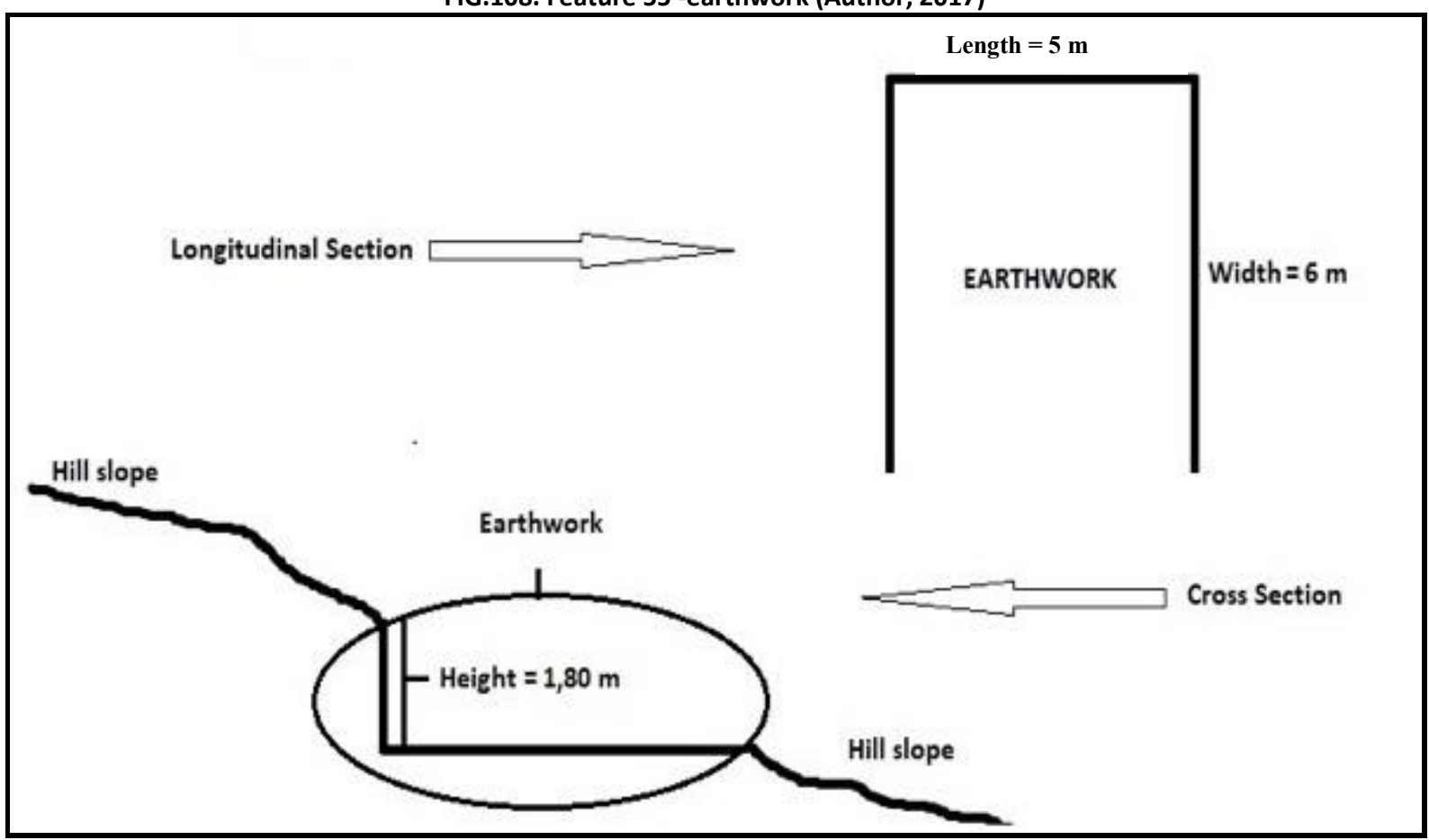


Feature 56 represents a 3 -sided earthwork, situated at $47.60834^{\circ} \mathrm{N}-24.85232^{\circ} \mathrm{E}$, at an altitude of 1409 m (FIG.109). The earthwork consists of an embankment excavated in the hill slope with a length of $5 \mathrm{~m}$, a width of $6 \mathrm{~m}$ and a maximum depth of $1.80 \mathrm{~m}$. Shaped stones can be seen on the site of the earthwork which is oriented to the S.

FIG.109. Feature 56 - earthwork (Author, 2017)

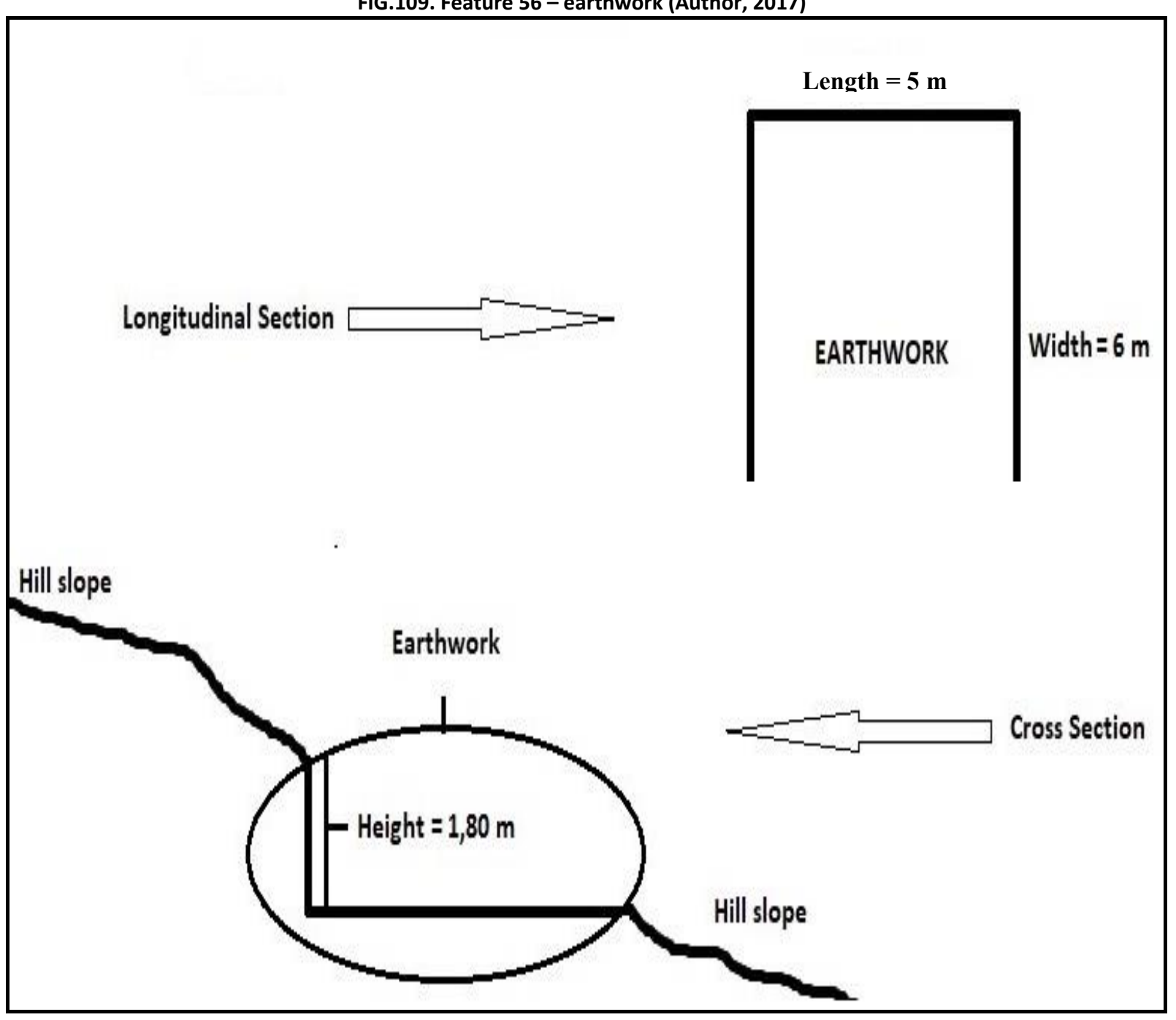

Feature 57 represents a 4 -sided earthwork, situated at $47.60830^{\circ} \mathrm{N}-24.85241^{\circ} \mathrm{E}$, at an altitude of $1400 \mathrm{~m}$ (FIG.110). The earthwork consists of an embankment excavated in the hill slope with a length of $6 \mathrm{~m}$, a width of $5 \mathrm{~m}$ and a maximum depth of $1.80 \mathrm{~m}$. The entrance is on the frontal side to the right. Shaped stones can be seen on the site of the earthwork which is oriented to the S-SW. 


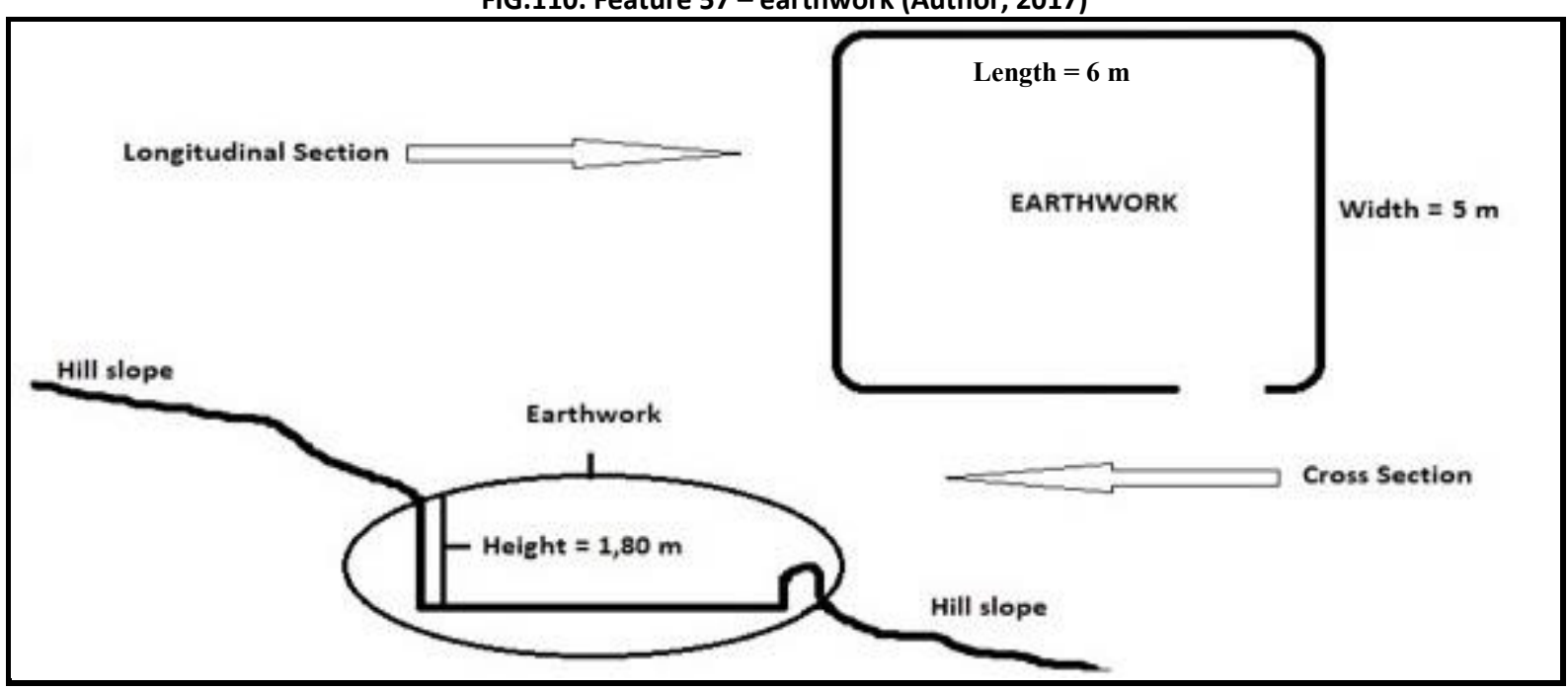

Feature 58 represents a mound situated at $47.60836^{\circ} \mathrm{N}-24.85274^{\circ} \mathrm{E}$, at an altitude of $1402 \mathrm{~m}$ (FIG.111 A, B, C, D). The mound has oval shape if seen from above. It has a length of $3 \mathrm{~m}$, a width of $2.50 \mathrm{~m}$, it has $40 \mathrm{~cm}$ above the hill level on the upper side and about $1.40 \mathrm{~m}$ above the hill level on the lower side.

FIG.111. Feature 58 - mound (Author, 2017)
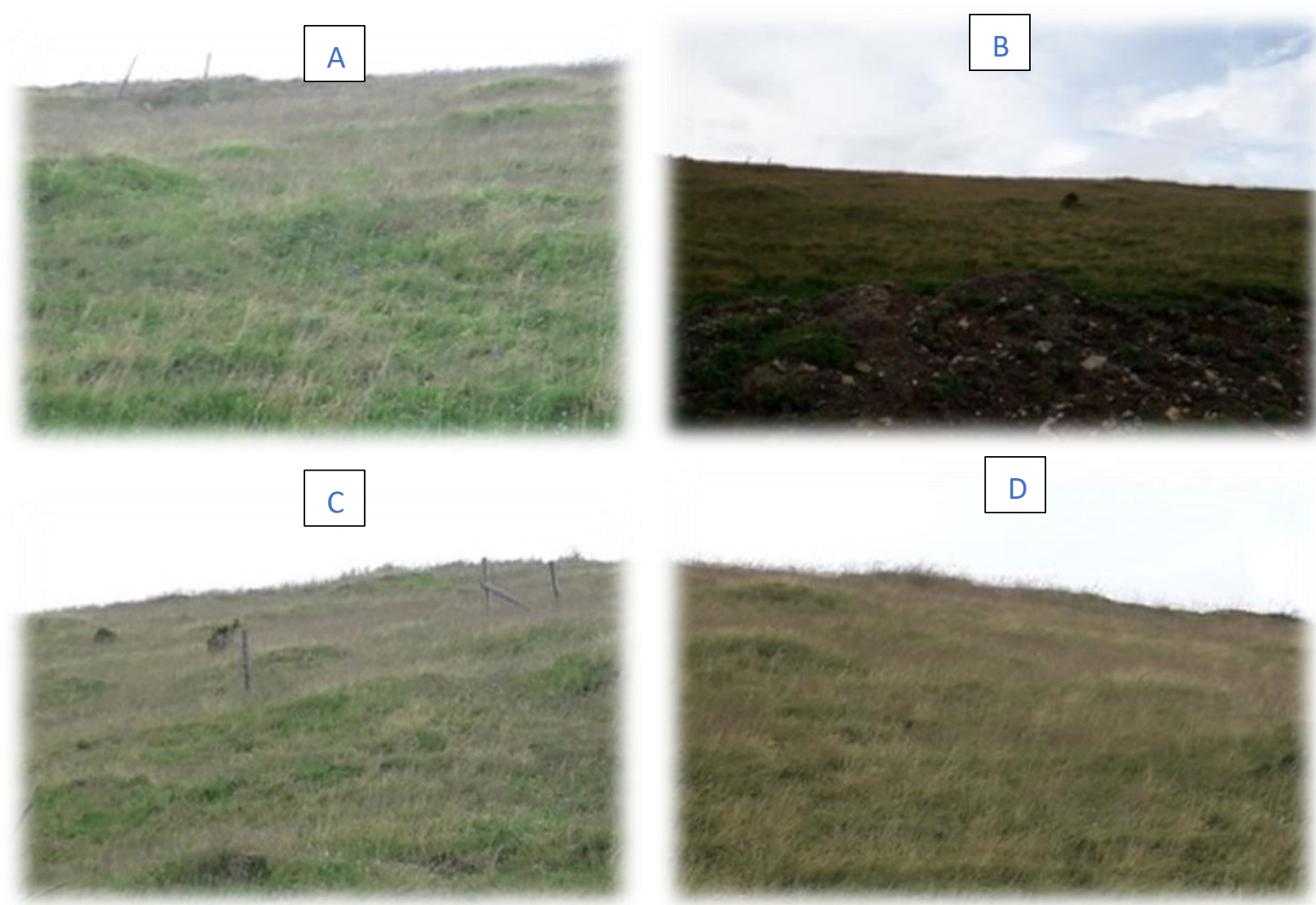
A multitude of such mounds are located on the hill near the monastery as can be seen in FIG.106 represented as blue dots. Local memory claims that the mounds on the hill are likely to be graves of soldiers. It is known that the higher ranks of the Austro-Hungarian army are buried in a military cemetery (FIG.113) on the other side of the hill, to the right of the monastery. The military cemetery is represented in FIG.114 as a viola rectangle. The only original WWI stone cross (FIG.112) that can still be seen on the spot, dating 20.11.16., confirms this theory.
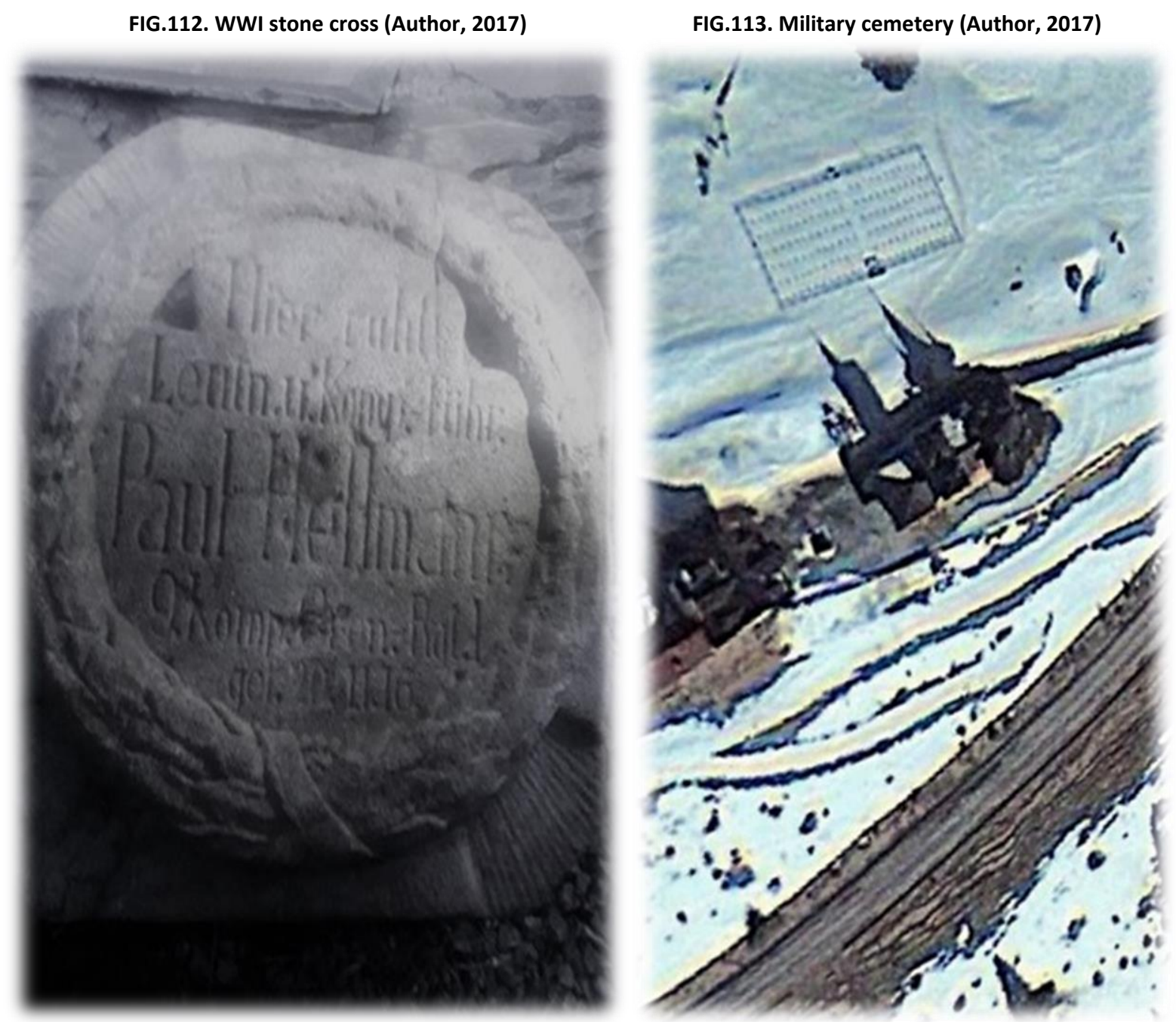

FIG.114 represents a map of the field location of features 59 to 71 along with the position of this section of the field (yellow rectangle) within research sector 1 (red rectangle). 
FIG.114. Map of field location of features 59 to 71 - research sector 1 (Author, 2018)

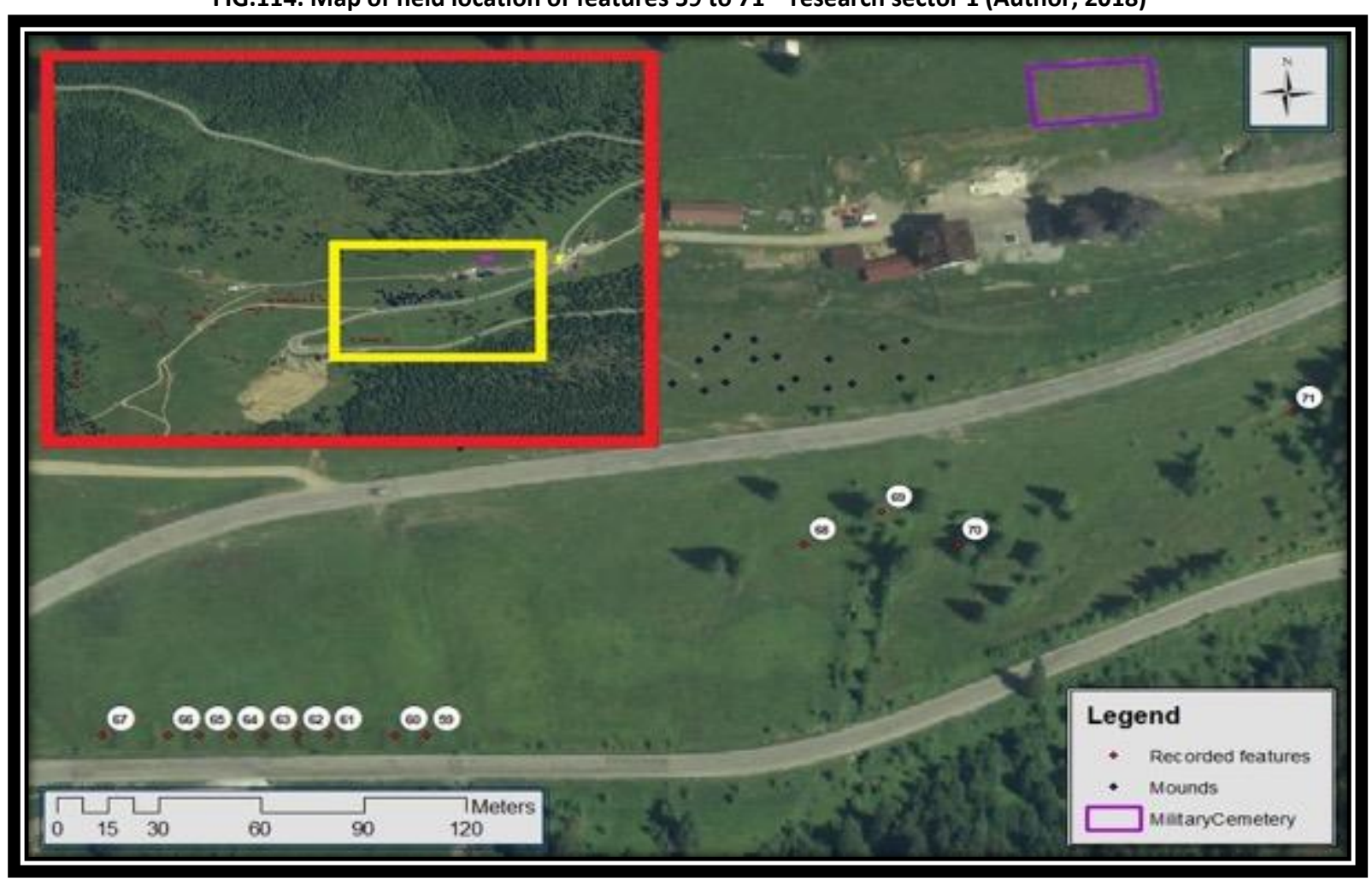

Feature 59 represents a common grave, situated at $47.60750^{\circ} \mathrm{N}-24.85286^{\circ} \mathrm{E}$, at an altitude of

$1394 \mathrm{~m}$. The common grave has an oval shape if seen from above, a length of $9 \mathrm{~m}$, a width of $5 \mathrm{~m}$, and a maximum height of $1.20 \mathrm{~m}$. It is the first of a series of nine common graves (FIG.115) arranged in parallel. According to local memory, in the common graves rest the bones of war prisoners used to construct the military earthworks and the railway during WWI.

FIG.115. Feature 59 to 67 - common graves (Author, 2017)

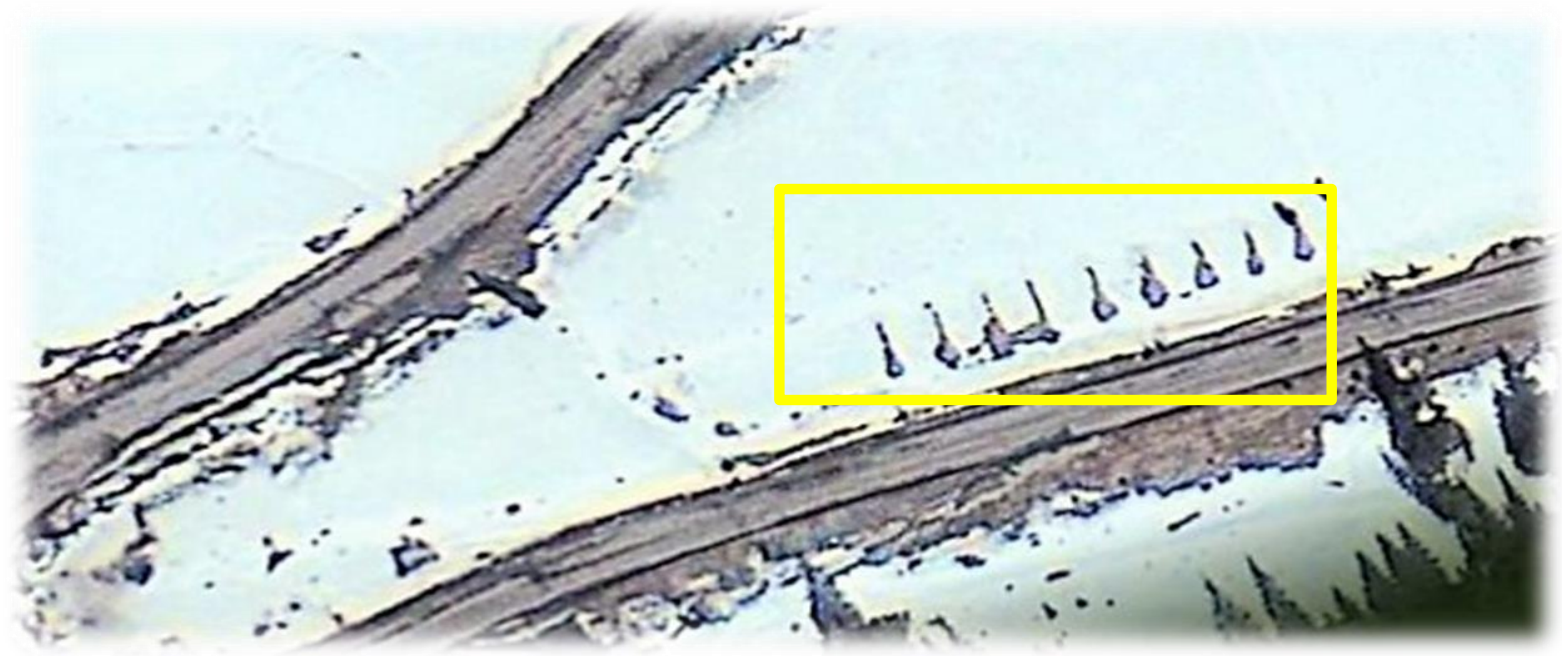


Feature 60 represents a common grave, situated at $47.60750^{\circ} \mathrm{N}-24.85276^{\circ} \mathrm{E}$, at an altitude of $1394 \mathrm{~m}$. The common grave has an oval shape if seen from above, a length of $10 \mathrm{~m}$, a width of $4.5 \mathrm{~m}$, and a maximum height of $1.25 \mathrm{~m}$.

Feature 61 represents a common grave, situated at $47.60750^{\circ} \mathrm{N}-24.85264^{\circ} \mathrm{E}$, at an altitude of $1394 \mathrm{~m}$. The common grave has an oval shape if seen from above, a length of $10 \mathrm{~m}$, a width of $5 \mathrm{~m}$, and a maximum height of $1.30 \mathrm{~m}$.

Feature 62 represents a common grave, situated at $47.60750^{\circ} \mathrm{N}-24.85251^{\circ} \mathrm{E}$, at an altitude of $1394 \mathrm{~m}$. The common grave has an oval shape if seen from above, a length of $10.50 \mathrm{~m}$, a width of $5.50 \mathrm{~m}$, and a maximum height of $1.60 \mathrm{~m}$.

Feature 63 represents a common grave, situated at $47.60750^{\circ} \mathrm{N}-24.85237^{\circ} \mathrm{E}$, at an altitude of $1394 \mathrm{~m}$. The common grave has an oval shape if seen from above, a length of $11 \mathrm{~m}$, a width of $4.50 \mathrm{~m}$, and a maximum height of $1.50 \mathrm{~m}$.

Feature 64 represents a common grave, situated at $47.60750^{\circ} \mathrm{N}-24.85226^{\circ} \mathrm{E}$, at an altitude of $1394 \mathrm{~m}$. The common grave has an oval shape if seen from above, a length of $10.50 \mathrm{~m}$, a width of $3.50 \mathrm{~m}$, and a maximum height of $1.30 \mathrm{~m}$.

Feature 65 represents a common grave, situated at $47.60750^{\circ} \mathrm{N}-24.85215^{\circ} \mathrm{E}$, at an altitude of $1394 \mathrm{~m}$. The common grave has an oval shape if seen from above, a length of $11 \mathrm{~m}$, a width of $4.50 \mathrm{~m}$, and a maximum height of $1.30 \mathrm{~m}$.

Feature 66 represents a common grave, situated at $47.60750^{\circ} \mathrm{N}-24.85205^{\circ} \mathrm{E}$, at an altitude of $1394 \mathrm{~m}$. The common grave has an oval shape if seen from above, a length of $11.20 \mathrm{~m}$, a width of $5 \mathrm{~m}$, and a maximum height of $1.20 \mathrm{~m}$. 
Feature 67 represents a common grave, situated at $47.60750^{\circ} \mathrm{N}-24.85194^{\circ} \mathrm{E}$, at an altitude of $1394 \mathrm{~m}$. The common grave has an oval shape if seen from above, a length of $11 \mathrm{~m}$, a width of $5.30 \mathrm{~m}$, and a maximum height of $1.30 \mathrm{~m}$.

Feature 68 represents a 3 -sided earthwork, situated at $47.60796^{\circ} \mathrm{N}-24.85444^{\circ} \mathrm{E}$, at an altitude of $1411 \mathrm{~m}$ (FIG.116). The earthwork consists of an embankment excavated in the hill slope with a length of $13 \mathrm{~m}$, a width of $4 \mathrm{~m}$ and a maximum depth of $1.20 \mathrm{~m}$. Shaped stones can be seen on the site of the earthwork which is oriented to the S-SW.

FIG.116. Feature 68 - earthwork (Author, 2017)

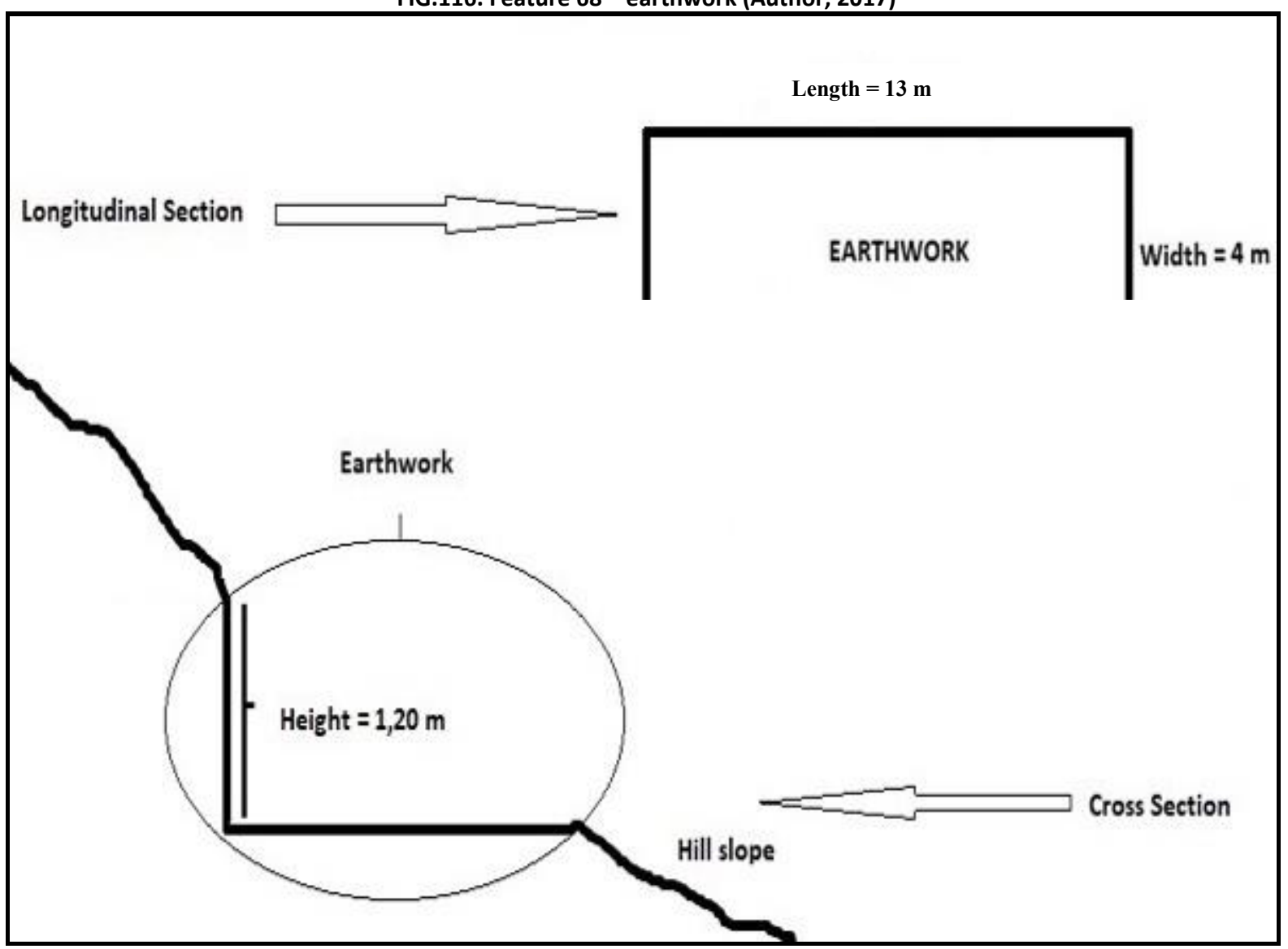

Feature 69 represents a 4 -sided earthwork, situated at $47.60807^{\circ} \mathrm{N}-24.85473^{\circ} \mathrm{E}$, at an altitude of $1409 \mathrm{~m}$ (FIG.117). The earthwork is a square pit, with $4 \mathrm{~m}$ sides and a depth of $1.50 \mathrm{~m}$. In the pit and around it, earth bricks and shaped stone can be found. The access way seems to be from the left of the lower side. 


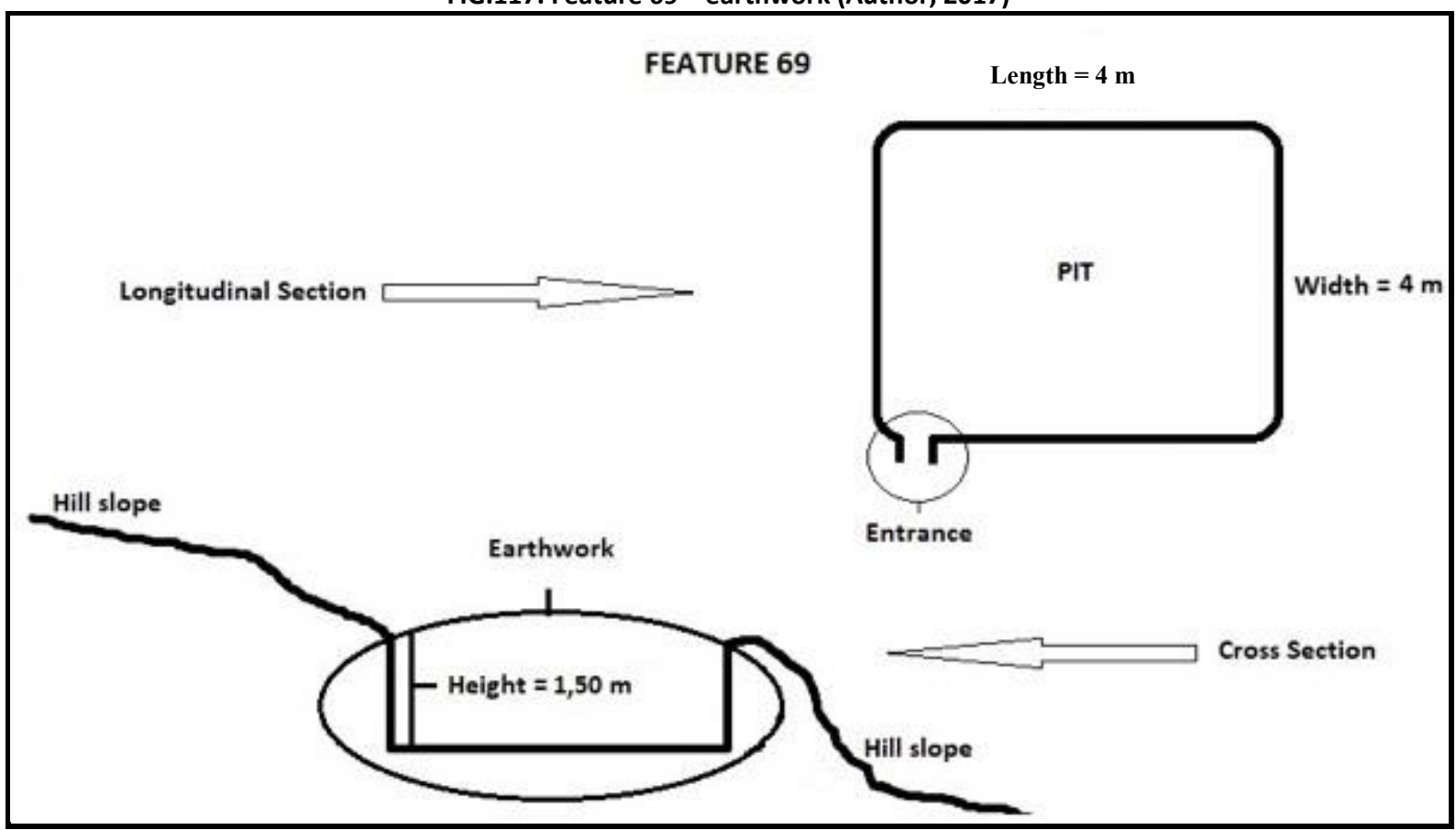

Feature 70 represents a 3 -sided earthwork, situated at $47.60803^{\circ} \mathrm{N}-24.85495^{\circ} \mathrm{E}$, at an altitude of $1410 \mathrm{~m}$ (FIG.118). The earthwork consists of an embankment excavated in the hill slope with a length of $25 \mathrm{~m}$, a width of $7 \mathrm{~m}$ and a maximum depth of $1.60 \mathrm{~m}$. Shaped stones can be seen on the site of the earthwork which is oriented to the S.

FIG. 118. Feature 70 -earthwork (Author, 2017)

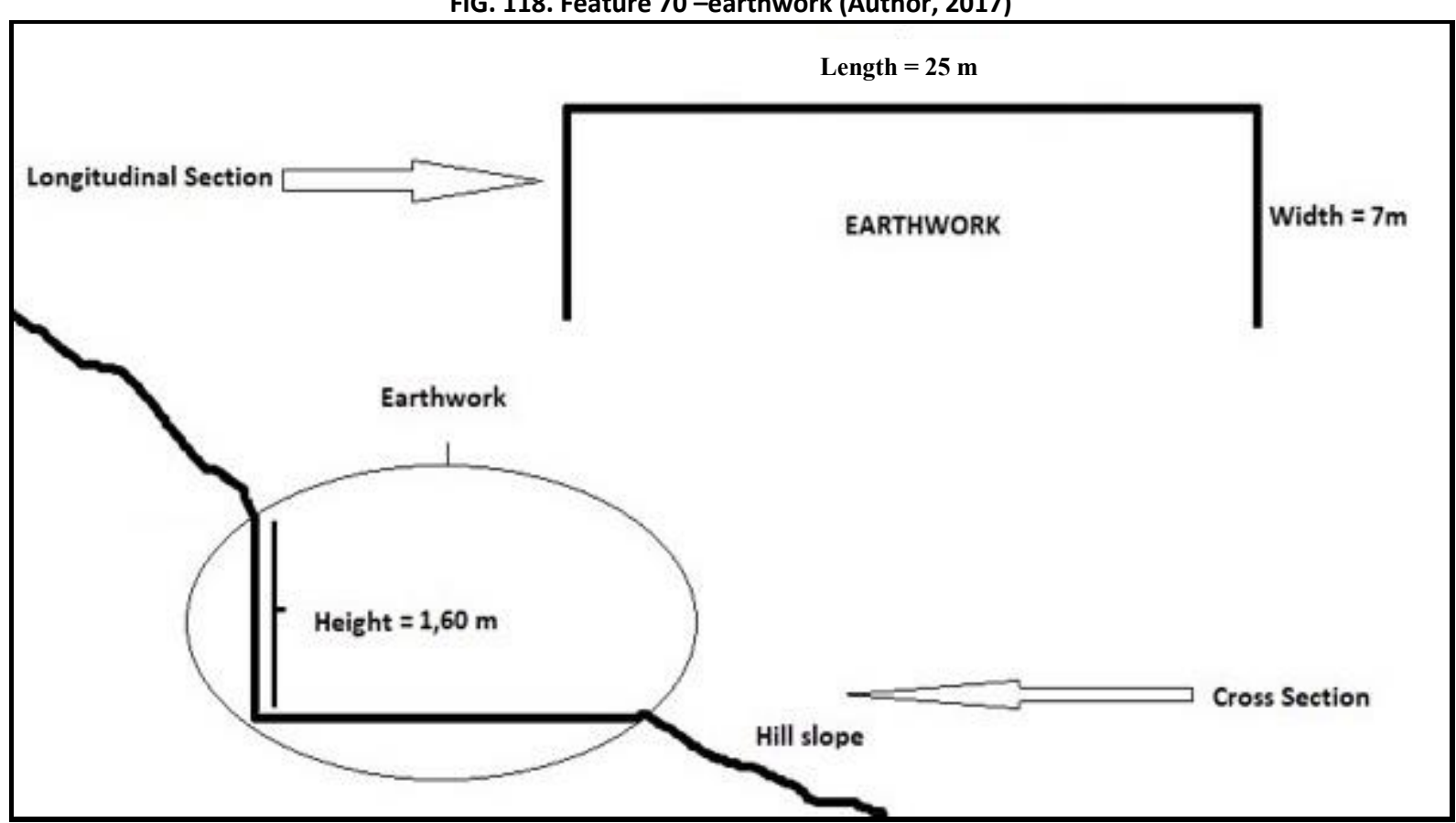


Feature 71 represents a bunker, situated at $47.60844^{\circ} \mathrm{N}-24.85625^{\circ} \mathrm{E}$, at an altitude of $1415 \mathrm{~m}$ (FIG.119.A, B, C, D, E, F). The bunker, made of reinforced concrete, was damaged by an explosion. It has a rectangular shape with a length of $10 \mathrm{~m}$ and a width of $5 \mathrm{~m}$. The walls imploded due to the explosion and the ceiling crashed. The walls have a diameter of $50 \mathrm{~cm}$ and the ceiling is $1 \mathrm{~m}$ thick. In 2016 it was still possible to enter the bunker, but the walls collapsed recently, maybe due to the construction works on the near road. Before the implosion, when access was still possible, another feature resembling a pillbox was visible inside the construction on the left side. Shaped stone with joints of cement and gravel can be seen on the site of the bunker which is oriented to the SE.

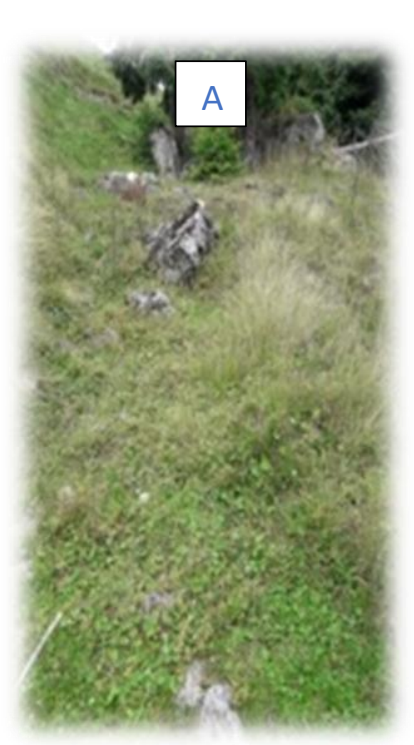

FIG.119. Feature 71 - bunker (Author, 2017)
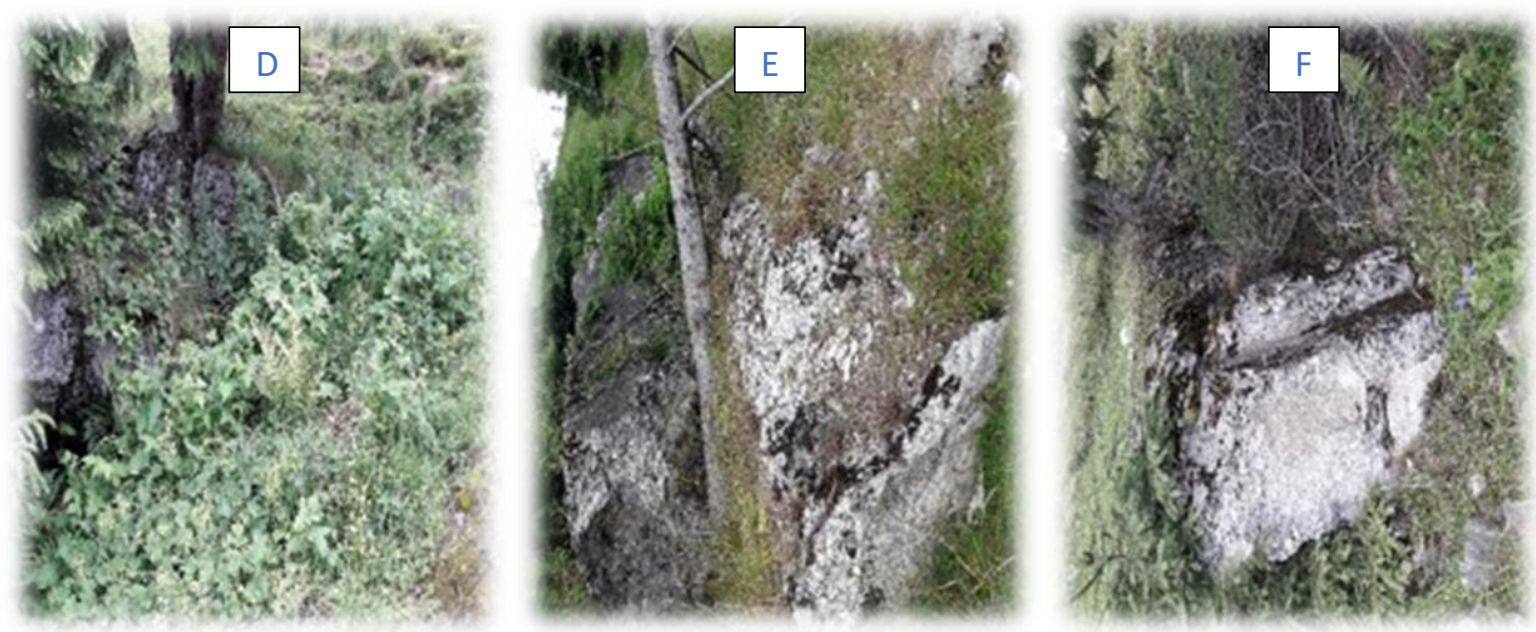
FIG.120. Research sector 1 (Author, 2017)

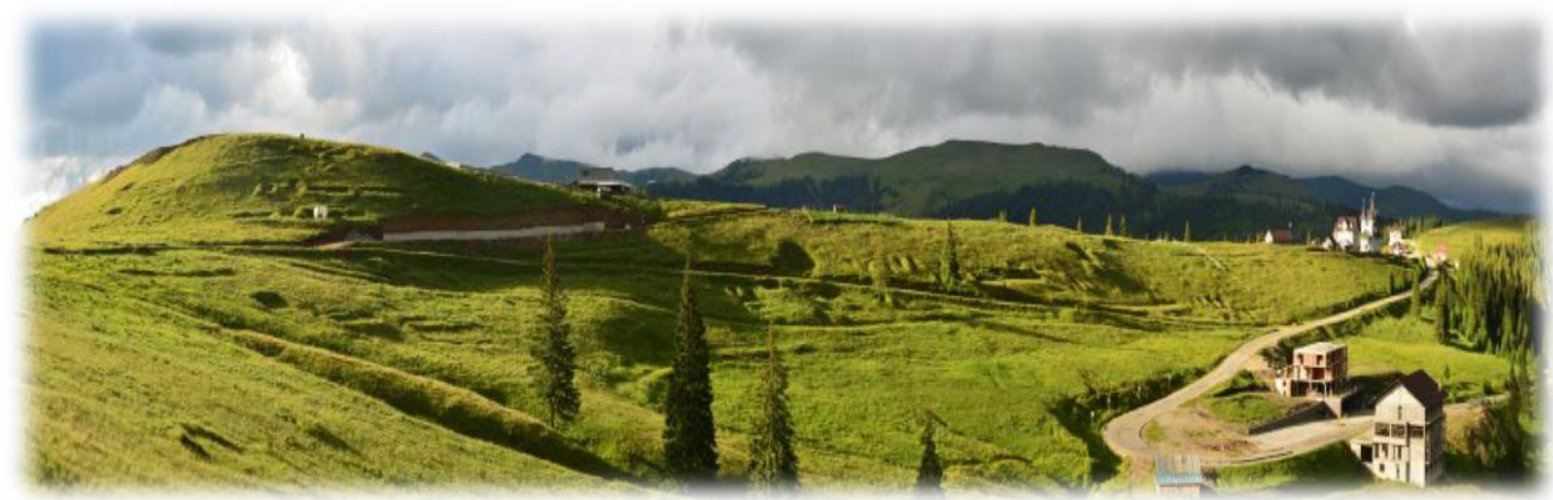

Feature 71 concludes the findings of the first research sector (FIG.120). As it emerges from the analysed images, the extent of the military command area was bigger than the one that emerges from the recordings. The reduction of the perimeter is down to the 2017 rehabilitation of the present-day national road (FIG.121 A,B,C,D) that crosses the pass connecting Maramureș to Bukovina, and to the development that has taken place in the last decade including the construction of the ski slope, hotels, chalets, of the monastery complex and parking lot.

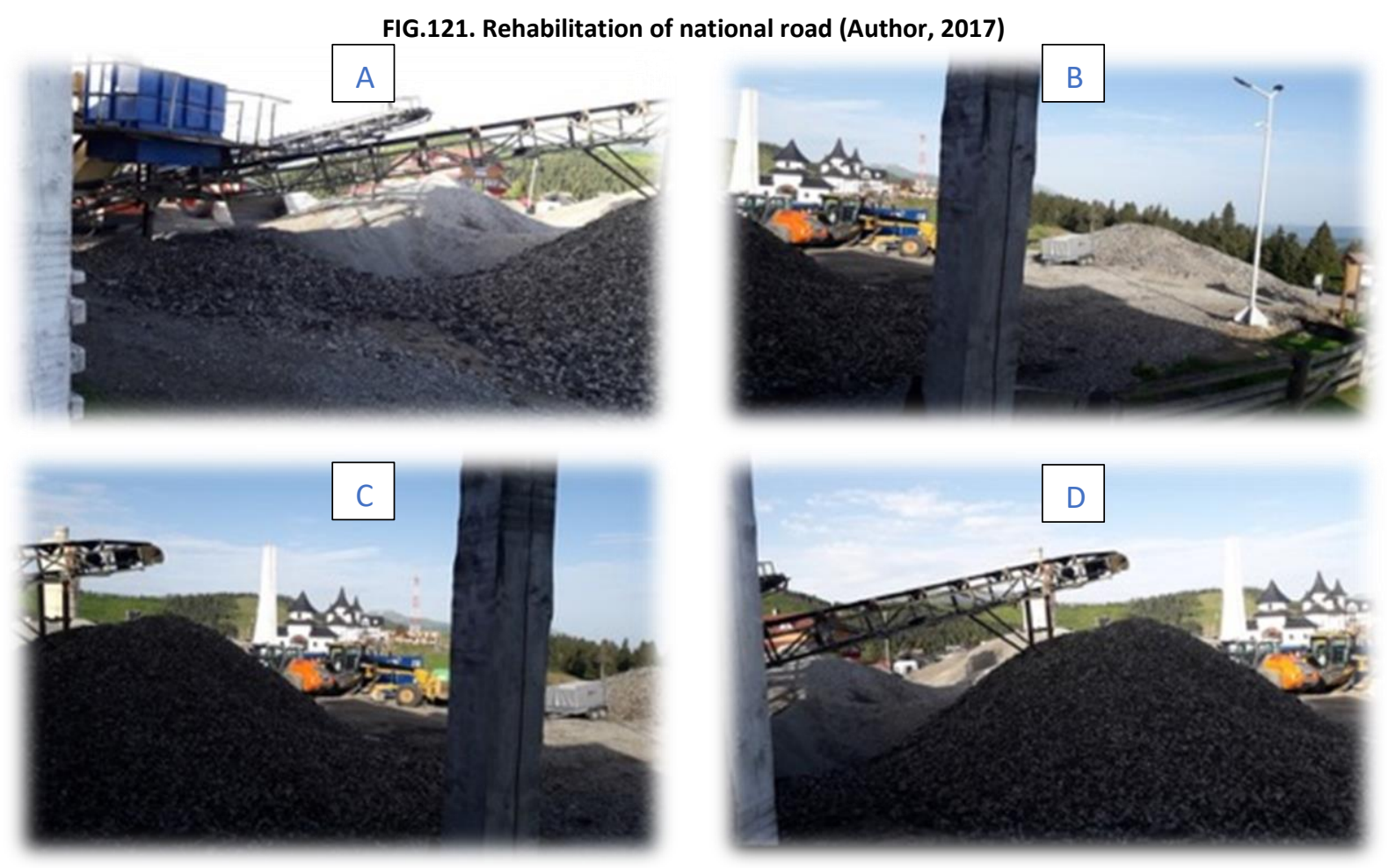


The monastery complex, parking lot and several chalets are currently standing on the Prislop saddle in the place known as the Krenzplatz during WWI which represented the central sector (FIG. 34,36,37,43) of the Prislop military command. The name comes from the cross that used to be in the centre of the plateau, and which was in place prior to the construction of the military command, as shown by a 1906 photograph (FIG.122). This landmark was not only preserved throughout the existence of the military city in Prislop but, by 1917, a military monument had been erected in front of the cross (FIG.18).

FIG.122. Prislop saddle-central plateau, 1906 (Brașcanu collection, 2016)

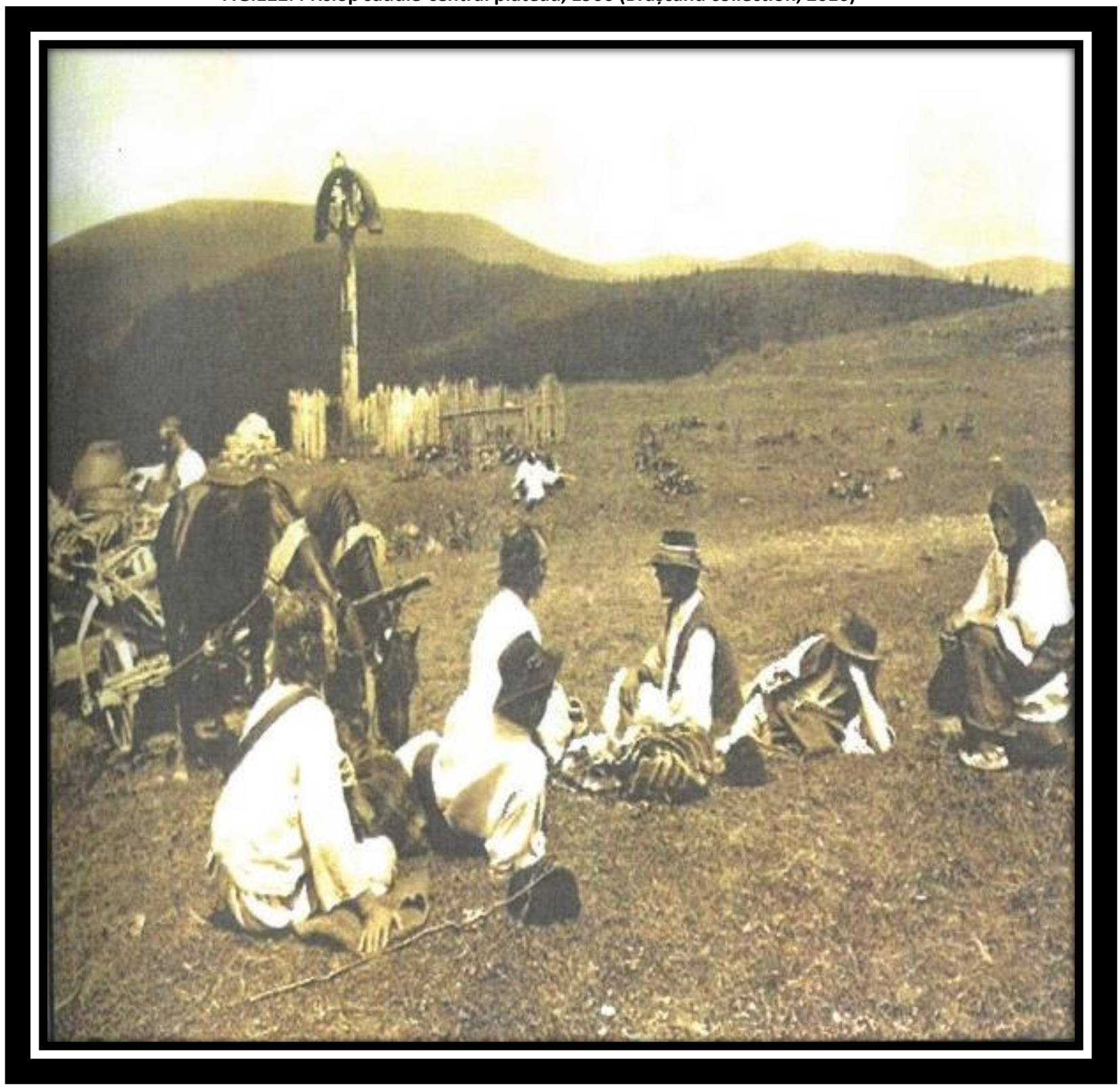


Construction works altered the visible traces of war and made recording impossible in those areas since excavation was not part of the investigation methods. Nevertheless, extensive field campaigns provided the opportunity of witnessing the underground resources of such inaccessible areas due to construction works conducted by the owner of the 'Alpine' chalet (FIG.123 A, B) where I was accommodated during the various fieldwork campaigns. In July 2018, during the works undertaken for the extension of the chalet which required the conduction of excavations in view of enlarging the foundation of the building, the workers came across several cartridges (FIG.125), pieces of barbed wire, an exploded WWI hand grenade (FIG.126 A,B) and an unusual small bottle bearing the inscription SCHUTZ MARKE and a dynamite symbol between the two words (FIG.124).

The rescue of part of the findings from the small excavation, conducted by non-specialised personnel with the aid of a bulldozer, provides evidence of underground material and advocates for the necessity of conserving the war sites in order to conduct a proper study even in areas where war signs are not visible at the ground surface.

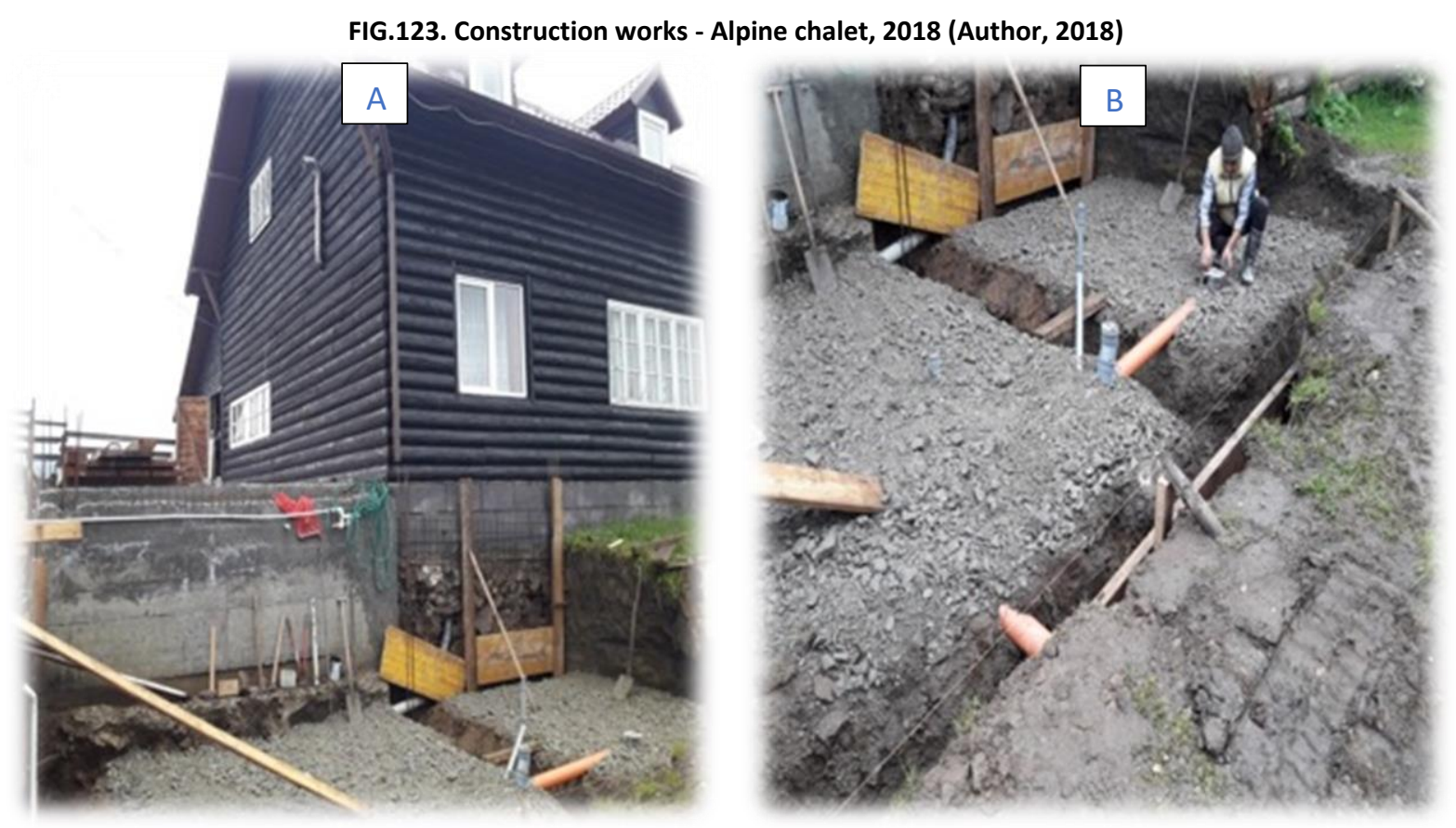


FIG.124. Schutz marke bottle (Author, 2018)

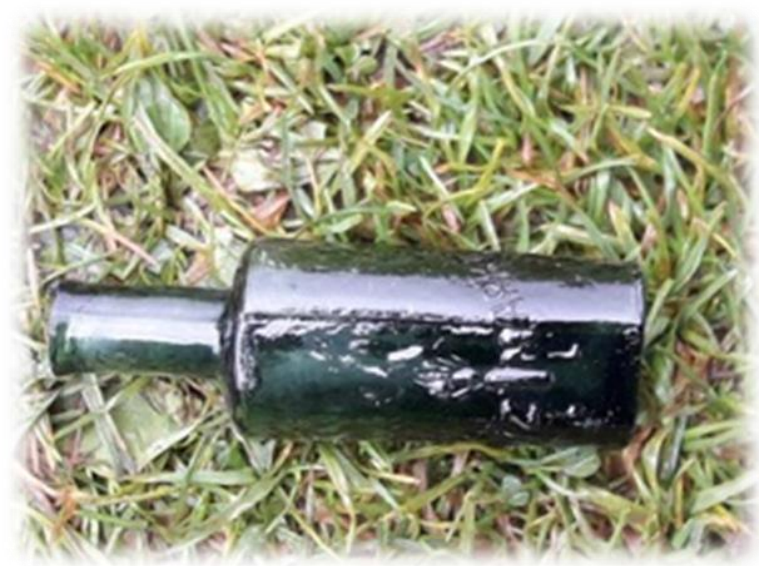

FIG.125. World wars' cartridges (Author, 2018)

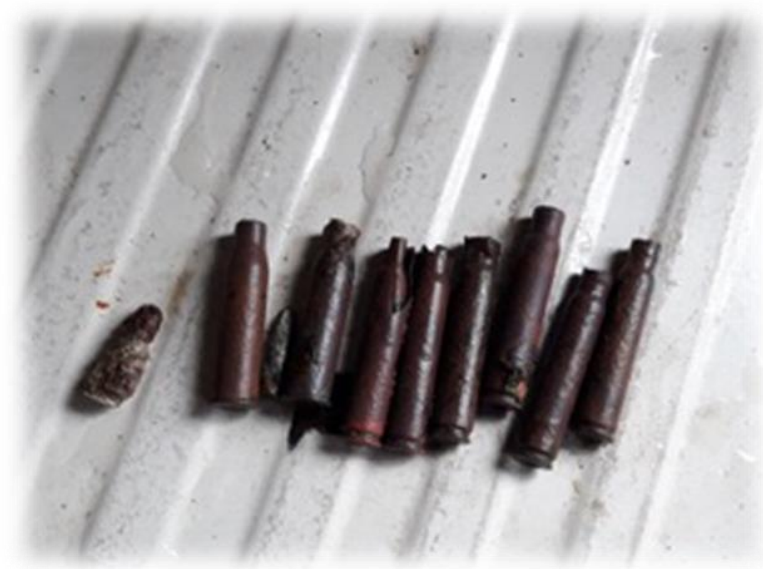

FIG.126. Exploded WWI hand grenade (Author, 2018)
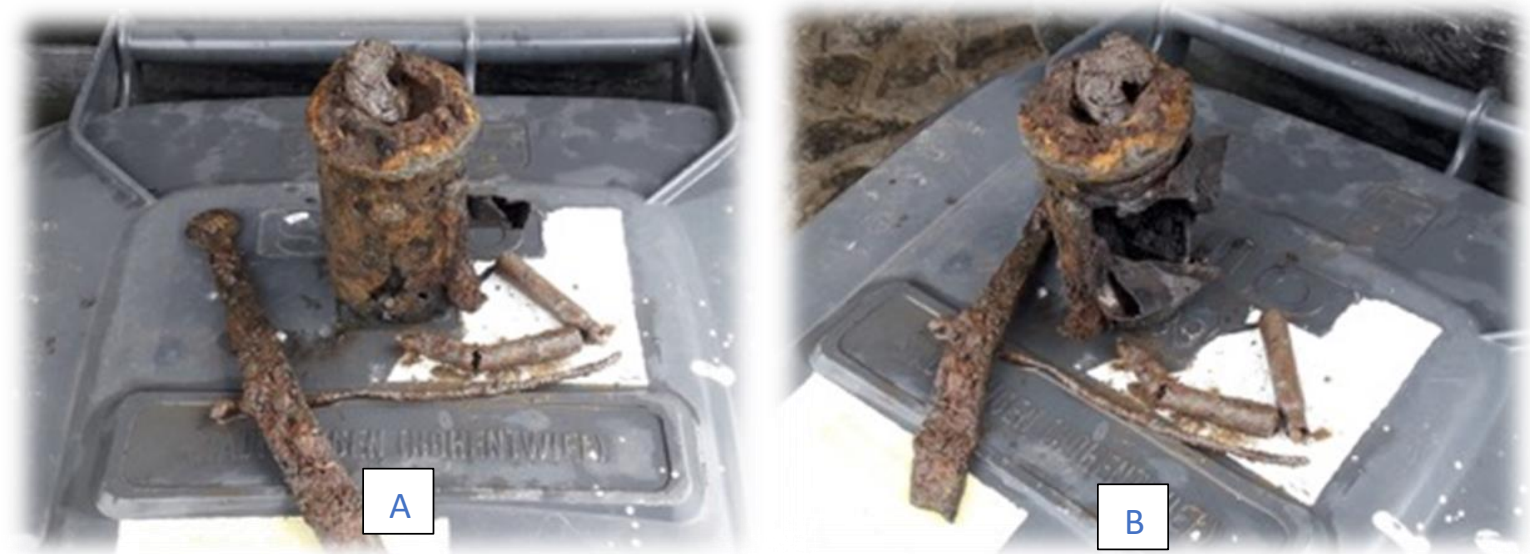

Similar ordnance material was found during the field surveys in the proximity of the bunkers as recorded in section 2. The findings include cartridges of various dimensions (FIG.127) and the head of a bomb shell. On some of the cartridges the year and/or code is still legible: H NF IV 1915 (FIG.129); another of the same shape and dimension has an unreadable code but the year 1916 is well preserved (FIG.130); 68B T 3;*A*39 (FIG.128), while the shell has the well-preserved inscription RAL 3/16 40 on the side that remained unaffected by the explosion. FIG.132 - Deutsche schwere Haubitze bei Kirlibaba (the German heavy shell canon of Cârlibaba) - reproduces a WWI photograph that features the typology of shells, to which the head shell presented in FIG. 131 A, B, C, D belongs. Furthermore, an identical- 
looking example can also be spotted in the profile picture of the website World War One Battlefields_(Available online: http://www.wwlbattlefields.co.uk/flanders/passchendaele/).

FIG.127. War ammunition (Author, 2016)

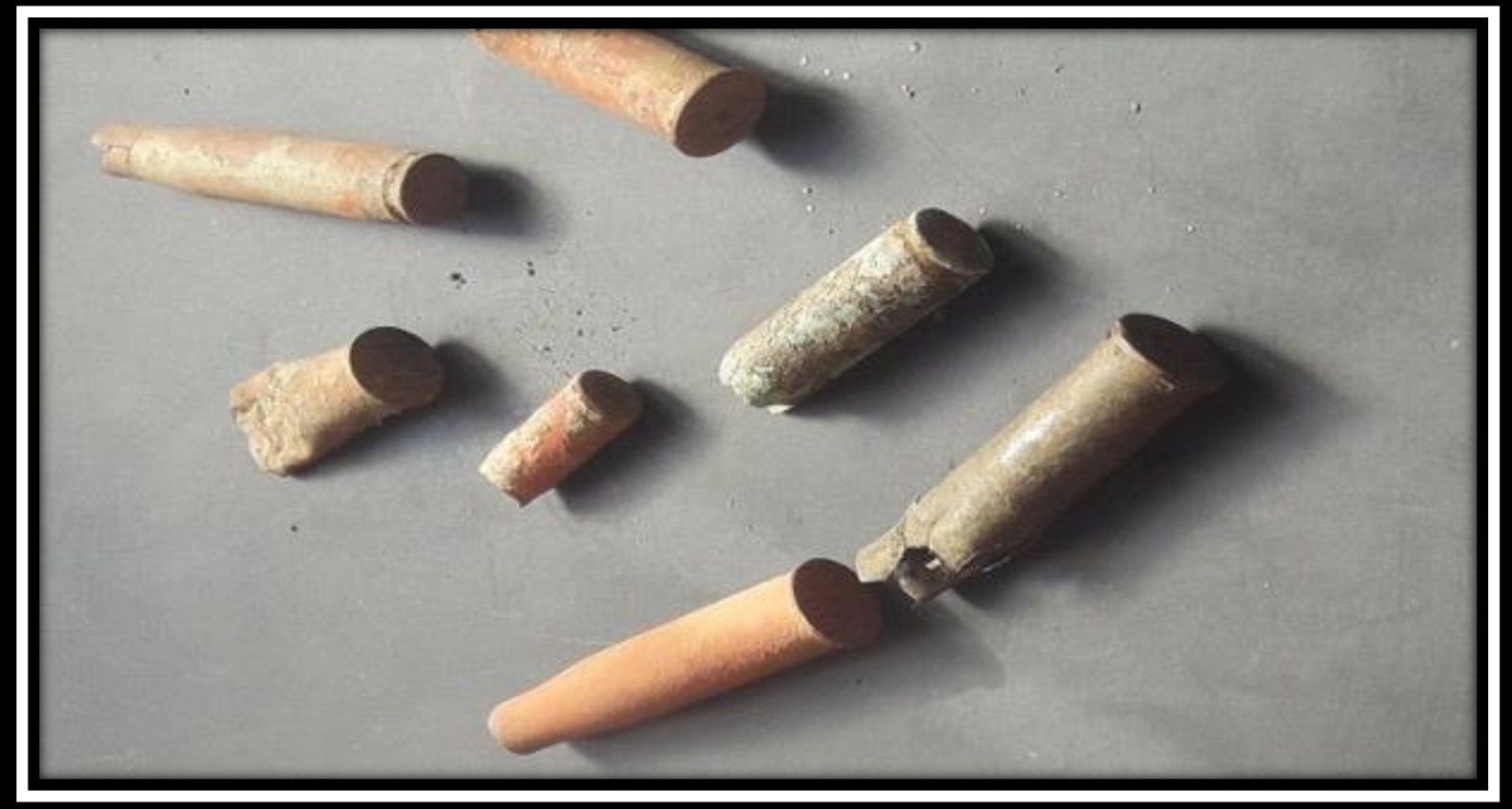

FIG.128. *A*39 cartridge (Author, 2016)

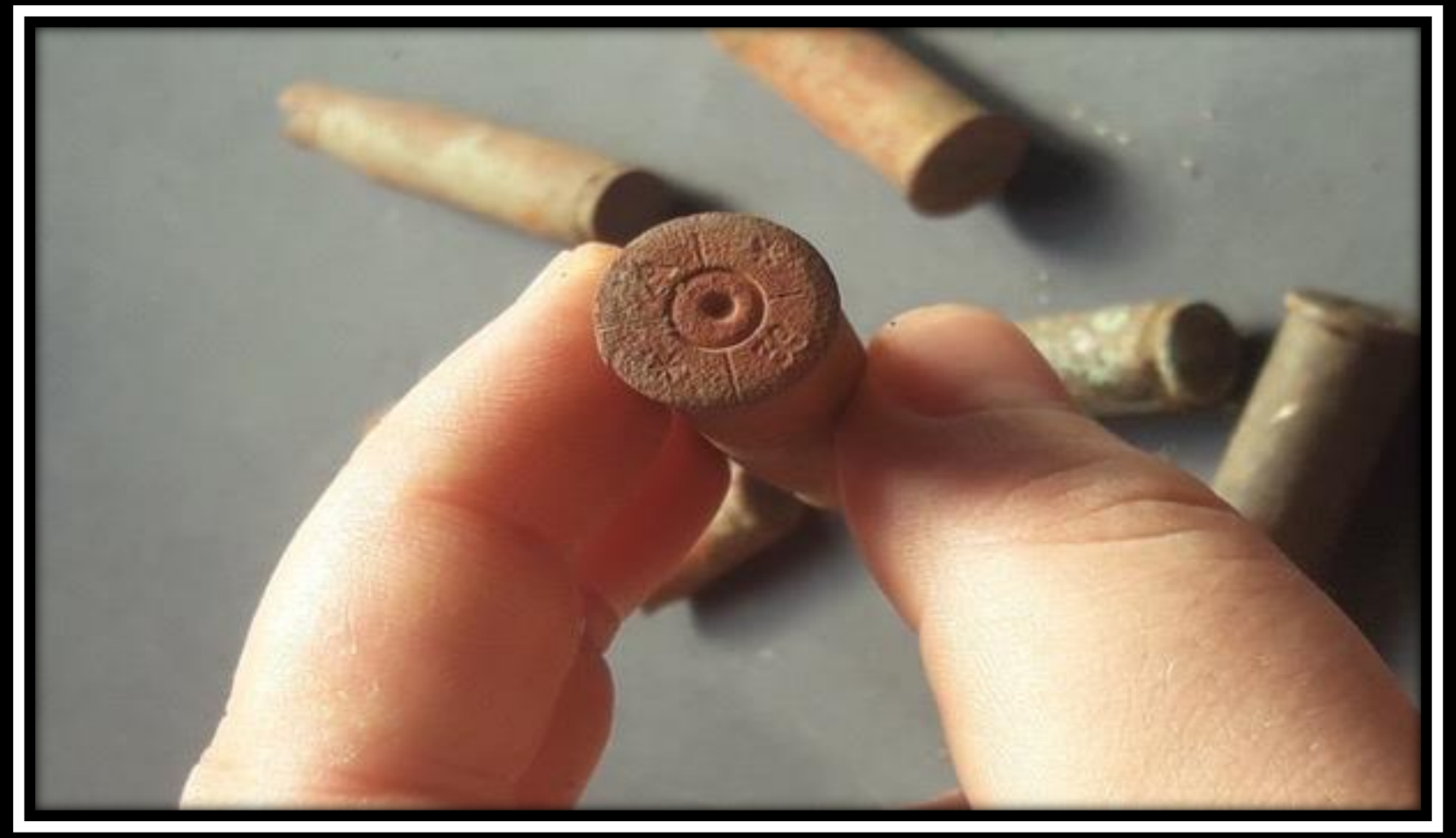


FIG.129. H NF IV 1915 cartridge (Author, 2016)

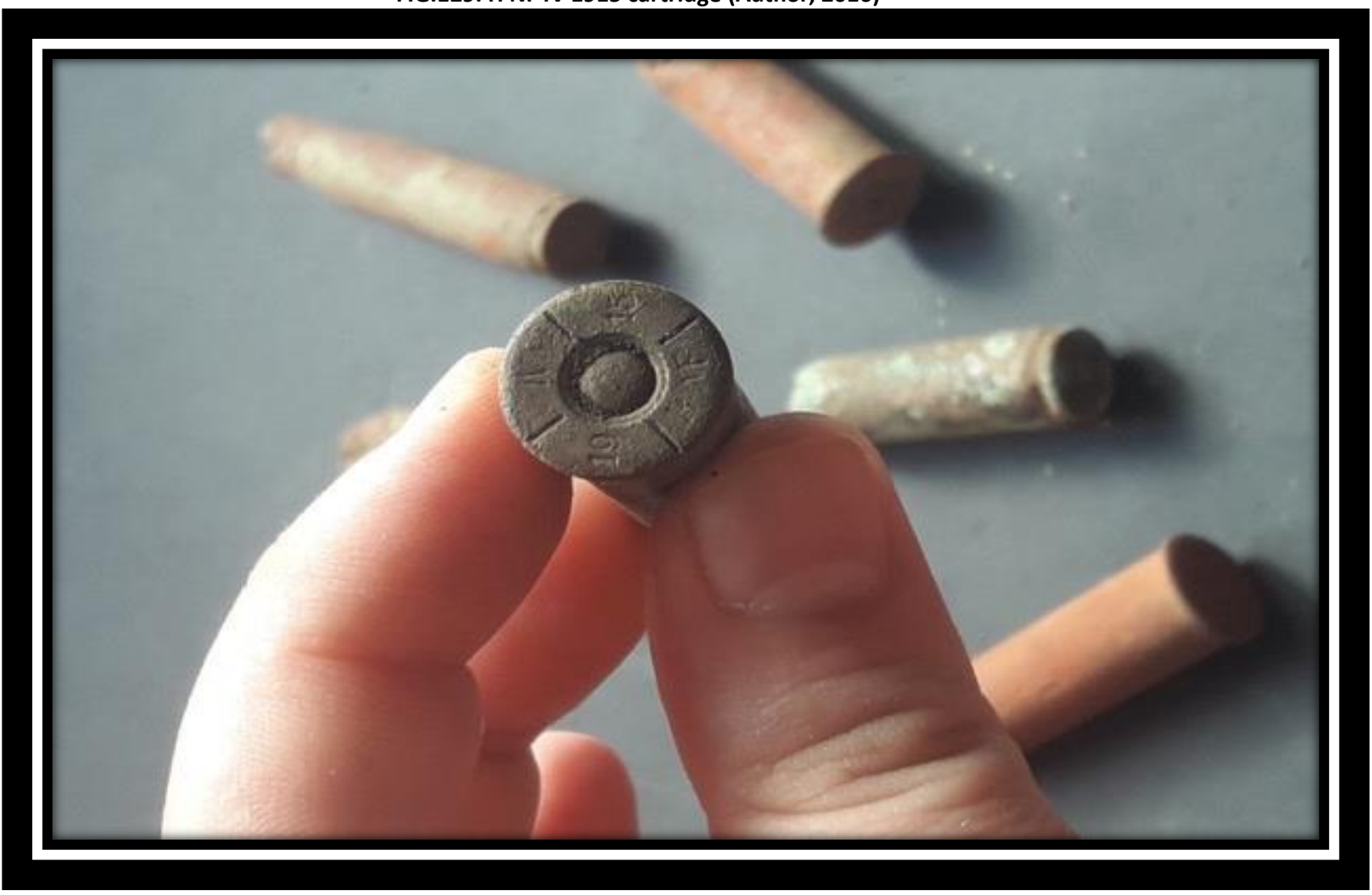

FIG.130. 1916 cartridge (Author, 2016)

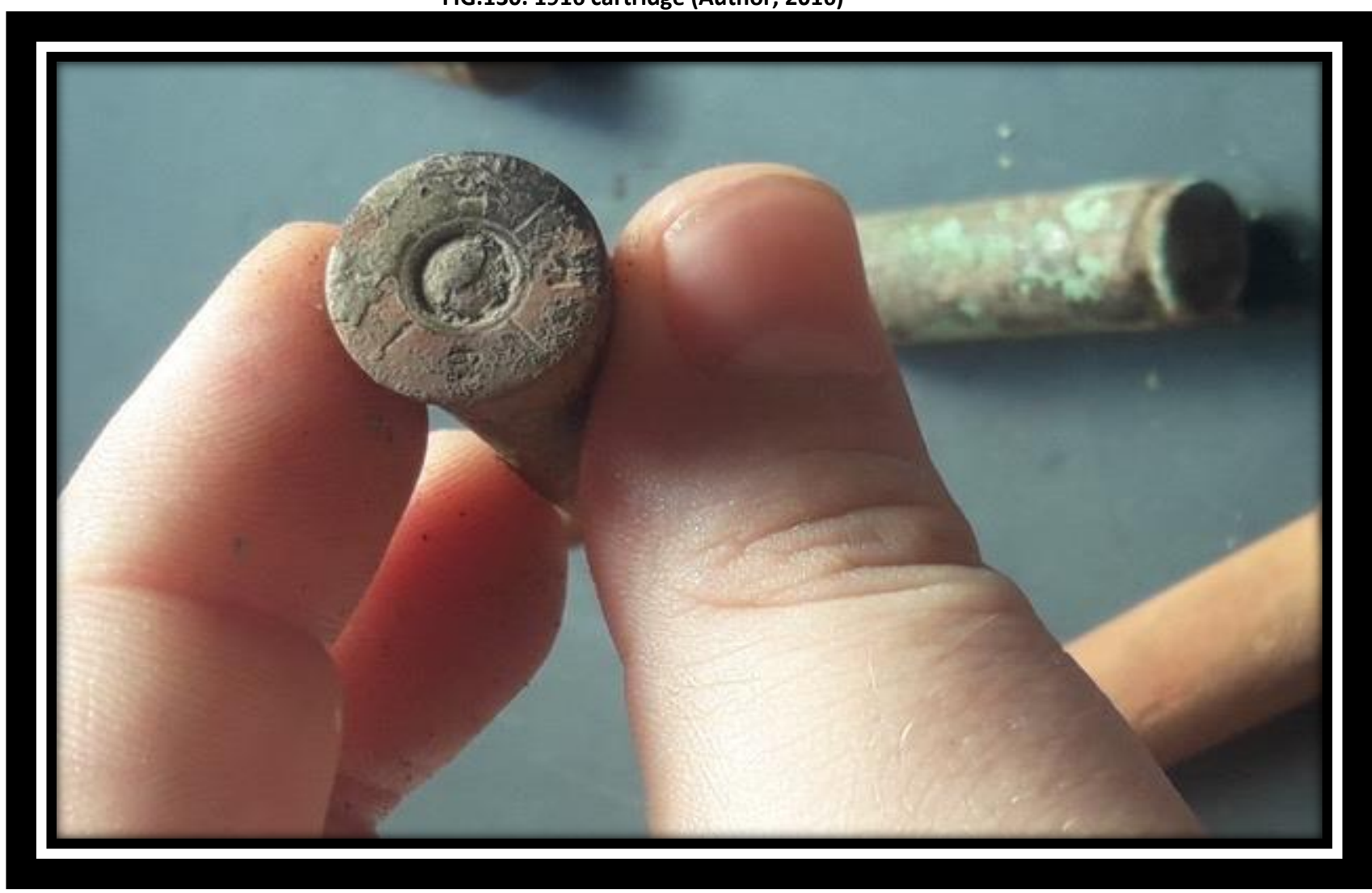



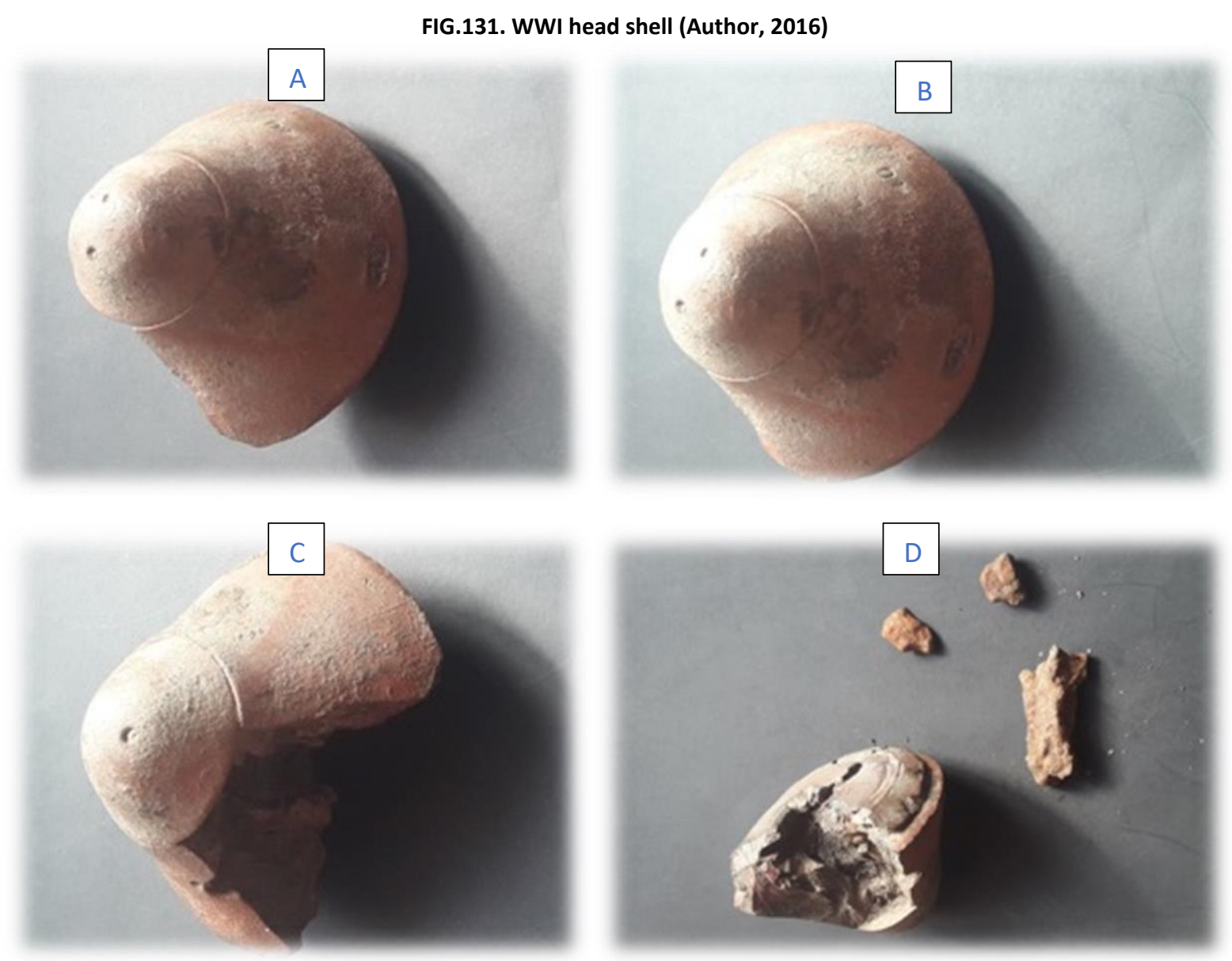

FIG.132. German heavy shell canon of Cârlibaba (Brașcanu collection, 2016)

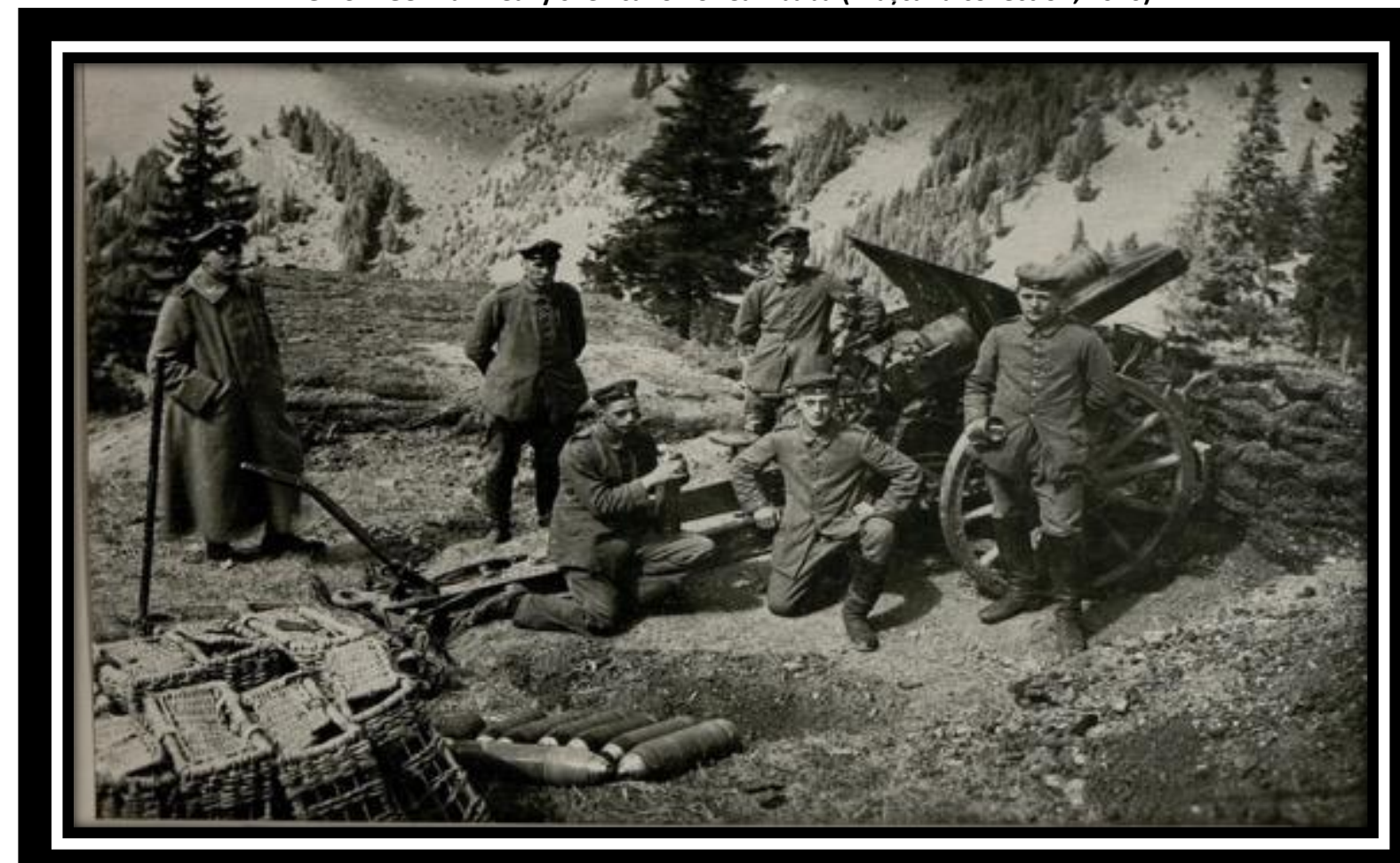




\subsection{Research sector 2}

The purpose of the second research sector is to present the recording of the remaining building foundations located in proximity to the WWI military command and documentation of the fortification system developed along the sides of the military roads.

FIG.133 represents a map of the field location of features 72 to 81 along with the position of this section of the field (yellow rectangle) within research sector 2 (red rectangle).

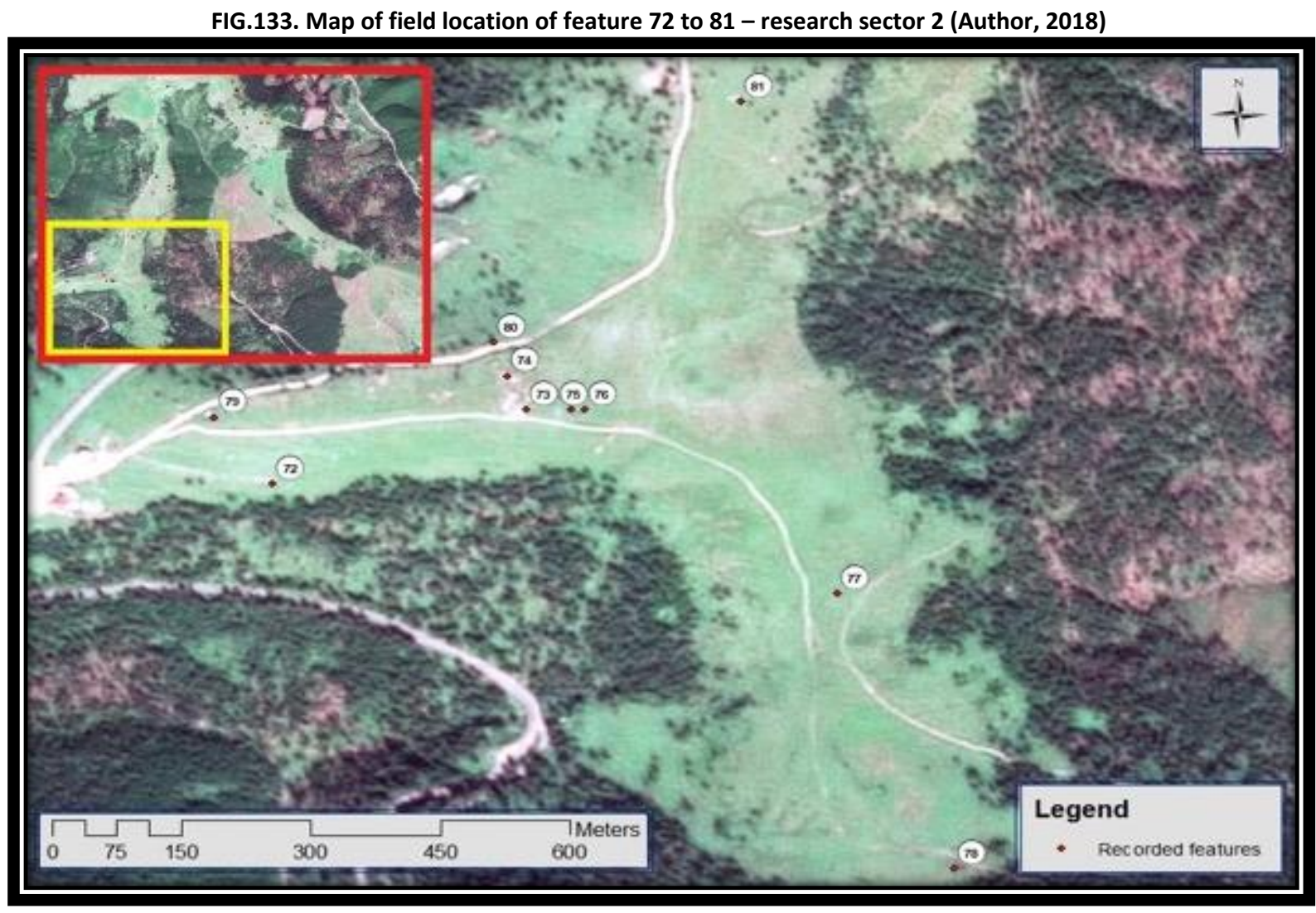

Feature 72 represents a bunker, situated at $47.60941^{\circ} \mathrm{N}-24.86115^{\circ} \mathrm{E}$, at an altitude of $1406 \mathrm{~m}$ (FIG.134 A, B). The bunker made of reinforced concrete was damaged by an explosion. It has a rectangular shape with a length of $8 \mathrm{~m}$ and a width of $4.5 \mathrm{~m}$. The walls have a diameter of 1 m. Currently the bunker is underneath an abandoned construction, a sort of platform suspended upon two pillars on the lower side. The construction has stairs on the left upper side, a length of $12 \mathrm{~m}$ and a width of $10 \mathrm{~m}$. There is a trench system leading to the bunker and 
shaped stone with joints of cement and gravel can be seen on the site of the bunker which is oriented to the SW.

FIG.134. Feature 72 - bunker (Author, 2017)
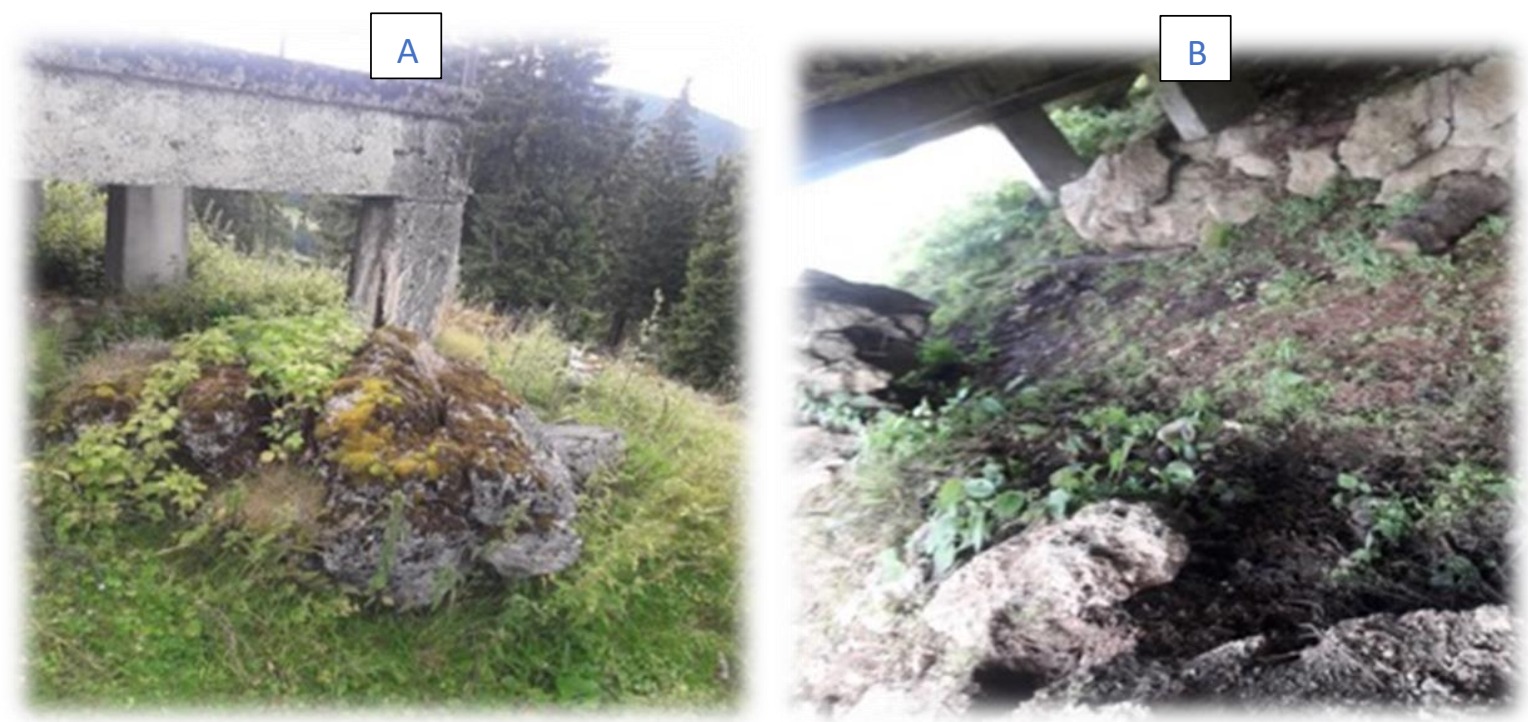

Feature 73 represents a bunker, situated at $47.61034^{\circ} \mathrm{N}-24.86508^{\circ} \mathrm{E}$, at an altitude of $1450 \mathrm{~m}$ (FIG.135 A, B). The bunker, made of reinforced concrete, was severely damaged by an explosion making it impossible to estimate its size and characteristics.

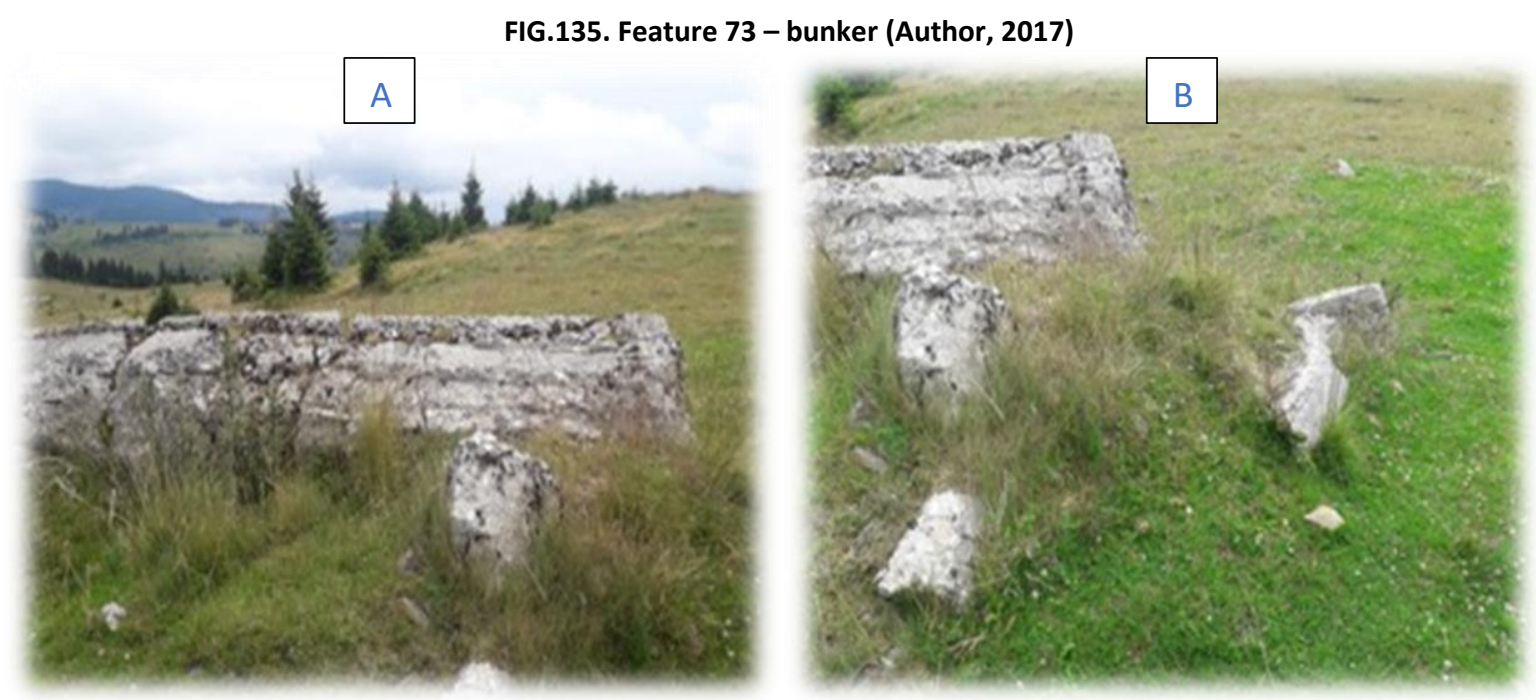

Feature 74 represents a bunker, situated at $47.61065^{\circ} \mathrm{N}-24.86480^{\circ} \mathrm{E}$, at an altitude of $1446 \mathrm{~m}$ (FIG.136 A, B). The bunker, made of reinforced concrete, was severely damaged by an 
explosion making it impossible to estimate its size and characteristics. There is a trench system leading to the bunker and shaped stone can be seen on the site.

FIG.136. Feature 74 - bunker (Author, 2017)
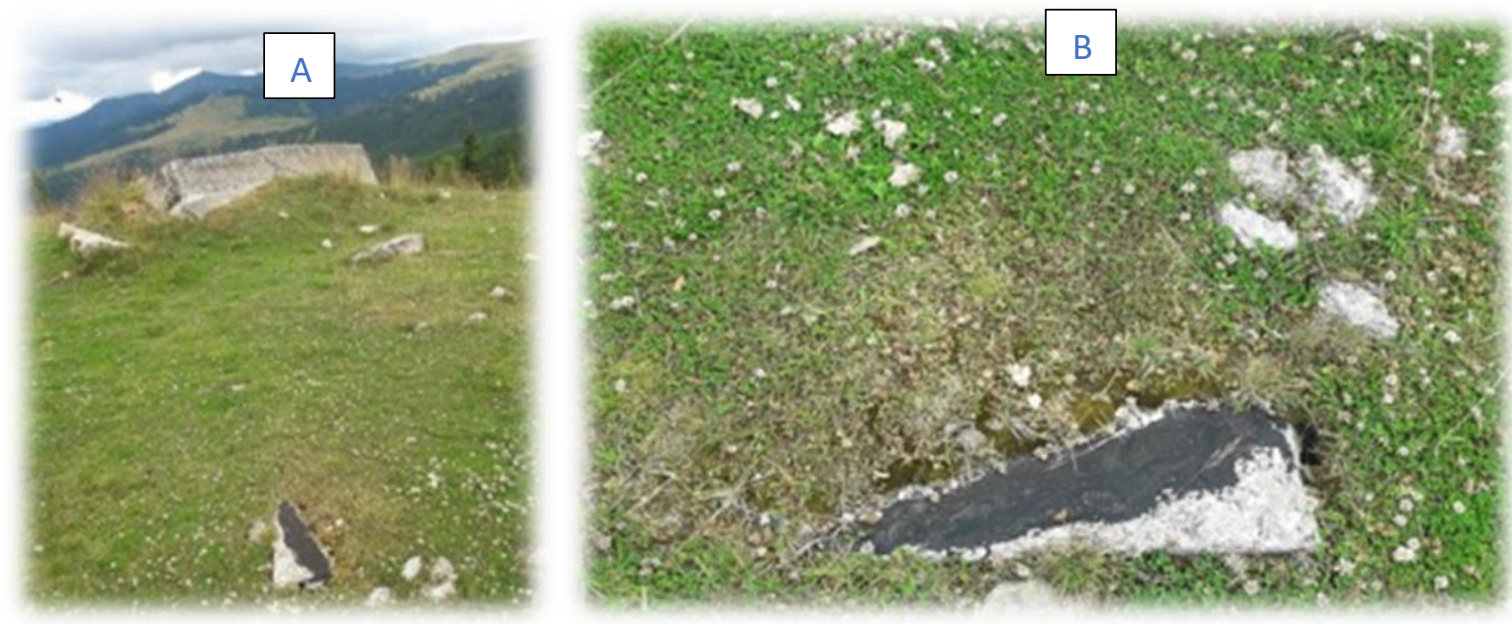

Feature 75 represents a square building foundation, situated at $47.61029^{\circ} \mathrm{N}-24.86579^{\circ} \mathrm{E}$, at an altitude of $1455 \mathrm{~m}$ (FIG.137 A, B, C). The foundation is made of cement and gravel and is covered with a layer of bitumen. On the foundation there is a sedimentary layer of approximately $15 \mathrm{~cm}$ and fragments of bricks can be seen in the vegetation layer. On the left side is a trench system leading to the building and continuing to the right towards a bunker. In front of the building at approximately $3 \mathrm{~m}$ there are 3 concrete pillars (FIG. $137 \mathrm{~B}$ ) arranged in triangle on top of which are some metal facilities.

FIG.137. Feature 75 - square building foundation (Author, 2017)
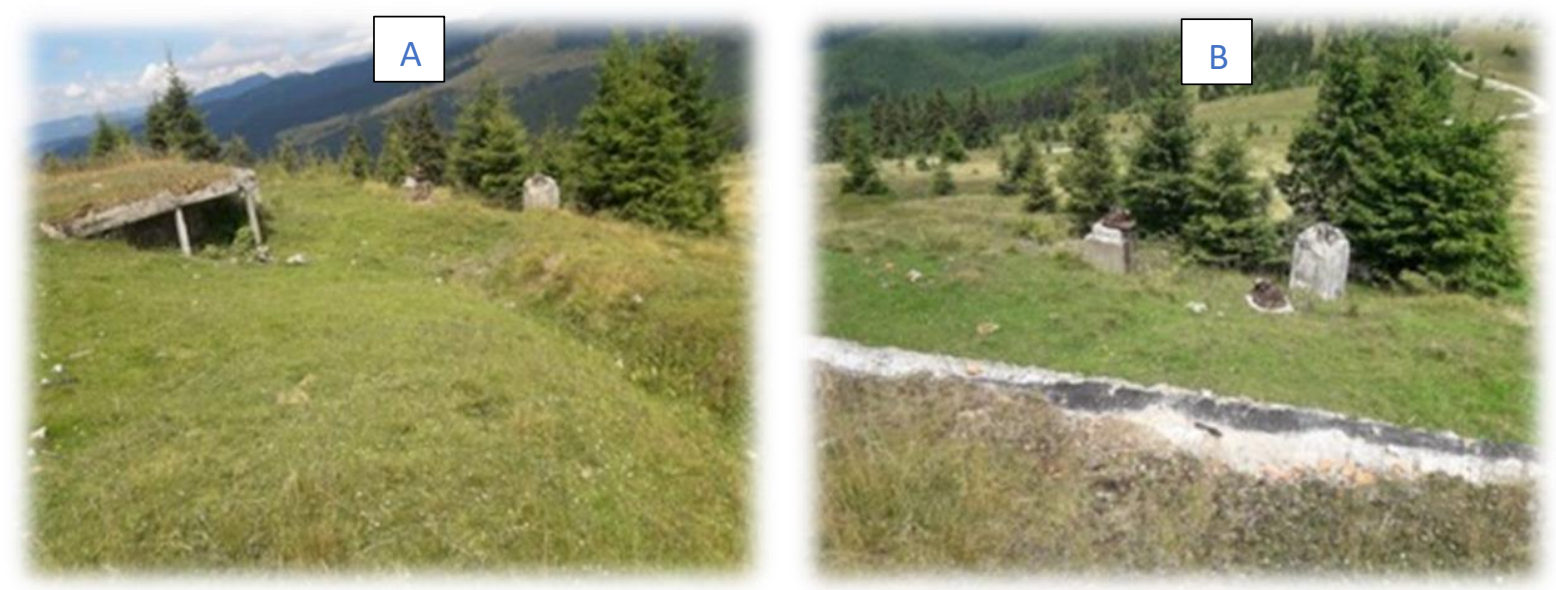


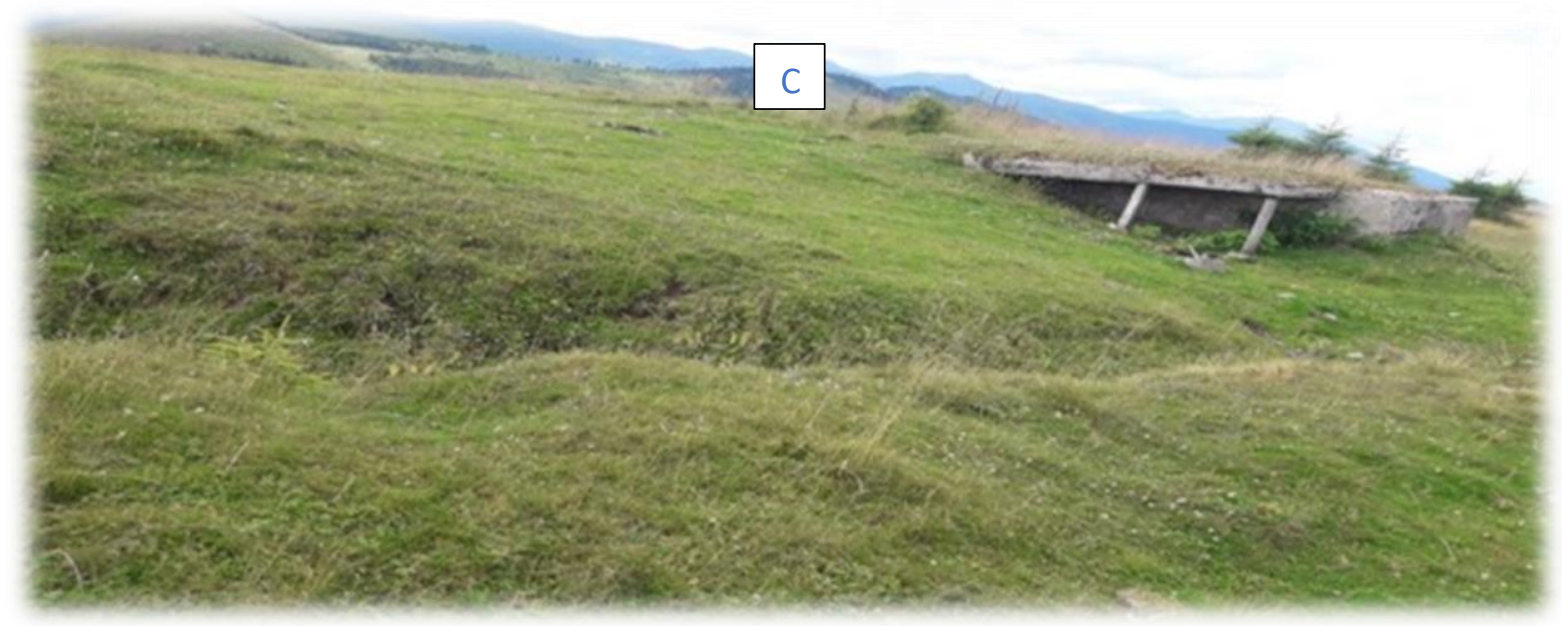

Feature 76 represents a bunker, situated at $47.61029^{\circ} \mathrm{N}-24.86603^{\circ} \mathrm{E}$, at an altitude of $1455 \mathrm{~m}$ (FIG.138 A, B). The bunker, made of reinforced concrete, was severely damaged by an explosion making it impossible to estimate its size and characteristics. There is a trench system connecting the bunker to the above building and shaped stone can be seen on the site of the bunker which is oriented to the N-NE.
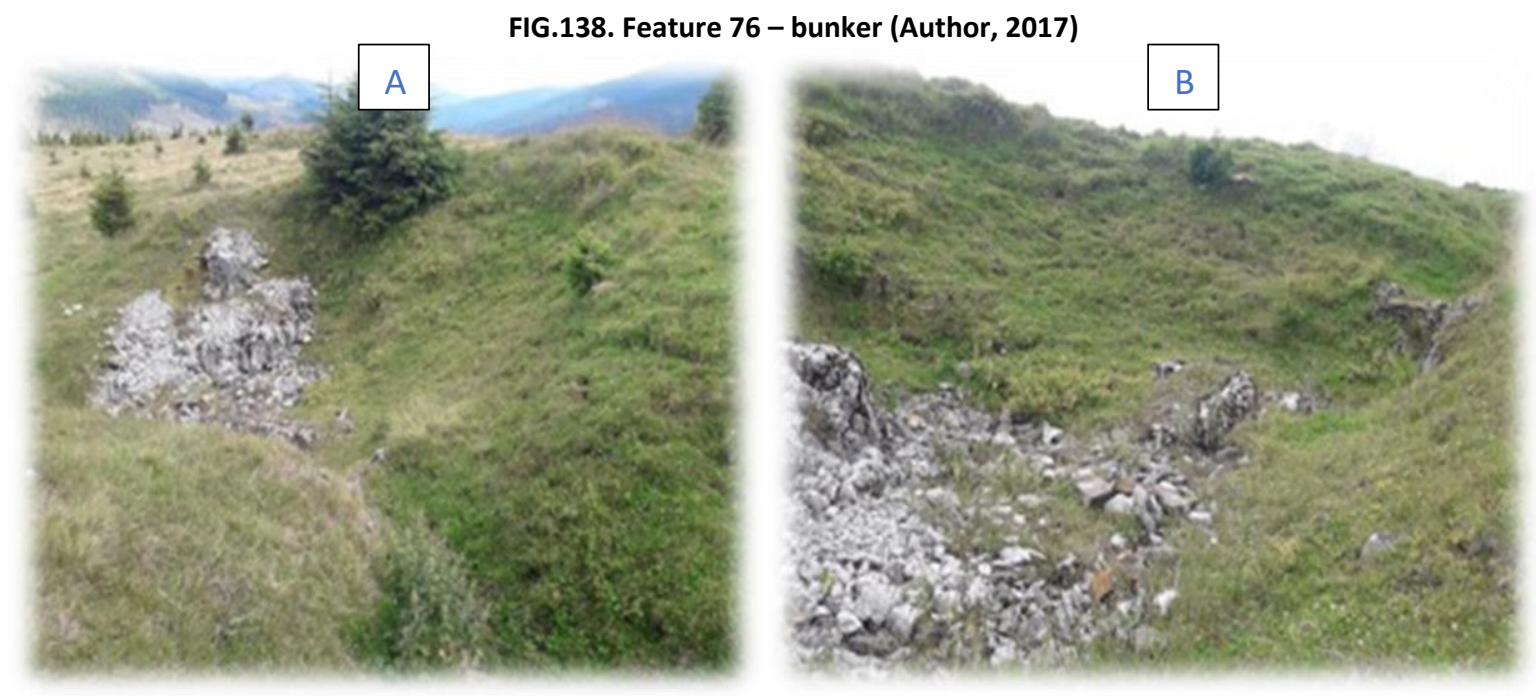

Feature 77 represents a bunker situated at $47.60807^{\circ} \mathrm{N}-24.86994^{\circ} \mathrm{E}$, at an altitude of $1418 \mathrm{~m}$ (FIG.139 A,B,C). The bunker, made of reinforced concrete, was severely damaged by an explosion making it impossible to estimate its original size. Nevertheless, most probably the bunker was underground and had semi-cylindrical interior. 
FIG.139. Feature 77 - bunker (Author, 2017)
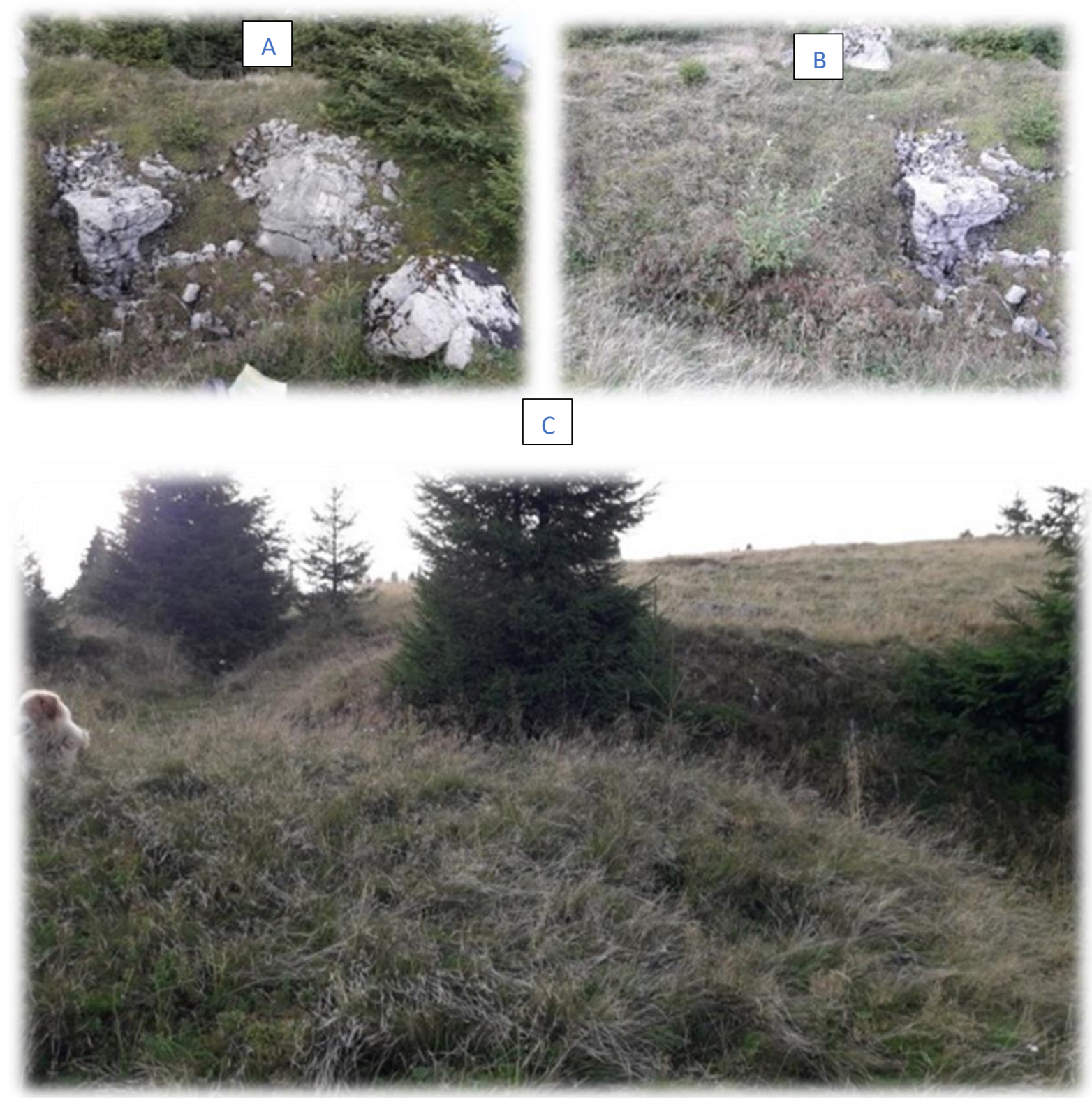

Feature 78 represents a bunker (FIG.140 B), situated at $47.60484^{\circ} \mathrm{N}-24.87170^{\circ} \mathrm{E}$, at an altitude of $1432 \mathrm{~m}$. As in the previous case it is likely that the bunker was underground and had a semi-cylindrical interior. The bunker has a parallel sibling (FIG.140 C) to the right, of the same shape and dimension, connected by a network of trenches. The two parallel bunkers were represented together on the map, by Feature 78, due to their proximity - they are located on the sides of the pines in the upper left corner of FIG.140 A, hidden by a pile of branches as is the adjacent trench. 
FIG.140. Feature 78 - parallel bunkers (Author, 2017)
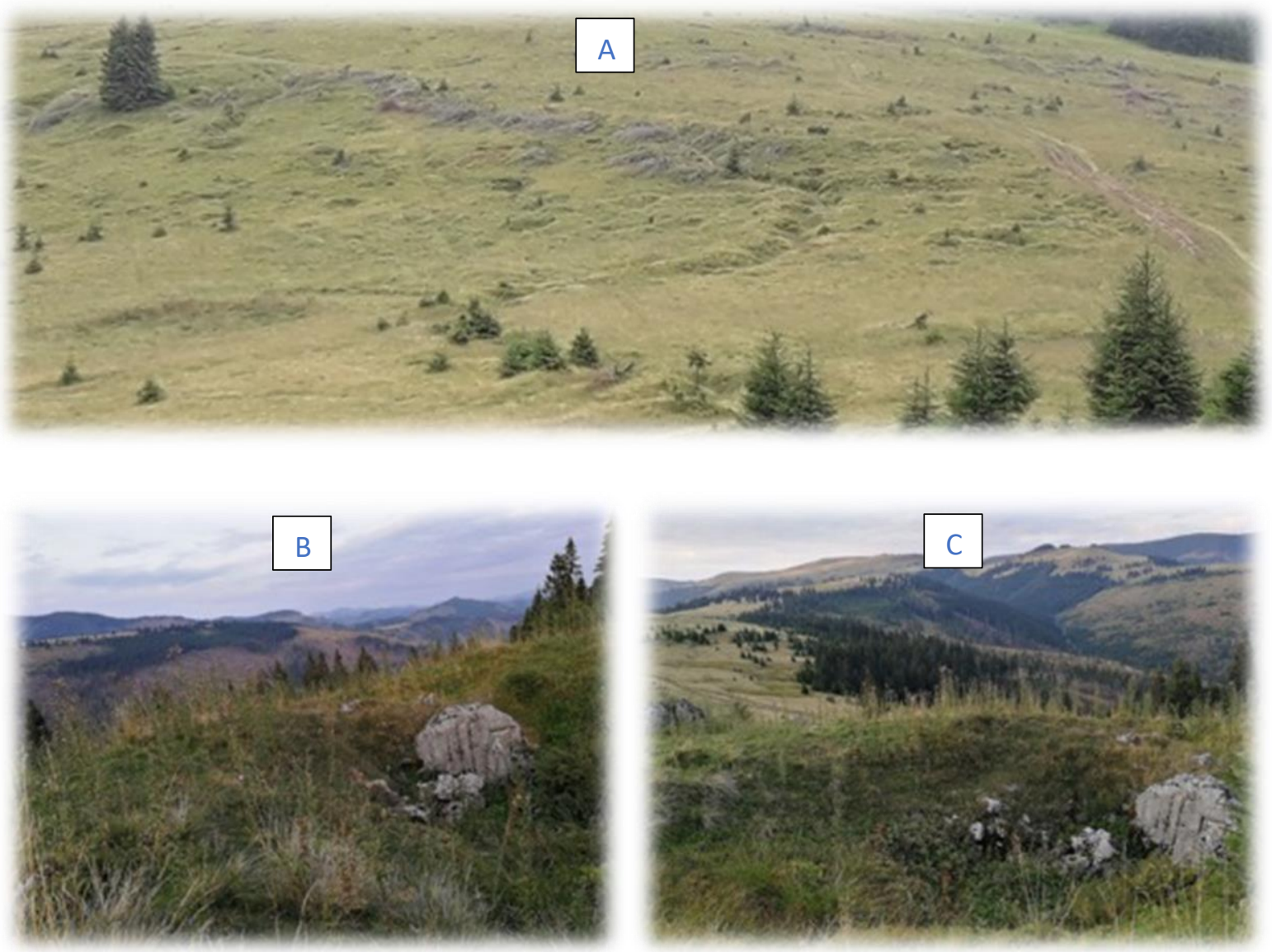

Feature 79 represents a large sized bunker, situated at $47.61023^{\circ} \mathrm{N}-24.86028^{\circ} \mathrm{E}$, at an altitude of $1401 \mathrm{~m}$ (FIG.141 A, B, C). The bunker, made of reinforced concrete, was severely damaged by an explosion making it impossible to estimate its original size and characteristics.

The bunker is oriented to the $\mathrm{W}$.

FIG.141. Feature 79 - bunker (Author, 2017)
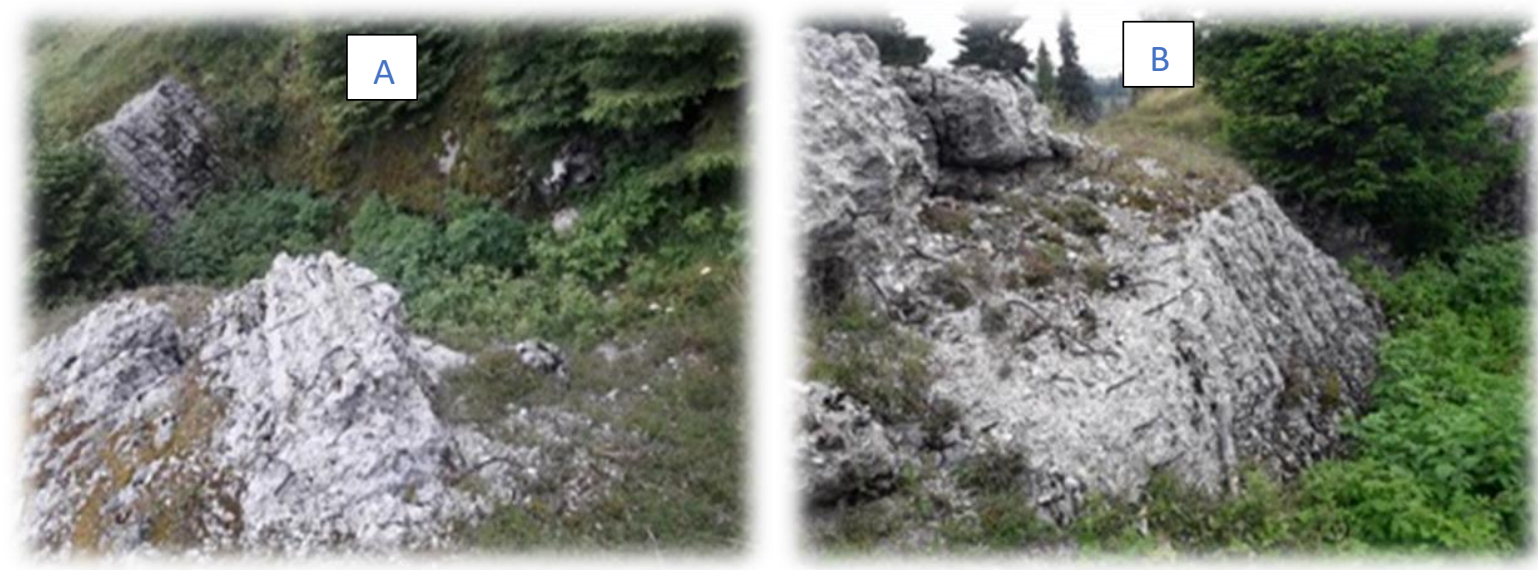


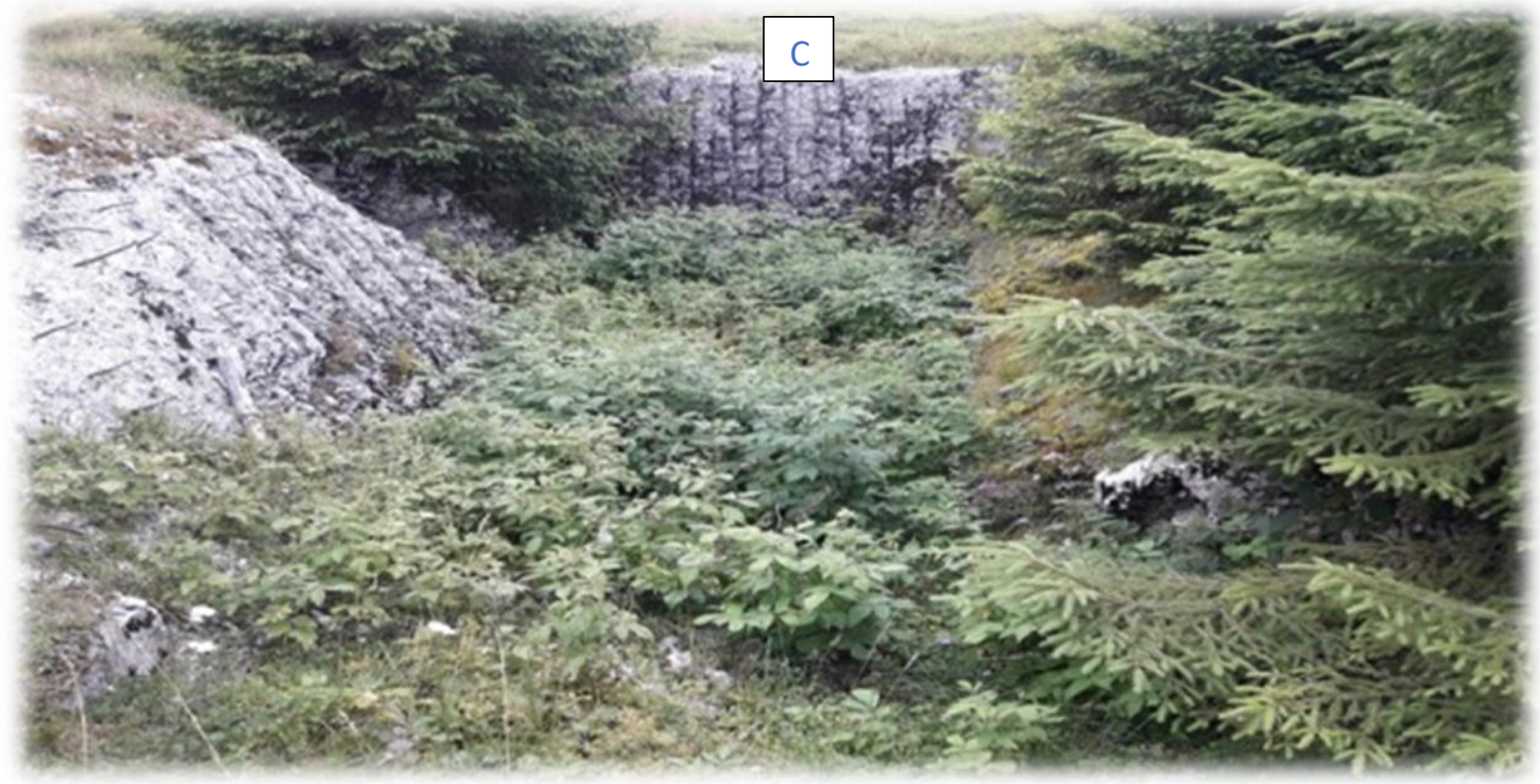

Feature 80 represents a bunker, situated at $47.61114^{\circ} \mathrm{N}-24.86458^{\circ} \mathrm{E}$, at an altitude of $1443 \mathrm{~m}$

(FIG.142 A, B, C). The bunker, made of reinforced concrete, was severely damaged by an explosion making it impossible to estimate its original size and characteristics. The bunker is oriented to the $\mathrm{W}$.

FIG.142. Feature 80 - bunker (Author, 2017)
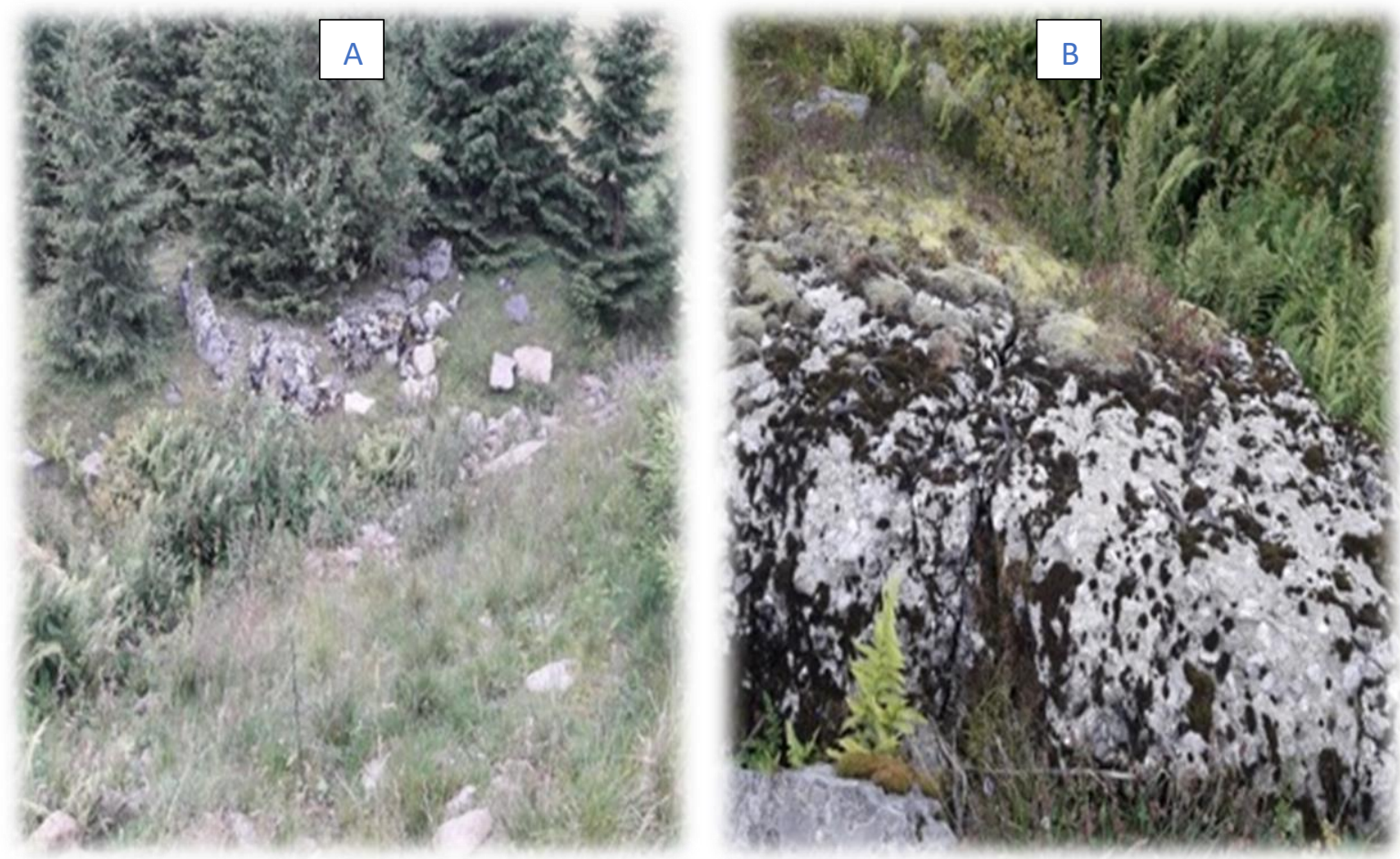


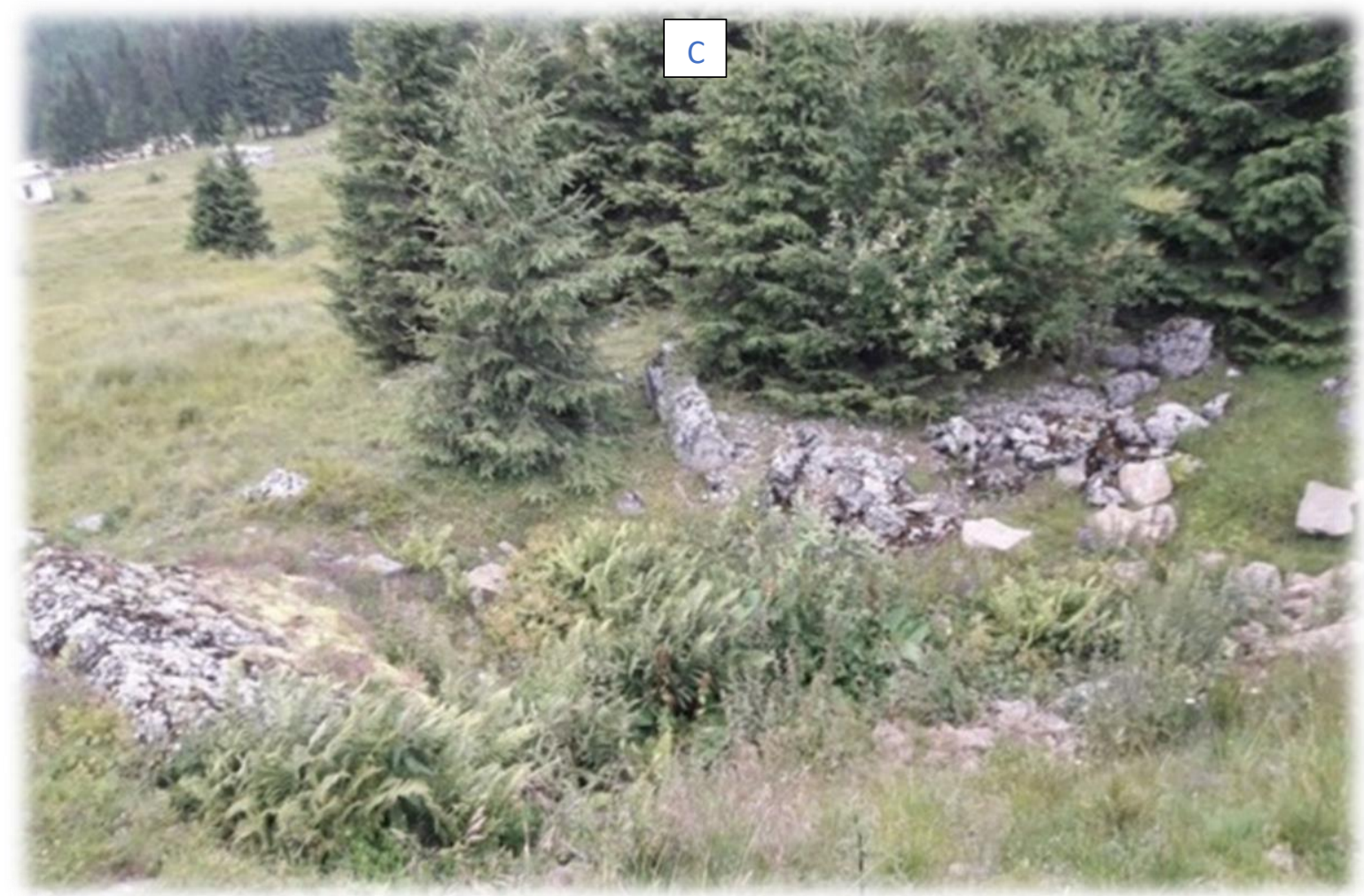

Feature 81 represents a bunker, situated at $47.61401^{\circ} \mathrm{N}-24.86841^{\circ} \mathrm{E}$, at an altitude of $1450 \mathrm{~m}$ (FIG.143 A, B). The bunker, made of reinforced concrete, was severely damaged by an explosion making it impossible to estimate its original size and characteristics.

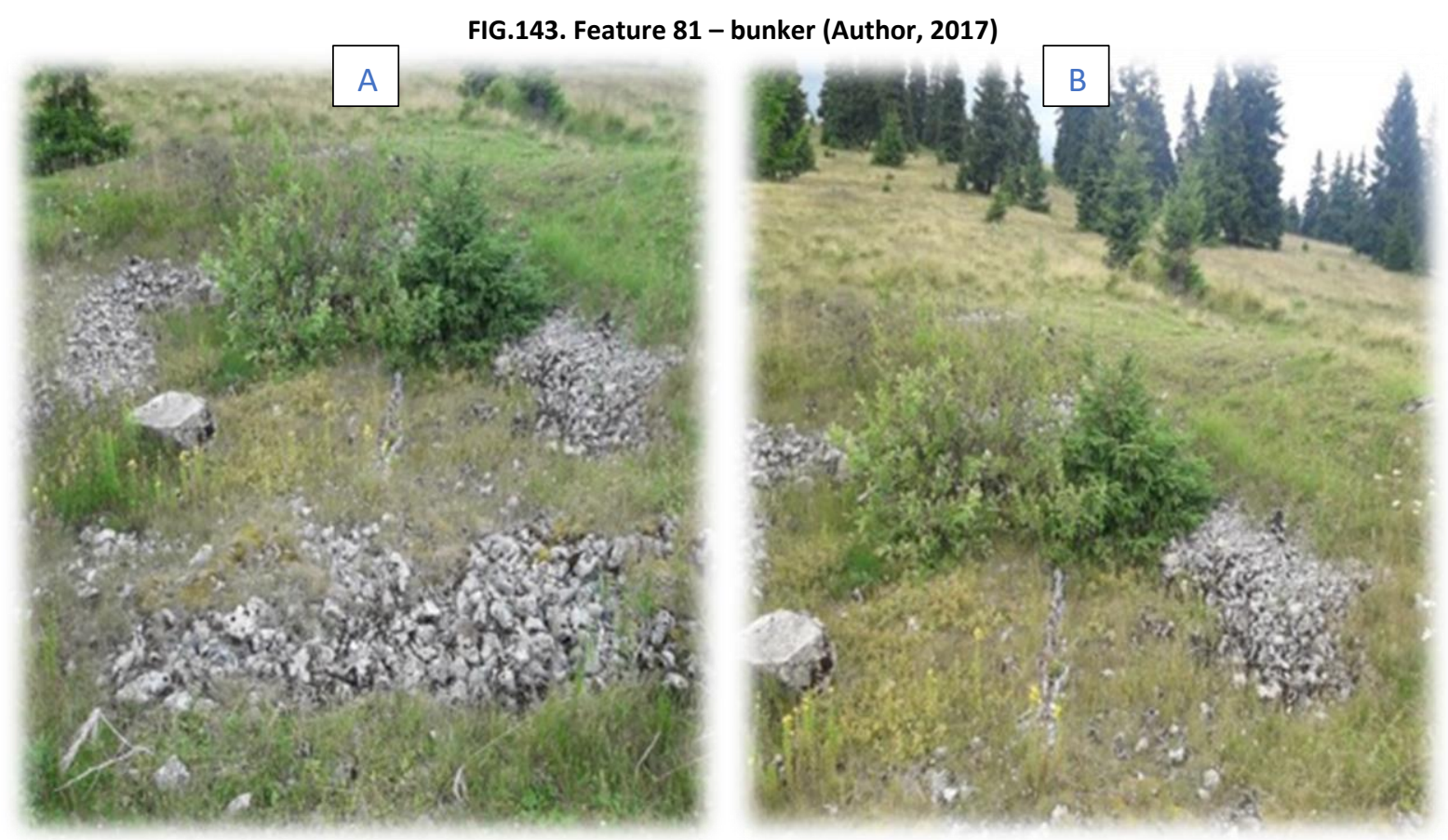


FIG.144 represents a map of the field location of Features 82 to 89 along with the position of this section of the field (yellow rectangle) within research sector 2 (red rectangle).

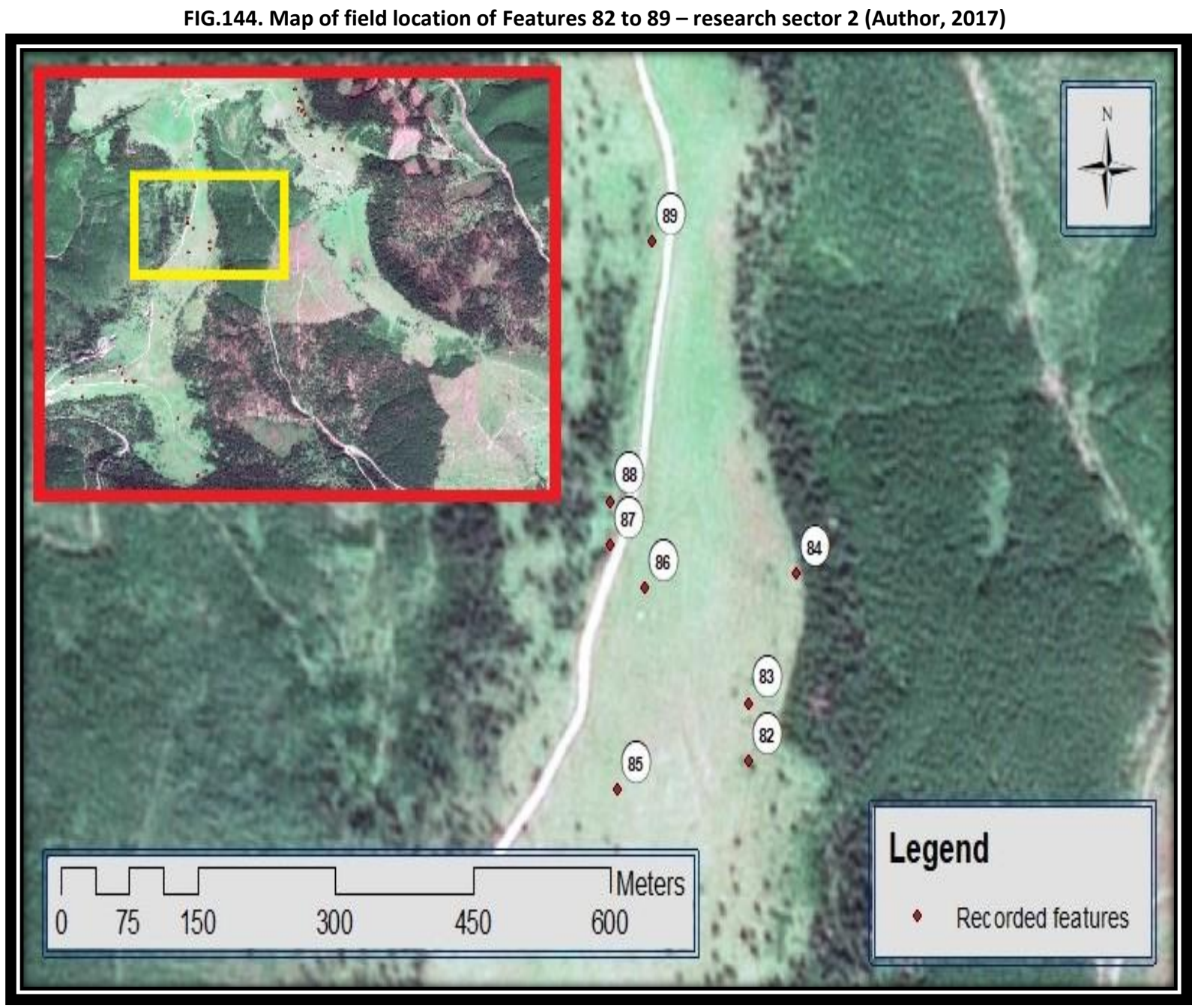

Feature 82 represents a bunker, situated at $47.61797^{\circ} \mathrm{N}-24.87270^{\circ} \mathrm{E}$, at an altitude of $1493 \mathrm{~m}$ (FIG.145 A, B, C, D). The bunker, made of reinforced concrete, has a length of $3 \mathrm{~m}$ and a width of $3.80 \mathrm{~m}$. The exterior height of the construction is of $2.10 \mathrm{~m}$ on the front side and $1 \mathrm{~m}$ at the back. The bunker has a pentagonal shape, with walls of concrete $1 \mathrm{~m}$ thick reinforced with $2.5 \mathrm{~cm}$ metal bars. The interior of the bunker has a weight of $2.46 \mathrm{~m}$, a height at the entrance of $1.23 \mathrm{~m}$ and of $1.70 \mathrm{~m}$ in the back. Inside the bunker $8 \mathrm{~cm}$ striations can be seen on the side walls. The exterior of the bunker was covered with a layer of bitumen and a layer of plaster. Shaped stones can be seen on the site of the bunker which is oriented to the SW-W. 

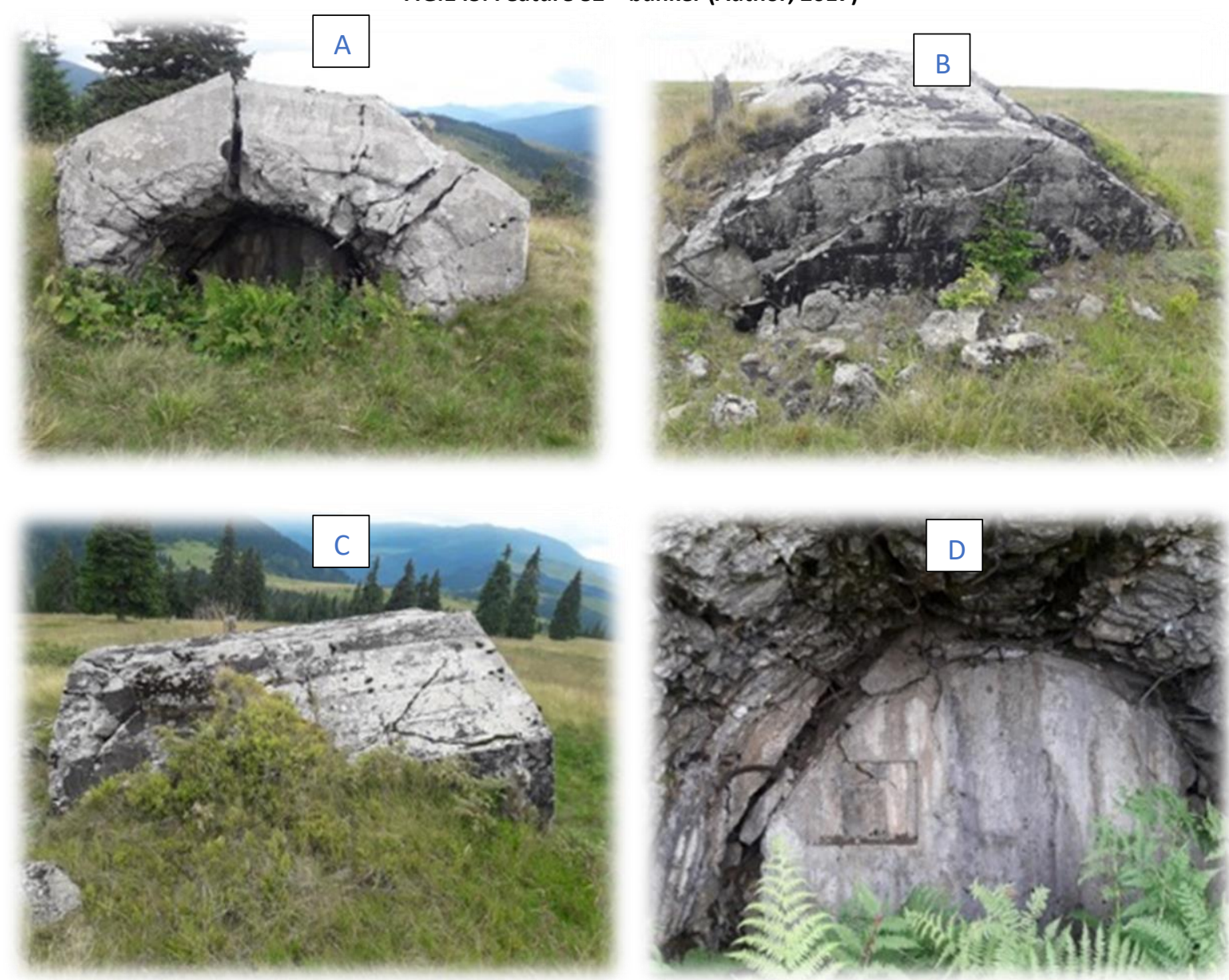

Feature 83 represents a bunker, situated at $47.61844^{\circ} \mathrm{N}-24.87265^{\circ} \mathrm{E}$, at an altitude of $1502 \mathrm{~m}$

(FIG.146 A, B). The bunker, made of reinforced concrete, was severely damaged by an explosion making it impossible to estimate its original size and characteristics.

\section{FIG.146. Feature 83 - bunker (Author, 2017)}
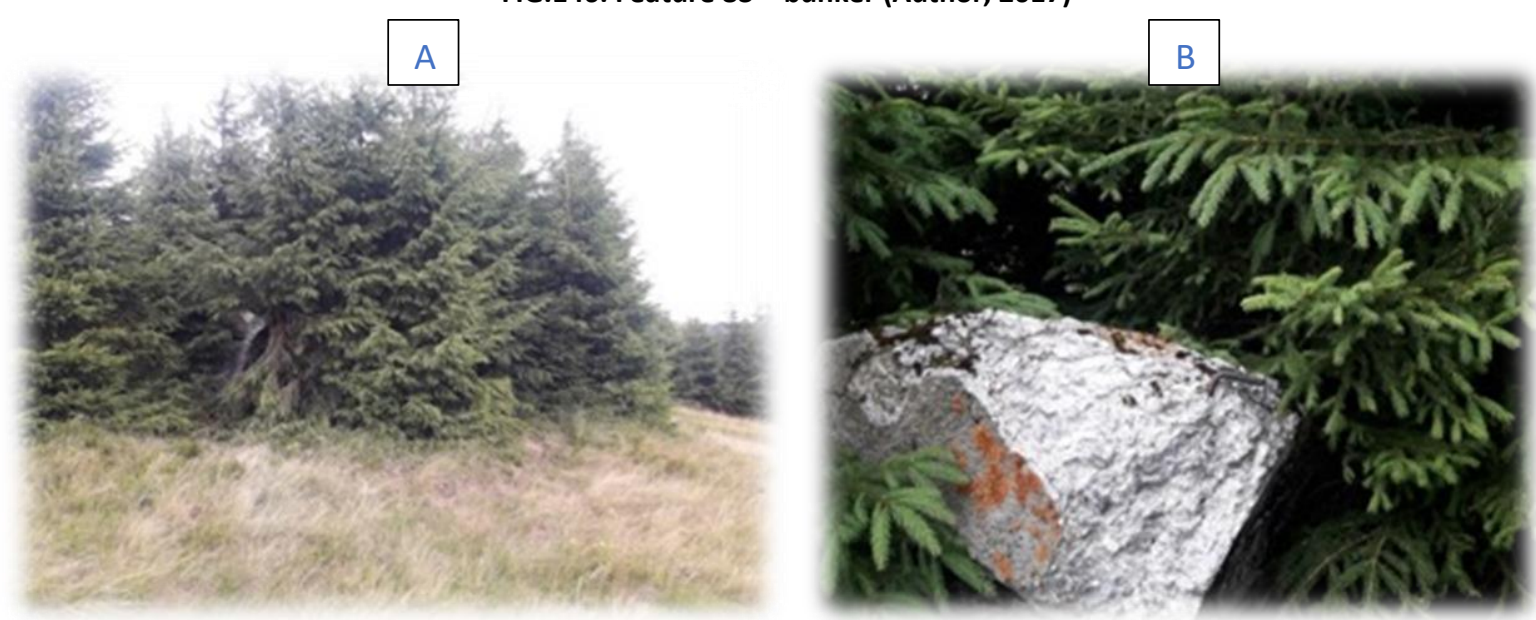
Feature 84 represents a bunker, situated at $47.61933^{\circ} \mathrm{N}-24.87340^{\circ} \mathrm{E}$, at an altitude of $1506 \mathrm{~m}$

(FIG.147 A,B,C). The bunker made of reinforced concrete was severely damaged by an explosion making it impossible to estimate its original size but allowing visualisation of characteristics similar to Feature 82.

FIG.147. Feature 84 - bunker (Author, 2017)
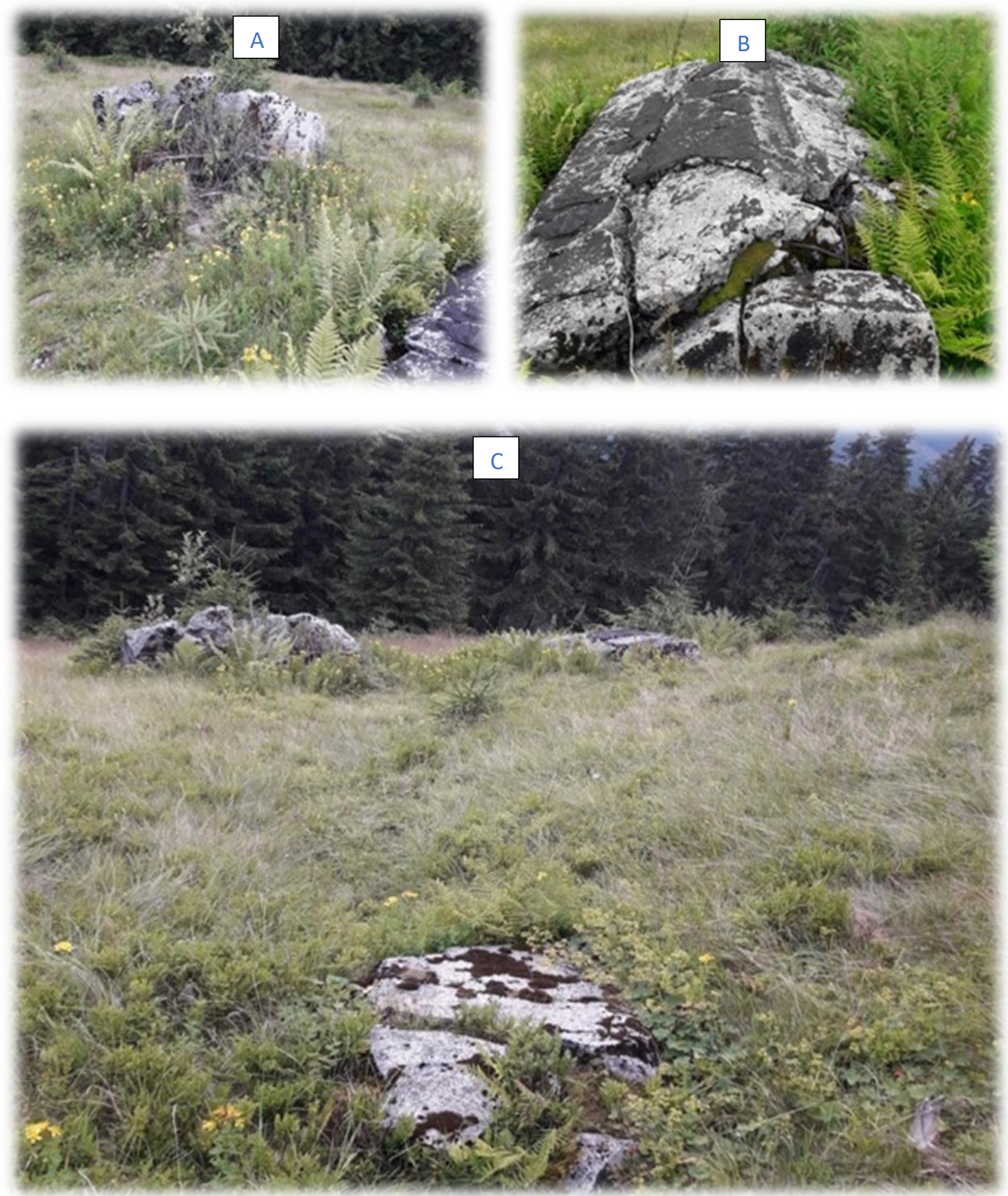
Feature 85 represents a bunker, situated at $47.61784^{\circ} \mathrm{N}-24.87077^{\circ} \mathrm{E}$, at an altitude of $1507 \mathrm{~m}$ (FIG.148 A,B). The bunker, made of reinforced concrete, was severely damaged by an explosion making it impossible to estimate its original size and characteristics.

FIG.148. Feature 85 - bunker (Author, 2017)
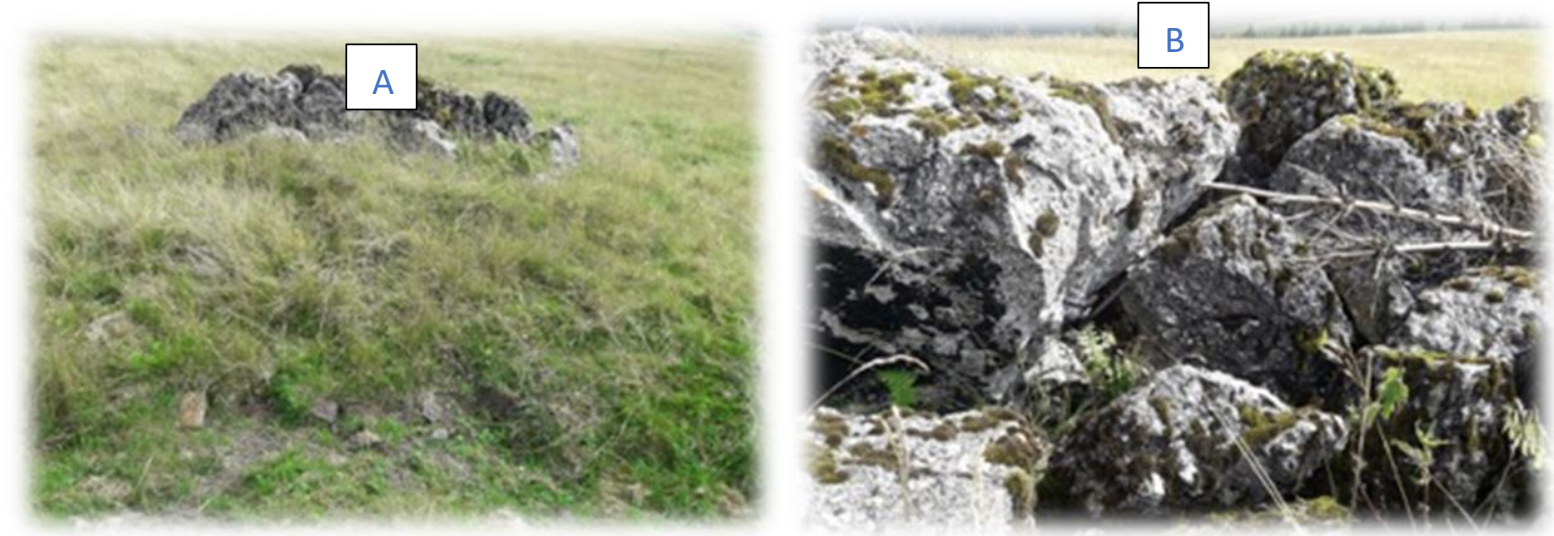

Feature 86 represents a large size bunker, situated at $47.61918^{\circ} \mathrm{N}-24.87122^{\circ} \mathrm{E}$, at an altitude of 1539 m (FIG.149 A, B). The bunker, made of reinforced concrete, was severely damaged by an explosion making it impossible to estimate its original size and characteristics.

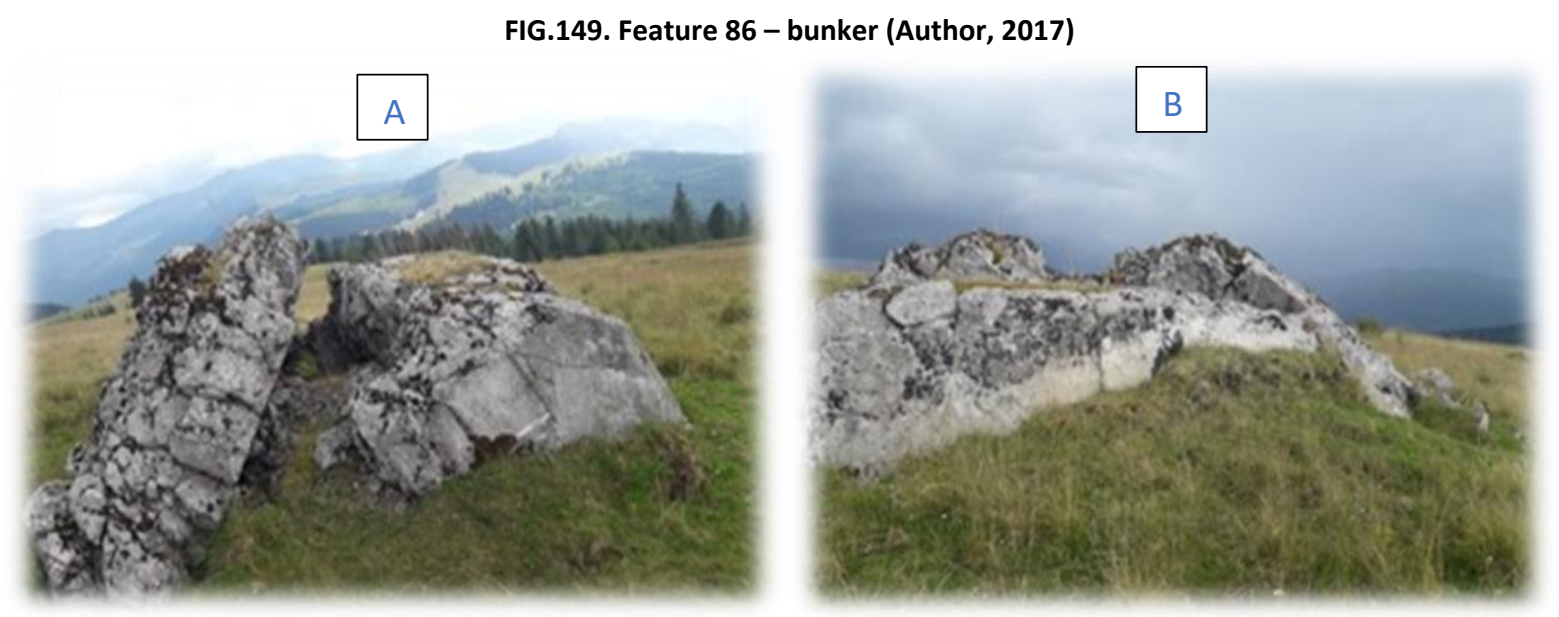

Feature 87 represents a bunker, situated at $47.61951^{\circ} \mathrm{N}-24.87065^{\circ} \mathrm{E}$, at an altitude of $1501 \mathrm{~m}$ (FIG.150 A). The bunker, made of reinforced concrete, was damaged by an explosion that catapulted the roof into the valley in front (FIG.150 B, C) but left the walls intact. The construction has a length of $5.50 \mathrm{~m}$, a width of $5 \mathrm{~m}$ and a height of $1.50 \mathrm{~m}$. The $50 \mathrm{~cm}$ thick 
walls are fixed in an excavation made in the hill slope. The lateral sides of the bunker are reinforced on the exterior with piles of earth and stone. The flor is also made of concrete and there is a circular hole in the left wall with a diameter of approximately $13 \mathrm{~cm}$. The bunker is oriented to the W-NW.

FIG.150. Feature 87 - bunker (Author, 2017)
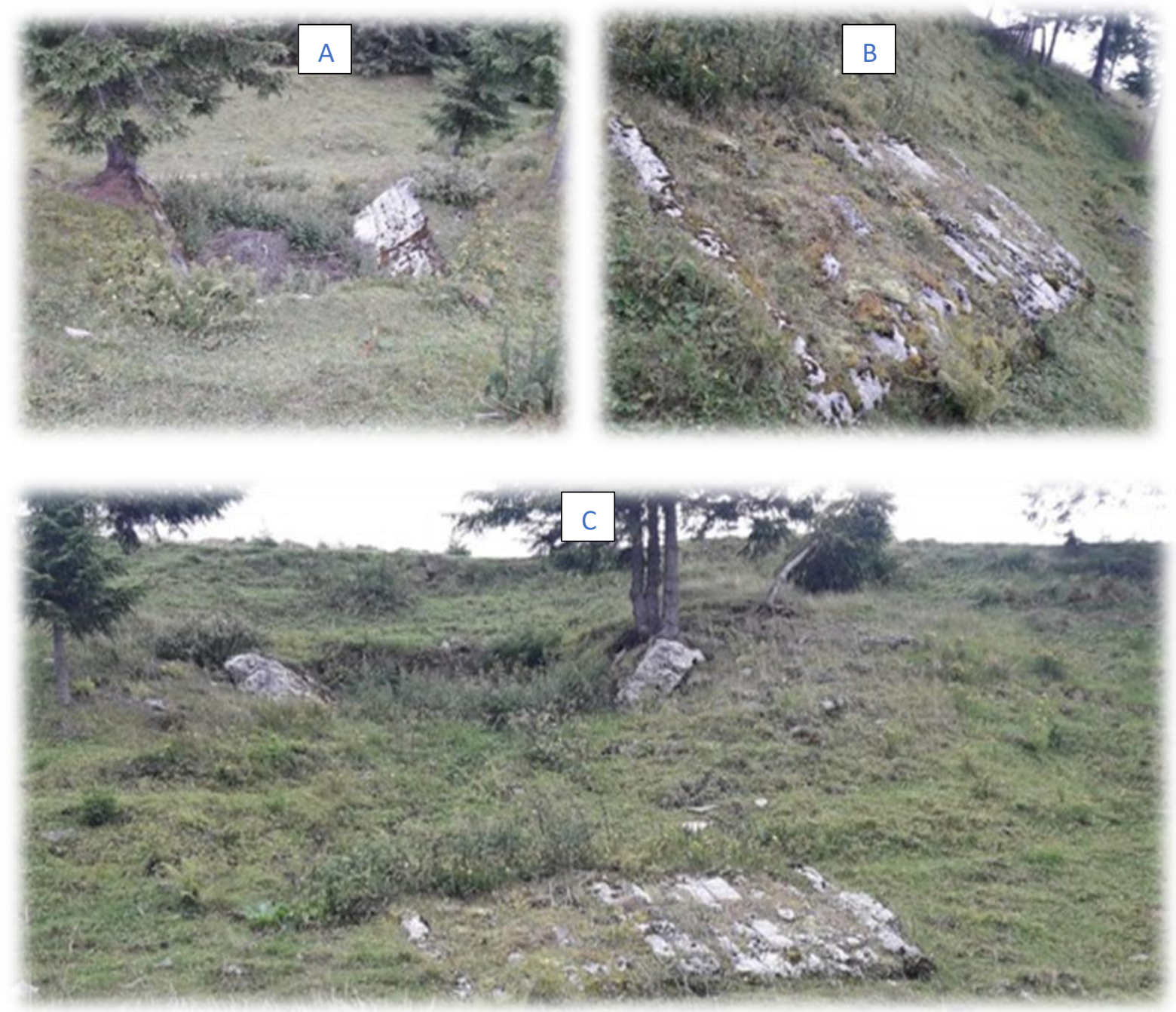

Feature 88 represents a bunker, situated at $47.61983^{\circ} \mathrm{N}-24.87067^{\circ} \mathrm{E}$, at an altitude of $1495 \mathrm{~m}$ (FIG.151 A, B). The bunker, made of reinforced concrete, was damaged by an explosion. Only the floor of the bunker is preserved intact. It has a length of $7.50 \mathrm{~m}$ and a width of 4.50 m. Traces of bitumen (FIG.151 C) can be seen on the site of the bunker. Near the bunker there is a building foundation $5.50 \mathrm{~m}$ long and $4 \mathrm{~m}$ wide. They are built on an embankment 
excavated into the hill slope and the lateral sides are reinforced on the exterior with piles of earth and stone. The bunker is oriented to the $\mathrm{W}$.

FIG.151. Feature 88 - bunker (Author, 2017)
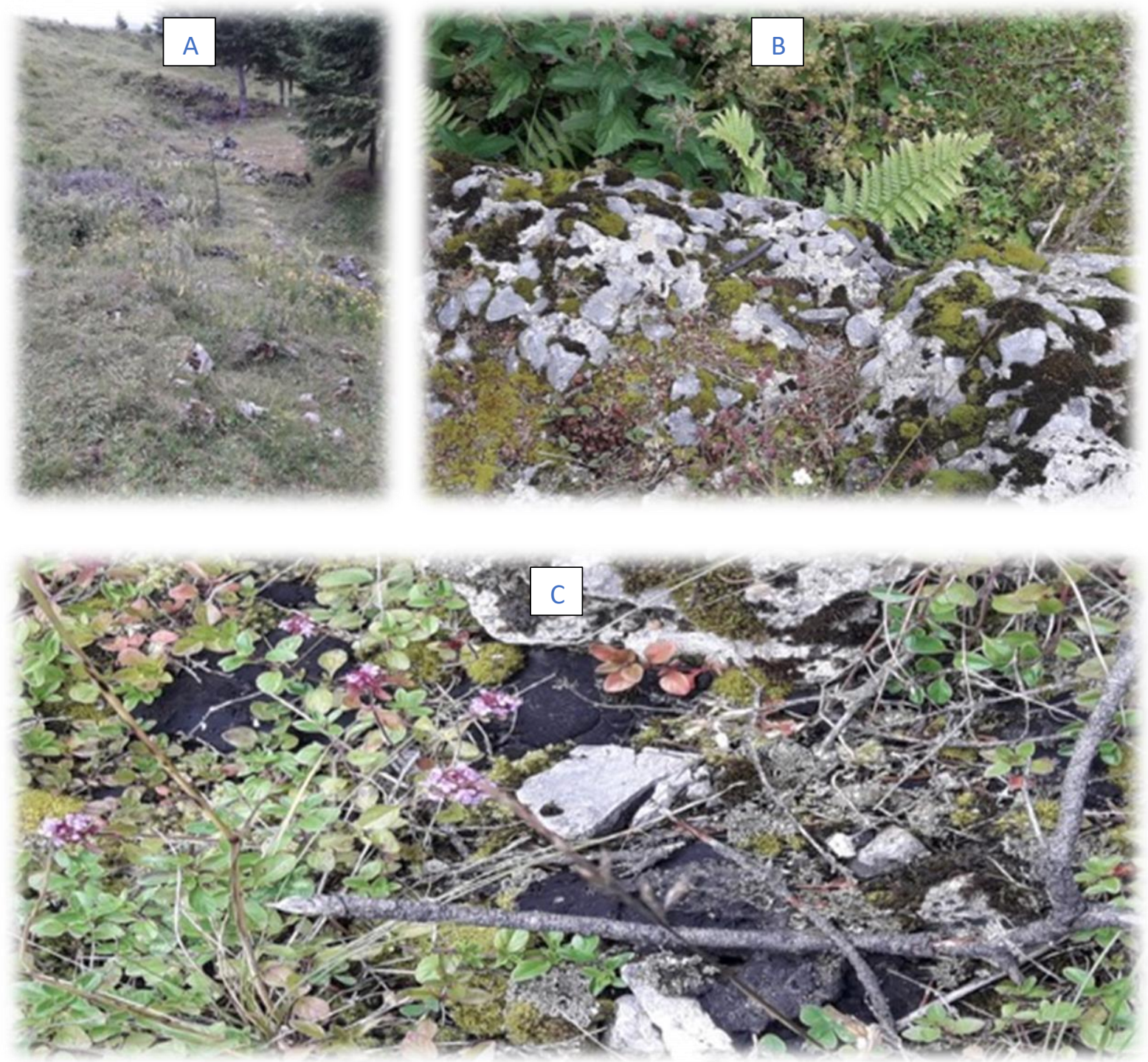

Feature 89 represents a bunker, situated at $47.62157^{\circ} \mathrm{N}-24.87129^{\circ} \mathrm{E}$, at an altitude of $1518 \mathrm{~m}$ (FIG.152 A). The bunker made of reinforced concrete was damaged by an explosion. The roof can be seen at a distance of $2 \mathrm{~m}$ from the bunker, largely unaltered (FIG.152 B, C). It consists of a flat concrete platform, covered by a layer of bitumen and a $10 \mathrm{~cm}$ layer of plaster. The construction has a length of $5.50 \mathrm{~m}$, a width of $5 \mathrm{~m}$ and a height of $1.50 \mathrm{~m}$. The $50 \mathrm{~cm}$ thick walls (FIG.152 D) are fixed in an excavation made in the hill slope. The lateral sides of the 
bunker are reinforced on the exterior with piles of earth and stone. The floor of the bunker is also made of concrete. The bunker is oriented to the $\mathrm{W}$.

FIG.152. Feature 89 - bunker (Author, 2017)
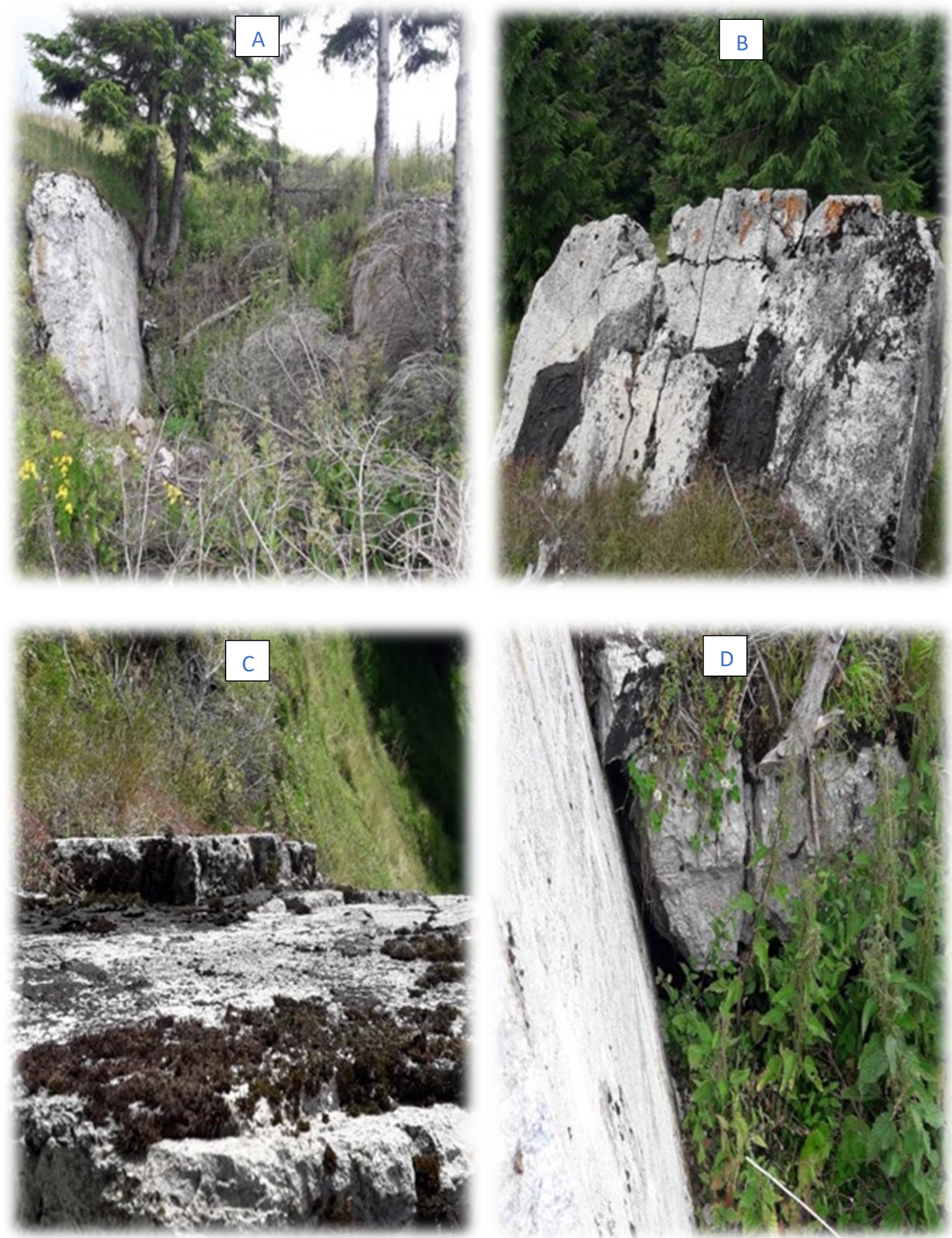
FIG.153 represents a map of the field location of Features 90 to 103, along with the position of this section of the field (yellow rectangle) within research sector 2 (red rectangle).

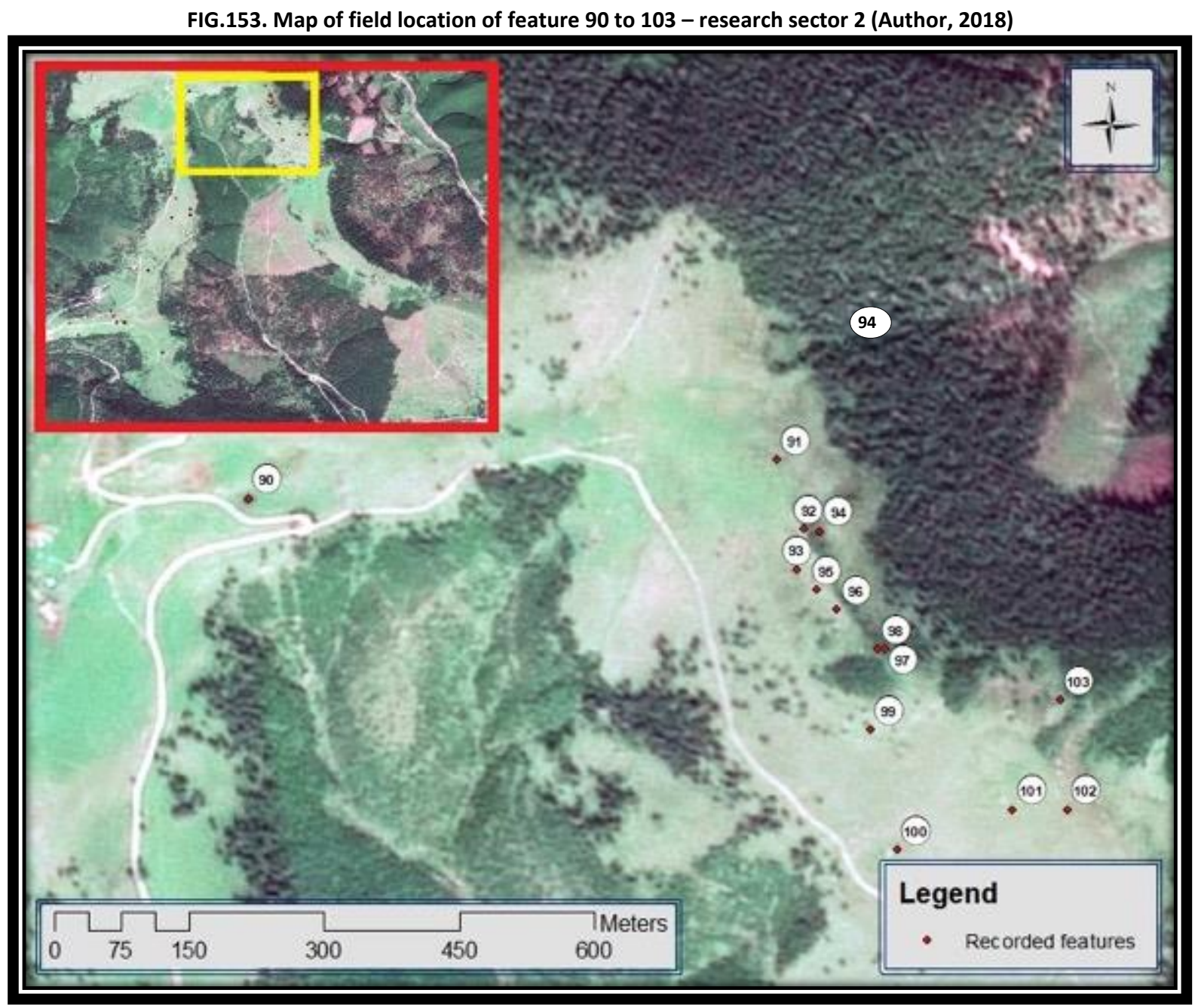

Feature 90 represents a bunker, situated at $47.62690^{\circ} \mathrm{N}-24.87261^{\circ} \mathrm{E}$, at an altitude of $1518 \mathrm{~m}$ (FIG.154 A, B, C, D, E). The bunker made of reinforced concrete was built in an excavation in the hill slope. It has a length of $7 \mathrm{~m}$ and a width of $5 \mathrm{~m}$ in the front side and of $3.50 \mathrm{~m}$ in the back. The height at the entrance is of $1.50 \mathrm{~m}$. The structure was damaged by an explosion that seems to have occurred in the back of the bunker where the roof is missing. The roof is flat; it has eaves of $20 \mathrm{~cm}$ in the front and is covered with a layer of bitumen and a layer of plaster. A $20 \mathrm{~cm}$ wide and $5 \mathrm{~m}$ long wooden board is fixed on the lower side of the eaves. The walls and the roof are $1 \mathrm{~m}$ thick. The bunker is oriented to the S-SE. 
FIG.154. Feature 90 - bunker (Author, 2017)
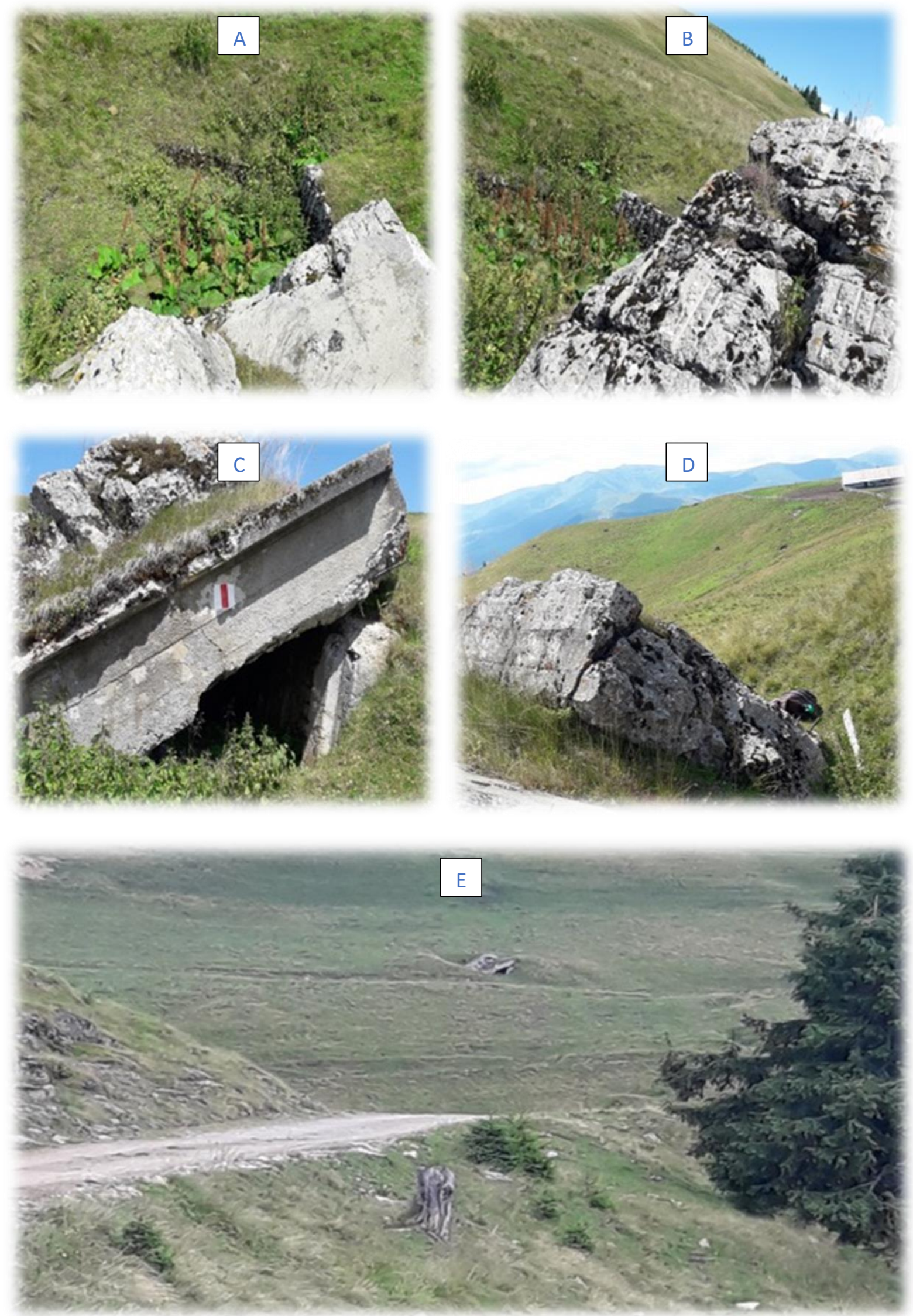
Feature 91 represents a trench system, whose highest point is situated at $47.62731^{\circ} \mathrm{N}-$ $24.88036^{\circ} \mathrm{E}$, at an altitude of $1568 \mathrm{~m}$ (FIG.155 A, B). The trench is $2 \mathrm{~m}$ wide and is approximately $1.50 \mathrm{~m}$ deep. The trench is excavated in stone.

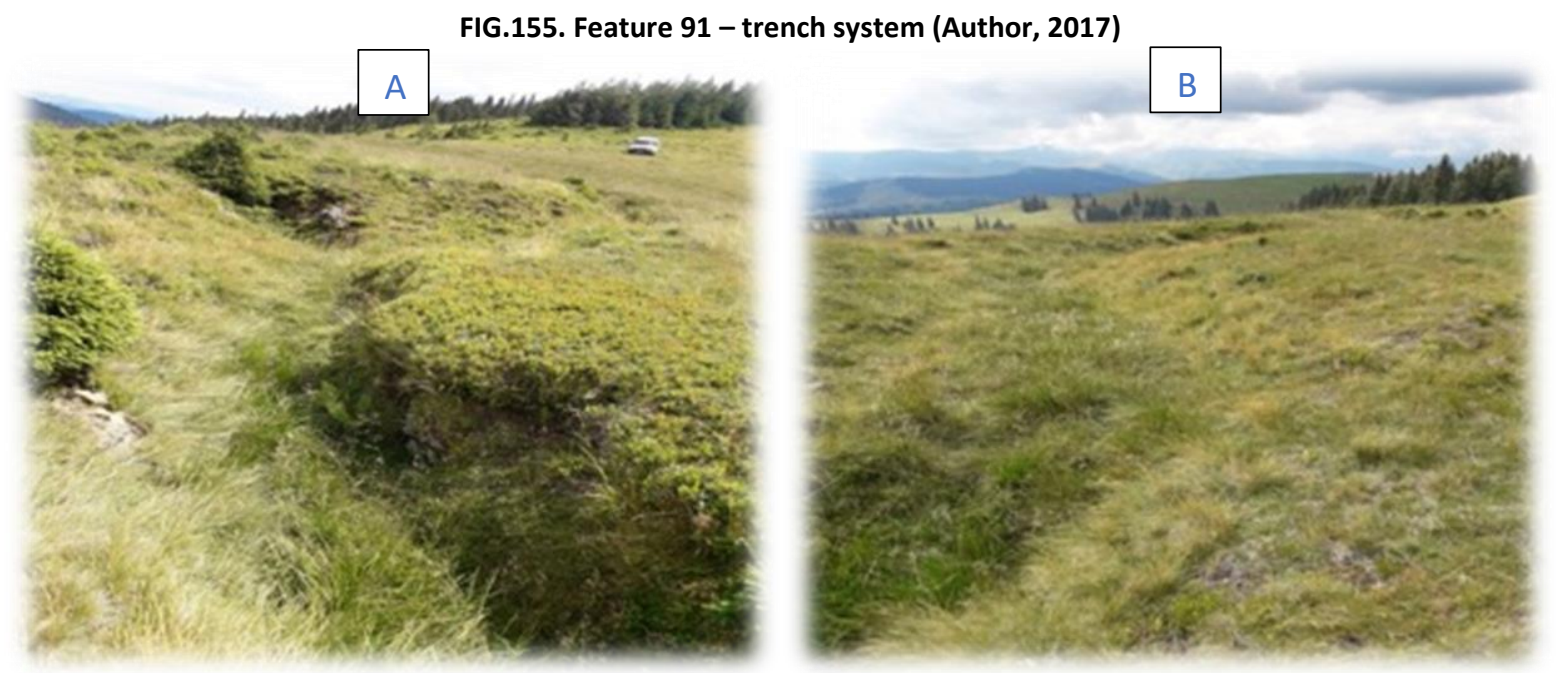

Feature 92 represents an earthwork situated at $47.62626^{\circ} \mathrm{N}-24.87902{ }^{\circ} \mathrm{E}$, at an altitude of $1595 \mathrm{~m}$ (FIG.156 A, B, C). The earthwork is a rectangular pit, $10 \mathrm{~m} \mathrm{long,} 9 \mathrm{~m}$ wide and approximately $2 \mathrm{~m}$ deep. The exterior sides of the pit are surrounded by piles of gravel.

FIG.156. Feature 92 - earthwork (Author, 2017)
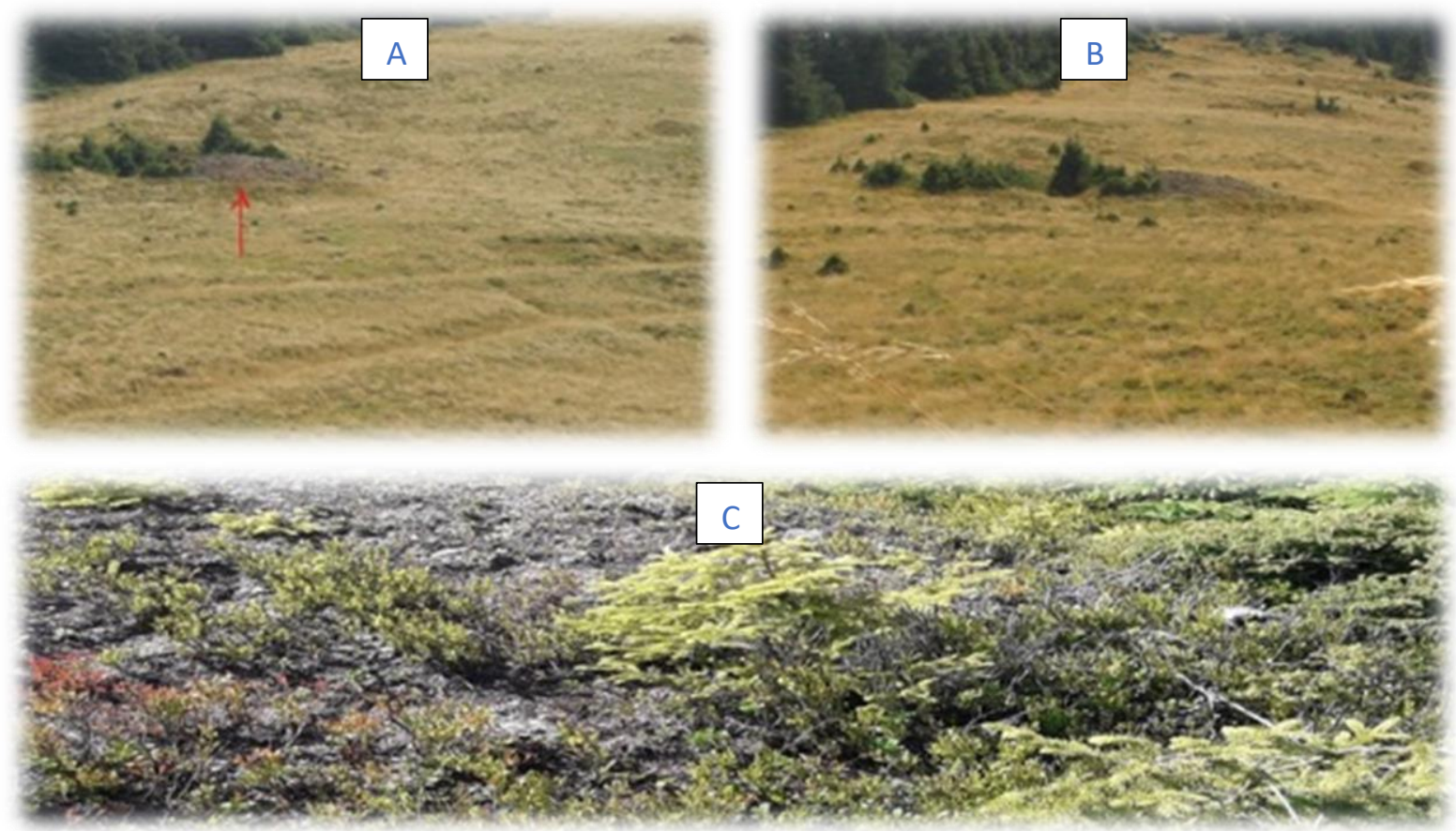
Feature 93 represents a bunker, situated at $47.62623^{\circ} \mathrm{N}-24.88069^{\circ} \mathrm{E}$, at an altitude of $1592 \mathrm{~m}$ (FIG.157 A). The bunker, made of reinforced concrete, was damaged by an explosion. The roof can be seen at a distance of $2 \mathrm{~m}$ from the bunker, largely unaltered. It consists of a flat concrete platform, covered by a layer of bitumen and a $10 \mathrm{~cm}$ layer of plaster. The interior of the construction has a length of $3.80 \mathrm{~m}$, a width of $2.40 \mathrm{~m}$ at the entrance and of $2.20 \mathrm{~m}$ at the back. The walls (FIG.157 B) are $60 \mathrm{~cm}$ thick, $1.50 \mathrm{~m}$ high and are fixed in an excavation made in the hill slope. The bunker is oriented to the $\mathrm{W}$.

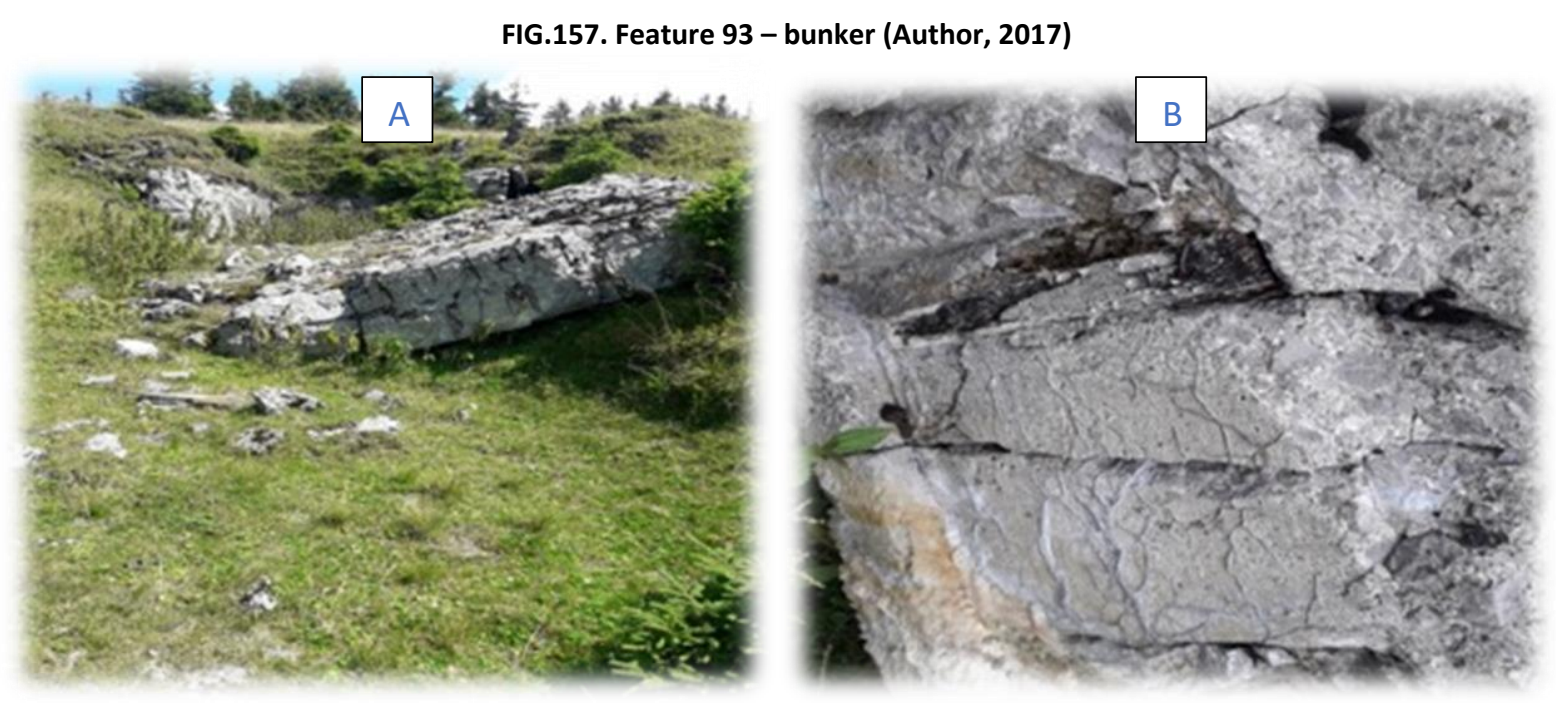

Feature 94 represents a pile of concrete (FIG.158), situated at $47.62612^{\circ} \mathrm{N}-24.88112^{\circ} \mathrm{E}$, at an altitude of $1601 \mathrm{~m}$.

FIG.158. Feature 94 - pile of concrete (Author, 2017)

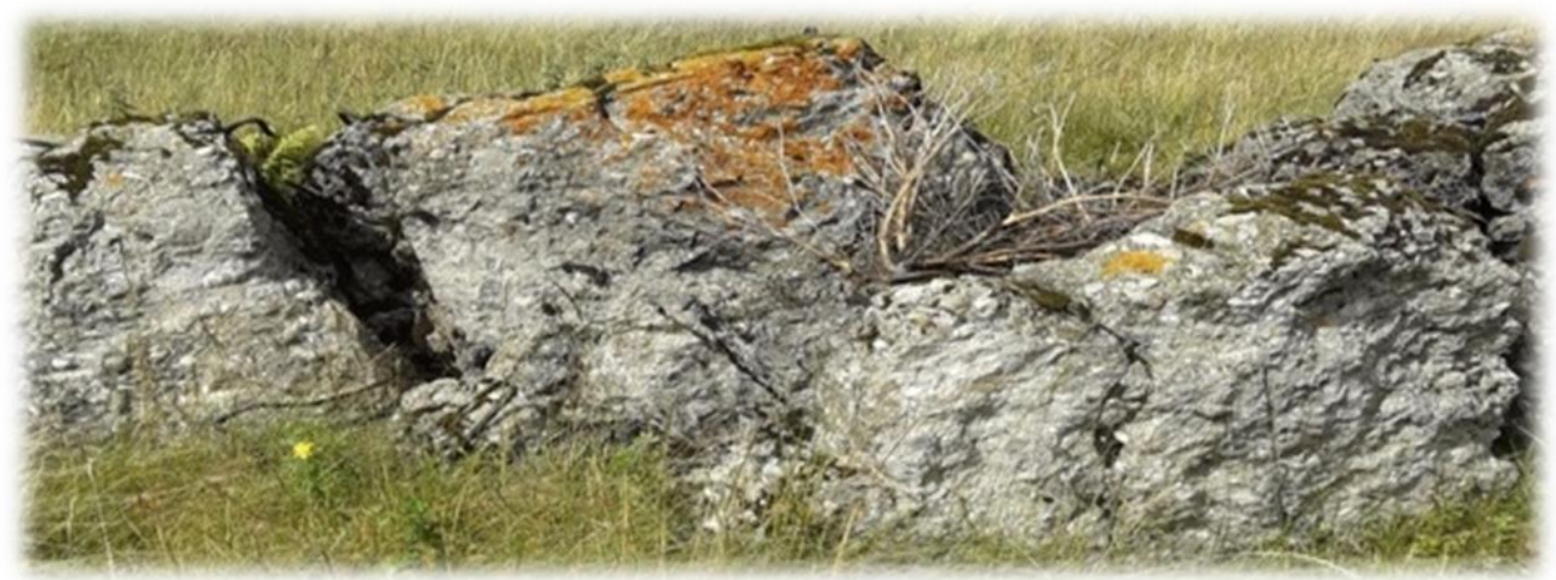


Feature 95 represents a pile of concrete (FIG.159), situated at $47.62597^{\circ} \mathrm{N}-24.88097^{\circ} \mathrm{E}$, at an altitude of $1596 \mathrm{~m}$.

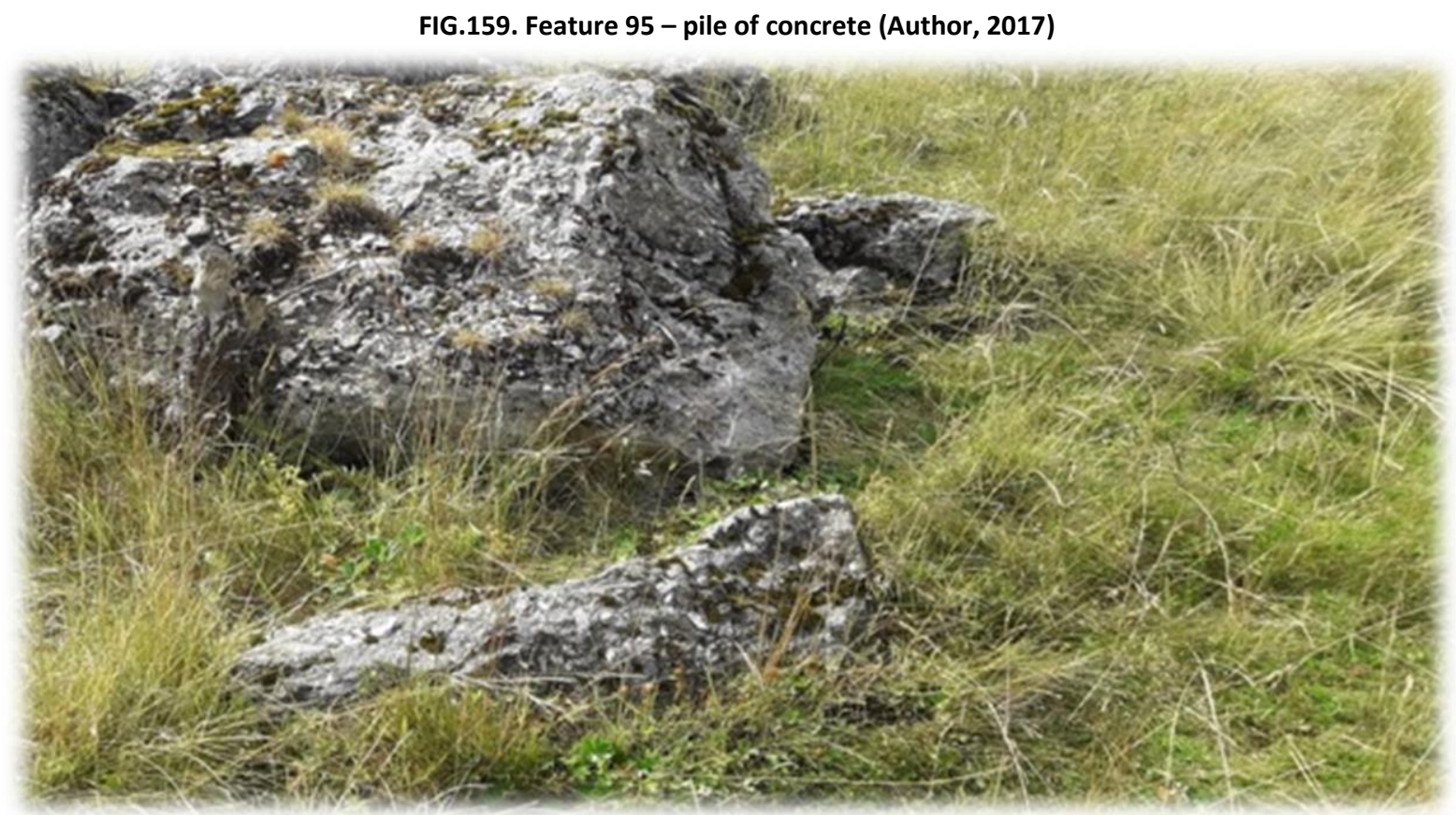

Feature 96 represents an earthwork (FIG.160 A, B), situated at $47.62542^{\circ} \mathrm{N}-24.87967^{\circ} \mathrm{E}$, at an altitude of $1606 \mathrm{~m}$. The earthwork is a pit, $12 \mathrm{~m}$ long, $10 \mathrm{~m}$ wide and approximately $3 \mathrm{~m}$ deep. The exterior sides of the pit are surrounded by piles of gravel.

FIG.160. Feature 96 - earthwork (Author, 2017)
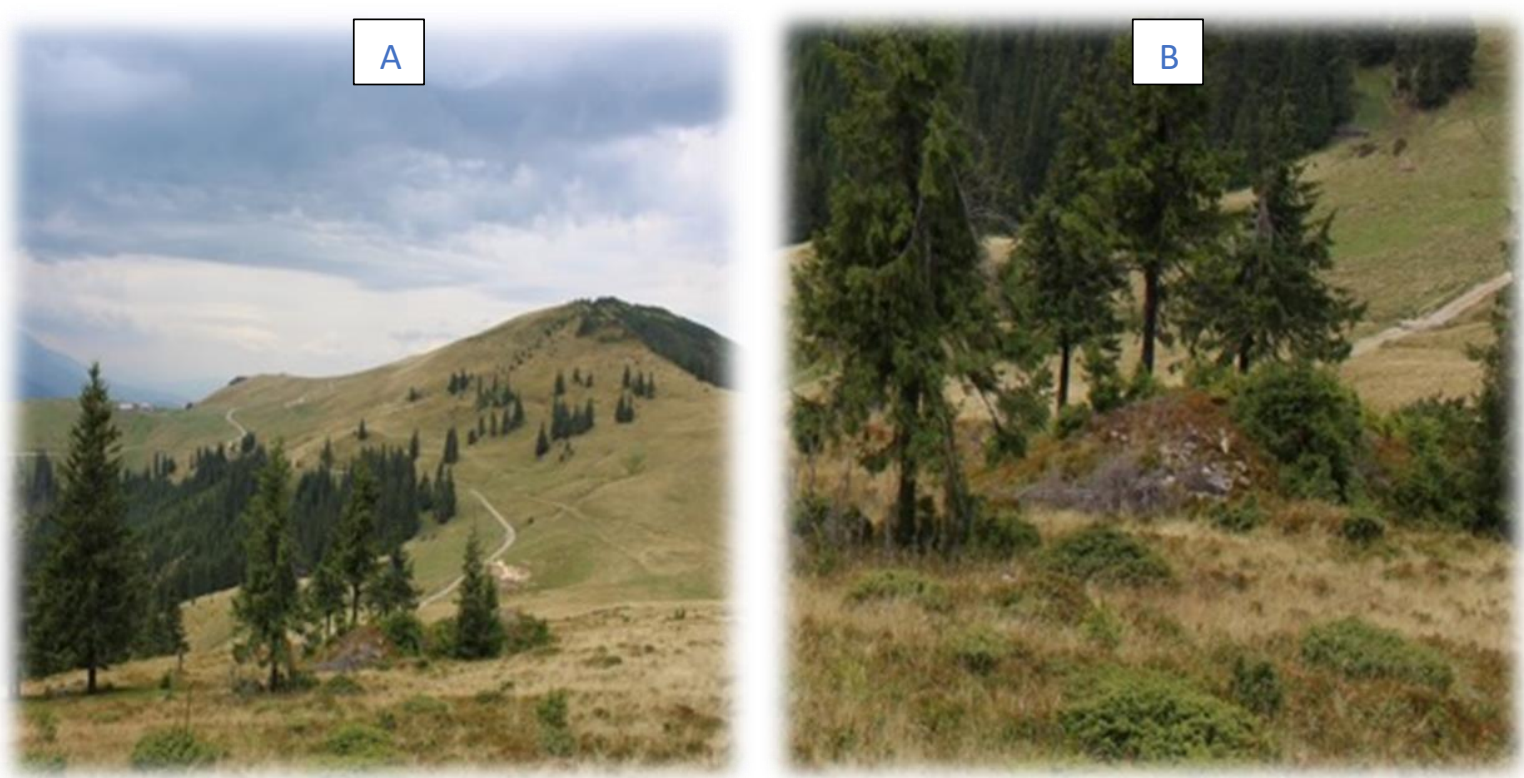
Feature 97 represents a large size bunker, situated at $47.62541^{\circ} \mathrm{N}-24.88204^{\circ} \mathrm{E}$, at an altitude of $1616 \mathrm{~m}$ (FIG.161 A, B, C). Local memory records the existence of a WWI large weapon depot in the area meant to supply the adjacent fortification system. The existence of good roads connections and the size of the bunker seem to confirm such theory.

The bunker, made of reinforced concrete, was built in an excavation in the hill slope. An explosion damaged the structure. The back walls of the bunker are still standing and have a height of $2.50 \mathrm{~m}$. The walls are $50 \mathrm{~cm}$ thick; the roof is $1 \mathrm{~m}$ thick and is covered by a layer of bitumen and plaster. The width on the front side of the bunker is of $9 \mathrm{~m}$ and at the back, $7 \mathrm{~m}$. Due to the fact that the walls imploded on the front side under the weight of the roof it is impossible to measure the exact length. The bunker is oriented to the $\mathrm{W}$.
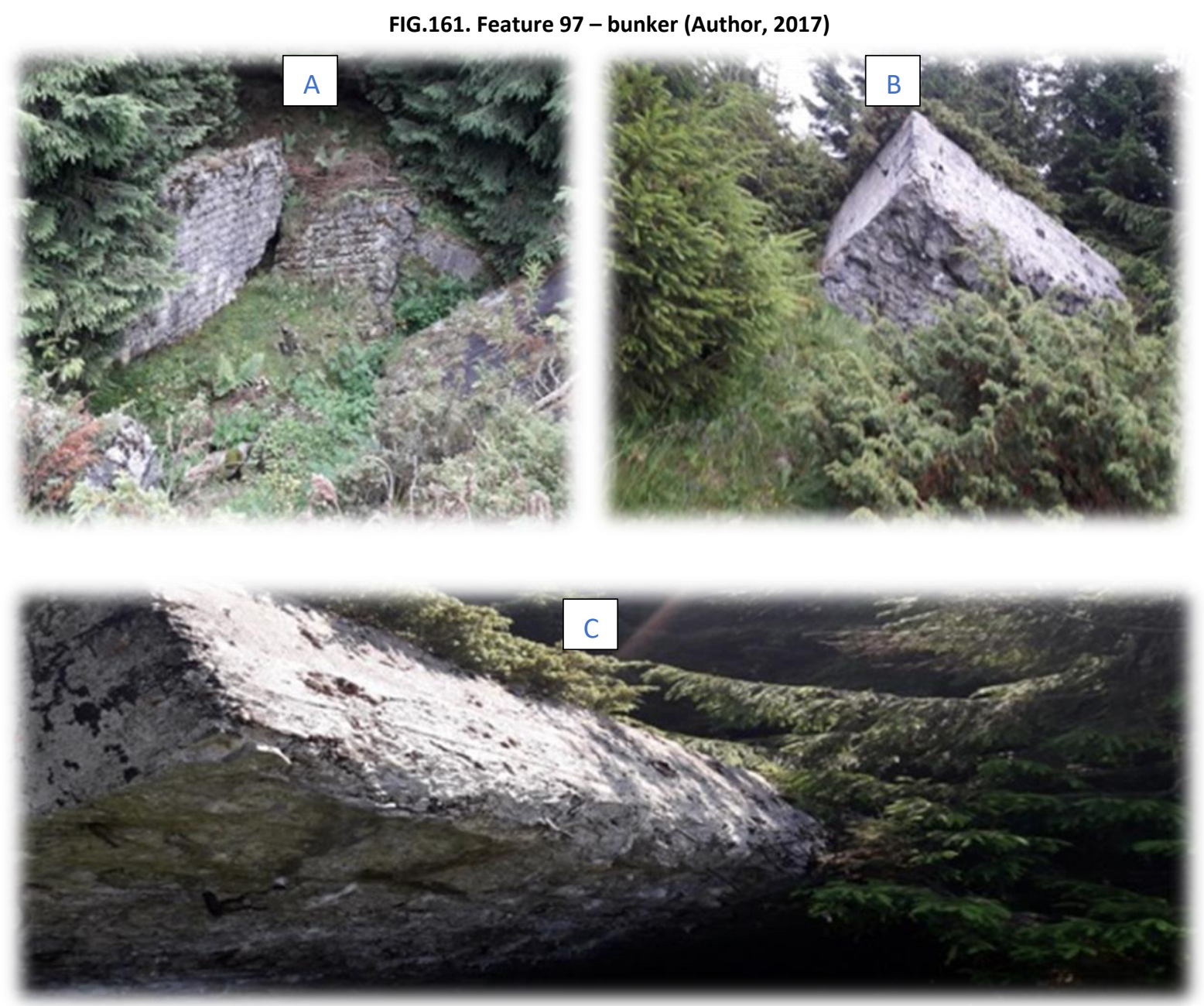
Feature 98 represents a concrete platform, situated at $47.62539^{\circ} \mathrm{N}-24.88186^{\circ} \mathrm{E}$, at an altitude of $1608 \mathrm{~m}$ (FIG.162 A, B, C). In front of the bunker at a distance of approximately $6 \mathrm{~m}$, there is a concrete platform $4 \mathrm{~m}$ wide. The platform is probably a fragment of the missing part of the roof, judging by the fact that it has attached to what seems to be a fragment of wall that has a width of $50 \mathrm{~cm}$; it is $1 \mathrm{~m}$ thick and it is plastered on the edge.
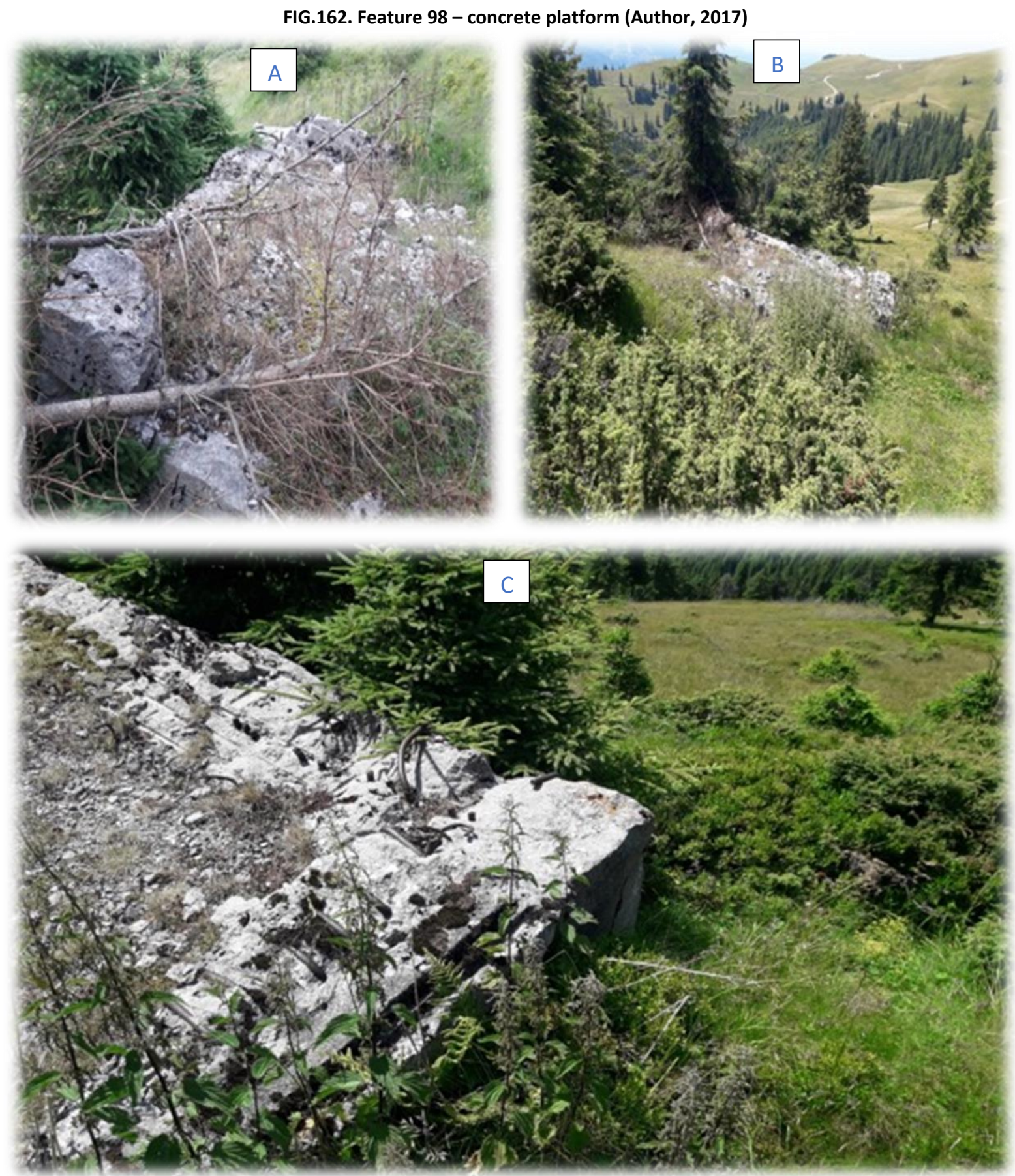
Feature 99 represents a bunker (FIG.163 A, B), situated at $47.62456^{\circ} \mathrm{N}-24.88179^{\circ} \mathrm{E}$, at an altitude of $1576 \mathrm{~m}$. The bunker. made of reinforced concrete. was severely damaged by an explosion making it impossible to estimate its original size and characteristics. There is a trench system leading to the bunker.

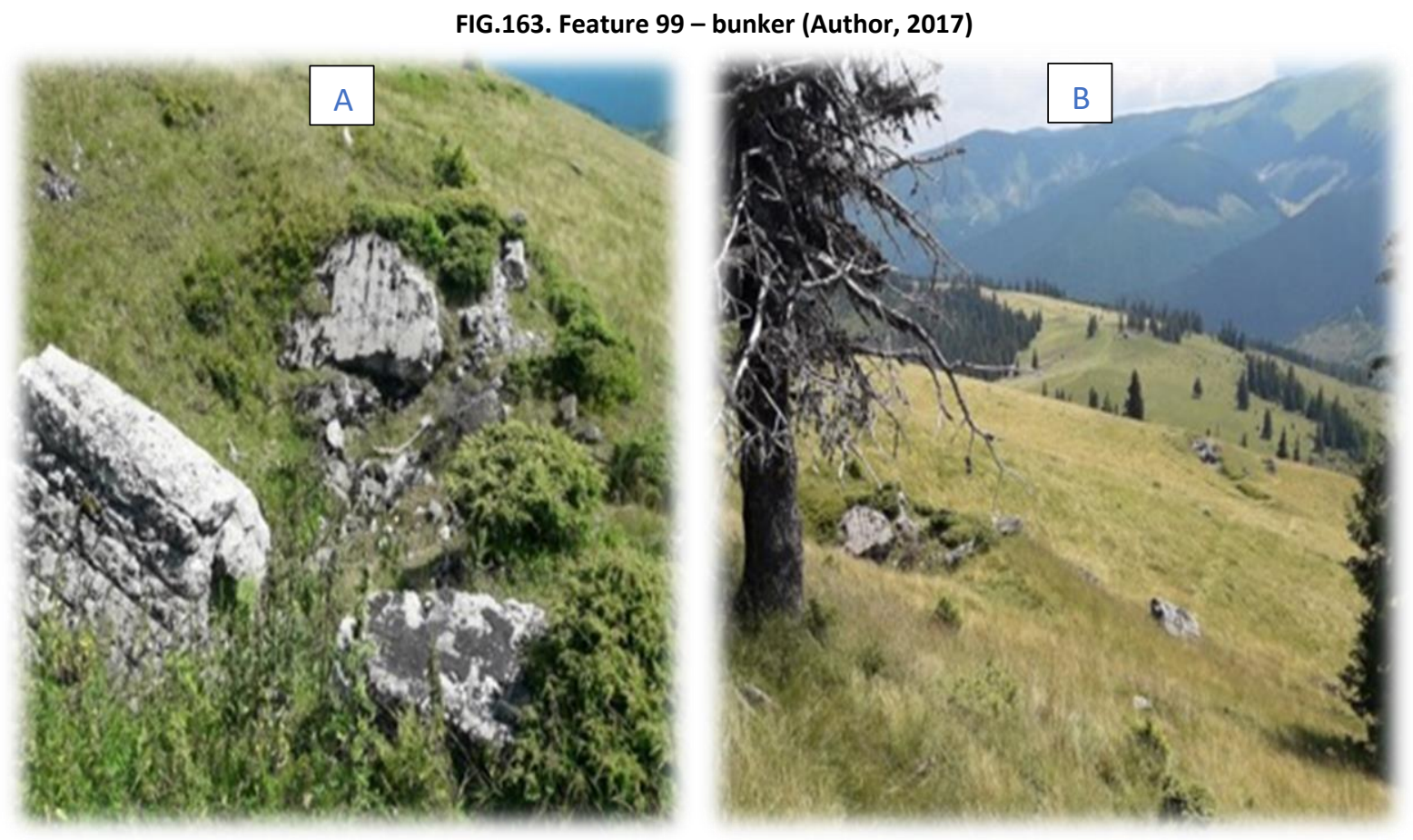

Feature 100 represents a bunker, situated at $47.62336^{\circ} \mathrm{N}-24.88217^{\circ} \mathrm{E}$, at an altitude of $1572 \mathrm{~m}$ (FIG. 164 A, B, C, D, E). The bunker, made of reinforced concrete, was built in an excavation in the hill slope. It has pentagonal shape externally and semi-cylindrical shape inside (FIG.164. F). It has a length of $6.70 \mathrm{~m}$, a width of $3.40 \mathrm{~m}$ and a height of $1.50 \mathrm{~m}$. In the back wall of the bunker there is a circular hole with a diameter of $13 \mathrm{~cm}$ (FIG 164.K). The walls and the ceiling are $1 \mathrm{~m}$ thick (FIG.164 G, H, J, L, M). There is a trench system leading to the bunker, which is oriented to the NW. Although it is difficult to attempt dating the bunkers without excavation, since the front lines of the two world wars coincide, local memory also reports that during the Great War concrete was made out of slaked lime, a calcium containing inorganic mineral and gravel, while WWII bunkers were made of sand and cement aggregate. 
The fact that only in some of the bunkers $5-6 \mathrm{~cm}$ calthemite ${ }^{12}$ formations can be found (FIG.164 I) seems to confirm such a hypothesis. The formation of calthemites need calcium and although cement also contains calcium the concentration is lower than that of slaked lime which makes it more likely for WWI bunkers to grow such formations. The above digression concerning dating will be resumed in the concluding section of the present chapter as it was introduced in this context only for the purpose of exemplifying the reported pictures.

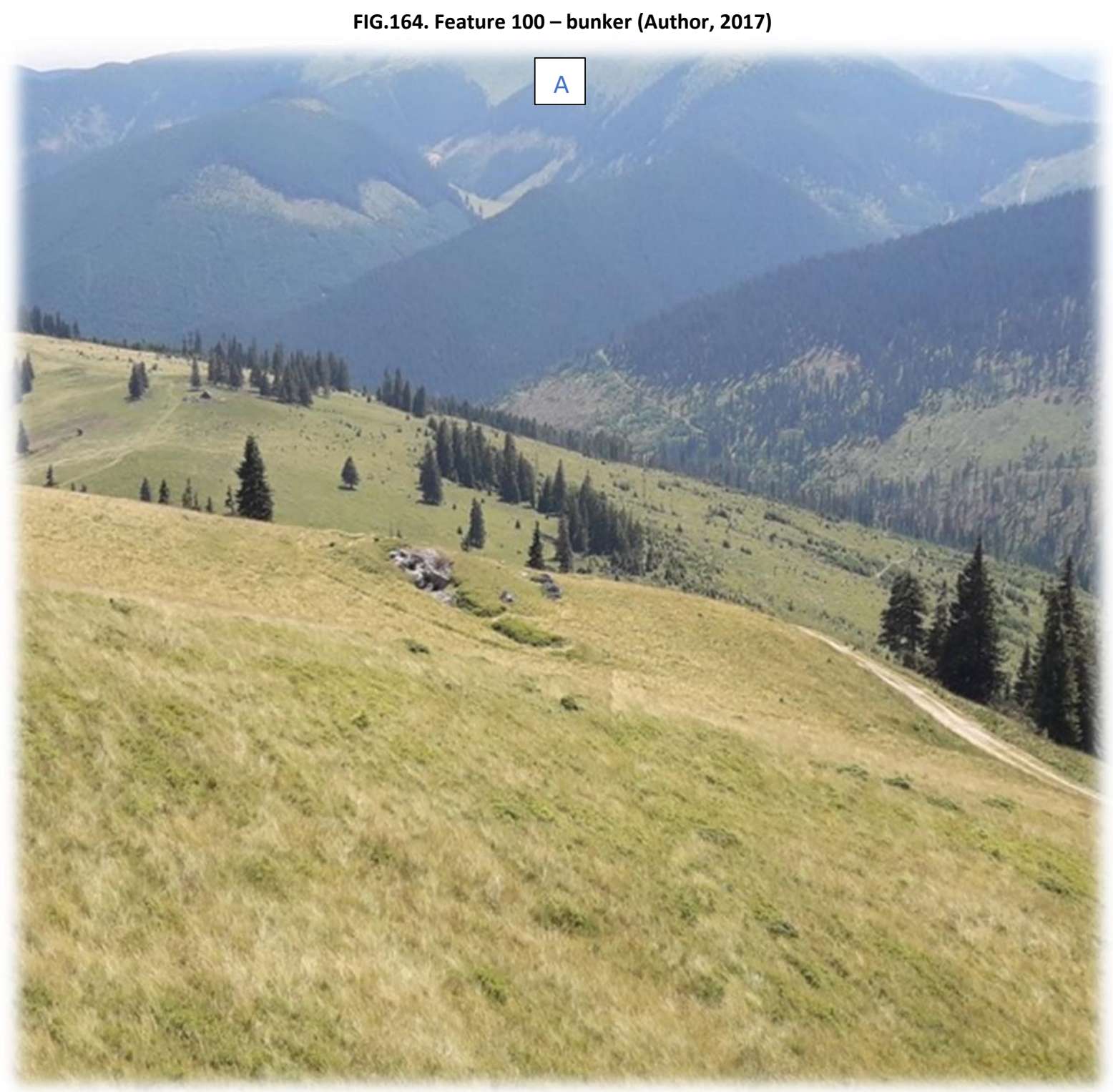

\footnotetext{
${ }^{12}$ Calthemites are the equivalent of stalactites outside the cave environment: they are secondary deposits derived from concrete constructions, which, like stalactites, are also tapering structures hanging from the roof of a cave-like environment and formed by dripping water that penetrates calcium salt deposits.
} 

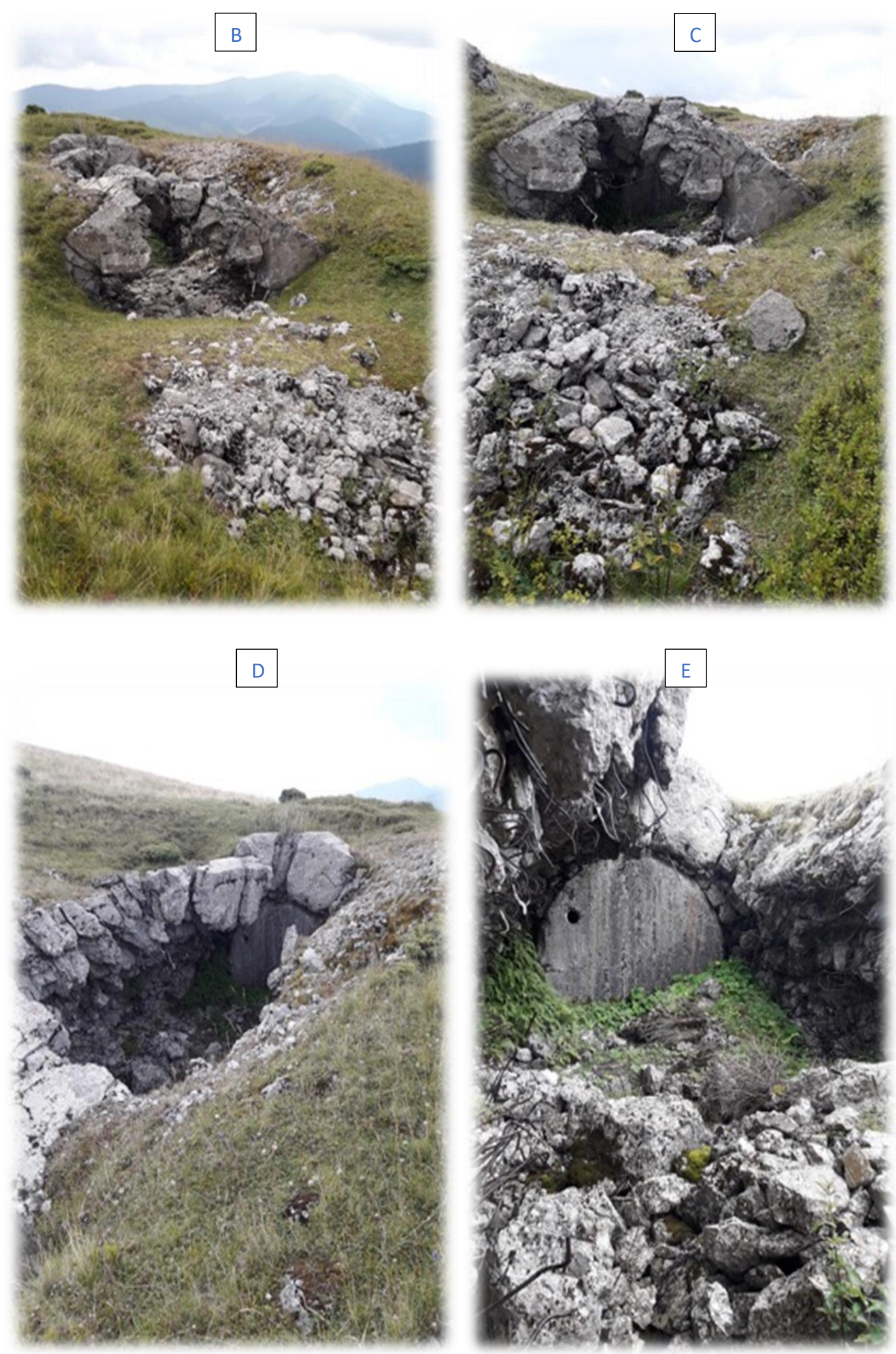

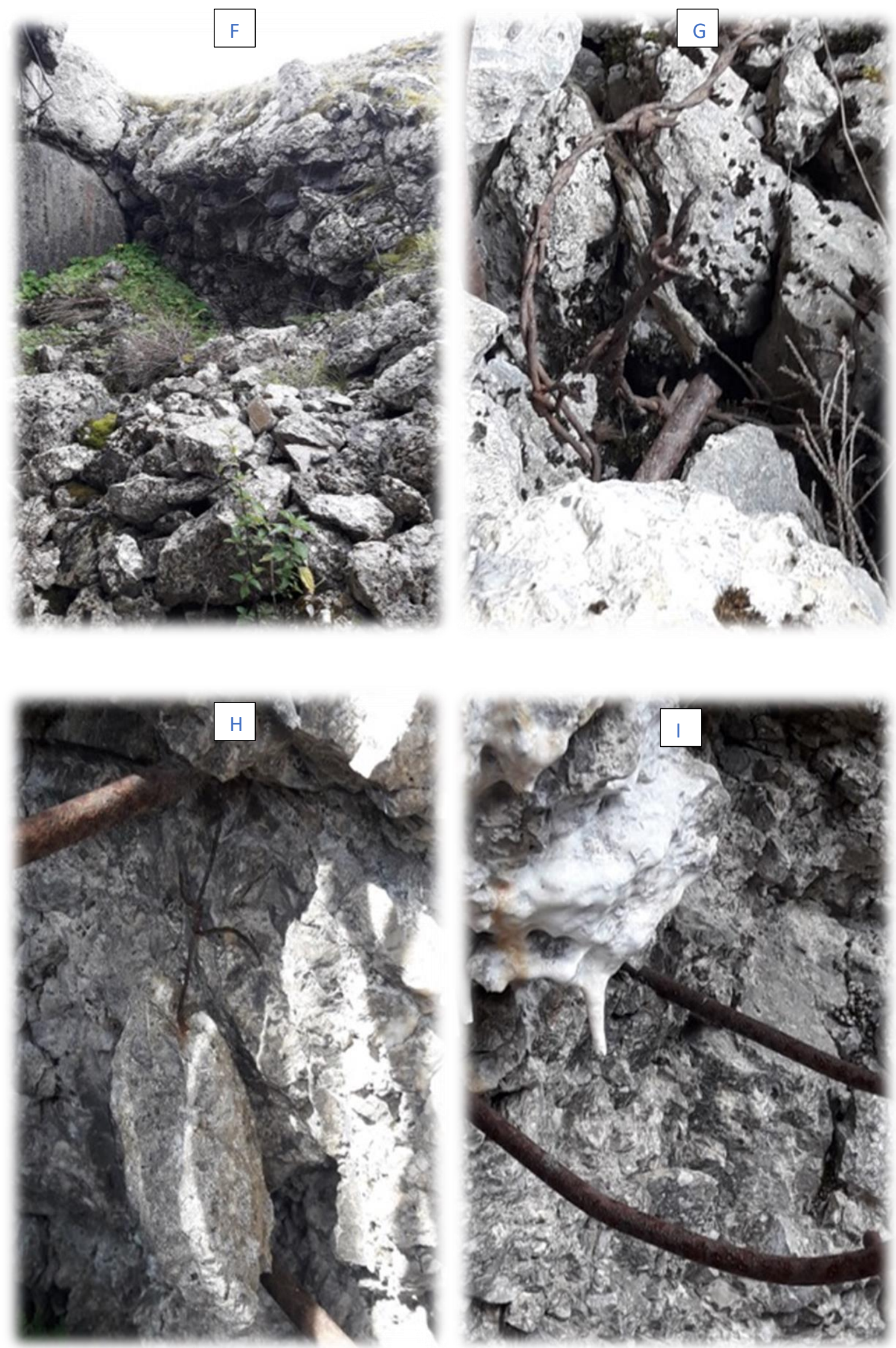

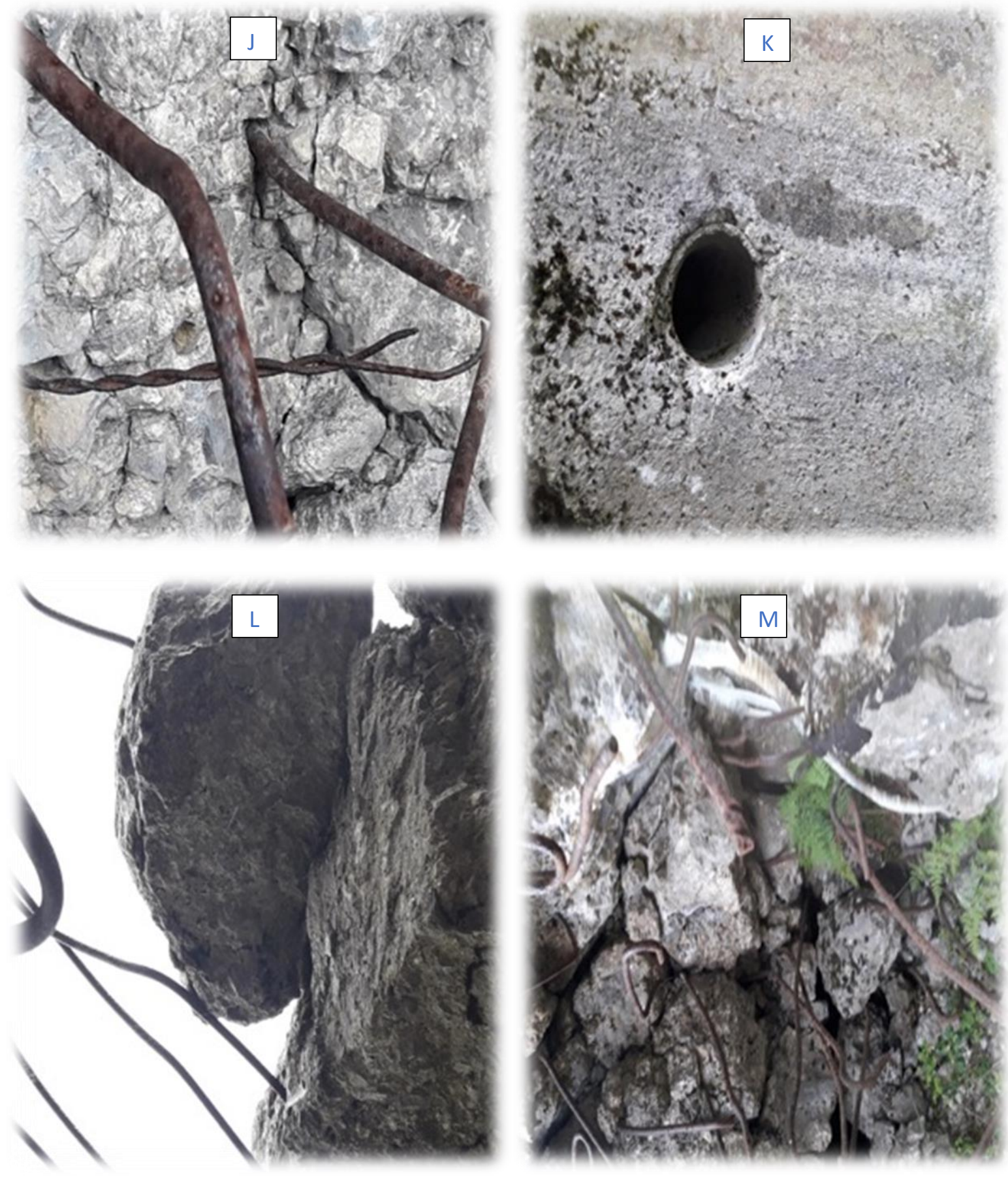

Feature 101 represents a bunker, situated at $47.62381^{\circ} \mathrm{N}-24.88390^{\circ} \mathrm{E}$, at an altitude of 1580 m (FIG.165 A, C, D, E). The bunker, made of reinforced concrete, was severely damaged by an explosion making it impossible to estimate the original size although the remains do allow recognition of the shape which has the same characteristics as Feature 100. There is a trench system (FIG.165 B) leading to the bunker. 
FIG.165. Feature 101 -bunker (Author, 2017)
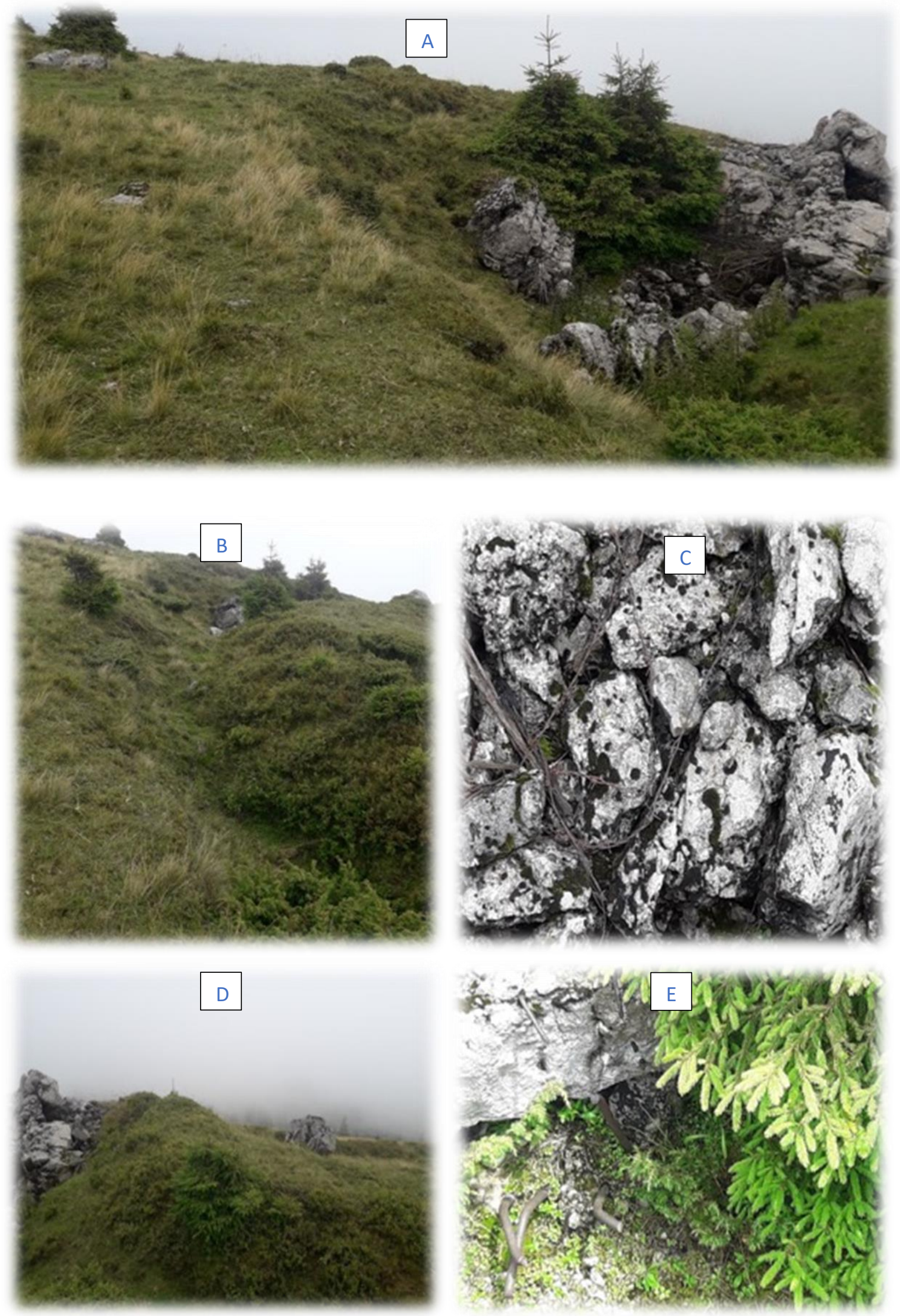
Feature 102 represents a bunker, situated at $47.62382^{\circ} \mathrm{N}-24.88468^{\circ} \mathrm{E}$, at an altitude of 1580 m (FIG.166 A, C, E). The bunker, made of reinforced concrete, was severely damaged by an explosion making it impossible to estimate its original size although it clearly belongs to same category as Features 100 and 101. There is a trench system (FIG.166 B, D) leading to the bunker.

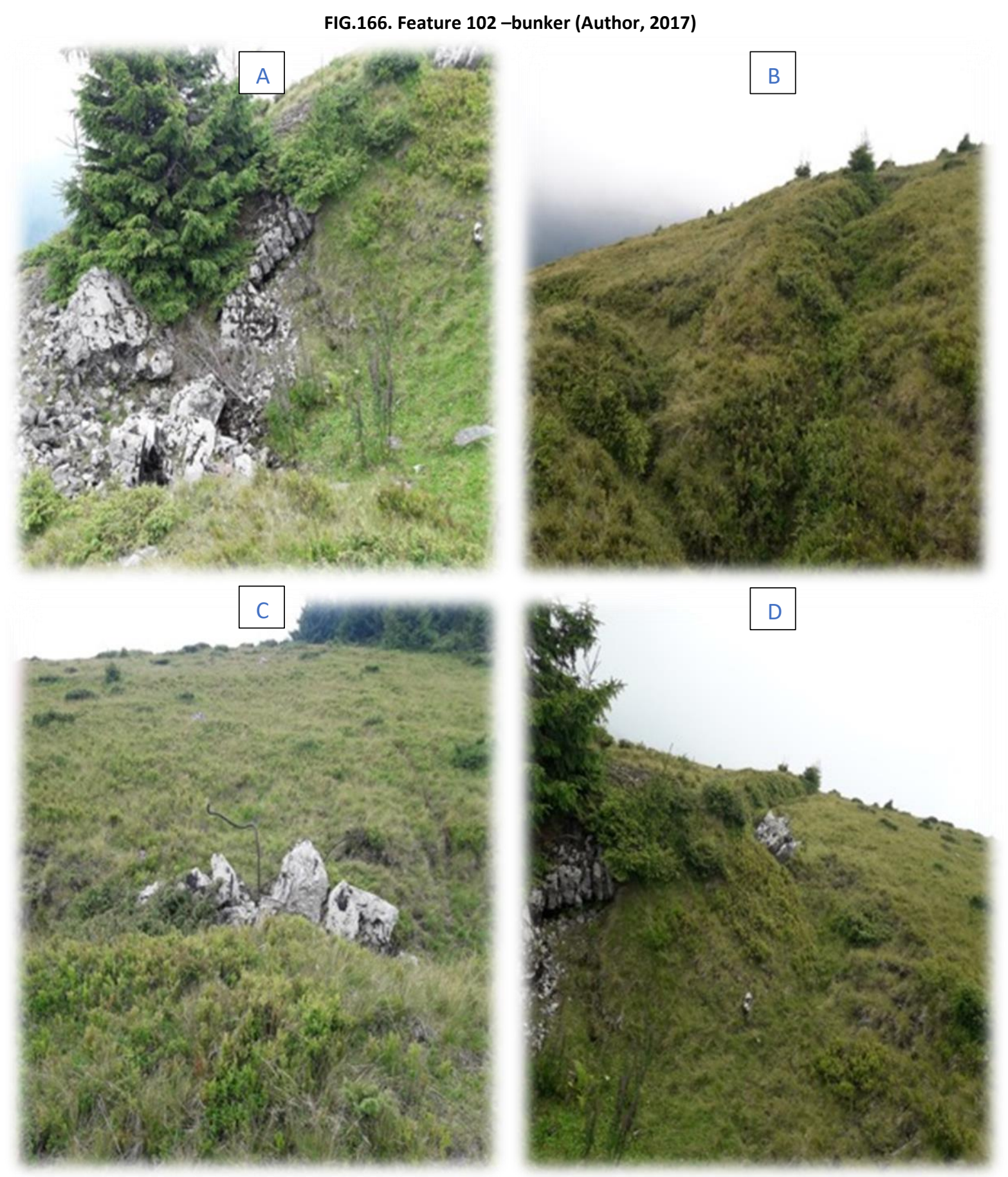




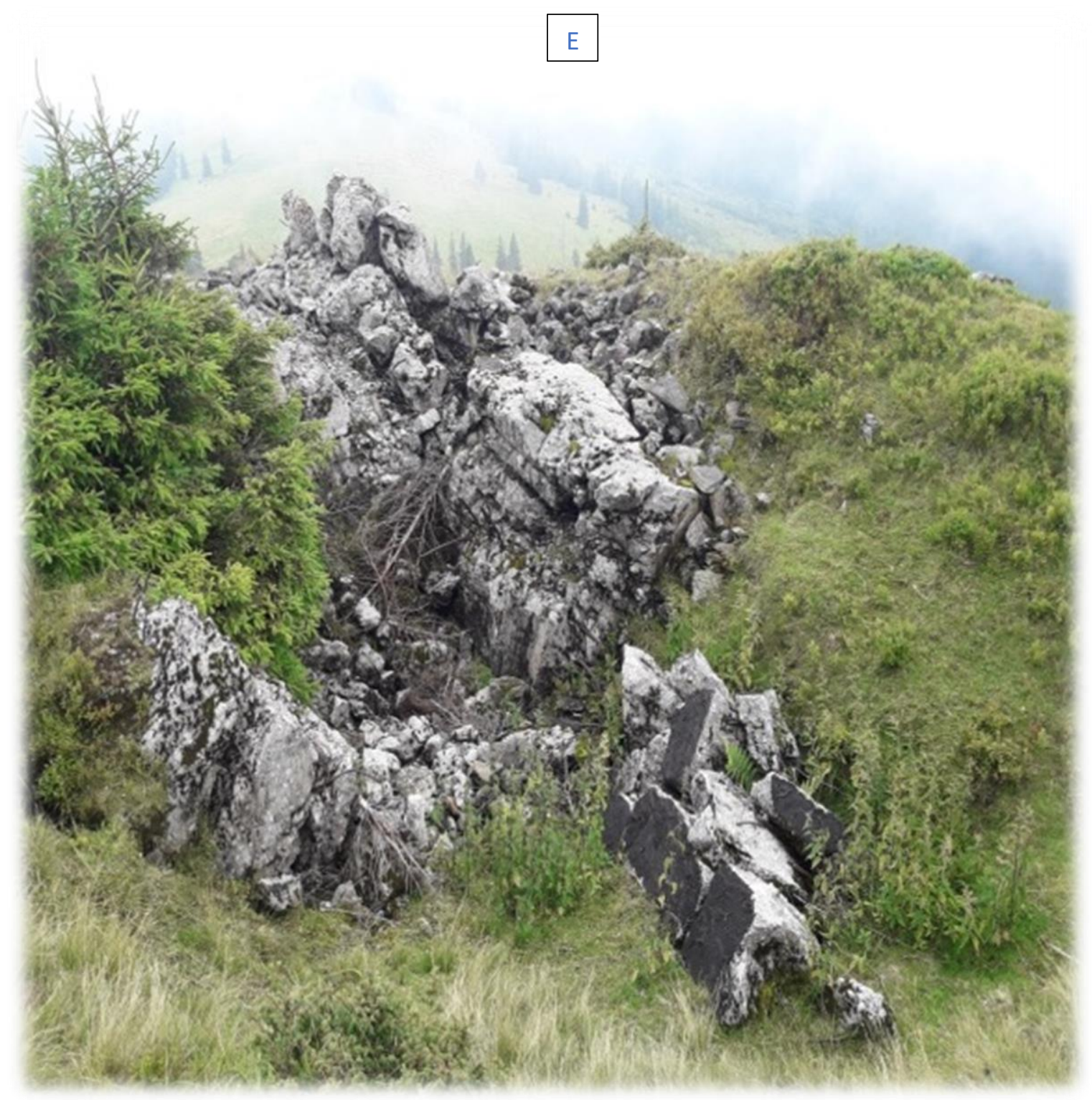

Feature 103 represents a fragment of what seems to be a side wall of a bunker or other reinforced concrete feature (FIG.167 B, C, D, E, F) surrounded by a double trench system (FIG.167 A), situated at $47.62443^{\circ} \mathrm{N}-24.88226^{\circ} \mathrm{E}$, and at an altitude of $1595 \mathrm{~m}$. The concrete feature has a width of $19 \mathrm{~cm}$, about $1 \mathrm{~m}$ high above ground, is made of reinforced concrete, it bends in a slightly semi-circular shape and it seems to have had more than one layer. The trench has a $2 \mathrm{~m}$ width and is approximately $1.10 \mathrm{~m}$ deep. It has a square shape and two parallel rows of trenches. The concrete feature is situated under a fir in the lower left corner of the double trench system visible in FIG. 167 A. 
FIG.167. Feature 103 -bunker (Author, 2017)
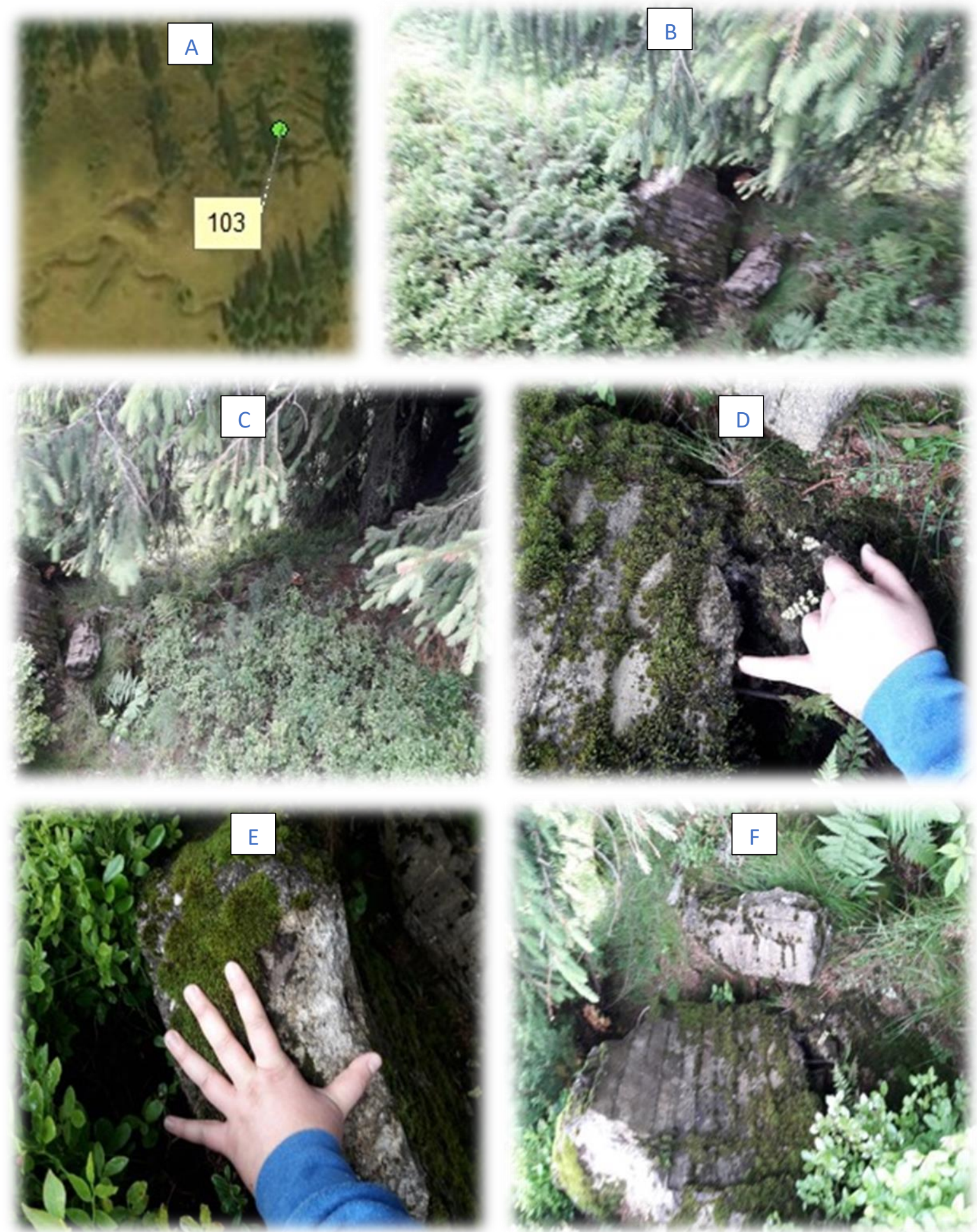

Feature 103 concludes the series of recordings belonging to the second research sector. A general map of all the earthworks described previously in sections 1 and 2 (FIG.168) is presented below in order to illustrate the distribution of the recorded features within the 
research area and highlight their relation to the military roads and their proximity to the central sector.

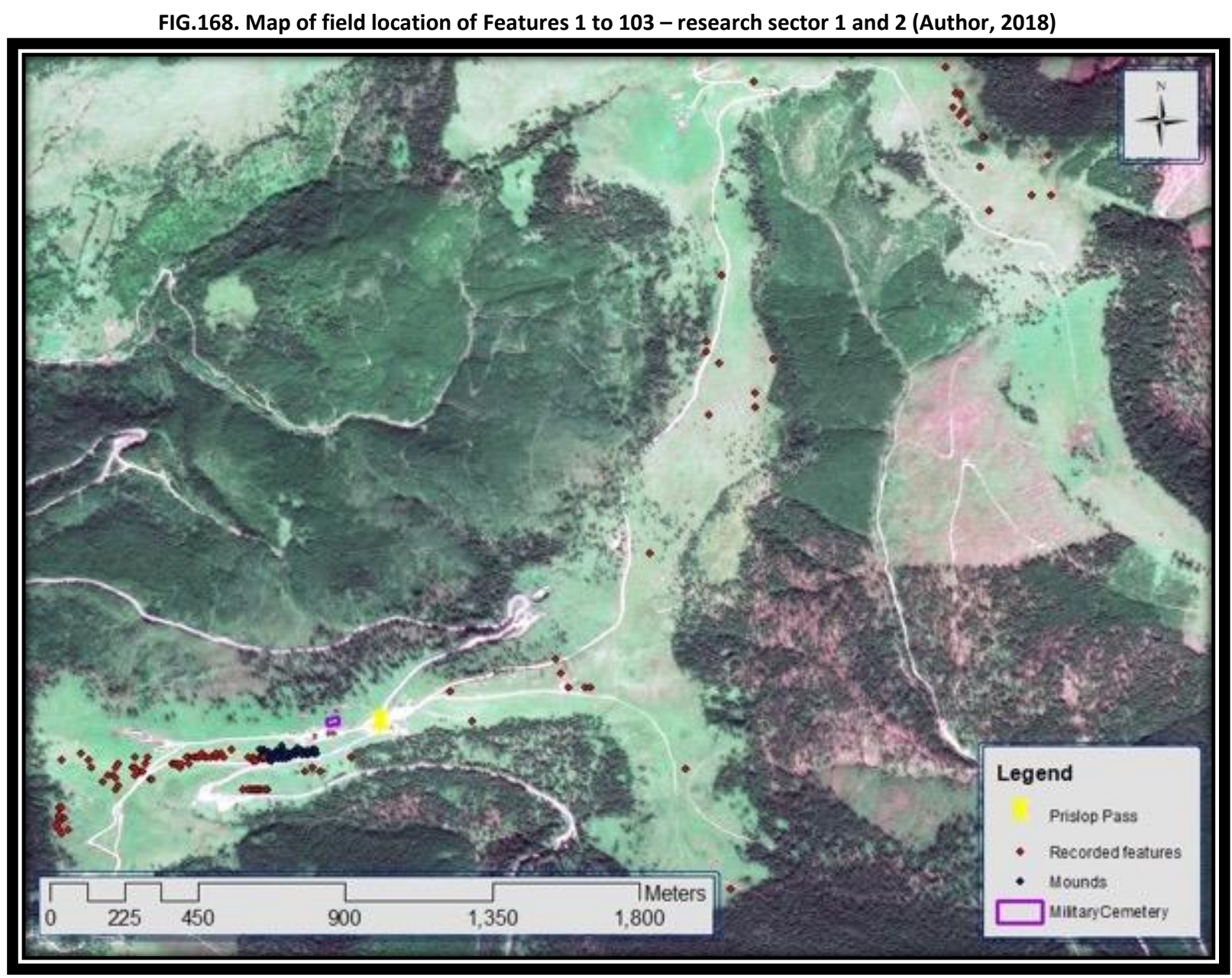

\subsection{Research sector 3}

The third research sector (FIG. 169) continues by following the road heading north towards the top of the map, progressing onto the registration of the extensive, elaborated network of trench systems that surrounds the Prislop Pass. As can be seen from the following satellite imagery, the research area is peppered with trench systems. The trench systems are quite linear in terms of accessibility as they are positioned in the proximity of county roads, while as far as their size is concerned, they vary from a width of $2 \mathrm{~m}$ to $1 \mathrm{~m}$, depths of $1 \mathrm{~m}$ to $2.5 \mathrm{~m}$ and have different shapes and styles. 
FIG.169. Map of field location of the trench systems recorded in sector 3 (Author, 2018)

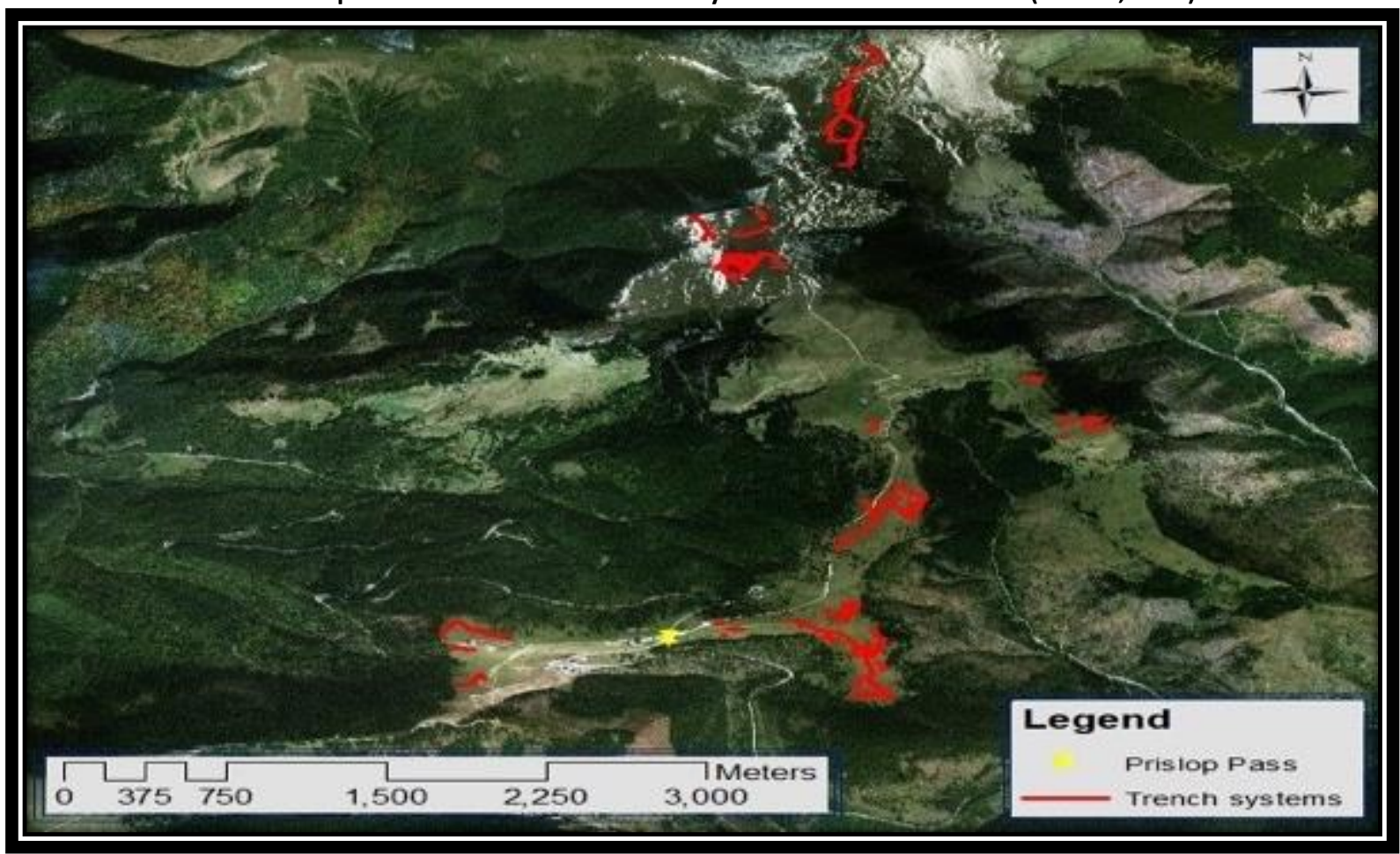

The trench systems network presents a great variety of typologies in terms of shape. For the purposes of this research, in order to facilitate a brief description and presentation of the different typologies, the trench systems are dived into six major areas (FIG. 170).

FIG.170. Map of the field location of the major areas of sector 3 (Author, 2018)

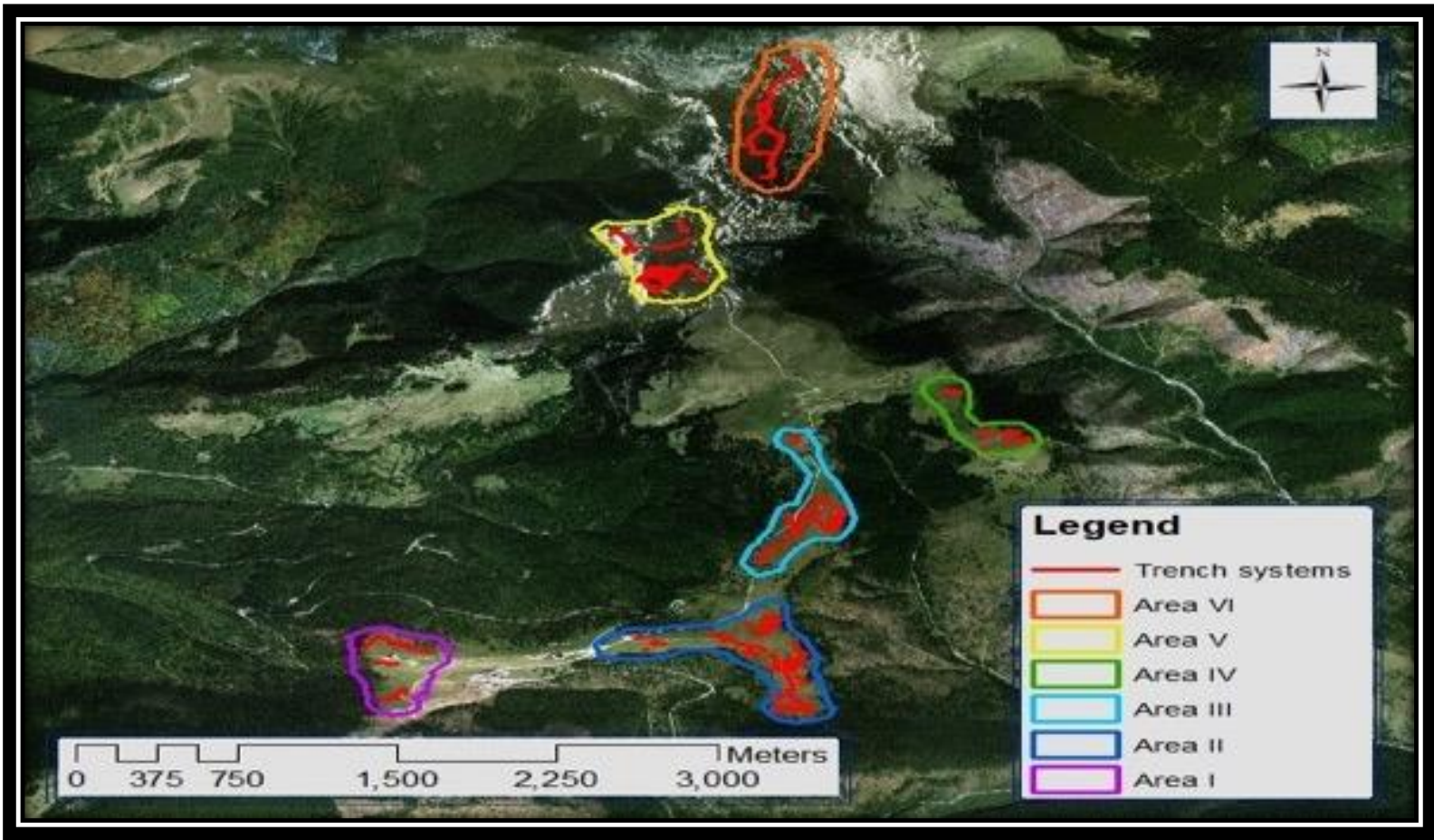


The first area (FIG. 171) surrounds the Western side of the Prislop Pass, orbiting the edges of the location where the WWI town of barracks was situated. The military camp stands as a reference point in recording the trenches. In this location wave-shaped trenches predominate, of approximately $1.5 \mathrm{~m}$ wide and $1.10 \mathrm{~m}$ deep.

FIG.171. Map of the trench systems in the $1^{\text {st }}$ area (Author, 2018)

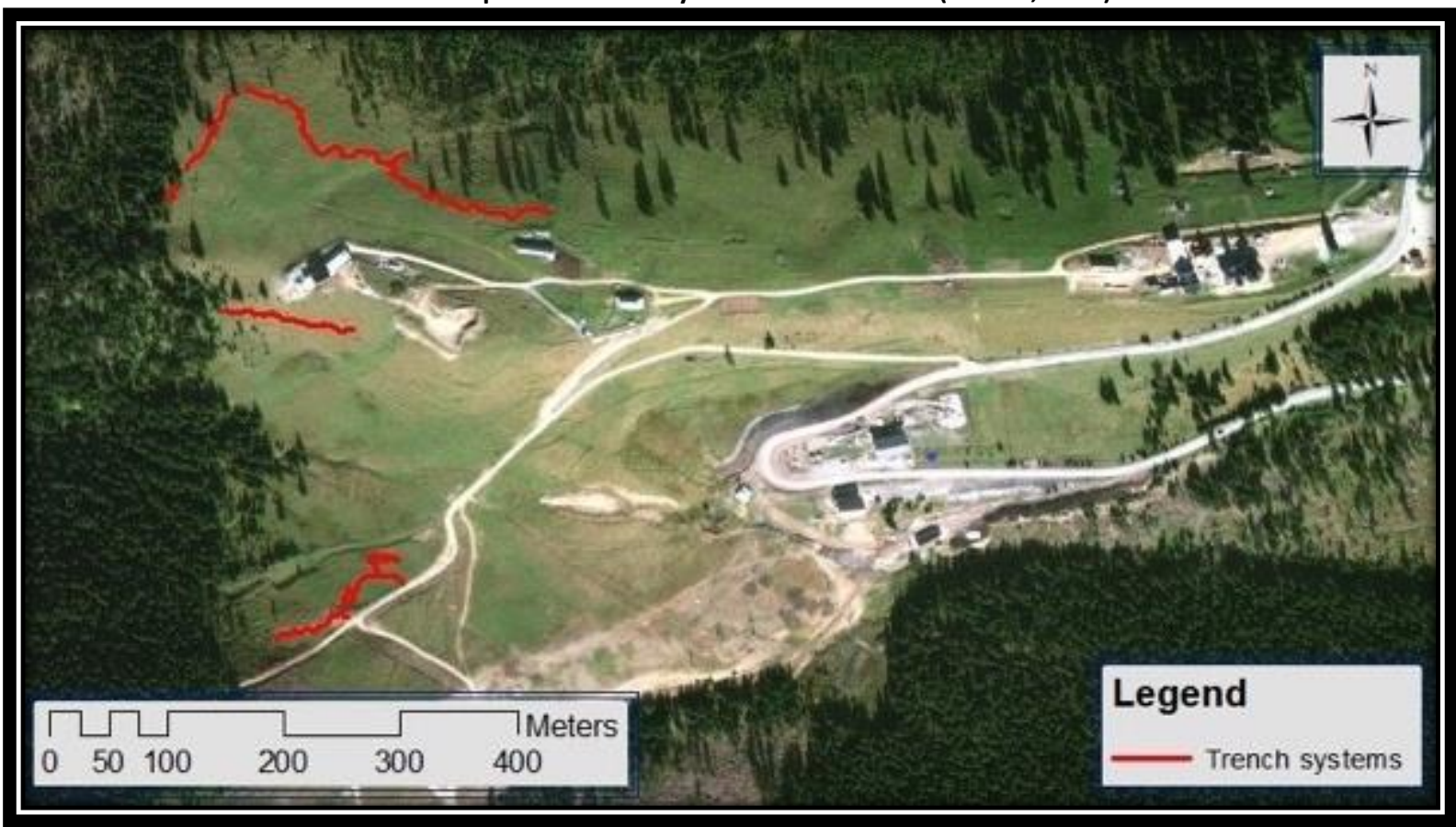

The trench system continues into the forest and it was also extended to the south on the present ski slope as can be seen from 2005 satellite imagery of the National Cadastre and Real Estate Advertising (ANCPI). Before the construction works there was also a bunker in the middle of the ski slope (FIG. 172).

FIG.172. Removed bunker (Author, 2018)

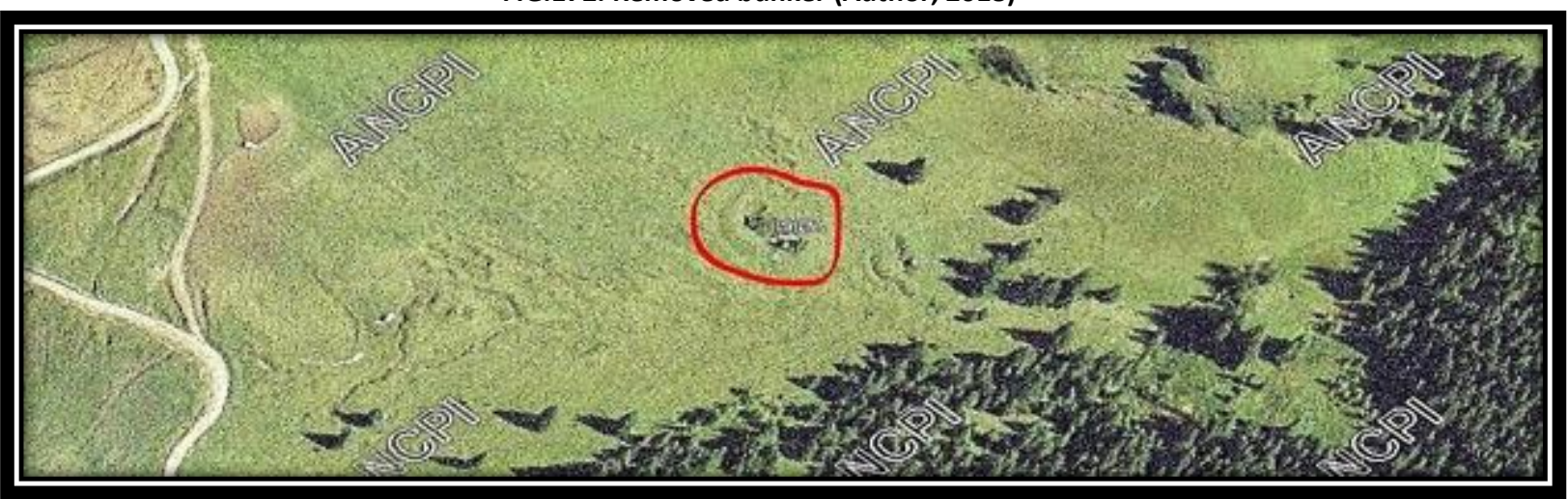


The second area (FIG. 173) begins on the Eastern side of the military camp and continues towards South-East. The area presents a combination of corrugated-shaped trenches and straight-line trenches, focus in this section being on the interconnections between the trenches that build up a network of intricate yet close relations. The trenches are generally $2 \mathrm{~m}$ wide and have depths from $1.10 \mathrm{~m}$ to $1.80 \mathrm{~m}$.

FIG.173. Map of the trench systems of the $2^{\text {nd }}$ area (Author, 2018)

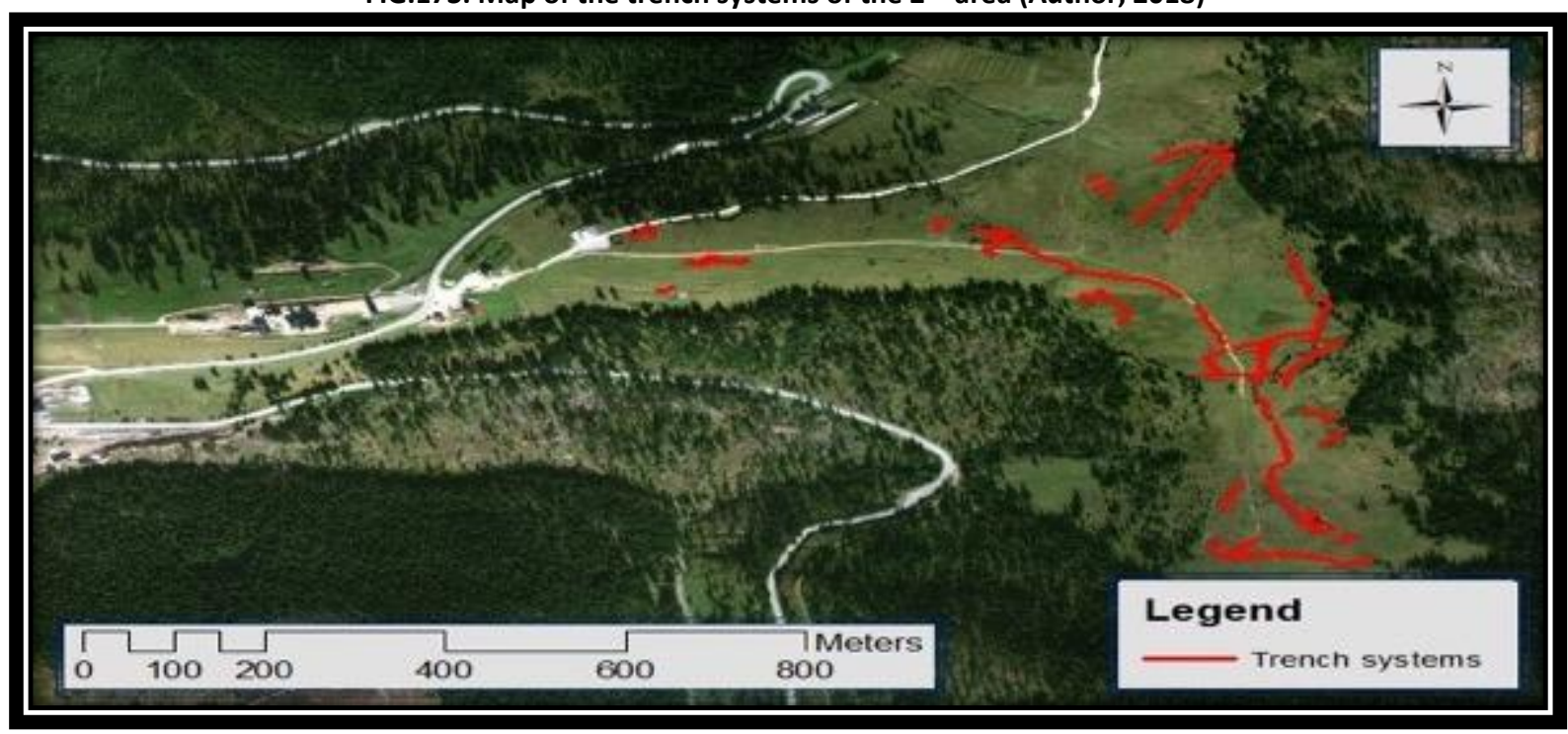

The North-West side of the military camp is covered by the third area (FIG. 174). It is characterised by its maze shape and coiled extremities towards the right side. The trench system has reduced dimensions compared to those of the previous area, having widths between $1 \mathrm{~m}$ to $1.5 \mathrm{~m}$ and depths of approximately $1 \mathrm{~m}$.

FIG.174. Map of the trench systems of the $3^{\text {rd }}$ area (Author, 2018)

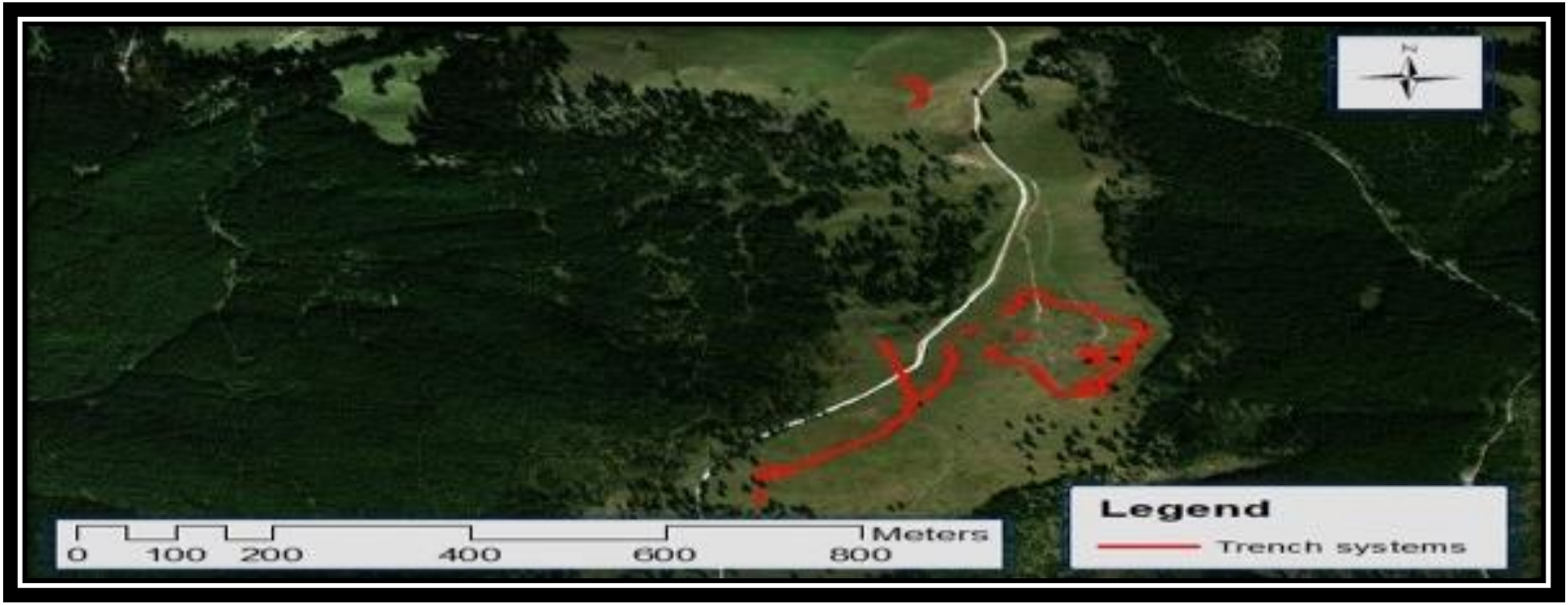


The forth area (FIG. 175) is situated North-West of the third area. The trenches in this sector are sternly bifurcated, mainly serving individual bunkers. Up to recent times they were very well preserved as they were mainly excavated in solid rock and were generally more than $2 \mathrm{~m}$ wide and up to $2 \mathrm{~m}$ deep. Still, during various field campaigns it emerged that although traditional farming left the war remains undamaged through the century following the end of WWI, the advent of intensive farming seems to have raise a threat to the preservation of the material culture of the war sites.

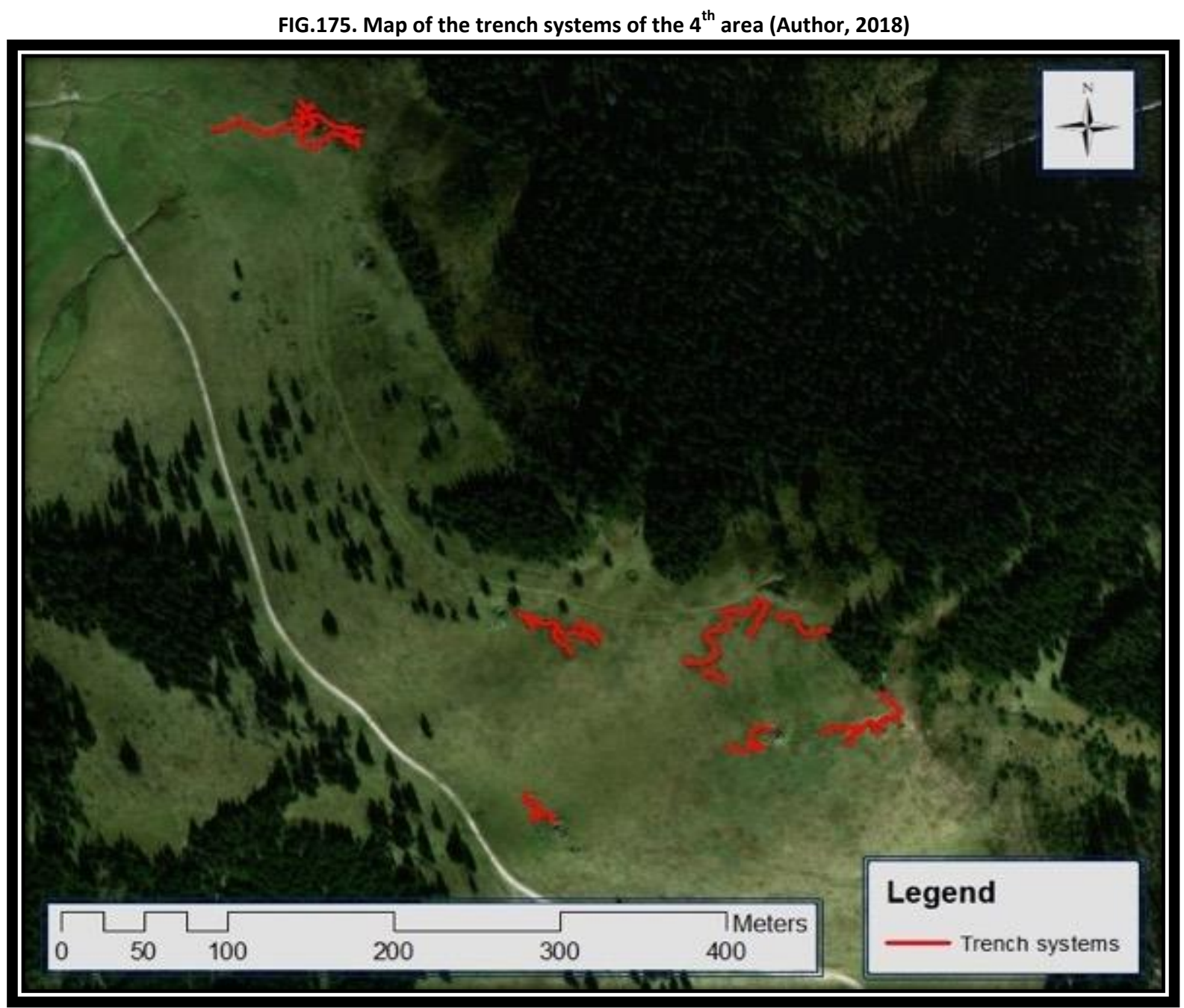

The fifth area (FIG.176) is situated to the North of the military camp. It covers the top of the mountain and it is mainly zig-zagged in shape (FIG. 177). It presents a variety of trench sizes ranging from $1 \mathrm{~m}$ to $2 \mathrm{~m}$ wide and from 1 to $2.5 \mathrm{~m}$ deep. 
FIG.176. Map of the trench systems of the $5^{\text {th }}$ area (Author, 2018)

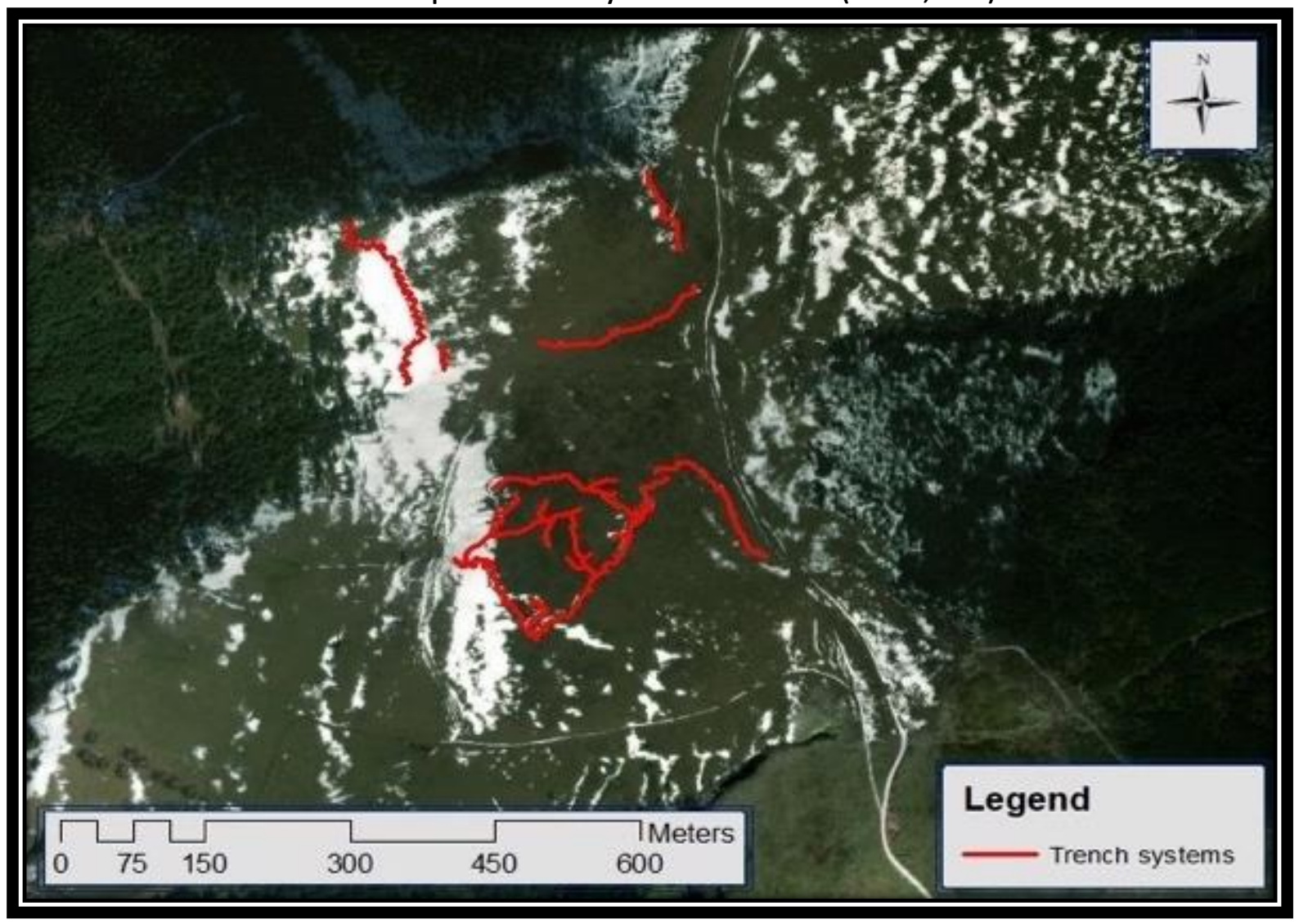

FIG.177. Zig-zag trench system (Author, 2018)

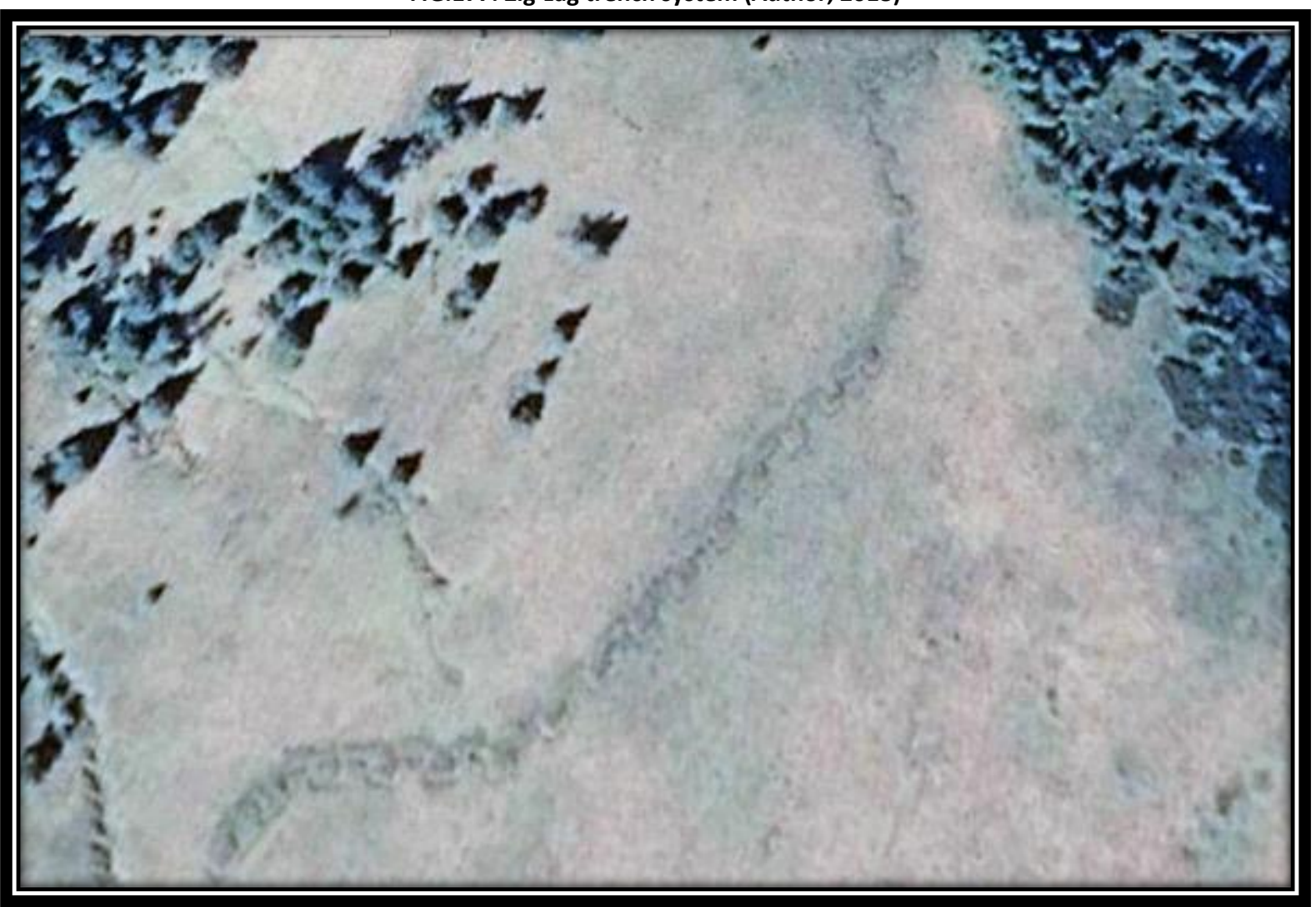


The sixth area (FIG. 178), which is located even further North than the previous one, registers the longest trench system with more than $3 \mathrm{~km}$ of continuous trenches. The trench system develops along the crest of the mountains for tens of $\mathrm{km}$, although in some areas is covered by woods, forming an extensive fortification line heading towards the Ukrainian border. The trench system is well connected to the other sectors by country roads, and allows mutual visual contact between the various locations.

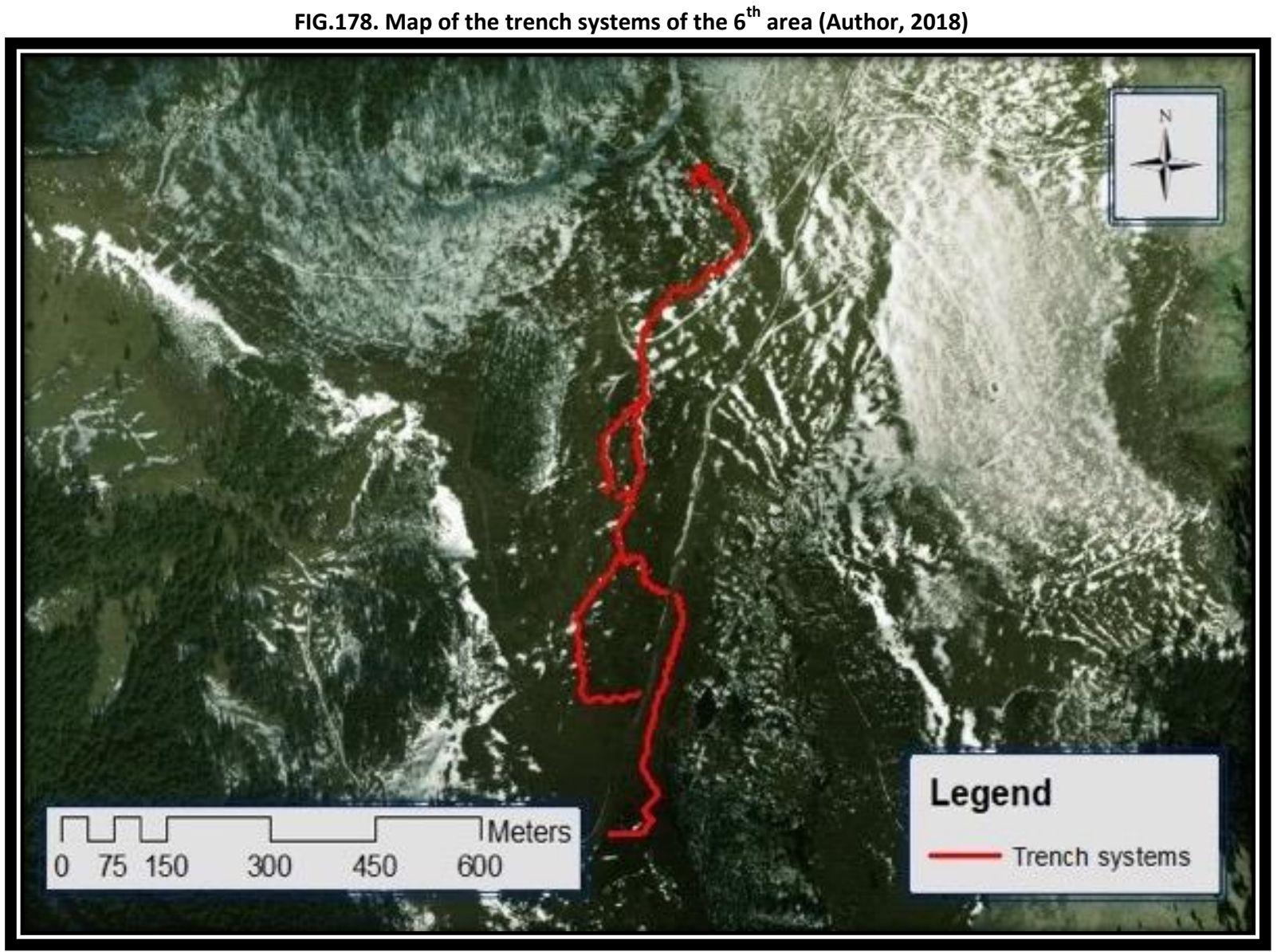

This concludes the series of results registered during the field campaign. The three research sectors (Sector 1 - FIG.11; Sector 2 - FIG.12; Sector 3 - FIG.13) build up what the present research refers to as war sites. Documentation of war remains in the research area was prerequisite to investigating the significance of the war sites as places of remembrance and heritage. The war sites documented in this chapter will be treated, in the following sections of 
the work, as potential heritage objects in the light of national and international legislation and in relation to other objectives holding official heritage status.

\section{$\underline{\text { 5.5. Conclusions }}$}

The previous sections of this chapter provide a database of the research area's war remains. The diligent recording of the material evidence in the three research sectors enables the characterisation of the war sites and allows for assessment of the rarity, authenticity and level of preservation of the war remains while concomitantly highlighting imminent and potential threats to preservation of the sites. In this context, the influence exerted by geography and development upon preservation of the war sites becomes a prominent aspect of the war remains survival over the past hundred years. The categorisation of the content and characteristics of the material culture constitutes the tangible dimension to which the intangible dimension emerged from the previous chapter will be anchored allowing the assessment of the places of war as heritage, and thus the evaluation of their value and significance.

The morphology of the conflictual landscape illustrates existent interconnections between the war remains of the three research sectors. The first sector, that summarises the remnant traces of the KuK Kommando der Prislopbahn, develops around the Prislop Pass examining the site of the WWI city of barracks (FIG.11). As seen previously, the military commandment was tasked to defend the Prislop Pass, which was an entrance gate to Maramureș and hence to the heart of the empire, as well as to protect this strategic railway node that assured not only the logistic demands of the front line but also answered the supply needs of the Transylvanian foundries and thus of the weapon plants, which required constant provisioning with prime materials in order to support the war effort. The second sector, featuring large concrete 
remains for the majority bunkers and their adjacent trench systems, constitutes the defence system of the KuK Kommando der Prislopbahn. As highlighted by FIG.12, the defence system of the Prislop military command develops along Mackensen's road mainly towards North and East, facing the direction of the Galician Front and of Bukovina. The third sector features the trench systems that develop all around the Prislop Pass (FIG.13) climbing up the heights of the mountains and following the same directions, as they were designed to prevent potential invasions from the North or East.

The spatial distribution of the war remains allows the understanding of the strategic defence system of the Austro-Hungarian army and the importance of this particular location in the economy of war. The fact that all six areas (FIG. 168) of the third research sector, which overlap the other research sectors, allow visual contact amongst each other and dominate the surroundings in terms of extensive viewshed demonstrates the strategic attributes of the area. The hypothesis of the strategic importance of the landscape is also sustained by the restoration of the defence line of the Maramureş Mountains during WWII, as part of the fortified Arpad line. Overall, the location maps of the three research sectors illustrate the rationales behind establishing a military command in the Prislop Pass and the construction of its adjacent logistic and defence systems, which were accounted for in the previous chapter's section dedicated to the Prislop Pass as a link between Maramureș and Bukovina.

In terms of characterisation of the war remains, it emerges that the features contained by the three research sectors build up several categories of war remains and various typologies within the same category, so providing a variegated collection of WWI material culture. The highest variety of categories is found in the first research sector as a consequence of the density of material traces resulting from the establishment of the military city in the Prislop 
Pass. As has emerged from the recorded data, there are several categories of materials that build up the places of war as shown in Table 2 .

Table 2. Catalogue of material remains typologies

\begin{tabular}{|c|c|}
\hline \multicolumn{2}{|r|}{ Categories of material remains } \\
\hline $\begin{array}{l}\text { Building } \\
\text { foundations }\end{array}$ & $\begin{array}{l}\text { - although uneven in terms of size they are all rectangular in shape and } \\
\text { made of stone with joints of slaked lime or cement and gravel, except } \\
\text { for Features } 19 \text { and } 75 \text { which are square in shape, made of concrete and } \\
\text { covered with a layer of bitumen. They might be the foundations of large } \\
\text { buildings such as the railway station, funicular warehouse, hospital, } \\
\text { stables, etc. }\end{array}$ \\
\hline Pits & $\begin{array}{l}\text { - found in the proximity of building foundations, earthworks and } \\
\text { trenches, the pits are mostly squarish holes in the ground of various } \\
\text { sizes from } 1 \text { to } 4 \mathrm{~m} \text { (sides) and approximately } 1 \mathrm{~m} \text { deep with surfaces } \\
\text { peppered with earth bricks and shaped stones. The only features in this } \\
\text { category that constitute an exception to this rule are Features } 92 \text { and } 96 \\
\text { which are slightly rectangular and present much bigger dimensions than } \\
\text { the previous cases, reaching a maximum length of } 12 \mathrm{~m}, 10 \mathrm{~m} \text { width } \\
\text { and } 3 \mathrm{~m} \text { depth. The first case is likely to represent dug-in defenses for } \\
\text { small cannons/machine-guns, dugouts or storage, while the second } \\
\text { might be the result of large-scale explosions. }\end{array}$ \\
\hline $\begin{array}{l}\text { 4-sided } \\
\text { earthworks }\end{array}$ & $\begin{array}{l}\text { - rectangular or square embankments excavated in the hill slope that } \\
\text { present an entrance usually on the side opposite the hill slope (except } \\
\text { Feature 16) with surfaces peppered with shaped stones. Such features } \\
\text { are probably embankments resulting from construction of the military } \\
\text { city as they are found only in this area and match the location of the } \\
\text { buildings of the historical photographs (FIG. } 30,38,44 \text { ). }\end{array}$ \\
\hline $\begin{array}{c}\text { 3-sided } \\
\text { earthworks }\end{array}$ & $\begin{array}{l}\text { - 3-sided embankments excavated in the hill slope of rectangular or } \\
\text { square shape and various dimensions. Unlike the previous case, this } \\
\text { category, by far the most well-represented category of embankments, } \\
\text { presents two subcategories. The first subcategory has smaller } \\
\text { dimensions and presents the same characteristics as the above category, } \\
\text { most probably being the same kind of embankment resulting from } \\
\text { building the shacks. The second subcategory, (Features } 30,48,49,68 \\
\text { and 70) has regular narrow rectangular shapes, considerably higher } \\
\text { lengths and follows a trajectory from the direction of the Prislop saddle } \\
\text { towards the building foundation of Feature } 11 \text {, while at the other end } \\
\text { the line it appears to start descending towards Cârlibaba-Iacobeni. } \\
\text { According to expertise presented in the articles of the railway } \\
\text { philatelists, the railway line must have followed this trajectory as it } \\
\text { would be impossible for a steam-operated train to travel on routes with } \\
\text { high declivities and tight curves. Such knowledge, along with clues } \\
\text { offered by the historical photographs (FIG. } 15,17,25,27,28,31,34 \text {, } \\
35,39,42,44 \text { ), make a plausible hypothesis of the embankments being } \\
\text { made to support the railway. }\end{array}$ \\
\hline
\end{tabular}




\begin{tabular}{|c|c|}
\hline $\begin{array}{l}\text { 2-sided } \\
\text { earthworks }\end{array}$ & $\begin{array}{l}\text { - 2-sided embankments excavated in the hill slope, of various shapes } \\
\text { and dimensions, with surfaces peppered with shaped stones. Like the } \\
\text { above categories they are probably embankments of the shacks. Still, it } \\
\text { is important to understand that within the morphology of the military } \\
\text { city the small shacks had defence purposes as well as accommodation } \\
\text { functions and, hence, were grouped according to an established } \\
\text { defensive strategy meant to protect the overall position. }\end{array}$ \\
\hline Craters & $\begin{array}{l}\text { - large roundish cavities in the hill slope, of approximately } 13 \mathrm{~m} \\
\text { diameter, oriented to the S. The position within the research area and } \\
\text { the proximity, size, orientation and shape of these craters points in the } \\
\text { direction of a bombardment operated most probably from the top of the } \\
\text { present ski slope that lies } S \text { of the hill. }\end{array}$ \\
\hline Mounds & $\begin{array}{l}\text { - oval shaped features of about } 3 \mathrm{~m} \text { long, } 2.50 \mathrm{~m} \text { wide, roughly } 40 \mathrm{~cm} \\
\text { above the hill level on the upper side and about } 1.40 \mathrm{~m} \text { above hill level } \\
\text { on the lower side. Written sources report that, during WWI, dead } \\
\text { soldiers were buried high in the Prislop Pass in graves that sheltered } 3-4 \\
\text { individuals. The harsh climatic condition, the ground density and the } \\
\text { high rate of mortality in the area due to the evacuation of the wounded } \\
\text { from the battlefields in Bukovina bear evidence to the above hypothesis. }\end{array}$ \\
\hline $\begin{array}{l}\text { Military } \\
\text { cemetery }\end{array}$ & $\begin{array}{l}\text { - higher ranks of the Austro-Hungarian army were buried in a military } \\
\text { cemetery (FIG. 111) placed on the hillside opposite the location of the } \\
\text { mounds, to the right of the present monastery. The WWI military } \\
\text { cemetery is represented in FIG. } 112 \text { as a viola rectangle. The only } \\
\text { original WWI stone cross (FIG. 110) to still be seen on the spot } \\
\text { belonged to Lieutenant Paul Hellmann, dating } 20.11 .1916 \text { confirms the } \\
\text { dating of the cemetery and the rank theory. Although it is claimed that } \\
\text { the monastery (built to honour the fallen soldiers of the world wars) } \\
\text { founded the military cemetery to accommodate human remains found } \\
\text { in loco during the excavations for its construction, WWI photos } \\
\text { contradict and invalidate such claims as it appears that the military } \\
\text { cemetery was already built on the same spot at the time of the war } \\
\text { (FIG. 38). }\end{array}$ \\
\hline Common graves & $\begin{array}{l}\text {-oval-shaped features, when viewed from above, of lengths ranging } \\
\text { from } 9 \mathrm{~m} \text { to } 11.20 \mathrm{~m} \text {, widths between } 3.5 \mathrm{~m} \text { and } 5.30 \mathrm{~m} \text { and heights } \\
\text { from } 1.20 \mathrm{~m} \text { to } 1.60 \mathrm{~m} \text {, presented in a parallel progression. Local } \\
\text { memory relegates the features to burial places of the remains of war } \\
\text { prisoners who were engaged in the construction of the military } \\
\text { earthworks and of the railway system during the Great War. }\end{array}$ \\
\hline Pillbox & $\begin{array}{l}\text { - dug-in guard post made of concrete, of } 60 \mathrm{~cm} \text { high and } 20 \mathrm{~cm} \text { thick } \\
\text { walls, equipped with a loophole of } 62 \mathrm{~cm} \text { long and } 22 \mathrm{~cm} \text { high on the } \\
\text { front side. }\end{array}$ \\
\hline Bunkers & $\begin{array}{l}\text { - concrete constructions of various shapes and styles which are part of a } \\
\text { large defence system that endemically spans across the research area. } \\
\text { According to their location they can be grouped in to two classes of } \\
\text { bunker: above-ground or underground bunkers. Also, by proceeding } \\
\text { along this line of analysis it emerges that the above-ground bunkers } \\
\text { tend to have pentagonal shape on the outside and the front of the bunker } \\
\text { larger than the back, while the underground ones are either box-shaped }\end{array}$ \\
\hline
\end{tabular}




\begin{tabular}{|c|c|}
\hline & $\begin{array}{l}\text { inside and out or are pentagonal outside with equal semi-circular tunnel } \\
\text { interiors. In terms of materials the great majority are made of reinforced } \\
\text { concrete, have roofs covered with a layer of bitumen and a layer of } \\
\text { plaster on top. The bunkers have adjacent trenches and a multitude of } \\
\text { shaped stones are spread around, especially in the front area. All the } \\
\text { bunkers had defence functions with the exception of Feature } 97 \text { which } \\
\text { is considerably bigger and relegated by local memory to the role of } \\
\text { weapon depot. }\end{array}$ \\
\hline Trenches & $\begin{array}{l}\text { - narrow channels dug into the ground, usually } 2 \mathrm{~m} \text { wide, with depths } \\
\text { ranging between } 1 \text { and } 2.5 \mathrm{~m} \text {, presenting various lengths and different } \\
\text { shapes and styles. Several shaped stones were found along the trenches. } \\
\text { The trench systems extend throughout the research area building the } \\
\text { defence system of the Prislop Pass along with the bunkers. The defence } \\
\text { system is quite linear in terms of accessibility as it is mostly positioned } \\
\text { near roads. }\end{array}$ \\
\hline Ordnance & $\begin{array}{l}\text { - cartridges of various dimensions, the head of a bomb shell, an } \\
\text { exploded WWI hand grenade and pieces of barbed wire. Various war } \\
\text { materials were found during the field campaigns near bunkers or } \\
\text { rescued from the excavation undertaken during construction works at } \\
\text { the 'Alpine' chalet situated on top of the Prislop saddle. }\end{array}$ \\
\hline
\end{tabular}

The documentation of the war remains within the research area provides an inventory of the materials present above ground in the research area that represents war sites. The documentation of the material remains of war within the research area allowed the understanding of the kind of materials represented, of the distribution of the material culture within the research area, and of the density and typologies of the material remains. Understanding the components of the war sites allows assessment of the places of war in relation to heritage concerns such as their state of preservation, rarity and authenticity, which are components of the heritage value.

In terms of preservation the surviving war remains are generally well preserved, if by preservation we refer to their state at the end of the war, which is not necessarily their initial state. In other words, most of the features accounted for throughout this chapter are preserved just as they survived the world wars. For instance, although the Prislop Pass military city was burned to the ground at the end of WWI and the military railway was dismantled, some of the 
building foundations and earthworks on which the shacks were built along with fragments of the railway embankment remain in place and, for the most, preserved their original features. The military cemetery is still in place, although missing its original crosses except for one, and the alignment of the nine common graves still exists. The fortification systems of the Maramureș Mountains were rebuilt during WWII implying that the WWI network of bunkers and trenches was re-used during WWII at the end of which most of the bunkers were blown up, which is exactly the form they have survived in to today. Consequently, when talking about preservation of the war remains, the historical journey of the material culture must be considered and through this lens the state of preservation of the war remains that did survive the last century is generally good.

As far as the dating is concerned, it would be hazardous to try to determine the exact dating of the recorded features at this level of research. Furthermore, reutilisation of WWI materials during WWII, to the point that it becomes hard to determine to which conflict a certain feature belongs, supplies evidence in favour of the authenticity of the war places and displays an evolving continuum of the WWI material remains. All material things evolve in time and it is precisely the time imprint component, that is the traces left by the passing of time, one aspect of heritage, that builds up the spectrum of heritage value.

The case of the shaped stones that are spread liberally around the research area supports the authenticity continuum hypothesis. The presence of this type of stone all over the war sites in the proximity of buildings/bunkers, in the pits and along the trench systems and the war road, indicates use of extremely large quantities of such material for paving roads, settings of the defence systems, both bunkers and trenches and their surroundings or even as flooring in buildings of the military city. The paving of the war road can still be seen in certain places on sectors of the present road that survived rehabilitation. The paving was probably a strategy to 
avoid the mud issue (FIG. 26) since the area is quite rainy most of the year and there was intense traffic through the Prislop Pass for several years (FIG. 31, 38, 40, 43, 44). The imperial transport system presented in the historical review chapter had the capacity to supply the location with such large quantities of materials, but transport facilities, such as the railway and the funicular, did not survive the end of the war nor were they rebuilt during WWII when only the defence system was reutilised. The imperial army also had human resources (especially disposable personnel such as war prisoners and local workforce to use for excavation works), logistics and the engineering capacity to produce such large-scale engineering works. This indicates that the shaped stones belong to the material culture of WWI although some were reutilised during WWII.

Although it is difficult to attempt dating the bunkers without excavation, since the front line of the two world wars coincides, local memory reports that during the Great War concrete was made out of slaked lime, which is a calcium containing inorganic mineral, and gravel, while WWII bunkers were made of sand and cement aggregate. The fact that in only some of the bunkers 5-6 cm calthemite formations can be found (picture 158) confirms the existence of a difference between the bunkers in terms of materials. Hence, given that the formation of calthemites needs calcium and that slaked lime has a higher calcium concentration than cement, it is more likely that WWI bunkers would grow such formations.

The dark side of the preservation discourse resumed previously is that several war remains did not survive recent times due to a development boom in the area. Although left unaltered/unharmed for most of the last century, building the monastery, parking lots, chalets, a tourist information centre that never got to function, the ski slope and its adjacent facilities like the chairlift and hotels, along with rehabilitation of the national road, drastically reduced the size of the WWI military command especially in the Prislop saddle area around the place 
known as the Krenzplatz during WWI. The first research sector presents material evidence that managed to survive the development undertaken in the area during the last decade reducing the central sector to much less than the WWI military city that emerged from the WWI photographic evidence. It infers that, although war remains must have been quite common along front-line areas in the aftermath of the war, development over the past hundred years concealed or wiped away most of the visible war relics. In terms of rarity, not only is the studied area amongst the last part of Maramureș that still preserves war remains visible to the naked eye, but it is also notable due to the significance of this particular location to the economy of war and to the great diversity of its component features that highlight the dimension of war architecture.

The different preservation levels of the three research sectors indicate that the further the relics are from inhabited areas, the more likely it is for the sites to remain unaltered. Although the first sector is apparently the most exposed to identified threats such as development, it appears that the other sectors are not immune either, as it emerges that intensive farming also threatens preservation of material culture of the war sites. Furthermore, without the aid of a legal protection framework, the overall morphology of the war sites is completely vulnerable to alteration especially on surface level as demonstrated by changes undertaken at the sites during the three-year research, illustrating a connection between the preservation of the war remains and their official heritage status.

The emergence of underground war relics and the presence of ordnance in several amateur collections within the research area signals the existence of an unexplored underground material culture. It follows that not only is there a need to prevent further deterioration of the war sites, but also an imperative need to preserve them for further study, even in areas where war signs are not visible at ground level. The importance of the war places is not therefore 
gauged by the sum of their component parts as evaluated in a disjointed manner, but from the consideration of the war sites as a whole, at landscape scale. These places of war are a fresco of history and memory condensed in a conflictual landscape that bears the mark of the world wars, which confers an undeniable grandeur and solemnity to the sites, aspects that will be discussed in the following chapters.

Conclusively, the absence of a catalogue of Romanian war sites brought about the need to create a gazetteer before conducting any further work, since consideration of the places of war in a heritage perspective is dependent upon the existence of a database containing information about the material remains. Diligent recording of the sites highlighted two types of good preservation, good preservation in terms of being as built, or good preservation in terms of what happened to sites after they were built. When considering war remains as heritage the second category becomes even more relevant, as it is fascinating to see the time evolution of the material remains, both during and after the war, as their current state narrates a story of authenticity and evolution. For instance, the fact that several bunkers were blown up points to plural stories depending on whether it occurred during the war or after, in addition to emphasising their original function. Furthermore, although at the end of the war there must have been an abundancy of war sites in the region, today the Mountains of Maramureș are the only known place to preserve visible war remains that constitute a conflictual landscape. If such conflictual landscapes turn out to be representative of the Eastern Front, to the point of providing the norm, then it follows that the material culture of war is richer on the Eastern Front than on the Western Front, calling for a different approach to the management of war remains. If on the other hand it turns out that this is just an isolated case that constitutes an exception to the overall norm, on account of the protection conferred by its environmental settings which successfully preserved the sites until recent times when development began 
taking place, then that also constitutes a fundamental finding which proves that out of an immense quantity of war remains spread throughout the region only a limited number of sites survived the century, nurtured by the mountains. Hence, the present work constructed the first comprehensive gazetteer of world war sites (WWI, and probably WWII) that demonstrates good preservation, both in terms of original material and materials damaged during the war, and that further research is indicated from different bases such as dating and extensive study of the Eastern Front; but it also demonstrates how the war sites are endangered as many are under threat of development. Hence, war remains in the research area plead firmly that the recorded material culture of war is good in terms of what remains, but is also endangered so that something has to be done. The answer to what could be done in such a situation will emerge from the focus of the following chapter. 


\section{CHAPTER 6 - HERITAGE BY LAW, NATIONALLY}

\subsection{Introduction}

The purpose of this chapter, as pertaining to achievement of Objective 2, is to inform the assessment of the places of war as heritage at national level by investigating the Romanian heritage legal framework and examining the premises for the granting of heritage status. Investigation of the national heritage legal frameworks highlights the premises for granting heritage status in Romania, and the attendant mechanisms. Understanding the Romanian heritage legislative evolution and characteristics allows contextualisation and characterisation of the heritage ranking process, thus underlining the constrictions and limitations of the legal system.

In order to enable the reading of the war remains registered in the previous part of the research, through a heritage perspective, the criteria according to which heritage is declared in Romania and the rigours of the heritage ranking process had to be clarified. The nature of the heritage management in Romania emerged from the examination of Romanian heritage legislation starting from the introduction of the first historical notions of heritage to the present legal framework. The application of the national heritage standards diachronically was explored by relying on the official Lists of Historic Monuments (1955, 1975, 1991, 1992, 2004, 2010) in relation to the County of Maramureş, while the present situation was tested relying on the current Lists of Historic Monuments (2015). Furthermore, present-day significance conferred upon the Great War in Romania emerges from exploration of the national legislative initiatives that were adopted in relation to the centennial of the Great Romanian Union and of the end of WWI, providing important hints about the relevance of the war sites to local and national identity. 
The chapter enables assessment of the significance of the war remains within the national legal frame, and in comparison to other heritage items, in view of clarifying their potential and worth from a heritage official perspective. In the context of examining the application of the selection criteria prescribed by national regulations, the most representative heritage category of Maramureş (churches) was used. The analytical inventory sheets used by the Ministry of Culture during the process of evaluating the heritage value of the only church that gained heritage status during the current legislation was used as a model for building the analytical inventory sheet of the war sites.

Building the analytical record of the war sites against the background of the legal framework provides valuable insights on why these war relics are not legally protected in Romania, besides enabling the conduction of comparative analysis with the church case in the discussion chapter.

\subsection{The evolution of heritage legislation in Romania}

The Romanian heritage legal protection system undertook a process of consolidations and transformations during a time spectrum of over a hundred years after the first ideas and concerns surfaced about preservation of the past for the sake of the future. The outset of the Romanian heritage protection framework occurred during the reign of King Carol I, who believed that "the nations that care for their monuments raise themselves above the others, because everywhere monuments are the living narration of history, the mirror of the past, true symbols for the future generations" (Tăbăcilă and Stoica, 2012, p.1). The 1874 Regulation regarding the Commission for Public Monuments institutionalised the king's desire to restore and preserve historic monuments for future generations. Chronologically speaking, the 
evolution of Romanian heritage legislation can be divided into three phases dependent on the historical-political context: 1892-1946, 1946-1990, 1990 to the present day.

The first actual law dedicated to heritage conservation, that is the Law for the Conservation and Restoration of Public Monuments, was promulgated by the High Royal Decree No. 3658 on $17^{\text {th }}$ March 1892 , along with Law 24 for the discovery of antique monuments and objects. The uniqueness of the first law was the creation of a commission for public monuments known as the Commission of Historic Monuments, which was composed of three members appointed in virtue of scientific excellence in the field of history and archaeology, the director of Bucharest's Antiquity Museum, and an architect. The main responsibilities of the commission regarded the restoration, conservation, maintenance, protection and inventory of historical monuments. The commission curated a collection of antiquities and buildings that was listed in an inventory of historic monuments that acquired legal power upon authorisation by means of royal decree (Coroamă, 1999). The inventory was subject to conservation measures and was to be revised every five years.

A year later, in 1893, Regulations of the Law for the Conservation and Restoration of Public Monuments were issued, with the aim of cultivating amongst the population a sense of care and responsibility oriented towards the conservation of monuments, with the aid of speciality publications. In the exercise of its prerogatives the Commission of Historic Monuments promoted a restoration programme that relied on financial aid from the state. The architectonic concept promoted by the commission relied on a restoration approach that was based on consolidation of the buildings, keeping intact as much as possible of the original elements, and rejecting ideas of demolition and reconstruction; it achieved positive results leading to the rescue of a series of historical monuments that still exist today, like the Stavropoleos Church in Bucharest. 
The Law for the discovery of antique monuments and objects was the first law that took into account both immobile and mobile heritage. It was also the first law to regulate the legal regime of archeological excavations, of fortuitous discoveries, the procedure of recognition of artistic and historic goods, and of the judicial status of heritage objects (art.1-6). It also regulated the sanctions system to be applied in cases of breaking the law and fixed conditions for state control over conducting archaeological excavations by making compulsory the authorisation of all excavations by administrative approval (art.7-8). The Regulations of Law 24/1892 were also issued in 1893 with the purpose of clarifying proper application of the law. The Regulations delineated the meaning and applicability of the property right; defined the mobile heritage ranking procedure, regulated the right to possess antiques and set out the rules and limits of the antiques trade.

The Decision No. 34329 issued by the Ministry of Cults and Instruction ${ }^{13}$ established the Bulletin of Historic Monuments. The gazette, that was subordinate to the commission, was first published in January 1908 with the purposes of clarifying the requirements of the 1893 Regulations, and contributing to the development and promotion of historical, artistic and architectonical studies, especially in relation to historical monuments. The gazette was also ideated as an archive of the content and preservational condition of the monuments for the use of the future generations.

On $25^{\text {th }}$ April 1913 a royal decree instated the law regarding the attributions and the functioning of the Commission of Historic Monuments, which broadened the commission's field of activity. The House of Historic Monuments was established during the same year with the aim of gathering and distributing the funds of the commission's restoration programs. The 1913 Law for the conservation and restoration of historic monuments was attempted with a

\footnotetext{
${ }^{13}$ The Ministry of Cults and Instruction was equivalent of the nowadays Ministry of Culture.
} 
view to adapting the prerogatives of French and Italian legislation regarding historical monuments and archeological excavations to the Romanian reality. Unfortunately, the begining of WWI and the death of the King Carol I, on the $10^{\text {th }}$ October 1914, arrested investments in the field of culture, so ending the first prolific stage of Romanian heritage concerns.

After the end of WWI and the achievement of the Great Romanian Union, concerns about cultural goods of the newly created Great Romania materialised in the 1919 decree, which on the $28^{\text {th }}$ June established a new set of regulations in the field of conservation and restoration of historic monuments. The new regulations are seen on the one hand, to respond to the specific needs of the Romanian historical provinces and, on the other, to assure proficient monitoring of the entire territory in order to assure the protection of national heritage. The regulations constituted an improvement of the previous legislation which was supplemented with relevant new elements such as the conservation and restoration of buildings and old objects of historic or artistic value regardless of the nature of the owner (private/state), the establishment of regional museums, the introduction of the concept of reservation and the criminalisation of acts of destruction, mutilation or alienation of cultural goods. Most importantly the provisional ranking as historical monuments of all churches and monasteries built before 1834, including their mobile possessions, constituted a milestone in the evolution of Romanian heritage.

The Superior Commission for Public Monuments was established on $5^{\text {th }}$ March 1930, and in 1938 the Regulations for Public Monuments was issued. The law for the protection of the monuments of nature was published on $7^{\text {th }}$ July 1930, simultaneously establishing a commission for the monuments of nature. Two years later, on $17^{\text {th }}$ November, Regulation No. 44 was adopted with the purpose of serving the public administration. The regulation had to 
do with application of the law regarding the protection of monuments of nature, including the category of reservations and sites of scientific interest. The legal frame for the protection of nature was sanctioned in Law No. 9/1932 while the Law No. 81/1932 regulated the organisation of public communal libraries and museums. Law No. 81 introduced the notion of museum object/musealia with reference to mobile heritage and established the Museum Council as the authority in charge of monitoring and incentivising those activities that make museums into research institutions.

The Second World War brought dreadful conditions and circumstances to Romania - damage caused by the war being worsened by a severe earthquake - that converged in the suspension of heritage prioritisation policies. After the end of the war, that caused great destruction, on $25^{\text {th }}$ April 1945 the Decree No. 1384 was issued with the purpose of ranking some surviving citadels/burgs/forts as monuments. On $20^{\text {th }}$ September 1946 the law-decree for the organisation of national museums was issued, establishing a functional framework for the national museum system to be able to assure conservation of Romania's mobile heritage and to guarantee access to historic and artistic information, both locally and nationally. The national Museum of Art and Archaeology was founded with such a purpose, subordinate to the Ministry of Arts, and for the first time in Romanian history the law specifically prescribed a formation/training/education system of the specialty personnel through the newly created Central School of Museology, while the Supreme Council of Museums functioned as the highest authority in the adjacent field of research.

Decision No. 501/1950, issued by the Council of Ministers, established the Committee for Cultural Settlements which, according to its prerogatives, regulated the protection of monuments and museums. The new administrative organisation that occurred in Romania in the fifties reorganised the national territory in regions - the present county of Maramureș 
being part of the region of Baia Mare. Territorial administrative divisions remained unaltered until 1968 when the counties formula was reinstated, and the Region of Baia Mare was divided into the county of Maramureș and the county of Satu Mare. A year later the Great National Assembly decreed the foundation of the Scientific Commission of Museums, Historic and Artistic Monuments, with the purpose of compiling an inventory of the monuments. Decree 46/1951 abolished the Commission of Historic Monuments, The Commission of Public Monuments and the Supreme Council of Museums.

On $22^{\text {nd }}$ April 1955, Decision No. 661 was adopted by the Council of Ministers with regard to the preservation and usage of cultural monuments (Opriş, 1980). The decision was particularly relevant firstly, because it included all types of cultural monuments and secondly, because it brought about the introduction of conceptual categories such as protection areas, usage regimes, and special funds for urgent intervention. The decision was sustained by a regulation that introduced the obligation to obtain authorisation for archaeological excavations and usage obligations for the utilisation of historical monuments that normalised the form of usage and protection/preservation requirements. During the same year the socialists produced regulations for the preservation and usage of cultural monuments and Decision No. 1160/1955 about ranking historical monuments, archaeological monuments, architectural monuments and fine arts monuments ${ }^{14}$ as heritage, which sanctioned and published the first Romanian List of Historic Monuments. The Scientific Commission of Museums, Historic and Artistic Monuments summoned the Council of Ministers with regard to the heritage needs, who in their turn proceeded to rank or downgrade historical monuments. The decision also contemplated the demarcation of protection areas around the monuments,

\footnotetext{
${ }^{14}$ According to the 1955 List of Historic Monuments, which was accompanied by a brochure published by the Publishing House of Academy of the Romanian Social Republic, at the time the historic monuments were divided into four separate heritage categories as follows: archaeological monuments, architectural monuments, fine art monuments and historic monuments.
} 
decided on the basis of in-depth studies conducted by experts/representatives of the State Committee for Architecture and Constructions, the Ministry of Culture, the Ministry of Agriculture and Forestry, and the Executive Committees of Local Administration, taking into account the landscape, importance and dimensions of the objective.

Decision No. 781/1959 of the Council of Ministers settled the legal and organisational heritage framework by creating the Direction of Historic Monuments. The directive was a complex national preservation system composed of multiple sectors that specialised in the various fields of research, statistics/monitoring, design and conservation-restoration, and which allowed the unitary tracing of the restoration methods and techniques so that they all abided to a common methodology.

Adopting the prescriptions of the Athens and Venice charters, Romania promoted a principle of bicephalous historical restoration which, on the one hand, promoted partial restoration of the original appearance, hence opting for the removal of subsequent additions and, on the other, struggling to preserve all the artistic and historical elements of subsequent additions in order to confer a dimension evolution over time to the monument (Opriș, 1986).

In 1974 the Socialist Republic of Romania issued the Law No. 63 that consolidated the basis of the cultural heritage law system by promoting a solid protection and preservation framework. Antonie Iorgovan claims that "as far as the scientific and legal aspects are concerned, such a law represents a truth code for the field of national cultural heritage; one of the most successful regulations of the kind at least as far as Eastern Europe is concerned" (Iorgovan, 2002, p.313). The law, structured in three chapters (1 - National Cultural Heritage; 2 - Inventory, preservation, conservation and valorisation of national cultural heritage; 3 Sanctions) contemplated both the mobile and immobile heritage of artistic, architectural and 
historic value along with the monuments of nature. Simultaneously, the Central State Commission of Cultural National Heritage, the Direction of Cultural National Heritage and county level Offices of Cultural National Heritage were created with the aim of assuring the unitary inventory, preservation, conservation and valorisation of national heritage.

In 1975 Decree No. 13 was issued by the State Council, establishing the attributions of the Direction and of county level Offices (art.12) offering practical support to the concept of unitary national heritage system promoted by Law 63/1974. The law, along with all its normative regulations, was abrogated after the fall of the communist regime by means of Law-Decree No. 90/1990 issued by the National Salvation Front which was intent on changing the entire Romanian governmental structure. The consequences of this decision proved disastrous for Romanian heritage, against the background of a misguided privatisation process, as the state lost its rights to prevent the subtraction or destruction of cultural national heritage. Although new heritage institutions were created by Decree 90/1990 ${ }^{15}$ and Decree $91 / 1990^{16}$, they all remained rather dysfunctional in the absence of an adequate legal framework, while the degradation of heritage proceeded. Nonetheless, the National Commission of Monuments, Ensembles and Historical Sites was designed to be operative, and was therefore ideated to collaborate with the Zonal Commissions that were established in every historic region of Romania to co-ordinate heritage-related activities. Hence, five distinct categories of monument were established covering the fields of archaeology, architecture and engineering, ensembles and historic areas, rural architecture and artistic components of monuments.

\footnotetext{
${ }^{15}$ Decree 90/1990 established the Commission of Museums and Collections and the Direction of Museums and Collections.

${ }^{16}$ Decree 91/1990 established the National Commission of Monuments, Ensembles and Historical Sites.
} 
On $7^{\text {th }}$ February, 1990 Decree No.101 for the establishment of the Inspectorates for Culture of the Counties was issued regulating the cultural administrative needs of the counties. The same year, on $30^{\text {th }}$ March, Decree No. 187 for the acceptance of the Convention Concerning the Protection of the World Cultural and Natural Heritage was published.

Government Ordinance No. 27, regarding measures for the protection of cultural national heritage, was issued on $26^{\text {th }}$ August 1992 setting up a provisional protection system that regulated both immovable and movable heritage. One of its most important provisions stated that, until further notice, the natural and legal persons in possession of mobile or immobile cultural goods were under obligation to preserve and conserve them, and that the List of Historic Monuments was to be revised annually (art.1-2). Furthermore, monitoring and surveillance of interventions on the monuments and their protection area was intensified, along with the authorisation requirements (art.6). Disregarding authorisation policy constituted a finable contravention. An entire arena of specialists were legally designated and validated for dealing with all categories of intervention concerning historic monuments.

A record of all specialists was kept in the Specialist Register, maintained by the National Commission of Monuments, Ensembles and Historical Sites. The domains, the number of members and their nomination in the Technical Authorization Commission were to be established by Government Decision subsequent to nominations initiated by the Ministry of Culture and the National Commission of Monuments, Ensembles and Historical Sites. Law No. 11 approved Ordinance No. 27/1992 on $7^{\text {th }}$ March 1994, with minor modifications regarding the competences and functioning of the National Commission of Monuments, Ensembles and Historical Sites. 


\subsection{The formation of contemporary heritage legislation}

On $26^{\text {th }}$ August 1994, the '90s decrees were abrogated by Governmental Ordinance No. 68 regarding the protection of cultural national heritage. The ordinance sought to demarcate the sphere of Romanian cultural heritage, delineate the ranking criteria of heritage, divide historical monuments into categories, formalise the ranking procedure, organise the national heritage account and establish obligations for those in possession of cultural goods. The ordinance organised immovable heritage into three categories based on the value criterion (universal, national, regional) according to which historic monuments were to be ranked and dived (art.2), although it was never actually applied. Nonetheless, it introduced the ranking of movable heritage ${ }^{17}$ into two categories, divisions that last up to the present day (art.3). Article 8 prescribes the various heritage duties of the Ministry of Culture, amongst which the creation of a Register of Experts in the Field of Historic Monuments Preservation and a Register of Experts in the Field of Historic Monuments Conservation and Restoration. Article 9a reorganised the National Commission of Monuments, Ensembles and Historical Sites into the National Commission of Historic Monuments that still functions in such interests today, while Article10 prescribed its attributions.

Ordinance No.68/1994 was approved by Law No. 41 on $24^{\text {th }}$ May 1995 , slightly modified. The most relevant modifications regarded the assignment of inventory attributions to the National Commission of the Historic Monuments, the creation of the National Institute of Historic Monuments and the modification of regulations regarding the protection areas of historic monuments.

\footnotetext{
${ }^{17}$ Romanian movable heritage is ranked either in the Treasure of Cultural National Heritage which gathers the mobile goods of exceptional value or in the Fund of the Cultural National Heritage that comprises movable goods of historic, documentary, artistic, ethnographic, scientific, and technical importance.
} 
Ordinance No. 43, regarding the protection of archaeological heritage and the ranking of some archaeological sites as areas of national interest, was issued on $30^{\text {th }}$ January 2000 . The ordinance was designed to protect archaeological heritage by regulating the legal regime of the discoveries and of the archaeological research (art.1). This included the totality of scientific, legal, administrative, financial-fiscal and technical measures meant to assure the exploration, identification, discovery, inventory, conservation and restoration, security, maintenance and valorisation of archaeological goods in view of their research or ranking as cultural mobile heritage or historic monuments (art.2).

The ordinance was revised on $24^{\text {th }}$ November 2006 and is still valid in its original form. The National Commission of Archaeology is tasked with elaborating the strategies, as well as approving national research programs and technical-scientific rules and regulations in the field of archaeological research. As the leading authority in the field of archaeological heritage it performs the roles of approving the annual national plan of systematic archeological research, elaborating the methodology for ranking archaeological sites in the List of Historic Monuments, and proposing the ranking of archaeological sites. Furthermore, the commission is also in charge of establishing the criteria and approving the attestation of the specialists/experts in the field of archeological research (art. 16).

On $31^{\text {st }}$ January 2000 Ordinance No. 47 regarding the establishment of protection measures for historic monuments on the UNESCO World Heritage List was issued to regulate special additional measures for the protection of Romanian UNESCO heritage objectives. The ordinance prioritised conserving, restoring and valorising the Romanian historical monuments that are ranked as World Heritage and, therefore, contemplated expropriation for public utility in order to assure their protection (art. 3, clause 3). Law 564/2001 approved Ordinance No. 47/2000 with minor modifications. The most significant additions of this normative concerned 
the requirement to develop a Protection and Management Programme for UNESCO historic monuments and their respective protection areas, to be detailed in annual protection and management plans elaborated by the county council in which the historic monument is located (art.6, clauses 3-4-5).

On $22^{\text {nd }}$ February 2000, the Ministry of Culture issued Ordinance No. 2013 regarding the endorsement of general criteria for ranking immovable cultural goods on the List of Historic Monuments. Appendix 3 of the Ordinance prescribed the categories of value to be as follows: Category A - Monuments of exceptional national value, representative at universal level; Category B - Monuments of National Value; Category C - Monuments representative of a certain area, age, a specified style, author or ethnographic area.

Law No. 5 regarding the approval of the Plan for the Arrangement of National Territory: Section III: Protected Areas was issued on $12^{\text {th }}$ April 2000. This law regulated the management of protected areas, either built or natural, that were "topographically or geographically delimited and that comprise values of natural and/or cultural heritage and that are ranked as such" (Romanian Parliament, 2000) and considered the rescue, protection and valorisation of such heritage as a matter of national interest and public utility. The law was modified on $31^{\text {st }}$ August 2016 by Emergency Ordinance No. 49 with the purpose of "highlighting the areas that are included in the national network of protected areas and identifying the national cultural heritage values which are in need of establishment of protected areas in order to assure their protection" (Romanian Government, 2016). The natural protected areas of national, international and communitarian interest are contained in Appendix 1 of the ordinance, and their management was ultimately to be regulated by special laws. 
On $25^{\text {th }}$ October 2000 Law No. 182 for the protection of the national mobile cultural heritage was issued. The law, that abrogated the prescriptions regarding mobile heritage prescribed in Ordinance 27/1992 and Ordinance 68/1994, defined the concept of mobile national heritage as being composed of goods of special or exceptional value, "representing material testimonies of the evolution of the natural environment in its interconnections with mankind, of the creative potential of humanity and of the Romanian contribution to the global/universal civilisation" and established its legal regime "in view of assuring the democratic access to culture and the transmission of value to the future generations" (art. 1).

A month later Emergency Ordinance No. 228/2000 for the protection of historic monuments was issued. This ordinance regulated the legal regime of all immovable goods, buildings and terrains, which were given the status of historic monuments by ranking in the List of Historic Monuments. The stipulations of Ordinance No. 228/2000 were overpowered by Law 422 for the protection of historical monuments on $18^{\text {th }}$ July 2001. Law 422/2001 establishes the legal regime of the historic monuments and the set of measures of scientific, legal, administrative, financial and technical character to assure the identification, research, inventory, ranking, conservation, restoration and valorisation of the historic monuments. Furthermore, it advocates the socio-economic and cultural integration of heritage into the life of the appropriate local communities (Pintea, 2014, p.39). The law also establishes the terminological extent of the notion of historical monuments in relation to the category of immobile heritage (aboveground, underground or underwater) as follows:

“a) monument - building or part of a building, along with the installations, artistic components, interior and exterior furnishing that are part of the buildings, as well as the artistic commemorative, funerary and public works, along with the related topographically delimited land/environment, which constitute cultural-historic testimonies that are significant from an architectural, archaeological, historic, artistic, ethnographic, religious, social, scientific or technical point of view;

b) ensemble - a group of urban and rural constructions that is coherent from a cultural, historic, architectural, urbanistic or museological point of view and which, along with the 
adjacent land/environment, constitutes a topographically delimited unity of culturalhistoric testimony significance from an architectural, archaeological, historic, artistic, ethnographic, religious, social, scientific or technical point of view;

c) site - topographically delimited field comprising human creations embedded in the natural environment that are cultural-historic testimony, significant from an architectural, urbanistic, archaeological, historic, artistic, ethnographic, religious, social, scientific, technical point of view or as cultural landscape" (art.3).

Article 13, paragraph 1 of Law 422/2001 prescribes the methodology and mechanisms of the ranking procedure. The ranking/downgrading file is prepared by the decentralised services of the Ministry of Culture, usually with input from authorised experts and specialists. The file is forwarded to the appropriate specialty department of the ministry, which analyses the file and presents it to the National Commission of Archaeology and/or the National Commission of Historic Monuments for further analysis and proposals. The secretary of the National Commission of Historic Monuments elaborates the project of the ranking/downgrading order and forwards it to the ministry for approval (art.13, paragraph 2).

The Ministry of Culture released Order No. 2260 regarding the approval of methodological norms for the ranking and inventory-compilation of historic monuments on $18^{\text {th }}$ April 2008 . Chapter III of the Methodological Norms prescribes the criteria for ranking immovable patrimony and details the standards to be considered in the evaluation process of every criterion. Article 7 states that a ranking criterion is a qualitative and quantitative standard, dependent upon which the significance and cultural importance of immovable proprieties are evaluated, and which determines the legal category and value group of the national cultural immovable patrimony to which they belong; respectively, group A (national importance) or B (local importance) of historic monuments. The ranking is based on the following criteria:
a) Age
b) Architectural, artistic, and urban value
c) Frequency (rarity and unicity)
d) Memorial-symbolic value. 
Each of these criteria is evaluated on a scale from zero to exceptional (zero, low, medium, high, very high, or exceptional). Immovable patrimony must meet the following criteria to be ranked in Group A of the Historic Monuments:

a) Having been qualified as exceptional in at least one of the four ranking criteria, except for those declared UNESCO heritage

b) Having been graded with at least high in all raking criteria, except for the criterion of memorial-symbolic value

c) Having been ranked with at least a very high grade, a high grade and a medium grade.

Whereas, for immovable patrimony ranked in group B of the Historic Monuments, it is sufficient to obtain at least three medium grades, except for cases in which, depending on the historical-geographic zone, age was allocated the 'low' grade.

There is also a section dedicated to the inventory of historic monuments which consists of all procedures that identify - through research and scientific analysis - those immovable goods that due to their characteristics are subject to being ranked as historic monuments. The inventory of historic monuments consists of compilating the analytic/minimal evaluation sheet of every monument, which contains all relevant technical and scientific information about the monument (art.3 paragraph 1 and 3). The second chapter of the law concerns the drafting procedure of the historic monument's analytic sheet and prescribes the requirement of validation by the signature of a specialist certified by the Ministry of Culture (art.4).

The requirement of such expertise creates several problems as many of the territorial divisions of the ministry do not have the necessary certified specialists and entering the Expert Register is a difficult process, especially for public servants. The conditions for gaining specialist status are prescribed by Order No. 2495/2010 about the approval of methodological norms regarding the attestation of specialists, experts and technical verifiers in the field of historic 
monuments' preservation. Out of the various specialisations attested by the ministry only position A regards the elaboration of studies, research, and inventory of historic monuments (art.8, paragraph 1). As far as attestation domains are concerned, only the third domain deals with studies, research, and inventory of historic monuments as it emerges from Article 9 of the order.

Subsequent to application of the above regulations in 2018, the Specialists Record had a total of 615 attested specialists, of which only 185 have specialisation level A and/or third domain attestation. Amongst the 185 specialists authorised to deal with studies, research, and inventor-compilation of historic monuments there are 26 painter-restorers, 18 engineers, 6 stone/wood/metal restorers, 1 physicist, 1 chemist, 4 art historians, 1 city planner, 14 historians/archaeologists, while the number of architects amounts to 114 (National Institute for Research and Cultural Training, 2018). Consequently, there is a huge deficiency of expertise in the field of history and archaeology which makes it impossible to cover the adjacent fields and conduct proper research throughout the national territory. This also negatively impacts the ranking and inventory of newly-discovered or undiscovered historic monuments.

Governmental Decision No. 90/2010, regarding the organisation and functioning of the Ministry of Culture and National Heritage, granted the ministry power to name and revoke the members and the leadership (president) of the various Romanian heritage and cultural commissions including the National Commission of Historic Monuments (art.14). In 2018 the National Commission of Historic Monuments had 21 members of which 9 were architects, 4 engineers, 1 art historian, 3 restorers, 1 plastic artist and 3 archaeologists (Ministry of Culture and National Identity, 2018). A network of decentralised public services of the Ministry of Culture, having legal capacity, was established throughout the territory. A County Direction 
for Culture and National Heritage led by a director named by order of the ministry was established in every county (art.16) as a public institution with administrative purposes, especially towards endorsement, monitoring and control activities within the field of cultural heritage.

Decision No. 24 regarding the initiation of the National Programme Romania 100 was issued on $15^{\text {th }}$ January 2014 , approving organisation of a national programme for the celebrating the centenary of the creation of the national, unitary, Romanian state and founding the National Committee for the preparation, organisation and coordination of scheduled events. On $6^{\text {th }}$ June 2016 the decision was overpowered by Decision No. 465/2016 regarding the establishment, organisation, functioning and attributions of the Centenary Department. The department functioned within the Government, subordinate to the Prime Minister, and was financed by the state with the aim of co-ordinating the preparation, organisation, and the progress of events, actions and projects for celebrating, at national level, the Centenary of Great Romania 1918-2018 and the commemoration of WWI.

Decision No. 597/2017 for the modification and completion of Governmental Decision No. 90/2010 regarding the organisation and functioning of the Ministry of Culture and the abolishment of Governmental Decision No. 465/2016, which is still valid, changed the name of the ministry to Ministry of Culture and National Identity (art.1). However, the main changes refer to the abolishment of the Centenary Department and the transfer of that department's prerogatives to the Ministery of Culture and National Identity with a view to promoting the national identity, celebration of the Centenary of Great Romania 1918-2018 and the commemoration of WWI. 


\subsection{The List of Historic Monuments}

As emerges from the above legislation, the first List of Historic Monuments was introduced in 1955 by Decision No. 1160 concerning the ranking as heritage of some historical monuments, archaeological monuments, architectural monuments and fine arts monuments. This was the first legalised inventory of Romanian historic monuments and carried a series of important legal implications, such as preservation and conservation exigencies.

In 1975, approximately two decades from publication of the first official evidence of the historic monuments, a new list was drawn up, although not published in any normative act and only circulated internally. Aura Pintea, Executive Director of the Maramureș County Direction for Culture and National Heritage in 2018, made an inventory of the evolution of the List of Historic Monuments in Maramureș in her dissertation entitled The pre-emption right in the field of Historic Monuments.

"In the archive of the Maramureș County Direction for Culture and National Heritage the list is non-existent, but for the great majority of historic monuments in the county there is documentation (short historic studies, topographic plans, and photographic materials) carried out in successive stages $(1964,1973,1983)$ " (Pintea, 2014, p.42).

After the communist regime was overthrown by the revolution, everything connected to the old system, especially in the legislative field, was suspended and substituted by new legal mechanisms. A new List of Historic Monuments ${ }^{18}$ was issued, individually for every county, revising, completing with new additions and updating the previous version. The 1991 Maramureș List of Historic Monuments had a total of 541 heritage objects divided into five categories of monuments as follows:

A - Monuments - archaeological reservations -66 items

B - Historic and architectural monuments -367 items

$\mathrm{C}-$ Memorial Buildings -8 items (7 memorial houses and a funerary monument)

\footnotetext{
${ }^{18}$ The full name of this version of the list was The List of Historic Monuments, Ensembles and Sites.
} 
D - Fine arts monuments including monuments holding memorial value - 28 items of category A and 65 items of category B (the great majority being World War I and II memorials, mostly dedicated to war heroes)

E - Architectural reservations -7 items.

In March 1992 a List of Historic Monuments approved by the National Commission of Monuments, Ensembles and Historical Sites was sent to the County of Maramureș Prefect's Office. This list, named The List of Historic Monuments, Ensembles and Sites had 492 monuments/ensembles/sites in Maramureș and was divided into five sections as follows:

A - Monuments and archaeologic sites -67 items

B - Monuments and architectural ensembles -370 items

$\mathrm{C}$ - Memorial buildings -7 items

$\mathrm{D}$ - Monuments of fine arts and with memorial value -35 items

E - Urban and rural historic areas -13 items.

"The novelty of this list consisted in the introduction of a unique code for every monument in the country" (Pintea, 2014, p.43). The code included a number corresponding to the county it belonged to, a letter indicating the ranking section and ordering number, but it did not consider a differentiation of the monuments based on their importance.

Although suffering several modifications, addressing both the ranking of new monuments and downgrading of existent ones, the 1992 list remained valid until 2004 when a new list was adopted by means of Order 2314, published by the Ministry of Culture. The 2004 List of Historic Monuments was also individual to every county unit, with each monument having a distinctive code, although this version of the list only had four categories of monument as follows:

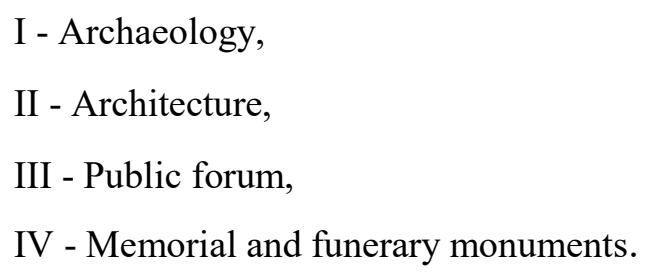


An additional lower-case letter followed after the category indicating the type of monument: $\mathrm{s}$ - archaeological site, $\mathrm{m}$ - monument, a - ensemble. As far as the element of value is concerned, distinction was made between monuments of national and universal value attributed to class $\mathrm{A}$, and monuments of local interest attributed to class B. Consequently, the code of a monument comprised the county abbreviation/code, the category, the value class and ended with an ordering number. According to the 2004 list Maramureș possessed a total of 585 monuments out of which 129 monuments were ranked under archaeology, 417 monuments under architecture, 13 monuments in the public forum category, and 26 in the category of memorial/funerary monuments.

Order 2361/2010 updated the above list on $12^{\text {th }}$ July 2010. The 2010 List of Historic Monuments had the same categories and code characteristics as the previous one, but the total number of historic monuments in the county of Maramureș decreased to 582, out of which 127 monuments were ranked under archaeology, 416 monuments under architecture, 13 monuments in the public forum category, and 26 in the category of memorial/funerary monuments.

The most recent version of the List of Historic Monuments, still valid today, was published on $24^{\text {th }}$ of December 2015 by means of Order No. 2828/2015. The 2015 list, like its previous two versions, was a product of Law 422/2001, which continues to dictate heritage rules and regulations today, bearing the same structure and characteristics. Still, through this latest addition, Maramureș totalled 610 monuments, of which 127 monuments were ranked under archaeology, 443 monuments under architecture, 13 monuments in the public forum category and 27 in the category of memorial/funerary monuments. 
The 2015 List of Historic Monuments reveals that in Maramureş from a total of 610 declared heritage items, 203 are related to "places of cult", of which 176 are churches, 3 synagogues, 9 cemeteries, 4 chapels, and 11 clerical facilities (parochial houses, curacies, etc). Since churches can be seen to be the most representative heritage category in Maramureş, that category was used when examining application of the selection criteria prescribed by the above regulations with regard to the ranking of historic monuments.

According to the Maramureș County Direction for Culture and National Heritage, the only church in Maramureș that was ranked in the List of Historic Monuments as a result of the application of the ranking criteria prescribed by the current legislation was church Saint "Ilie Tesviteanul", located in Borșa. The church entered the list in December 2011 and was ranked by means of Order No. 2787 issued by the Ministry of Culture and National Heritage. The analytical inventory sheets used by the Ministry of Culture in the ranking process of the church are reproduced in Appendix 15 in order to exemplify application of the analysed legislation, but also to provide terms of comparison with the analytical inventory sheet of the war sites (see Appendix 16).

According to the data of the county direction, the ranking file of the church, as for that matter of all monuments undergoing the ranking process, must comprise technical documentation (analitical inventory sheet, maps and territorial framing plans, photos, data relating to the usage regime), historical documentation (historical-architectural study), documentation of the legal status of the building (copies of property documents, cadastral plan and land registry), administrative papers (application form, speciality report of the County Direction for Culture and National Heritage, approval of the Regional Comission of Historic Monuments and the ranking proposal). Hence, the most important elements that inform the ranking procedure, and are directly related to the characterisation of the monument in view of allowing the assesment 
of its heritage value, are the analytical inventory sheet and the historical-architectural study. In view of this, the historical study of the church is made available in Appendix 17 as to allow comparisan with the examined war sites in the disscusion chapter.

\subsection{Romania and the heritage arena/The Romanian Territorial Development Strategy}

The document that currently embraces the whole set of administrative regulations for the application of the Romanian legal framework, both in the field of heritage and several other domains, with the purpose of supporting/aiding national development is the Territorial Development Strategy. The strategy presents a compendium of Romanian laws and practices, research and studies, policies and recommendations for directing the "complex strategic planning action that transposes Romania's development directions and objectives for the 2035-time horizon at a territorial level." (Concordia, 2014).

The strategy is based upon, and justified by, a series of grounding studies conducted in various development fields and sectors. Study no.12 covers the protection of natural, cultural and landscape heritage. The purpose of this study was to examine and diagnose the state of natural/cultural/landscape heritage and develop a set of measures able to assure their protection/conservation and to allow their reasonable utilisation and management in accordance with the principles of sustainable development.

The study has a section dedicated to analysis of the List of Historic Monuments in relation to the present European notions of heritage. The analysis concludes that the present structure of the list fails to fully cover the range of diversity of the historical monuments in terms of specific forms of value aggregation. Also, it emphasises that an unnatural demarcation between archaeological, historical, architectural, scientific, artistic or memorial value is being operated when ranking a monument, obscuring the fact that beyond the dominant value the 
monument holds a plurality of complementary values that may also be ethnographic, technical or social (Study No.12, 2014, p.47).

The fact that the methodological norms for the ranking and inventory of historic monuments do not contemplate scientific, social, technical or religious value but maintain focus on traditional standards such as age and artistic/architectural value, was also highlighted by the study. "The ethnographic value is not considered as such, which generates a marked lack of landmarks in the ranking of vernacular heritage, and the memorial-symbolic values - one of the fundamental dimensions of the social value of the historic monuments - is unclearly operationalized"' (Study No.12, 2014, p.50).

Furthermore, another difficult aspect underlined by the study regards the concept of landscape and its failure to achieve heritage status. Law 451/2002, for the ratification of the European Landscape Convention, sanctions the Romanian state's commitment to promote the concept of landscape, understood as part of a territory perceived as such by the population, whose character is the result of the action and interaction of natural and human factors. Even so, no specific measures were undertaken in view of identifying, evaluating, and managing landscape. Hence the landscape status issue remained unelucidated and neglected by both heritage and territorial arrangement/urbanism legislation. Nonetheless, the most relevant amongst the numerous findings of the study was the identification of a tendency towards landscape degradation throughout the national territory, but especially accentuated in developing rural areas, especially in emerging touristic destinations such as Maramureș and Bukovina (Study N.12, 2014, p.63). 


\subsection{Conclusions}

The understanding of the evolution of the Romanian heritage legislation and of the formation of the contemporary heritage legislative framework, summarised in the attributes of the List of Historic Monuments, has allowed contextualisation and characterisation of the heritage ranking process. The derived knowledge has highlighted the factual inadequacies derived from the operationalisation of national heritage regulations.

Romanian heritage legislative evolution led to the creation of a well-rooted tradition focused on the valorisation of two main categories in the field of immovable heritage, rigidly confined to architectural heritage (mostly equivalent to various typologies of standing monumental buildings amongst which churches occupy a privileged place) and archaeological heritage (strictly focused on prehistory, antiquity and the middle ages). The sedimentation of the habit of privileging the above categories has led to confining the heritage notion mainly to standing constructions and prehistoric, ancient and medieval sites.

The perpetuation of the limitations of heritage, up to the present, has been aided by the fact that the great majority of the experts in charge of ranking heritage are architects. This drastically reduces the chances of historical and archeological heritage, other than the classical fields accounted for previously, to be granted official heritage status. The consequences of such a situation clearly emerge from the present contents of the List of Historic Monuments. The fact that Romanian archaeology does not contemplate recent or contemporary archaeology, nor recognises conflict archaeology, further complicates the heritage ranking issue. This entails a total lack of expertise in the field of contemporary and historical archaeology, cutting all related heritage out of the mainstream. Consequently, 
potential historic monuments such as WWI sites are automatically disregarded as heritage although clearly holding historic, memorial and scientific value.

Romanian legislation prescribes the need to hold an authorisation to conduct archaeological excavations and to notify the authorities in case of fortuitous discoveries. Still, if an excavation of any nature were to be made on a WWI site and the need for authorisation by the national commission of archaeology arose, it would nonetheless prove impossible for the commission to authorise or oversee the excavation. That is because the commission has no specialised department to deal with such an event; the world wars are not considered archaeological domain and war sites in general are disregarded as archaeological objects of interest. Consequently, it is an unsolved mystery what should happen to the material culture of war, including human remains ${ }^{19}$, discovered during construction works. Such a case is the Prislop Pass monastery, which claims to have buried the human remains discovered during its construction in a cemetery that was actually built during WWI as accounted for in the previous chapter. The above situation results in the fact that not even a single war site is presently regarded as heritage although the territory of present-day Romania has witnessed several wars that defined national identity, over a time arch of more than 2000 years.

The Romanian Territorial Development Strategy, by means of the study regarding the protection of natural, cultural and landscape heritage, diagnosed the current state of national heritage. The analysis of the List of Historic Monuments concluded that there are significant gaps in the coverage of heritage diversity, particularly in relation to specific forms of value aggregation. The rigid categorisation of value during the ranking process ignores the existence of plural complementary values alongside the dominant value. Scientific, social, technical and

\footnotetext{
${ }^{19}$ Presumably, when encountering human remains, the police are notified and the works suspended until the case is clarified. Nonetheless, since human remains from the world wars are not a matter of police concern, it is likely that once dated the construction works will be allowed to continue, as the war relics do not have the benefit of heritage status and therefore are not protected by law.
} 
religious values are disregarded during the ranking process due to the fixation on traditional standards of age and artistic/architectural value, despite being specifically prescribed by the law. Ethnographic value is not recognised either, which causes a paucity of landmarks in the ranking of vernacular heritage, and the concept of memorial-symbolic value is ambiguously put into practice.

The study bears testimony to the fact that the most neglected and endangered category of heritage that failed to achieve heritage status is, by far, the landscape. Although Law 422/2001 included cultural landscape as one of the typologies of sites that are contemplated as historical monuments (art.3, letter c), hence enabling their ranking as heritage, no specific measures were undertaken to identify, evaluate, and manage landscape. The study concludes with a warning about a dangerous tendency towards landscape degradation spread endemically nationwide but particularly conspicuous in developing rural areas, especially in emerging tourist destinations such as Maramureș and Bukovina.

From examination of the Romanian legislation it emerges that although both the law and the heritage ranking criteria would allow the inclusion of wider categories of heritage, such as the war sites, the lack of adequate expertise disables the ranking process. The comparative analysis, between the church case chosen to highlight the application of the ranking criteria and the war sites case, will bring further evidence to the above hypothesis in the discussion chapter.

The research conducted throughout the chapter enables the reading of the significance of the war remains from a heritage perspective. The present-day significance of the Great War and of the Great Romanian Union clearly derives from legislative initiatives adopted around the time of the centennial celebrations. The high degree of importance and solemnity officially 
conferred to the century of the Great Union/the end of the Great War, and spread wide throughout the national territory, emphasis the relevance that such an occasion held for local and national identity. It infers that the memorial-symbolic value of the WWI sites alone would validate these places of war as worthy candidates for heritage status. 


\section{CHAPTER 7 - HERITAGE BY LAW, INTERNATIONALLY}

\subsection{Introduction}

The present chapter seeks achievement of the third objective pertaining to the assessment of the international significance of WWI sites and thus to the contextualisation of the Romanian case. The examination of the international heritage legal framework and of the premises/criteria for World Heritage status allows the understanding of the international heritage standards, hence providing common ground for comparison of Romanian war sites to similar international cases. The World Heritage status was chosen as reflection of international approaches to heritage as the World Heritage List is the most common and widely accepted international official instrument of heritage value/worth assessment and recognition. The current international heritage perspective is mirrored by the ranking mechanism and standards of the World Heritage List, providing the basis for the comparison of international cases, which would otherwise be difficult to manage given the fact that the different legislations by the different states lack the common ground (standards, ranking procedure) required in order to conduct meaningful comparison. Furthermore, at international level the World Heritage List is symmetrical to the List of Historic Monuments used for the national level analysis in the previous chapter, providing context for the assessment of war sites as heritage on different scales.

The evolution of international heritage legislation that led to the development of the current criteria of World Heritage standards is explored in the first part of the chapter. The characterisation of the criteria and the understanding of the World Heritage ranking process enables the building of a hypothetic nomination of the Romanian war sites, emphasising the downside of the overall ranking procedure/mechanism. The simulation allows the comparison 
of the places of war against the equating background of the World Heritage Tentative List requirements since national heritage legislation and practices are different from one country to another. Furthermore, it benefits the comparison between the Maramureș places of war and other local heritage categories that hold World Heritage status, in this case the Wooden Churches of Maramureș. Analysis of differences between the administrative files of the wooden churches and the content of present-day submissions to the World Heritage Tentative List highlights the evolution of the requirements for World Heritage status.

The framework for international heritage legislation and global practices was completed with the emergent new heritage trends as extrapolated from examination of the programmes and policies promoted during the European Year of Cultural Heritage. Synthetically, since the previous chapter was dedicated to heritage by law in Romania, the present chapter situates itself within international heritage legislation and its main stakeholders, the selection norms and ranking criteria of the notorious World Heritage status, and emergent new trends in the field of World Heritage. The itinerary highlights the intimate interconnections that exist between Romanian heritage legislation and the international heritage framework that regulates heritage worldwide using the instrument of international relations.

\subsection{The link between national and international heritage legislation}

The study of national legislation inevitably ends up converging with international legislation as a consequence of the international heritage agreements and conventions ratified by Romania and of the European Union membership of the Romanian state. The common ground between national and international heritage legislation is provided by the heritage obligations of international emanation, subscribed to by Romania, which thereby translate into national heritage practices and regulations. Therefore, a brief inventory of the international heritage 
legislation, as ratified by Romania, will be included, providing the link between the national heritage legal frame and the international heritage framework.

Romania ratified international treaties that dictate a certain line of conduct regarding the treatment of national heritage in accordance with a principle of universality of cultural values and preservation needs for the sake of future generations that eludes borderline limitations/demarcations. The 1954 Convention for the Protection of Cultural Property in the Event of Armed Conflict was ratified by Romania in 1958. Romania also adhered to the First Haga Protocol in 1968, the 1954 European Cultural Convention was ratified by Romania in 1991, the 1970 Paris Convention on the Means of Prohibiting and Preventing the Illicit Import, Export and Transfer of Ownership of Cultural Property was ratified by Romania in 1993, the 1972 Paris Convention Concerning the Protection of the World Cultural and Natural Heritage was adopted by Romania in 1990, the 1985 Granada Convention for the Protection of Architectural Heritage of Europe (Council of Europe, 1985) was ratified by Romania in 1997, the 1992 Valletta Convention for the Protection of the Archaeological Heritage of Europe (Council of Europe, 1992) was ratified by Romania in 1997, the 1995 Rome UNIDROIT Convention on stolen or illegally exported cultural objects was ratified by Romania in 1997, the 2000 Florence European Landscape Convention was ratified by Romania in 2002 and the 2003 Paris Convention for the Safeguarding of the Intangible Cultural Heritage (UNESCO, 2003) was accepted by Romania in 2005.

As a member of the European Union Romania is subject to Article 128 (title IX Culture) of the 1992 Maastricht Treaty on European Union, having the obligation to "contribute to the flowering of the cultures of the Member States, while respecting" their "national and regional diversity and at the same time bringing the common cultural heritage to the fore", to improve "the knowledge and dissemination of the culture and history of the European peoples" and to 
assure "conservation and safeguarding of cultural heritage of European significance" (Council of Europen Communities/Commision of European Comunities, 1992, pp. 48-49). The Romanian state also declared its intention to adhere to the Convention on the Value of Cultural Heritage for Society - FARO Convention adopted by the Council of Europe in 2005.

\subsection{International heritage legislation}

The 1954 Convention for the Protection of Cultural Property in the Event of Armed Conflict marked the debut of the first international conventions that contemplated heritage in its contemporary assertion. This lens suggests that it was conflict that internationally activated a legitimate concern for the inheritance of the past for the sake of the future. The convention advocated the protection of cultural property in the international arena and promoted respect for cultural property in the relations between states in reaction to the severe damage induced by armed conflicts as a result of modern war techniques. The convention was adopted under the conviction that "damage to cultural property belonging to any people whatsoever means damage to the cultural heritage of all mankind, since each people makes its contribution to the culture of the world" (UNESCO, 1954).

The Council of Europe adopted The European Cultural Convention on $19^{\text {th }}$ December 1954 with the purpose of encouraging the contracting parties to undertake "appropriate measures to safeguard and to encourage the development of its national contribution to the common cultural heritage of Europe" (Council of Europe, 1954, art.1). The focal stipulation of the convention concerned promotion of the idea of European common cultural heritage, where national heritage was to be treated as an integral part of a larger frame under the mediation of the Council of Europe. 
The initial international concern for safeguarding heritage against war hazards gradually seasoned, developing a more complex and diverse apprehension of heritage threats. The 1970 Paris Convention on the Means of Prohibiting and Preventing the Illicit Import, Export and Transfer of Ownership of Cultural Property warns about the dangers of criminal alienation of cultural property ${ }^{20}$ and frames it as leading cause of cultural heritage impoverishment. The convention denounces illicit import, export and transfer of ownership of cultural property and promotes international co-operation as antidote to such practices (UNESCO, 1970).

The 1972 UNESCO Convention Concerning the Protection of the World Cultural and Natural Heritage brought an additional contribution to the protection of heritage by contemplating both its natural and cultural dimension. The State Parties to the convention are guarantors of the safeguard of cultural and natural heritage, and in that capacity, hold the responsibility to actively engage in its identification, protection, conservation, presentation and transmission to future generations, self-reliantly or with international assistance and/or co-operation (art.4). The international protection system is guided by the Intergovernmental Committee for the Protection of the Cultural and Natural Heritage of Outstanding Universal Value known as the World Heritage Committee (art.8-14). The convention also fixed terms for the creation and administration of the Fund for the Protection of the World Cultural and Natural Heritage of Outstanding Universal Value - the World Heritage Fund - and established the rules and regulation for requesting/providing/receiving international assistance (UNESCO, 1972).

The derivative measures allowed the practical adaptation of the stipulations of the convention to the national legislative reality of each state (art.5) concerning the following:

\footnotetext{
${ }^{20}$ The definition of the cultural property as prescribed by the convention has state grounding based upon its archaeological, prehistoric, historic, literary, artistic or scientific importance including:

- property relating to history, such as technological, military and social history;

- property relating to events of national importance;

- products of archaeological excavations (including regular and clandestine) or of archaeological discoveries;

- antiquities more than one hundred years old.
} 
- assuring the inclusion of cultural and natural heritage in communitarian life;

- assuring its protection, conservation and presentation by means of appropriate specialized services;

- sustaining research, promoting scientific and technical studies and developing the operative methodology for the prevention and neutralisation of heritage hazards;

- assuring the legal, scientific, technical, administrative and financial means for the identification, protection, conservation, presentation and rehabilitation of heritage; - nurturing the necessary education/training centres at national and regional levels.

The 1985 Granada Convention for the Protection of the Architectural Heritage of Europe constituted an ulterior complexification of heritage concerns in the trail of international legal developments. The convention engaged the States Parties to undertake measures for the identification and protection of architectural heritage, defined as monuments, groups of building and sites holding conspicuous historical, archaeological, artistic, scientific, social or technical interest (art.1-3). The removal of monuments was prohibited by law except for rescue reasons. Financial support for restoration was to be provided by the states along with conservation policies and sustainable development plans. As far as the co-ordination of the conservation policies at European level was concerned, the exchange of know how between the States Parties was encouraged and a Committee of Experts was established by the Committee of Ministers of the Council of Europe in view of monitoring the application of the convention (art. 20). The convention was ideated in co-ordination with the Convention for the Protection of World Cultural and Natural Heritage and the 1969 European Convention on the Protection of the Archaeological Heritage and must therefore not infringe but integrate the application of their prescriptions (art.21).

The 1969 European Convention on the Protection of the Archaeological Heritage was revised in 1992 by the Council of Europe and has been known ever since as the Valetta Convention. The convention aimed to foster archaeological heritage as a promotor of the collective 
memory of the old continent, and as an instrument for scientific/historical study (art.1). The convention established procedures for the identification of archaeological heritage along with adjacent protection measures, convergent in updated inventories of archaeological heritage, archaeological reserves preserved for study by future generations and compulsory reporting of fortuitous discoveries (art. 2). The parties agreed to regulate the authorisation and supervision process of archaeological activities, such as excavations, in order to assure the scientific and professional conduction of the archaeological process and assure the prevention of illicit actions and activities (art.3). The archaeological heritage was to be protected, conserved and maintained, ideally in situ, and assured adequate storage if removed (art.4). The convention also dealt with integrated conservation strategies, the financial research and conservation framework, the gathering and diffusion of scientific information and the promotion of public awareness, prevention of archaeological traffic and the encouragement of reciprocal technical and scientific assistance (art. 5-12).

The 1995 Rome UNIDROIT Convention on stolen or illegally exported cultural objects completed the international heritage legal system in relation to the traffic of cultural property. According to the prescribed definition, cultural objects are holders of archaeological, prehistorical, historical, literary, artistic or scientific importance of either religious or secular emanation (art.2). The convention aimed to regulate the recovery of stolen or illegally exported cultural objects by their rightful owner, define the terms of the restitution and clarify the semantic field of unlawfully detained cultural property (UNIDROIT, 1995).

A key stage in the maturation of international heritage legislation was reached in 2000 . The Florence European Landscape Convention enlarged the concept of cultural heritage extending its patrimonial content to landscape units defined as places built up by the conjunct actions 
and interactions of anthropic - natural - factors. The landscape was framed as a cultural, ecological, environmental and social catalyst, a vital component of European identity and an unreplaceable pillar of individual and social welfare. The convention aimed to enhance European co-operation on the subject matter and promote protection, management and planning of both outstanding landscapes and everyday or degraded landscapes (art. 2, 3). The obligations of the States Parties regarded the enactment of laws that frame "landscape as an essential component of people's surroundings, an expression of the diversity of their shared cultural and natural heritage, and a foundation of their identity" (Council of Europe, 2000, art.5), awareness raising, the promotion of landscape training and education, landscape identification/assessment and the creation/implementation of quality objectives.

In 2003 UNESCO brought an important contribution to the international heritage legislation by means of the Paris Convention for the Safeguarding of Intangible Cultural Heritage. The terms of the international legal protection conferred on intangible cultural heritage were established in accordance with the existent human rights legislation specifically highlighting the dimension of intercultural respect. The convention was also meant to enforce the Convention on the World Cultural and Natural Heritage by only recognising, as objects of regulation, the intangible cultural heritage that is compatible with the principles of sustainable development (art.3).

One of the latest landmarks in the evolutionary process of the international heritage legislation was the Framework Convention on the Value of Cultural Heritage for Society adopted by the Council of Europe in 2005. The FARO Convention centred around recognition of the right to cultural heritage and cultural life participation as emergent from the Universal Declaration of Human Rights, enhancing the existence of individual and collective heritage responsibilities 
and highlighting the role of heritage in life quality, development and welfare within the framework of a peaceful and democratic society (art.1).

A new heritage dimension was reached by means of the definitions conferred upon cultural heritage and the introduction of the additional heritage concepts of heritage community and European common heritage:

"- cultural heritage is a group of resources inherited from the past which people identify, independently of ownership, as a reflection and expression of their constantly evolving values, beliefs, knowledge and traditions. It includes all aspects of the environment resulting from the interaction between people and places through time;

- a heritage community consists of people who value specific aspects of cultural heritage which they wish, within the framework of public action, to sustain and transmit to future generations" (Council of Europe, 2005, art.2).

The common heritage of Europe consists of "all forms of cultural heritage in Europe which together constitute a shared source of remembrance, understanding, identity, cohesion and creativity, and the ideals, principles and values, derived from the experience gained through progress and past conflicts, which foster the development of a peaceful and stable society, founded on respect for human rights, democracy and the rule of law" (Council of Europe, 2005, art.3).

The convention enhanced diversity, multiculturalism and promotion of a climate of trust by increasing the level of inter-cultural understanding and promoting mutual confidence and respect. The prescriptions of the convention, on the one hand, aimed to regulate the convergence of cultural heritage and, on the other, to promote social dialogue, environment and life quality, sustainability, public engagement, democratic participation, information society and knowledge.

Within the frame of the European Union the legal instrument regulating the field of cultural heritage is the European Agenda for Culture. The 2007 Agenda was approved by the European Commission with the purpose of sustaining the EU members in their cultural efforts and helping them face commonly-encountered challenges in the spirit of cultural diversity and in recognition of "the transversal role of culture" (European Union, 2007). The promotion of 
cultural heritage as one of the main pillars of cultural policy was promoted by the 2015-2018 Work Plan for Culture which engaged the States Parties in a series of strategic actions prescribed as priorities (European Union, 2014). The current agenda was approved in 2018 with the aim of strengthening European identity through education and culture while the 2019-2022 Work Plan for Culture mainly focuses on sustainability in cultural heritage, international cultural relations and the creation of a cultural ecosystem at/of European level/emanation (European Union, 2018).

\subsection{The European Year of Cultural Heritage}

The European Commission declared 2018 as the European Year of Cultural Heritage (EYCH) with the aim of exhibiting the abundance and variety of European cultural heritage and emphasising its leading role in the creation of European common identity and the promotion of a shared sense of belonging. The official website dedicated to the occasion presents the focal thematic under the slogan "Our heritage: where the past meets the future" (European Year of Cultural Heritage, 2018). Concretely, the initiative consists in the promotion of a series of events and initiatives that took place throughout Europe with the purpose of augmenting civic engagement with cultural heritage and celebrating it regardless of its shape and form of expression. The four promoted categories included tangible, intangible, natural and digital heritage.

The initiatives were promoted and sustained by the EU Member States, the European Commission, the European Parliament, The Council of the European Union, The Committee of the Regions, the European Economic and Social Committee and various cultural stakeholders. Such vast support was also reflected in joint co-operation projects specifically dedicated to cultural heritage under the Creative Europe programme, Erasmus+, Europe for Citizens, Horizon 2020, etc. Furthermore, an initiative launched by UNESCO, the Council of 
Europe and The European Commission in collaboration with other partners is meant to assure the long-term effect of the event. The Emphasis was put on ten long-term projects focused on engagement, sustainability, protection and innovation (EYCH, 2018). Amongst the four main sectors, the most interesting addition and also the most relevant to the present research was contributed in the field of sustainability. Two subsections of sustainability were identified as heritage in transition, and tourism and heritage. While the content of the second was predictably centred around the promotion of responsible and sustainable tourism focused on cultural heritage, the first, dedicated to heritage in transition, was rooted in re-imagining industrial, religious, military sites and landscapes.

Statistics reported on the official website of the European Year of Cultural Heritage, $19^{\text {th }}$ March 2019, counted 37 participant countries, 11,700 events and 6,260,000 participants (European Year of Cultural Heritage, 2019), standing as a proof of the importance of and commitment to cultural heritage in Europe. Furthermore, substantial efforts were made to assure an international dimension to the European Year of Cultural Heritage. "A framework for cultural co-operation between the EU and the rest of the world" was proposed on behalf of the belief that "cultural heritage helps us learn about each other and ourselves", being a "powerful tool to build bridges between people, communities and countries, reinforcing cultural dialogue and mutual understanding” (European Commission, 2018). The international profile of EYCH was sustained by “celebrating Europe's cultural heritage around the world, engaging with young people through supporting capacity-building for the heritage sector worldwide, and valorising EU actions in cultural heritage international co-operation" (ibid). 


\subsection{The World Heritage ranking process and criteria}

Current Operational Guidelines for the Implementation of the World Heritage Convention was issued by the United Nations Educational, Scientific and Cultural Organization on $12^{\text {th }}$ of July 2017. Its guidelines regulate, amongst others, the World Heritage ranking procedure overseen by the World Heritage Committee aided by its advisory bodies: the International Centre for the Study of the Preservation and Restoration of Cultural Property (ICCROM), the International Council on Monuments and Sites (ICOMOS) and the International Union for Conservation of Nature (IUCN) which all have advising, assistance, monitoring and evaluation roles.

The World Heritage List is set to incorporate multiple manifestations and assertions of heritage: cultural heritage, natural heritage, mixed cultural and natural heritage and cultural landscapes of outstanding universal value. The concept of outstanding universal value contemplates a "cultural and/or natural significance which is so exceptional as to transcend national boundaries and to be of common importance for present and future generations of all humanity" (UNESCO, 2017, p.19). The ranking of a property as World Heritage and hence its inscription in the World Heritage List is dependent upon the attribution of the outstanding universal value standard as a result of an evaluation process that examines the nominated properties in relation to the UNESCO assessment criteria. The nominees must meet one or more of the following criteria in order to enter the World Heritage List:

"- represent a masterpiece of human creative genius;

- exhibit an important interchange of human values, over a span of time or within a cultural area of the world, on developments in architecture or technology, monumental arts, townplanning or landscape design;

- bear a unique or at least exceptional testimony to a cultural tradition or to a civilisation which is living, or which has disappeared;

- be an outstanding example of a type of building, architectural or technological ensemble or landscape which illustrates (a) significant stage(s) in human history; 
- be an outstanding example of a traditional human settlement, land-use, or sea-use which is representative of a culture (or cultures), or human interaction with the environment especially when it has become vulnerable under the impact of irreversible change;

- be directly or tangibly associated with events or living traditions, with ideas, or with beliefs, with artistic and literary works of outstanding universal significance. (The committee considers that this criterion should preferably be used in conjunction with other criteria);

- contain superlative natural phenomena or areas of exceptional natural beauty and aesthetic importance;

- be outstanding examples representing major stages of earth's history, including the record of life, significant on-going geological processes in the development of landforms, or significant geomorphic or physiographic features;

- be outstanding examples representing significant on-going ecological and biological processes in the evolution and development of terrestrial, fresh water, coastal and marine ecosystems and communities of plants and animals;

- contain the most important and significant natural habitats for in-situ conservation of biological diversity, including those containing threatened species of Outstanding Universal Value from the point of view of science or conservation" (UNESCO, 2017, pp.25-26).

The ranking in the World Heritage List is not independently guaranteed by meeting one or more of the criteria but is also dependent upon meeting the integrity and authenticity conditions and the existence of a viable protection and management system.

The third annexe of the Operational Guidelines includes a section about the inscription of specific types of properties in the $21^{\text {st }}$ World Heritage List. The first position deals with cultural landscapes and therefore incorporates a great variety of anthropic and natural elements emphasising their interactions in a definable geo-cultural area. The various typologies of cultural heritage are grouped into three major categories. The first regards landscape that was designed and created intentionally by man, as such holding a monumental dimension, such as gardens and parks. The second deals with organically evolved landscape which "results from an initial social, economic, administrative, and/or religious imperative and has developed its present form by association with and in response to its natural environment" (UNESCO, 2017, p.81). The evolutionary process is reflected in the attributes of such landscape further dividing it into two subcategories: 
Relict (fossil) landscape - "a relict (or fossil) landscape is one in which an evolutionary process came to an end at some time in the past, either abruptly or over a period. Its significant distinguishing features are, however, still visible in material form.

Continuing landscape - a continuing landscape is one which retains an active social role in contemporary society closely associated with the traditional way of life, and in which the evolutionary process is still in progress. At the same time, it exhibits significant material evidence of its evolution over time" (ibid.).

The third category accommodates the associative cultural landscape, which is an expression of powerful cultural, artistic or religious associations regarding the natural element that makes the immaterial aspect prevail over the material evidence, which is mostly negligible/absent.

At procedural level the ranking in the World Heritage List is dependent on the submission of draft nominations by the States Parties to the UNESCO Secretariat. The nominations are to be evaluated by ICOMOS if concerning cultural heritage, by IUCN if regarding natural heritage, by joint expertise of ICOMOS and IUCN in case of mixed properties, and by ICOMOS in consultation with IUCN if dealing with cultural landscapes. The report of the evaluation of the advisory bodies must be forwarded to the World Heritage Committee which will make its decision towards ranking or denial of the nominations. The diagram of the evaluation process of ICOMOS is reported in FIG.179, and of IUCN in FIG.180.

FIG.179. ICOMOS evaluation process (Work Plan for culture 2015-2018, Annexe 6, p.113)

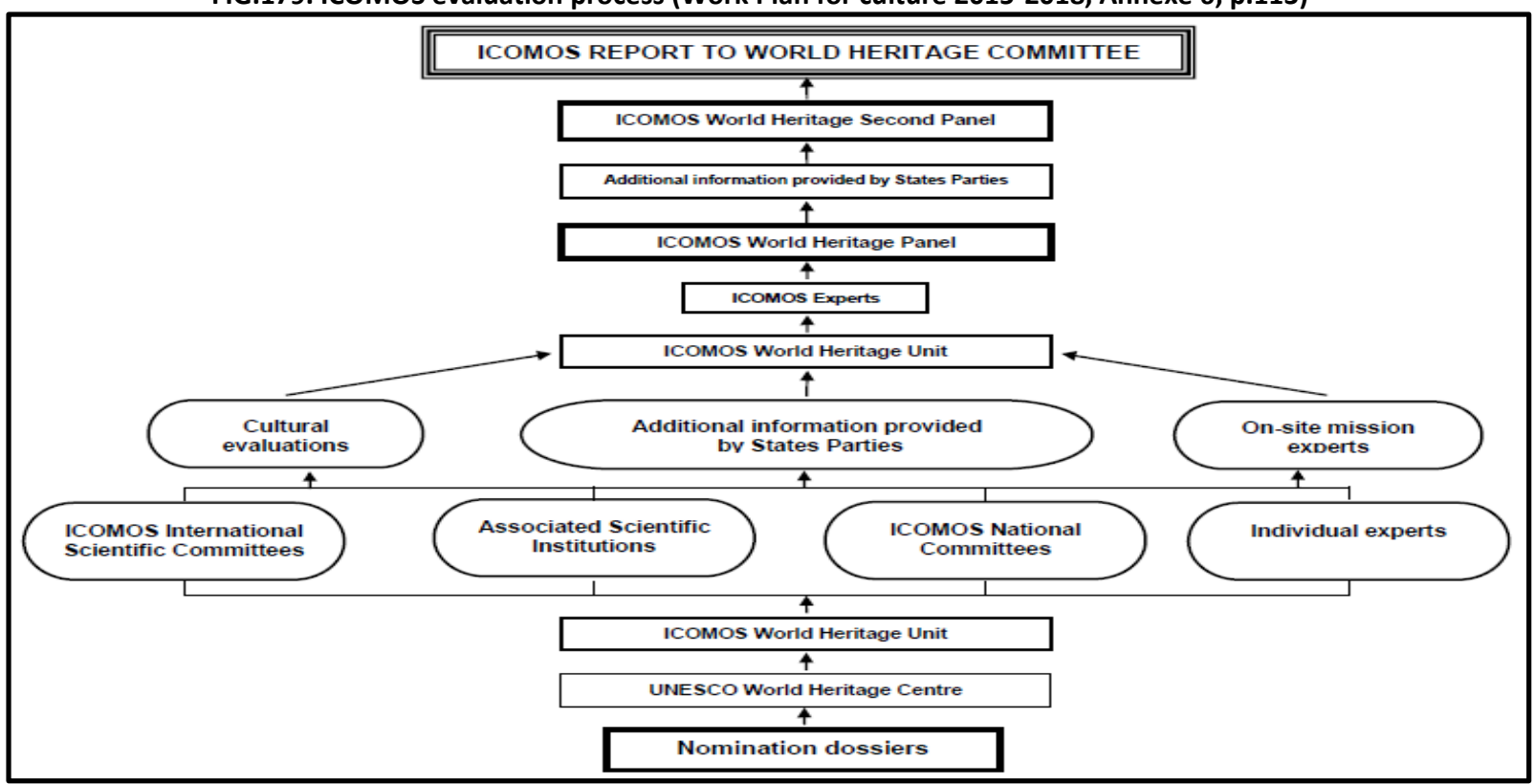




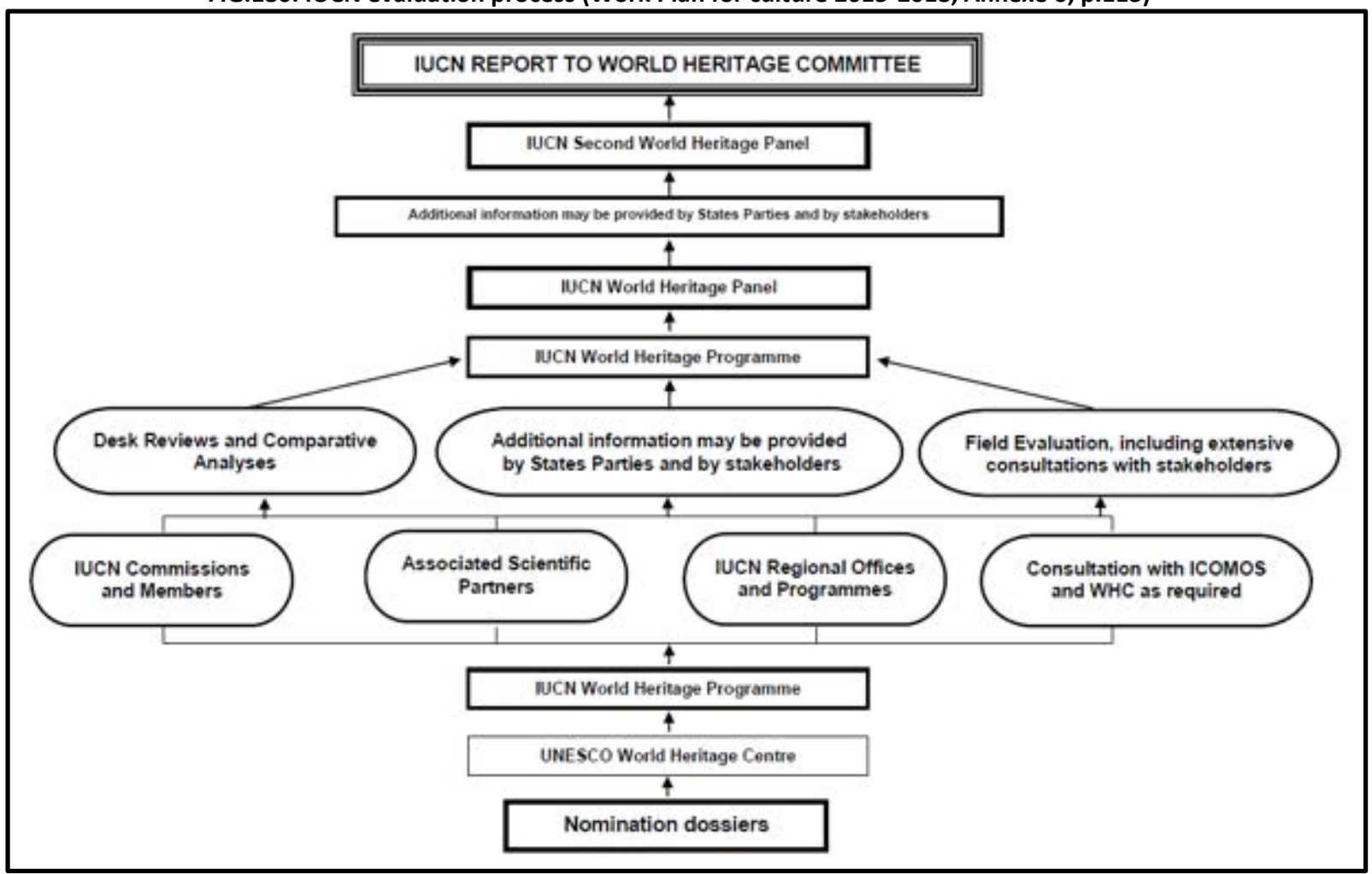

Prior to nomination the properties must be inscribed on the World Heritage Tentative List.

The Tentative List must be submitted to the UNESCO Secretariat at least one year before the nomination and should be revised at least every ten years by the State Parties. If the proposed Tentative List complies with the requirements the Secretariat registers it and forwards the list to the Advisory Bodies.

"The Tentative List is an inventory of those properties situated on its territory which each State Party considers suitable for nomination to the World Heritage List. States Parties should therefore include, in their Tentative Lists, details of those properties which they consider to be of potential Outstanding Universal Value and which they intend to nominate during the following years. Nominations to the World Heritage List are not considered unless the nominated property has already been included on the State Parties Tentative List” (UNESCO, 2017, p.23).

Evidence of all current Tentative Lists can be found on the UNESCO website (UNESCO, 2018). Recently, the attempt to include WWI sites in the World Heritage List made the titles of several newspapers signalling the formation of new international heritage trends. Deutsche Welle, the German international broadcaster, published an article featuring "UNESCO World 
Heritage sites: WWI memorials among the contenders" referring to the French and Belgian WWI graveyards and memorials that made it to the UNESCO Tentative Lists. The World Heritage label is presented as a catalyst of international attention and a touristic augmenter. Luc Vandael - project manager for the Flemish region - declared that, although in the aftermath of the war the graveyards and memorials were primarily places of mourning, they now become "an appeal to peace and reconciliation" and that by being associated with the slogan "no more wars" they transcend their nature, going beyond the significance and function of normal cemeteries (Deutsche Welle, 2018).

The Telegraph also has an article on the subject "France and Belgium make case for First World War memorials to be given Unesco World Heritage status”, dated $24^{\text {th }}$ June 2018. The Minister-President of Belgium's Flemish region stated that "these sites force us to draw lessons from the past in order to construct a more peaceful future" (The Telegraph, 2018). The article stresses that although the region possesses several trenches and battlefields, France and Belgium chose to make the run for UNESCO status with cemeteries and memorials in order to avoid the glorification of war. The position of the two countries is at least debatable as war sites hold a great historic, archaeological and scientific value beyond their immense evocative power and therefore hold the potential to commemorate and decode the war phenomenon in its entirety without descriminating between its actors and attributing problematic labels. War cemeteries and memorials on the other hand were created just for soldiers and are more likely to glorify militarism since in every European country an extremely extended network of WWI memorials was dedicated to war heroes, regardless of contemporary reinterpretations. Nonetheless, such sites became pilgrimage places and witnessed an increase in popularity since the debut of the four years of WWI centennial remembrance that was concluded on the $11^{\text {th }}$ November 2018 with the hundred-year celebration of the armistice. 
EURONEWS (Euronews, 2018), AP News (AP News, 2018), ITV News (ITV News, 2018), KatiaZEV News \& More (KatiaZEV News \& More, 2018), etc. all reported more or less the same content. The official website of the 2014-18 Great War Centenary also published an article on the subject on $16^{\text {th }}$ January 2017 , emphasising the outstanding universal value of the proposed cemeteries and memorials on the basis of the following considerations:

- It is the first time in history that all fallen soldiers, regardless of rank, class or nationality, are commemorated individually. The bodies were buried individually, and names of missing persons were inscribed on the monumental memorials.

- The military cemeteries and memorials are also unique because of the high quality of their architectural design and their scenic implantation.

- The sites have also become places for reflection. They are an ethnical appeal to man and society" (The Great War Centenary, 2017).

Still Belgium and France are not the only ones who made it to the UNESCO Tentative Lists with a nomination concerning WWI. There is another contender although less publicised by the mass media, whose efforts are only reported on the news page of I FEEL SLOVENIA website. The article, "Slovenia's WWI heritage project on UNESCO's tentative list" was published on $19^{\text {th }}$ February 2016 presenting the "Walk of Peace". The Walk of Peace is the Slovenian UNESCO nomination that presents WWI memorials and war remains of the Isonzo Front, a "network of 230 kilometres of hiking trails that reveal the cultural and natural heritage of one of the bloodiest mountain fronts in world history" (I FEEL SLOVENIA, 2016). The article states that both Italy and Austria support the Slovenian initiative.

"The Walk of Peace from the Alps to the Adriatic takes you along the former territory of the Soča Front (1915-1917), where a series of battles between the armies of Italy and the Austro-Hungarian Empire took place. It is dedicated to the memory of all those who suffered during World War I, and promotes the values of peace, mutual respect and cooperation. Apart from preserving the heritage of the Battles of the Soča Front, it is also stunningly beautiful, with unspoilt natural wonders of the Alpine, pre-Alpine and Karst areas. [...] The main aim of The Walk of Peace is to promote the value of peace and opportunities for common development. By presenting the rich cultural and natural heritage along the Isonzo (Soča) Front, featuring military cemeteries, caves, trenches, charnel houses, chapels, monuments, outdoor museums and other memorials, it is regarded as part of the significant material and non-material heritage of European history" (ibid). 
The official Tentative Lists of the various State Parties published on the UNESCO website confirm the information of the articles and signal a predisposition to new thematic additions and heritage trends, such as the concern for WWI heritage/legacy. The French-Belgian initiative can be found under "Funerary and memorial sites of the First World War (Western Front)" in the Tentative List section of the UNESCO website. The Slovenian initiative is also confirmed by the UNESCO official Tentative Lists. Like the previously presented case, "The Walk of Peace from the Alps to the Adriatic - Heritage of the First World War" also respects the UNESCO form and structure requirements regarding organisation of the submission into four standard sections: description, justification of outstanding universal value, statements of authenticity and/or integrity and comparison with other similar properties. Furthermore, in view of facilitating comparision between the submissions, a hypothetic nomination of the Maramureș Romanian war sites that has been developed using UNESCO's standard format is provided in Appendix 18.

On $20^{\text {th }}$ April 2018 FlandersToday published an article on the outcome of the French-Belgian application by the title "Unesco advisory board rejects First World War as heritage" based on the report published by flandersnews.be on the same subject (FlandersToday, 2018). The Advisory Body expressed its opinion towards the rejection of the French-Belgian Joint application. The reason behind the recommendation of the ICOMOS panel boils down to the belief that UNESCO's recognition of WWI monuments and sites would mean a glorification of war, violence and military conquest.

"However, Mr Bourgeois told VRT Radio 1's morning news and current affairs programme De ochtend that this was the very opposite of what the application for World Heritage status had sought to achieve. It is about cemeteries and monuments to remember the dead; about peace, values, individuals and reconciliation" (FLANDERSNEWS.BE, 2018). 
The same source reported that the Flemish authorities forwarded additional information to UNESCO regarding the sites and awaited a reviewed appraisal at the $42^{\text {nd }}$ session of the World Heritage Committee due to take place in Bahrain between $24^{\text {th }}$ June- $4^{\text {th }}$ July 2018 . The report closes with Mr Bourgeois' promise to undertake a diplomatic offensive in support of his cause in order to persuade UNESCO to reconsider its position before the final verdict. The Archaeology and Metal Detecting Magazine also reported the rejection in an article by the title "Advisory body tells UNESCO that WWI sites aren’t World Heritage" commenting that ICOMOS considers the French-Belgian cemeteries and memorials to "have no exceptional universal value" (The Archaeology and Metal Detecting Magazine, 2018).

Indeed, the French-Belgian nomination did not make it to the UNESCO 2018 New Inscribed Properties and, for the time being, no WWI site of either memorial or archaeological nature has been granted World Heritage status. However, justification of the advisory body's decision appears at least questionable since conflict has accompanied humanity throughout its existence; it has been an agent of change and at times of emancipation throughout the course of history as, in a certain way, it was conflict itself that forged the evolution of humanity on several occasions. Many sites ranked as World Heritage are by-products of conflict and considered as representative of various historic times without anyone interpreting this as a promotion of violence and war. It is inductively absurd to disregard the entire sphere of WWI sites as heritage, especially since it was in reaction to the world wars that UNESCO and the World Heritage List was founded. It was, in fact, in reaction to the destructiveness of world conflicts that people started to understand the importance of creating an international system that would contemplate the protection of the patrimony of humanity worldwide. If it is expected of future generations to respect heritage and understand its educational purposes, 
how can heritagisation of the sites that commemorate events that, for better or worse, shaped their own world and identity by giving birth to the mentality of their time, be denied?

Nevertheless, an obvious trend towards recognition of international heritage status of WWI objectives seems to be forming, as WWI becomes an historical domain and the memorialisation needs have changed along with the generations. The interposed time distance between new generations and the Great War intensifies into a mounting need for better understanding of the war.

\subsection{The Wooden Churches of Maramures}

The inclusion of WWI sites in the World Heritage List will aid and complement the understanding of other properties that are already included. WWI sites are also markers of historically contended territories, one of the obvious causes of the war. The places of war are authentic forms of expression of all dimensions of the war that generated them, encapsulating great scientific importance for understanding the war phenomenon and its causes. They constitute earth documents and live testimonials unaltered by human propagandist intentions or social reconstruction needs. The war sites reflect the condition of a given territory at a given time and its interconnections with other places, against the background of a conflictual state.

In support of the previous hypothesis, a case of UNESCO properties that have already been granted heritage status and present no evident connection to the heritage value of WWI sites is

presented. Since the present work is about Romanian WWI sites located in the county of Maramureș the chosen example also belongs to this region. Romania has eight properties inscribed in the World Heritage List, out of which 1 (The Wooden Churches of Maramureș) is 
located in the same county as the war sites. The Wooden Churches of Maramureș is a circuit of eight wooden churches ranked in the World Heritage List in the 1990's.

"The eight churches are outstanding examples of a range of architectural solutions from different periods and areas. They show the variety of design and craftsmanship adopted in these narrow, high, timber constructions with their characteristic tall, slim clock towers at the western end of the building, either single - or double - roofed and covered by shingles. As such, they are a particular vernacular expression of the cultural landscape of this mountainous area of northern Romania" (UNESCO, 1999).

The ranking of the Maramureș Wooden Churches Complex ${ }^{21}$ in the list was justified on the basis of meeting criterion IV:

"The Maramureș wooden churches are outstanding examples of vernacular religious wooden architecture resulting from the interchange of Orthodox religious traditions with Gothic influences in a specific vernacular interpretation of timber construction traditions, showing a high level of artistic maturity and craft skills" (Ibid).

The 1999 UNESCO rational concerning the statement of significance reports that in Maramureș there are ninety-three wooden churches officially ranked as monuments of architecture, out of which the eight selected churches are considered to be the most representative constructions.

"Their old age, location and atmosphere, architectural pattern, construction technique, interior painting and state of conservation define the Maramureș wooden churches as heritage sites of exceptional universal value. They exemplify the construction type initiated in the $17^{\text {th }}$ century, through the collective effort of often anonymous artists, endowed with an undeniable creative genius. They have been selected also with the intention of revealing to the world the main wooden churches of this region: six of them define the typical Maramureș church, one (the Rogoz one) represents the north Transylvania type of churches, and one (the Plopis one), the transition between these two types." (CIMEC, 1999).

The UNESCO description centres on the architectonic and artistic value of the churches, in line with a traditional interpretative standard promoted by Romanian heritage practitioners as emphasised in the previous chapter. Still, the wooden churches present a much higher degree of complexity, representing more than mere beautiful buildings. They are wooden documents,

\footnotetext{
${ }^{21}$ The Maramures Wooden Churches Complex is composed of The Presentation of the Virgin to the Temple Church of Bârsana, the Saint Nicholas Church of Budești, Pious Parascheva Church of Desești, The Nativity of the Mother of God Church of leud, The Holy Archangels Church of Plopiș, the Pious Parascheva Church of Poienile Izei, The Holy Archangels Church of Rogoz and The Holy Archangels Church of Șurdești.
} 
not only of the culture and civilisation of the people that produced them but also of their socio-political circumstances.

The sculpted wood and the paintings are filled with a multitude of symbols from the Christian to reminiscences of ancient traditions such as the solar rosette, and thematically range from religious beliefs to social and legal matters. For instance, the high towers of the wooden churches also had a landmark function, being visible from great distance, the reason why the churches were usually located on higher ground. Furthermore, four smaller turrets disposed at the base of the main tower meant that the village where the church was built had a council of elders, which functioned like a court of law, that had the authority to judge simple trials not requiring the attention of the official authorities during the Hungarian dominion.

The wooden churches were entirely wooden, using no metal nails so that they could be assembled and disassembled like a giant 3D puzzle and moved to another place in case of need. During the development period of this typology of wooden churches the area was threatened by Tatars, Ottomans, Hungarians, and eventually ended up under AustroHungarian dominion. The details of the paintings, the architectural elements and the various decorations all narrate such a story. The height of the church entrance is unusually small and the reason for this aspect has a double cord: on the one hand, it had the function of forcing those who entered the church to bow in symbolic humility and, on the other, there was a widely spread mythology about pagan ${ }^{22}$ invaders in the region, who used to ride their horses into churches up to the altar - consequently, the low entrance was meant to prevent desecration of the holy ground.

\footnotetext{
${ }^{22}$ All non-Christian believers were considered to be pagans, but in this case, it refers mainly to Ottomans and Tatars.
} 
The old metal crosses erected on top of the tower, turrets and/or on the top of the roof of the churches used to combine a crescent shape or a star-crescent element in their design, a habit inherited from the Tatar invasion periods when the device was used to trick the Tatars into believing that the edifice was Ottoman property and thus to prevent its destruction. In addition, during the Austro-Hungarian domination, since Romanians were deprived of memorialisation rights, local heroes were commemorated by fixing epitaph wooden crosses on the external walls of the wooden churches.

All these characteristics (and several others) of the Wooden Churches of Maramureș were developed in reaction to conflict and reflect the adaptive capacity of people threatened by/under foreign domination in their ingenious struggle for conserving their identity in times of distress. Declaring WWI sites as World Heritage would mark the adjacent places as conflictual landscape and allow the reading of other heritage items through one lens leading to clearer historical contextualisation and cultural understanding.

\subsection{Conclusions}

The work conducted in the first section of the present chapter highlighted the evolution of international heritage legislation. The international concerns with heritage sprouted a maturation process that gradually developed and diversified into the accepted spectrum of heritage. The initial international concern of safeguarding heritage against war hazards grew into a complex field of knowledge that added new dimensions to the initial assertion of heritage, enlarging the heritage value spectrum to include aspects such as intangible value, social value, landscape and digital heritage.

Heritage rose to be a global concern that gave birth to perpetually changing interpretations whose mutations reflect more general changes in social and political mentalities. At European 
level the prominence given to the subject is reflected in initiatives promoted by the European Year of Cultural Heritage and its achieved results. Heritage, as the place "where the past meets the future" (European Year of Cultural Heritage, 2018), was framed as a common possession of all humanity and managed to gather a high number of global supporters.

Officially speaking the common possessions of humanity, in terms of heritage, are listed in the World Heritage List and, hence, the evolution of heritage legislation is also reflected in the World Heritage ranking process. The premises/criteria of the World Heritage status mirror the state of international heritage standards at a given time being, therefore, subject to change. The file contents of proprieties currently ranked in the World Heritage List stand as a proof of the gradual complexification of World Heritage requirements. The case of the Wooden Churches of Maramureș, which were ranked in the 1990s, emphasises the consistent augumentation and diversification of World Heritage criteria against the background of present World Heritage requirements.

The characterisation of the criteria and the understanding of the World Heritage ranking process allowed the simulation of the Romanian war sites submission for ranking. The common ground for comparison provided by the frame of World Heritage Tentative List enabled analysis of the Romanian case in relation/contrast to similar international cases in the following chapter. Furthermore, the approach taken allows testing of whether the Romanian war sites meet the international legal requirements of World Heritage standards, and allows their cultural integration with the case of the wooden churches.

The downside of the overall World Heritage ranking procedure is the subordination of the entire process to the capability of the States Parties to file successful applications. It infers that the entire process depends upon the administrative and economic capacity of these states, 
thus making their political and economic strength a factor of greater importance than the actual possession of heritage of exceptional universal value. The ranking process greatly disadvantages underdeveloped and developing countries while simultaneously favouring developed western countries, so generating an uneven representation of World Heritage in the World Heritage List (economically wealthy cultures are over-represented while economically poor cultures are under-represented).

A further downside of the World Heritage ranking mechanism shows it to be interpretation sensitive. Although, according to the UNESCO criteria the WWI sites would definitely be eligible, UNESCO standards seem to be unevenly applied and evaluated by assessors during the ranking process. Once more, mirroring the national level situation presented in the previous chapter, it becomes the interpretation of the specialists to decide the fate of heritage, such as the places of war, rather than meeting the legal criteria, which reveals a malfunction of the value ascription mechanism.

Nonetheless, although up to the moment there are no WWI sites with World Heritage status, recent additions to/developments of international heritage demonstrate the coagulation of new dimensions of heritage. The new heritage trends reflected by the introduction of wider assertions of heritage, like the concept of continuing landscape or the heritage in transition initiatives (meant to re-imagine military sites), signal favourable winds for the recognition of the universal value of WWI sites.

In conclusion, the results of the present chapter enable re-integration of the case study into the local-national-international layer matrix while simultaneously emphasising their solid interconnections, aspects which will become the focus of the following chapter. 


\section{CHAPTER 8 - RESEARCH OUTCOMES}

\subsection{Introduction}

The aim of this work was to find out what is the significance of Romanian WWI sites as places of remembrance and heritage. Chapter 2 emphasised that the Eastern Front remained mainly unapproached in terms of studies and archaeological works conducted on war remains, hence identifying a gap in WWI knowledge, setting the general frame of the thesis, providing context for the research into a wider field of studies, and making available the theoretical background to allow construction of the methodology. The overall approach to research presented in the methodology section of Chapter 3, stated the specific work methods and separated the research question into three overall objectives that dictated the focus and structure of the following chapters.

This chapter is dedicated to discussion of the findings in chapters pertaining to the three objectives guiding the subject matter's overall approach. The integrated results provide the basis for discussion against the background rendered by the literature review, with a view to recomposing and providing answers to the research question. Reflecting the structure of the thesis, this chapter dedicates individual sections to each objective and concludes by discussing the emergent data and its implications. Therefore, the first part of the chapter deals with the achievement of the first objective and explores the dimension of the material evidence of WWI within the research area. The war sites are unitarily engaged, in both material and immaterial dimensions, by anchoring the memorial-symbolical characterisation of the places of war to the physical aspects of the war sites. Recording the material evidence of WWI in Maramureş was a precondition of understanding the material culture of war that has been considered for analysis throughout this work. Elucidation of the tangible and 
intangible traits of the material remains informs the assessment as heritage of the war sites under consideration.

The second part of the chapter reflects upon the Romanian heritage legal framework and on the official legal process of heritage creation. Romanian legal evolution in the field of heritage provided a framework for contextualisation and analysis of the heritage assessment process at national level, allowing for comparison of different typologies of heritage and highlighting the limitations of the legal system. The examination of the criteria upon which the legal assessment of heritage relies and of the mechanism that is activated in view of institutionalising heritage in Romania reveals the reasons why certain categories of heritage receive legal protection as a result of being granted legal heritage status, while others do not. By drawing upon the process of deciding what is worthy of heritage status according to Romanian legislation, an understanding of the official potential and worth of the war remains was developed.

The third part of the chapter considers the international significance of WWI sites as derived from the investigation of the international legal framework and examination of the premises of World Heritage status. The understanding of the characteristics of international heritage legislative evolution, along with the characterisation of the criteria according to which the World Heritage status is granted and the adjacent procedure, underlines features of the heritage making process at international level. A comparative analysis of the categories of heritage presented in Chapter 3 was conducted against this background. The above approach allowed contextualisation of the Romanian case within the international heritage debate and, equally, provided terms of comparison for results of previous parts of the work, with similar international cases, against the background of the World Heritage List standards, in reflection of the AHD. Interpretation of the comparative analysis results, within the international legal 
framework and in relation to the World Heritage ranking criteria, has enabled assessment of the international significance of WWI sites as places of remembrance and heritage.

The fourth part of the chapter deals with the main findings of the above sections discussing them in an integrated manner and draws upon the research implications, while the final part is dedicated to future research and thesis conclusions. The central aim of the thesis was addressed by reconstructing the research structure and discussing the collected results of previous chapters, in order to understand the relevance of Romanian World War I sites as places of remembrance and heritage.

\subsection{The material culture of war in Maramures - The Prislop Pass conflictual landscape}

This section of the chapter answers the question, what is the material culture of World War I in Maramureș? The work conducted in Chapter 5 emphasised the material characteristics of the Prislop Pass war sites, while Chapter 4 provided immaterial characterisation of the places of war providing the basis for their heritage assessment. The assessment of the value of the war sites was determined relying on characterisation of the studied material culture in relation to heritage standards such as preservation, age, rarity and authenticity.

Chapter 5 was dedicated to investigation of the war remains which are still visible above ground in the established research area. Prior to conduction of this research there was no record of what war remains existed in this area, no one had ever studied them and therefore there was no record of their existence. Hence there was a need to construct a record of the war remains in accordance with the recording method (Bowden, 1999) established in Chapter 3. The fieldwork campaigns lead to identification of the material culture of war, providing both individual documentation of the remains and the categorisation of war materials. The arising categories, from buildings foundations to pits, various earthworks, craters, mounds, a military 
cemetery built during the war, common graves, a pillbox, bunkers, trench systems and ordnance are all available to the naked eye without the need for excavation.

Documentation of the material remains of war within the research area allowed the understanding of the kind of materials that we are dealing with, of the distribution of the material culture within the research area and of the density and typologies of the material remains. It also supplied evidence for the fact that the overall war sites present good levels of preservation, excellent degrees of authenticity, they are particularly valuable in terms of rarity but are also fragile against the settings of recent development trends taking place in the area. The various levels of preservation of the sites across the research area are mostly due to current threats such as redevelopment, which constitutes a factor of obliteration unlike other causes/cases of destruction in the past (such as the explosion of bunkers during the war) that combined to show the authenticity of these places of war factually constituting a heritage dimension.

In terms of heritage, recording the material culture of war allowed the observation of its state of preservation, layers of significance, rarity, authenticity and fragility, factually drawing upon the quality of the war remains against the criteria generally implied to estimate/measure value. The contribution brought about by documenting the above aspects in relation to the chosen war sites constitutes an innovation for the region, as "vast areas of the old Eastern Front have so far remained virtually untouched" (Saunders, 2007, p.202) and since the work led to creation of the first gazetteer of the East European material culture of war in a heritage perspective. Evidence for the value of the sites emerges from the fieldwork results, which identified the war sites and provided a characterisation of the war remains in line with the criteria against which heritage is assessed (De la Torre, 2002) in view of setting the scene for the following chapter. The gazetteer provided in Chapter 5 presents the material components 
of the war sites, their state of preservation, their distribution and variation across the study area and the threats they are likely to meet, flagging up not only their potential value but also warning that they are currently endangered.

In terms of remembrance, the physical war traces peppered throughout the research area reflect and call upon the historical context presented in Chapter 4, augmenting the resonance of war accounts. The war traces anchor multiple historical accounts and plural memory perspectives (Saunders, 2012) to the ground, as it is war remains that trigger memory. The WWI historical photography and the literary/ethnographic creations presented in Chapter 4 bear evidence of the fact that the physical remains are containers through which multiple war stories are told, ending up incorporating an intangible dimension that greatly exceeds the mundane implications of the features' tangible traits.

Framing the studied materials in a heritage perspective implies not just recording the physical characteristics of various materials, but rather the unveiling of symbolic aspects and remembrance functions embedded in the materials (Grenville and Fairclough 2004-5, p. 2) and the surrounding environment. The need to enhance the global traits of the studied conflictual landscape derives from the existing bond between contemporary heritage and memory. Nowadays, heritage does not represent the sum of the items it curates, but rather condenses the memory of objects that are to be remembered (Carman, 2009, p.197). It is this condensation of meanings and symbols into the material culture that generates a new dimension of significance and that animates materials, enabling the conversion of the war sites into places of war.

The work is iterative, starting with the historical context and then moving to identification of the material remains that represent historical accounts on the ground. The resultant gazetteer, 
besides documenting and characterising war materials, encapsulates the national, regional and international layers of memorial-symbolic significance of the registered remains. The memorial-symbolic dimension of the material culture and the remembrance functions of the places of war build up solid value premises pleading for the favourable assessment of their heritage worth.

The results of the research established the heritage worth of the war places, which, if officially recognised by law, would entitle the sites to legal protection. In a heritage perspective this normally implies compiling a selection of sites that are to benefit from the heritage legal system, in other words, sites that are to be saved. Still, in the context of the present research, operating a selection of a limited number of war remains would be a mistake regardless of the selection criteria. That is because the main point that emerged from the considered data was that the study area should not be approached as a collection of war sites but as a conflictual landscape, which is, in fact, the most distinctive attribute of the case study. It is within the landscape dimension that the war phenomenology is reflected.

The research area holds the potential to highlight the morphology of the war architecture and the management of space during the conflict, building up a particularly rare case that, up to the moment, remains unapproached on such scale. By taking an individual approach to war remains, isolating various features of the war sites and treating them separately, the resultant heritage will end up conveying specific aspects of war such as bunkers, common graves, military cemeteries, etc, but will never reveal all the knowledge and symbolism that the combined conflictual landscape holds. Hence, where material culture is still available on the surface of the ground, WWI sites should be approached at landscape level because it is within this dimension that all the other dimensions come together integrating with each other, allowing the emergence of meaningful war accounts and thus augmenting their heritage value. 
Although heritage is also about setting out preservation priorities, since there is a limit to the things we can preserve, the fact that in the case of WWI sites not many visible conflictual landscapes have been preserved above ground pleads favourably for their preservation. Furthermore, the approached sites are located in the mountains and have survived the century due to their environmental setting; they present a great diversity of war remains that mark a very particular location in the economy of war and built up a category of war heritage that is still unexplored. It follows that little or nothing is known about what the war sites could reveal, further justifying the need to preserve the war sites at landscape level as conflictual landscape. Also, the fact that the war sites are already in a natural protected area narrows down the legal procedure in conferring them additional cultural heritage protection in order to facilitate further research, assure the preservation of the remains and forbid their physical destruction.

WWI inaugurated and produced extensive networks of fortifications and defence systems, very few of which were preserved in such a manner as to allow the study of a conflictual landscape even without excavating. The Prislop Pass material culture of war has the capacity of giving the observer a hint of what the land looked like at the time of the war, how the defence and logistic systems functioned, how the space was organised, the role it held in the economy of war and how it linked to other places. The categorisation of the importance of the sites reveals that, by choosing to protect individual features such as the common graves, the bunkers, the buildings foundations, the railway embankments, the trench system, etc. the overall mechanisms of both the strategic and logistic systems would be missed out. For instance, one could choose to protect the best-preserved feature from each category of remains, but that would mean little or nothing in relation to the underground materials which are yet unexplored, and would annul the added value of the dynamic relations existent 
between various components of material culture and the land settings. By simply cutting out and isolating disparate components of the material culture of war, more insight might be acquired into a specific war aspect, but this information would come at the cost of losing track of the functioning of the overall ensembles and the obliteration of the complex inter-relations that fuelled the war and informed determinate war theatres.

An understanding of the war phenomenon able to reflect the reason why this conflict is so import to our culture globally can only be derived from approaching the war sites at landscape scale, because otherwise the value of the war remains would be reduced to a sum of unrelated features. Furthermore, considerable research on specific aspects of the war has already been conducted on the Western Front (King, 1998; Saunders, 2002; Pollard and Banks, 2008; Robertson and Kenyon, 2008; Brown, 2009; Brown and Osgood, 2009; Hanson, 2011) and war remains, examined individually, might be quite similar between one site and another, therefore such an approach could be liable to offer little additional knowledge to the overall war phenomenon. Hence this research deals with a landscape context, arguing strongly that it needs to be preserved as such since it is quite rare to discover a landscape where you can understand the dynamics of war in a large-scale way. It derives that it is not a matter of which site to preserve but it is actually the landscape itself which is important due to the paramount value supplied by the combined war remains against the background of the sheltering land. Landscape scale is the only approach that allows plural versions of history to feed into the texture of the material culture of war, so informing multiple layer of memory. This also complements the individual nature of the war sites by managing to reflect plural actors, war accounts and traditions at national and international level.

One of the aspects that justified the choice of the research area was its distinctiveness and ambiguity. The problematic nature of the sites on account of the fact that they were built by 
the Austro-Hungarian and German armies which were fighting against the Romanians, made the task of assessing them as heritage on Romanian ground a particularly challenging endeavour. Nonetheless is was precisely such alterity that added to the overall significance of the sites in a heritage perspective that allowed the assessment of their heritage worth and value in a frame larger than the national state.

All in all, results Chapter 5 presented, for the first time, a gazetteer of the material remains of war within the study area, presenting a great variation of material remains but ultimately showing that the sum of all these features at landscape scale was much more valuable than their parts. It conclusively emerges that the landscape in its entirety should be regarded as heritage as, in a holistic form it holds the highest degree of value. Concerning this, when talking about the war sites/places of war the present research actually refers to the landscape scale of the environmental setting that connects the material remains thereby forming the conflictual landscape. In such a way, the research picks up (from Chapter 2) Saunders' approach to modern conflict archaeology and extends it to heritage enabling the field to see "objects and landscapes not as separate entities, but as complexly embedded and interconnected materialisations of the human experience of conflict"' (Saunders, 2012, pp.xi-xiv).

This first section, which discussed the field work results in the context of what they mean in terms of intrinsic content, highlighted that the material culture is important because of its rarity, research potential, the war knowledge it encapsulates and its historical and memorial functions. It emerges that these sites are significant in the context of a conflict that is particularly important nationally and internationally; they are authentic and well preserved, they amalgamate in a rare conflictual landscape and are yet unexplored scientifically, but, significantly, they are threated - hence something needs to be done in order to save them from 
destruction and looting. The resultant necessity to undertake measures with a view to preserving the war sites constitutes the rationale for the work conducted Chapters 6 and 7.

\subsection{Heritage by law in Romania}

This section of the chapter answers the question, what are the premises for granting heritage status in Romania and do the war sites meet the national heritage standards? The work conducted in Chapter 6 investigating the Romanian heritage legal framework and examining the premises for heritage status in Romania provides the basis for discussion in this section of the work. The approach allows comparisons of the war sites with other national heritage categories and thus enables assessment of the places of war as heritage.

The evolution of the Romanian heritage legislation led to the creation of a well-rooted tradition focused on the valorisation of two rigidly-confined categories in the field of immovable heritage:

- architectural heritage (mostly equivalent to various typologies of standing monumental buildings amongst which churches occupy a privileged place)

- archaeological heritage (strictly focused on prehistory, antiquity and middle ages).

Outputs of legislative evolution and the standards of the contemporary national heritage framework condense into the attributes and content of the List of Historic Monuments. The downfalls derived from the operationalisation of the national heritage regulations are responsible for the general confinement of heritage to classic assertions centred around the valorisation of standing buildings and prehistoric/ancient/medieval sites. The mechanism that fuels the heritage ranking process designated architects as leading experts in charge of the ranking of heritage. The perpetuation of over-empowering architects drastically reduces the chances of heritage of non-architectural value being granted official heritage status. In 
addition, the fact that Romanian archaeology does not recognise historical and contemporary archaeology, including conflict archaeology, excludes a significant number of potential historic monuments such as war/WWI sites from the heritage mainstream. That is because it is up to the National Commission of Archaeology to elaborate the strategies, approve national research programs and the annual national plan of systematic archeologic research, the technical-scientific rules and regulations in the field of archaeological research, enhance the methodology for the ranking of archaeological sites in the List of Historic Monuments and propose the ranking of archaeological sites. Furthermore, the commission is responsible, for establishing criteria for the selection of experts and approval of the specialists and experts attestation concerning the archeologic dimension of heritage.

The lack of adequate expertise due to the factual management of heritage not by law but by custom, negatively impacts the legal conduction of archaeological research, excavations and the management of fortuitous discoveries related to the material culture of war, consequently disabling their heritage outreach. As seen in Chapter 6 Law No. 422/2001 identifies as heritage all the monuments, ensembles and sites that constitute cultural-historic testimonies significant from an architectural, archaeological, historic, artistic, ethnographic, religious, social, scientific or technical point of view, while Order No. 2260/2008 prescribes the ranking criteria of immovable patrimony and details the standards to be considered in the evaluation process of every criterion. It follows that, according to the prescriptions of Law No. 422 the war sites qualify as heritage both in the category of ensembles, if approached from the perspective of a group of constructions that are coherent from a cultural, historical and architectural point of view, or in the category of sites. Diversely, Order No. 2260/2008 fixes a more restrictive heritage frame by relegating the assessment of heritage value to compliance 
with the primary evaluation criteria of age, architectural/artistic/urban value, frequency (rarity and unicity) and memorial-symbolic value.

Vitiation of the ranking process is emphasised by the comparative analysis between the church case chosen to highlight the application of the ranking criteria and the war sites. Chapter 6 showed how the Saint "Ilie Tesviteanul" church of Borșa was the only monument in Maramureș that was ranked as heritage and hence included in the List of Historic Monuments as a result of application of the ranking criteria and procedures prescribed by current legislation. The church was ranked as an historic monument of local importance (group B) as a consequence of obtaining two medium scores and two high scores in the evaluation of the criteria, which are reproduced in the Table 3 along with a replica of the same ranking procedure made available for the war sites by relying on data provided by the analytic sheet built in Chapter 6 (Appendix 16).

Table 3. Comparison between the heritage ranking scores of Saint "Ilie Tesviteanul" church of Borșa and Prislop Pass conflictual landscape

\begin{tabular}{|c|c|}
\hline Saint "Ilie Tesviteanul" Church of Borșa & Prislop Pass war sites \\
\hline \multicolumn{2}{|c|}{ 1. AGE CRITERION ${ }^{23}$} \\
\hline $\begin{array}{l}\text { SCORE } 1-\text { HIGH } \\
\text { The construction of the church began in } 1864 \\
\text { therefore belongs to the } 1830-1870 \text { time- } \\
\text { frame. }\end{array}$ & $\begin{array}{l}\text { SCORE 1- MEDIUM } \\
\text { Construction of the war sites began in } 1915 \\
\text { therefore it belongs to the } 1870-1920 \text { time- } \\
\text { frame. }\end{array}$ \\
\hline \multicolumn{2}{|c|}{ 2. ARCHITECTURAL/ARTISTIC/URBAN VALUE } \\
\hline $\begin{array}{l}\text { SCORE 2-MEDIUM } \\
\text { Under the voice planimetric and structural } \\
\text { coherence and technical conception the } \\
\text { church meets the standard by respecting the } \\
\text { special division characteristic of hall- }\end{array}$ & $\begin{array}{l}\text { SCORE } 2 \text { - EXCEPTIONAL } \\
\text { Under the voice planimetric and structural } \\
\text { coherence and technical conception the war } \\
\text { sites meet the standard by respecting the } \\
\text { special spatial division characteristic of the }\end{array}$ \\
\hline
\end{tabular}

\footnotetext{
${ }^{23}$ The heritage ranking regulations prescribe that an establishment is to be ranked the following score for the age criterion based upon their construction date:

- establishment built before 1775 - exceptional (value)

- $\quad$ establishment built between 1775-1830 - very high

- establishment built between 1830-1870 - high

- establishment built between 1870-1920 - medium

- establishment built between 1920-1960 - small

- establishment built after 1960 - zero
} 
churches and by being well executed although not exceptional from a structural and technical point of view. As representativeness of a certain historic age/author/style the church is part of the masonry churches that took the place of the wooden churches at the end of the $19^{\text {th }}$ century. In terms of significance for a certain historicalgeographic area it is representative of the religious life of the Maramureș region. As far as the elements of plastic arts and valuable artistic components are concerned, the church meets the criterion by its western façade, the artistic iconostasis and the recent date mural painting. The relation with the urban and natural context/the pertaining to an ensemble or natural or constructed site standard is assured, by contrast rather than analogy, with the communist blocks of flats that surround the church and which, according to the expert who ranked the church as monument, stands as a true redoubt of faith within such context. Finally, the representativeness within a program/urban policy/typology is met by the fact that the church is the oldest masonry church of Borssa, which, along with the Holy Archangels wooden church (also ranked as historic monument), constitutes elements of local identity that evoke a tradition that deserves to be preserved and valorised.
WWI battlefields and by being exceptionally well executed from a strategical, structural and technical point of view. As representativeness of a certain historic age/author/style the war sites are part of the material culture of WWI, represent an age of transition in warfare evolution, and present marked specificity due to the close relation between the Prislop Pass sites and the WWI military railway, projected and executed under the guidance of the famous Felix von Tarbuk Sensenhorst, that represented a technological breakthrough at the time. In terms of significance for a certain historicalgeographic area, the representativeness of the war sites is conferred by their belonging to WWI heritage and remembrance and thus to the memory of the Great Romanian Union from a perspective of time, while from a spatial perspective the sites are representative at local and regional level representing both the general condition of the Romanian population of the historic provinces dominated by the Austro-Hungarians as well as the overall norm of countries of the Eastern Front that were under imperial domination. Although at this level of analysis it would be hazardous to estimate elements of plastic arts and valuable artistic components, the nullity of this dimension of the war sites should not be taken for granted as the present research did not contemplate excavations and, therefore, the possibility of underground trench art, military decorations, medals and badges subsists. Furthermore, the Prislop Pass WWI photography should be regarded as a significant artistic component of the war sites. In relation to the natural context the war sites emphasise the close interconnections between anthropic and natural elements, by embedding the war architecture pertaining to the WWI Prislop military city and the adjacent defence system into the strategic mountainous landscape. The wound inflicted by war upon the lands, patiently nurtured by the natural environment, cicatrised through the century, branded the landscape with the world wars' mark and converted space into 


\begin{tabular}{|c|c|}
\hline & $\begin{array}{l}\text { place powered by its memory hallmark. The } \\
\text { integration of the material remains of the } \\
\text { industrial war in the picturesque landscape of } \\
\text { the Maramures Mountains, on the one hand } \\
\text { testifies the regenerative power of nature and, } \\
\text { on the other, it adds value to the natural } \\
\text { landscape due to the significance of the war } \\
\text { sites as places of remembrance and heritage. } \\
\text { As far as representativeness within a } \\
\text { program/urban policy/typology is concerned, } \\
\text { the war sites are a significant typology of } \\
\text { strategic defensive war sites that } \\
\text { simultaneously incarnate Romanian local } \\
\text { specificity and Austro-Hungarian imperial } \\
\text { warfare traditions. }\end{array}$ \\
\hline \multicolumn{2}{|c|}{ 3. FREQUENCY CRITERION } \\
\hline $\begin{array}{l}\text { SCORE } 3 \text { - HIGH } \\
\text { In terms of unicity of the building, of its } \\
\text { components or of the ensemble, the edifice is } \\
\text { unique on local level and constitutes a rarity } \\
\text { in the area as far as style is concerned, } \\
\text { although as top of the class } \\
\text { representativeness, the church is not a top- } \\
\text { class edifice. As far as the rarity criterion or } \\
\text { belonging to a narrow series/limited edition in } \\
\text { relation to a certain historical-geographic } \\
\text { area, ethnographic area or historic period is } \\
\text { concerned, the church belongs to a limited } \\
\text { series of neogothic cult buildings of the area } \\
\text { of Maramures. Still, in terms of typicity for a } \\
\text { historical-geographic area, ethnographic area } \\
\text { or historic period, the monument is atypical. } \\
\text { In reference to the frequency of valuable } \\
\text { objects within a built historic ensemble, the } \\
\text { church is framed as holding relevance in } \\
\text { terms of rarity and unicity. }\end{array}$ & $\begin{array}{l}\text { SCORE } 3 \text { - EXCEPTIONAL } \\
\text { The unicity of the war sites ensemble is } \\
\text { conferred by the characteristics of the Prislop } \\
\text { Pass material culture of war forged by the } \\
\text { Austro-Hungarian empire against the } \\
\text { background of the Romanian local specificity } \\
\text { within the framework of WWI. The war sites } \\
\text { also hold a top-class representativeness as the } \\
\text { morphology of the conflictual landscape was } \\
\text { generated by a series of specific } \\
\text { circumstances culminating with the } \\
\text { importance of this geostrategic position in the } \\
\text { economy of war (as Maramures bordered the } \\
\text { Galician front and constituted the gate to the } \\
\text { heart of the empire), the establishment of the } \\
\text { Austro-Hungarian military command in the } \\
\text { Prislop Pass, and the building of the military } \\
\text { railway. The above reasons also reflect } \\
\text { inclusion of the war sites in a narrow } \\
\text { series/limited edition as far as a specific } \\
\text { historical-geographic area, ethnographic area } \\
\text { or historic period is concerned, as they } \\
\text { represent a particular category of WWI } \\
\text { strategic architecture (logistic-defensive } \\
\text { fortifications) as well as a limited number of } \\
\text { such sites. The Maramures Mountains } \\
\text { defence system also emerges as the only } \\
\text { visible network of war remains in the county } \\
\text { that survived the last century, qualifying the } \\
\text { sites as outstanding in terms of rarity. The } \\
\text { standard of typicity for a historical- } \\
\text { geographic area, ethnographic area or historic }\end{array}$ \\
\hline
\end{tabular}




\begin{tabular}{|c|c|}
\hline & $\begin{array}{l}\text { period is met by the fact that the sites are an } \\
\text { integral part of WWI history, they emphasise } \\
\text { the nuances of the Romanian fight for } \\
\text { national unity and emancipation in the } \\
\text { Romanian historical provinces against the } \\
\text { frame of the larger historic process that } \\
\text { allowed the expression of national } \\
\text { consciousness internationally, and highlight } \\
\text { the specificity of the war phenomenon within } \\
\text { the ethnographic area of Maramures. } \\
\text { Furthermore, the war sites not only display a } \\
\text { multitude of significant architectural } \\
\text { components only available in this particular } \\
\text { location but also coagulate the various } \\
\text { elements into a rare and unique conflictual } \\
\text { landscape. }\end{array}$ \\
\hline \multicolumn{2}{|c|}{ 4. MEMORIAL-SYMBOLIC VALUE } \\
\hline $\begin{array}{l}\text { SCORE } 4-\text { MEDIUM } \\
\text { In terms of connections to certain historical, } \\
\text { cultural, political and social moments and } \\
\text { places/representativeness for certain } \\
\text { personalities the church is not connected to } \\
\text { any cultural, political and historic event. In } \\
\text { relation to anterior constructions of renowned } \\
\text { historical importance which are missing, } \\
\text { recorded by any source, documentary or } \\
\text { archaeological, the church is known to } \\
\text { replace the wooden church destroyed by the } \\
\text { Tatars in } 1717 \text {. In reference to its presence in } \\
\text { the memory of the community, at European, } \\
\text { national and local level the edifice seems to } \\
\text { be present in the memory of the community } \\
\text { due mainly to its designation as a cult edifice } \\
\text { and to its age. As far as the connection to } \\
\text { local traditions is concerned, the church is } \\
\text { integrated in the life of the community and } \\
\text { brings its contribution to the preservation of } \\
\text { local traditions. }\end{array}$ & $\begin{array}{l}\text { SCORE } 4 \text { - EXCEPTIONAL } \\
\text { The Prislop Pass war sites are simultaneously } \\
\text { connected to historical, cultural, political and } \\
\text { social moments and places. As shown in } \\
\text { previous parts of the research, the war sites } \\
\text { are relevant as symbolic places in relation to } \\
\text { the Romanian national fight for freedom and } \\
\text { emancipation culminating in the } 1918 \text { Great } \\
\text { Union. Hence, they incarnate the social and } \\
\text { political movements that fuelled the } \\
\text { Romanian fight for liberty, sovereignty, } \\
\text { national emancipation and liberation from } \\
\text { foreign domination. The war sites also give } \\
\text { material expression to the well-represented } \\
\text { field of war writings, anchoring Great War } \\
\text { literature, folkloric and ethnographic } \\
\text { creations to the tangibility of physical places } \\
\text { depicting a fresco of WWI remembrance } \\
\text { embedded in the material culture of war. } \\
\text { Furthermore, the Prislop Pass war sites are } \\
\text { also connected to important historical } \\
\text { personalities who were present in the area } \\
\text { during WWI such as Carol IX, Wilhelm II, } \\
\text { the Archduke of Austria Karl Franz Josef, the } \\
\text { Kaiser Wilhelm II, Feldmarschal Hermann } \\
\text { Kovess von Kovesshaza (the last Supreme } \\
\text { Commander of the Austro/Hungarian army) } \\
\text { and the Field Marshal Friedrich (Archduke of } \\
\text { Austria and Duke of Teschen), Czar Nicholas } \\
\text { II of Russia, General A.A. Brusilov, the } \\
\text { Great Duke Mihail Alexandrovici Romanov, }\end{array}$ \\
\hline
\end{tabular}




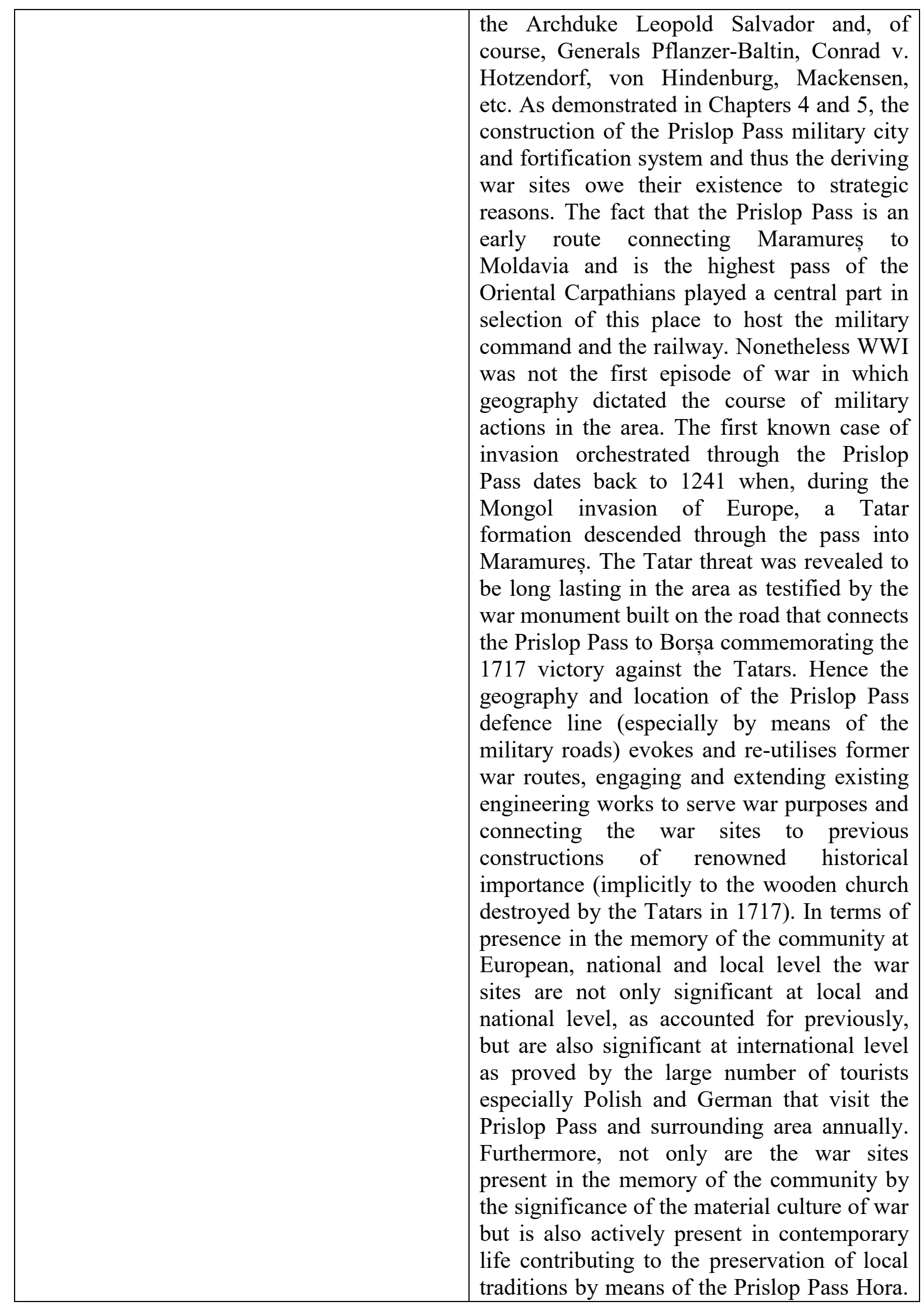




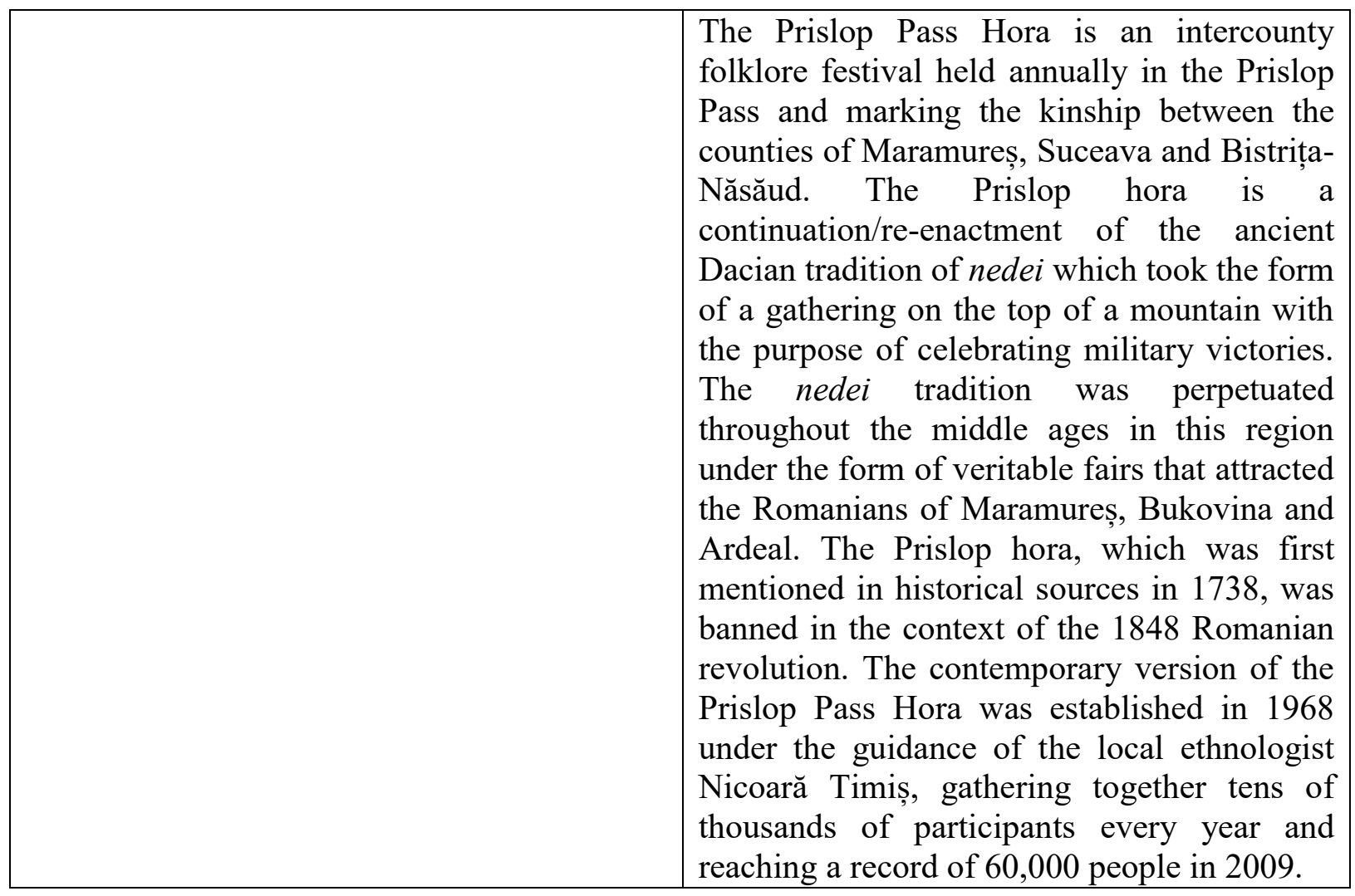

The meeting of Romanian heritage standards prescribed by the current legislation with the above scores implies the appropriateness of ranking the war sites as group A historical monuments, that is, monuments of national and international value. By comparing characteristics of the war sites with the church case it emerges that the sites constitute by far a more valuable heritage category in a local, regional, national and international perspective. In the evaluation of the criteria, at all levels of analysis with the only exception of the age standard, the war sites are likely to be granted higher scores than the church case. As seen above, the places of war present a plurality of levels of significance that coagulate at different scales and relate to different fields and heritage aspects/domains. Still, as far as Romanian legislation and national identity is concerned, even the sole memorial-symbolic dimension of the sites connected to the Romanian national master narrative whose epicentre resides in the Great Romanian Union would be enough to grant the war sites heritage status and thus legal protection. The events that occurred on the occasion of the 2018 centenary of the Great 
Romanian Union faithfully testify the national importance of the Great Union for the Romanian people. On $1^{\text {st }}$ of December 2018 more than 200,000 people gathered in Alba Iulia to celebrate the Great Union, and similar celebrations were organised endemically throughout the country. Furthermore, the county of Maramureș organised a delegation that travelled to Alba Iulia by horse-led carts, paying tribute to the Great Union by peregrinating the 1918 union road for more than $300 \mathrm{~km}$ in spite of harsh meteorological conditions. The carriages convoy started its journey from Apșa de Jos, a locality in present-day Ukraine that was Romanian territory at the end of WWI and whose Romanian population solicited to celebrate the centenary of the Great Union alongside the delegation of the county of Maramureș to which they used to belong.

Contrary to law prescriptions and despite meeting the heritage ranking criteria, the lack of adequate expertise shows up in the fact that not a single war site is regarded as heritage although the territory of present Romania witnessed several wars that defined national identity over a time arch of more than 2000 years. Factual disregard of value valences that transcend the boundaries of traditional demarcations (such as scientific, social, technical and memorialsymbolic value) in disagreement with national heritage legislation, generates heritage coverage gaps and thus excludes the war sites from the mainstream. Thus, such operationalisation of the national heritage laws and the consequent failure to materialise heritage status poses an ultimate threat to the preservation of already endangered heritage such as the war sites. The assessment of war sites against the Romanian legal heritage criteria reveals that these sites better fit the national heritage standards than some that are already ranked in the List of Historic Monuments. The places of war are nowadays subject to degradation on account of development and intensive farming, and constitute a vulnerable landscape in absence of the legal protection framework that would be derived from official 
recognition of their heritage status. The lack of legal protection of the war sites silently confers carte blanche to the destruction of these cultural landmarks of local, national, regional and international significance, hence implying a need to act towards an official elevation of their heritage status.

\section{$\underline{\text { 8.4. Heritage by law, internationally }}$}

This section of the chapter answers the question, what are the premises of the World Heritage status and what is the international significance of WWI sites in relation to World Heritage standards? The third objective of the thesis, dealt with in Chapter 7, regarded investigation of the international legal framework and the examination of the premises for granting World Heritage status in view of allowing the assessment of the international significance of WWI sites and contextualisation of the Romanian case in the wider heritage debate. The investigation of the international legal framework and characterisation of the World Heritage standards and ranking process allowed the understanding of heritage at international level and provided solid ground for the assessment of WWI sites as World Heritage. Also, it allowed contextualisation of the Romanian war sites while simultaneously providing terms of comparison for the Romanian case with other international cases against the background of the authorised heritage discourse.

The evolution of international heritage legislation registered a gradual maturation process that allowed the development of the concept of heritage and thus the diversification and broadening of the official heritage spectrum. The original concern about safeguarding heritage against war hazards generated a fertile field of heritage debates at international level that, beyond translating into an international legal field that extended worldwide, also led to an extension of the accepted assertions of heritage value that leaked into national legislations by 
means of instruments of international relations. The initial apprehension of heritage threats identified as causes of cultural heritage impoverishment grew in a complex field of international legislation that was gradually adopted by, and adapted to, the national legislative reality of several states. In fact, national and international heritage legal evolution mutually interacted. On the one hand national heritage traditions ended up being influenced by international heritage trends and practices but, on the other, it was the single states that dictated the changes in and the updates of international heritage mentalities by means of international stakeholders who in good or bad ways raised heritage to the level of a global concern.

The perpetually changing interpretations of heritage mirror the changes in social and political mentalities. In accordance with current international assertions heritage is framed as a common possession of all humanity which stands as a barometer of international ethos at the crossroads of past and future. The official international heritage pulsations derived from the international heritage legal framework materialise in the World Heritage status and are thence reflected in the content of the World Heritage List. The heritage ranking process and standards are consequently a dynamic process that evolves alongside international heritage assertions. The general official understanding of heritage at a given point in time (and space) is reflected by the premises of the World Heritage status, both in terms of criteria and ranking procedure.

Understanding the World Heritage ranking process provided the context for interrogation of the international heritage value of WWI sites within the framework of official international heritage standards. Although at the moment there are no WWI sites with World Heritage status the inclusion of WWI sites in the World Heritage Tentative List demonstrates the coagulation of an international acknowledgement of the latent universal value of the war sites. 
The emergence of these new additions proves a raised awareness that WWI heritage does qualify as a heritage category with the potential to meet World Heritage standards, as it has exceptional value beyond national boundaries and is able to coagulate high degrees of importance for contemporary and future generations worldwide. Concretely, WWI sites not only meet the rigours of international heritage legislation but also have outstanding universal value potential on account of being able to meet World Heritage selection criteria numbers II, III, IV, V, VI. In fact, the French-Belgian joint submission, and Slovenian submission presented in Chapter 7, made the run for inclusion in the World Heritage List by relying on criteria II , III, IV and VI criteria whereas the simulation of the hypothetic nomination of the Romanian war sites which constitute the focus of the present research, and which is presented in Appendix 18, accounts for meeting World Heritage criteria II, III, IV, V and VI.

Approaching the international significance of the war sites in the perspective of the World Heritage status provided both international context and suitable terms of comparison for the Romanian case. Table 4 highlights how every individual nomination meets the World Heritage standards in terms of justification of outstanding universal value, statements of authenticity and/or integrity and in comparison to other similar properties.

Table 4. Comparison between the French-Belgian, Slovenian and Romanian WWI heritage nominations against the World Heritage criteria JUSTIFICATION OF OUTSTANDING UNIVERSAL VALUE

\begin{tabular}{|c|c|c|}
\hline \multicolumn{3}{|c|}{ World Heritage criteria } \\
\hline \multicolumn{3}{|c|}{ JUSTIFICATION OF OUTSTANDING UNIVERSAL VALUE } \\
\hline $\begin{array}{l}\text { French-Belgian joint } \\
\text { nomination }\end{array}$ & Slovenian nomination & Romanian hypotl \\
\hline $\begin{array}{l}\text { The monuments and sites are } \\
\text { a testimonial of the mass } \\
\text { dying of soldiers during } \\
\text { WWI and therefore reflect } \\
\text { the industrial and total } \\
\text { dimension of the war along } \\
\text { with its international } \\
\text { character. The French- } \\
\text { Belgian description claims } \\
\text { that "only a new cult of the }\end{array}$ & $\begin{array}{l}\text { The criterion is satisfied by } \\
\text { the symbiosis between the } \\
\text { genuine memorial landscape } \\
\text { and adjacent natural elements } \\
\text { that feature a peculiar } \\
\text { war/peace narrative. The } \\
\text { justification focuses on the } \\
\text { collective experience and } \\
\text { transnational character of the } \\
\text { Walk of Peace. }\end{array}$ & $\begin{array}{l}\text { The Prislop Pass war places } \\
\text { have several concurrent levels } \\
\text { of significance that inform } \\
\text { plural remembrance functions } \\
\text { at local, regional, national or } \\
\text { international scale. Dependent } \\
\text { upon the perspective taken, } \\
\text { the conflictual landscape } \\
\text { evokes different dimensions } \\
\text { of the war phenomenon out of }\end{array}$ \\
\hline
\end{tabular}




\begin{tabular}{|c|c|c|}
\hline 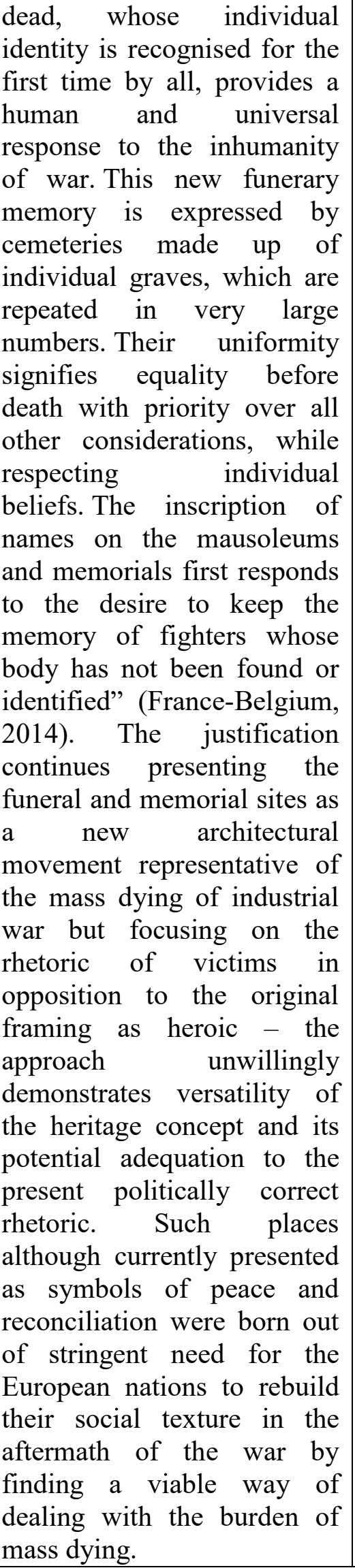 & 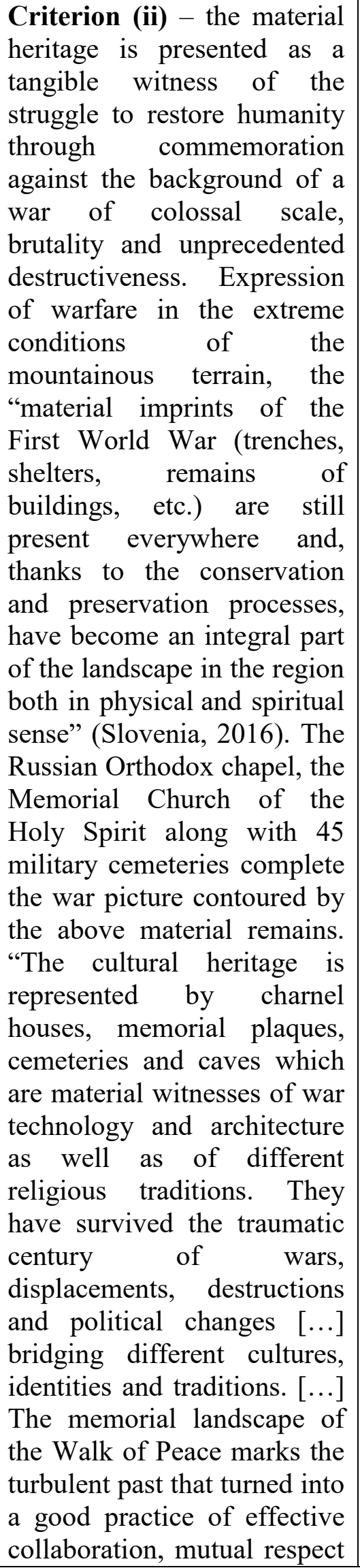 & $\begin{array}{l}\text { Tyers. The places of war } \\
\text { isplay the everlasting story } \\
\text { f the Great War, } \\
\text { imultaneously encapsulating } \\
\text { te human dimension of the } \\
\text { ar, the technological } \\
\text { reakthroughs and } \\
\text { novations, the war typology } \\
\text { nd military specificity, the } \\
\text { istorical military and } \\
\text { olitical personalities } \\
\text { elegated to the place, the fall } \\
\text { f the great empires, the fight } \\
\text { or freedom of eastern } \\
\text { uropean nations, the } \\
\text { iternational affirmation of } \\
\text { le nationality and self- } \\
\text { etermination principles, and } \\
\text { ence the roots of a new } \\
\text { iternational mentality. The } \\
\text { lemorial-symbolic }\end{array}$ \\
\hline
\end{tabular}




\section{Criterion (iii) - the WWI cemeteries and memorials witness the formation of a new tradition of the military dead cult.}

Criterion (iv) - WWI cemeteries and memorials represent the creation of a new large-scale architectural category dedicated to the remembrance of war deaths whose size mirrors the scale of the global war.

Criterion (vi) - the immense destructive power of the Great War induced "the desire to perpetuate the individual identity of the war victim" responding "to the need for the re-humanization of societies decimated by the disappearance of much of their youth. For the first time in human history, all victims are equally recognized in death. This celebration is expressed by the individual grave, cemeteries, necropolises and memorials, organised according to national establishments and styles" (Ibid). and awareness of the shared, not separate or dividing, history of the past hundred years. It represents serious reflection on contemporary societies, on the importance of peace promotion being a joint effort of neighbouring states that share the region of the former frontiers and barriers between cultural traditions, identities, which eventually culminated in violent conflicts" (ibid).

Criterion (vi) - Explains the meeting of the criterion due to the documentation of the military and political events which forged the history of the region in all its political, social and cultural dimensions. The justification continues by highlighting the marginalisation within the European and collective memory and within the historical accounts of WWI. It also states the universal value of the documentary evidence reported in diaries, letters and memoirs and emphasises the dual nature of the war expressed in its simultaneous destructive and creative capacity. "Within the span of a hundred years, remembrance in many different forms has emerged through diaries and memoirs, photographs, experience of civil population, refugees, occupational politics, military strategies, battles, life and death. But in the course of the hundred years, a common awareness of the suffering and loss inflicted on people regardless of their
Romanian local specificity
and Austro-Hungarian
imperial warfare traditions.
Furthermore, they present a
marked specificity due to the
close relation between the
Prislop Pass sites and the
WWI military railway
projected and executed under
the guidance of the famous
Felix von Tarbuk
Sensenhorst, which represented a technological miracle at the time of the war. In terms of significance within a cultural area of the world, the sites are representative of the general WWI East European memory and remembrance and hence of the values and ideals that motivated the fight for national emancipation and freedom of the peoples who were subjugated by imperial domination. At national level the war sites bear testimony to the Romanian quest for national unity, being closely related to the memory of the Great Romanian Union, while at local and regional level they account for the general condition of the Romanian population of the historic provinces dominated by the Austro-Hungarians

consequently emphasising the norm of the countries of the Eastern Front that were under imperial domination.

Criterion (iii) - The unicity of the war sites ensemble is conferred by the characteristics of the Prislop Pass material culture of war forged by the Austro- 


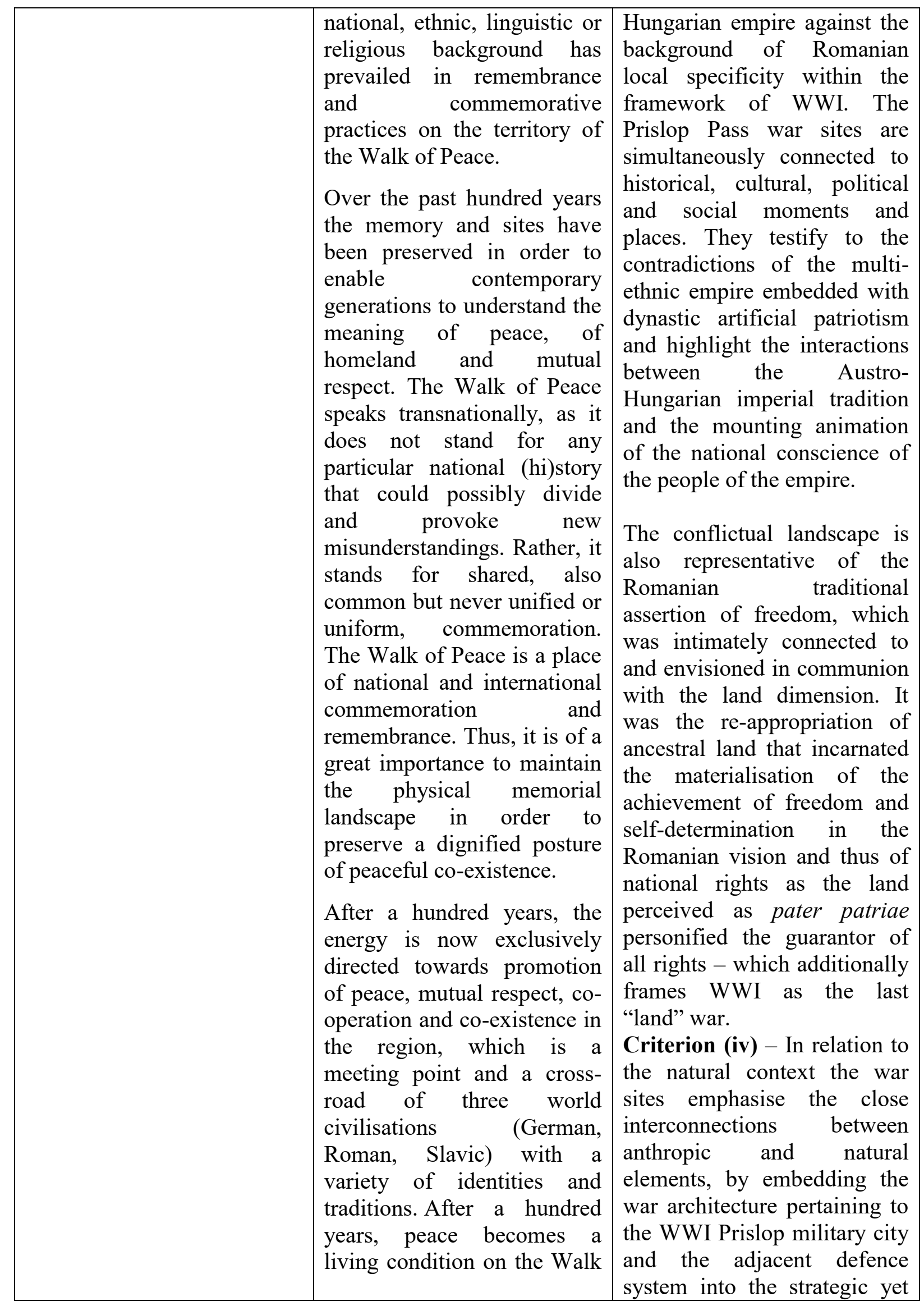




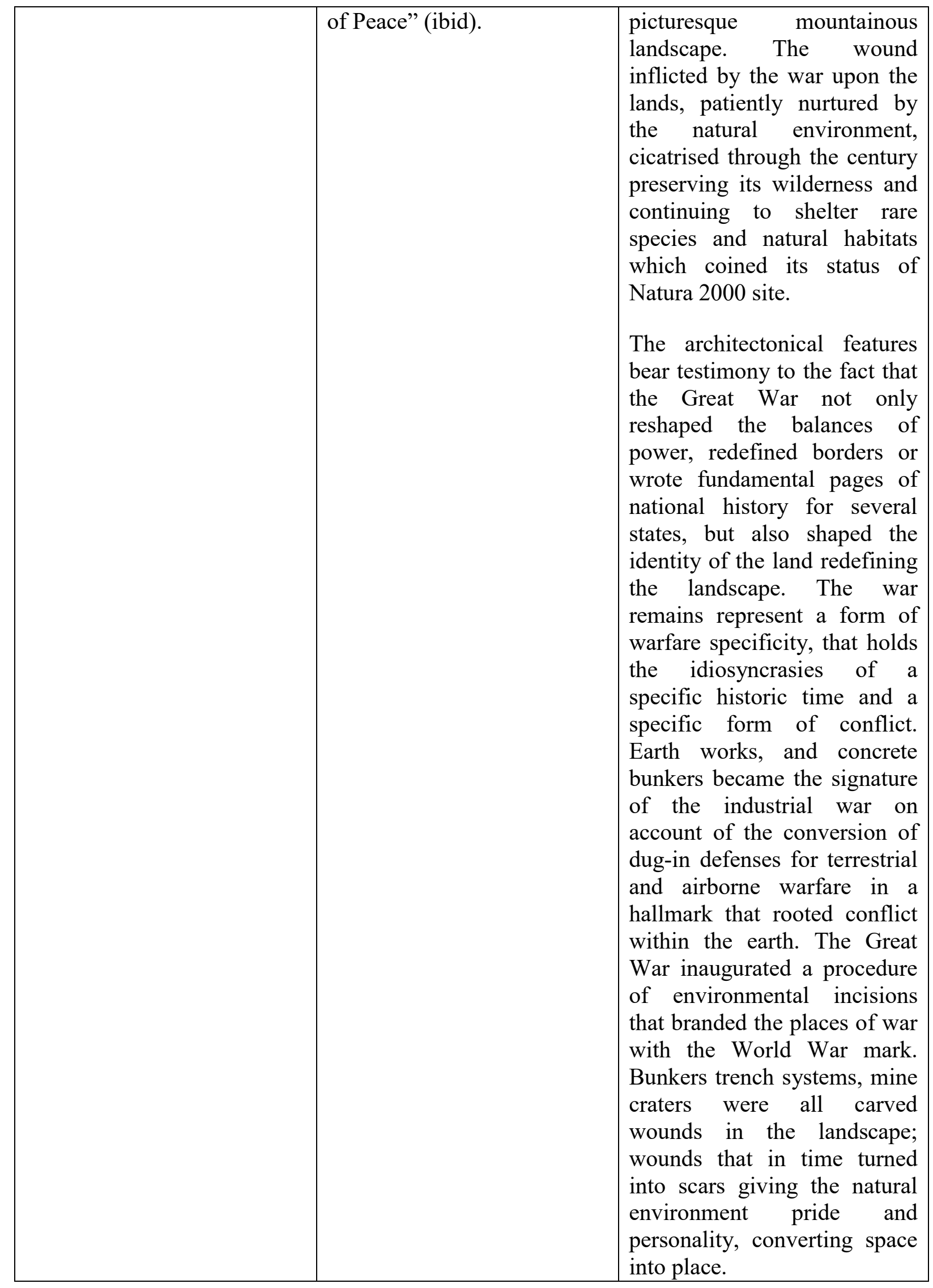




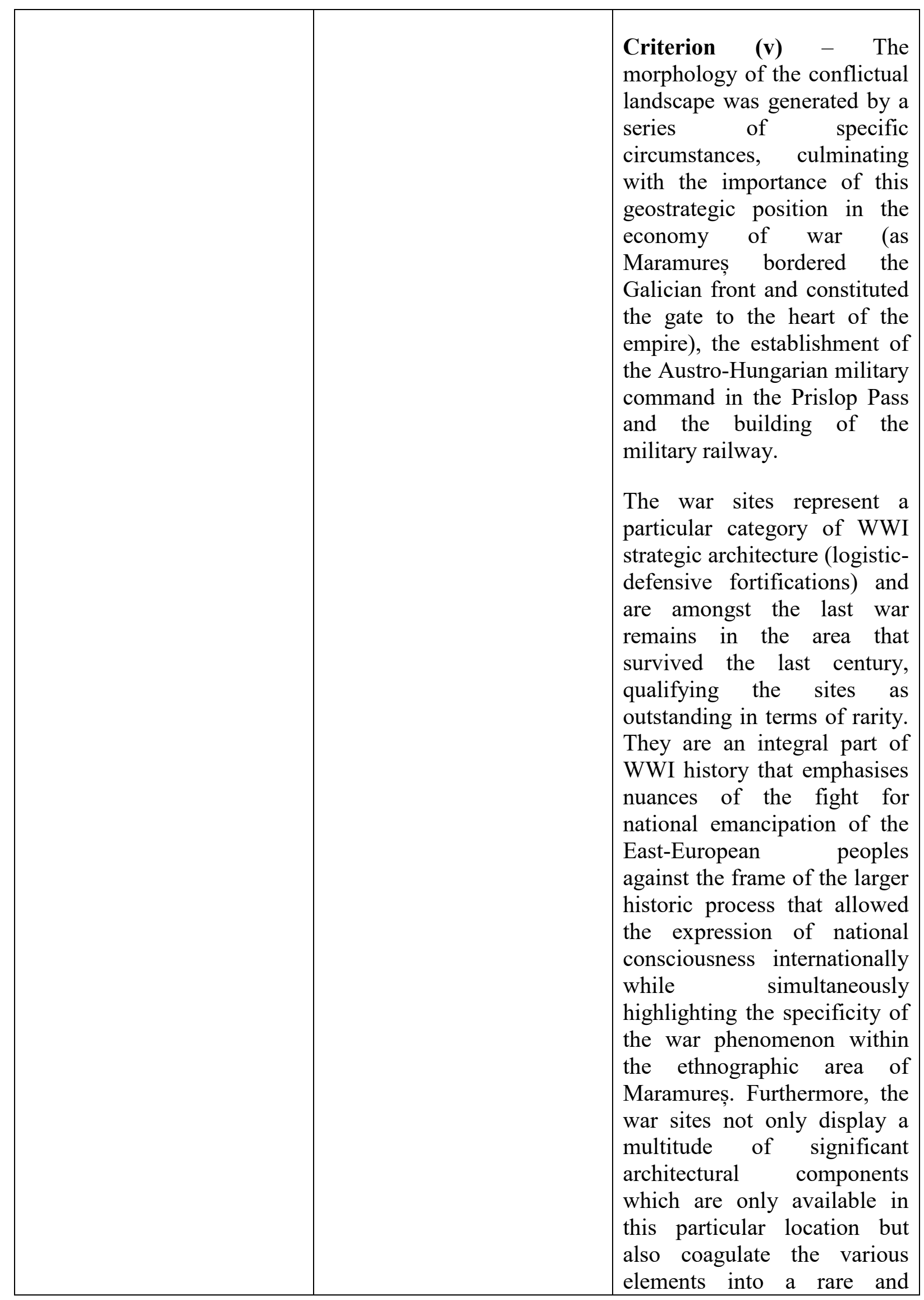




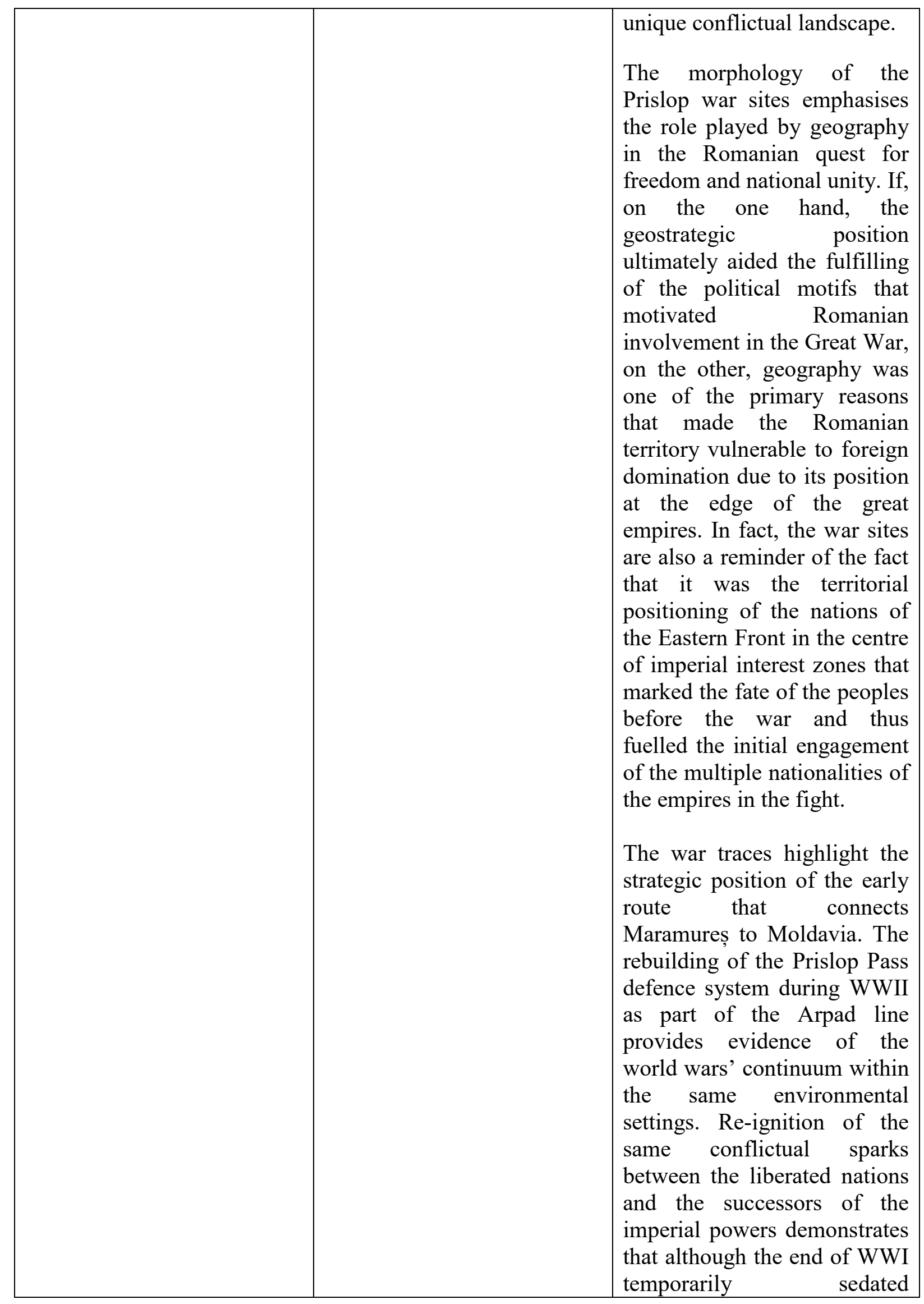




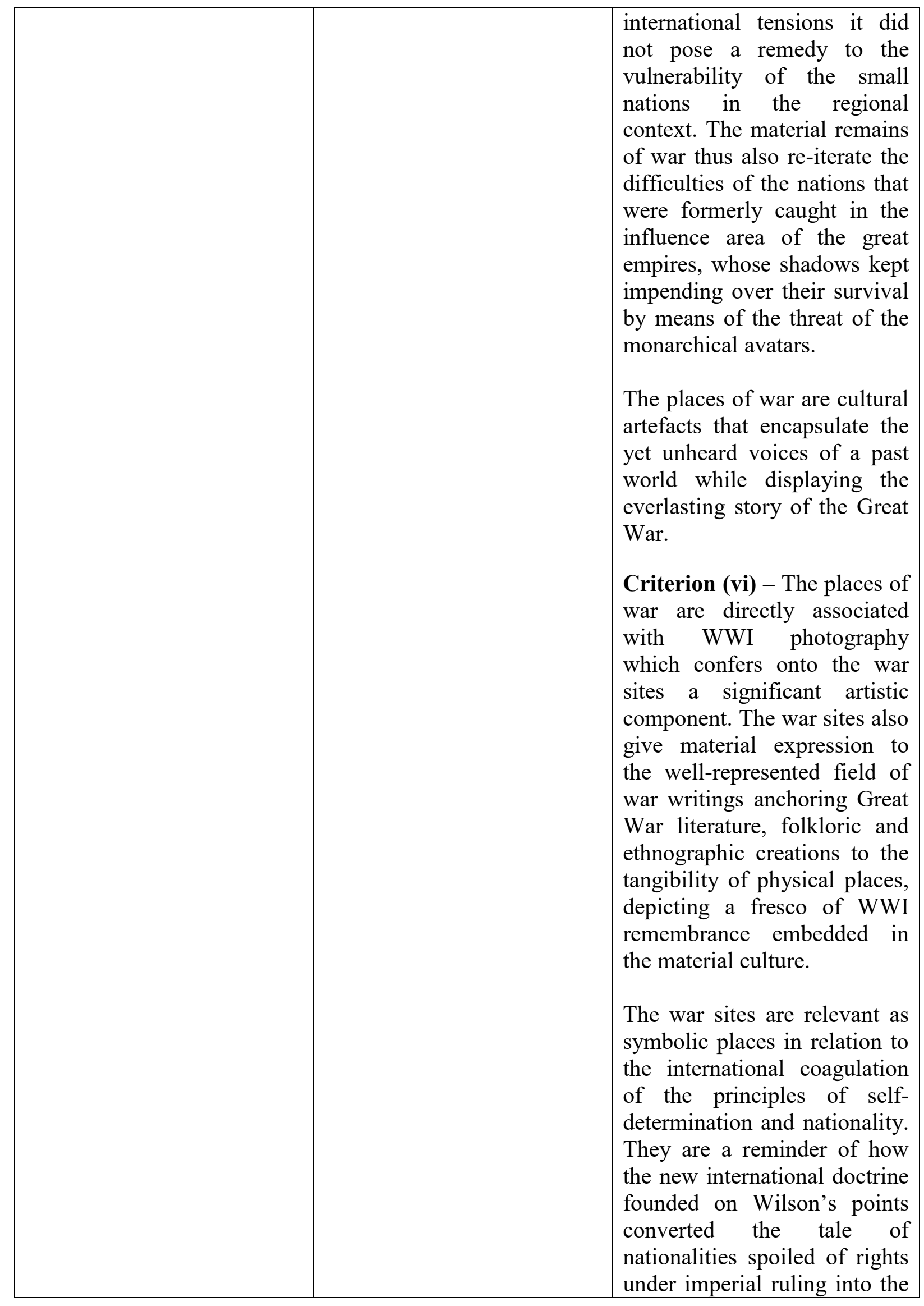




\begin{tabular}{|c|c|c|}
\hline & & $\begin{array}{l}\text { history of sovereign nations. } \\
\text { In fact, it was this } \\
\text { international predisposition } \\
\text { towards recognition of the } \\
\text { national rights of the whole } \\
\text { population of the state that } \\
\text { allowed the creation and } \\
\text { recognition of the rights of } \\
\text { minorities, which became a } \\
\text { fundamental principle of the } \\
\text { contemporary world. } \\
\text { The war sites simultaneously } \\
\text { encapsulate the human } \\
\text { dimension of the war, war } \\
\text { typology/military specificity, } \\
\text { technological } \\
\text { breakthroughs/innovations, } \\
\text { the fall of the great empires, } \\
\text { the fight for freedom of } \\
\text { eastern European nations, the } \\
\text { international affirmation of } \\
\text { the principles of nationality } \\
\text { and self-determination, and } \\
\text { hence the roots of a new } \\
\text { international mentality and } \\
\text { above all the people's dream } \\
\text { of freedom. }\end{array}$ \\
\hline \multicolumn{3}{|c|}{ STATEMENTS OF AUTHENTICITY AND / OR INTEGRITY } \\
\hline $\begin{array}{c}\text { French-Belgian joint } \\
\text { nomination }\end{array}$ & Slovenian nomination & $\begin{array}{c}\text { Romanian hypothetic } \\
\text { nomination }\end{array}$ \\
\hline $\begin{array}{l}\text { The stated declaration reports } \\
\text { that authenticity results from } \\
\text { the fact that all the } \\
\text { cemeteries and monuments } \\
\text { are used for the purposes } \\
\text { they were built (that is, } \\
\text { funeral and memorial } \\
\text { functions), and which forms } \\
\text { their exclusive use. It is also } \\
\text { stated that they bear witness } \\
\text { to an "authentic way of war" } \\
\text { and the homage paid to the } \\
\text { deceased, building up } \\
\text { "additional places of memory } \\
\text { attached to the events of the } \\
\text { First World War, of which } \\
\text { they express the different }\end{array}$ & $\begin{array}{l}\text { The authenticity of the sites } \\
\text { is proposed by preservation } \\
\text { of the component parts of the } \\
\text { Walk of Peace within their } \\
\text { original settings and by the } \\
\text { maintenance of their original } \\
\text { shape and materials as they } \\
\text { emerged from the war. The } \\
\text { fact that over the past } 100 \\
\text { years they were influenced } \\
\text { only by climatic factors } \\
\text { allows them to vividly } \\
\text { transmit their functional, } \\
\text { visual and historical } \\
\text { dimension to the public, } \\
\text { telling a story about the } \\
\text { "uniqueness of the human }\end{array}$ & $\begin{array}{l}\text { The places of war display a } \\
\text { fresco of the contradictions of } \\
\text { the war fought under the } \\
\text { imperial flag, of the moral } \\
\text { dilemmas, of the persecutions, } \\
\text { of the resistance, of the fight } \\
\text { for national rights and of the } \\
\text { epopee of freedom. The great } \\
\text { diversity of the component } \\
\text { features of the war sites } \\
\text { highlights the dimensions of } \\
\text { war architecture and of } \\
\text { conflictual space } \\
\text { management. The authenticity } \\
\text { dimension of the war sites is } \\
\text { conferred by physical } \\
\text { preservation of the component }\end{array}$ \\
\hline
\end{tabular}




\begin{tabular}{|c|c|c|}
\hline $\begin{array}{l}\text { lal, historical and } \\
\text { rial aspects as well as } \\
\text { ural, architectural and } \\
\text { ative variants. In } \\
\text { on, the construction of } \\
\text { ments commemorating } \\
\text { var and its deaths is } \\
\text { oping near the old front } \\
\text { but also in the villages } \\
\text { wns of the nations and } \\
\text { ss wo were engaged in } \\
\text { fighting. The most } \\
\text { tant memorial } \\
\text { ments, retained in the } \\
\text { visually and } \\
\text { of the front. Beyond } \\
\text { unique symbolic art, } \\
\text { rial monumentalism } \\
\text { the landscape of } \\
\text { eries express a deep } \\
\text { for peace. All the } \\
\text { nts proposed testify to } \\
\text { material and immaterial } \\
\text { with a very great } \\
\text { aticity" (ibid). The text } \\
\text { lues with the } \\
\text { ation of integrity which } \\
\text { arguments for the } \\
\text { ity of the goods } \\
\text { sed for World Heritage } \\
\text { which, although being } \\
\text { structural, also } \\
\text { its intangible } \\
\text { sion. }\end{array}$ & $\begin{array}{l}\text { creative genius in the } \\
\text { troubled war times" and } \\
\text { preaching about "the values } \\
\text { of freedom and mutual } \\
\text { respect to every generation to } \\
\text { come" (ibid). The sites are } \\
\text { granted legal protection as } \\
\text { they are ranked in the } \\
\text { Slovakian National Heritage } \\
\text { Registry and natural heritage } \\
\text { components of the sites are } \\
\text { either part of the Triglav } \\
\text { National Park or the } \\
\text { European network Natura } \\
2000 .\end{array}$ & $\begin{array}{l}\text { war remains in the same } \\
\text { setting and form as created } \\
\text { through the agency of the } \\
\text { world wars against the } \\
\text { settings of the environmental } \\
\text { conditions. The material } \\
\text { culture of war narrates the } \\
\text { historical journey of the traces } \\
\text { of a war long gone but whose } \\
\text { legacy reaches up to today. } \\
\text { The imprint conferred by the } \\
\text { passing of time confirms the } \\
\text { authenticity of the war places } \\
\text { by displaying the unmediated } \\
\text { evolution of the WWI } \\
\text { material remains over a time } \\
\text { arch of more than } 100 \text { years. } \\
\text { The authenticity continuum } \\
\text { represents one of the aspects } \\
\text { of heritage that, in accordance } \\
\text { with contemporary assertions, } \\
\text { augments the spectrum of } \\
\text { heritage value. In terms of } \\
\text { integrity, the importance and } \\
\text { significance of the war places } \\
\text { does not derive from the sum } \\
\text { of the component parts } \\
\text { evaluated in a disjointed } \\
\text { manner, from } \\
\text { consideration of the war sites } \\
\text { as a whole; the fact that only a } \\
\text { limited amount of materials } \\
\text { survived the last century } \\
\text { brings ulterior proof of their } \\
\text { rarity and scientific value. } \\
\text { The places of war are a fresco } \\
\text { of history and memory } \\
\text { condensed in a conflictual } \\
\text { landscape that bears the mark } \\
\text { of the world wars. }\end{array}$ \\
\hline \multicolumn{3}{|c|}{ COMPARISON WITH OTHER SIMILAR PROPERTIES } \\
\hline $\begin{array}{c}\text { French-Belgian joint } \\
\text { nomination }\end{array}$ & Slovenian nomination & \\
\hline $\begin{array}{lcc}\text { Presents an inventory } & \text { of } \\
\text { properties } & \text { recognised } & \text { as } \\
\text { World } & \text { Heritage } & \text { by } \\
\text { UNESCO, } & \text { inscribed } & \text { on }\end{array}$ & $\begin{array}{l}\text { After restating the } \\
\text { importance and significance } \\
\text { of the Walk of Peace the } \\
\text { argument mainly centres }\end{array}$ & $\begin{array}{l}\text { The Prislop Pass war site owe } \\
\text { their existence to strategic } \\
\text { reasons related to the fact that } \\
\text { the Prislop Pass is an early }\end{array}$ \\
\hline
\end{tabular}




\begin{tabular}{|c|c|c|}
\hline $\begin{array}{l}\text { tentative lists or which do not } \\
\text { possess such qualities but are } \\
\text { considered to be related to } \\
\text { the theme proposed by the } \\
\text { joint nomination. The first } \\
\text { category consists of military } \\
\text { elements/additions, the } \\
\text { second concerns the } 20^{\text {th }} \\
\text { century conflicts while the } \\
\text { third regards funeral heritage } \\
\text { that made it into the World } \\
\text { Heritage List or various } \\
\text { Tentative Lists. Also, it is } \\
\text { noted that "the major trauma } \\
\text { of the First World War, } \\
\text { which marks a profound } \\
\text { change in the modes of } \\
\text { governance and societies in } \\
\text { all parts of the world, is } \\
\text { ignored in the World } \\
\text { Heritage List and almost } \\
\text { non-existent in the Tentative } \\
\text { Lists" (ibid). }\end{array}$ & $\begin{array}{l}\text { around the properties } \\
\text { recognised as World } \\
\text { Heritage by UNESCO, those } \\
\text { inscribed on tentative lists } \\
\text { and paralleling in several } \\
\text { cases the Franco-Belgian } \\
\text { joint nomination. The central } \\
\text { themes of the argument are } \\
\text { related to war, military, } 20^{\text {th }} \\
\text { century conflicts, the world } \\
\text { wars, memorialization and } \\
\text { funeral heritage. }\end{array}$ & $\begin{array}{l}\text { route that connects } \\
\text { Maramureș to Moldavia and } \\
\text { is the highest pass of the } \\
\text { Oriental Carpathians. } \\
\text { Nonetheless WWI was not the } \\
\text { first episode of war in which } \\
\text { geography dictated the course } \\
\text { of military actions in the area. } \\
\text { The first known case of } \\
\text { invasion orchestrated through } \\
\text { the Prislop Pass dates back to } \\
\text { 1241 when, during the } \\
\text { Mongol invasion of Europe, a } \\
\text { Tatar formation descended } \\
\text { through the pass in } \\
\text { Maramureș. The Tatar threat } \\
\text { turned out to be long lasting } \\
\text { in the area as testified by the } \\
\text { war monument built on the } \\
\text { road connecting the Prislop } \\
\text { Pass to Borșa commemorating } \\
\text { the 1717 victory against the } \\
\text { Tatars. Hence the geography } \\
\text { and location of the Prislop } \\
\text { Pass defence line evokes and } \\
\text { re-utilises former war routes, } \\
\text { engaging and extending } \\
\text { existing engineer works to } \\
\text { serve war purposes. This } \\
\text { connects the war sites to } \\
\text { anterior constructions of } \\
\text { renowned historical } \\
\text { importance like the Romanian } \\
\text { wooden church destroyed by } \\
\text { the Tatars in } 1717 . \\
\text { The existent link between the } \\
\text { places of war and the Wooden } \\
\text { Churches of Maramures is } \\
\text { highlighted in the trail of the } \\
\text { influence exerted by by } \\
\text { geography on the historical } \\
\text { evolution of a place and the } \\
\text { deriving events that marked } \\
\text { the fate of its inhabitants. } \\
\text { Although, according to the } \\
\text { World Heritage List, the } \\
\text { outstanding universal value of }\end{array}$ \\
\hline
\end{tabular}




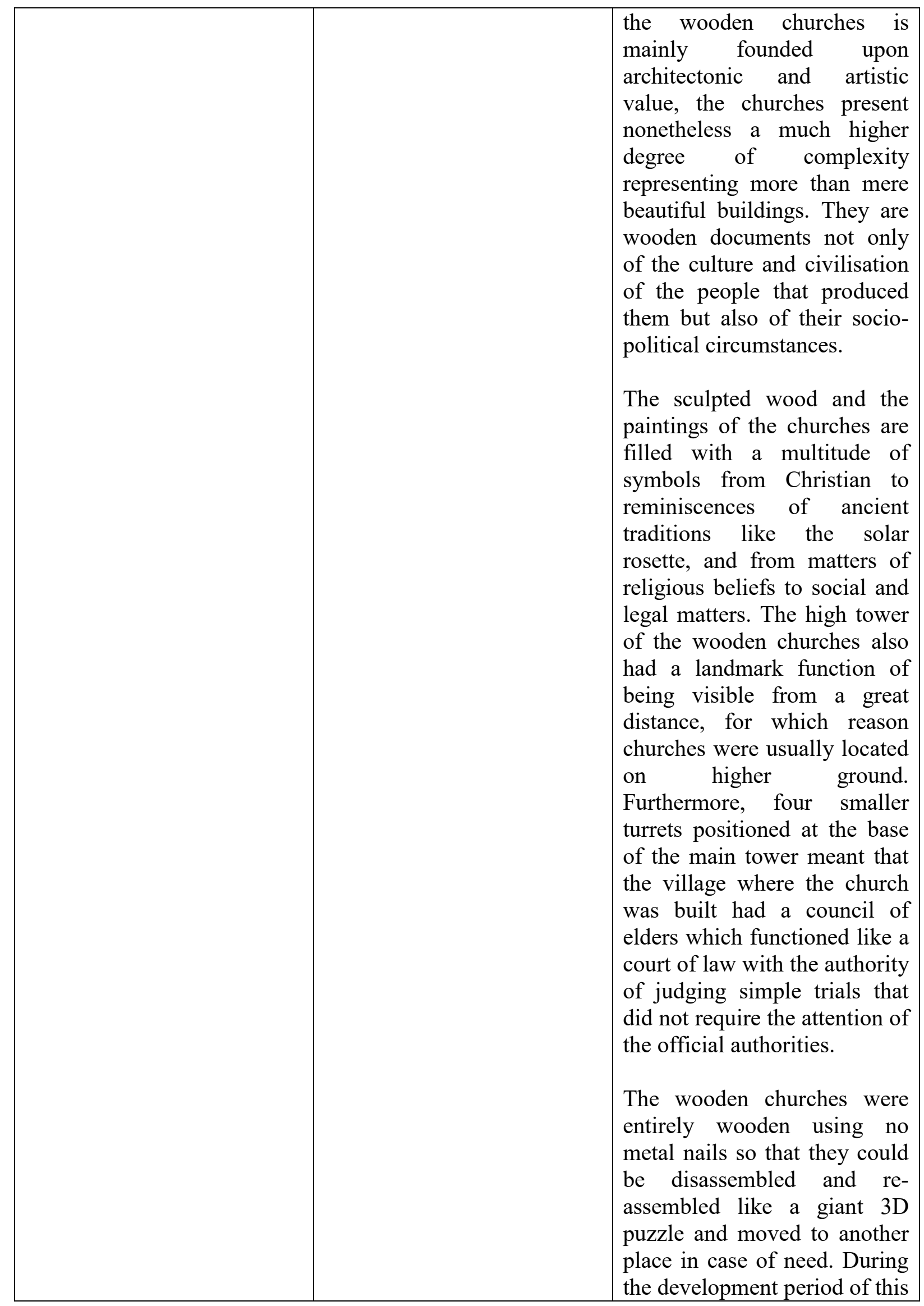




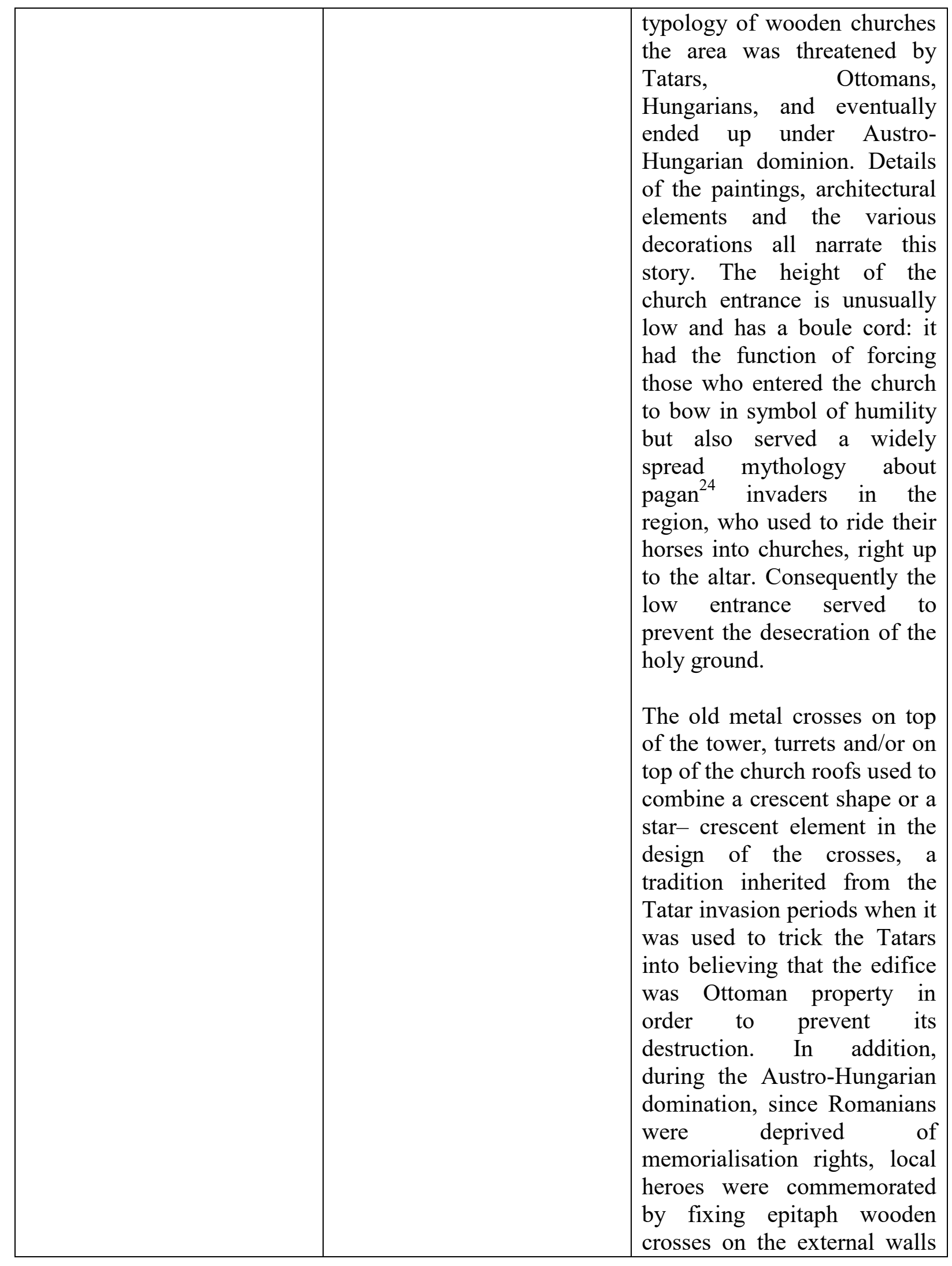

\footnotetext{
${ }^{24}$ All non-Christian believers were considered to be pagans, but in this case, it refers mainly to Ottomans and Tatars.
} 


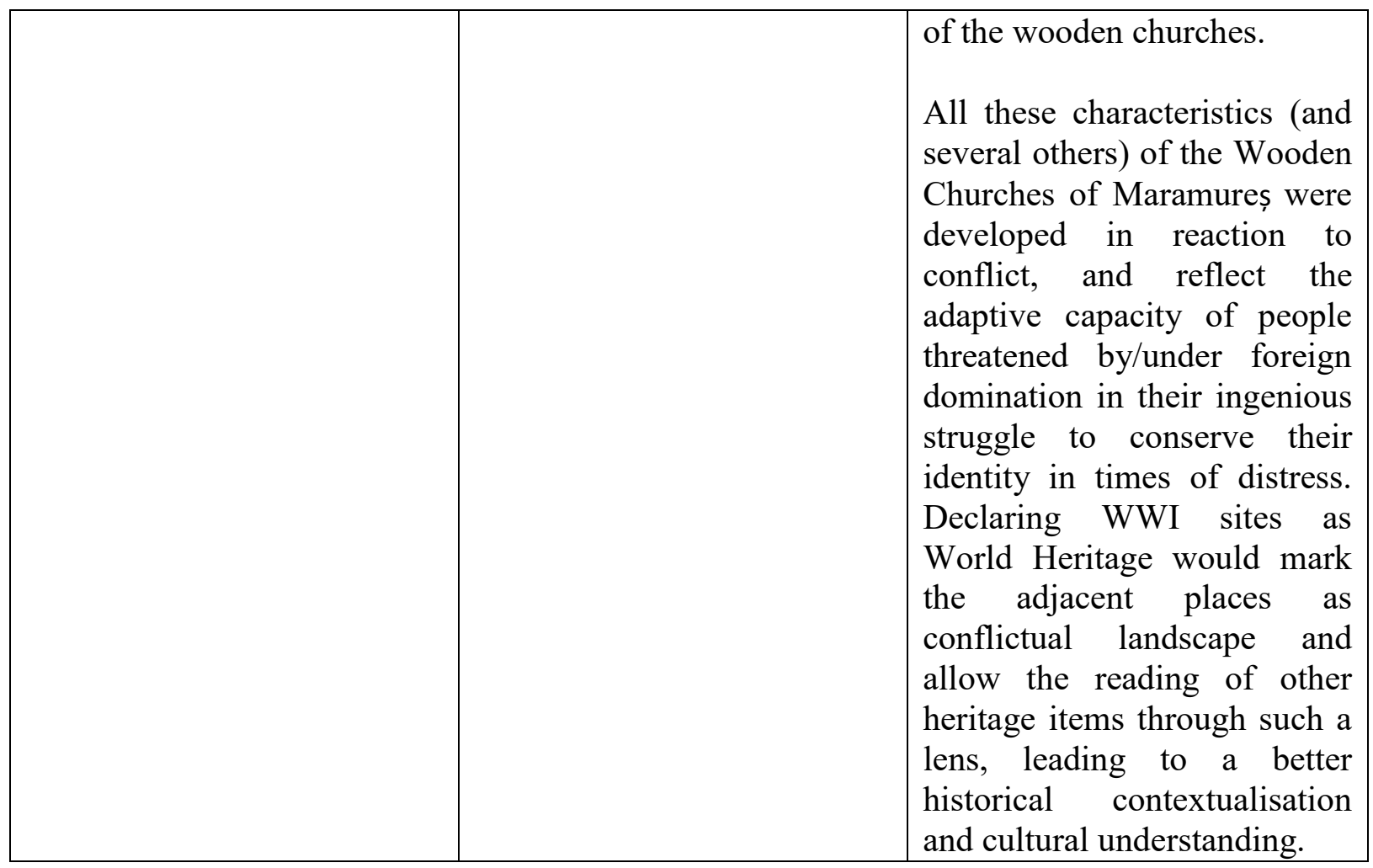

The existing differences between the presented cases derive from the focus of the approach taken to WWI heritage. While the French-Belgium case identifies memorials and funerary sites as holding outstanding universal value in relation to the Great War phenomenon, the Slovenian case presents a mix of memorials, military cemeteries, chapels, trenches and fortresses, while the Romanian case fixes its attention on a coherent conflictual landscape whose component parts were not only produced by the war but also during the war. The choice to study war sites that were direct products of the ongoing war phenomenon, on the one hand, serves the need to preserve authentic war sites for further study and, on the other, it is meant to highlight the memorial-symbolic evolution of places of war. Furthermore, the conflictual landscape also holds a monumental dimension beyond the scientific, architectural and memorial value, but one that eludes instrumentalisation and representation dilemmas due to its archival dimension which converts the war sites into a container of war documents, 
symbols and meanings. It is, in fact, the very lack of specific dedication to particular actors and state-driven rhetoric that bears the potential to convert the latent traits of the war sites into genuine, authentic and inclusive war monuments of outstanding universal value.

Other visible differences of focus, between the official nominations of the French, Belgian and Slovenian cases generated at state level and the hypothetic Romanian nomination generated at individual level, reside in the justification of value. Consequent to being state initiatives, the submissions of the first case are more concerned with being politically correct hence the emphasis is on the peace values, while the second, having a scholastic cut, is more concerned with being scientifically correct and significant hence emphasising historical, memorial, social and technical values. Nonetheless, the second position should not be perceived as disregarding peace values but, on the contrary, it serves to stress valuable lessons held by the material culture of war, whether or not there exists an international willingness to accept them.

Despite the multitude of potential approaches to WWI heritage, this infers that the war sites have the potential to meet international legal requirements of World Heritage standards. As far as the Romanian war sites are concerned it emerges that recognition of the universal value of the war sites is also capable of generating a better understanding of other World Heritage proprieties such as the Wooden Churches of Maramureș and of several other monuments of local importance. The comparison of the war sites with the wooden churches highlights the evolution of the requirements for World Heritage status at procedural level. It also emphasises how the factual recognition of plural levels of World Heritage value influences the overall understanding of World Heritage proprieties, which seem to manifest a tendency of mutual complementation by reciprocally augmenting their levels of significance and value. The assessment of the international value of the war sites against the background of the World 
Heritage standard enables the re-integration of the case study into the local-nationalinternational layer matrix while simultaneously emphasising solid interconnections between the various layers.

Furthermore, an inseparable relation emerges between the recognition of heritage status at national level and the international granting of World Heritage status. The official recognition of heritage worth at national level arises as a premise of the international official recognition of heritage value since it is the States Parties that initiate the World Heritage ranking process and since the granting of World Heritage status is dependent upon the existence of a viable protection and management system generated at state level. Consequently, the outstanding universal value of World Heritage is just as dependent, if not more so, on the economic and administrative capacity of the state as it is value reliant. The problematic subordination of the overall World Heritage ranking procedure to the administrative capacity for states to file successful nominations, hence factually putting political and economic strength above the exceptional universal value factor, betrays the basic principles that theoretically inform the World Heritage List.

The power-driven ranking process leads to an uneven representation of World Heritage in the World Heritage List which reproduces the power continuums of the developed countries in line with a western-centric approach, ending up greatly disadvantaging the so-called underdeveloped and developing countries - a label that is also a by-product of the western culture that does not necessarily reflect reality but cultural diversity ${ }^{25}$. As emphasised by Chapter 2, the socio-political circumstances created after WWII favoured the globalisation of

\footnotetext{
${ }^{25}$ The underdeveloped countries or developing countries of the world are only framed as such in relation to the standards of the western culture: they are only poor because evaluated against standards, norms, criteria coined by a culture different from their own and were persuaded to follow a development model which was not created for their cultural and environmental realities. It is basically the cultural expropriation and the imposing of sterile development path models that creates and perpetuates world poverty powering environmental disasters and instigation of conflicts.
} 
a version of heritage imbued with the values of the western culture. Hence the power-driven mechanism should not come as a surprise since it was mainly by means of international politics that the AHD was created and upgraded to the rank of UHD with a view to serving the cause of global heritage. It was precisely in reaction to such dimension of international heritage that scholars of the field raised concerns, warning that heritage as "symbolic representation of identity" (Smith, 2006, p.30) should always be thought of as plural as it produces myriad outputs and could never be relegated to a single cultural conception.

Results also show that the World Heritage ranking mechanism is interpretation sensitive since there are still no WWI sites with heritage status although, as accounted for previously, they are theoretically eligible. This reveals either a malfunctioning of the value ascription mechanism or the fact that it is ultimately the evaluation of the experts to decide the worth of places of war by assessment of their heritage value and interpretation of the criteria. This is made possible by the fact that heritage as inheritance from the past, meant to serve the future as a fusion of history, policy and identity, is officialised by a process of selection operated by society, by means of delegation of power to its representatives, with a view to highlighting the values it wishes to develop, negotiate and hand on to future generations. This further points the international heritage discourse towards questioning who interprets heritage worth and how that interpretation is operated, thereby narrowing the concept of World Heritage to the perception of the assessors of how the global cultural anthology should look.

The coagulation of the self-perception of the global society, like any other social phenomenon, is dynamic, making the significance of World Heritage liable to change and conferring to the UHD an inherently mobile predisposition. The sensitivity to broader social changes of World Heritage standards is accounted for by the evolution of the World Heritage List. This confirms that the countable tangible features used as criteria to assess heritage have 
no inherent value prior to the ascription of significance by people, and thus that heritage value is equivalent to the projection of social ethos onto the heritage object. It derives that in assessing World Heritage value the extrinsic factors - such as the assertion of heritage promoted by the experts - might end up weighing more than the intrinsic factors of the heritage object, such as social resonance, historic and scientific significance.

The counterweight to the downfalls of the World Heritage ranking process reside in acknowledgement that it is, after all, competition over attributing meanings through the reinterpretation of the past that fuels the motor of heritage worldwide. On this topic, it is worth mentioning that the decision of the UNESCO advisory bodies to turn down the FrenchBelgian nomination is understandable given the implications of re-iterating fragmented versions of the collective past, especially in absence of a counterbalance. In fact, this was the only nomination regarding WWI heritage that has so far been rejected on account of being interpreted as promoting militarism. Although the declared intentions of the submission made an effort to prove otherwise, its focus on military cemeteries and memorials, which were specifically created to honour and monumentalise military death and thus giving a dimension of grandeur to an otherwise tragic event, could indeed be interpreted as sending the wrong message beyond being quite common throughout Europe and elsewhere. The fact that, in the aftermath of WWI, nationalistic master narratives propelled war commemoration to the position of the spinal cord of the national state thus giving predilection to remembrance by means of large-scale memorials is widely known. It is also known that in time this practice translated into ostracisation of other memorial forms and remembrance categories, leaving no space for the consideration of actual war sites as holding potential monumental value. Nonetheless, genuine WWI sites, that is those not created to serve national reconstruction needs and propaganda purposes, but generated by the war and during the war for various 
practical needs and functions, elude the representation issues posed by standard war memorials. The war sites provide an authentic war memorial category which does not celebrate militarism but stands as a memento of what occurred, opposing an entire archive of material culture and memory to the instrumentalisation of the past, and thus holding outstanding universal scientific value beyond the latent memorial-symbolic value.

\subsection{Main findings}

As highlighted by Chapter 2, the dissociation of the events from the core context, and their presentation as fact of general validity supported by the scientific knowledge label, constituted the main binaries via which power and authority leaked into heritage. In order to avoid the instrumentalisation of the past international heritage needs to allow space for expression of the denied historical accounts, repressed memories and, hence, subdued knowledge in order to reach its purpose of reflecting the global past it claims to represent. It is exactly this aspect of heritage that legitimises systems of authority and social order on the basis of re-interpretations of the past, that is heavily criticised by scholars and must be overcome.

Hence, although a tendency to broaden the focus of WWI research beyond the limits of traditional approaches is forming internationally, the Eastern Front is still in need of receiving scientific attention and being re-integrated into WWI heritage. Excluding the legacy of the Eastern Front from the mainstream does not only undermine the importance of its memorialisation rights but also mutilates the war phenomenon by diminishing its true extension and overall meaning and ostracising its social emancipation dimension. Furthermore, stigmatisation of that conspicuous part of the past related to the untold stories of the Eastern Front and cleaving the historical accounts of the two fronts at 
international/European level constitutes an infringement of the FARO Convention on the value of cultural heritage for society. As highlighted in Chapter 7, the European common heritage frame introduced by the convention promotes "all forms of cultural heritage in Europe which together constitute a shared source of remembrance, understanding, identity, cohesion and creativity, and the ideals, principles and values, derived from the experience gained through progress and past conflicts, which foster the development of a peaceful and stable society, founded on respect for human rights, democracy and the rule of law" (FARO Convention, 2005, art.3) with the aim of enhancing inter-cultural understanding, mutual confidence and respect. It follows that the suppression of a fundamental page of European history connected to the national emancipation of several East European states as a consequence of the fall of the empires at the end of WWI, which equalled the freedom of several peoples, the creation of democratic premises and the implementation of human right principles in East European societies after centuries of oppression, would stand against all the principles that theoretically inform international heritage legislation and more.

The fact that heritage does not represent the sum of the things it curates, but rather condenses the memory of the things that are to be remembered as an antidote against identity loss and cultural alienation, makes heritage a catalyser of social and cultural movements. Furthermore, the filtration of the past through the lens of the existing social ethos informs the construction of historical awareness at a given time and place engendering a perpetual re-iteration of the sites of memory. On this path, growing global claims to memorialisation rights flourished in the fertile field provided by the development of new international mentalities, gradually making heritage significantly open to inclusiveness. The human rights trend gave voice and space for expression to plural, alternative memories/histories that concur together in reflecting a more authentic re-iteration of the past. Against such a framework the latent memorial and 
commemorative spectrum of the Prislop Pass war sites arises as an argument in favour of the legal recognition of the heritage value of the places of war, which would allow their preservation and study.

Furthermore, the maturation of the remembrance process, which has evolved from being social to cultural, has brought about the necessity to reflect upon war phenomenon considering the entire areal of meanings, ambiguities, contradictions, implications and actors embedded in the surviving material culture of WWI. Engagement of the material culture of the past as part of the present provides a bridge to understanding of the alienated past by decoding both tangible and intangible features of the material remains and bringing new perspectives on human and natural landscapes.

Understanding the true nature of the industrial war becomes even more important against the fact that it was the unprecedented violence and destructive capacity of the world wars that promoted international heritage practices to a global concern. The fact that the contemporary international heritage framework emerged in reaction to conflict brings about the necessity to start supporting the materialisation/manifestation of an international heritage space able to contemplate war voices that, for various reasons, were silent up to the present day. The plural heritage spectrum characterised by the existence of simultaneous scales of heritage ranging from local to national, regional or global, and various levels of dissonance in time and space, became the norm for contemporary assertions of heritage. Hence, the stigmatisation and exclusion from the international heritage mainstream of conspicuous parts of the collective past is no longer acceptable and calls for reconsideration. The international legislative evolution, which shifted heritage focus to the binaries of cultural significance and social resonance, provides fertile ground for the re-integration of WWI sites into the frame of World Heritage as carriers of a plurality of meanings and values displayed within a multitude of 
physical, mental and emotional layers that project snapshots of history and memory from the past into the present.

The fact that the places of war meet current heritage criteria both at national and international level brings support to the urgency for dealing with their heritage status at official level. The need for official recognition of the war sites' heritage status becomes imperative as a consequence of the vulnerability of the conflictual landscape in absence of a legal protection frame. Although changes brought about in the international heritage debate have led to overcoming the rigidities of the institutional heritage framework and the top down heritage approach, the legal normativity that legalises, objectifies and authorises heritage remains indispensable for imposing viable preservation practices in countries such as Romania.

The strong existing bonds between international and national legislation becomes manifest in the international conventions and agreements that are sanctioned by a state, and which translate into national heritage practices and regulation. Therefore, on account of the heritage national-international legal intersections, Romania has heritage obligations of international emanation that make legal protection of the war sites not simply in line with the prescriptions of national heritage legislation but also compulsory in order to avoid trespassing the ratified international heritage regulations. Hence, not only under current Romanian legislation should the war sites be granted heritage status and thus have the benefit of legal protection, but there is also an imperative need for doing so to fulfil Romanian international heritage obligations, particularly those prescribed by the Paris Convention on the Means of Prohibiting and Preventing the Illicit Import, Export and Transfer of Ownership of Cultural Property (ratified by Romania in 1993) and by the 1995 Rome UNIDROIT Convention on stolen or illegally exported cultural objects (ratified by Romania in 1997). That is because, by not declaring the war remains as heritage, the illegal traffic of war relics is encouraged due to the law having no 
jurisdiction over objects whose heritage status is not officially regulated. Consequently, state authorities cannot prevent any interventions on the war sites, stop excavation or claim rights over fortuitous archaeological discoveries related to war remains, especially since the world wars are not considered archaeological domain and war sites in general are disregarded as archaeological objects of interest. Hence, it is impossible to prohibit the expropriation of elements pertaining to the material culture of war, although some of the concerned objects are more than a hundred years old and according to international legislation qualify as antiquities. Nonetheless, several such items, such as WWI Prislop Bahn badges end up being sold on auction sites, which is in obvious contrast to the prescriptions of the international regulations quoted previously.

Disregarding the war sites as heritage also goes counter to the 1992 Valetta Convention (ratified by Romania in 1997) set to foster archaeological heritage as promotor of the collective memory of the old continent and as an instrument for scientific/historical study. Besides restating the importance of preventing archaeological traffic and demanding the compulsory reporting of fortuitous discoveries, the convention specifically prescribes the identification of archaeological heritage, the promotion of public awareness and the preservation of archaeological reserves for future study as obligation of the States Parties. Similar measures were also promoted by the 1972 UNESCO Convention Concerning the Protection of the World Cultural and Natural Heritage, adopted by Romania in 1990. The 1972 UNESCO convention highlighted the role held by the states as guarantors of the safeguard of cultural and natural heritage, which in such a capacity, are responsible for actively engaging in the identification, protection, conservation, presentation and transmission of heritage to future generations. Additionally, the lack of protection of the Prislop Pass conflictual landscape at national level disregards the prescriptions of the European Landscape 
Convention (ratified by Romania in 2002), which specifically prescribes the protection of landscapes in the assertion of places built up by the conjunct actions and interactions of anthropic-natural factors ${ }^{26}$, especially if holding outstanding value or presenting tendencies towards degradation. Furthermore, the Romanian national development strategy has already confirmed that the landscape is one of the most endangered categories of heritage and subject to an accentuated process of degradation in developing rural areas, especially in emerging touristic destinations such as Maramureș and Bukovina.

Synthetically, the observation of the prescriptions of the international heritage regulations subscribed to by Romania turns out to be of fundamental relevance against the threats that impend over the physical survival of WWI material culture in absence of state regulations specifically oriented towards the protection of war heritage. Preservation of the Prislop Pass war sites became precarious in context of the development boom that took place in the region in recent times bringing about the urgent need to officialise its heritage status. The legal recognition of the heritage status of the war sites is a sine qua non condition for protection and preservation of the sites under current legislation and despite the obsolete national common laws regarding archaeology.

Having discussed the implications of the results, these all draw together to address the question of the significance of Romanian war sites as places of remembrance and heritage. The research highlighted that the Prislop Pass material culture is exceptionally well preserved compared to most of the Western Front. It is a landscape scale issue, not a site-specific site matter, that fits into heritage legal prescriptions both at national and international level but, as it stands, is currently under threat. It also emerged that the conflictual landscape holds a great

\footnotetext{
${ }^{26}$ The Mountains that surround the northern side of the Prislop Pass and hence the research area are part of the Maramureș Mountains National Park which is part of the Natura 2000 network.
} 
deal of significance at local, regional, national or international level by anchoring an entire archive of war phenomenology that concurrently shelters the actions, goals, mentalities, the dreams and dramas of individuals, institutions, nations and supra-national alliances. The war sites simultaneously encapsulate the human dimension of the war, the technological breakthroughs and innovations, the war typology and military specificity, the historical military and political personalities relegated to the place, the fall of the great empires, the reconfiguration of international balances of power, the fight for freedom of Eastern European nations, the international affirmation of the principles of nationality and self-determination and hence the roots of a new international mentality and world order.

The study of the Prislop Pass war sites also has implications for the broader field of research in conflict archaeology, heritage and memory studies. As far as conflict archaeology is concerned the working method showed that meaningful archaeological research into war remains can be conducted by non-invasive means. In fact, although excavation is always tempting for a field professional and in some cases may be compulsory to elucidate definite aspects such as dating, the specificity of the research area demonstrated that in some cases it is better to leave the sites undisturbed as conducting invasive research could cause further deterioration and destruction of the sites, not to mention the encouragement of looting in absence of legal protection. Additionally, it emphasised the need to look at war architecture as a specific form of man-constructed environment that reflects the specificity of the industrial war that brought about the international metamorphosis of traditional approaches to warfare.

The work formed an instrument for study of the material remains of war in a landscape perspective that can be used as a pilot project for studying the material culture of war on the Eastern Front as well as other fronts. Not only can the employed methodology be extended to the study of various fronts and various conflicts, for that matter, but it can also be employed 
to prompt thinking about other categories of unrecognised heritage that are not necessarily related to conflict. The fact having emerged that the international recognition of heritage is dependent upon its framing as heritage at national level highlights an important contribution of the present work to heritage studies in general, even outside the outreach of conflict archaeology. It opens a window to testing the heritage potential of unrecognised heritage regardless of its nature and provenience or location. All countries have some sort of heritage legal systems and are interconnected in one way or another to the international heritage legal frame, hence the deriving regulations and standards can be used to assess the worth of heritage against the background of national and international legal criteria, and to test the heritage potential of yet unrecognised heritage.

All in all, the work conducted with a view to answering the research question ended up doing much more than simply that. It did not only provide an answer to a pressing issue elucidating the significance of the war sites as place of remembrance and heritage, bringing a contribution to the work of the authorities that have the responsibility of deciding their fate, but it also contributed to the broader field of research and to anyone interested in the study of war remains, conflict, or other forms of so-far neglected potential heritage whatever materials it contains and wherever situated. The research also flagged up the importance of the landscape scale of heritage in relation to the study of conflicts, bringing about the need to question the way war heritage is approached and managed both nationally and internationally. All this opens a whole new path for future research on account of the fact that recent international heritage legislation has largely promoted the concept of landscape heritage. The explicit prescription of the landscape-scale approach in relation to particular kinds of heritage, and the overall absence of landscape-scale archaeological works, show that in practice the landscape approach is still insufficiently applied. From a scholastic perspective it implies that the 
heritage landscape concept is either insufficiently operationalised to produce concrete effects, particularly in relation to cultural heritage, (in terms of natural heritage the landscape approach is majorly applied) or that concurrent interests such as development priorities are given major importance, linking back to the issue of the prevalence of the political-economic factors over the actual heritage value factor discussed in Chapter 2. Regardless of the potential cause, the above aspects are yet to be explored opening exciting new opportunities for research.

The landscape approach also raises the need to develop new approaches to preservation and hence to research. Heritage as a landscape-scale matter implies the preservation of remains in loco which raises the question of how to study the materials without causing damage. For instance, in the case of a common grave, should excavation be conducted and, if so, what is to be done with the remains? If no one claims them and they are replaced in a beautifully constructed military cemetery wouldn't their voice be silenced, and their story lost to the world? If extracted from the land and relocated wouldn't the materials lose the value derived from their overall significance in that specific context and wouldn't the complex interrelations amongst them be annulled? The above questions, and several others, are stimulated by the present work; therefore, it does not only fill a gap in our knowledge of the war but also contributes towards the filling of others within a larger perspective by bringing the attention of scholars towards such matters.

\subsection{Implications}

Tangible and intangible dimensions of the Prislop Pass war remains emerged from the collective display of the overall results, allowing their reading as heritage. The bunkers, the trench systems, the graves, the railway embankments, the building foundations all concur in 
narrating a fascinating multi-facted war story and as such should not be regarded merely as what they are physically but as what they represent (Carman, 2009, p.192). On this subject, the material characteristics of the studied war sites are containers of a wide set of war data ranging from general war information concerning logistics, strategy etc., to memorial functions, national symbolism and local/regional/international significances. Table 5 reports and explains the various layers of significance held by the studied war sites at different scales.

Table 5. Layers of significance of the Prislop Pass conflictual landscape

\begin{tabular}{|c|c|}
\hline & Levels of significance of the war sites \\
\hline $\begin{array}{l}\text { LOCAL/ } \\
\text { NATIONAL/ } \\
\text { REGIONAL } \\
\text { LEVEL }\end{array}$ & $\begin{array}{l}\text { In Romanian culture the several categories of war materials building up } \\
\text { the war sites and adjacent landscape bear testimony to the memory of } \\
\text { the Great War and its highly symbolic power that materialised in the } \\
\text { Grand Union national narrative. The Great War and the Great Union } \\
\text { share intimate interconnections featuring a leitmotif of Romanian } \\
\text { historiography. The conflictual landscape evokes re-iteration of the } \\
\text { most sacred goal of the Romanian people - territorial unity and } \\
\text { national emancipation - and summons remembrance of the most } \\
\text { significant episode of Romanian national history. } \\
\text { The morphology of the Prislop war sites emphasises the role played by } \\
\text { geography in the Romanian quest for freedom and national unity during } \\
\text { WWI and during the historic process of national emancipation. If, on } \\
\text { the one hand, the geostrategic position ultimately aided the fulfilling of } \\
\text { the political motifs that motivated the Romanian involvement in the } \\
\text { Great War, on the other, geography was one of the primary reasons that } \\
\text { made Romanian territory vulnerable to foreign domination due to its } \\
\text { position at the edge of the great empires. In fact, the war sites are also a } \\
\text { reminder of the fact that it was the territorial positioning of the nations } \\
\text { of the Eastern Front in the centre of imperial interest zones that marked } \\
\text { the fate of the peoples before the war and thus fuelled initial } \\
\text { engagement in the war of the multiple nationalities of the empires. } \\
\text { In congruence with the above, the visible traces of war - the bunkers } \\
\text { and earth works, the military road, the remains of the historical } \\
\text { buildings, the military cemetery and common graves, the trench } \\
\text { systems - of the highest pass of the Oriental Carpathians highlight the } \\
\text { strategic position of the early route that connects Maramures to } \\
\text { Moldavia. The rebuilding of the Prislop Pass defence system during } \\
\text { WWII as part of the Arpad line provides evidence of the world wars' } \\
\text { continuum within the same environmental settings. Re-ignition of the } \\
\text { same conflictual sparks between the liberated nations and the } \\
\text { successors of the imperial powers demonstrates that although the end of } \\
\text { WWI temporarily sedated international tensions it did not present a }\end{array}$ \\
\hline
\end{tabular}




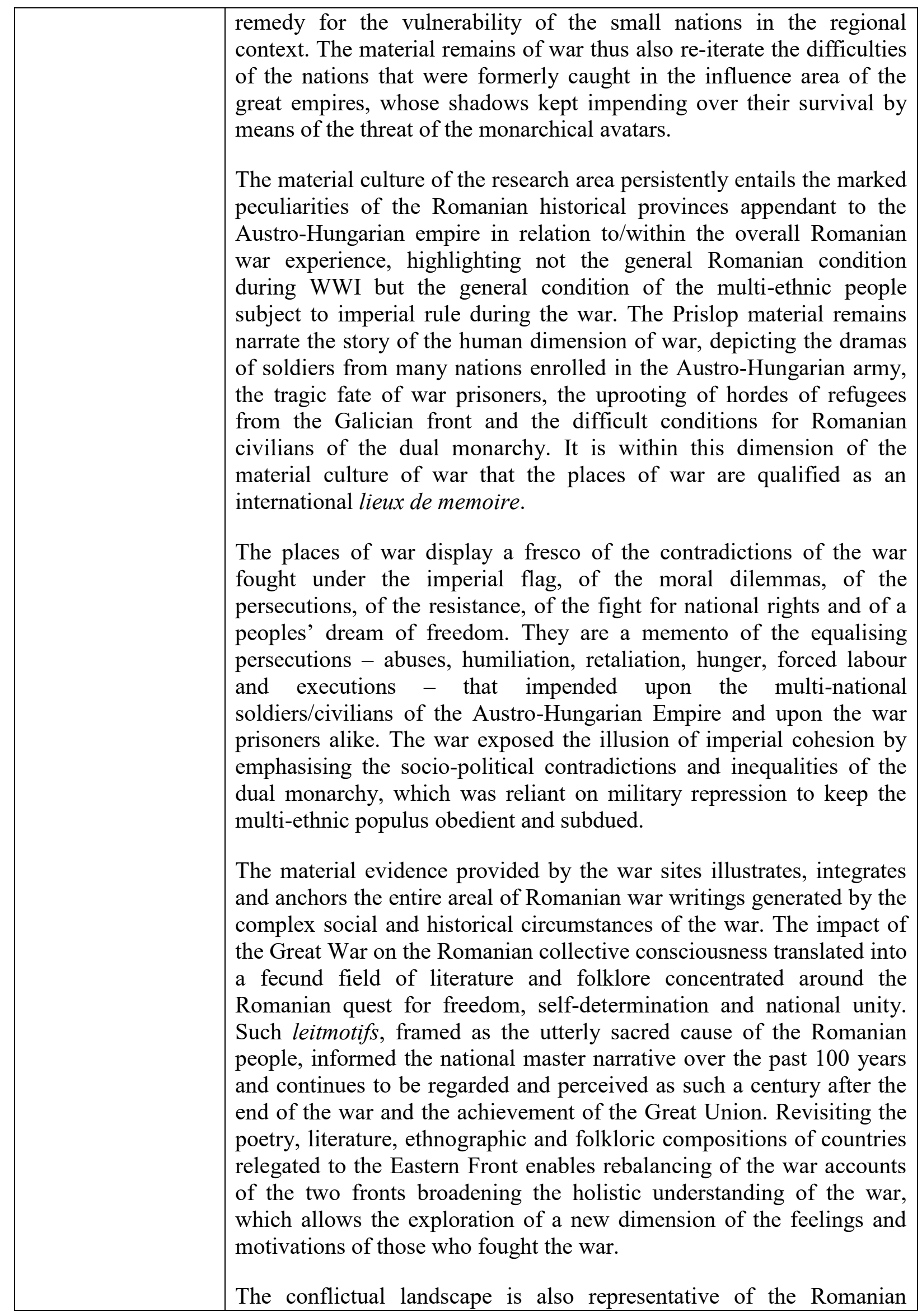




\begin{tabular}{|c|c|}
\hline & $\begin{array}{l}\text { traditional assertion of freedom that was intimately connected to and } \\
\text { envisioned in communion with the dimension of the land. It was the re- } \\
\text { appropriation of the ancestral land that, in the Romanian vision, } \\
\text { incarnated materialisation of the achievement of freedom and self- } \\
\text { determination and, thus, of national rights. For countries such as } \\
\text { Romania, the recovery of the lost territories constituted the main reason } \\
\text { that fuelled their involvement/participation in WWI as the land } \\
\text { perceived as pater patriae personified the guarantee of their national } \\
\text { rights framing WWI as the last 'land' war. }\end{array}$ \\
\hline $\begin{array}{l}\text { INTERNATIONAL } \\
\text { LEVEL }\end{array}$ & 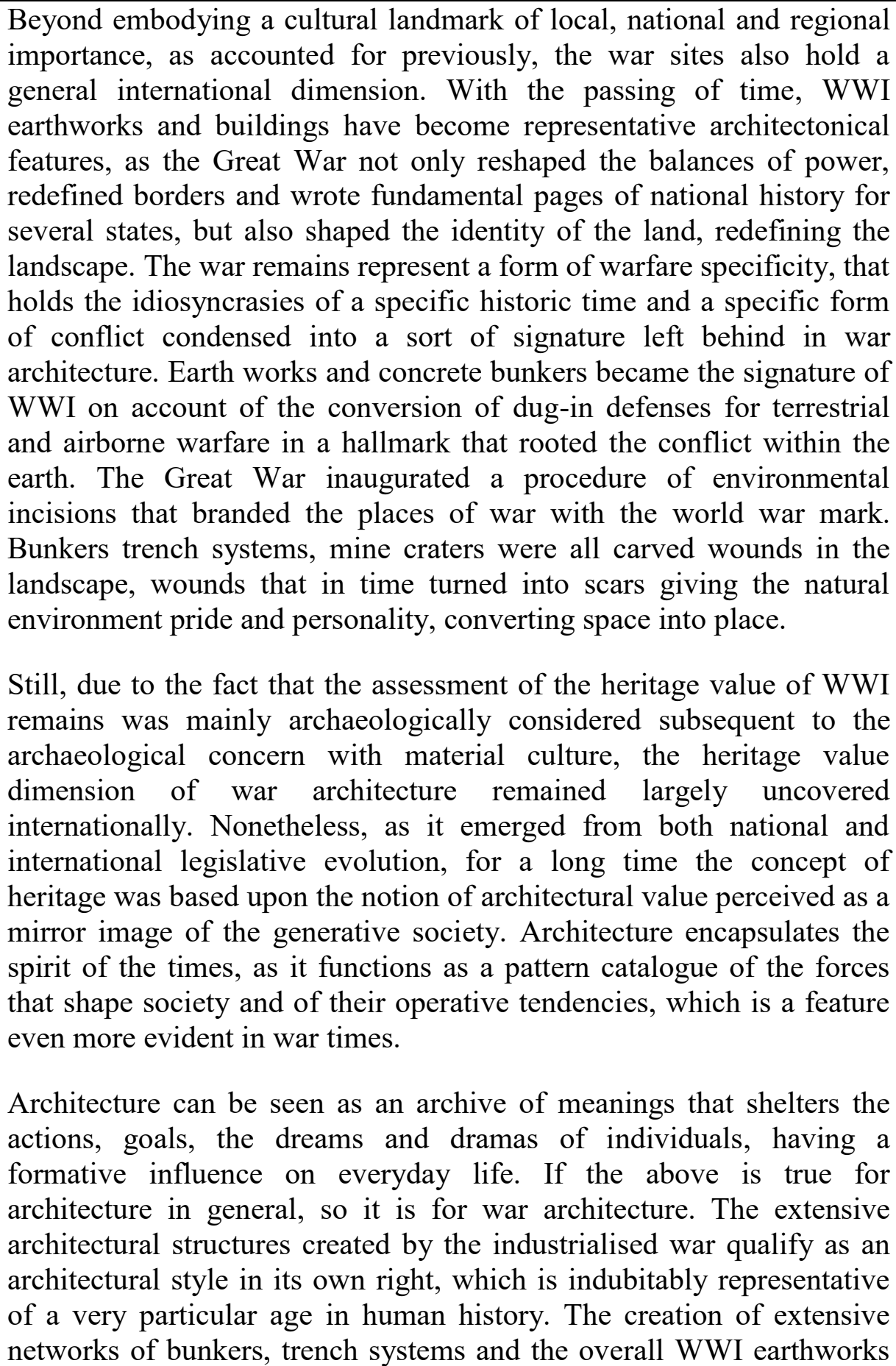 \\
\hline
\end{tabular}




\begin{tabular}{|l|l|}
\hline are symptoms of a metamorphosing world which, now cumulated to \\
their hundred years of age, brings about the need for re-evaluation. \\
Although, so far, there has been a firm belief that the architecture of the \\
industrial war was plain, ugly and impersonal, such an architectonic \\
style is not as automatic as one might think, and it is nonetheless \\
illustrative of a particular transition in human history and of a specific \\
age in human evolution. Life goes on during war times, and war sites \\
also narrate a story about how life is reorganised and adapted in times \\
of conflict in addition to encapsulating warfare knowledge and the \\
added value of remembrance. \\
$\begin{array}{l}\text { Architecture, as all other heritage objects, has no value of its own; its } \\
\text { value is derivative of the meanings attributed to it, symbols it bears, } \\
\text { both consciously and unconsciously, associations it raises and the } \\
\text { interpretation it evokes. The spatial structures of society speak not only } \\
\text { of potential uses but also of wealth / poverty, } \\
\text { individuals/institutions/organizations. In accordance with the fact that } \\
\text { the changes that the building styles undergo mirror changes that occur } \\
\text { in broader society, it is high time to start reflecting upon what cultural } \\
\text { values are embodied in WWI architecture. By "taking into account the } \\
\text { role played by man as an agent of landscape change"(Sharpe, 1986, } \\
\text { p.54) we can approach war sites as cultural artefacts that encapsulate } \\
\text { the untold stories of a past world. }\end{array}$
\end{tabular}

This infers that the war sites have several concurrent levels of significance that inform plural remembrance functions of local, regional, national or international scale. It is not about the intrinsic value of a pile of concrete or a hole in the ground but about what lies behind, what they evoke and stand for. Dependent upon the perspective taken, the conflictual landscape evokes different dimensions of the war phenomenon from the multiplicity of overlaying layers. The places of war display the everlasting story of the Great War, simultaneously encapsulating the human dimension of the war, the technological breakthroughs and innovations, the war typology and military specificity, historical military and political personalities relegated to the place, the fall of the great empires, the fight for freedom of eastern European nations, the international affirmation of the principles of nationality and self-determination and hence the roots of a new international mentality. 
Both national and international heritage are intimately connected to the dimension of collective memory. As collective memory is vital for building social cohesion by means of national master narratives at state level, so it is at international level by means of a so-called global culture which translates into accepted international practices, mentalities and traditions. In fact, there are a plurality of memory scales that function simultaneously, both nationally and internationally, and which are particularly evident in symbolically charged heritage such as WWI sites. The fact that the war sites encapsulate multiple social, cultural and political significances opens a window to understanding the plural versions of history that have informed the creation of present European identity and culture. The multiple historical perspectives displayed by the war sites promote the holistic complexity of the total war, as opposed to the historical fragmentation characteristic of the history of the winners and the politically significant. The recognition of the heritage value of the war sites promotes the core contextualisation of the Great War while concomitantly discouraging the proliferation of a dangerously selective version of the past. Through this lens the places of war and the overall conflictual landscape represent authentic memorial sites as they provide a genuine allinclusive category of memorials that are able to gather highly diversified memories and commemorate a large spectrum of actors.

The complexity of the war sites demands diversification of the angles and perspectives that inform the scientific study on which heritagisation relies. One of the most important significances of the first world conflict, which was mostly minimised up to the moment, is that WWI presented the foundation of a new international mentality whose by-products eventually concretised in the age of human rights and of the theoretical abolishment of war as an instrument of international relations which incarnate the very cornerstone of present societies. The fact that a conspicuous part of those involved in the conflict fought for freedom, 
self-determination and for gaining long-denied national rights gives the war strong social connotations that go beyond the rhetoric of the political ambitions of the militarily powerful states. Acknowledging that the industrialised war was fuelled by a historical process of national emancipation that, although it had reached maturity at the time of the war, started developing well before that time and way beyond the borders of the liberated nations, as outlined in Chapter 4, opens new perspectives on the war phenomenon.

At European level there is an uneven representation of WWI in terms of scientific studies which mainly focused on a small number of western countries such as France, Belgium and Britain. The operation of a forced dissociation of the various fronts, as if they were distinct phenomena, leads to creation of a fractal camp of knowledge marked by the mutilation of the war phenomenon. As shown in Chapter 4 there was a great amount of interaction between the Eastern and Western Front as the war was not carried out by pieces of land but by people, a conspicuous portion of whom unwillingly peregrinated between various fronts as a consequence of being imperial subjects. Underestimating the importance of this aspect favours the proliferation of an unbalanced and unrealistic version of the re-iterated past. Integrating the war heritage discourse with the legacy of the Eastern Front would rebalance the war knowledge and benefit its overall understanding.

Recognition of the heritage value of the war sites enables the preservation of a myriad of layers that were authentically built in time and by time in a monumental memento of WWI symbology and phenomenology. The monumental dimension of the conflictual landscape avoids the speculation of power continuums in heritage and eludes the propagandistic interpretation of the past that so frequently impends on classic war memorials. Hence, in a way, the work also explored the concept of monumental landscape bypassing the selective 
commemoration of historically representative characters, fallen soldiers or local heroes and shedding new light on the war itself with all its peculiarities and contradictions, and hence filling a gap in the memorialisation of the war. Moreover, it provided a timely solution to contemporary memorialisation needs that claim plural representation rights in line with an internationally amounting social ethos. By reflecting the challenging dynamics of conflict in all their typical compounds of spaces and people, revealing multiple stories of land, soldiers, military leaders, local civilians and war prisoners who all come together, intersect and inhabit the same places, the war sites have the ability to answer such needs. The Great War was a complex phenomenon whose call to arms echoed in both masses and individuals, soldiers and civilians, a summons that gathered and collided empires, nations, armies, weaponry, humans, animals, all within the landscape framework. It is, therefore, only in the context of the above apotheosis that the memories of WWI can be reconciliated and allowed to achieve their wholeness by mutual completion.

\subsection{Future research}

In line with the above, the work has emphasised the need to create a network of WWI sites, preferably integrated with WWII remains, extended at least to European level. It is important to create a network of world war sites which gathers together all known sites in an integrated frame that is widely accessible to researchers, heritage practitioners and the civil society in general. A potential solution would be the creation of a free of charge mobile app that would allow the recording of the war sites (including geographic localisation, photographs and a brief description of the material remains). As a consequence of my research I am personally working on developing an application - SOS WORLD WARS HERITAGE - having the above characteristics, which, once made available and populated with data, would provide valuable insights on the extension of the war phenomenon in Europe and elsewhere, providing 
a valuable resource for future research. The mobile app has been conceived as a handy instrument for the management of war sites, since anyone who comes across a site can check in for location, upload some pictures and make a brief description, so populating the network with data free of charge. Any interested scholar would thereby have an online archive available as a basis for further investigation. In time the crowd-source supported network would develop, revealing the real extent of the world wars and opening a whole new area of possibilities for research, researchers and overall understanding of the world wars. The network has the potential to reveal the extent of the wars on various levels: the number of sites still available, the nature of the environmental settings in which they survived, the interacting influences, and the way in which they map together to build that holistic dimension of the war phenomenon that we are currently lacking. This would be an important step in international research because, for the time being and as far as the study of WWI is concerned, only dissociated research of separate sites is available, the individual cases are not able to reflect the essence of the war phenomenon, and the Eastern-Western Front approach fails to consider the intimate interconnections between the fronts and excludes the so-called secondary fronts.

Conclusively, although the present research dealt with Romanian WWI sites in a heritage perspective and its main argument was concerned with the exploration of their significance as places of remembrance and heritage, the work has implications far beyond the study of WWI heritage. The research approach turned out to be potentially valuable for the assessment of the heritage value of yet unrecognised heritage. In this perspective, the overall results of the work exceed the matter of the material culture of war and conflictual landscapes extending to other kind of materials that are not currently protected but which could be assessed as heritage by applying the developed methodology. By opening a window onto one particular type of 
heritage that has been assessed against all criteria prescribed by current heritage regulations in accordance to the accepted ranking procedures and showing that it does qualify as heritage, hence is implicitly worthy of protection, the research has raised broader questions about unrecognised heritage, such as WWII remains or other categories of materials pertaining to the realm of conflict archaeology or surpassing the interests of the field. In fact, if the case for the heritage worth of WWI sites can be argued, then it is probable that by relying on the same methods a different case in a different location can be explored as heritage. There is a large quantity of unrecognised heritage and it becomes clear that the method developed by the thesis can also be used to prompt thinking about diverse types of heritage.

\subsection{Conclusions}

In recent years growing interest in wartime heritage has mounted internationally. Despite the growth in interest about WWI material culture, the Eastern Front has remained scientifically unapproached from this perspective, resulting in the lack of heritage recognition of identified war sites. The research presented in this thesis addressed the problem by exploring and presenting the case of Maramureș against the standards of national and international heritage. The work provided the first ever survey of WWI sites on the Eastern Front, showing that the Prislop Pass conflictual landscape holds undeniable national and international heritage value both in terms of physical preservation and in terms of mapping on the memorial-historical record. The war sites demonstrate heritage and remembrance value, meeting heritage criteria on account of their preservation state, rarity, authenticity, research potential, embedded war knowledge and historical-memorial functions. The results of the research established the heritage value of the war places, which, if officialised by law, would entitle the sites to legal protection. Furthermore, it emerges that the war sites not only satisfy heritage legal requirements at various levels but are also endangered. Hence the threats that impend upon 
this valuable, but as yet unrecognised, heritage calls for urgent measures to officialise legal heritage status and thus assure its preservation. In addition to elucidating the significance of Romanian WWI sites as places of remembrance and heritage, the research has identified a new coherent scale of WWI heritage research, coining the notion of conflictual landscape, and hence approaching a category of war heritage that had remained unexplored.

Concurrently, the results of the research hold implications towards the recognition of the war sites as being of World Heritage status, by providing evidence of their heritage worth in accordance with the World Heritage List standards and procedures. The war sites have international significance as WWI was a global event that influenced the course of history by posing an end to a world order and setting the foundations of another. Although WWI turned out not to be the war to end all wars it did certainly redefine warfare, ended one age of human history and introduced another ruled by different laws and beliefs, both in peace and war. By reshaping the international balances of power, the Great War crafted the foundations of the ideology/mentality that forms the very basis of the world we live in and which provided the condition for the international manifestation of heritage as a global concern. The framework of the international heritage conventions stands as a proof of the above, as many conventions were adopted in reaction to the utter violence and destruction of the new forms of conflict that stemmed from the total war.

What makes this war unique is that, in addition to being the first global conflict, WWI brought to conclusion a previously matured historical process triggering the formation of our world. Hence it is widely relevant, because it was not significant for merely one or two states, although the level of significance might vary from one place to another, but it holds global significance due to the collateral implications it exerted even on states and cultures that were 
not directly involved in the conflict. It follows that all these aspects entitle the material culture of WWI to the title of World Heritage status in line with its overall complex significance.

The Great War provides a fundamental aspect of European common heritage and one that until now had not been thoroughly approached. The case study provided by the research offered evidence of the many dimensions and layers of significance which hold importance to several categories of actors at several levels and which, if approached holistically, inform a broader understanding not just of the war phenomenon but also of the present-day European identity. Furthermore, the research highlighted how the inclusion of WWI sites in the World Heritage List would aid understanding of other World Heritage proprieties such as the Wooden Churches of Maramureș. WWI sites can also be approached as markers of historically contended territories, clearly one of the causes of the war, complementing the understanding of other forms of heritage in their proximity. The war sites are authentic forms of expression of all dimensions of the war that generated them, encapsulating great scientific importance for understanding the war phenomenon, its causes and implications. They constitute earth documents and live testimonials, unaltered by human propagandistic intentions or the needs of social reconstruction, which reflect the condition of a given territory at a given time and its interconnections with other places against the background of a conflictual state.

What emerges is that the inclusion of WWI sites in the World Heritage List would assure a reasonable representation of the complexity of the war and allow its proper understanding by providing a mosaic of cultural traditions, national interpretations and historical accounts. In doing so it would reflect the global dimension of the war, avoid the international proliferation of unequal war accounts, prevent mutilation of the overall significance of the war 
phenomenon by means of over-representation of certain fronts and under-representation of others, and avert the alienation of the intimate interconnections between the fronts. Moreover, is only recently, as a consequence of the new international ethos that the world has rejected war as a primary tool of international relations. Wars, especially wars-of-conquest, were the norm throughout historic times and only having witnessed the price of the new wars persuaded humanity's most belligerent nations to convert to pacifism. Denying the universal heritage value of war sites on account of their supposedly promoting militarism not only contradicts the legal prescriptions of World Heritage but also deprives humanity of reiterating a fundamental page of its recent history that should never be forgotten, especially as memory becomes an historical domain. Nevertheless, as highlighted by the present research, there are some downfalls to the operationalisation of World Heritage standards, such as heavy reliance of the ranking mechanism on the political-economic capacity of the states which may result in unequally representations of the material culture of war and, therefore, of the war legacy. It infers that, for the moment, it is up to scholars and responsible heritage professionals to deal with the issue of war sites as places of remembrance and heritage.

Briefly, from the literature review it emerged that East-European war sites have neither been considered archaeologically nor in a heritage perspective, and there is a noticeable lack of studies regarding the Eastern Front in this regard. Chapter 3 constructed a method to address and fill such a gap. Assessed against the background rendered by heritage legislation, the chosen case study proved that the war sites meet both national and international heritage criteria and hence are liable of official heritage status if the law was to be applied. The fact that they map onto the border heritage discourse, on the one hand, infers that the war sites should be regarded and approached as heritage and, on the other, advocates the need for further research on the Eastern Front and other secondary fronts. The further investigation of 
these fronts would answer a need to complete the Western Front perspective and provide a fuller account of the war in terms of phenomenology and of memory.

The limitations in our knowledge of the war brought about the necessity of taking different perspectives on the material culture of conflict. The present research brings a valuable contribution to the study of WWI by integrating the story of the Western Front with the legacy of the Eastern Front. The alterity of the research area proved resourceful in terms of its complex levels of significance, its plurality of historical accounts, and its multi-layered memories and cultural traditions. As well as achieving its purpose of answering the research question, the work, ideated as a pilot project for the study of war remains on the Eastern Front, ended up creating a methodology which can be applied for dealing with war remains generally, regardless of the front or type of conflict. It also shed light on the fact that the conflictual landscape dimension is the only valid scale through which to approach WWI remains in determinate research contexts.

Within the landscape scale the dimension of war architecture comes to matter as a cultural artefact filled with the untold stories of a lost world. Although it is widely accepted that architecture mirrors its emanation source, the study of WWI architecture as footprint of the generative society had not been approached scientifically, so leaving unexplored an entire archive of meanings embedded in buildings and earthworks that narrate a story about the actions, goals, dreams and dramas of the war actors. The architectural structures produced by the industrialised war form an architectural style representative of a highly peculiar age of human history, in addition to encapsulating warfare knowledge and remembrance value that constitutes a yet to be filled gap in our knowledge. 
Metaphorically speaking, this work, dedicated to unravelling the legacies of the Edge of Europe in a heritage perspective, could be extended and applied to other categories of heritage in an attempt to provide space for expression to a plurality of unheard voices from the past. Hence, the itinerary of this work not only assessed the significance of Romanian WWI sites as places of remembrance and heritage giving voice to yet untold stories of the Great War, but also channelled other submerged forms of heritage to a potential point of emergence where they could speak out loud to those willing to listen. 


\section{APPENDIX 1 \\ Cultural tourism as highlighter of the versatility of heritage value}

The concept of public value, which is frequently used by authorities to justify heritage interventions and the very importance of heritage itself, is an example of the versatility of the concept of value in heritage. The thematic field of the concept lies at the confluence of three types of value which together concur in creating a new and greater scale of value. The first type concerns intrinsic value, gathering an entire areal of cultural heritage meanings and implications such as scientific, symbolic and associational worth. The second typology regards the instrumental value (amenity value) that reflects the social or communitarian utility of sites and monuments preservation, such as the augmentation of tourism or the stimulation of economic regeneration. The third typology is that of institutional value, which consists of the organisational dimension of sites/monuments management along with the intrinsic relations between them and the target audience (Hewison and Holden, 2006, p.15). "While it was recognized that instrumental and institutional values would represent tangible returns that can be measured, albeit with some difficulty, it was generally agreed that the measurement of intrinsic cultural value was inherently more problematic" (Carman, 2009, p.201).

The instrumental value of heritage is intrinsically linked to the social dimensions of economy and consequently to the phenomenon of tourism. Although debates on the topic reflect some well rooted clichés regarding heritage, this instrumental view also captured the interest of both scholars and institutions, producing a well-represented field of research.

The advent of heritage (Meskell, 2015) and heritagisation (Roigé and Frigolé, 2010; Boniface and Fowler, 1993) has exercised a decisive influence on the phenomenon of cultural tourism. A significant heritage category that has been successfully adapted to the needs, tastes and requirements of tourism are the archaeological sites, which have consequently been growing in popularity during the last decades as cultural ventures (Russell, 2006). Scholars like Ashworth and Duke debated that the interaction between archaeological sites and tourism rooted a thriving tendency of past decoding for the general public with a view to augmenting the marketable dimension of heritage (Duke, 2007; Ashworth, 1995). The benefits of such prolific mutuality (Slick, 2002) have complemented not only the growth of the touristic industry (Holtorf 2006) but also the accountability of funds designated to archaeological projects and conservation (Weaver and Oppermann, 2000). Still, the above dynamic presents a downside derived from the profit-oriented usage of exhaustible archaeological resources, leading to a careless abuse of heritage for the sake of customer satisfaction (Herbert 1995, Silverman 2002). Further contestations of the prolific outputs of the above duel-effect refer to its interference with authenticity as a consequence of its tendency to idealise and romanticise the past (Cornelissen, 2005), converting it into cultural products that pander to the taste of the targeted audience (Holtorf, 2006: 20) and reflect the requirements of the industry it serves (Ashworth, 1995: 78). 
Motivations of tourists visiting the archaeological sites are also questioned by scholars, as it seems touristic interest is mainly oriented towards the entertainment dimension of the heritage site (Costa 2004, Bender 1998, Slick 2002, Gazin-Schwartz 2004). Some critiques relegate this practice to "spatial legitimation of class difference" (Mont, 1994, p. 119) while others follow the trail of damage caused to archaeological sites by visitors (Hoffman et al., 2002). The concern for the treatment of heritage resources led to a florid field of research that reflects the implication of tourism on archaeological sites, taking into account issues that go from historical commodification (Ashworth and Larkham, 1994; McIntosh and Prentice 1999; Cole, 2007; Lovata, 2007; Gustafsson and Karlsson, 2014) to ethics (Hodder, 2003; Meskell and Pels, 2005; Bowers, 2014; Herrera, 2015), management (Hall et al., 1998; Walsh-Heron et al., 1990; Comer, 2012; Hofman et al., 2015) and authenticity and identity (Waitt ,2000; McLean, 2006; Gonzalez, 2008). 


\section{APPENDIX 2}

\section{$\underline{\text { King Ferdinand's proclamation to all Romanians }}{ }^{27}$}

28 August 1916

"Romanians!

The war that for the last two years has been encircling our frontiers more and more closely has shaken the ancient foundations of Europe to their depths and elucidated the fact that in the future the peaceful life of the nations can only be assured on national basis.

For our nation it has brought the day that has been awaited for centuries by the national conscience, the day of its union.

Today, it is up to us to release from foreign dominion our brothers from beyond the mountains and from the plains of Bukovina, where Stephen the Great rests in eternal peace.

Their liberation relies on our virtues and bravery, it is up to us to give them back the right to prosper in peace in accordance to the customs and traditions of our ethnic family, in a free and reunited Romania from Tisza to the Black Sea.

\section{Romanians!}

Animated by the holy duty that falls upon us, determined to bear manfully all the sacrifices imposed by an arduous war, we will march into battle with the impetuosity of a nation that holds an immovable faith in its destiny.

The glorious fruits of victory shall be our reward. Forward, with the help of God!

\section{Soldiers!}

I have summoned you to carry your flags beyond the frontiers where our brothers are waiting for you impatiently and with hearts filled with hope.

You shall fight side by side with the men of the great nations to which we are allied. A fierce fight awaits you. But we shall manfully bear the hardships and, with God's help, victory shall be ours.

Therefore, prove yourselves worthy of the glory of your ancestors. In the centuries to come a whole nation will bless and glorify you" (Ferdinand, 1922).

\footnotetext{
${ }^{27}$ The translation from Romanian to English was made by the author of the thesis.
} 


\section{APPENDIX 3}

The offensive in Transylvania

The offensive campaign in Transylvania started on $27^{\text {th }}$ August and lasted until $26^{\text {th }}$ September 1916. The operation was to be conducted by the $1^{\text {st }}$ Army, the $2^{\text {nd }}$ Army and the North Army. The total amount of soldiers to participate in the offensive was approximately 420,000 , almost $80 \%$ of the operative armed forces. The first operations of the campaign were a success, which allowed Romanian armies to make their way to the passages in the Carpathians Mountains and force the Austro-Hungarian units to retreat. Still, on $10^{\text {th }}$ September, operations were temporarily suspended (Cioflină, 1996).

Unaware of the official decisions, and therefore of what was to come on $17^{\text {th }}$ September 1916, the Romanian journal The Transylvanian Gazette published an endearing article by the title At the Transylvanian foot of the Carpathian Mountains waves the blue-yellow-red flag, describing the overwhelming joy of having achieved the strenuously-aspired dream of national unity.

"The dream for whose sake our ancestors and parents perished is about to be achieved. So many generations of Romanians drenched this child of sufferance with tears so that today, when the blue-yellow-red flag waves on the hillsides and in the foothills of the Carpathian Mountains, we remain enchanted and we can hardly believe our eyes. The Carpathians, which form a cursed wall between sons of the same nation, became overnight the backbone of Romanianism. From Oroșova to the springs of the Tisa River, over both side of the Carpathians, over yesterday's chains, today rules a single language a single flag: the Romanian language and the Romanian flag.

The tragedy of our nation suddenly ceased before the final act had the chance to commence. From today onwards brother shall not fight again against brother. We will be one and inseparable. And today we have eyes filled with tears as before. But how different it is... In yesterday's tears the darkness of a sad, murderous night was reflected, with only one glance of light: the waking candle that burned on the graves of tens of thousands of martyred brothers, fallen for a foreign cause. In today's tears, the sunrays of liberty play in the sparkles of the highest and holiest emotion that could have ever been revealed to mortals of this earth.

Our lips, which until yesterday cursed the torturers of our kind, unite today in the grateful blessing of the brave Romanian Army. Yesterday's deceased joined hands with today's dead of the Romanian Army. Now is the turn of the living to shake hands on the foundation cemented with the blood of these heroes, and to wholly fulfil the national ideal in all its splendour: the dream of the Greater Romania" (Căzănișteanu, 1984, p.347-348).

Unfortunately, things did not turn out as expected and, on $15^{\text {th }}$ September, the War Council decided to initiate and give priority to another operation at Flămânda. The failure of the Flămânda operation and arrival on the Transylvanian front of four German divisions 
compromised the outcome of the initial offensive plan. The Transylvanian offensive was suspended on $26^{\text {th }}$ September and substituted with the defence of the strategic line of the Carpathian Mountains (Grandhomme, et al, 2000).

The $9^{\text {th }}$ German Army attacked the city of Sibiu on $26^{\text {th }}$ September 1916 . The battle was won by the Germans on $29^{\text {th }}$ September. General Falkenhayn declared that the operation was a success because the Romanian commandment had acted hesitantly and uncertainly (Falkenhayn, 1937). During the successive counteroffensive, against the Romanian $2^{\text {nd }}$ Army, the whole territory between Mureș and Olt was lost, and on $7^{\text {th }}$ October the final battle against the retreating Romanian forces commenced in Brașov. The following day, the city of Braşov had to be evacuated and the troops retreated to the old frontier (Kirițescu, 1989). By the end of September, the Romanian troops had lost the territory gained during the August offensive returning to their initial demarcation point. With regard to General Crăiniceanu's command of the $2^{\text {nd }}$ Army, Radu Rosetti, head of the operations office at Romanian Headquarters, affirmed that "chaos and uncertainty reigned in the command and amongst troops of the $2^{\text {nd }}$ Army" and continued by saying that the General had been forced into a position of ordering the troops to retreat. The persistent request of the Lieutenant-Colonel Gheorghe Dajiba to discharge General Crăiniceanu from command of the troops was also noted (Rosetti, 1997).

The failure of the offensive in Transylvania was attributed by most historians and men of arms, like the American General Vincento Esposito, to faulty planning and management (Esposito, 1997). During the September War Council, the Romanian General Constantin Prezan persistently opposed the idea of the Flămânda operation, arguing how it would give the Central Powers an advantageous position and annul the efficiency of Transylvanian operations. He believed that the Transylvanian offensive campaign should be continued and that the engagement of the armies in other simultaneous operations would be a careless dissipation of forces (Cioflină, 1996). Although his voice remained unheard, he turned out to be right. General Erich Ludendorff confessed in his memoirs that the sudden Romanian advancement in Transylvania not only threatened to break the forces of the Central Powers but, if pursued, "it would have opened the road to the heart of Hungary and blocked communications with the Balkan Peninsula." The General also believed that this would have led to the defeat of the Central Powers (Ludendorff, 1920). 


\section{APPENDIX 4 \\ The defence of the South Front}

The defence of the South Front was delegated to the $3^{\text {rd }}$ Army. According to the initial plan, their mission was to defend the south frontier from Calafat to the Black Sea and to conduct a resounding offensive on the Rusciuc-Șumla-Varna alignment after the arrival of the $47^{\text {th }}$ Russian Army Group (Serviciul Istoric al Armatei, 1934-Vol.I.). The city of Turtucaia was chosen as a strategic point in eventuality of a Romanian attack on Bulgaria. In such a hypothesis, a pontoon bridge was to be built across the Danube between the city of Turtucaia and Olteniţa. Still, since the 1916 campaign plan assigned a defence mission to the $3^{\text {rd }}$ Army, the bridge was never built (Constantiniu, 1997).

The battle of Turtucaia begun on $1^{\text {st }}$ September and concluded on $6^{\text {th }}$ September with a Romanian defeat. Although Turtucaia should not have represented a strategic position, the famous unbuilt bridge marked the fate of 34,000 men (dead, missing or wounded) and constituted one of the main strategic mistakes that sabotaged the outcomes of the 1916 campaign (Averescu, 1918). The consequences of the Turtucaia operation were huge as they created preconditions for the German-Bulgarian troops to attack Dobrogea as well as subtracting seven divisions from the North Front blocking the Transylvanian offensive and giving the German and Austro-Hungarian troops the needed time to regroup, strengthen their forces and launch an attack against the Romanians on the Carpathian Mountain line. The Romanian defeat also made von Mackensen realise that its opponents were lacking experience of a modern warfare, since their goal in battle was clearly the defence of territory at all costs rather than annihilation of the enemy's human resources as modern war ordained. It also highlighted the incapacity of the Romanian leadership to take risks, which enabled the German-Bulgarian troops to play this card in their future operations (Torrey, 2003).

On $1^{\text {st }}$ September the $3^{\text {rd }}$ Bulgarian Army crossed the Romanian frontier and advanced towards Dobrogea, commencing a series of attacks and counter-attacks that lasted until $21^{\text {st }}$ September. The mission of the Russian troops, led by the Russian General Andrei Medardovici Zaioncikovski, was to prevent the enemy from conquering the BucharestConstanta railway. General Mackensen carefully panned and launched a further offensive in Dobrogea on $20^{\text {th }}$ October successfully forcing the demoralised Russians to retreat from Constanța towards the Danube Delta, without provisions. Furthermore, Mackensen correctly deduced the situation and moved half of his Army to Sistova with the intention of preparing an attack on the course of the Danube (Ioanițiu, 1929).

By $15^{\text {th }}$ September 1916 King Ferdinand had summoned a War Council. The military leaders had different opinions that converged into the antagonistic position of General Alexandru Averescu who supported the idea of ceasing the Transylvanian offensive and initiating an offensive to the south of the Danube, as against that of General Constantin Prezan who pleaded to continue the offensive on the Northern Front (Serviciul Istoric al Armatei, 1934- 
Vol.I.). The initiative of Averescu and his supporters prevailed and the $3^{\text {rd }}$ Army received a reinforcement of 150,000 soldiers withdrawn from the Northern Front. On $23^{\text {rd }}$ September the Flămânda operation was initiated. The plan was to cross the Danube with six divisions and to attack the Central Powers from behind while Russian-Romanian contingents of Dobrogea would attack at Corbadin and Kurtbunar (Turker, et al, 2005).

On $1^{\text {st }}$ October, two Romanian divisions built a bridge out of ships, at Flămânda, and crossed the Danube. Simultaneously Russian-Romanian divisions launched an attack on the Dobrogea Front. During the following night a strong storm badly damaged the bridge, which, combined with failure to break the front at Flămânda, made General Averescu decide to cancel the operation on $2^{\text {th }}$ October (Averescu, 1926). Troops retreated to north of the Danube on $3^{\text {rd }}$ and $4^{\text {th }}$ October. The armed forces were regrouped to launch a counteroffensive against the Great Powers in Transylvania. Averescu's approach to war led to the dissipation of forces and the exhaustion of soldiers marching between the different fronts. The Flămânda manoeuvre continued the trend of hasty and enigmatic military decisions that had started at Turtucaia and led to the loss of those strategic advantages initially gained in Transylvania (Grandhomme 2000). General Erich Ludendorff expressed consternation about this episode, confessing that he could not understand what the Romanian command would have possibly wanted to achieve from an operation that had no strategic influence over the course of the events, neither in Ardeal nor in Dobrogea (Averescu, 1926). 


\section{APPENDIX 5 \\ The defence of the Carpathian Mountains' passages}

The defence operation of the Carpathian passages started in mid-September and lasted until the beginning of October. The goal was to stop the enemy offensive in Transylvania by consolidating the defence system on the Carpathian alignment in order to create conditions to rerun the strategic offensive (Ceaușescu, 1989). Austro-Hungarian forces engaged in the area summed up three armies led by Archduke Carol, heir to the Austro-Hungarian throne. The $7^{\text {th }}$ Austro-Hungarian Army was engaged in Bukovina, the territory between Târnava Mare and the river Olt was allocated to the $1^{\text {st }}$ Austro-Hungarian Army, while the $9^{\text {th }}$ German Army led by General Erich von Falkenhayn covered the South Transylvanian front (Falkenhayn, 1937).

The Central Powers' plan was to engage the $1^{\text {st }}$ Army in the area of Trotus-Oituz in order to occupy the passage and intercept communications in the Siret Valley, with intent to prevent the arrival of Russian reinforcements. Concomitantly, the $9^{\text {th }}$ Army was to assure the shortest passage to Bucharest through the mountains. In the case of both operations having positive outcomes, General Mackensen's troops were supposed to cross the Danube allowing the Central Powers to deploy a circular attack on Bucharest. The Romanian strategy was to defend the entire North front by holding the mountain alignment until the falling of snow when the operations would be stopped by winter (Kirițescu, 1989). On $8^{\text {th }}$ October German troops tried to penetrate the Rucăr-Bran corridor in the Carpathians. The battles that followed, and lasted until $23^{\text {rd }}$ October, are known as the Bran-Câmpulung battles and were concluded with the failure of the German initiative (Serviciul Istoric al Armatei, 1934- Vol.II). On $9^{\text {th }}$ October, Germans began the offensive in the Prahova valley. The invading troops, unable to breach the Romanian defences, were stopped on the Clăbucet-Azuga alignment - a front line with strong Romanian fortification systems that forced General Falkenhayn to cease the attacks and to take a defence stance on the $25^{\text {th }}$ October (Serviciul Istoric al Armatei, 1934Vol.III.).

Between $16^{\text {th }}$ and $26^{\text {th }}$ November, the $9^{\text {th }}$ German Army made efforts to breach the defence of the Carpathian passages on the Olt and Topolog valleys. The Germans planned to engage the mountain divisions in a double outflanking manoeuvre of the Romanian Troops, while the Alpine Corps were to deliver the decisive strike. The course of the events did not work out as planned and the Germans were forced to cease their offensive (Iosipescu, 1967). General Falkenhein related that "the advancing of the troops was made through the heaviest battles. The Romanians desperately resisted. Every mountain had to be taken by assault" and, although the spoils of war were abundant, the advance was paid for with significant German sacrifices which, in time, would have resulted in a negative balance of the operation (Falkenhein, 1937). 
On $19^{\text {th }}$ October 1916, the $1^{\text {st }}$ Austro-Hungarian Army began the offensive in the Oriental Carpathians. There were several attempts to break through the passages, but none succeeded against the Romanian North Army. The final battle of Oituz was won by the Romanian troops who pushed the Austro-Hungarians back across the border forcing the imperial command to cease operations on $27^{\text {th }}$ October and turn to defensive (Kirițescu, 1989).

On $23^{\text {rd }}$ October the German and Austro-Hungarian troops planned to pass through the Carpathians via the Surduc and Vâlcan valley and to outflank the Romanian troops. Simultaneously, the $6^{\text {th }}$ Cavalry Division was meant to cross the Arcan Hill and proceed towards the plain, in order to assure a free path for the troops to deliver the frontal attack. The Germans units managed to break Romanian defences on $24^{\text {th }}$ October when, during a surprise attack, they captured the detachment in charge of guarding the Vâlcan pass (Kiriţescu, 1989). The commander of the Romanian $1^{\text {st }}$ Army asked headquarters to approve the abandonment of Oltenia and the retreat of the troops. As a response, on $25^{\text {th, }}$ King Ferdinand removed the commander from charge and replaced him with General Iona Dragalina. The new commander ordered nearby divisions to attack the enemy's flanks at the same time as the Germans were being held north of Târgu Jiu. After three days of heavy fights, the German troops were forced beyond the original frontier and the battle ceased on $29^{\text {th }}$ October (Armata Română, 1987).

Orders for the $9^{\text {th }}$ Army were to cross the mountains together with the enemy or, in a worstcase scenario, before it had time to settle in the fortifications that existed on the heights of the border passages (Falkenhayn, 1937). The passages of the Meridional Carpathians were to be attacked until one of them was conquered, in order to allow German forces to pass south of the Carpathians. The plan failed, as the Romanian resistance forced Falkenhayn to abandon the initial plan on $29^{\text {th }}$ October and to focus efforts on one pass only. The main forces of his army were concentrated near the Lainici Pass in the Jiu Defile. The attack was launched on $11^{\text {th }}$ November and, after five days of fighting, the Romanian defence system was broken giving the Germans free access to the Oltenia plane. The outcome of the battle is attributed to a strategic error of Romanian Headquarters who misjudged the capacity of the enemy to strike again after the defeat of the $29^{\text {th }}$ and left the Jiu Defile poorly defended. "Falkenhayn managed to break the Romanian front line with the formidable mass of four infantry divisions in a place where the guard was assured by the troops of a poor brigade" (Kirițescu, 1989,p.460). The passing of the German troops into plain grounds compromised the Romanian defence system, which progressively collapsed. 


\section{APPENDIX 6 \\ The defence of the Muntenia territory}

The offensive of the Central Powers in Muntenia was ideated with the aim of conquering the Romanian capital city, Bucharest, and triggering the capitulation of the country. The commanders in charge, General von Mackensen and General von Falkenhayn were leading approximately 250,000 men against the 150,000 Russian-Romanian forces led by General Constantin Prezan (Hamric, 2005). The battle for Bucharest started on $30^{\text {th }}$ November with a concentric attack by the German-Bulgarian-Turkish troops from Oltenia and from south of the Danube. General Prezan led a counterattack at the junction of the German forces, managing to force von Mackensen's troops across the Danube and to turn the flank of Falkenhayn's troops (Cioflină, 1996). The Romanians captured thousands of prisoners and large quantities of war materials. General Erich Ludendorff testified that "on the $1^{\text {st }}$ December the left wing of the Danube Army was strongly attacked south-west of Bucharest and pushed backwards. The German troops that had already passed Neajlovul were isolated. The situation certainly had become very critical" (Ludendorff, 2001).

On $2^{\text {nd }}$ December the intervention of the $26^{\text {th }}$ Turkish division prevented von Mackensen's troops from being encircled and gave German troops the time needed to reorganise (Clark, 1971). This combined with the fact that General von Falkenhayn came into possession of the Romanian battle orders, so discovering the field display of the Russian-Romanian troops, led to the notion of a striking attack that forced the Romanians to redraw, leaving open the path to Bucharest. On $6^{\text {th }}$ December the German troops occupied Bucharest (Petin, 1932) forcing the Romanian government to retreat to Moldavia along with the army. 


\section{APPENDIX 7}

The declaration of self-determination presented by Alexandru Vaida-Voevod to the Hungarian Parliament of Austria-Hungary ${ }^{28}$

"We know the magnitude of the time we are leaving; we know that these colossal issues cannot be handled guided by selfishness. We know the truth that emerges from one of Wilson's points, which is that we should not leave space for hate and selfishness, when it comes to these issues, whose real and serious resolution can only be achieved with the aid of full honesty. That is why, the representatives of the Romanian national organization, decided to state its attitude towards these points and, entrusted by it, I bring before the honourable chamber the following declaration:

«The executive committee of the Romanian National Party of Ardeal and Hungary, in its capacity as political body of the Romanian nation of Ardeal and Hungary, finds that the consequences of the war strengthen the historical claims of the Romanian nation to full national freedom. On the basis of the natural right that entitles each nation to dispose of and decide freely and autonomously its own fate [...] the Romanian nation of Ardeal and Hungary wishes now to employ this right and consequently reclaims for itself the right of being amongst the free nations and being able to decide upon the co-ordination of its relations with other free nations, according to its own will and free of all foreign interference. The national political body of the Romanians of Hungary and Ardeal does not recognise as legitimate the claim of this parliament and this government to consider themselves as representatives of the Romanian nation, able to represent the national interests of the Romanians of Hungary and Ardeal at the general peace conference, because the Romanian nation can only entrust the defence of its interests to political factors designated by its own National Assembly. Except from the political bodies delegated by the National Assembly or elected from the Romanian nation, that is with the exception of the executive committee of the Romanian National Party, no one is entitled to handle and to decide matters that concern the political situation of the Romanian nation. Any decisions and agreements to be taken or sealed without the agreement of this political body, we shall regard as null and without legal value and therefore they will not in any way engage the Romanian nation. The Romanian nation that lives in the AustroHungarian monarchy awaits and requests - after centuries of countless sufferings - the affirmation and valorisation of its abiding and inalienable rights to national life»»" (Căzănișteanu, 1984, p.367-369).

This declaration, that formed part of the speech of Alexandru Vaida-Voevod, was adopted by the Romanian National Party on $12^{\text {th }}$ October 1918 in Oradea, upon which occasion the Executive Committee was provisionally given the status of political national leading body.

\footnotetext{
${ }^{28}$ The translation from Romanian to English was made by the author of the thesis.
} 


\section{APPENDIX 8}

The New York Times article describing the National Assembly of Alba Iulia

that decided the

Great Union on $1^{\text {st }}$ December 1918

"A great festival of Transylvanian Rumanians was held at Gyula Fehervar, or Klausengurg, north of Hermanstadt, on Dec. 1, when the National Assembly solemnly proclaimed the union of Transylvania with Rumania. According to Magyar papers a crowd of 100,000 people in all sorts of picturesque costumes filled the military training ground and enthusiastically acclaimed the speeches of the national leaders. Perfect order was maintained by the National Guard and armed peasants, and there was no drunkenness.

The National Assembly of 200 members met in the offices of the Casino, among the guests being a Rumanian General and French airmen. National leader Pop presided. A resolution was unanimously passed declaring the union of all Rumanian people in all the territories they inhabit and affirming the inalienable right of Rumanians to all the Banat Territory between Maros Theiss and the Danube. Full liberties are to be guaranteed to all national minorities in respect to language and administration.

Other points of the declaration are universal suffrage, religious equality, radical reform of labour legislation, and the formation of a National Council, with full authority to represent the nation internally and externally during the preliminary negotiations" (The New York Times, 1918). 


\title{
APPENDIX 9
}

\section{Iuliu Maniu's speech at the National Assembly of Alba Iulia -}

\section{Great Union}

$1^{\text {st }}$ December $1918^{29}$

\begin{abstract}
"Today, we are like a blind man who for decades has not seen the light of day, until a divine blessing opens his eyes and he finally sees the light of the holy sun. Here we represent the eyes of the people whom can today see the light of the freedom of nations. [...] In order to remove all doubts of the foreigners regarding what we want to achieve through our union and our national freedom, the Great Romanian National Council declares that it is not pursuing the foundation of a reign of oppression.
\end{abstract}

We do not want to turn from being oppressed, as we were until not long ago, to becoming oppressors. We want to guarantee liberty for all and emancipation for all co-inhabiting nations: Our Great National Council desires to emphasise the fact that it has every intention of acting as our old proverb has it: do not do to others what you do not desire for yourself. On this land of the Great Romania we want to enthrone national freedom for all. We want every nation to be able to educate itself in its own language, to pray to God according to its faith, and to demand justice in its mother tongue. We, who spilled tears seeing our language removed from schools, churches, justice, shall not do the same to others. We shall not rob other people of their life opportunities. We do not want to live by taking advantage of the hard work of others, because we can make a living from our own work, relying on our worth and strength. $[\ldots]$

Only with the aid of a democratic regime can we strengthen our Romanian country, especially as we need to consider the requirements of modern state life. Only by having a regime based on rights and freedoms inside our country shall we be able to validate our cause outside. Full liberties for all social strata are a guarantee of the wellbeing of the country. That is why the Great Romanian National Council included, in its resolution project, a clause referring to the accomplishment of democracy. [...] We kindly ask you to unanimously accept our resolution project.

This project shows the way on which, by walking onwards, we will be able to reach our ideal and to lay the foundation of a united Great Romania, which forever shall be so and that will shelter the spirit of beatific democracy and social justice" (Murgescu, 2001, p.284).

\footnotetext{
${ }^{29}$ The translation from Romanian to English was made by the author of the thesis.
} 


\section{APPENDIX 10 \\ The resolution of the National Assembly of Alba Iulia \\ $\underline{1^{\mathrm{ST}} \text { December } 1918}$}

"I. The National Assembly of all Romanians in Transylvania, Banat and the Hungarian Country, gathered by its rightful representatives at Alba Iulia on the 18th November/1st December, decrees the unification of those Romanians and of all the territories inhabited by them with Romania. The National Assembly proclaims above all the inalienable right of the Romanian nation to the whole of Banat bordered by the Mures and Tisa rivers and the Danube.

II. The National Assembly grants to the territories mentioned above provisional autonomy until the meeting of the Constituency chosen by suffrage universal.

III. Regarding this matter, the National Assembly proclaims the following fundamental principles for the foundation of the new Romanian State:

Full national freedom for all the co-inhabiting peoples. Each people will study, manage and judge in its own language by individuals of its own stock and each people will get the right to be represented in legal bodies and to govern the country in accordance with the number of its people.

Equal rights and full autonomous religious freedom for all religions in the State. Full democratic system in all realms of public life. Suffrage universal, direct, equal, secret, in each commune, proportionally for both sexes over the age of 21 years at the representation in communes, counties or parliament.

Full freedom of the press, association and meeting; free expression of all human thoughts. Radical agrarian reform. All assets, above all the sizable ones, will be inscribed. The wills by which the heir consigns land to a third party will be abolished; meanwhile, on the basis of the right to cut down estates freely, the peasant will be able to own his property (ploughing land, pasture, forest), occupying at least one for him and his family to labour on. The guiding principle of this agrarian policy is promoting social balancing, on the one hand, and giving power to production, on the other.

Industrial workers will be granted the same rights and privileges that are in force in the most advanced western industrial states.

IV. The National Assembly would like the peace congress to bring about a community of free 
nations so that justice and freedom be ensured for all large and small nations alike and, in future, war as a means of controlling international relations is abolished.

V. The Romanians gathered in this National Assembly greet their brothers in Bukovina who broke away from the Austro-Hungarian Empire yoke and united in their fatherland, Romania.

VI. The National Assembly greets with love and enthusiasm the liberation of the nations subjugated until now in the Austro-Hungarian Empire, namely the nations: Czechoslovak, Austro-German, Yugoslav, Polish and Carpatho-Russian and decides that this greeting should be conveyed to all the other nations.

VII. The National Assembly meekly evokes the memory of those brave Romanians, whose blood was shed in this war for our dream to come true, as they died for the freedom and unity of the Romanian nation.

VIII. The National Assembly expresses its gratefulness and admiration towards all the Allied Powers, which, by their brilliant battles waged stubbornly against an enemy trained for many decades for war, released civilisation from under the terror of barbarity.

IX. To continue to manage the affairs of the Romanian nation in Transylvania, Banat and The Hungarian Country, the National Assembly decides to found a Great National Romanian Convention, that will have all rights to represent the Romanian nation at any time and place in relating with all the nations of the world and to make all the necessary decisions in the interest of the nation" (State Archives of Bucharest, 1918). 


\section{APPENDIX 11 \\ The Union of Basarabia, Bukovina and Banat with Romania}

\section{$\underline{\text { Basarabia }}$}

Between $23^{\text {rd }}$ and $27^{\text {th }}$ October 1917 the autonomy of Bessarabia was proclaimed, and a legislative body known as the Country Council was created. After the dissolution of the Czarist Empire the chaotic retreat of the Russian Army spread violence and disorder in Basarabia. The Country Council was obliged to request the intervention of the Romanian Army to stop the looting (Clark, 1927). On $24^{\text {th }}$ January, the independence of the Moldavian Republic was proclaimed and, on $27^{\text {th }}$ March 1918, the union of Moldavia with "the mother country, Romania” was voted by the County Council (Constantiniu, 1997, p.290).

On $28^{\text {th }}$ October 1920 this union was ratified in Paris by England, France, Italy, Japan and of course Romania. Russia never ratified the treaty, nor did it accept the rights conferred to Romania by the Supreme Council of the Paris Peace Conference in accordance with the peoples' aspirations and based upon historic and economic reasons.

For twenty-two years the union with Romania saved Basarabia from the horrors of the Russian civil war, of the collectivisation, of the Famine-Genocide (Holodomor), of the red terror and of the gulag deportations. According to the data of the UN Refugee Agency, tens of thousands of Ukrainian and Russian refugees came to Basarabia during this period, all of whom were labelled as reactionaries and counter revolutionists by the Soviets and were deported to Siberia when the Red Army occupied the country (Nistor, 1918).

\section{$\underline{\text { Bukovina }}$}

At the end of the Great War, both the Romanian and Ukrainian population of Bukovina claimed territorial rights over the region. During the month of November 1918 both groups sought the union of the territory where they represented the majority with either the Romanian Kingdom or the West Ukrainian People's Republic. Negotiations between the two countries were long overdue as there was open dispute over important cities that were claimed by both sides such as Cernăuți, Rădăuți, Siret.

The disorders created in the region required the intervention of the Romanian Army. The arrival of the $8^{\text {th }}$ Romanian Division on $29^{\text {th }}$ October was meant to protect the entire population, regardless of its nationality and religious orientation, against the looting and terror policy of criminal gangs active in the area. The city of Cernăuți was liberated without a fight as the remaining Ukrainian troops retreated towards Galicia while the leaders that had abusively taken the power fled away (Diacon, 2012). 
On the $28^{\text {th }}$ November the General Congress of Bukovina was convened. The meeting, which took place in Cernăuți, was concluded with the unanimous vote of the Congress (including the vote of the German and Polish representatives) in favour of the union with Romania. The Union Motion stated that:

"The General Congress of Bukovina that reconvened today, Thursday $15^{\text {th }}$ November [until $28^{\text {th }}$ ] 1918, in the Synodal Hall of Cernăuți, considers that from the foundation of the Romanian Principalities, Bukovina, including the old lands of Suceava and Cernăuţi, has always been part of Moldavia, which collected around these lands forming a state.

Taking into consideration that traces of the old reign of Suceava can be found throughout the territory between the borders of this country, along with the rulers' burial grounds of Rădăuți, Putna, Suceava, and other historical traces and precious memories of the Moldavian past/history;

Taking into consideration that the sons of this country, shoulder to shoulder with their Moldavian brothers and under the lead of the same rulers, have defended the existence of their nation against all outsiders' infringements and pagan invasions over the centuries;

Taking into consideration that in 1774 Bukovina was mischievously torn from the body of Moldavia and forcefully joined to the Hapsburg Crown;

Taking into consideration that for 144 years the Bukovinian people have endured the sufferings of foreign rule, which spurned their national rights and which, relying on injustice and persecutions, tried to alter and alienate their national conscience and promote feuds with other nationalities amongst whom the Bukovinian people wanted to live as siblings;

Taking into consideration that for 144 years Bukovinians fought as martyrs on all the battlefields of Europe, under a foreign flag, to maintain the glory and magnification of their oppressors, and that as a reward they had to endure the decrease of their inherited rights, their expulsion/banishment from public life, from school and even from church;

Taking into consideration that all this time the native people were systematically deterred from using the richness of the resources of this country and were for the most robbed of their old heritage;

Taking into consideration that, regardless of all this, the people of Bukovina did not lose faith that the hour of their redemption, awaited with restless longing and suffering, would arrive and that their ancient heritage, hacked by iniquitous borders, would be reunified [...] and that the people of Bukovina always nourished faith that the great dream of the nation would come true, when all Romanian countries from Nistru to Tisa would be united in a unitary national state; 
Congress ascertains that the glorious time has come!

Today, when after enormous efforts and sacrifices undertaken by Romania and its noble and powerful allies, the principles of law and humanity have been enthroned in the world for all nations, and when after smashing strikes the Austro-Hungarian Monarchy shook to its foundations and finally crashed, when all the nations chained within its reign gained the right to self-determination, the first thought of the liberated Bukovina turns to the Kingdom of Romania, to whom we have always anchored the hope of our emancipation.

Consequently we, the General Congress of Bukovina, incarnating the supreme power of the country and being the only legitimate holder of legal power, in the name of national sovereignty, we decide:

The unconditional and eternal union of Bukovina in all its ancient boundaries between Ceremuş, Colacin and Nistru with Romania” (Murgescu, 2001, p281).

The Union Motion was handed to the Romanian authorities, King Ferdinand sanctioned the union act and on $19^{\text {th }}$ December 1918 the decree was published in the Official Monitor no.217. On $10^{\text {th }}$ September 1919 the Treaty of Saint-Germain-en-Laye conferred international recognition upon the union. Austria officially gave up its rights upon the former Duchy of Bukovina (art.59) while Romania agreed to protect the rights of the minorities (language, race and religion) within the Romanian territory (art.60).

\section{$\underline{\text { Banat }}$}

In Banat the tensions and disorders escalated during the autumn of 1918. There was mounting dissatisfaction amongst the population that was facing great difficulties as consequence of the war. Soldiers who made it back home returned only to find themselves facing further atrocities as they discovered their families burdened with shortages of all kinds, sick and starving, and brutally repressed by the Hungarian authorities. In response to the chaos created in Banat by the Hungarian gendarmes and "Steel Guards" the Romanians organised themselves into Councils and National Guards in order to stop the abuses (Scorpan, 1997, p.659).

As manifestations against the Hungarian rule grew in intensity and frequency, Hungarian leaders decided to put an end to street demonstrations by proclaiming the Autonomous Republic of Banat. The event was to happen on $31^{\text {st }}$ October 1918 when the Council of the People of Banat was also to be established. Ironically, the Autonomous Republic would have continued to be part of Hungary and the council subordinated to the Budapest government. The Romanian population perceived this manoeuvre as further denial of their native rights and a further attempt to prevent their national emancipation. The Romanian people were aspiring to unite with Romania therefore their representatives could not abide by decisions of the Hungarian rulership. Consequently, the Romanian leaders left the meeting to constitute their 
own representative national council. In the evening of the same day a National Assembly was organised in Freedom Square in Timisoara, recording the participation of thousands of Romanians who acclaimed Dr. A. Cosma when he announced "the braking of the slavery chains for the Romanian nation". The Military National Romanian Council constituted on this occasion promoted the interest of the Romanians of Banat and concentrated all its efforts towards the union with Romania. The Council rejected the idea of the republic and adhered to the Central Romanian National Council, whose sole authority it acknowledged as reflection of the people's will of unity (Suciu, 2003).

The Central Romanian National Council gave the Hungarian National Council an ultimatum on $10^{\text {th }}$ November asking them to hand over the rule of Transylvania and Banat over the following two days. In response, the Budapest Government solicited a time extension until $14^{\text {th }}$ November as it was conducting peace negotiations with the Entente at the time. On $13^{\text {th }}$ November the armistice of Belgrade was signed, further complicating the fate of the Banat region by postponing its resolution until after the Paris Peace Conference. Furthermore, the Hungarian army was ordered to retreat north of the Mureş River leaving the territory to the French and Serbian troops (Drăghicescu, 2001).

Taking advantage of the subsequent favourable situation, Serbian troops invaded Banat before the terms of the agreement became operative. In just a few days they took control of the military administration and, shortly afterwards, they took control of the civilian administration as well, while the Romanian Army was still fighting von Mackensen's troops. The Romanian population initially welcomed the Serbian troops, since they were meant to come as allies, but they soon began to be persecuted by the new administration who, like the Hungarians, saw great danger in the Romanian national movement (Păiuşan, 1993). The goal of the Serbian administration was suppression of the national movement, which led to them abolishing the Romanian national councils and guards. The Hungarians supported such a policy in hope of still gaining the region, while the newcomers aimed to instate decisive Serbian control over the region at the end of the war. Although it was impossible for the Serbians to raise historical claims upon the region they relied on the geography of their capital city, which was on the border with Banat, to persuade their international allies to grant them control for strategical reasons.

Nevertheless, when the Central Romanian National Council called the Romanians to the National Assembly in Alba Iulia, thousands of Romanians came from Banat defying all obstacles and constraints. The election of representatives of the region that were to represent the population of Banat at the Great Assembly was strongly sabotaged and Serbian troops keenly guarded the border with Ardeal in order to prevent the population from attending. Even the vice-president of the Assembly, Bishop Miron Cristea was deterred for over twentyfour hours but finally managed to arrive in time to witness the climax of the Assembly. Against all odds, although the Serbs had forbidden travel to Ardeal, 359 official members elected from all social classes and main political organisations managed to represent the 
region at the assembly and participants from more than 255 different locations of the region managed to attend (Munteanu, 1992).

This Romanian defiance triggered an intensification of reprisals throughout the region after the Great Union was proclaimed. The Serbian army was not willing to accept the will of the Romanian population and therefore started a campaign of persecutions against civilians (Păiușan, 1993). This situation persisted until the arrival of French troops led by General Berthelot who persuaded the Entente to gradually withdraw Serbian troops. The French managed to take over the eastern part of Banat in January 1919. In June 1919 the Peace Conference of Paris established the borders of Romania and Serbia splitting the region between the two countries. On $28^{\text {th }}$ June Romanian administration was established in Banat. On $4^{\text {th }}$ August 1919, the Romanian Kingdom signed a treaty with the allies that recognised the inclusion of Banat within the borders of the Romanian state (Dan, 2005). 


\section{APPENDIX 12 \\ The Union of Maramures with Romania}

The resolution of the National Assembly of Alba Iulia proclaimed the union of Satmar, Crisana and Maramureș with Romania, these historical regions being previously gathered under the title T,ara Ungurească. Although this resolution talks about the inclusion of the entire territory of Maramureș in the Romanian Kingdom, only the southern part was attributed to Romania by the Paris Peace Conference which fixed the Tisa River as its northern border.

After the signing of the armistice of Villa Giusti by Austria-Hungary on $3^{\text {rd }}$ November 1918 , the soldiers started to return home, constituting national guards in every village in Maramureș. More than 10,000 people gathered together in Sighet on $22^{\text {nd }}$ November 1918 to choose delegates that were to represent Maramureș at the National Assembly of Alba Iulia. On $1^{\text {st }}$ December, in concomitance with the National Assembly, a large assembly was also held in Sighet, deciding the unconditional union of Maramureș with Romania (Filipascu, 1940).

Nevertheless, Ukrainian troops invaded Maramureș in January 1919. The $14^{\text {th }}$ Romanian regiment arrived at Maramureș on $16^{\text {th }}$ January, engaging the enemy in battle at Cămara Sighet and winning the battle the following day. The regiment, along with the national guards, managed to eradicate terrorism on Tisa's shores as far as Câmpulung, but the west and north of Maramureș was still under Hungarian control. The decision of the Hungarian Soviet troops to join up with with the Russians in Transylvania led to recommencement of fighting in the spring of 1919 . The $14^{\text {th }}$ Romanian Regiment won the battle, creating positive conditions for the establishment of Romanian administration (Batin, 2014).

On the subject of Maramureș at the Paris Peace Conference, the Czech delegation took advantage of the 1916 Romanian alliance with the Entente, which stipulated the Northern Romanian border to be on the Tisa River. The Czechs requested the northern part of Maramureș, even though the Romanian Army had supported the Czechoslovak army against invading Hungarian Soviet troops. Actually, at the time, rulers of the two armies had mutually agreed upon a demarcation line between the two countries, one that attributed the Maramureș region almost entirely to Romania. During the Vaida-Voevod Government relationships between the two delegations at the peace conference improved, mostly due to the expertise of Gavrila Iuga with regards to the historic characteristics of Maramureș. Iuga's historic and documentary work proved the indisputable Romanian right to claim this historic province. Such facts were admitted, even by the Czech delegation in March 1920, by showing its will to yield to Romania the whole of Maramureș except for the Dolha region.

On $13^{\text {th }}$ March 1920 the Vaida-Voevod Government was dismissed, and the Czech delegation took advantage of the situation, refusing to sign the agreement by appealing to an assumptive lack of legal authority of the new government. The peace talks were ceased by the Averescu Government who ordered the retreat of the Romanian Army on the left shore of the Tisa River 
in July 1920. The resulting vacuum of power gave the Czechoslovakian Army the opportunity to permanently occupy the area, while in the international relations arena this move was interpreted as a willing renunciation of the Romanian state to the northern side of Maramureș (Ardelean, 2016).

Regardless of the countless declarations of principles made by various leaders of the allied forces during the war, all supportive of the Romanian cause, at the Paris Peace Conference the discourse changed, and the situation of the small nations turned out to be quite exceptional. In December 1919, on this subject, Ion I. C. Brătianu declared in a discourse to the Deputies Assembly that the Peace Conference ended up suppressing the very reasons for which the war was fought by counties such as Romania as it relegated the small nations to states with secondary or limited interests, hence with limited independence.

"The organization of the Conference was made in such conditions that almost all the small states were obliged to protest. And the first to protest in their name was Belgium, a protest to which all representatives of other small nations joined successively. But then, to our great and painful surprise, the President of the Conference, the head of government of the most generous democracies in the world, opposed our objections by proposing the theory that every state's worth to the commission should equal its military capacity.

It was, gentlemen, a principle and a theory that was not in accordance with our beliefs nor with what we thought was rightfully ours nor with the very reasons for which the war was conducted.

And then, in order to systemize this new system and work procedure, that is a new but somehow obsolete cliché of international life, special definitions were invented for states such as those that we represented. Seriatim, they were called states with peripheral interests and then states with limited interests. I protested in all my intercessions against these definitions. I tried to convince the powerful that states are states and not some with general interests and others with limited interests, but that the interests of any states are equally vivid, and every state is entitled to defend its interest in the same way as a great power and that no one is entitled to limit the extent of the interests of another.

The concept of the definition was so dangerous that it was impossible for it not to lead to the consequences that eventually occurred when we came to be treated as in the Minorities Treaty, being abased from states with limited interests to states with limited independence. Gentlemen, such a work system was introduced in the Conference that it actually constituted a real suppression of the Conference. Meaning that the representatives of the four Great Powers, plus the representative of Japan, with regard to the problems that were of his interest, decided upon all the matters without the participation of the other states" (Murgescu, 2001, p.284).

By privileging the military capacity of states as being indicator of a state's worth the Paris Peace Confrence aided proliferation of the international tensions that eventually re-ignited the conflictual sparks that resulted in the outburst of WWII within the same the settings. 


\author{
APPENDIX 13 \\ Between two front lines, 1914-1918 \\ (fragment describing the Maramureș-Bukovina front
}

by Lieutenant Stanca Dominic)

"I am in the city of Sighet, where I have to wait for the arrival of the detachment order to be sent to another unit on the front in Bukovina. I am waiting in this city built at foot of the mountains to depart again towards the tornado of death. For now, until I receive the order, I am assigned to the Sighet railway station, at the office in charge of the transport of the wounded, under the command of Colonel Maniu.

Today such transport was awaited. The 40 Division and the Units Dănilă Papp and Rus, both in the Valley of T,ibău and on Tătarca Mountain, have been engaged in heavy fights for several days. The deafening roar of the cannons penetrates even here, as if the crushed land was groaning from its entrails. We are getting ready to receive the wounded. The train composed of freight carriages arrives panting. It has barely stopped when, from inside the sealed carriages, arises the horrid bawls of the wounded. Some strike the sealed doors heavily with their clenched fists, while others shout for help, terrified. Bawls, horrifying snorts, roam through the bars of the windows. The sanitarians with the stretchers remain astounded in front of this hell of voices. In the clean, warm and bright air the rumble of enemy airplanes can be heard. We open wide the doors of the carriages. Those lightly injured get off by themselves.

Inside a frightening view: on the dirty floor, on a bed of bloody straw, lie the severely injured, the crippled. Some unconscious, with their eyes wide open and their faces as white as lime. Others pray in panic, moaning and shouting: Dear Mother! ...Help! ... My days...My children... My beloveds...I'm dying! ...Words babbled in Russian can also be heard but we didn't understand the language. Indescribable torture. Severely injured, some with broken bones, crippled, with their abdomen mangled, with torn limbs, others without jawbones, hit by bullets and splinters of bombshells, slammed like the cattle in the abattoir on the floor of the carriages, shaken by the iron wheels for more than a $80 \mathrm{~km}$ ride ... Terrible torment!

In some carriages, contorted in the spasms of death, with the fists clanged in a last strain, those who have already died stay still - without a trace of candle without a trace of solace. Amongst ours are Russian prisoners, wounded as well, some scared, others resigned, lying immobile with the fear of death in their hearts. On the floor bloody bandages, sloughs of blood abundantly drained, torn rags, the pervasive smell of coagulated blood and purulent wounds.

${ }^{30}$ The translation from Romanian to English was made by the author of the thesis. 
[...] From the recess of the Prislop Mountains, like from the depth of the earth, rises the deafening roar of the cannons. Death plays its mad dance on the peaks of the mountains and in the dead ends of the valleys... Other transports, other tortures, other mothers who shall cry their eyes out, other orphans becoming homeless...

In the afternoon I am called to the commandment, where I am given the detachment order for Iacobeni, in Bukovina where I have to present myself to the $11^{\text {th }}$ Cavalry Division.

I depart in a hurry for Borșa with my eyes fixed on the horizon that vanishes above the peaks of the tall mountains.

We hastily enter Borșa $[\ldots]$ We climb higher and higher along frightening serpentines to the crest of the Prislop Mountain. The locomotive lights up, gasps, strains along the curved climb crackling its chains. We pass the night on the heights of Prislop and early in the morning we descend in a mad rush towards Cârlibaba. The rattle of the wheels mixes with deaf thuds, which become louder and louder as we descend into the valley. We are in Bukovina, in the battlefield area. After a turn concealed by the Valley of Bistrița, Aurie Cârlibaba appears. From behind the ridge of the hills, deafening thuds... black funnels of smoke and soil squirt in the air... The joints of the mountains crackle under the fire of the weapons. On the forestdepleted peaks I can see units hurriedly sneaking into clouds of dust and smoke, and vanishing beyond the crest of the mountains.

Down in the valley improvised barracks cling to the rocks on the verge of the road. Soldiers, crushed by the weight of haversacks, their eyes lost on the sad horizon await resigned for their moment of departure and of death. Whip smacks and curses stimulate the oppressed, limp and drained horses to pull the heavy cannons and ammunition carts...In folds, morose cattle frazzled by hunger and thirst await too their supreme moment of sacrifice, of death, of comfort.

[...] On the $11^{\text {th }}$ January I finally receive permission for a two week leave. It has been eight months since I've been home. How many events have happened since then! How many tragedies! Tomorrow evening by this time I'll be on my way to Rodna Veche.

My soul is weighed down by a weird painful feeling. I am going home. But I don't have a home anymore. At home there has been war too, heavy fighting. Our home is destroyed and deserted, we don't have anything anymore. "Your father died in exile," my mother wrote to me. Where am I going? How happy I've been in the past during the school breaks when I returned to my parents' house, where every object, every corner reminded me of my childhood. Now it is over. War has happened; rivers of blood have flowed. The whirlwind has collapsed my parents' home and frozen the smile on our lips.

[...] I pass through Cârlibaba. The cemetery is filled with crosses which pierce my heart. The cattle and the hungry horses grieve my soul as the roack of Fluturica appears in front of me. The rumble of the cannons, the clicking of the machine guns have accompanied me far away, 
pressing on my brain. We cross the Bistriţa Bridge and turn left onto the slopes of the Rotunda Mountain. It's very dark only the white coating of snow lightens our way.

We barely pass over the slope before, in front of us, appear the Russian prisoners who are kept here for maintenance of the roads. Transfigured by cold, hunger and misery, in mangled cloths and with their feet wrapped in rags and straw, they run after the sleigh begging for food. The scene is horrible! I throw them my cigars and cigarettes, almost all that I have on me. I can see at the light of the fires along the road, how they run around the sleigh and how they struggle to get a hold of the offerings that are fallen on the frozen ground. On the other side of the slope, going down, I find Italian prisoners, many in summer clothes, contorted by the cold in improvised board shacks. "They die by the dozens the poor souls; they come from warm countries to here in the dreadful cold. Some sit coiled up around the fire staring with flabbergasted eyes as if they were condemned to death. Their misery, hunger and death horrifies me. I forget my own suffering; at least I have a little warmth and food and I am relatively free in comparison to their slavery. I shelter deeper in the blankets and straws. The sleigh flees away with me. I leave behind the great misfortune of the thousands of slaves.

It's a terrible cold. The tired horses barely crawl along the road. Late at night we reach Rodna. The bodies of the extenuated horses emanate steam. The teamster complains: "I have nothing left to feed them. The poor beasts are starving, I pity them so much that I can't eat either," said the hussar.

I climb on the heated train. But not even the stifling heat of the carriage can un-numb my heart. I bemoan the misfortune of the poor prisoners and beasts, innocents whipped on frozen roads..." (Stanca, 1935, p.1-3) 
APPENDIX 14

$\underline{\text { Romanian National Anthem }}^{31}$

\begin{tabular}{|c|c|c|}
\hline Original Romanian Verses & Phonetic transcription (IPA) & Literal Translation \\
\hline $\begin{array}{l}\text { Deșteaptă-te, române, din } \\
\text { somnul cel de moarte, } \\
\text { În care te-adânciră barbarii } \\
\text { de tirani } \\
\text { Acum ori niciodată } \\
\text { croiește-ți altă soarte, } \\
\text { La care să se-nchine și } \\
\text { cruzii tăi dușmani. }\end{array}$ & 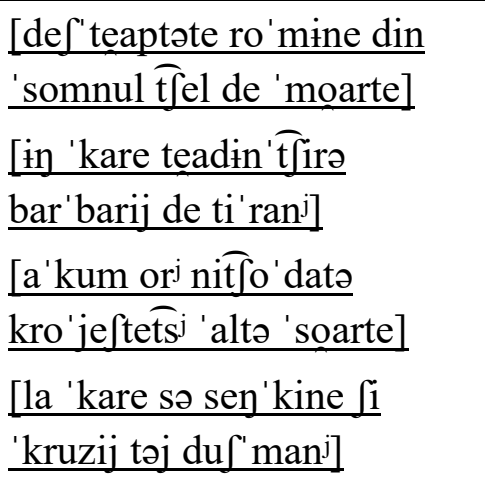 & $\begin{array}{l}\text { Wake up, Romanian, from the } \\
\text { sleep of death } \\
\text { Into which you have been } \\
\text { sunk by the barbaric tyrants } \\
\text { Now, or never, make a new } \\
\text { fate for yourself, } \\
\text { To which even your cruel } \\
\text { enemies will bow. }\end{array}$ \\
\hline $\begin{array}{l}\text { Acum ori niciodată să dăm } \\
\text { dovezi la lume } \\
\text { Că-n aste mâni mai curge } \\
\text { un sânge de roman, } \\
\text { Și că-n a noastre piepturi } \\
\text { păstrăm cu fală-un nume } \\
\text { Triumfător în lupte, un } \\
\text { nume de Traian. }\end{array}$ & 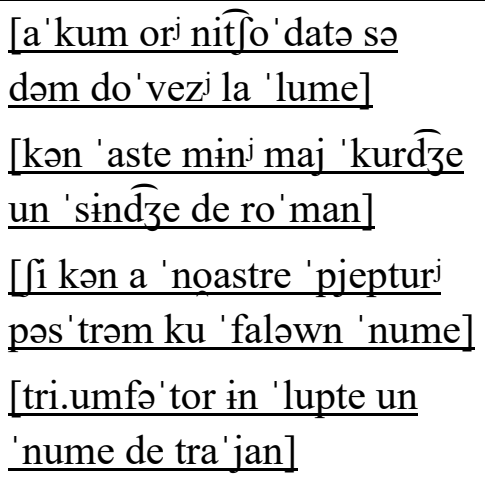 & $\begin{array}{l}\text { Now or never let us give } \\
\text { proof to the world } \\
\text { That in these veins a Roman } \\
\text { blood still flows, } \\
\text { That in our chests we hold a } \\
\text { name with pride, } \\
\text { Victorious in battle, the name } \\
\text { of Trajan! }{ }^{32}\end{array}$ \\
\hline $\begin{array}{l}\text { Înalță-ți lata frunte și caută- } \\
\text { n giur de tine, } \\
\text { Cum stau ca brazi în munte } \\
\text { voinici sute de mii; } \\
\text { Un glas ei mai așteaptă și } \\
\text { sar ca lupi în stâne, } \\
\text { Bătrâni, bărbați, juni, tineri, } \\
\text { din munți și din câmpii. }\end{array}$ & 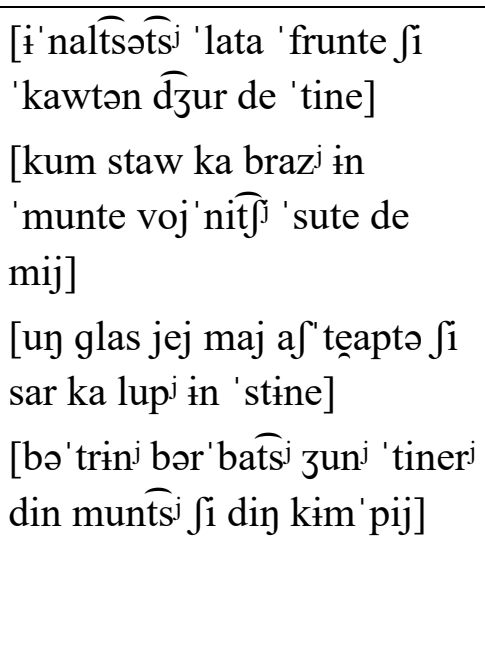 & $\begin{array}{l}\text { Raise your broad forehead } \\
\text { and see around you } \\
\text { How, like fir trees on a } \\
\text { mountain, hundreds of } \\
\text { thousands of strong men } \\
\text { stand; } \\
\text { Just waiting for a voice to } \\
\text { pounce like wolves on sheep, } \\
\text { Elders, men, youths, boys, } \\
\text { from the mountains and from } \\
\text { the plains. }\end{array}$ \\
\hline $\begin{array}{l}\text { Priviți, mărețe umbre, } \\
\text { Mihai, Ștefan, Corvine, }\end{array}$ & $\begin{array}{l}\text { [pri'vits }{ }^{\mathrm{j}} \text { mo'retse 'umbre } \\
\text { mi'haj]te'fan kor'vine] }\end{array}$ & $\begin{array}{l}\text { Behold, great shadows, } \\
\text { Michael, Stephen, Corvinus, }\end{array}$ \\
\hline
\end{tabular}

\footnotetext{
${ }^{31}$ Article available on-line at: https://en.wikipedia.org/wiki/De\%C8\%99teapt\%C4\%83-te, rom\%C3\%A2ne!

${ }^{32}$ The Roman emperor Trajan conquered Dacia, covering roughly the same territory as modern Romania, for the Roman Empire.
} 


\begin{tabular}{|c|c|c|}
\hline $\begin{array}{l}\text { Româna națiune, ai voștri } \\
\text { strănepoți, } \\
\text { Cu brațele armate, cu focul } \\
\text { vostru-n vine, } \\
\text { "Viața-n libertate ori } \\
\text { moarte" strigă toți. }\end{array}$ & 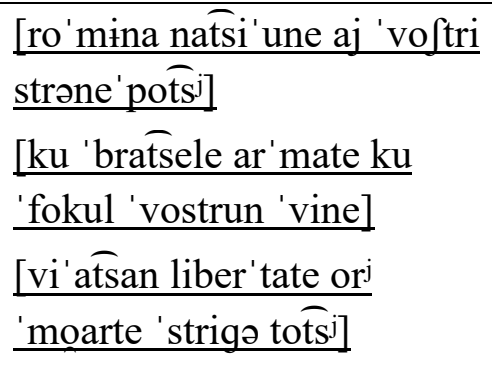 & $\begin{array}{l}\text { The Romanian Nation, your } \\
\text { great-grandchildren, } \\
\text { With weapons in their arms, } \\
\text { with your fire in their veins, } \\
\text { "Life in freedom or death!" } \\
\text { shout all. }\end{array}$ \\
\hline $\begin{array}{l}\text { Pre voi vă nimiciră a } \\
\text { pizmei răutate } \\
\text { Și oarba neunire la Milcov } \\
\text { și Carpați } \\
\text { Dar noi, pătrunși la suflet } \\
\text { de sfânta libertate, } \\
\text { Jurăm că vom da mâna, să } \\
\text { fim pururea fraţi. }\end{array}$ & 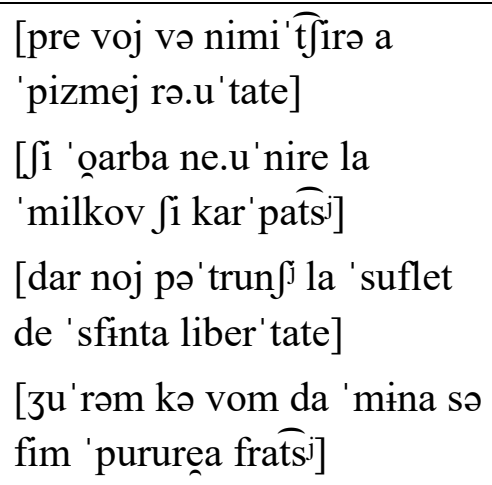 & $\begin{array}{l}\text { You were vanquished by the } \\
\text { evils of your envy } \\
\text { And by your blind disunity, at } \\
\text { Milcov and the Carpathians } \\
\text { But we, whose souls were } \\
\text { pierced by holy liberty, } \\
\text { Swear that forever in } \\
\text { brotherhood will join. }\end{array}$ \\
\hline $\begin{array}{l}\text { O mamă văduvită de la } \\
\text { Mihai cel Mare } \\
\text { Pretinde de la fiii-și azi } \\
\text { mână d-ajutori, } \\
\text { Și blastămă cu lacrămi în } \\
\text { ochi pe orișicare, } \\
\text { În astfel de pericul s-ar face } \\
\text { vânzători. }\end{array}$ & 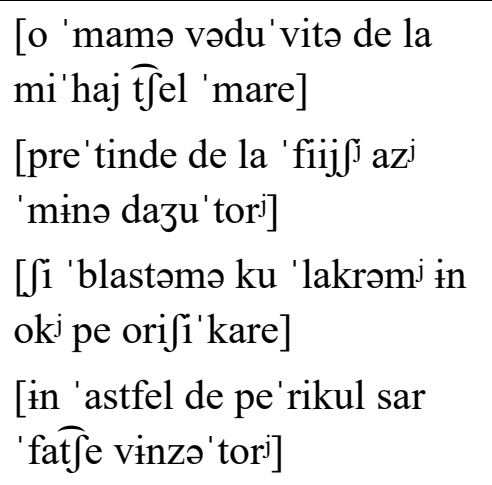 & $\begin{array}{l}\text { A widowed mother from the } \\
\text { time of Michael the Great } \\
\text { Claims from her sons today a } \\
\text { helping hand, } \\
\text { And with tears in her eyes } \\
\text { curses whomsoever, } \\
\text { In such great peril, a traitor } \\
\text { would become. }\end{array}$ \\
\hline $\begin{array}{l}\text { De fulgere să piară, de } \\
\text { trăsnet și pucioasă, } \\
\text { Oricare s-ar retrage din } \\
\text { gloriosul loc, } \\
\text { Când patria sau mama, cu } \\
\text { inima duioasă, } \\
\text { Va cere ca să trecem prin } \\
\text { sabie și foc. }\end{array}$ & 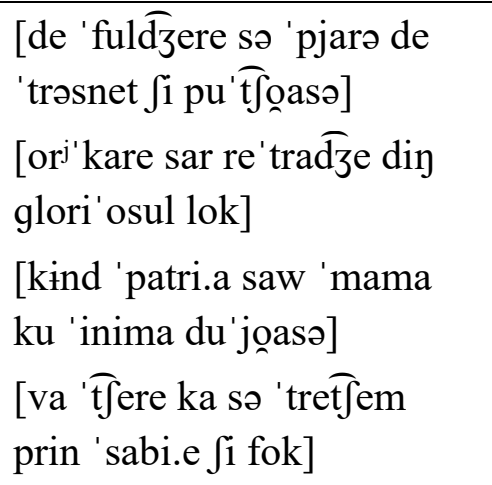 & $\begin{array}{l}\text { Of thunder and of brimstone } \\
\text { should they perish } \\
\text { Anyone who would flee the } \\
\text { glorious place } \\
\text { When our land or our mother, } \\
\text { with a sorrowful heart, } \\
\text { Will ask us to cross through } \\
\text { swords and blazing fire. }\end{array}$ \\
\hline $\begin{array}{l}\text { N-ajunge iataganul } \\
\text { barbarei semilune, } \\
\text { A cărui plăgi fatale şi azi le } \\
\text { mai simţim; } \\
\text { Acum se vâră cnuta în }\end{array}$ & 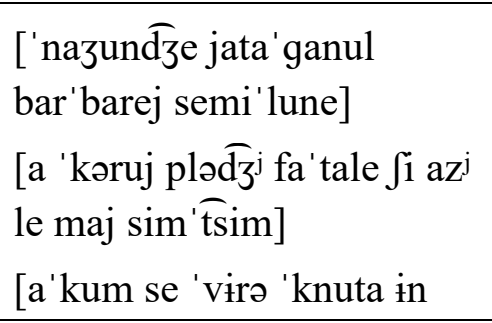 & $\begin{array}{l}\text { Didn't we have enough of the } \\
\text { yatagan of the barbaric } \\
\text { crescent } \\
\text { Whose fatal wounds we still } \\
\text { feel today; }\end{array}$ \\
\hline
\end{tabular}

\footnotetext{
${ }^{33}$ Michael briefly ruled the principalities of Wallachia, Moldavia and Transylvania, covering roughly the same territory as modern Romania.
} 


\begin{tabular}{|c|c|c|}
\hline $\begin{array}{l}\text { vetrele străbune, } \\
\text { Dar martor ne e Domnul că } \\
\text { vii nu o primim. }\end{array}$ & $\begin{array}{l}\text { 'vetrele stro'bune] } \\
\text { [dar 'martor ne je 'domnul } \\
\text { kə vij nu o pri' mim] }\end{array}$ & $\begin{array}{l}\text { Now the knout }{ }^{34} \text { is intruding } \\
\text { in our ancestral homes, } \\
\text { But the Lord is our witness } \\
\text { that we shall not accept it } \\
\text { alive. }\end{array}$ \\
\hline $\begin{array}{l}\text { N-ajunge despotismul cu- } \\
\text { ntreaga lui orbie, } \\
\text { Al cărui jug de seculi ca } \\
\text { vitele-l purtăm; } \\
\text { Acum se-ncearcă cruzii, cu } \\
\text { oarba lor trufie, } \\
\text { Să ne răpească limba, dar } \\
\text { morți numai o dăm. }\end{array}$ & 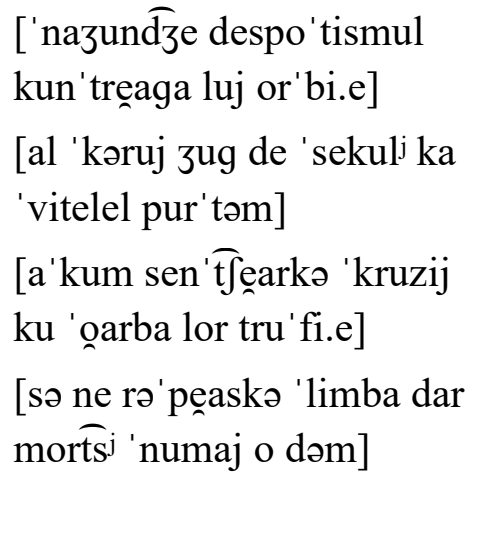 & $\begin{array}{l}\text { Didn't we have enough of the } \\
\text { blinded despotism, } \\
\text { Whose yoke, like cattle, for } \\
\text { centuries we have carried? } \\
\text { Now the cruel ones are trying, } \\
\text { in their blind arrogance, } \\
\text { To take away our language, } \\
\text { but only dead will we } \\
\text { surrender it. }\end{array}$ \\
\hline $\begin{array}{l}\text { Români din patru unghiuri, } \\
\text { acum ori niciodată } \\
\text { Uniți-vă în cuget, uniți-vă- } \\
\text { n simțiri. } \\
\text { Strigați în lumea largă că } \\
\text { Dunărea-i furată } \\
\text { Prin intrigă și silă, viclene } \\
\text { uneltiri. }\end{array}$ & 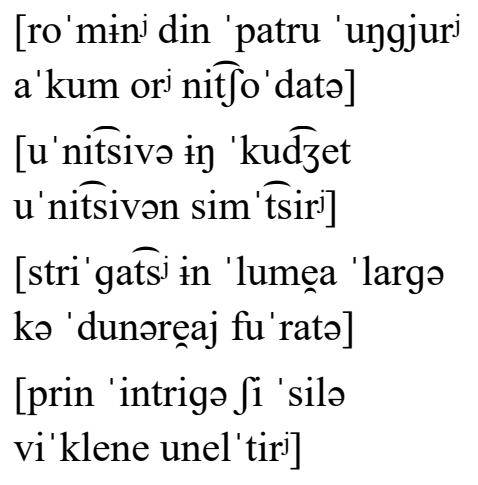 & $\begin{array}{l}\text { Romanians from the four } \\
\text { corners, now or never } \\
\text { Unite in thought, unite in } \\
\text { feeling } \\
\text { Proclaim to the wide world } \\
\text { that the Danube is stolen } \\
\text { Through intrigue and } \\
\text { coercion, sly machinations. }\end{array}$ \\
\hline $\begin{array}{l}\text { Preoți, cu crucea-n frunte } \\
\text { căci oastea e creștină, } \\
\text { Deviza-i libertate și scopul } \\
\text { ei preasfânt. } \\
\text { Murim mai bine-n luptă, cu } \\
\text { glorie deplină, } \\
\text { Decât să fim sclavi iarăși în } \\
\text { vechiul nost' pământ. }\end{array}$ & 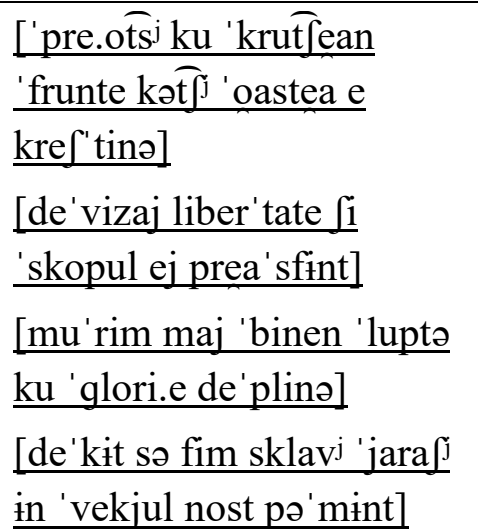 & $\begin{array}{l}\text { Priests, lead with your } \\
\text { crucifixes, for our army is } \\
\text { Christian, } \\
\text { The motto is Liberty and its } \\
\text { goal is holy, } \\
\text { Better to die in battle, in full } \\
\text { glory, } \\
\text { Than to once again be slaves } \\
\text { upon our ancient ground! }\end{array}$ \\
\hline
\end{tabular}

\footnotetext{
${ }^{34}$ A whip usually associated with Russia, as the yatagan was with the Ottomans.
} 
APPENDIX 15

The analytical inventory sheet of the Saint Ilie Tresviteanul Church $^{35}$

\begin{tabular}{|c|c|c|}
\hline \multicolumn{3}{|c|}{ 1. IDENTIFICATION } \\
\hline 1.1. & LHM Code & - \\
\hline 1.2 . & Category & II. Architecture \\
\hline 1.3 . & Official Name & Parochial church Saint Ilie Tresviteanul \\
\hline \multicolumn{3}{|c|}{ 2. ADMINISTRATIVE LOCATION } \\
\hline 2.1. & State & Romania \\
\hline 2.2 . & County & Maramureș \\
\hline 2.3 . & Locality & Borșa \\
\hline 2.4 . & Postal Code & 435200 \\
\hline 2.5 . & Street, current number & Decebal, No.15 \\
\hline 2.6 . & Previous locality & - \\
\hline 2.7 . & Street, previous number & - \\
\hline 2.8 . & Geographic co-ordinates & $\begin{array}{l}\text { Urban land } \\
\text { Land registry No. 51636, Topographic No. } 758 \mathrm{C} 1\end{array}$ \\
\hline 2.8.1. & Geographic references & - \\
\hline 2.8 .2 . & Cartographic identification & - \\
\hline 2.8.3. & Used co-ordinates system & - \\
\hline 2.8.4. & $\mathrm{X}, \mathrm{Y}, \mathrm{Z}$ Co-ordinates & - \\
\hline \multicolumn{3}{|c|}{ 3. Type of property } \\
\hline 3.1. & State & - \\
\hline 3.1.1. & State public property & - \\
\hline 3.1 .2 . & State private property & - \\
\hline 3.2 . & Mixt. property & - \\
\hline 3.3 . & Private property & Romanian Orthodox parish Borșa \\
\hline \multicolumn{3}{|c|}{ 4. Dating } \\
\hline 4.1. & Era & - \\
\hline 4.1.1. & Initial dating & - \\
\hline 4.1.2. & Conclusive dating & - \\
\hline 4.2. & Dating through periods & - \\
\hline 4.3 . & Dating through date intervals & - \\
\hline 4.4. & Exact dating & $1864-1886$ \\
\hline \multicolumn{3}{|c|}{ 5. Historic account. Persons and events associated with the history of the monument } \\
\hline 5.1. & \begin{tabular}{|l|} 
Historic account \\
\end{tabular} & $\begin{array}{l}\text { The parochial church Saint Prophet Ilie Tresviteanul } \\
\text { was built on the location of the wooden church that } \\
\text { was set on fire by the Tatars in } 1717 \text {. From the old }\end{array}$ \\
\hline
\end{tabular}

${ }^{35}$ The translation from Romanian to English was made by the author of the thesis. 


\begin{tabular}{|c|c|c|}
\hline & & $\begin{array}{l}\text { church only a few cult objects, old books and some } \\
\text { icons painted on wood are left. Construction of the } \\
\text { church began in } 1864 \text {, during the service of Dean } \\
\text { Alexiu Anderco, when the church was built as far as } \\
\text { the roof. In 1886, during the service of priest Basiliu } \\
\text { Dan, works at the church were continued and the } \\
\text { church tower was also finalised. Between } 1909 \text { and } \\
1939 \text {, the parish, guided by priest Gavrilă Timis, } \\
\text { created the iconostasis of the church. Between } 1942- \\
1959 \text { the interior and exterior of the church was } \\
\text { renovated and between 1959-1962 the tower was } \\
\text { rebuilt, and the roof covered with plate iron. The } \\
\text { painter Cenan Cornel from Cluj painted the church } \\
\text { between 1974-1977. }\end{array}$ \\
\hline 5.2 . & Author & - \\
\hline 5.3 . & Associate/Dormant Partner & - \\
\hline 5.4. & Founder/Benefactor & $\begin{array}{l}\text { During the service of Dean Alexiu Anderco, the } \\
\text { parishioners founded the church building while priest } \\
\text { Basiliu Dan founded the church tower. }\end{array}$ \\
\hline 5.5 . & Artisan & Ioan Bodorjocu and Iosif Grensner from Sighet \\
\hline 5.6. & Painter & Cornel Cenan from Cluj (1907-1992) \\
\hline \multicolumn{3}{|c|}{ 6. Description } \\
\hline 6.1. & Area & $\begin{array}{l}\text { The church and the cemetery are situated within a } \\
\text { collective housing complex developed in the 1970s. }\end{array}$ \\
\hline 6.2 . & $\begin{array}{l}\text { Elements of natural and } \\
\text { cultural landscape }\end{array}$ & - \\
\hline 6.2 .1 & Cultural landscape & - \\
\hline 6.2 .2 & Natural landscape & - \\
\hline 6.3. & Architectural category & Cult building/edifice \\
\hline 6.3 .1$. & Current function & Orthodox church \\
\hline 6.3 .2$. & Previous function & Greek-Catholic church \\
\hline 6.4. & $\begin{array}{l}\text { Description of individual } \\
\text { objective }\end{array}$ & \\
\hline 6.4 .1 & Plan & $\begin{array}{l}\text { The building is a hall-church, with an unhooked } \\
\text { pentagonal altar apse and the western side above the } \\
\text { entrance. }\end{array}$ \\
\hline 6.4 .2 & Façade & $\begin{array}{l}\text { The western façade, which shelters the entrance, is } \\
\text { flanked at the corners by buttresses, organised on two } \\
\text { levels. At the lower level it has a door framed by two } \\
\text { windows while the second level has three windows } \\
\text { separated by a semi-circular contour above which lies }\end{array}$ \\
\hline
\end{tabular}




\begin{tabular}{|c|c|c|}
\hline & & $\begin{array}{l}\text { a tympanum flanked by two turrets and a median } \\
\text { tower. } \\
\text { Both the northern and southern façade have four } \\
\text { bays, separated by two level buttresses, four windows } \\
\text { in broken arch style, with a simple semi-circular } \\
\text { cornice backed up by ornamental frieze. } \\
\text { The eastern facade of the pentagonal unhooked altar } \\
\text { has three windows in broken-arch style on the eastern } \\
\text { side, with cornices and friezes that continue onto the } \\
\text { lateral facades. }\end{array}$ \\
\hline 6.4.3. & Roof shape & $\begin{array}{l}\text { There is a two-sloped roof above the nave, connected } \\
\text { at the same level with the pyramidal roof above the } \\
\text { altar and having an octagonal crest above the tower. }\end{array}$ \\
\hline 6.4.4. & Extensions & None \\
\hline 6.4 .5 . & Annexes & None \\
\hline 6.5. & Structure & $\begin{array}{l}\text { The walls are made of stone with masonry buttresses, } \\
\text { the vault of wooden boards fixed on soffits; wooden } \\
\text { double arches lean on pilasters; the tower is of stone } \\
\text { masonry, wooden floors and wooden roof framing. }\end{array}$ \\
\hline 6.6 . & Construction materials & Stone, bricks, coniferous wood, plate iron. \\
\hline 6.6 .1 . & Roof construction materials & $\begin{array}{l}\text { Coniferous wood roof framing covered by painted } \\
\text { flat iron. }\end{array}$ \\
\hline 6.7 . & Construction techniques & Traditional \\
\hline 6.8 . & Stylistic framing & Neo-Gothic \\
\hline 6.9 . & Inscriptions & None \\
\hline \multicolumn{3}{|c|}{ 7. Conservation, restoration, threats } \\
\hline 7.1. & General conservation state & Good \\
\hline 7.2 . & Previous restoration works & $\begin{array}{l}\text { 1492-1959 exterior and interior repairs (decorative } \\
\text { plaster) } \\
1959-1962 \text { tower restoration, replacement of the roof } \\
\text { flat iron cover } \\
1974-1977 \text { interior painting }\end{array}$ \\
\hline 7.3 . & Risks/threatens & Inadequate intervention works \\
\hline 7.3.1. & Erosion & - \\
\hline 7.3.2. & Flooding & - \\
\hline 7.3.3. & Landslide & - \\
\hline 7.3.4. & Agriculture & - \\
\hline \multicolumn{3}{|c|}{ 8. Documentation } \\
\hline 8.1. & Bibliography & $\begin{array}{l}\text { Archive of Borșa II parish } \\
\text { www protopopiatVișeu }\end{array}$ \\
\hline 8.2 . & Archival records and reports & None \\
\hline
\end{tabular}




\begin{tabular}{|c|c|c|}
\hline 8.3 . & $\begin{array}{l}\text { Maps, plans, drawings/ } \\
\text { sketches }\end{array}$ & None \\
\hline 8.4 . & Photographs & \\
\hline 8.4 .1 . & Satellite imagery & Google Earth map \\
\hline 8.4 .3 . & Aerial photography & None \\
\hline 8.4 .3 . & $\begin{array}{l}\text { Black and white } \\
\text { photography }\end{array}$ & $\begin{array}{l}\text { The collection of Borșa's city library: } \\
\text { 1. Borșa in } 1940 \\
\text { 2. Borșa panoramic } 1940 \\
\text { 3. The Saint Ilie Church - undated } \\
\text { 4. The Painter Cenan Cornel visiting Saint } \\
\text { Nicholas Church in Teuș (1953-1956) } \\
\text { 5. The monument wooden church Holy } \\
\text { Archangels and the masonry Church } \\
\text { Constantin and Elena (1937). }\end{array}$ \\
\hline 8.4.4. & Colour photography & Attached to the file \\
\hline 8.5. & Documentary attestation & $1864-1886$ \\
\hline \multicolumn{3}{|c|}{ 9. Ranking level } \\
\hline 9.1. & Value class & B \\
\hline 9.2 . & $\begin{array}{l}\text { Category in merit of the } \\
\text { nature of the object } \\
\text { I } \\
\text { II } \\
\text { III } \\
\text { IV }\end{array}$ & II \\
\hline 9.3 . & Global evaluation criterions & $\begin{array}{l}\text { a) Age criterion: } \\
\text { Mark HIGH } \\
\text { b) Criterion concerning the architectural, artistic and } \\
\text { urban value: } \\
\text { Mark MEDIUM } \\
\text { c) Frequency criterion: } \\
\text { Mark HIGH } \\
\text { d) Criterion regarding memorial-symbolic value: } \\
\text { Mark MEDIUM }\end{array}$ \\
\hline 9.4. & $\begin{array}{l}\text { Data and number of the } \\
\text { ranking document }\end{array}$ & - \\
\hline 9.5. & Urban regulations & - \\
\hline \multicolumn{3}{|c|}{ 10. Inventory } \\
\hline 10.1. & $\begin{array}{l}\text { Name of the institution that } \\
\text { built up the sheet }\end{array}$ & - \\
\hline 10.2 . & $\begin{array}{l}\text { Author of the sheet and its } \\
\text { quality }\end{array}$ & - \\
\hline
\end{tabular}




\begin{tabular}{|c|c|c|}
\hline 10.2.1. & Surname & Mitru \\
\hline 10.2.2. & First Name & Ildiko \\
\hline 10.2.3. & Capacity & $\begin{array}{l}\text { Architect, Ministry of Culture and National Heritage } \\
\text { expert }\end{array}$ \\
\hline 10.2.4. & $\begin{array}{l}\text { Autograph signature of the } \\
\text { specialist who prepared the } \\
\text { sheet }\end{array}$ & - \\
\hline 10.2.5. & $\begin{array}{l}\text { Signature and stamp of chief } \\
\text { of the institution that issued } \\
\text { the sheet }\end{array}$ & - \\
\hline 10.3 . & $\begin{array}{l}\text { The number of the validation } \\
\text { minutes issued by the } \\
\text { Regional commission of } \\
\text { Historic Monuments }\end{array}$ & - \\
\hline 10.3.1. & $\begin{array}{l}\text { Number of the ranking } \\
\text { document }\end{array}$ & - \\
\hline 10.3.2. & Date of ranking order & - \\
\hline 10.4 & Date of sheet composition & 11.07 .2011 \\
\hline
\end{tabular}




\section{APPENDIX 16}

Hypothetic analytical inventory sheet of the Prislop Pass war sites

\begin{tabular}{|c|c|c|}
\hline \multicolumn{3}{|c|}{ 1. IDENTIFICATION } \\
\hline 1.1. & LHM Code & - \\
\hline 1.2 . & Category & IV Memorial monuments \\
\hline 1.3 . & Official Name & Prislop Pass war sites \\
\hline \multicolumn{3}{|c|}{ 2. ADMINISTRATIVE LOCATION } \\
\hline 2.1. & State & Romania \\
\hline 2.2 . & County & Maramureș \\
\hline 2.3 . & Locality & Borşa \\
\hline 2.4. & Postal Code & \\
\hline 2.5 . & Street, current number & \\
\hline 2.6. & Previous locality & - \\
\hline 2.7. & Street, previous number & - \\
\hline 2.8 . & Geographic co-ordinates & See results chapter 1 \\
\hline 2.8 .1 & Geographic references & - \\
\hline 2.8 .2 . & Cartographic identification & - \\
\hline 2.8 .3 & Used co-ordinates system & $W G S 84$ \\
\hline 2.8 .4 & $\mathrm{X}, \mathrm{Y}, \mathrm{Z}$ Co-ordinates & - \\
\hline \multicolumn{3}{|c|}{ 3. Type of property } \\
\hline 3.1. & State & - \\
\hline 3.1.1. & State public property & - \\
\hline 3.1 .2 & State private property & - \\
\hline 3.2. & Mixt. property & Mixed state-private property \\
\hline 3.3. & Private property & \\
\hline \multicolumn{3}{|c|}{ 4. Dating } \\
\hline 4.1. & Era & - \\
\hline 4.1.1. & Initial dating & - \\
\hline 4.1.2. & Conclusive dating & - \\
\hline 4.2. & Dating through periods & - \\
\hline 4.3. & $\begin{array}{lll}\text { Dating } & \text { through } & \text { date } \\
\text { intervals } & & \\
\end{array}$ & - \\
\hline 4.4. & Exact dating & $1915-1918$ \\
\hline \multicolumn{3}{|c|}{ 5. Historic account. Persons and events associated with the history of the monument } \\
\hline 5.1. & Historic account & $\begin{array}{l}\text { The first battles of the Russian invasion in the } \\
\text { Carpathians during WWI occurred in the region of } \\
\text { Maramureș starting from September 1914. The } \\
\text { Russian incursion was perceived as a great threat }\end{array}$ \\
\hline
\end{tabular}




\begin{tabular}{|c|c|c|}
\hline & 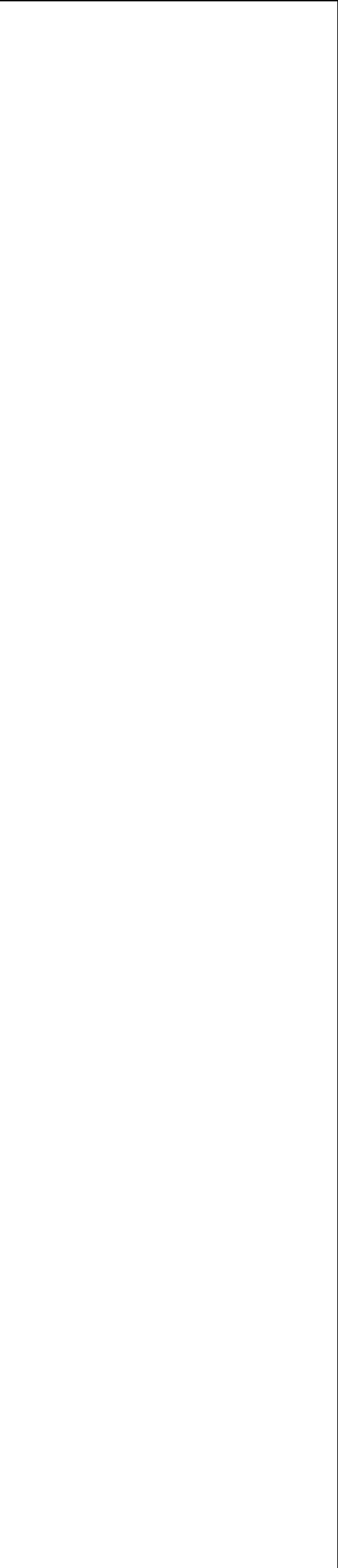 & 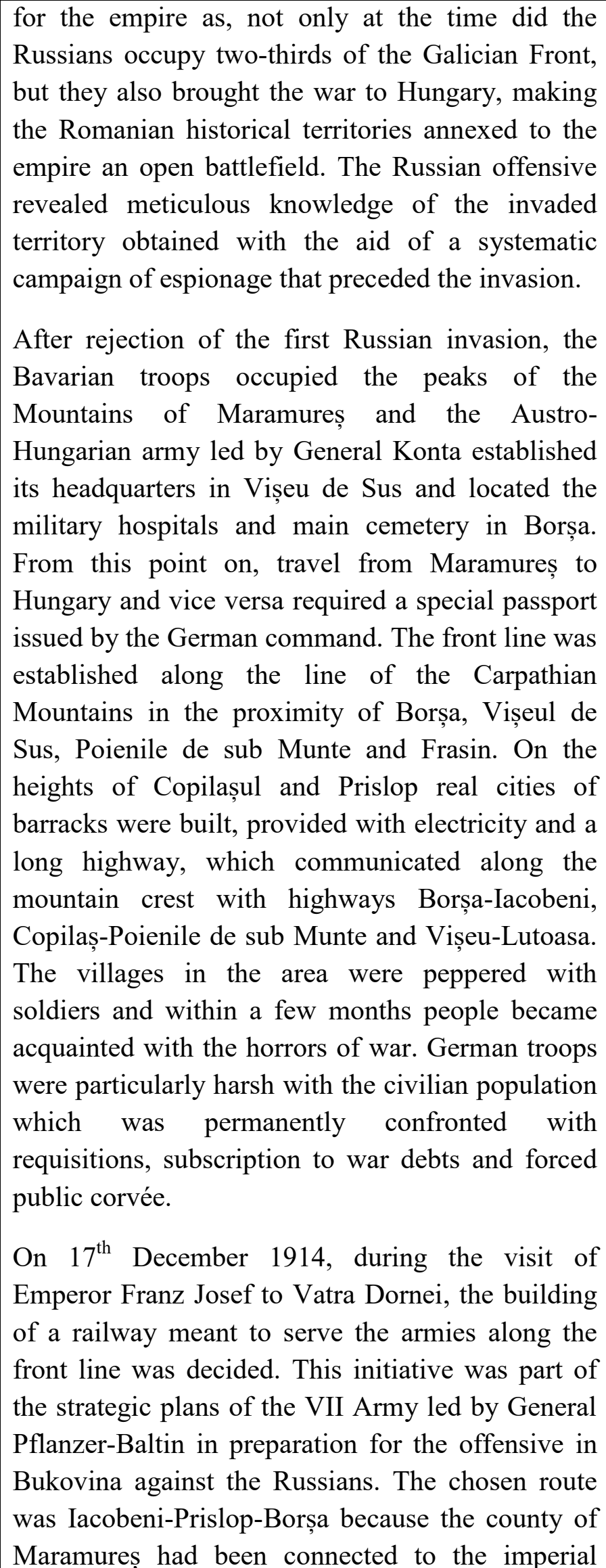 \\
\hline
\end{tabular}




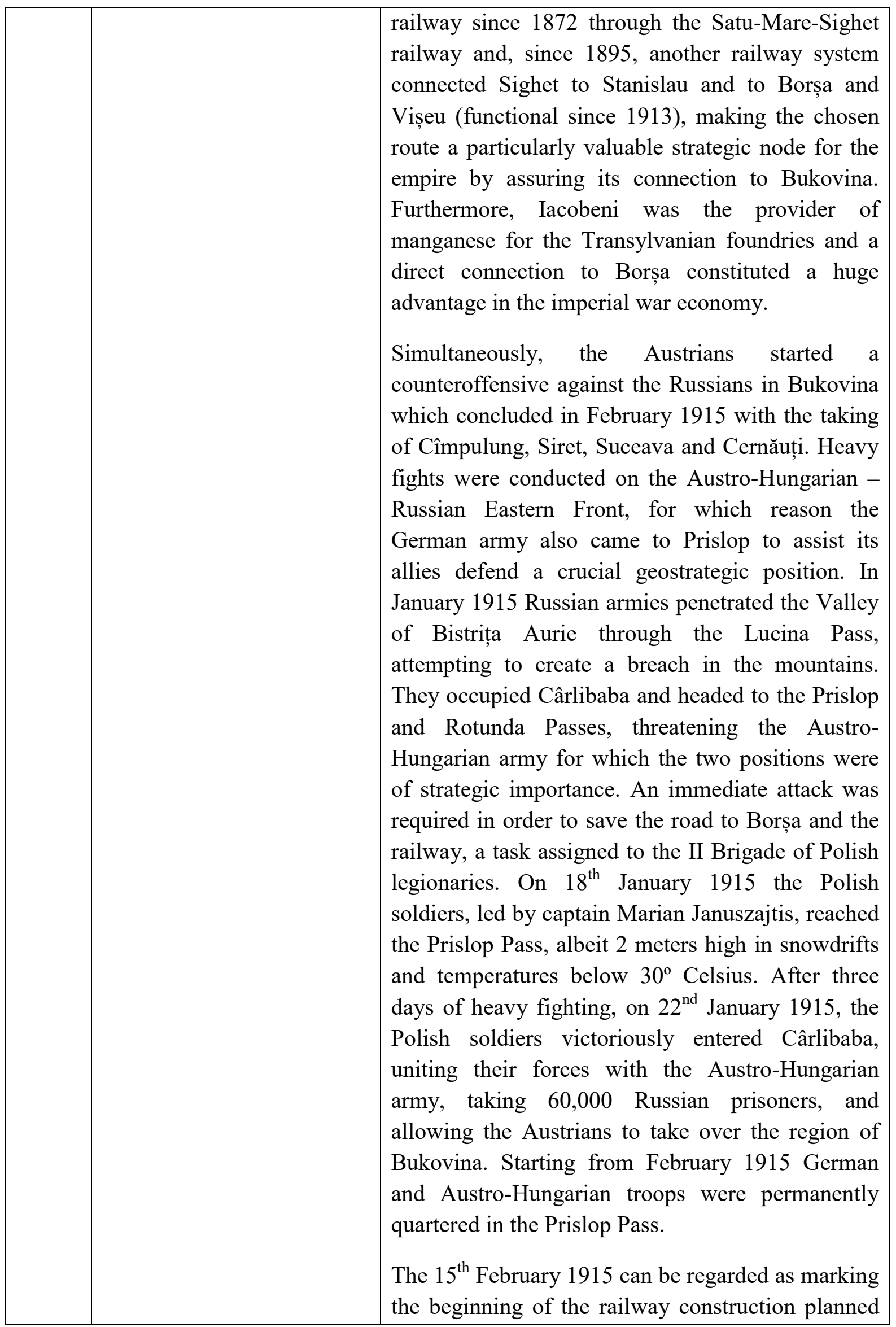




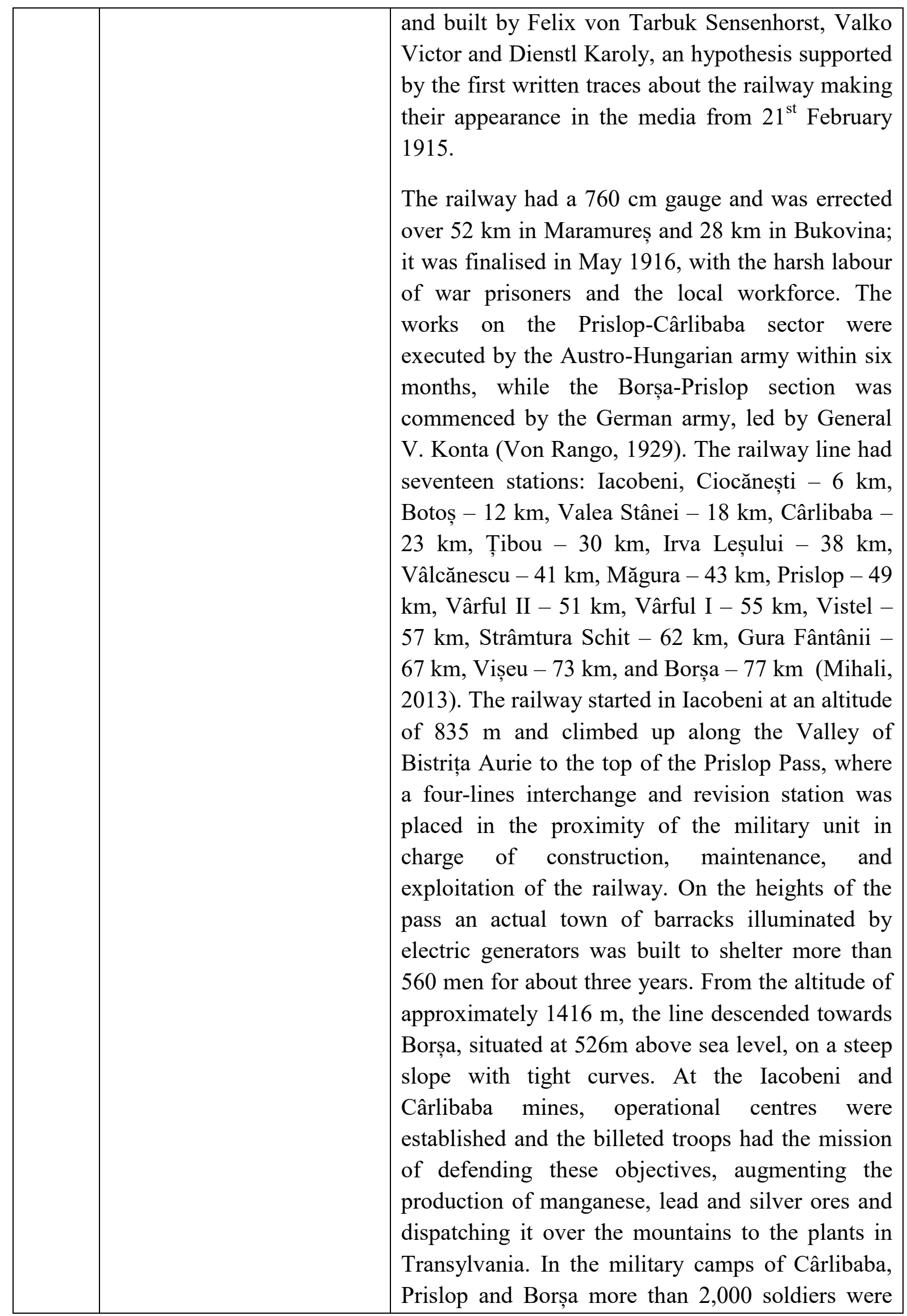




\begin{tabular}{|c|c|c|}
\hline & 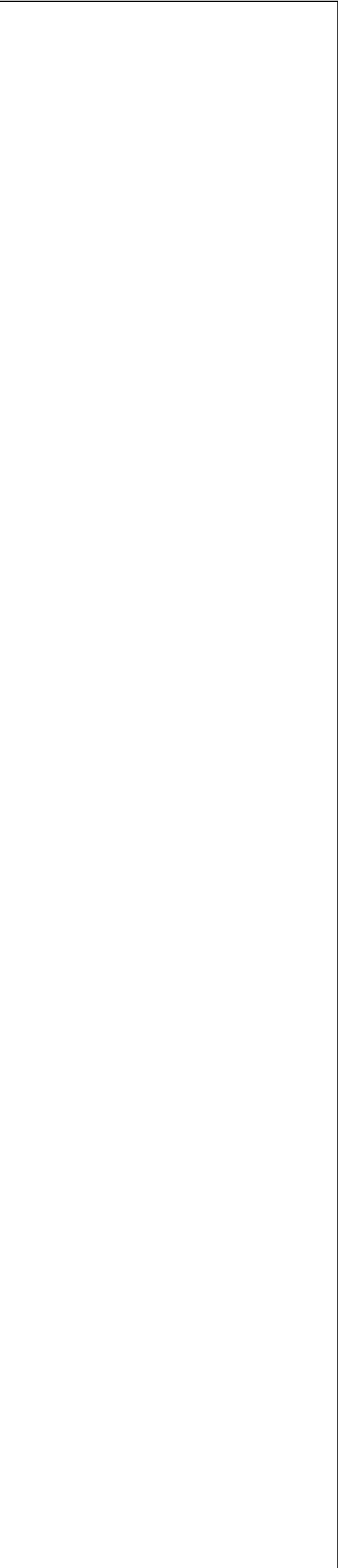 & 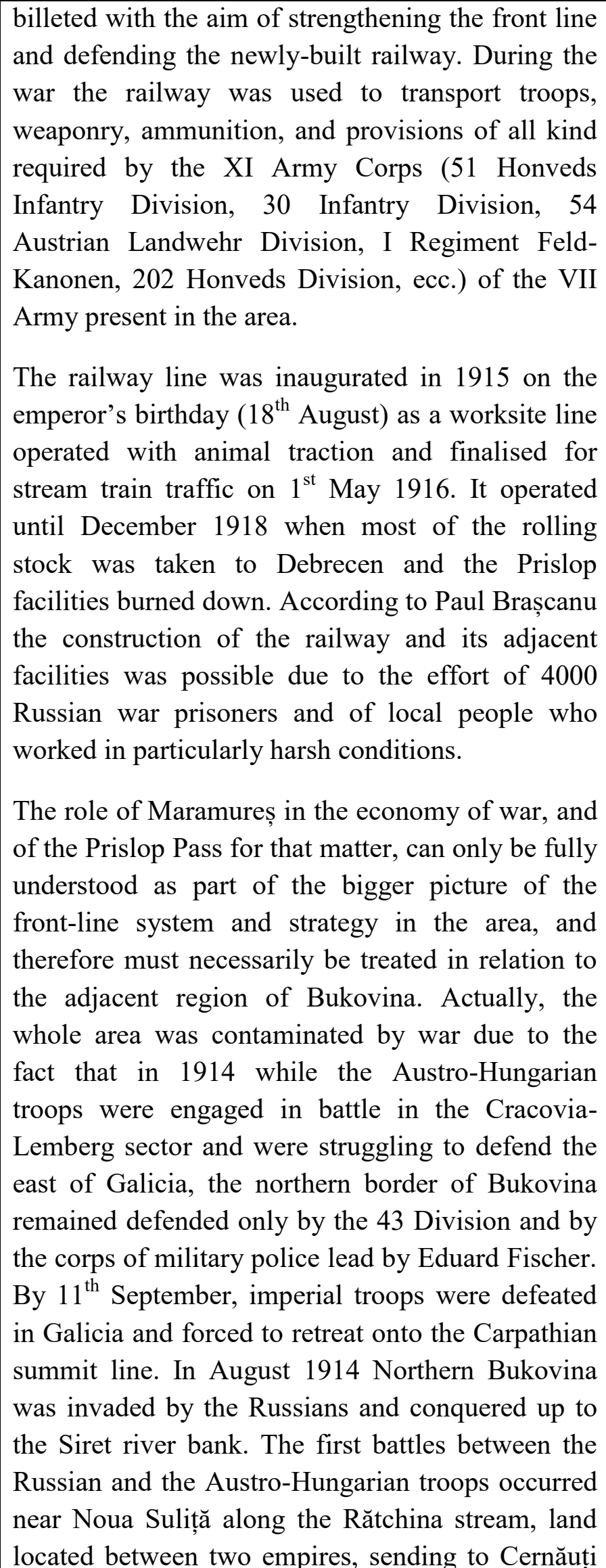 \\
\hline
\end{tabular}




\begin{tabular}{|c|c|c|}
\hline & & $\begin{array}{l}\text { the first cargo of wounded. The situation in Galicia } \\
\text { largely dominated by the Russians led to the } \\
\text { isolation of Bukovina by cutting off its connections } \\
\text { to the Austro-Hungarian empire. At the end of } \\
\text { 1914, since the front line was established in the } \\
\text { direction of Huszt-Sighet-Borșa-Cârlibaba- } \\
\text { Mestecănis, the Austro-Hungarians found } \\
\text { themselves in desperate need of new transport } \\
\text { routes to supply the troops blocked in Bukovina } \\
\text { and sustain the war effort in this strategic region. It } \\
\text { was from these roots that the construction of the } \\
\text { Iacobeni-Prislop-Borșa railway was decided. } \\
\text { The strategic importance of this front line is also } \\
\text { proven by interest in the area shown by great } \\
\text { historic personalities such as Carol IX, Wilhelm II, } \\
\text { the Archduke of Austria Karl Franz Josef, Kaiser } \\
\text { Wilhelm II, Feldmarschal Hermann Kovess von } \\
\text { Kovesshaza - last Supreme Commander of the } \\
\text { Austro/Hungarian army - and Field Marshal } \\
\text { Friedrich, Archduke of Austria and Duke of } \\
\text { Teschen. Czar Nicholas II of Russia, General A.A. } \\
\text { Brusilov, the Great Duke Mihail Alexandrovici } \\
\text { Romanov, Archduke Leopold Salvador and, of } \\
\text { course, Generals Pflanzer-Baltin, Conrad von } \\
\text { Hotzendorf, von Hindenburg, von Mackensen, and } \\
\text { others, also made their presence felt in loco as } \\
\text { emerges from WWI photography (Brășcanu, 2015, } \\
\text { pp.72-100). }\end{array}$ \\
\hline 5.2. & Author & $\begin{array}{l}\text { Austro-Hungarian army, German army, Romanian } \\
\text { locals and international war prisoners. }\end{array}$ \\
\hline 5.3. & Associate/Dormant Partner & - \\
\hline 5.4 . & Founder/Benefactor & $\begin{array}{l}\text { Emperor Franz Josef, Felix von Tarbuk } \\
\text { Sensenhorst, Valko Victor and Dienstl Karoly }\end{array}$ \\
\hline 5.5 . & Artisan & - \\
\hline 5.6 . & Painter & - \\
\hline \multicolumn{3}{|c|}{ 6. Description } \\
\hline 6.1 . & Area & $\begin{array}{l}\text { The Prislop War sites are situated within the } \\
\text { administrative territory of the city of Borșa and } \\
\text { embedded in a natural area of several square }\end{array}$ \\
\hline
\end{tabular}




\begin{tabular}{|c|c|c|}
\hline & & $\begin{array}{l}\text { kilometres that, along with the material culture of } \\
\text { war, constitute a veritable and magnificent } \\
\text { conflictual landscape. }\end{array}$ \\
\hline 6.2 . & $\begin{array}{l}\text { Elements of natural and } \\
\text { cultural landscape }\end{array}$ & $\begin{array}{l}\text { In relation to the natural context, the war sites } \\
\text { emphasise close interconnections between } \\
\text { anthropic and natural elements by embedding war } \\
\text { architecture pertaining to the WWI Prislop military } \\
\text { city and the adjacent defence system into the } \\
\text { strategic yet picturesque mountainous landscape. } \\
\text { The wound inflicted by the war upon the lands, } \\
\text { patiently nurtured by the natural environment, } \\
\text { cicatrised along the century preserving its } \\
\text { wilderness and continuing to shelter rare species } \\
\text { and natural habitats which coined its status of } \\
\text { Natura } 2000 \text { site. } \\
\text { The architectonical features bear testimony to the } \\
\text { fact that the Great War not only reshaped the } \\
\text { balances of power, redefined borders or wrote } \\
\text { fundamental pages of national history for several } \\
\text { states, but also shaped the identity of the land, } \\
\text { redefining the landscape. The war remains } \\
\text { represent a form of warfare specificity that hold the } \\
\text { idiosyncrasies of a specific historic time and a } \\
\text { specific form of conflict. Earth works and concrete } \\
\text { bunkers became the signature of the industrial war } \\
\text { on account of the conversion of dug-in defences for } \\
\text { terrestrial and airborne warfare in a hallmark that } \\
\text { rooted conflict within the earth. The Great War } \\
\text { inaugurated a procedure of environmental incisions } \\
\text { that branded the places of war with the world war } \\
\text { mark. Bunkers, trench systems, mine craters were } \\
\text { all carved wounds in the landscape, wounds that in } \\
\text { time turned into scars giving the natural } \\
\text { environment pride and personality, converting } \\
\text { space into place. }\end{array}$ \\
\hline 6.2 .1 . & Cultural landscape & $\begin{array}{l}\text { In the Romanian culture the several categories of } \\
\text { war materials that build up the war places and the } \\
\text { adjacent landscape bear testimony to the memory } \\
\text { of the Great War and its highly symbolic power as } \\
\text { materialised in the Grand Union national narrative. } \\
\text { The Great War and the Great Union share intimate }\end{array}$ \\
\hline
\end{tabular}




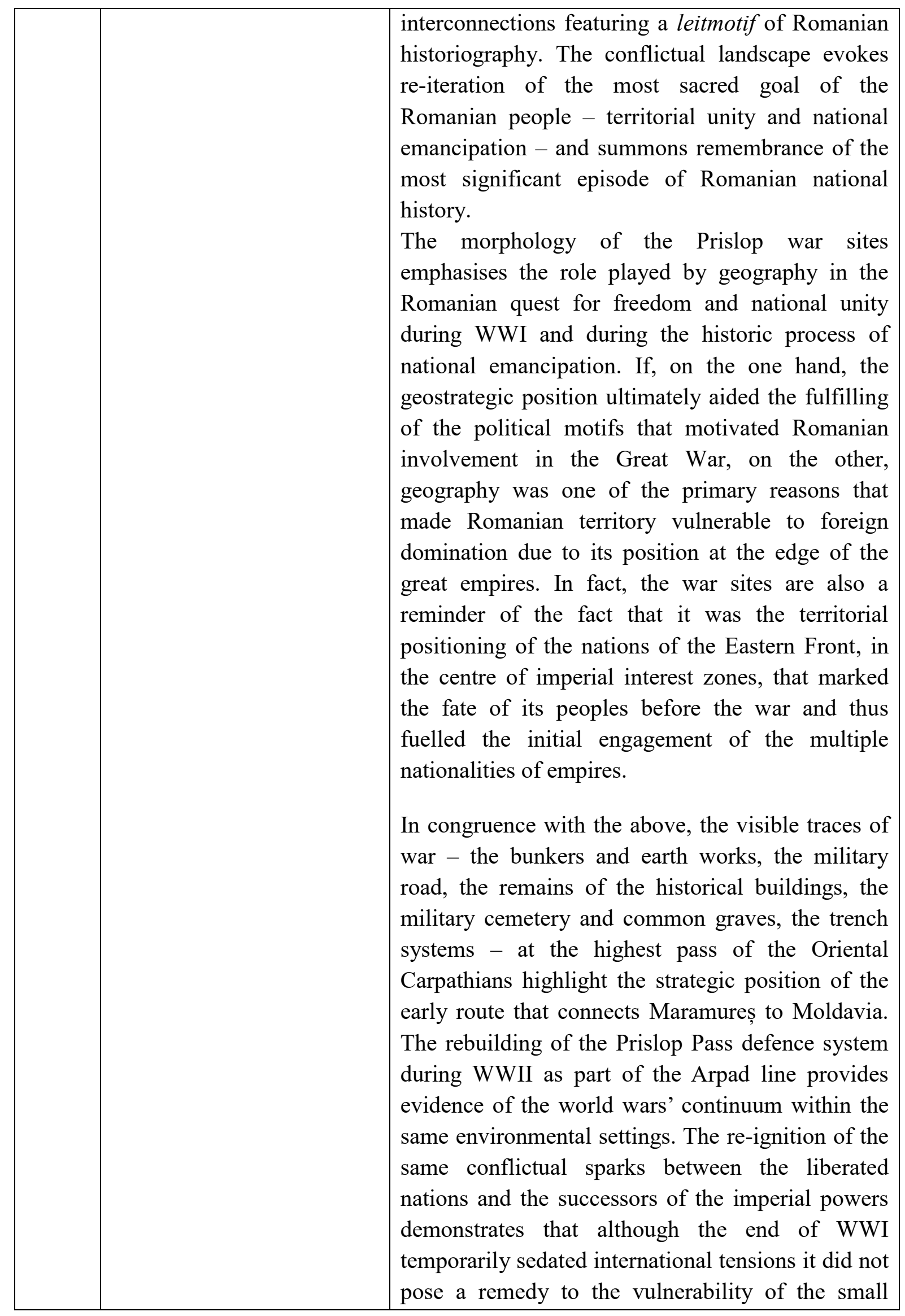




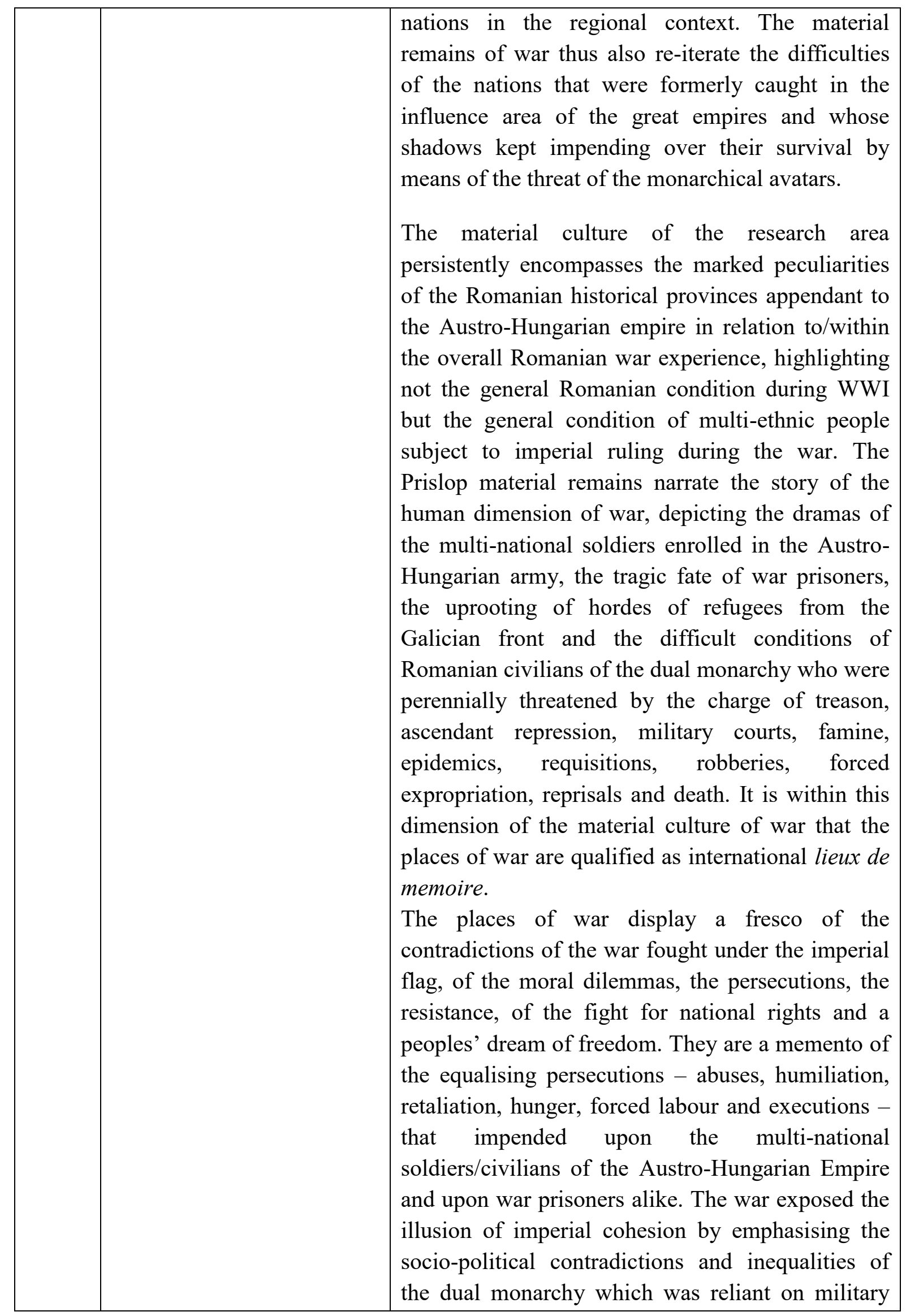




\begin{tabular}{|c|c|c|}
\hline & & $\begin{array}{l}\text { repression to keep the multi-ethnic populus } \\
\text { obedient and subdued. } \\
\text { The material evidence provided by the war sites } \\
\text { illustrates, integrates and anchors the entire arena } \\
\text { of Romanian war writings generated by the } \\
\text { complex social and historical circumstances of the } \\
\text { war. The impact of the Great War on Romanian } \\
\text { collective consciousness translated into a fecund } \\
\text { field of literature and folklore concentrated around } \\
\text { the Romanian quest for freedom, self- } \\
\text { determination and national unity. Such leitmotifs, } \\
\text { framed as the utterly sacred cause of the Romanian } \\
\text { people, have informed the national master narrative } \\
\text { over the past hundred years and continue to be } \\
\text { perceived as such a century after the end of the war } \\
\text { and achievement of the Great Union. Revisiting the } \\
\text { poetry, literature, ethnographic and folkloric } \\
\text { compositions of countries relegated to the Eastern } \\
\text { Front enables the rebalancing of war accounts of } \\
\text { the two fronts, broadening an holistic } \\
\text { understanding of the war, which allows exploration } \\
\text { of a new dimension of the feelings and motivations } \\
\text { of those who fought the war, one that is less } \\
\text { monolithic and unanimous. } \\
\text { The conflictual landscape is also representative of } \\
\text { the Romanian traditional assertion of freedom, } \\
\text { which was intimately connected to and envisioned } \\
\text { in communion with the land dimension. It was the } \\
\text { re-appropriation of their ancestral land that, in the } \\
\text { Romanian vision, incarnated materialisation of the } \\
\text { achievement of freedom and self-determination and } \\
\text { thus of national rights. For countries such as } \\
\text { Romania the recovery of lost territories constituted } \\
\text { the main reason that fuelled their involvement in } \\
\text { WWI as the land, perceived as pater patriae } \\
\text { personified the guarantee of their national rights, } \\
\text { which frames WWI as the last 'land' war. } \\
\text { Furthermore, beyond embodying a cultural } \\
\text { importance, as accounted for previously, the war }\end{array}$ \\
\hline
\end{tabular}




\begin{tabular}{|c|c|c|}
\hline & & 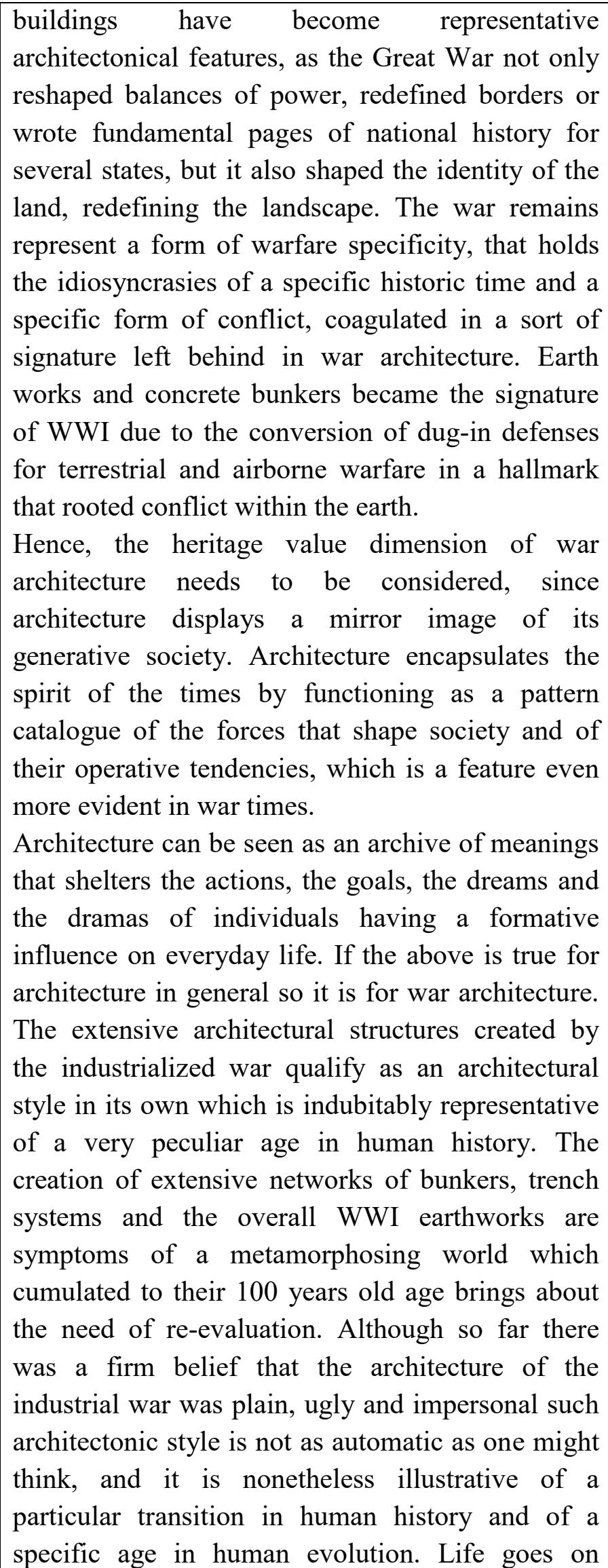 \\
\hline
\end{tabular}




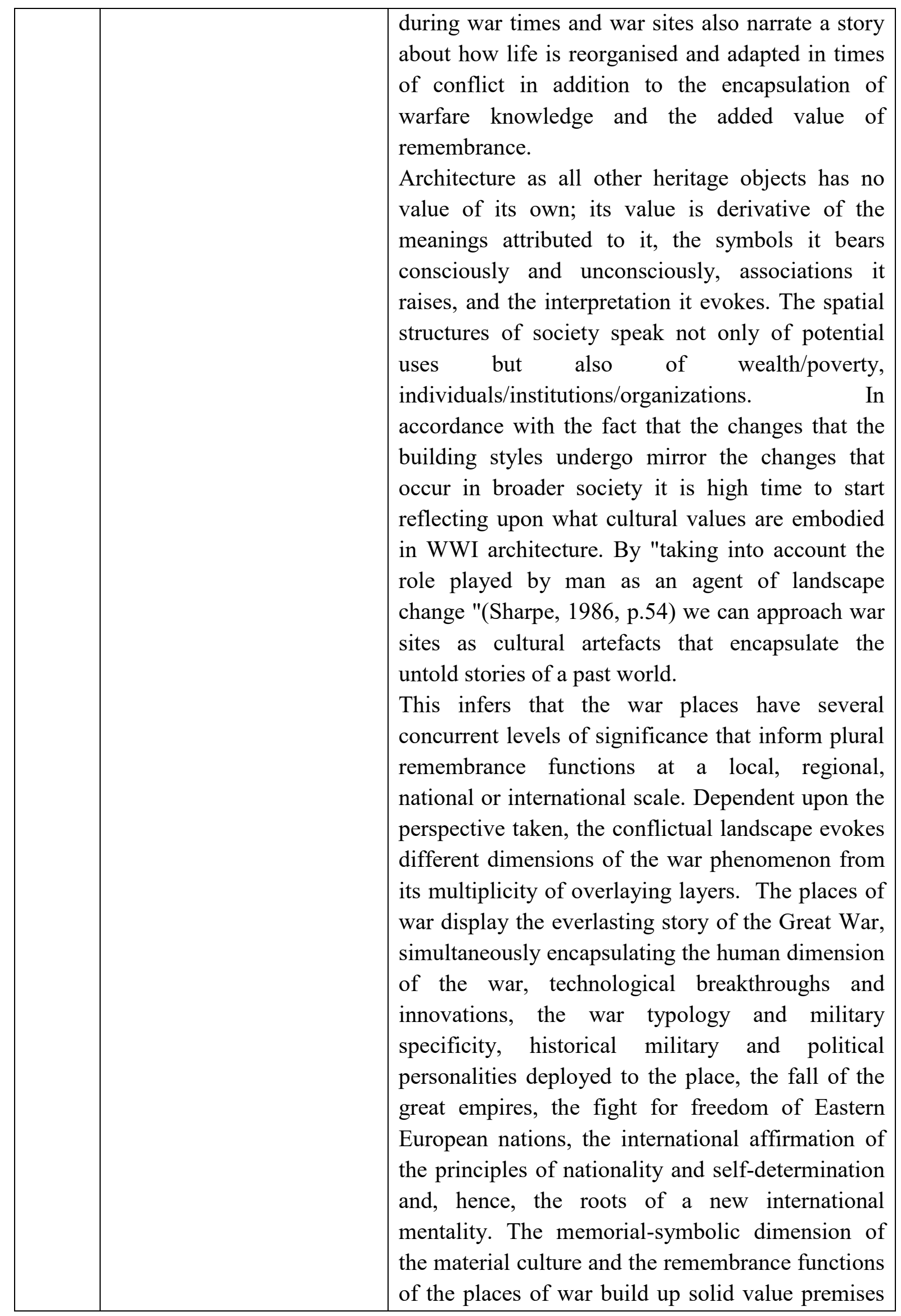




\begin{tabular}{|c|c|c|}
\hline & & $\begin{array}{l}\text { favourably pleading for assessment of their } \\
\text { heritage worth. }\end{array}$ \\
\hline 6.2 .2 . & Natural landscape & $\begin{array}{l}\text { The war sites are embedded in a natural protected } \\
\text { site due to belonging to the territory of the } \\
\text { Maramures Mounains National Park which has } \\
\text { Natura } 2000 \text { site status. }\end{array}$ \\
\hline 6.3 . & Architectural category & War architecture \\
\hline 6.3 .1$. & Current function & - \\
\hline 6.3 .2 . & Previous function & \\
\hline 6.4. & $\begin{array}{l}\text { Description of individual } \\
\text { objective }\end{array}$ & $\begin{array}{l}\text { The various components of the war sites build up } \\
\text { several categories of war remains and various } \\
\text { typologies within the same category providing a } \\
\text { varied collection of WWI material culture. The } \\
\text { several categories of materials that build up the } \\
\text { conflictual landscape are: } \\
\text { - Building foundations - although uneven in terms } \\
\text { of size they all have rectangular shape and are } \\
\text { made of stone with joints of slaked lime or cement } \\
\text { and gravel, except for feature } 19 \text { and } 75 \text { which } \\
\text { have square shape, are made of concrete and are } \\
\text { covered with a layer of bitumen. They might be the } \\
\text { foundations of large buildings such as the railway } \\
\text { station, the funicular warehouse, the hospital, } \\
\text { stables, etc. } \\
\text { - Pits - found in the proximity of the building } \\
\text { foundations, earthworks and trenches, the pits are } \\
\text { mostly squarish holes in the ground of various sizes } \\
\text { from } 1 \text { to } 4 \text { m (sides) and approximately } 1 \text { m deep } \\
\text { whose surface is peppered with earth bricks and } \\
\text { shaped stones. The only features in this category } \\
\text { that constitute an exception to this rule are features } \\
92 \text { and } 96 \text { which are slightly rectangular and } \\
\text { present much bigger dimensions than the previous } \\
\text { cases, reaching a maximum length of } 12 \text { m, } 10 \text { m } \\
\text { width and } 3 \text { m depth. The first case is likely to } \\
\text { represent dug-in defenses for small cannons/ } \\
\text { machineguns, dugouts or storage while the second } \\
\text { might be the result of large-scale explosions. } \\
\text { - four-sided earthworks - rectangular or square } \\
\text { embankments excavated in the hill slope that } \\
\text { present an entrance, usually on the side opposing } \\
\text { the hill slope (exception for Feature } 16 \text { ), whose }\end{array}$ \\
\hline
\end{tabular}




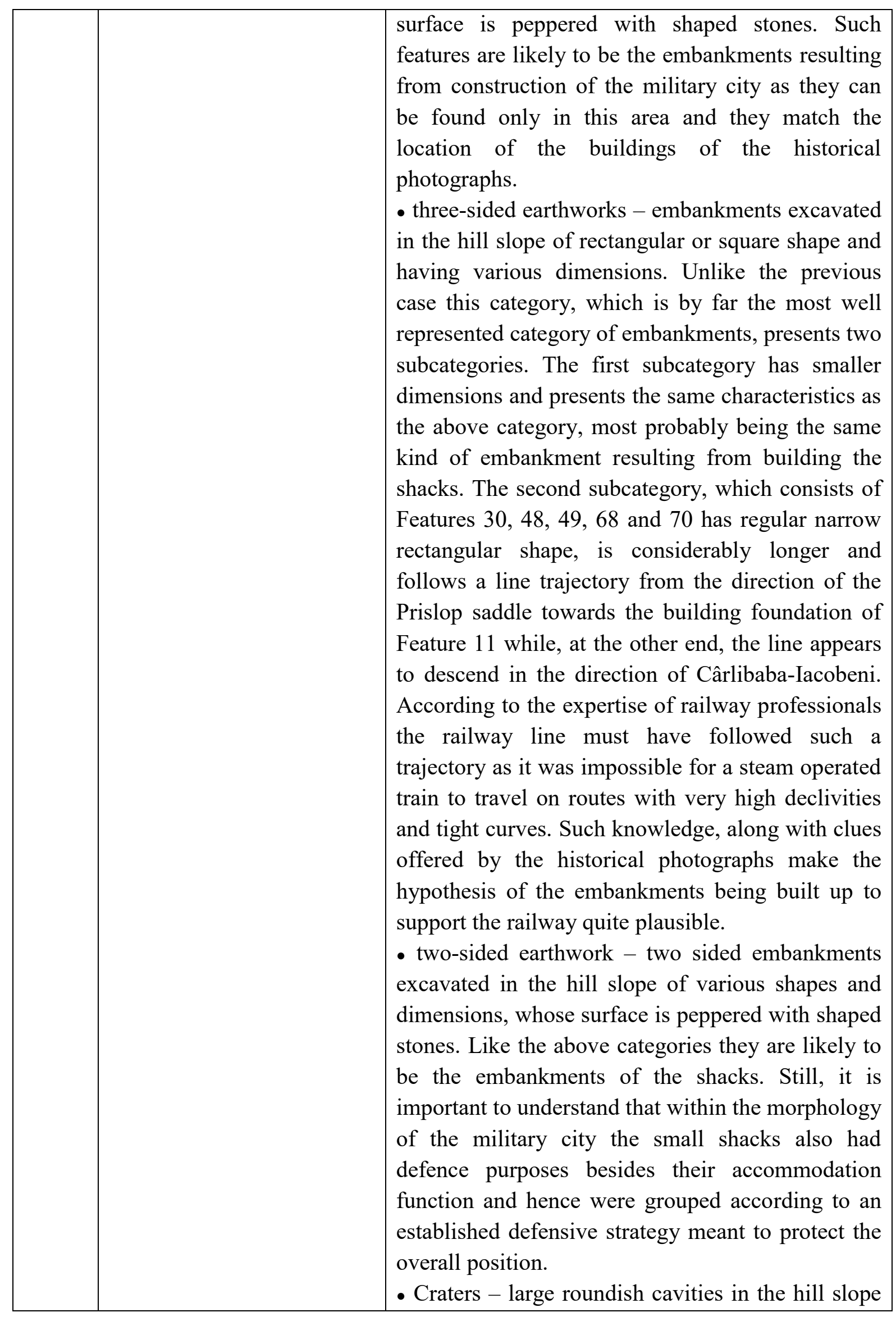




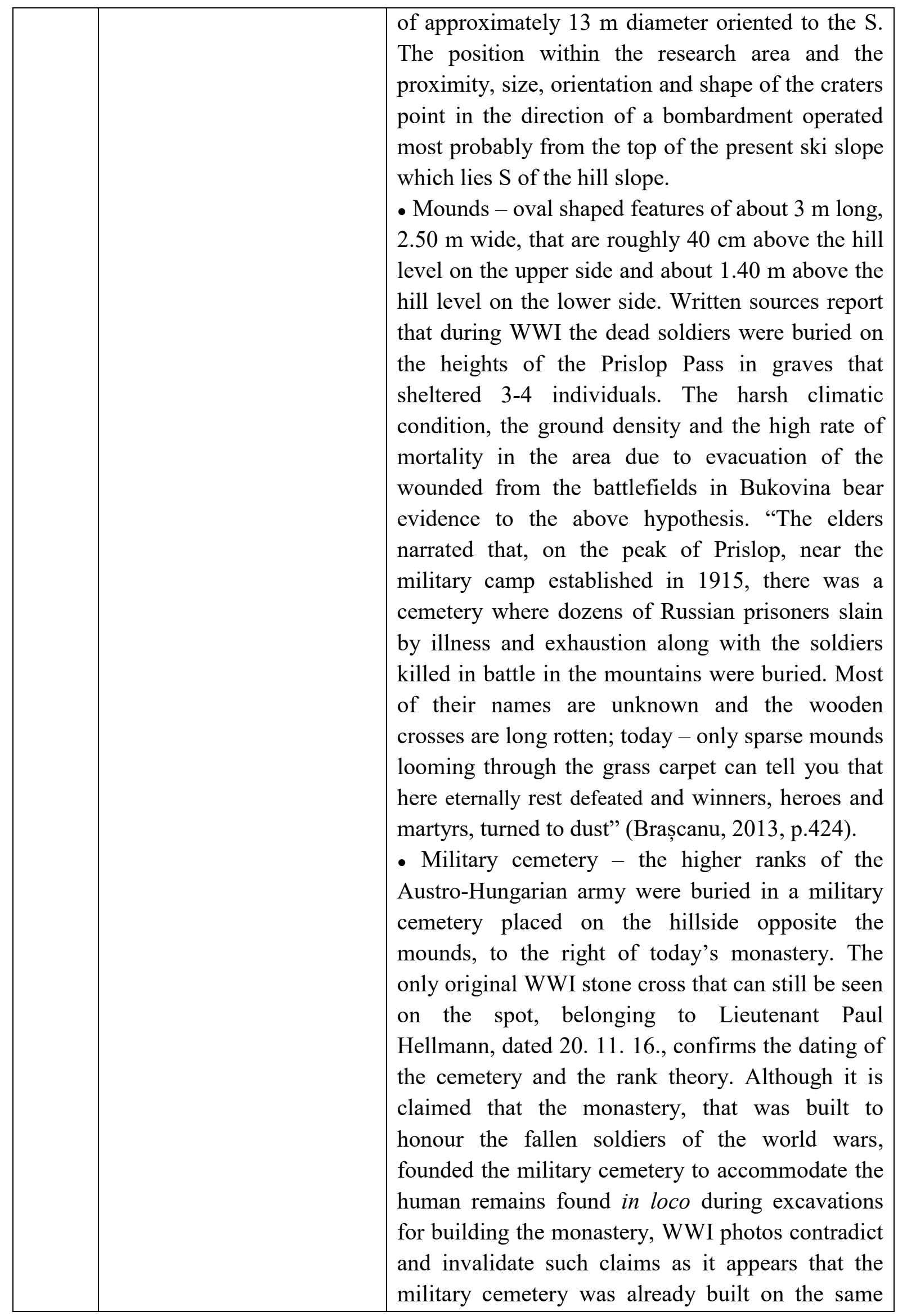




\begin{tabular}{|c|c|c|}
\hline & & $\begin{array}{l}\text { spot at the time of the war. } \\
\text { - Common graves - oval-shaped features if seen } \\
\text { from above, of lengths ranging from } 9 \mathrm{~m} \text { to } 11.20 \\
\mathrm{~m} \text {, widths between } 3,5 \mathrm{~m} \text { and } 5.30 \mathrm{~m} \text { and heights } \\
\text { ranging from } 1.20 \mathrm{~m} \text { to } 1.60 \mathrm{~m} \text {, presented in a } \\
\text { parallel progression. Local memory delegates the } \\
\text { features to burial places of the remains of war } \\
\text { prisoners who were engaged in the construction of } \\
\text { the military earthworks and of the railway system } \\
\text { during the Great War. } \\
\text { - Pillbox - dug-in guard post made of concrete, of } \\
60 \text { cm high and } 20 \text { cm thick walls equipped with a } \\
\text { loophole of } 62 \text { cm long and } 22 \text { cm high on the front } \\
\text { side. } \\
\text { - Bunkers - concrete constructions of various } \\
\text { shapes and styles which are part of a large defence } \\
\text { system that endemically develops across the } \\
\text { research area. According to their location they can } \\
\text { be grouped in to two classes of bunker: above- } \\
\text { ground or underground. Also, by proceeding along } \\
\text { this line of analysis it emerges that the above- } \\
\text { ground bunkers tend to have pentagonal shape on } \\
\text { the outside and the front side of the bunker is larger } \\
\text { than the back side, while the underground ones are } \\
\text { either box-shaped inside and out or have } \\
\text { pentagonal shape on the outside and equal semi- } \\
\text { circular tunnel interiors. In terms of materials the } \\
\text { great majority are made of reinforced concrete, } \\
\text { have roofs covered with a layer of bitumen and a } \\
\text { found along the trenches. The trench systems } \\
\text { layer of plaster on top. The bunkers have adjacent } \\
\text { trenches and a multitude of shaped stone is spread } \\
\text { around them especially in the front area. All the } \\
\text { bunkers had defence purposes with the exception } \\
\text { of Feature } 97 \text { which is considerably bigger than the } \\
\text { others and is delegated by local memory to the role } \\
\text { of weapon depot. } \\
\text { - Trenches - narrow channels dug into the ground, }\end{array}$ \\
\hline
\end{tabular}




\begin{tabular}{|c|c|c|}
\hline & & $\begin{array}{l}\text { defence system of the Prislop Pass along with the } \\
\text { bunkers. The defence system is quite linear in } \\
\text { terms of accessibility as it is mostly positioned in } \\
\text { the proximity of roads. } \\
\text { - Ordnance - cartridges of various dimensions, the } \\
\text { head of a bomb shell, an exploded WWI hand } \\
\text { grenade and pieces of barbed wire. The various war } \\
\text { materials were found during field campaigns in the } \\
\text { proximity of bunkers or rescued from the } \\
\text { excavation undertaken during the construction } \\
\text { works conducted at the 'Alpine' chalet situated on } \\
\text { top of the Prislop saddle. }\end{array}$ \\
\hline 6.4.1. & Plan & - \\
\hline 6.4.2. & Facade & - \\
\hline 6.4 .3$. & Roof shape & - \\
\hline 6.4 .4 & Extensions & - \\
\hline 6.4.5. & Annexes & - \\
\hline 6.5. & Structure & $\begin{array}{l}\text { The morphology of the sites reflects the specific } \\
\text { structure of logistic-defensive fortifications. }\end{array}$ \\
\hline 6.6. & Construction materials & $\begin{array}{l}\text { Earth, stone, bricks, wood, re-inforced iron, } \\
\text { concrete, bitumen, slaked lime, cement, gravel }\end{array}$ \\
\hline 6.6.1. & Roof construction materials & - \\
\hline 6.7. & Construction techniques & Military engineering \\
\hline 6.8 . & Stylistic framing & Industrial war architecture \\
\hline 6.9 . & Inscriptions & - \\
\hline \multicolumn{3}{|c|}{ 7. Conservation, restoration, threats } \\
\hline 7.1. & General conservation state & Good \\
\hline 7.2 . & Previous restoration works & $\begin{array}{l}\text { The defence line of the Maramureş Mountains was } \\
\text { restored during WWII as part of the fortified Arpad } \\
\text { line. }\end{array}$ \\
\hline 7.3 . & Risks/threatens & $\begin{array}{l}\text { Development in the area presents the biggest threat } \\
\text { to the preservation of the war sites. }\end{array}$ \\
\hline 7.3.1. & Erosion & - \\
\hline 7.3 .2 & Flooding & - \\
\hline 7.3 .3 & Landslide & - \\
\hline 7.3.4. & Agriculture & $\begin{array}{l}\text { Intensive agriculture presents a threat to the } \\
\text { preservation of the war sites. }\end{array}$ \\
\hline \multicolumn{3}{|c|}{ 8. Documentation } \\
\hline 8.1. & Bibliography & See the bibliographies of Chapters 4 and 5 \\
\hline 8.2 . & $\begin{array}{l}\text { Archival records } \text { and } \\
\text { reports }\end{array}$ & See the bibliographies of Chapters 4 and 5 \\
\hline
\end{tabular}




\begin{tabular}{|c|c|c|}
\hline 8.3 . & $\begin{array}{l}\text { Maps, plans, drawings/ } \\
\text { sketches }\end{array}$ & See Chapter 5 \\
\hline 8.4. & Photographs & See Chapter 5 \\
\hline 8.4.1. & Satellite imagery & See Chapter 5 \\
\hline 8.4.3. & Aerial photography & See Chapter 5 \\
\hline 8.4.3. & $\begin{array}{l}\text { Black and white } \\
\text { photography }\end{array}$ & See Chapter 5 \\
\hline 8.4.4. & Color photography & See Chapter 5 \\
\hline 8.5 . & Documentary attestation & 1915-1918 \\
\hline \multicolumn{3}{|c|}{ 9. Ranking level } \\
\hline 9.1. & Value class & A \\
\hline 9.2 . & $\begin{array}{l}\text { Category in merit of the } \\
\text { nature of the object } \\
\text { I } \\
\text { II } \\
\text { III } \\
\text { IV }\end{array}$ & IV \\
\hline 9.3 . & Global evaluation criterions & $\begin{array}{l}\text { a) Age criterion: } \\
\text { Mark MEDIUM } \\
\text { b) Criterion concerning the architectural, artistic } \\
\text { and urbanistic value: } \\
\text { Mark EXCEPTIONAL } \\
\text { c) Frequency criterion: } \\
\text { Mark EXCEPTIONAL } \\
\text { d) Criterion regarding memorial-symbolic value: } \\
\text { Mark EXCEPTIONAL }\end{array}$ \\
\hline 9.4 . & $\begin{array}{l}\text { Data and number of the } \\
\text { ranking document }\end{array}$ & - \\
\hline 9.5. & Urbanistic regulations & - \\
\hline \multicolumn{3}{|c|}{ 10. Inventory } \\
\hline 10.1. & $\begin{array}{l}\text { Name of the institution that } \\
\text { built up the sheet }\end{array}$ & - \\
\hline 10.2 . & $\begin{array}{l}\text { Author of the sheet and its } \\
\text { quality }\end{array}$ & - \\
\hline 10.2.1. & Surame & Roman \\
\hline 10.2.2. & First Name & Roxana-Talida \\
\hline 10.2.3. & Quality & - \\
\hline 10.2.4 & $\begin{array}{l}\text { The autograph signature of } \\
\text { the specialist that prepared } \\
\text { the sheet }\end{array}$ & - \\
\hline 10.2.5. & The signature and the stamp & - \\
\hline
\end{tabular}




\begin{tabular}{|c|c|c|}
\hline & $\begin{array}{l}\text { of the chief of the } \\
\text { institution that issued the } \\
\text { sheet }\end{array}$ & \\
\hline 10.3 . & $\begin{array}{l}\text { The number of the } \\
\text { validation minutes issued } \\
\text { by the Regional } \\
\text { commission of Historic } \\
\text { Monuments }\end{array}$ & - \\
\hline 10.3.1. & $\begin{array}{l}\text { Number of the ranking } \\
\text { document }\end{array}$ & - \\
\hline 10.3.2. & Date of ranking order & - \\
\hline 10.4 & Date of sheet writing up & - \\
\hline
\end{tabular}




\section{APPENDIX 17 \\ The historical architectural study of the parochial church Saint Prophet Ilie Tresviteanul $^{36}$}

Architect Mitru Ildiko,

Expert of the Ministry of Culture N.102

\section{Brief historic account}

The parochial church Saint Prophet Ilie Tresviteanul was built on the location of the wooden church that was set on fire by the Tatars in 1717. From the old church only a few objects of cult, old books and some icons painted on wood are left. The construction of the church began in 1864, during the service of Dean Alexiu Anderco, when the church was built up to the roof. In 1886 during the service of priest Basiliu Dan the works at the church were continued and the tower of the church was also finalised. Between 1909 and 1939 the parish, guided by priest Gavrilă Timiş, bought the iconostasis of the church. Between 1942-1959 the interiors and exterior of the church were renovated and between 1959-1962 the tower was rebuilt and the roof was covered with plate iron. The painter Cenan Cornel from Cluj painted the church between 1974-1977.

\section{Emplacement}

The parochial church Saint Prophet Ilie Tresviteanul was built on the location of the wooden church destroyed by the Tatars in an area occupied by houses. In 1940 the city of Borșa still preserved a semi-rural aspect, as shown in images retained by the city library.

The massive urbanisation that occurred during the 1970s radically modified the appearance of the area where the church is located. Currently, the worship edifice, the cemetery and the parochial house are surrounded by four flours blocks of flats.

\section{Architecture}

The church fits the specific typology of masonry churches built by communities in the second half of the $19^{\text {th }}$ century, in the city's period of urbanisation, and is characteristic of the Greek Catholic Church.

It is a hall-church, with an unhooked pentagonal altar, a square-shaped tower built on the western side, above the octagonal crested entrance.

The western façade, which shelters the entrance, is flanked at the corners by buttresses, and organised on two levels; at the lower level is a door, framed by two windows, while the

\footnotetext{
${ }^{36}$ The translation from Romanian to English was made by the author of the thesis.
} 
second level has three windows separated by a semi-circular contour, above which lies a tympanum flanked by two turrets and a median tower.

The southern facade, has four bays, separated by two level buttresses, four windows in broken-arch style, with a simple semi-circular cornice backed up by ornamental frieze; the western façade was obturated during construction of the tower.

The northern façade is the mirror image of the southern façade seen from the cemetery.

The eastern façade of the pentagonal unhooked altar has three windows in broken-arch style, with cornice and frieze that continue on the lateral façades.

\section{The evaluation of the building in view of its ranking}

\section{a. Age criterion}

- establishment built before 1775 - exceptional (value)

- establishment built between 1775-1830 - very high

- establishment built between 1830-1870 - high

- establishment built between 1870-1920 - medium

- establishment built between 1920-1960 - small

- establishment built after 1960 - zero

The building of the church began in 1864 and was finalised in 1886; the original architectural elements are mainly preserved.

- Mark HIGH

\section{b. criterion concerning the architectural, artistic and urbanistic value}

- planimetric and structural coherence and technical conception:

It respects the special division characteristic of hall-churches and is well executed, although it is not an exceptional achievement from a structural or technical point of view.

- representativeness of a certain historic age, author, or style:

It is part of the group of masonry churches, which replace wooden churches that were overwhelmed by demographic growth in Maramureș at the end of the $19^{\text {th }}$ century.

- significance for a certain historical-geographic area:

It is representative of the religious life of the Maramureș region

- facades and interiors elements of plastic arts:

The western facade, the church entrance, is the one that through the harmony of the relations between fullness and emptiness and its ornamentation, along with the silhouette of the bell tower, represent elements of effective plastic art, which have been obturated by inadequate finishes added in the late $20^{\text {th }}$ century (decorative plaster and fake traditional ornaments).

- valuable artistic components:

The iconostasis and the recent mural painting are artistic components that give the edifice added value. 
- the value of the various component parts and the share/percentage of those that give the building a certain character:

The shape of the windows, their dimensions, the triple presence of windows in front of the altar along with the windows of the western façade grant a light in the inner space that creates a veritable atmosphere of illumination - ascension.

- the relation to its urban and natural context, pertaining to an ensemble or natural or constructed site, partially or totally preserved:

The brutal nature of the communist blocks of flats that have invaded the surroundings make the church, which still stands protected by an elevation of the land and an opaque fencing as old as the edifice, a true redoubt of faith.

- representativeness within a program, urban policy, or typology:

Along with the Holy Archangels wooden church, which also is a historic monument, this cult edifice, the oldest masonry church of Borșa, may constitute elements of local identity which evoke a tradition that deserves to be preserved and valorised.

- Mark MEDIUM

\section{c. frequency criterion (rarity and unicity)}

- unicity of the building, of its components or of the ensemble:

On a local level the edifice is unique, and its style is a rarity in the area.

- top of the class representativeness:

It does not represent a top class edifice.

- rarity or belonging to a narrow series/limited edition regarding a particular historical-geographic area, ethnographic area or historic period:

It belongs to a limited series of neogothic cult buildings of the area of Maramureș

- typicity of a historical-geographic area, ethnographic area or historic period:

It is not typical of the historical-geographic area.

- frequency of valuable objects within a built historic ensemble:

It is a relevant object in terms of rarity and unicity.

- Mark HIGH

\section{d. criterion regarding the memorial-symbolic value}

- buildings connected to certain historical, cultural, political and social movements and places along with buildings representative of certain personalities:

Not connected to any cultural, political or historic event.

- anterior constructions missing of renowned historical importance, certificated by documentary or archaeological source:

It replaces another cult edifice, the wooden church destroyed by the Tatars

- presence in the memory of the community, at European, national and local level: 
As any other cult edifice, this one is also present in lives of the believers and thanks to its age it has entered the memory of the community.

- connection of the building to any local traditions:

The church is integrated into the life of the community and contributes to the preservation of local traditions.

- Mark MEDIUM" 


\section{APPENDIX 18 \\ Hypothetic World Heritage List nomination of the Prislop Pass war sites}

\section{- Description}

In Romanian culture the several categories of war materials that build up the war places and their adjacent landscape bear testimony to the memory of the Great War and of its high symbolic power that has materialised in the Grand Union national narrative. The Great War and the Great Union share intimate interconnections featuring a leitmotif of Romanian historiography. The conflictual landscape evokes the re-iteration of the most sacred goal of the Romanian people - territorial unity and national emancipation - and summons remembrance of the most significant episode of Romanian national history.

The morphology of the Prislop war sites emphasises the role played by geography in the Romanian quest for freedom and national unity during WWI, and during the historic process of national emancipation. If, on the one hand, the geostrategic position ultimately aided the fulfilling of the political motifs that motivated Romanian involvement in the Great War, on the other, geography was one of the primary reasons making Romanian territory vulnerable to foreign domination due to its position at the edge of the great empires. In fact, the war sites are also a reminder of the fact that it was the territorial positioning of the nations of the Eastern Front, in the centre of imperial interest zones, that marked the fate of the peoples before the war and thus fuelled the initial engagement of the multiple nationalities of the empires in the fight for a purpose and ideal which eluded their understanding and will.

The visible traces of war - the bunkers and earthworks, the military road, the remains of the historical buildings, the military cemetery and common graves, the trench systems - of the highest pass of the Oriental Carpathians highlight the strategic position of the early route that connects Maramureș to Moldavia. The rebuilding of the Prislop Pass defence system during WWII as part of the Arpad line provides evidence of the world wars' continuum within the same environmental settings. The re-ignition of the same conflictual sparks between the liberated nations and the successors of the imperial powers demonstrates that although the end of WWI temporarily sedated international tensions it did not offer a remedy to the vulnerability of the small nations in the regional context. The material remains of war thus also re-iterate the difficulties of those nations that were formerly caught in the influence area of the great empires, whose shadows kept impending over their survival by the threat of the monarchical avatars.

The material culture of the research area persistently contains the marked peculiarities of the Romanian historical provinces appendant to the Austro-Hungarian Empire in relation to the overall Romanian war experience, highlighting not the general Romanian condition during 
WWI but the general condition of the multi-ethnic people subject to imperial ruling during the war. The Prislop material remains narrate the story of the human dimension of war, depicting the dramas of the multi-national soldiers enrolled in the Austro-Hungarian army, the tragic fate of war prisoners, the uprooting of hordes of refugees from the Galician front and the difficult conditions of the Romanian civilians of the dual monarchy perennially threatened by the charge of treason, ascendant repression, military courts, famine, epidemics, requisitions, robberies, forced expropriation, reprisals and death. It is within this dimension of the material culture of war that the places of war are qualified as international lieux de memoire.

The places of war display a fresco of the contradictions of the war fought under the imperial flag, of the moral dilemmas, the persecutions, the resistance, the fight for national rights and of a peoples' dream of freedom. They are a memento of the equalising persecutions - abuses, humiliation, retaliation, hunger, forced labour and executions - that impended upon multinational soldiers/civilians of the Austro-Hungarian Empire and upon war prisoners alike. The war exposed the illusion of imperial cohesion by emphasising the socio-political contradictions and inequalities of the dual monarchy, which was reliant on military repression to keep the multi-ethnic populus obedient and subdued.

The material evidence provided by the war sites illustrates, integrates and anchors an entire range of Romanian war writings generated by the complex social and historical circumstances of the war. The impact of the Great War on the Romanian collective consciousness translated into a fecund field of literature and folklore, collected around the Romanian quest for freedom, self-determination and national unity. Such leitmotifs, framed as the utterly sacred cause of the Romanian people, have informed the national master narrative over the past hundred years and continue to be perceived as such a century after the end of the war and achievement of the Great Union. Revisiting poetry, literature, ethnographic and folkloric compositions of countries ascribed to the Eastern Front enables rebalancing of the war accounts of the two fronts, broadening the holistic understanding of the war, which allows the exploration of a new, less monolithic and unanimous, dimension of the feelings and motivations of those who fought the war.

The conflictual landscape is also representative of the Romanian traditional assertion of freedom which was intimately connected to and envisioned in communion with the land dimension. For countries such as Romania the recovery of lost territories constituted the main reason that fuelled their involvement in WWI. It was the re-appropriation of their ancestral land that in the Romanian vision incarnated the materialisation of freedom and selfdetermination and thus of national rights.

War architecture itself emerges as a cultural artefact filled with untold stories of a lost world. Although it is widely accepted that architecture mirrors its source, the study of WWI architecture as a footprint of the generative society was never scientifically approached, leaving unexplored an entire archive of meanings embedded in buildings and earthworks that 
narrate a story of the actions, goals, dreams and dramas of the war actors. The architectural structures produced by the industrialised war build up an architectural style representative of a highly representative age of human history in addition to the encapsulation of warfare knowledge and remembrance value which constitutes a still vacant gap in our knowledge.

It follows that the war places have several concurrent levels of significance that inform plural remembrance functions of local, regional, national or international scale. Dependent upon the perspective, conflictual landscape evokes different dimensions of the war phenomenon out of the multiplicity of overlapping layers. The places of war display the everlasting story of the Great War, simultaneously encapsulating the human dimension of the war, technological breakthroughs and innovations, war typology and military specificity, historical military and political personalities assigned to the place, the fall of the great empires, the fight for freedom of Eastern European nations, the international affirmation of the principles of nationality and self-determination and, hence, the roots of a new international mentality. The memorialsymbolic dimension of the material culture and remembrance functions of the places of war build up solid value premises in favour of the outstanding universal value of the war sites.

\section{- Justification of Outstanding Universal Value}

Criterion (ii) - The war sites reflect the spatial division characteristic of the AustroHungarian defence systems and new frontline strategical architecture introduced by the industrial war, presenting an exceptional conceptual execution from a strategical, structural and technical point of view. The war sites are part of the material culture of WWI and thus represent an age of transition in warfare evolution. They represent a significant typology of strategic defensive war sites that simultaneously incarnate Romanian local specificity and Austro-Hungarian imperial warfare traditions. Furthermore, they present a marked specificity due to the close relation between the Prislop Pass sites and the WWI military railway that was planned and executed under the guidance of the famous Felix von Tarbuk Sensenhorst, and which represented a technological miracle at the time of the war. In terms of significance within a cultural area of the world, the sites are representative of the general WWI East European memory and remembrance and, hence, of the values and ideals that motivated the fight for national emancipation and freedom of the peoples subjugated by imperial domination. At national level the war sites bear testimony to the Romanian quest for national unity, being closely related to the memory of the Great Romanian Union, whilst at local and regional level they account for the general conditions of the Romanian population of the historic provinces dominated by the Austro-Hungarians, consequently emphasising norms of countries of the Eastern Front that were under imperial domination.

Criterion (iii) - The unicity of the war sites ensemble is conferred by the characteristics of the Prislop Pass material culture of war, forged by the Austro-Hungarian empire against the background of Romanian local specificity within the framework of WWI. The Prislop Pass war sites are simultaneously connected to historical, cultural, political and social moments and places. They testify to contradictions in the multi-ethnic empire embedded with dynastic 
artificial patriotism, and highlight the interactions between the Austro-Hungarian imperial tradition and mounting animation of the national conscience of the people of the empire.

The conflictual landscape is also representative of the Romanian traditional assertion of freedom which was intimately connected to and envisioned in communion with the land dimension. The re-appropriation of the ancestral land incarnated the materialisation of the achievement of freedom and self-determination, in the Romanian mind, and thus of national rights as the land, perceived as pater patriae, personified the guarantor of all rights - which additionally frames WWI as the last 'land' war.

Criterion (iv) - In relation to the natural context, the war sites emphasise close interconnections between anthropic and natural elements by embedding the war architecture pertaining to the WWI Prislop military city and its adjacent defence system into the strategic yet picturesque mountainous landscape. The war wound inflicted upon the lands, patiently nurtured by the natural environment, cicatrised across the century preserving its wilderness and continuing to shelter rare species and natural habitats which coined its status of Natura 2000 site.

Architectonical features bear testimony to the fact that the Great War not only reshaped the balances of power, redefined borders or wrote fundamental pages of national history for several states, but also shaped the identity of the land, redefining the landscape. The war remains represent a form of warfare specificity, that holds the idiosyncrasies of a specific historic time and a specific form of conflict. Earthworks, and concrete bunkers became the signature of the industrial war due to the conversion of dug-in defences for terrestrial and airborne warfare into a hallmark that rooted conflict within the earth. The Great War inaugurated a procedure of environmental incisions that branded the places of war with the world war mark. Bunkers, trench systems, mine craters were all carved wounds in the landscape, wounds that in time turned into scars giving the natural environment pride and personality, converting space into place.

Criterion (v) - The morphology of the conflictual landscape was generated by a series of specific circumstances culminating with the importance of this geostrategic position in the economy of war (as Maramureș bordered the Galician front and constituted the gate to the heart of the empire), the establishment of the Austro-Hungarian military command in the Prislop Pass, and the building of the military railway.

The war sites represent a particular category of WWI strategic architecture (logistic-defensive fortifications) and are amongst the last war remains in the area that survived the last century, qualifying the sites as outstanding in terms of rarity. They are an integral part of WWI history that emphasise nuances of the fight for national emancipation of the East-European peoples against the framework of the larger historic process, which allowed the expression of national consciousness internationally while simultaneously highlighting the specificity of the war phenomenon within the ethnographic area of Maramureș. Furthermore, the war sites not only 
display a multitude of significant architectural components that are only available in this particular location, but also blend the various elements into a rare and unique conflictual landscape.

The morphology of the Prislop war sites emphasises the role played by geography in the Romanian quest for freedom and national unity. If the geostrategic position ultimately aided the fulfilling of the political motifs that motivated Romanian involvement in the Great War, geography was also one of the primary reasons that made Romanian territory vulnerable to foreign domination due to its position at the edge of the great empires. In fact, the war sites are also a reminder of the fact that it was the territorial positioning of the nations of the Eastern Front, in the centre of imperial interest zones, that marked the fate of the peoples before the war and thus fuelled the engagement of the multiple nationalities of the empires in the fight.

The war traces highlight the strategic position of the early route that connects Maramureș to Moldavia. The rebuilding of the Prislop Pass defence system during WWII, as part of the Arpad line, provides evidence of the world wars' continuum within the same environmental settings. The re-ignition of the same conflictual sparks between the liberated nations and the successors of the imperial powers demonstrates that although the end of WWI temporarily sedated international tensions it did not proffer a remedy to the vulnerability of the small nations in the regional context. The material remains of war thus also re-iterate the difficulties of the nations formerly caught in the influence area of the great empires, whose shadows kept impending over their survival by means of the threat of the monarchical avatars.

The places of war are cultural artefacts that encapsulate the yet unheard voices of a past world while displaying the everlasting story of the Great War.

Criterion (vi) - The places of war are directly associated with WWI photography which confers on the war sites a significant artistic component. The war sites also give material expression to the well-represented field of war writings anchoring Great War literature, folkloric and ethnographic creations to the tangibility of physical places and depicting a fresco of WWI remembrance embedded in the material culture.

The war sites are relevant as symbolic places in relation to the international coagulation of the principles of self-determination and nationality. They are a reminder of how the new international doctrine, founded on Wilson's points, converted the tale of nationalities deprived of rights under imperial ruling into the history of sovereign nations. In fact, it was this international predisposition towards recognition of the national rights of the state's whole population that allowed the creation and recognition of the rights of minorities that became a fundamental principle of the contemporary world.

The war sites simultaneously encapsulate the human dimension of the war, war typology/military specificity, technological breakthroughs/innovations, the fall of the great 
empires, the fight for freedom of eastern European nations, the international affirmation of the nationality and self-determination principles and, hence, the roots of a new international mentality and above all the peoples' dream of freedom.

\section{- Statements of authenticity and/or integrity}

The places of war display a fresco of contradictions of the war fought under the imperial flag, of the moral dilemmas, persecutions, resistance, the fight for national rights and of the epopee of freedom. The great diversity of component features of the war sites highlight the dimension of war architecture and of conflict space management. The authenticity dimension of the war sites is conferred by the physical preservation of the component war remains in the same setting and form as created through the agency of the world wars against the settings of the environmental conditions. The material culture of war narrates the historical journey of the traces of a war long gone but whose legacy reaches us up to this day. The imprint conferred by the passing of time confirms the authenticity of the war places by displaying the unmediated evolution of the WWI material remains over a time-arch of more than a hundred years. The authenticity continuum represents one of the aspects of heritage that, in accordance with contemporary assertions, increases the spectrum of heritage value. In terms of integrity, the importance and significance of the war places are not derived from the sum of component parts evaluated in a disjointed manner, but from considerating the war sites as a whole, and the fact that only a limited amount of materials survived the last century provides ultimate proof of their rarity and scientific value. The places of war are a fresco of history and memory condensed in a conflictual landscape that bears the mark of the world wars.

\section{- Comparison with other similar properties}

The Prislop Pass war sites owe their existence to strategic reasons related to the fact that the Prislop Pass is an early route that connects Maramureș to Moldavia and is the highest pass of the Oriental Carpathians. Nonetheless, WWI was not the first episode of war in which geography has dictated the course of military actions in the area. The first known case of invasion through the Prislop Pass dates back to 1241 when, during the Mongol invasion of Europe, a Tatar formation descended through the pass into Maramureș. The Tatar threat to the area is shown to have been long lasting, as testified by the war monument built on the road that connects the Prislop Pass to Borșa commemorating the 1717 victory against the Tatars. Hence, the geography and location of the Prislop Pass defence line evokes and re-utilises former war routes, engaging and extending existing engineer works to serve war purposes. This relegates the war sites to anterior constructions of renowned historical importance, such as the Romanian wooden church destroyed by the Tatars in 1717.

Tracking the influence exerted by geography on the historical evolution of a place and the consequent events that mark the fate of its inhabitants, highlights the link between the places of war and the wooden churches of Maramureș. Although according to the World Heritage List the outstanding universal value of the wooden churches is mainly founded upon architectonic and artistic value, the churches nonetheless present a much higher degree of complexity, representing more than merely beautiful buildings. They are wooden documents 
not only of the culture and civilisation of the people that produced them but also of their socio-political circumstances.

The sculpted wood and paintings of the churches are filled with a multitude of symbols from Christian to reminiscences of ancient traditions such as the solar rosette, and from subjects of religious belief to social and legal matters. The high tower of the wooden churches also had a landmark function of being visible from great distance, for which reason the churches were usually located on higher ground. Furthermore, four smaller turrets at the base of the main tower identifies that the village where the church was built had a council of elders that functioned like a court of law with authority to judge simple trials that did not require the attention of the official authorities.

The wooden churches were also entirely wooden using no metal nails so that they could be disassembled like a giant 3D puzzle and re-assembled in another place in case of need. During the development period of this typology of wooden churches the area was threatened by Tatars, Ottomans, Hungarians, and eventually ended up under Austro-Hungarian dominion. Details of the paintings, architectural elements and the various decorations all narrate this same story. The height of the church entrance is unusually small and has a boule cord: it had the function of forcing those who entered the church to bow in symbol of humility, but also served a widely spread mythology about pagan invaders who used to ride their horses into churches right up to the altar - consequently the low entrance served to prevent the desecration of holy ground.

The old metal crosses on top of the tower, turrets and/or on the top of the roof of the churches used to combine a crescent shape or a star crescent element in the design, a tradition inherited from the Tatar invasion periods when it was used to trick the Tatars into believing that the edifice was of Ottoman property in order to prevent its destruction. In addition, during the Austro-Hungarian domination, since Romanians were deprived of memorialisation rights, local heroes were commemorated by fixing epitaph wooden crosses on the external walls of the wooden churches.

All these characteristics (and several others) of the Wooden Churches of Maramureș were developed in reaction to conflict and reflect the adaptive capacity of people threatened by/under foreign domination in their ingenious struggle for conserving their identity in times of distress. Declaring WWI sites as world heritage would mark these adjacent places as conflictual landscape and allow the reading of other heritage items through the same lens, leading to a better historical contextualisation and cultural understanding. 


\section{BIBLIOGRAPHY}

Achim V., Socolan A. (1968), Dr. Vasile Lucaciu, luptător pentru drepturile românilor şi Unirea Transilvaniei cu România, Baia Mare, Comitetul pentru Cultură și Artă al Județului Maramureș.

Albani, T. (1938), Douazeci de ani de la unire. Monografie comemorativa a unirii, Vol.I, Oradea, Grafica Oradea.

Anderson, B. (1983), Imagined Communities: Reflections on the Origin and Spread of Nationalism, London, Verso.

Andreica, Ș. (2015), Istorie și tradiție pe valea râului Vaser, Cluj-Napoca, Grinta.

AP News (2018), France, Belgium seek UNESCO recognition for WWI memorials, Available ONLINE: https://apnews.com/d39caab486c4434dbfbba3133f3631c2 (Accessed: 22.04.2019).

Ardelean, T. (2016), File de cronica. Tinuturile Chioar, Codru, Lapus, Maramureș (din paleolitic pana in 1918), Vol.I., Baia Mare, Biblioteca Judeteana Petre Dulfu.

Armata Română (1987), România în anii primului Război Mondial, București, Editura Militară.

Ashplant T. G., Dawson G., Roper M. (2000), The Politics of War Memory and Commemoration, London, Routledge.

Ashworth G. J., Graham B., Tunbridge J. E. (2007) Pluralising Pasts Heritage, Identity and Place in Multicultural Societies, London, Pluto Press.

Ashworth G. J., Larkham P. J. (1994), Building a New Heritage: Tourism, Culture and Identity in the New Europe, London, Routledge.

Ashworth, G. J. (1995) Heritage, Tourism and Europe: A European Future for a European Past? In: Herbert D., Heritage, Tourism and Society, New York, Mansell Publishing, pp.6884.

Ashworth, G. J. (1997), 'Conservation as Preservation or as Heritage', Built Environment, Vol.23, N.2, pp.92-102.

Askew, M. (2010), The magic list of global status UNESCO, World Heritage and the agendas of states. In: Labadi S, Long C, Heritage and Globalisation, London, Routledge, pp.19-44.

Assmann, A. (2010), Re-framing memory. Between individual and collective forms of constructing the past, In: Tilmans K., Van Vree F., Winter J., Performing the Past: Memory, History and Identity in Modern Europe, Amsterdam, Amsterdam University Press, pp.35-50.

Assmann, J. (2008), Communicative and Cultural Memory, In: Astrid E., Ansgar N., Cultural Memory Studies. An International and Interdisciplinary Handbook, Berlin - New York, Walter de Gruyter, pp. 109-118. 
AUSTRALIA ICOMOS (2013) Practice Note: Understanding and assessing cultural significance, Available ONLINE: https://australia.icomos.org/publications/charters/ (Accessed: 22.04.2019).

Averescu, A. (1918) Răspunderile, București, Editura „Ligei Poporului”.

Averescu, A. (1926), Operațiile de la Flămânda, București, Editura Cultura Națională.

Averescu, A. (1937), Notițe zilnice din războiu (1916-1918), București, Editura Cultura Națională.

Avrami, E. (2009), Heritage, Values, and Sustainability, In: Richmond A., Bracker A., Conservation Principles, Dilemmas and Uncomfortable Truths, Oxford, Elsevier, pp.177-182.

Bagwell, M. N. (2012), The diary of an American 'Doughboy': interpreting a textual artefact of the First World War, In: Saunders N.J., Beyond the dead horizon: studies in modern conflict archaeology, Oxford, Oxbow Books, pp.43-53.

Bailey G., Newland C., Nilsson A., Schofield J., Davis S., Myers A. (2009), 'Transit, transition: excavating J641 VUJ', Cambridge Archaeological Journal, Vol.19, N.1, pp.1-27.

Batin, L. (2014), Maramureșul și Maramureșenii in Primul Razboi Mondial, Cluj-Napoca, Grinta.

Băldescu, R. (1934), Războiul național. Operațiunile din anii 1917, 1918 și 1919, vol. II, Sibiu, Tipografia Cavaleriei.

Bărbulescu M., Deletant D., Hitchins K., Papacostea Ș., Teodor P. (1998), Istoria României, București, Editura Enciclopedică.

Bărlea, E. (2004), Perspectiva lumii rurale asupra Primului Război Mondial, Cluj-Napoca, Editura Argonaut.

Beaudry, M. C. (1988), Documentary archaeology in the New World, Cambridge, Cambridge University Press.

Beckett I. F. W. (2013), The Great War, 1914-1918, New York, Routledge.

Belgium (2014), Funerary and memorial sites of the First World War (Western Front), Available ONLINE: https://whc.unesco.org/en/tentativelists/5886/ (Accessed: 22.04.2019).

Bender, B. (1998), Stonehenge. Making Space. Materializing Culture, Oxford. Berg.

Bennett, T. (2004), Pasts Beyond Memory: Museums, Evolution, Colonialism, London, Routledge.

Bianu, V. (1926) Însemnări din răsboiul României Mari. Tomul II. De la Mobilizare Până la Pacea din București, Cluj, Institutul de Arte Grafice Ardealul.

Biehl P.F, Prescott C (2013), Heritage in the context of globalization: Europe and the Americas, New York-London, Springer. 
Bleed P., Scott D. (2011), 'Context for Conflict: Conceptual Tools for Interpreting Archaeological Reflections of Warfare', Journal of Conflict Archaeology, Vol.6, n.1, pp.4264.

Bold E., Ciupercă I. (2010), Europa în derivă (1918-1940). Din istoria relaţiilor internaționale, Iași, Casa Editorială Demiurg Plus.

Boniface P., Fowler P. J. (1993), Heritage and Tourism: In 'The Global Village', London, Routledge.

Boorman, D. (2005), A Century of Remembrance: One Hundred Outstanding British War Memorials, Barnsley, Pen \& Sword Books Ltd.

Bowden, M. (1999), Unravelling the landscape. An inquisitive approach to archaeology, StroudTempus Publishing.

BOWERS, J. (2014), Tourism, Archaeology, and Ethics: A Case Study in the Rupununi Region of Guyana, In: SMITH., Encyclopedia of Global Archaeology, New York, Springer, pp. 7352-7355.

Boyd G., Linehan D. (2013), Ordnance: War + Architecture and Space, London, Routledge.

Brașcanu, P. (2013), Tunuri la porțile Bucovinei. 1914-1918, Iași, Editura Ștef.

Brașcanu, P. (2015), Drum de fier prin praf de puşcă și ploaie de stele, Iași, Editura Ștef.

Bridgford, S. (1997), Mightier than the pen? An edgewise look at Irish Bronze Age swords In: Carman J., Material harm: archaeological studies of war and violence, Glasgow, Cruithne Press, pp.95-115.

Brown M., Osgood R. (2009), Digging up Plugstreet: the archaeology of a Great War battlefield, Sparkford, Haynes Publishing.

Brown, M. (2009), Strange meetings: archaeology on the Western Front, In: Forbes N., Page R., Pérez G., Europe's deadly century: perspectives on 20th century conflict heritage, Swindon, English Heritage, pp.59-64.

Bruce D., Creighton O. (2006), 'Contested identities: The dissonant heritage of European town walls and walled towns', International Journal of Heritage Studies, Vol.12, N.3, pp.234254.

Buchli V., Lucas G. (2001), Archaeologies of the contemporary past, London, Routledge.

Bulei, I. (1996), Scurtă istorie a românilor, București, Editura Meronia.

Bushaway, B. (1992), Name Upon Name: the Great War and Remembrance. In: Porter R, Myths of the English, Cambridge, Polity Press, pp.136-167.

Bushaway, B. (2001), The Obligation of Remembrance or the Remembrance of Obligation: Society and the Memory of World War, In Liddle P., Bourne J., Whitehead I., The Great World War 1914-45: The Peoples Experience, London, Harper Collins, p.491-507.

Butler R., Suntikul W. (2012), Tourism and War, London - New York, Routledge. 
Calafeteanu I., Popișteanu C. (1986), Politica externă a României. Dicționar cronologic, București, Editura Științifică și Enciclopedică.

Carman J., Carman P. (2006), Bloody meadows: investigating landscapes of battle, Stroud, Sutton Publishing Limited.

Carman, J. (2002), Archaeology and Heritage: an introduction, London, Continuum Press.

Carman, J. (2005), 'Battlefields as cultural resources', Post-Medieval Archaeology, Vol.39, N.2, pp.215-223.

Carman, J. (2009), Where the Value Lies: the importance of materiality to the immaterial aspects of heritage, In: Smith L., Waterton E., Taking Archaeology Out of Heritage, Cambridge, Scholars Publishing, pp. 192-208.

Carman, J. (2013), Archaeologies of Conflict, London, Bloomsbury.

Carman, J. (2015), Archaeological Resource Management: an international perspective, New York, Cambridge University Press.

Casey, E.S. (2000), Remembering. A Phenomenological Study, Bloomington, Indiana University Press.

Căzănișteanu, C. (1984), Documente ale Unirii (1600-1918), București, Editura Militară.

Cârja I. (2016), 'Românii în armata austro-ungară 1914-1918: contribuţii ale istoriografiei româneşti postcomuniste', Eroii Neamului, Vol.28, N.3, pp.8-16.

Ceaușescu, I. (1989), Istoria militară a poporului român, vol. V, București, Editura Militară.

Chapman, H. (2006), Landscape archaeology and GIS, Stroud, Tempus.

CIMEC (1999), The Maramureș Wooden Churches, Available ONLINE: http://www.cimec.ro/Monumente/unesco/UNESCOen/indexC57.htm (Accessed: 22.04.2019).

Ciobanu N., Zodian V., Mara D., Șperlea F., Mâță C., Zodian E. (2000), Enciclopedia Primului Război Mondial, București, Editura Teora.

Cioflină, D. (1996), Marele Cartier General al Armatei României. Documente 1916-1920, București, Editura Machiavelli.

Ciorogariu, R. (1926), Zile trăite, Oradea, Tipografia Diecezană.

Clark, C. (1971), United Roumania, New York, Arno Press.

Clark, C.U. (1927), Bessarabia. Russia and Romania on the Black Sea, New York, Dodd, Mead \& company.

Cleere, H. F. (1989), Archaeological Heritage Management in the Modern World, London Boston, Unwin Hyman. 
Cleere, H. F. (1984), Approaches to the archaeological heritage, Cambridge, University Press.

Cole, S. (2007), 'Beyond Authenticity and Commodification', Annals of Tourism Research, Vol.34, N.4, pp.943-960.

Comer, D. (2012), Tourism and Archaeological Heritage Management at Petra: Driver to Development Or Destruction?, New York, Springer.

Concordia (2014), Romania's Territorial Arrangement Strategy, Available ONLINE: http://www.confederatia-concordia.ro/en/news/territorial-development-strategy-of-romania/

(Accessed: 22.04.2019).

Connerton, P. (1989), How Societies Remember, Cambridge, Cambridge University Press.

Constantiniu, F. (1997), O istorie sinceră a poporului român, București, Editura Univers Enciclopedic.

Cornelissen, S. (2005), 'Producing and Imaging Place and People: The Political Economy of South African International Tourist Representation', Review of International Political Economy, Vol.12, N.4, pp.674-699.

Coroamă R., Tomescu D. (1999), 'Regele Carol I ctitor si protector al patrimoniului cultural', Muzeul Național, Vol. XI, p. 107-109.

Costa, K. A. (2004), Conflating Past and Present: Marketing Archaeological Heritage Sites in Ireland, In: Rowan Y, Baram U, Marketing Heritage. Archaeology and the Consumption of the Past, Oxford, AltaMira Press, pp.69-91.

Council of Europe (1954), European Cultural Convention, Available ONLINE: https://www.coe.int/en/web/conventions/full-list/-/conventions/treaty/018 (Accessed: 22.04.2019).

Council of Europe (1985), Convention for the Protection of Architectural Heritage of Europe, Available ONLINE: https:/www.coe.int/en/web/culture-and-heritage/granada-convention (Accessed: 22.04.2019).

Council of Europe (1992), European Convention on the Protection of the Archaeological Heritage of Europe, Available ONLINE: https://www.coe.int/en/web/culture-and-heritage/vallettaconvention (Accessed: 22.04.2019).

Council of Europe (2000), European Landscape Convention, Available ONLINE: https://www.coe.int/en/web/conventions/full-list/-/conventions/rms/0900001680080621 (Accessed: 22.04.2019).

Council of Europe (2005), Framework Convention on the Value of Cultural Heritage for Society, Available ONLINE: https:/www.coe.int/en/web/conventions/full-list//conventions/rms/0900001680083746 (Accessed: 22.04.2019).

Council of Europen Communities/Commision of European Comunities (1992), Treaty on European Union, Available ONLINE: https:/europa.eu/european-union /sites/europaeu/files/docs/body/treaty_on_european_union_en.pdf (Accessed: 22.04.2019). 
Cowley, R. (2003), The Great War: perspectives on the First World War, New York, Random House.

Craig Wight, A. (2006), 'Philosophical and Methodological Praxes in Dark Tourism: Controversy, Contention and the Evolving Paradigm', Journal of Vacation Marketing, Vol.12, N.2, pp.119-129.

Cupsa I. (1967) Marasti, Marasesti, Oituz, București, Editura Militara.

Dabija, G. A. (1936), Armata română în războiul mondial (1916 - 1918), vol. IV, București, Editura I. Hertz.

Dan, M. (2008), Istoria ce am petrecut în crâncenul razboi, Satu Mare, Editura Muzeului Sătmărean.

Dan, P. (2005), Hotarele românismului în date, București, Editura Litera Internațional.

Daşcovici, N. (1936), Interesele şi drepturile României în texte de drept internaţional public, Iaşi, Tip. Terek.

De La Torre, M. (2013), 'Values and Heritage Conservation', Heritage \& Society, Vol.6, N.2, pp.155-166.

De La Torre, M. (2002), Assessing the Values of Cultural Heritage, Los Angeles, The Getty Conservation Institute.

De Meyer M., Pype P. (2009), Scars of the Great War (Western Flanders, Belgium) In: Scott D., Babits L., Haeker C., Fields of conflict: battlefield archaeology from the Roman Empire to the Korean War, Westport, Praeger, pp.359-382.

Denize, E. (2009), Propaganda comunista in Romania 1948-1953, Targoviste, Editura Cetatea de Scaun.

Deutsche Welle (2018),UNESCO World Heritage sites: WWI memorials among the contenders, Available ONLINE: https://www.dw.com/en/unesco-world-heritage-sites-wwimemorials-among-the-contenders/a-44370620 (Accessed: 22.04.2019).

Di Giovine, M. A. (2009), The Heritage-Scape: UNESCO, World Heritage, and Tourism, Lanham, Lexington Books.

Diacon, V. (2012), Bucovina în secolul XX. Istorie și cultură. Iași, Tipo Moldova.

Dicks, B. (2003), Culture on display: the production of contemporary visitability, Berkshire, Open University Press.

Dirks B. N. (1990), 'History as a Sign of the Modern', Public Culture, Spring, Vol.2, N.2, pp. 25-32.

Drăghicescu, D. (2001), Marea Unire a românilor cu românii: 1918. Banatul si Transilvania; Bucovina si Basarabia, București, Editura Albatros. 
Duca, I.G. (1981), Amintiri politice, Vol. I, München, Jon Dumitru Verlag.

Duca, I.G. (1981), Amintiri politice, Vol. II, München, Jon Dumitru Verlag.

Duke, P. (2007) The Tourist Gaze, the Cretans Glance. Archaeology and Tourism on a Greek Island. Heritage, Tourism and Community, Walnut Creek, Left Coast Press.

Dumitru, T. (2009), Cronologie, tabel cronologic la vol. Liviu Rebreanu, Adam și Eva, București, Editura Litera Internațional.

Edward, S. C. (1996), How to Get From Space to Place in a Fairly Short Stretch of Time: Phenomenological Prolegomena, In: Feld S., Basso K., Senses of Place, Santa Fe, School of American Research Press, pp.13-52.

Esposito, V.J. (1997), The West Point Atlas of American Wars. Vol. II: 1900-1918, New York, Henry Holt \& Company.

Euronews (2018), WWI memorial sites bid for World Heritage status, Available ONLINE: http://www.euronews.com/2018/06/24/wwi-memorial-sites-bid-for-world-heritage-status $\quad$ (Accessed: 22.04.2019).

European Commission (2018), International dimension of the European Year of Cultural Heritage 2018, Available ONLINE: https:/ec.europa.eu/culture/content/international-dimensioneuropean-year-cultural-heritage-2018 en (Accessed: 22.04.2019)

European Union (2007), European Agenda for Culture, Available ONLINE: https://eurlex.europa.eu/legal-content/EN/TXT/?uri=CELEX:32007G1129(01) (Accessed: 22.04.2019).

European Union (2014), Work Plan for Culture 2015-2018, Available ONLINE: https://eurlex.europa.eu/legal-content/EN/TXT/?uri=CELEX:52014XG1223(02) (Accessed: 22.04.2019)

European Union (2018), Work Plan for Culture 2019-2022, Available ONLINE: http://data.consilium.europa.eu/doc/document/ST-13948-2018-INIT/en/pdf (Accessed: 22.04.2019).

European Year of Cultural Heritage (2018), Events around Europe, Available ONLINE: https://europa.eu/cultural-heritage/eych-events-grid_en (Accessed: 22.04.2019).

EYCH (2018), Ten European Initiatives, Available ONLINE: https://europa.eu/culturalheritage/sites/eych/files/eych-initiatives_en.pdf (Accessed: 22.04.2019).

Evans M., Lunn K. (1997), War and Memory in the Twentieth Century, Oxford, Berg.

Falkenhayn, E. (1937), Campania Armatei a 9-a împotriva românilor și a rușilor, București, Atelierele Grafice Socec \& Co S.A.

Falls, C. B. (1959) The Great War, New York, Capricorn Books.

Fentress J., Wickham C. (1992), Social Memory: New Perspectives on the Past, Oxford, Blackwell Publishers.

Ferdinand, I (1922), Cuvântări de Ferdinand I Regele României. 1889-1922, București, Fundația Culturală Principele Carol. 
Filipașcu, A. (1940), Istoria Maramureșului, București, Tipografia ziarului Universul.

Filipașcu, A. (1997), Istoria Maramureșului, Baia Mare, Editura Gutinul.

Finney, P. (2017), 'Politics and technologies of authenticity: the Second World War at the close of living memory', Rethinking History, Vol.21, N.2, pp.154-170.

Fiske, J. (1987), Television culture, London/New York, Routledge.

FLANDERSNEWS.BE (2018), Advisory body tells UNESCO that WWI sites aren't world heritage, Available ONLINE: https://www.vrt.be/vrtnws/en/2018/04/20/ advisory body tellsunescothatwwisitesarentworldheritage-1-3183436/ (Accessed: 22.04.2019).

FlandersToday (2018), Unesco advisory board rejects First World War as heritage, Available ONLINE: http://www.flanderstoday.eu/unesco-advisory-board-rejects-firstworld-war-heritage (Accessed: 22.04.2019).

Foard G., Morris R. (2012), The archaeology of English battlefields: conflict in the preIndustrial landscape, York, Council for British Archaeology.

Foard, G. (2005), History from the field: the Edgehill battlefield survey, London, Battlefields Trust.

Forbes N., Page R., Pérez G. (2009), Europe's deadly century: perspectives on 20th century conflict heritage, Swindon, English Heritage.

Forty A., Küchler S. (1999), The art of forgetting, Oxford, Berg.

France (2014), Funerary and memorial sites of the First World War (Western Front), Available ONLINE: https://whc.unesco.org/en/tentativelists/5884/(Accessed: 22.04.2019).

Fraser A.H., Brown M. (2008), Mud, blood and missing men: excavations at Serre, Somme, France, In: Pollard T., Banks I., Scorched earth: studies in the archaeology of conflict, Leiden, Brill NV, pp.147-171.

Fussell, P. (1975), The Great War and Modern Memory, New York, Oxford University Press.

Gane, C. (1936), P. P. Carp și locul său în istoria politică a țării, vol. I-II, București, Editura ziarului „Universul”.

Gazin-Schwartz, A. (2004), Mementos of the Past: Material Culture of Tourism at Stonehenge and Avebury, In: Rowan Y., Baram U., Marketing Heritage. Archaeology and the Consumption of the Past, Oxford, Alta Mira Press, pp.93-102.

Ghergheș, I. (2017), Maramureșenii și Marea Unire de la 1 Decembrie 1918, Baia Mare, Editura Gutinul.

Gheyle W., Dossche R., Bourgeois J., Stichelbaut B., Van Eetvelde V. (2014), 'Integrating Archaeology and Landscape Analysis for the Cultural Heritage Management of a World War I Militarised Landscape: The German Field Defences in Antwerp', Landscape Research, Vol.39, n.5, p.502-523. 
Ghișa, S. (2009), Luptele Românilor cu bolșevicii în Siberia 1918-1920, Baia Mare, Editura Marist.

Gibson E., Ward G. K. (1989), Courage Remembered: the Story Behind the Contruction and Maintenance of the Commonwealth's Military Cememeteries and Memorials of the Wars 1914-1918 and 1939-1945, London, H.M.S.O.

Gilchrist, R. (2003), 'Introduction: towards a social archaeology of warfare', World Archaeology, Vol.35, N.1, pp.1-6.

Gillings M., Mattingly D., van Dalen J. (2000), Geographical information systems and landscape archaeology, Oxford, Oxbow.

Gillings M., Pollard J. (2016), Landscape archaeology, New York, Routledge.

Gillis, J. R. (1994), Commemorations: The Politics of National Identity, Princeton, Princeton University Press.

Giurescu, D. C. (2010), Istoria României în date, București, Editura Enciclopedica.

Gonzalez, M. V. (2008), 'Intangible heritage tourism and identity', Tourism Management, Vol.29, N.4, pp.807-810.

Gonzalo L. M., Roberts M., Telfer N. (2014) 'The Archaeology and Anthropology of the First World War. A multidisciplinary approach for the study of a global conflict', The Historian, Vol. 3, No. 3, pp. 19-24.

Goss, J. (1988), 'The Built Environment and Social Theory: Towards an Architectural Geography', Professional Geographer, Vol.40, N.4, pp.392-403.

Gould R. A., Schiffer M. B. (1981), Modern material culture studies: the archaeology of us, New York, Academic Press.

Graham B., Ashworth G., Tunbridge J. (2000), A Geography of Heritage: Power, Culture and Economy, London, Arnold.

Grandhomme J. N., Roucaud M., Sarmant T. (2000), La Roumanie dans la Grande Guerre et l'effondrement de l'armée russe : Édition critique des rapports du général Berthelot chef de la mission militaire française en Roumanie (1916-1918), Paris, L'Harmattan.

Graves-Brown, P. (2000), Matter, materiality and modern culture, London, Routledge.

Grenville J., Fairclough G. (2004), 'Characterisation: Introduction', Conservation Bulletin, N.47 Winter, pp.2-3.

Gustafsson A., Karlsson H. (2014), Authenticity in Practice: A comparative discussion of the authenticity, staging and public communication at eight World Heritage classified rock art sites, Goteborg, Bricoleur Press.

Gusti, D. (1944), 'Trei academicieni dispăruți', Revista Fundațiilor Regale, București, Vol. XI, N. 10. 
Hakan, K. (2005), 'The Contemporary Archaeology of Recent Conflict', European Journal of Archaeology, Vol.8, N.3, pp.292-295.

Halbwachs, M. (1992), On Collective Memory, Chicago, University of Chicago Press.

Hall C. M., McArthur S. (1998), Integrated heritage management: Principles and practice, London, Stationery Office.

Hall, M. (2000), Archaeology and the modern world: colonial transcripts of South Africa and the Chesapeake, London, Routledge.

Hammami, F. (2012), Heritage in Authority-Making: Appropriating Interventions in Three Socio-Political Contexts, PhD Thesis, Stockholm, KTH Royal Institute of Technology.

Hamric, J. L. (2005), 'Germany's Decisive Victory: Falkenhayn's Campaign in Romania, 1916', Michigan War Studies Review, n.3, Available ONLINE: http://www.miwsr.com/2005/20050501.asp (Accessed: 22.04.2019).

Hanson, J. (2011), Assessing the potential contribution of airborne Light Detection and Ranging (LiDAR) towards the archaeological prospection of twentieth-century landscapes of conflict. MSc Thesis, Birmingham, University of Birmingham.

Harrison R., Jameson J. H., Schofield J. (2008), The Heritage Reader, London, Routledge.

Harrison R., Schofield J. (2010), After Modernity: Archaeological Approaches to the Contemporary Past, Oxford, Oxford University Press.

Harrison, R. (2010), Understanding the Politics of Heritage, Manchester, Manchester University Press.

Harrison, R. (2012), Heritage: critical approaches, Abingdon, Routledge.

Harrison, R. (2013), 'Forgetting to remember, remembering to forget: late modern heritage practices, sustainability and the crisis of accumulation of the past', International Journal of Heritage Studies, Vol 19, n.6, p.579-595.

Hart, P. (2013), The Great War: a combat history of the First World War, Oxford, Oxford University Press.

Harvey, D. (2000), 'Continuity, authority and the place of heritage in the Medieval world', Journal of Historical Geography, Vol.26, N.1, pp.47-59.

Harvey, D. (2001), 'Heritage pasts and heritage presents: temporality, meaning, and the scope of heritage studies', International Journal of Heritage Studies, Vol.7, N.4, pp.319-338.

Harvey, D. (2008), 'The Right to the City', New Left Review, Vol. 53, September-October, pp.23-40.

Harvey, D. (2009), Cosmopolitanism and the Geographies of Freedom, New York, Columbia University Press.

Herbert, D. (1995), Heritage places, leisure and tourism, In: Herbert D., Heritage, tourism and society, London, Pinter, pp.1-20. 
Herrera, A. (2015), Archaeology and Development: Ethics of a Fateful Relationship, In: Haber A., Shepherd N., After Ethics: Ancestral Voices and Post-Disciplinary Worlds in Archaeology, New York, Springer, pp.39-53.

Hewison R., Holden J. (2006), Public value as a framework for analysing the value of heritage: The ideas, In: Clark K., Capturing the public value of heritage, London, English Heritage, pp.14-18.

Hicks D., Beaudry M. C. (2006), The Cambridge companion to historical archaeology, Cambridge, Cambridge University Press.

Hicks, D. (2004), 'Historical archaeology and the British', Cambridge Archaeological Journal, Vol.14, N.1, pp.101-106.

Hitchins, K. (2013), România 1866-1947, București, Editura Humanitas

Hobsbawm E., Ranger T. (1983), The Invention of Tradition, Cambridge, Cambridge University Press.

Hodder, I. (2003), 'Archaeological reflexivity and the local voice', Anthropological quarterly, Vol.76, N.1, pp.55-69.

Hoelscher S., Alderman D. H. (2004), 'Memory and Place: Geographies of a Critical Relationship', Social and Cultural Geography, Vol.5, N.3, pp. 347-355.

Hoffman T. L, Kwas M. L, Silverman H. (2002), 'Heritage Tourism and Public Archaeology', The SAA Archaeological Record, Vol.2, N.2, pp.30-32.

Hofman C. L., Haviser J. B. (2015), Managing our past into the future: Archaeological heritage management in the Dutch Caribbean, Leiden, Sidestone Press.

Holtorf C., Piccini A. (2011), Contemporary archaeologies: excavating now, Frankfurt, Peter Lang.

Holtorf, C. (2006), Archaeology Is a Brand! The Meaning of Archaeology in Contemporary Popular Culture, Walnut Creek, Left Coast Press.

Hooper-Greenhill, E. (2000), Museums and the interpretation of visual culture, New York, Routledge.

Horne, C. F. (1923), Source Records Of the Great War, New York, National Alumni.

Howard, P. (2003), Heritage; Management, interpretation and identity, London, Continuum.

Hume, N. (1964), 'Handmaiden to history', North Carolina Historical Review, Vol.41, N.2, pp.215-225.

HUNGARICANA WEBSITE, Available ONLINE: https://maps.hungaricana.hu len/search/results/?list=eyJxdWVyeSI6ICIxOTE0LTE5MTgifQ (Accessed: 22.04.2019). 
Huyssen, A. (2000), 'Present Pasts: Media, Politics, Amnesia', Public Culture, Vol.12, N.1, pp.21-38.

Hynes, S. (1992), A War Imagined: The First World War and English Culture, London, Pimilico.

I FEEL SLOVENIA (2016), Slovenia's WWI heritage project on UNESCO's tentative list, Available ONLINE: https://www.slovenia.info/en/press-centre/news-of-the-tourism-pressagency/5690-slovenias-wwi-heritage-project-on-unesco-s-tentative-list (Accessed: 22.04.2019).

Iliescu, D. (1924), Documente privitoare la războiul pentru întregirea României, București, Imprimeria Statului.

Ioaniţiu, A. (1929), Războiul României: 1916-1918, Vol. I, București, Tipografia Geniului.

Ioanițiu, A (1929), Războiul Romaniei: 1916-1918, Vol.II, București, Tipografia Geniului.

Ionescu, M. E. (2013), 'Un secol de la Al Doilea Război Balcanic', Revista de Istorie Militară, N. 3-4, pp.1-3

Iorga, N. (1915), Istoria Românilor din Ardeal și Ungaria, București, Editura Stiintifica și Enciclopedica.

Iorgovan A. (2002), Tratat de drept administrativ, Vol. 2, Bucuresti, All Beck.

Iosipescu V., Preda G. (1967), Generalul David Praporgescu, București, Editura Militară.

ITV News (2018), France and Belgium seek Unesco recognition for WWI memorials, Available ONLINE: http://www.itv.com/news/2018-06-24/france-and-belgium-seek-unescorecognition-for-wwi-memorials/ (Accessed: 22.04.2019).

Jaszi, O. (1966), The Dissolution of the Hapsburg Monarchy, Chicago, The University of Chicago Press.

Johnston, C. (1992), What is social value? a discussion paper, Canberra, Australian Government Publishing Services.

Jonker G. (1995), The topography of remembrance: the dead, tradition and collective memory in Mesopotamia, Boston, Brill Academic Publishers.

Jukes, G. (2002), The First World War. The Eastern Front 1914-1918, Oxford, Osprey Publishing.

KatiaZEV News \& More (2018), UNESCO World Heritage sites: WWI memorials among the contenders, Available ONLINE: http://katiazev.com/unesco-world-heritage-sites-wwimemorials-among-the-contenders/ (Accessed: 22.04.2019).

Keegan, J. (1994), A history of warfare, New York, Vintage.

Keegan, J. (1999), The First World War, New York, Alfred A. Knopf 
King, A. (1998), Memorials of the Great War in Britain: The Symbolism and Politics of Remembrance, Oxford, Berg.

King, A. (1980), Buildings and Society, London, Routledge \& Kegan Paul.

Kirițescu, C. (1925), Istoria Războiului pentru Intregirea României, 1916-1919, Vol.III., București, Casa Școalelor.

Kirițescu, C. (1989) Istoria războiului pentru întregirea României, Vol. I, București, Editura Ştiinţifică și Enciclopedică.

Kirițescu, C. (1989), Istoria războiului pentru întregirea României, Vol. II, București, Editura Științifică și Enciclopedică.

Kirmayer, M. G. (1996), Landscapes of Memory: Trauma, Narrative and Dissociation, In: Antze P., Lambeck M., Tense Past. Cultural Essays in Trauma and Memory, New-York, Routledge, pp.173-198.

Klein, K. L. (2000), 'On the Emergence of Memory in Historical Discourse', Representations, Special Issue: Grounds for Remembering, Winter, N.69, pp. 127-150.

Knox, P. (1987), The Social Production of the Built Environment, Progress in Human Geography, Vol.11, N.2, pp.354-377.

Kulhanek, H. (2009), 'Prislop Bahn - the military railway Borșa-Iacobeni. Peculiar novelties in the light of philatelic documents', The railway philatelist, N.54, pp.24-36.

Kulhanek, H. (2017), 'Prislop Bahn - the military railway Borșa-Iacobeni, updates 1', The railway philatelist, N.86, pp.50-54.

Kulhanek, H. (2017), 'Prislop Bahn - the military railway Borșa-Iacobeni, updates 2', The railway philatelist, N.87, pp.37-40.

Labadi S., Long C. (2010), Heritage and Globalisation, London, Routledge.

Labadi, S. (2013), UNESCO, Cultural Heritage, and Outstanding Universal Value. Valuebased Analyses of the World Heritage and Intangible Cultural Heritage Conventions, Plymouth, Alta Mira Press.

Le Miroir (1916), LE REGNE DE LA TERREUR EN AUTRICHE-HONGRIE, Available ONLINE: https://gallica.bnf.fr/ark:/12148/bpt6k6522748t/texteBrut (Accessed: 22.04.2019).

Leech, R. (1999), The processional city: some issues for historical archaeology, In: Tarlow S., West S., The familiar past? Archaeologies of later historical Britain, London, Routledge, pp.19-34.

Legg, S. (2005), 'Contesting and surviving memory: space, nation, and nostalgia in Les Lieux de Mémoire', Society and Space, Vol.23, N.4. pp.481-504.

Levy D., Sznaider N. (2002), 'Memory Unbound: The Holocaust and the Formation of Cosmopolitan Memory', European Journal of Social Theory, Vol.5, N.1, pp. 87-106. 
Levy D., Sznaider N. (2006), The Holocaust and Memory in the Global Age, Philadelphia, Temple University Press.

Lindqvist, S (2001), A history of bombing, London, Granta.

Little, B.J. (1992), Text-aided archaeology, Boca Raton, CRC Press Inc.

Little, B.J. (2007), Historical archaeology: why the past matters, Walnut Creek, Left Coast Press Inc.

Lovata, T. (2007), Inauthentic Archaeologies: Public Uses and Abuses of the Past, Walnut Creek, Left Coast Press.

Lowenthal, D. (1985) The Past is a Foreign Country, Cambridge, Cambridge University Press.

Lowenthal, D. (1996), Possessed by the past: The heritage crusade and the spoils of history, Toronto, Free Press.

Lowenthal, D. (1998), The Heritage Crusade and the Spoils of History, Cambridge, Cambridge University Press.

Ludendorff, E. (1920), Souvenirs de guerre (1914-1918), Vol. I, Paris, Payot.

Ludendorff, E. (2001), My War Memories 1914-1918, Uckfield, Naval \& Military Press.

Macdonald, S. (2013), Memorylands: Heritage and Identity in Europe Today, London, Routledge.

Magyarorszag (1914), 'Raportul Corespondentului', Unirea, N.10, p.2.

Maior, L. (2004), Romanians in Habsburg Army: Forgotten Soldiers and Officers, Bucharest, Military Publishing House.

Mamina, I. (1997), Consilii de Coroană, București, Editura Enciclopedică.

Mansfield, N. (1995), 'Class Conflict and Village War Memorials 1914-24', Rural History, Vol.6, N.1, pp.67-87.

Marshall, S. L. A. (1971), World War I, New York, American Heritage Press.

Masters P., Stichelbaut B. (2009), 'From the air to beneath the soil - revealing and mapping great war trenches at Ploegsteert (Comines-Warneton), Belgium', Archaeological Prospection, Vol.16, N.4, pp.279-285.

Mărdărescu, G. D. (2009), Campania pentru desrobirea Ardealului si ocuparea Budapestei (1918-1920), București, Editura Militara.

Mărgineanu G., Lacrițeanu Ș. (2016), Railway premiers and the evolution of traction activities on the Regional C.F. Iași 1870-2000, București, Editura Agir.

McCarroll, C. (2018), Remembering from the outside: personal memory and the perspectival mind, New York, Oxford University Press. 
Mcintosh A., Prentice R. (1999), 'Affirming Authenticity: Consuming Cultural Heritage', Annals of Tourism Research, Vol.26, N.3, pp.589-612.

McIntyre, C. (1990), Monuments of War: How to Read a War Memorial, London, Hale.

McLean, F. (2006), 'Introduction: Heritage and identify', International Journal of Heritage Studies, Vol.12, N.1, pp.3-7.

McManamon F. P, Hatton A. (2000), Cultural Resource Management in Contemporary Society: Perspectives on Managing and Presenting the Past, London, Routledge.

Meskell L., Pels P. (2005), Embedding ethics: Shifting Boundaries of the Anthropological Profession, London, Bloomsbury Academic.

Meskell, L. (2015) Global Heritage: A Reader, London, Wiley Blackwell.

Messenger P. M, Smith, G. S. (2010), Cultural Heritage Management: a global perspective, Gainesville, University Press of Florida.

Mihali, N. (2013), Neamul Găborenilor. O frescă a Maramureșului la începutul secolului XX, Baia Mare, Editura Eurotip.

Mikolos Banffy, The Transylvanian Trilogy, Vol.I, New York-London-Toronto, Everyman's Library.

Miller, D. (1988), Material cultures, London, UCL Press.

Ministerul Apărării Naţionale, (1996), Revista de istorie militară, N. 3, p. 14.

Ministry of Culture and National Identity (2018), National Commision of Historic Monuments, Available ONLINE: http://www.cultura.ro/comisia-nationala-monumentelor-istorice (Accessed: 22.04.2019).

Misztal, B.A. (2003), Theories of Social Remembering, Maidenhead, Open University Press.

Molina-Burguera, G. (2010), 'Managing Conflict: The Management and Interpretation of Spanish Civil War Sites', Conservation and Management of Archaeological Sites, Vol.12, N.1, pp.39-59.

Molloy, D. (2016), Cultural memory and literature: re-imagining Australia's past, LeidenBoston, Brill.

Mont, I. (1994) 'Other Postmodern Tourism: Culture, Travel, and the New Middle Classes, Theory', Culture \& Society, Vol.11, N.3, pp.101-123.

Moreland, J. (2001), Archaeology and text, London, Gerald Duckworth and Company Limited.

Moriarty, C. (1995), 'The Absent Dead and the Figurative First World War Memorials', Transactions of the Ancient Monuments Society, Vol.39, pp.7-40. 
Moriarty, C. (1999), 'The Material Culture of Great War Remembrance', Journal of Contemporary History, Vol. 34, N.4, pp. 653-662.

Mosse, G. L. (1990), Fallen Soldiers: Reshaping the Memory of the World Wars, Oxford New York, Oxford University Press.

Mosse, G. L. (1990), Fallen Soldiers: Reshaping the Memory of the World Wars, Oxford New York, Oxford University Press.

Muller, J. W. (2002), Memory and Power in Post-war Europe: Studies in the Presence of the Past, Cambridge, Cambridge University Press.

Mumford, L. (1938). The Culture of Cities, New York, Harcourt, Brace \&World.

Munteanu, I. (1992), Banatul și Marea Unire, Timișoara, Editura Mitropoliei Banatului.

Murgescu, B. (2001), Istoria României în texte, București, Editura Corint.

Naroș, I. (2013) Romanele lui Rebreanu, Iași Editura, Tipo Moldova.

National Institute for Research and Cultural Training (2018), Specialists Register, Available on-line: http://www.culturadata.ro/atestare/ (Accessed: 01.09.2018).

Nelson R., Olin M. (2003), Monuments and memory, made and unmade, Chicago - London, University of Chicago Press.

Nemoiu, P. (1933), Prizonier la ruși, rob la unguri, București, Tipografia Cărților Bisericești.

New York Times (1918), Proclaims Union of All Rumanians, December 11. 1918.

Nicolescu G., Dobrescu G., Nicolescu A. (2006), Calvarul prizonierilor români din primul război mondial. Mărturii documentare, Vol. I, Bucureşti, Editura Universităţii din Piteşti.

Nistor, I. (1928), Unirea Bucovinei cu România, 28 noiembrie 1918. Studii și documente, București, Cartea Româneacă.

Nistor, I. (1991) Istoria Basarabiei, București, Editura Humanitas.

Nistor, P. (1922), 'Corpul Voluntarilor români ardeleni-bucovinineni. Istoricul înfiintării, până la sosirea la Iași', Gazeta Transilvaniei, Nr.178-198.

Nora, P. (1996), Realms of memory: the construction of the French past - Conflicts and divisions, Vol. 1, New York, Columbia University Press.

Nora, P. (1997), Realms of memory: the construction of the French past - Traditions, Vol. 2, New York, Columbia University Press.

Nora, P. (1998), Realms of memory: the construction of the French past - Symbols, Vol. 3, New York, Columbia University Press. 
Nora, P. (1996), Realms of Memory: Rethinking the French Past, Vol. 1, New York, Columbia University Press.

Nora, P. (2002), Reasons for the current upsurge in memory, Available ONLINE: https://www.boell.de/sites/default/files/assets/boell.de/images/download de/Nora Synopse b 1.pdf (Downloaded: 11.03.2016).

Nouzille, J. (1997), Calvarul prizonierilor de război români în Alsacia şi Lorena, 1917-1918, Bucureşti, Semne '94.

Oosterbeek, L. (1997), War in the Chalcolithic? The meaning of the west Mediterranean hillforts, In: Carman J., Material harm: archaeological studies of war and violence, Glasgow, Cruithne Press, pp.116-132.

Opriş I., Soveja M., Burlacu I. (1980), Mărturii ale trecutului (album de documente), Bucureşti, Direcţia Generală a Arhivelor Statului.

Opriş I. (1986), Ocrotirea patrimoniului cultural. Tradiţii, destin, valoare, Bucureşti, Editura Meridiane.

Otu, P. (2011), '150 de ani de la nașterea mareșalului Constantin Prezan', Studii şi Comunicări a Comitetului Român pentru Istoria și Filosofia Științei și Tehnicii, Vol. IV, pp. 231-248.

Otu, P. (2017), România în primul război mondial. Marea Unire 1918, București, Editura Litera.

Parker Pearson, M. (1982), Mortuary Practices, Society and Ideology; an Ethnoarchaeological Study, In: Hodder I., Symbolic and Structural Archaeology, Cambridge, Cambridge University Press, pp.99-113.

Păcățian, T. (1923), Jertfele Românilor din Ardeal, Banat, Crișana, Sătmar și Maramureș aduse în războiul mondial din 1914-1918, Sibiu, Editura Asociațiunii.

Păiuşan, R. (1993), Mişcarea naţională din Banat şi Marea Unire 1895-1919, Timişoara, Editura de Vest.

Pearce, S. (2000), The Making of Cultural Heritage, In: Avrami E., Mason R., De La Torre M., Values and Heritage Conservation Research Report, Los Angeles, The Getty Conservation Institute, pp.59-64.

Pearson, C. (2012), 'Reaching Militarised Landscapes: A literature Review on War and the Militarization of the Environment', Landscape Research, Vol. 37, N.1, pp.115-133.

Penny, N. (1981), 'English Sculpture and the First World War', The Oxford Art Journal, Vol.4, N.2, pp.36-43.

Percivale, T. A. J. (2000), Monarhia Habsburgică: 1809-1918. O istorie a imperiului Austriac și a Austro-Ungariei, București, Editura All Istoric.

Petin, V. (1932), Le Drame Roumain 1916-1918, Paris, Payot. 
Otu, P. (2017), România în primul război mondial: Marea Unire 1918, București, Editura Litera.

Pintea, A. (2014), Dreptul de preemptiune în domeniul monumentelor istorice, PhD Thesis, Baia Mare, Universitatea de Vest Vasile Goldiş - Facultatea de ştiinţe juridice, specializarea drept.

Plămădeală, A. (1986), Românii din Transilvania sub teroarea regimului dualist austro-ungar (1867-1918), Sibiu, Tiparul Tipografiei Eparhiale.

Pollard T., Banks I. (2008), Scorched Earth. Studies in the archaeology of Conflict, LeidenBoston, Brill.

Pred, A. (1984), 'Place as Historically Contingent Process: Structuration and the TimeGeography of Becoming Places', Annals of the Association of American Geographers, Vol.74, N.21, pp.279-297.

Price, J. (2005), 'Orphan Heritage: Issues in Managing the Heritage of the Great War in Northern France and Belgium', Journal of Conflict Archaeology, Vo1, N. 1, pp.181- 196.

Purseigle P., Macleod J. (2004), Uncovered Fields: Perspectives in First World War Studies, Leiden-Boston, Brill.

Pușcariu, S. (1978), Memorii, București, Editura Minerva.

Radstone, S. (2000), Memory and Methodology, Oxford-New York, Berg.

Radstone, S. (2005), 'Reconceiving Binaries: The Limits of Memory', History Workshop Journal, Vol.59, N.1, pp. 134-150.

Rădulescu-Zoner, Ș. (1977), România și Tripla Alianță la începutul secolului al XX-lea. 1900-1914, București, Editura Litera.

Rebreanu, I. (2000), 'Erori și inadvertențe', România literară, Vol.XXX, N. 35, pp.6-12.

Richard F., Hamilton R. F, Herwig H. H. (2003), The Origins of World War I, New York, Cambridge University Press.

Robertson A., Kenyon D. (2008), Digging the trenches: the archaeology of the Western Front, Barnsley, Pen and Sword Military.

Roigé X., Frigolé J. (2010), Constructing cultural and natural heritage: Parks, museums and rural heritage, Girona, ICRPC (Institut Català de Recerca en Patrimoni Cultural).

Romanian Government (2016), Emergency Ordiance N. 49/2016 for the modification of the Law N.5/2000 regarding the approval of the Plan for the Arrangement of National TerritorySection III - Protected Areas, Available ONLINE: http://legislatie.just.ro/Public/DetaliiDocument/181506 (Accessed: 22.04.2019).

Romanian Parliament (2000), Plan for the Arrangement of National Territory - Section III Protected Areas, Available ONLINE: http://www.cdep.ro/pls/legis/legis_pck.htp act text?idt=22636 (Accessed: 22.04.2019). 
Românul (1911), 'Congresul internațional al raselor', Românul, Vol.I, N.158.

Ros, A. (2012), The post-dictatorship generation in Argentina, Chile, and Uruguay: collective memory and cultural production, Basingstoke, Palgrave Macmillan.

Rosenfeld G. D. (2009), 'A Looming Crash or a Soft Landing? Forecasting the Future of the Memory Industry', The Journal of Modern History, Vol.81, N.1, pp.142-144.

Rosetti, R. R. (1997), Mărturisiri (1914-1919), București, Editura Modelism.

Roszkowski W., Kofman J. (2015), Biographical Dictionary of Central and Eastern Europe in the Twentieth Century, London - New York, Routledge.

Russell, I. (2006), Images, representations and heritage: Moving beyond Modern Approaches to Archaeology, New York, Springer.

Samuel, R. (1994), Theatres of Memory. Past and Present in Contemporary Culture, London, Verso.

Samuels, K. L. (2008), 'Value and significance in archaeology', Archaeological Dialogues, Vol.15, N.1, pp.71-97.

Saunders, N. J. (2001), Matter and memory in the landscapes of conflict: the Western Front 1914-1999, In: Bender B., Winer M., Contested landscapes: movement, exile and place, Oxford, Berg, pp.37-53.

Saunders, N. J. (2002), 'Excavating memories: archaeology and the Great War, 1914-2001', Antiquity, Vol.76, N. 291, pp.101-108.

Saunders, N. J. (2003), Trench art: materialities and memories of war, Oxford, Berg.

Saunders, N. J. (2004), Matters of conflict: material culture, memory and the First World War, London, Routledge.

Saunders, N. J. (2007), Killing time: Archaeology and the First World War, Stroud, Sutton.

Saunders, N. J. (2012), Beyond the dead horizon: studies in modern conflict archaeology, Oxford, Oxbow Books.

Schmitt, T. M. (2009), 'Global cultural governance: Decision-making concerning world heritage between politics and science', Erdkunde, Vol.63, N.2, pp.103-121.

Schofield J., Gray Johnson W., Beck M. (2002), Matériel Culture: The Archaeology of twentieth century conflict, London, Routledge.

Schofield J., Johnson W. G. (2006), Archaeology, heritage and the recent and contemporarypast, In: Hicks D., Beaudry M. C., The Cambridge companion to historical archaeology, Cambridge, Cambridge University Press, pp.104-122.

Schofield, J. (2005), Combat Archaeology. Material culture and modern conflict, Bath, Duckworth.

Schofield, J. (2005), Combat archaeology: matérial culture and modern conflict, London, Gerald Duckworth and Company Limited. 
Scorpan, C. (1997), Istoria României. Enciclopedie, București, Editura Nemira.

Scott D., Babits L., Haecker C. (2007), Fields of Conflict. Battlefield archaeology from the Roman empire to the Korean war, London, Praeger Security International.

Scott D. D., Fox R. A, Connor M. A, Harmon D. (1989), Archaeological perspectives on the Battle of the Little Big Horn, Norman-Oklahoma, University of Oklahoma Press.

Scurtu I., Alexandrescu I., Bulei I., Mamina I. (2001), Enciclopedia de istorie a Romaniei, Bucuresti, Editura Meronia.

Scurtu, I. (1993), România Documentele Unirii 1918, București, Editura Fundației Culturale Române.

Seasholes, N. S. (1998), On the use of historical maps, In: Beaudry M. C., Documentary archaeology in the New World, Cambridge, Cambridge University Press, pp.92-118.

Sebastian L., Lipe W. D. (2009), Archaeology and Cultural Resource Management: visions for the future, Santa Fé NM, SAR Press.

Serviciul Istoric al Armatei (1934), România în războiul mondial 1916-1919, Documente, Anexe, Vol. I, București, Monitorul Oficial și Imprimeriile Statului.

Serviciul Istoric al Armatei (1934), România în războiul mondial (1916-1918), Vol. II, București, Tipografia Monitorul Oficial și Imprimeriile Statului.

Serviciul Istoric al Armatei (1934), România în războiul mondial (1916-1918), Vol. III. Documente-Anexe, partea I, București, Tipografia Monitorul Oficial și Imprimeriile Statului.

Seton-Watson, R. W. (1929), First impressions of Transylvania 1906-1907, Transilvania, Banatul, Crisana, Maramureșul. 1918-1929, Vol.III, Bucuresti, Ed. Cultura Nationala, pp.1341-1346.

Sharpe, C. A. (1986), 'The Teaching ofUrban Morphogenesis', The Canadian Geographer, Vol.30, N.1, pp.53-79.

Sherman, D. J. (1999), The Construction of Memory in Interwar France, Chicago, University of Chicago Press.

Shiels, D. (2007), 'Battle and siege maps of Elizabethan Ireland: blueprint for archaeologists?', Journal of Conflict Archaeology, Vol.3, N.1, pp.217-232.

Silverman, H (2011), Contestedculturalheritage: religion, nationalism, erasure, and exclusion in a global world, New York-London, Springer.

Silverman, H. (2002), 'Touring Ancient Times: The Present and Presented Past in Contemporary Peru', American Anthropologist, Vol.104, N.3, pp.881-902.

Skeates, R. (2000), Debating the archaeological heritage, London, Duckworth.

Slick, K. (2002), Archaeology and the Tourism Train, In: Little B., Public Benefits of Archaeology, Gainesville, University of Florida Press, pp.219-227. 
Slovenia (2016), The Walk of Peace from the Alps to the Adriatic - Heritage of the First World War, Available ONLINE: https://whc.unesco.org/en/tentativelists/6077/ (Accessed: 22.04.2019).

Slusanschi, E. (1915), Bucovina în zilele rusilor. Fragmente din carnetelul meu, Bucuresti, pp.33-34.

Smith, A. D. (1986), The Ethnic Origins of Nations, Oxford, Blackwell.

Smith A. D. (1995), Nations and Nationalism in a Global Era, Oxford, Polity Press.

Smith L., Audoin-Rouzeau S., Becker A. (2003), France and the Great War, 1914-1918, Cambridge, Cambridge Univerisity Press.

Smith, L. (2004), Archaeological Theory and the Politics of Cultural Heritage, London, Routledge.

Smith, L. (2006) Uses of Heritage, London - New York, Routledge.

Smith, L. (2009), Deference and humility: The social values of the country house In: Gibson L., Pendlebury J., Valuing Historic Environments, London, Ashgate, pp.33-50.

Smith L., Akigawa N. (2009), Intangible heritage, Abingdon, Routledge.

Smith L., Waterton E. (2009), Heritage, communities and archaeology, London, Duckworth.

Smith G., Messenger P. M., Soderland H. A. (2010), Heritage Values in Contemporary Society, Walnut Creek CA, Left Coast Press.

Sørensen M. L. S, Carman J. (2009) Heritage Studies: methods and approaches, London, Routledge.

Spennemann, D. H. R. (2006), 'Gauging community values in Historic preservation', CRM: The Journal of Heritage Stewardship, Vol.3, N.2, pp.6-20.

Stan, A. (1996), Liberalismul politic în România, București, Editura Enciclopedică, p. 358.

Stanca, D. (1935), Intre doua fronturi, 1914-1918, Cluj-Napoca, Editura Patria.

Starn, R. (2002), 'Authenticity and historic preservation: Towards an authentic history', History of the Human Sciences, Vol.15, N.1, pp.1-16.

State Archives of Bucharest (1918), The Resolution of the National Assembly of Alba-Iulia, Available ONLINE: http://www.cimec.ro/Istorie/Unire/rezo_eng.htm (Accessed: 22.04.2019).

Stevenson, G. (2001), Archaeology as the design history of the everyday, In: Buchli V., Lucas G., Archaeologies of the contemporary past, London, Routledge, pp.51-62.

Stone, N. (1966), 'Army and Society in the Hasburg Monarchy (1900-1914)', Past and Present, N.33, pp. 95-111.

Suciu, I. D. (2003), Unitatea poporului român: Contribuții istorice bănățene, Timișoara, Editura de Vest. 
Swyngedouw. E. (1997), Neither global nor local: Glocalization and the Politics of Scale, In: Cox K., Spaces of Globalisation: Reasserting the Power of theLocal, New York, Guilford Press, pp.137-166.

Șerban, I. I. (1998-1999), 'Românii în armata austro-ungară în anii primului război mondial', Annales. Universitatis Apulensis, Series Historica, Vol.2-3, pp.201-215.

Tarlow, S. (1997), 'An Archaeology of Remembering: Death, Bereavement and the First World War', Cambridge Archaeological Journal, Vol.7, pp. 105-121.

Tăbăcilă F.M., Stoica C. (2012), Carol I - activitatea legislativă în domeniul protejării monumentelor publice si politica sa edilitară, Available ONLINE: http://monumentul.ro/monumentul/?p=1745 (Accessed: 22.04.2019).

Tăslăuanu, O. C. (1915), Trei luni pe cîmpul de războiu, București, Editura Librăriei Şcoalelor C Sfetea.

Terraine, J. (1997), The Great War, Ware, Wordsworth Military Library.

The Archaeology and Metal Detecting Magazine (2018), Advisory body tells UNESCO that WWI sites aren't world heritage, Available ONLINE: https://archmdmag.com/advisory-bodytells-unesco-that-wwi-sites-arent-world-heritage/ (Accessed: 22.04.2019).

The Great War Centenary (2017), World War I Cemeteries and memorial sites proposed as Unesco World Heritage, Available ONLINE: http://www.2014-18.be/en/news/world-war-icemeteries-and-memorial-sites-proposed-unesco-world-heritage (Accessed: 22.04.2019).

The Telegraph (2018), France and Belgium make case for First World War memorials to be given Unesco world heritage status, Available ONLINE: https://www.telegraph.co.uk/news/2018/06/24/france-belgium-make-case-first-world-war-memorialsgiven-unesco/ (Accessed: 22.04.2019)

Theodosiou, C. (2010), 'Symbolic narratives and the legacy of the Great War: the celebration of Armistice Day in France in the 1920s', First World War Studies, Vol. 1, N.2, pp. 185-198.

Thomas, J. (2004), Archaeology and modernity, London, Routledge.

Tisza, E. (1932), Lettres de guerre (1914-1916), Paris, Les Oeuvres représentatives.

Tomi, M. N. (2005), Maramureșul Istoric în date, Cluj-Napoca, Editura Grinta.

Torrey, G. E. (1978), 'Romania's Entry into the First World War: The Problem of Strategy', The Emporia State Research Studies, Vol. 26, N. 4, pp.5-19

Torrey, G. E. (1980), 'The Rumanian Campaign of 1916: Its Impact on the Belligerents', Slavic Review, Vol. 39, N.1, pp.27-43

Torrey, G. E. (2003), 'The Battle of Turtucaia (Tutrakan) (2-6 September 1916): Romania's Grief, Bulgaria's Glory', East European Quarterly, Vol. 37, N.4, pp.396-397. 
Traverso, E. (2012), Il secolo armato. Interpretare le violenze del Novecento, Milano, Feltrinelli.

Tucker S., Roberts P. M. (2005), Encyclopedia of World War I, Santa Barbara, ABC-Clio.

Tunbridge J., Ashworth G. (1996), Dissonant Heritage: The Management of the Past as a Resource in Conflict, Chichester, John Wiley and Sons Limited.

U.S. Department of State (1918), Texts of the Roumanian Peace, Washington, United States Government Printing Office, pp. 5-28, Available ONLINE: https://www.mtholyoke.edu/acad/intrel/routreat.html (Accessed: 22.04.2019)

UNESCO (1954), Convention for the Protection of Cultural Property in the Event of Armed Conflict, Available ONLINE: http://portal.unesco.org/en/ev.phpURL_ID=13637\&URL_DO=DO_TOPIC\&URL_SECTION=201.html (Accessed: 22.04.2019).

UNESCO (1970), Paris Convention on the Means of Prohibiting and Preventing the Illicit Import, Export and Transfer of Ownership of Cultural Property, Available ONLINE: http://portal.unesco.org/en/ev.php-URL_ID=13039\&URL_DO=DO_TOPIC\&URL_SECTION=201.html (Accessed: 22.04.2019).

UNESCO (1972), Convention Concerning the Protection of the World Cultural and Natural Heritage, Available ONLINE: http://whc.unesco.org/en/conventiontext/ (Accessed: 22.04.2019)

UNESCO (1999), Wooden Churches of Maramureş, Available ONLINE: https://whc.unesco.org/en/list/904 (Accessed: 22.04.2019)

UNESCO (2003), Convention for the Safeguarding of the Intangible Cultural Heritage, Available ONLINE: http://portal.unesco.org/en/ev.phpURL_ID=17716\&URL_DO=DO_TOPIC\&URL_SECTION=201.html (Accessed: 22.04.2019).

UNESCO (2017), The Operational Guidelines for the Implementation of the World Heritage Convention, Available ONLINE: https://whc.unesco.org/en/guidelines/ (Accessed: 22.04.2019)

UNESCO (2018), Tentative Lists, Available ONLINE: https://whc.unesco.org/en/tentativelists/ (Accessed: 22.04.2019)

UNESCO, (1946), The Constitution, Available ONLINE: http://www.unesco.org/new/en/unesco/about-us/who-we-are/history/constitution/ (Accessed: 22.04.2019)

UNIDROIT (1995), Convention on stolen or illegally exported cultural objects, Available ONLINE: https://www.unidroit.org/instruments/cultural-property/1995-convention (Accessed: 22.04.2019). 
Van Hollebeeke Y., Stichelbaut B., Bourgeois J. (2014), 'From Landscape of War to Archaeological Report: Ten Years of Professional World War I Archaeology in Flanders (Belgium)', European Journal of Archaeology, Vol.17, N.4, pp.702-719.

Vecco, M. (2010), 'A Definition of Cultural Heritage: From the Tangible to the Intangible', Journal of Cultural Heritage, Vol.11, pp. 321-324.

Verdery, K. (1999), The political lives of dead bodies. Reburial and Postsocialist Change, New-York, Columbia University Press.

Vesa, V. (1980), România și Franța la începutul secolului al XX-le (1900-1916), Pagini de istorie diplomatică, Cluj, Editura Dacia.

Virilio, P. (2008), Bunker Archaeology, New York, Princeton Architectural Press.

Von Rango, R. (1929), Das Jager Regiment Nr.3, Berlin, Oldenburg Stalling.

Waitt, G. (2000), 'Consuming heritage perceived historical authenticity', Annals of Tourism Research, Vol.27, N.4, pp.835-862.

Wakely, J. (1997), Identification and analysis of violent and non-violent head injuries in osteo-archaeological material, In: Carman J., Material harm: archaeological studies of war and violence, Glasgow, Cruithne Press, pp.24-46.

Walker, M. (1998), Protecting the Social Value of Public Places: An Illustrated Guide, Canberra, Australian Council of National Trusts.

Walsh- Heron J., Stevens T. (1990), The management of visitors attractions and events, London, Prentice Hall.

Wang, Z. (2018), Memory Politics, Identity and Conflict. Historical Memory as a Variable, London, Palgrave Macmillan.

Waterton E., Smith L., Campbell G. (2006), 'The utility of discourse analysis to heritage studies: The Burra Charter and social inclusion', International Journalof Heritage Studies, Vol.12, N.4, pp.339-355.

Waterton, E. (2010), Politics, Policy and the Discourses of Heritage in Britain, New York, Palgrave Macmillan.

Weaver D., Oppermann M. (2000), Tourism Management, Brisbane, John Wiley \& Sons.

Wertsch, J. (2002), Voices of collective remembering, Cambridge, Cambridge University Press.

West, S. (1999), Introduction In: Tarlow S., West S., The familiar past? Archaeologies of later historical Britain, London, Routledge, pp.1-15.

White, P. L. (2006), Globalization and the Mythology of the Nation State, In Hopkins A.G, Global History: Interactions Between the Universal and theLocal, New York, Palgrave Macmillan, pp. 257-284. 
Wilkie, L. A. (2006) Documentary archaeology, In: Hicks D., Beaudry, M. C., The Cambridge companion to historical archaeology, Cambridge, Cambridge University Press, pp.13-33.

Wilson, L. K. (2007), Out to the waste: Spadeadam and the Cold War, In: Schofield J, Cocroft W. D, A fearsome heritage: diverse legacies of the Cold War, Walnut Creek, Left Coast Press, pp.155-180.

Wilson, R. J, (2013), Cultural Heritage of the Great War in Britain, Burlington, Ashgate.

Wilson, R. J. (2007), 'Archaeology on the Western Front: the Archaeology of Popular Myths', Public Archaeology, Vol. 6, N.4, pp. 227-241.

Wilson, R. J. (2013), Cultural Heritage of the Great War in Britain, Burlington, Ashgate.

Winter J., Sivan E. (1999), War and Remembrance in the Twentieth Century, Cambridge New York, Cambridge University Press.

Winter, J. (1995), Sites of Memory, Sites of Mourning: the Great War in European Cultural History, Cambridge, Cambridge University Press.

Winter J., Prost A. (2005), The Great War in History: Debates and Controversies, 1914 to the Present, Cambridge - New York, Cambridge University Press.

Winter, J. (2006), Remembering War: the Great War between Memory and History in the Twentieth Century, London, Yale University Press.

Winter, J. (2010), Thinking about silence, In: Winter J., Ben-Zeeev E., Ginio R., Shadows of War: A Social History of Silence in the Twentieth Century, Cambridge, Cambridge University Press, pp.3-31.

Winter, J. (2017), War beyond words: languages of memory from the Great War to the present, Cambridge, Cambridge University Press.

Winter, Y. (1995) Sites of Memory, Sites of Mourning: The Great War in European Cultural History, Cambridge-New York, Cambridge University Press.

Winterburn, J. B. (2012), Hadrian and the Hejaz Railway: linear features in conflict landscapes, In: Saunders N. J., Beyond the dead horizon: studies in modern conflict archaeology, Oxford, Oxbow Books, pp.172-187.

World War One Battlefields (2019), Available ONLINE: http://www.wwlbattlefields.co.uk/flanders/passchendaele/(Accessed: 22.04.2019)

Zorin, Z. (1995), Primul război mondial, București, Editura Didactică și Pedagogică. 